

\title{
Educación XX1
}

Revista de la Facultad de Educación

\author{
17.1 \\ 2014
}

Facultad de Educación

Universidad Nacional de Educación a Distancia MADRID (ESPAÑA) 
La Revista Educación XX1, publicación arbitrada, se configura como órgano de la Facultad de Educación de la UNED para la difusión de trabajos de investigación, ensayos, experiencias y reseñas bibliográficas relevantes en el área educativa, contribuyendo con ello al desarrollo de la educación en todas sus vertientes.

Esta publicación tiene una periodicidad semestral.

Educación XX1 no se hará responsable de las ideas y opiniones expresadas en los trabajos publicados. La responsabilidad plena será de los autores de los mismos.

Educación XX1 se gestiona a través del Open Journal System (OJS), gestor de gestión y difusión de revistas en abierto.

Valoración del Comité Científico. Todos los artículos recibidos serán remitidos por la Dirección de la Revista al Comité Científico, una vez comprobado que cumplen con los objetivos de esta publicación y con las normas formales establecidas. El Comité Científico lo evalúa por el sistema de doble ciego y elabora el correspondiente informe, en un plazo máximo de 1 mes, para la aceptación o rechazo del artículo, basado en los criterios de calidad tanto formales como de contenidos propios de esta Revista.

\section{INTERCAMBIOS:}

Revista Educación XX1 - Decanato de la Facultad de Educación. UNED.

c/ Juan del Rosal, 14 - 28040 MADRID (España)

Tels. +34913986911/ 7216

Correo electrónico: educacionxx1@edu.uned.es

http://www.uned.es/educacionXX1/

VENTA:

Librería UNED: Bravo Murillo, 38 - 28015 Madrid

Tels. 91.398.75.60/73

Correo electrónico: libreria@adm.uned.es

Precio/ejemplar $12.00 €$

https://serviweb.uned.es/publicaciones/catalogo/revistas.asp?issn=1139-613X

EDUCACIÓN XX1 ESTÁ INDIZADA, ENTRE OTROS, EN LAS SIGUIENTES:

\section{BASES DE DATOS:}

- DIALNET

- EBSCO

- HEDBIB

- IRESIE

- ISOC

- LATINDEX

- PSICODOC

- RECYT

- REDALYC

- REDINED

- RESH

- SCOPUS

- SOCIAL SCIENCES CITACION INDEX

- ULRICH'S

\section{CATÁLOGOS:}

- BRITISH LIBRARY

$-\mathrm{CCPP}$

- CCUC

- CENDOC

- CIRBIC

- CISNE

- COMPLUDOC

- CREDI/OEI

- HUMBOLDT UNI. ZU BERLIN

- I. N. RECHERCHE PEDAGOGIQUE

- LIBRARY OF CONGRESS (USA)

- REBIUN

- WORLDCAT

C C UNIVERSIDAD NACIONAL DE EDUCACIÓN A DISTANCIA

Madrid, 2014

Reservados todos los derechos y prohibida su reproducción total o parcial.

ISSN: 1139-613X

Depósito legal: M. $31468-1998$

Impreso en España - Printed in Spain

Educación XX1 pertenece a la Red Española de Revistas Científicas de Educación (RERCE) www.rerce.es 
DIRECTOR DE LA REVISTA

Jose Luis Garcia Llamas, Decano de la Facultad de Educación. UNED

\section{EQUIPO EDITORIAL}

\section{EDITORA}

Marta Ruiz Corbella, Facultad de Educación. UNED

\section{EDITORES ASOCIADOS}

Belén Ballesteros, Facultad de Educación. UNED

Ramón Pérez Pérez. Universidad de Oviedo

Sonia Santoveña, Facultad de Educación. UNED

José Manuel Suárez Riveiro, Facultad de Educación. UNED

\section{CONSEJO CIENTÍFICO}

Ignacio Javier Alfaro Rocher, Universidad de Valencia

Víctor Benito Álvarez Rojo, Universidad de Sevilla

Rafael Bisquerra Alzina, Universidad de Barcelona

Joao Boavida, Universidad de Coimbra, Portugal

Leonor Buendía Eisman, Universidad de Granada

M. ${ }^{a}$ Cristina Cardona Moltó, Universidad de Alicante

José Antonio Caride Gómez, Universidad de Santiago de Compostela

Peter S. Cookson, Delaware State University, USA

Fátima Cunha Ferreira, Fundación CESGRANRIO, Brasil

Saturnino de la Torre, Universidad de Barcelona

Iñaki Dendaluce Segurola, Universidad del País Vasco

Tatyana Dronzina, Universidad de Sofía, Bulgaria

Hermano Duarte de Almeida, Universidade Aberta, Portugal

Joaquín Gairín Sallán, Universidad Autónoma de Barcelona

Narciso García Nieto, Universidad Complutense de Madrid

José Luis Gaviria Soto, Universidad Complutense de Madrid

M. a Ángeles Gervilla Castillo, Universidad de Málaga

Enrico Gori, Universidad de Udine, Italia

Suzy Harris, University of Roehampton (UK)

Fuensanta Hernández Pina, Universidad de Murcia

José A. Ibáñez-Martín Mellado, Universidad Complutense de Madrid

Carmen Jiménez Fernández, Universidad Nacional de Educación a Distancia

Manuel Lorenzo Delgado, Universidad de Granada

Miquel Martínez Martín, Universidad de Barcelona

Roberto Óscar Páez, Universidad Nacional de Córdoba, Argentina

Miguel Pérez Ferra, Universidad de Jaén

Richard Pring, Universidad de Oxford

Claudio Rama, IESALC/UNESCO, Venezuela

Marco Antonio Rodrigues Dias, UNESCO

Jaume Sarramona i López, Universidad Autónoma de Barcelona

Bernd Schorb, Universidad de Leipzig, Alemania

Luis Sobrado Fernández, Universidad de Santiago de Compostela

Dieter Spanhel, Universidad de Nürenberg, Alemania

Marc Spoelders, Universidad de Gent, Bélgica

Juan Carlos Tedesco, IIPE, Buenos Aires, Argentina

Javier Tourón Figueroa, Universidad de Navarra

Gerhard Tulodziecki, Universidad de Paderborn, Alemania 
Amando Vega Fuentes, Universidad del País Vasco Conrad Vilanou Torrano, Universidad de Barcelona

Miguel Ángel Zabalza Beraza, Universidad de Santiago de Compostela 


\section{ÍNDICE}

\section{Estudios}

1. EL ACCESO Y LA ENTRADA DEL ESTUDIANTE A LA UNIVERSIDAD: SITUACIÓN Y PROPUESTAS DE MEJORA

FACILITADORAS DEL TRÁNSITO

(ACCESS AND STUDENT ENTRANCE TO THE

UNIVERSITY: STATUS AND IMPROVEMENT PROPOSALS

FACILITATING TRANSIT)

Mar Lorenzo Moledo

Universidad de Santiago de Compostela

Javier Argos

Universidad de Cantabria

Jesús Hernández García

Universidad de Oviedo

Julio Vera Vila

Universidad de Málaga

2. INVESTIGADORAS CON ÉXITO EN LA UNIVERSIDAD... ¿CÓMO LO HAN LOGRADO?

(SUCCESSFUL WOMEN RESEARCHERS AT THE

UNIVERSITY... HOW HAVE THEY COME TO ACHIEVE IT?)

Mar Duran-Bellonch

Georgeta Ion

Universidad Autónoma de Barcelona

3. VALORACIONES DE LOS ESTUDIANTES DE CIENCIAS DE LA EDUCACIÓN SOBRE LA CALIDAD DE LA DOCENCIA UNIVERSITARIA

(ASSESSMENT OF STUDENTS STUDYING EDUCATIONAL SCIENCIES IN RESPECT THE QUALITY OF UNIVERSITY TEACHING)

Ángel De-Juanas Oliva

Universidad Nacional de Educación a Distancia 
Jesús A. Beltrán Llera

Universidad Complutense de Madrid

$59-82$

4. APROXIMACIÓN A LAS REPRESENTACIONES Y

CREENCIAS DEL ALUMNADO DE MAGISTERIO SOBRE

LOS ESTILOS DE ENSEÑANZA.

(APPROACH TO REPRESENTATIONS AND BELIEFS OF

STUDENTS OF THE TEACHER TRAINING DEGREE IN

RELATION TO TEACHING STYLES)

Margarita González-Peiteado

Universidad Nacional de Educación a Distancia

Margarita Pino-Juste

Universidad de Vigo

$83-110$

5. FORMACIÓN DEL PROFESORADO UNIVERSITARIO

EN TIC. APLICACIÓN DEL MÉTODO DELPHI PARA LA

SELECCIÓN DE LOS CONTENIDOS FORMATIVOS

(UNIVERSITY TEACHER TRAINING IN ICT. APPLICATION

OF DELPHI METHOD FOR THE SELECTION OF TRAINING CONTENT)

Julio Cabero Almenara

Universidad de Sevilla

6. LA SOSTENIBILIDAD EN LA FORMACIÓN

UNIVERSITARIA: DESAFÍOS Y OPORTUNIDADES

(SUSTAINABILITY IN HIGHER EDUCATION: CHALLENGES AND OPPORTUNITIES)

Pilar Aznar Minguet, M. ${ }^{a}$ Angels Ull, Albert Piñero y M. Pilar

Martínez-Agut

Universitat de Valencia

$133-158$

7. LAS OPORTUNIDADES DE LAS ACADÉMICAS EN EL

DESARROLLO PROFESIONAL DOCENTE UNIVERSITARIO:

UN ESTUDIO CUALITATIVO

(THE OPPORTUNITIES FOR WOMEN IN PROFESSIONAL

ACADEMIC DEVELOPMENT: A QUALITATIVE RESEARCH)

Inés Lozano Cabezas, Marcos Jesús Iglesias Martínez

y María Ángeles Martínez Ruiz

Universidad de Alicante

$159-182$ 
8. LA CESIÓN DE RESPONSABILIDAD EN LA EVALUACIÓN:

UNA ESTRATEGIA ADAPTADA AL ESPACIO EUROPEO DE EDUCACIÓN SUPERIOR (ASSIGNMENT OF RESPONSIBILITY IN EVALUATION: A STRATEGY ADAPTED TO THE EUROPEAN HIGHER EDUCATION AREA)

Juan Antonio Moreno-Murcia, Adolfo Aracil y Raúl Reina Universidad Miguel Hernández de Elche

9. LA OBSERVACIÓN COMO ESTRATEGIA DE INVESTIGACIÓN PARA CONSTRUIR CONTEXTOS DE APRENDIZAJE Y FOMENTAR PROCESOS PARTICIPATIVOS (OBSERVATION AS A RESEARCH STRATEGY FOR BUILDING LEARNING CONTEXT AND ENCOURAGING PARTICIPATORY PROCESSES)

Itziar Rekalde, Maria Teresa Vizcarra, Ana María Macazaga

Universidad del País Vasco $201-220$

10. COACHING EDUCATIVO: MODELO PARA EL DESARROLLO DE COMPETENCIAS INTRA E INTERPERSONALES (EDUCATIONAL COACHING: A MODEL FOR THE DEVELOPMENT OF INTRA AND INTERPERSONAL SKILLS)

Beatriz Sánchez Mirón y Julia Boronat Mundina

Universidad de Valladolid

11.LA ESCUELA 2.0: REFLEXIONES EN TORNO A SU

EFICACIA EN LOS CENTROS EDUCATIVOS DE LA RIOJA (SCHOOL 2.0: TEACHERS' PERCEPTION TOWARDS ITS EFFICACY IN LA RIOJAS' SCHOOLS)

Raúl Santiago Campión y Fermín Navaridas Nalda

Universidad de La Rioja

Charo Repáraz Abaitua

Universidad de Navarra

12.ANÁLISIS DEL USO DE CUESTIONARIOS

EN CONTABILIDAD FINANCIERA

(USING QUESTIONNAIRES IN FINANCIAL ACCOUNTING)

Carmen Pilar Martí Ballester y Neus Orgaz Guerrero

Universitat Autònoma de Barcelona

$271-290$ 
13. LA RELACIÓN EDUCATIVA CON MUJERES EN CONTEXTOS DE PROSTITUCIÓN: LA DIMENSIÓN PEDAGÓGICA DE LA INTERVENCIÓN (THE EDUCATIONAL RELATIONSHIP WITH WOMEN IN PROSTITUTION CONTEXTS: THE PEDAGOGICAL DIMENSION OF THE INTERVENTION) Ana Ayuste González y Montserrat Payá Sánchez Universidad de Barcelona $291-308$

14.EL PROCESO DE COMPRENSIÓN EN UNA LENGUA EXTRANJERA: UNA PROPUESTA PARA EVALUAR ESTRATEGIAS DE LECTURA. (THE READING COMPREHENSION PROCESS IN A FOREIGN LANGUAGE: A PROPOSAL TO EVALUATE READING STRATEGIES)

Eugenio Hidalgo Diez

Universidad de Granada Mirtha Manzano Díaz

Universidad de Ciego de Ávila, Cuba $309-326$

15.LOS PROGRAMAS DE ENSEÑANZA PRIMARIA DE 1938. UN CURRÍCULO (INÉDITO) PARA LA ESCUELA DEL NUEVO ESTADO (1938 PRIMARY EDUCATION PROGRAMS. AN (UNPUBLISHED) CURRICULUM FOR THE NEW STATE SCHOOL) José Ramón López Bausela Universidad de Cantabria

16.LA EVALUACIÓN DEL ALUMNADO NORMALISTA CORDOBÉS EN EL PRIMER TERCIO DEL SIGLO XX. INVESTIGACIÓN BASADA EN UNA METODOLOGÍA CUANTITATIVA (THE EVALUATION OF THE TEACHER TRAINING SCHOOLS STUDENTS 'OF CORDOBA IN THE FIRST THIRD OF THE XXTH CENTURY. RESEARCH BASED ON A QUANTITATIVE METHODOLOGY) Antonia Ramírez García Universidad de Córdoba $345-366$

\section{Recensiones}




\section{Editorial}

Comenzamos un nuevo año, un momento oportuno para plantear nuevos objetivos o para revisar la marcha y la situación de nuestros proyectos. No es ninguna novedad destacar que la Universidad continúa sumida en grandes cambios en todos los órdenes. Y, como no podía ser de otra forma, la investigación, dentro del ámbito universitario, también se ha visto afectada, positivamente, por nuevas exigencias, formas de trabajar y la necesidad de abrirse a la sociedad, a otros grupos... A la vez que se le exige el logro de resultados, que deben ser expuestos a la comunidad científica y a la sociedad lo antes posible.

Dentro de este mundo de la investigación, y como clara consecuencia de ésta, están —estarnos- las revistas científicas, que hemos experimentado, en muy poco tiempo, una nueva forma de trabajar y de editar. En este primer número de 2014, veo de gran interés mencionar un reciente informe de Baiget y Torres-Salinas (2013) sobre cómo publicar, en estos momentos tema estrella en encuentros científicos, en jornadas de formación para el profesorado universitario, etc. Resulta lógico querer publicar, ya que no hay duda, indican estos autores, que «es deber ético de los investigadores comunicar sus investigaciones, y hacerlo de la forma más eficaz para que su mensaje llegue al mayor público de su ámbito científico posible. Junto a este inexcusable deber moral, se asienta la otra gran justificación de la publicación en medios de alta circulación: el reconocimiento por parte de los pares, y la promoción académica en las instituciones de investigación» (p. 8).

Ahora bien, el tema que queremos destacar en esta ocasión no es la relevancia del valor social de la transmisión de conocimiento, sino la presión a la que estamos siendo sometidos por publicar. En esta línea, la publicación en determinadas revistas científicas se ha transformado en el valor indiscutible del mérito académico, convirtiéndose en la llave de gran parte de las opciones científicas y académicas del profesorado universitario. «La publicación científica ha entrado en una situación de ser una lucha con una feroz competición: los investigadores batallan para acumular puntos a partir de sus publicaciones en revistas arbitradas, a veces y por desgracia contando más en términos de números que de calidad» (Baiget y TorresSalinas. 2013, 50).

Ante esta presión por publicar, los equipos editoriales nos estamos enfrentando a una serie de situaciones a lo largo del proceso editorial que 
ponen en entredicho la dimensión ética de nuestros autores-investigadores. Por supuesto que hay otros problemas éticos y malas prácticas, pero en este momento queremos hacer notar estas situaciones que debernos afrontar, ya que se están presentando con una frecuencia preocupante. Nos referimos principalmente a:

- La duplicidad total o parcial de versiones de los mismos resultados de una investigación.

- El plagio.

— El envío simultáneo de un original a 2 revistas.

- La presentación como artículo de la comunicación ya incluida en las actas de un Congreso. blicables mínimas.

— La falta de honestidad en la bibliografía aportada.

— La falta de honestidad en la autoría.

Si en el ámbito de las Ciencias y de las Ciencias de la Salud encontramos ya numerosos Códigos Éticos de las Publicaciones Científicas. Buenas Prácticas. Códigos Éticos de la Investigación, etc., en el campo de las Ciencias Sociales, y en especial, en la Educación, estos códigos no son tan comunes ni conocidos. No planteo aquí el que se elabore un Código Ético para las publicaciones científicas de nuestra área. Este sería otro tema. Sino llamar la atención ante estas prácticas que, al final, dañan a la investigación educativa, a los profesionales que trabajan, trabajamos, en este ámbito y a nuestras publicaciones. «El incumplimiento de las normas éticas - va sea debido a ignorancia, al engaño intencional inducido por un deseo de obtener ganancias comerciales o avances académicos, o por la indiferencia mostrada ante la importancia de la ética en la publicación-corroe nuestra confianza en la ciencia y en la sociedad» (Baiget y Torres-Salinas, 2013, 50).

El trabajo de un Equipo Editorial no está en intentar descubrir, por encima de sus otros objetivos, estas malas prácticas, sino en poner todos los recursos disponibles para que el proceso editorial, y en el delicado proceso de revisión de los originales, se lleve a cabo de la mejor forma posible, atendiendo a criterios de calidad. Entrar en la cultura de la sospecha daña y perjudica a toda la comunidad científica. De ahí la relevancia de tratar y debatir estos temas, darlos a conocer, desarrollarlos de acuerdo a las deman- 
das, recursos y situaciones a las que nos enfrentamos día a día, etc. En esta línea Educación $X X 1$, se ha sumado al Código aprobado por el Committe on Publication Ethics-COPE y ha propuesto, dentro de su estructura, un Comité de Ética que vele por la conducta ética y las buenas prácticas tanto de editores, revisores, como de los autores. Son temas tan importantes que no pueden dejarse en aras de la buena voluntad, sino de la profesionalización y que deben ser exigidos cuando se detecta una mala conducta.

Esperamos que esta propuesta ayude a sensibilizar y crear una cultura ética en torno a la publicación científica, tanto por parte de los autores, como de los editores y revisores, lo que redundará, sin duda, en beneficio de nuestras propias investigaciones. La transparencia actúa siempre en beneficio de todos y en este caso, de la educación y de sus profesionales. Y, en especial, de la Universidad como institución que continúa siendo garante de la ciencia.

Por último, recordar en este editorial al profesor Dr. Julio Ruiz Berrio, Catedrático de Historia de la Educación de la Universidad Complutense. Colaboró con Educación XX1 desde los inicios de su andadura, y siempre nos mostró su buen hacer, su saber y, sobre todo, su sabe: ser. Sin duda, permanecerá en la memoria de todos. Desde aquí nuestra gratitud.

\section{Marta Ruiz Corbella Editora}

BAIguet, T. y ToRREs-Salinas, D. (2013) Informe APEI sobre Publicación en revistas científicas. Gijón: Asociación Profesional de Especialistas en Información. Recuperado de http://www. udg.edu/Portals/160/docs/centre_redaccio/Informe_APEI_Baiget.pdf 


\section{Estudios}


EL ACCESO Y LA ENTRADA DEL ESTUDIANTE A LA UNIVERSIDAD: SITUACIÓN Y PROPUESTAS DE MEJORA FACILITADORAS DEL TRÁNSITO

\author{
(ACCESS AND STUDENT ENTRANCE TO UNIVERSITY: STATUS AND \\ IMPROVEMENT PROPOSALS FACILITATING TRANSIT)
}

\author{
Mar Lorenzo Moledo \\ Universidad de Santiago de Compostela \\ Javier Argos \\ Universidad de Cantabria \\ Jesús Hernández García \\ Universidad de Oviedo \\ Julio Vera Vila \\ Universidad de Málaga
}

DOI: 10.5944/educxx1.17.1.9951

\begin{abstract}
Cómo referenciar este artículo/How to reference this article:
Lorenzo Moledo, M.; Argos, J.; Hernández García, J. y Vera Vila, J. (2014). El acceso y la entrada del estudiante a la universidad: Situación y propuestas de mejora facilitadoras del tránsito. Educación XX1, 17 (1), 17-38. doi: 10.5944/educxx1.17.1.9951.

Lorenzo Moledo, M.; Argos, J.; Hernández García, J. y Vera Vila, J. (2014). Access and student entrance to University: Status and improvement proposals facilitating transit. Educación XX1, 17 (1), 17-38. doi: 10.5944/educxx1.17.1.9951.
\end{abstract}

\title{
RESUMEN
}

En este artículo, se estudian y analizan dos aspectos clave que pueden modular la trayectoria académica del alumnado universitario. En primer lugar, se aborda el ingreso en la Universidad, con sus diversas vías, posibilidades y límites, planteando la efectividad del proceso actual y considerando de modo especial las funciones, y su cumplimiento o no, que tradicionalmente se vienen señalando a la correspondiente prueba de acceso desde el Bachillerato: homologar conocimientos, estimar la madurez del alumnado, evaluar externamente el sistema, predecir el «éxito» de los estudios universitarios y ubicar a alumnos y alumnas en las distintas titulaciones. En segundo lugar, se plantea la entrada en el escenario universitario; un singular y relevante proceso de transición en el que es fundamental la conexión e interrelación de la institución superior con los estudios secundarios postobligatorios y que ha de centrarse en dos aspectos esenciales: el valor de las competencias en el proceso formativo y la adopción de una perspectiva integral e integradora en la forma de entender al alumnado universitario. Se concluye señalando algu- 
nas propuestas que creemos pueden ayudar a generar, favorecer y mejorar los procesos de acceso y de transición de los estudiantes a la etapa universitaria.

\section{ABSTRACT}

This article analyses two key issues that may modulate the academic career of a university student. In the first place, we study the issue of the university access, with its implications regarding pathways, possibilities and limits. We raise the issue of the effectiveness of the current process, especially considering the functions traditionally assigned to the entrance exam from secondary education: the match of knowledge, the valuation of the student maturity, external assessment system, the prediction of the success of the university studies, and the placement of students at different degrees. Secondly, we approach the issue of the entrance into the university scene, a singular and important transition procedure where the connection between this institution and postcompulsory secondary education is vital. This issue is specially focused on two important points: competence's values in the formative progress and the adoption of a whole and comprehensive perspective to understand university student. To conclude, we note some proposals that, from our point of view, may help to create, promote and improve the processes of access and transition of students to university level.

\section{INTRODUCCIÓN}

Sin lugar a dudas, la trayectoria universitaria de los miles de alumnos y alumnas que año tras año acuden a la Universidad va a estar, en buena medida, definida por dos procesos: las posibilidades de acceso a la Universidad y, más en concreto, a los estudios con los que han soñado, y por la entrada, la acogida, el asesoramiento y la guía que va a tener cada estudiante a lo largo de su periplo formativo en la minerva universitaria.

El itinerario universitario debe comenzar por la superación de toda una serie de requisitos institucionales que tienen que ver con el número de plazas disponibles y con la nota de acceso exigida; pero, una vez dentro, asentado ya en una titulación concreta, el alumno universitario tiene que enfrentarse a nuevos retos ante los que muchas veces se encuentra solo y que pueden determinar su éxito académico.

Justamente, en este artículo nos proponemos analizar estos dos aspectos profundizando en las cuestiones clave de cada uno de ellos.

\section{EL ACCESO DE LOS ESTUDIANTES A LA UNIVERSIDAD: VÍAS, POSIBILIDADES, LÍMITES}

El RD 1892/2008 que regula el acceso a la Universidad, además de lo señalado para estudiantes extranjeros, contempla tres vías: con el título de 
Bachillerato, con los títulos de Técnico Superior y Técnico Deportivo Superior, y según la edad y la experiencia profesional.

Antes de considerar brevemente estos tres caminos, centrándonos primordialmente en el primero, habríamos de precisar algunos matices semánticos sobre los términos «acceso»y «admisión». El primero implica la posibilidad de ingresar en alguna de las carreras universitarias mediante una de las vías señaladas. "Admisión», en la pragmática del discurso académico-administrativo en que nos movemos, entraña también la prerrogativa de las universidades para que un alumno pueda realizar determinados estudios con límite de plazas; para seleccionar, en suma, al alumnado cuando se produzca lo que ahora eufemísticamente se denomina «procedimiento de concurrencia competitiva»: «númerus clausus».

\section{Bachillerato y acceso a la Universidad}

El acceso a la Universidad desde el Bachillerato, como procedimiento más significativo y de mayor relevancia académica y social, desde el curso 2009-2010, viene determinado por una nueva prueba que, además de buscar adaptarse al contexto socioeconómico, pretende también hacerlo al nuevo contexto académico: adecuarse al reciente Bachillerato y responder, asimismo, a los estudios de Grado y su adscripción a las ramas de conocimiento (RD 1393/2007): Artes y Humanidades, Ciencias, Ciencias de la Salud, Ciencias Sociales y Jurídicas, Ingeniería y Arquitectura.

Sin pretender describir la nueva prueba, sí al menos queremos señalar que, respecto de la anterior, quizás gane en flexibilidad, aunque también en complejidad y complicación, pero nunca en exigencia; al menos para la gran mayoría del alumnado, que puede optar por examinarse sólo de la «fase general», para acceder a estudios sin límite de plazas; y no de la «específica», necesaria para poder ser admitido en las enseñanzas con «númerus clausus».

Tradicionalmente, a la hora de justificar la necesidad de una prueba de acceso, al tiempo que criticado el cumplimiento o no de los objetivos pretendidos (Martínez Bisbal y Guardiola, 2001), se han esgrimido razones diversas. Dicho de otro modo: a la prueba de selectividad, suelen atribuírsele varias funciones. Baste recordar cómo el Senado (1997, p. 7), tras la comparecencia de diversas personalidades, señala que ha de lograr tres objetivos: homologar y certificar —entendemos que en el sentido de «confirmar», "validar»- los conocimientos adquiridos en la Educación Secundaria, evaluar la madurez del alumnado y ubicarlo adecuadamente; cómo el propio RD de acceso insiste en la valoración de la madurez de los estudiantes y de su 
capacidad para seguir con éxito las enseñanzas universitarias; o cómo el Consejo Escolar del Estado (2009) señala que esta prueba ha servido tanto de evaluación externa del sistema como para ordenar a los alumnos y darles prioridad en la elección de estudios.

Al hilo de ello, al tiempo que plantear diversos interrogantes, podríamos preguntarnos también si en verdad la prueba de acceso cumple con estas funciones:

- ¿Sirve para, en un sentido amplio, homologar y certificar los conocimientos adquiridos en Secundaria? Si nos atenemos a los datos de la Secretaría General de Universidades (2012), en los últimos cursos la tasa de aprobados en España supera el 80\%; llegando en el año 2011 al 86\%, 91,8\% en la fase general celebrada en la convocatoria de junio. Con estas cifras, los conocimientos quedan sin duda homologados. Ahora bien, $\dot{c}$ sucede, entonces, que no estaban suficiente y válidamente evaluados por el profesorado de Educación Secundaria? ¿Ha la Universidad de ratificar, o de rectificar, mediante una prueba de uno o dos días, y en la que no se atiende a todas las materias, la evaluación realizada en el nivel educativo inferior durante varios cursos y de modo singular en 2..$^{\circ}$ de Bachillerato? Es más: ¿pueden entrar en conflicto ambas consideraciones?

- ¿Sirve para evaluar la madurez? Lo primero que debería hacerse sería acordar qué entendemos y qué medida puede tener la madurez; porque a menudo los términos, de tan manidos, se prostituyen y se escapan por muchas rendijas semánticas. No olvidemos, empero, cómo esta prueba fue conocida como "prueba de madurez». En todo caso, si es necesario estimarla, ¿significa que el Bachillerato quizás no ha cumplido con la finalidad de proporcionar a los estudiantes «madurez intelectual y humana», como veíamos señalar en el RD correspondiente? O por decirlo con palabras de antes: ¿sucede, entonces, que la madurez no estaba suficientemente conseguida gracias al profesorado de Secundaria? ¿Ha la Universidad de ratificar, o de rectificar, pues, la consecución o no de una finalidad propia del Bachillerato?

- ¿Sirve para la evaluación externa del sistema, para «contrastar las calificaciones obtenidas por los alumnos y la consecución de los objetivos de aprendizaje»? (Muñoz-Repiso y otros, 1997, p. 16). Hoy, en todo caso, es la única evaluación externa existente; pero ¿podemos entenderla válida para tal evaluación? ¿Va más allá de acreditar externamente la Secundaria postobligatoria y de servir, quizás, para homologar centros, públicos y privados? 
- ¿Sirve como valoración de la capacidad del alumnado para seguir con éxito enseñanzas universitarias? Volviendo a las andadas, ¿no es también finalidad del Bachillerato capacitar «para acceder a la educación superior»? ¿Ha, entonces, la Universidad de «re-capacitar» sobre la consecución de una finalidad del Bachillerato? Es más, si se pretende valorar tal capacidad, ¿entraña, entonces, la prueba valor predictivo, validez predictiva? En este sentido, los estudios han sido varios y distintos (Boal y otros, 2008; Escudero, 1997; Gaviria, 2005; Marcenaro y Navarro, 2007), y distintas y varias sus estimaciones según lleguen a una u otra correlación; según se correlacione con la parte común o la específica; según las titulaciones, y hasta las materias, consideradas; según se analice la equiparación entre expediente y prueba; según se estime o no sólo el primer año de carrera; según se valore el conocimiento en determinadas disciplinas; según las distintas universidades, etc. La conclusión es que, sin que deje de haber ciertas tendencias de que el rendimiento previo pueda avalar en parte el inmediato, las conclusiones son dispares.

- Por último, ¿sirve para ubicar adecuadamente al alumnado, ordenarlo y darle prioridad en la elección? No sabemos si su ubicación será o no adecuada, pero la función de ubicarlo y de ordenarlo se cumple tajantemente, por cuanto deriva a unos a la carrera deseada si ésta no tiene límite de admisión; a buscar a otros distintas opciones si la carrera sí lo tiene y su calificación es insuficiente; y, sobre todo, encamina a algunos a los estudios buscados si se acota su entrada - especialmente en Ciencias de la Salud-y se alcanza la nota exigida. Tal ordenación, al menos en el segundo caso, puede producir efectos no deseados en la medida en que diversos alumnos no admitidos en ciertas titulaciones desembocan con expectativas a la baja en estudios distintos a los previstos.

Dicho esto, si de todas las funciones señaladas sólo se cumple de manera efectiva la última, ¿no sería menos oneroso y quizás más adecuado plantear un acceso universal desde el Bachillerato y hacer sólo una prueba específica para ingresar en estudios con límite de plazas? Otra cuestión sería el modo de llevarla a cabo de modo justo y equitativo.

Y planteando la situación a la inversa: en estos momentos en que abundan las quejas sobre la disminución o inadecuación de conocimientos con que llegan los estudiantes al primer año de carrera - no olvidemos los «cursos cero»-, además de instar a una mayor coordinación UniversidadBachillerato, ¿no sería conveniente no sólo no devaluar la prueba, sino elevar su nivel de exigencia para elevar también el nivel universitario? Entre otras 
cosas, porque algo no ha funcionado cuando siguen sonando a hoy estas palabras de hace catorce años: «Los profesores de Secundaria tienen que velar porque se respeten los objetivos formativos del Bachillerato y se vean reflejados en la prueba. Los profesores de Universidad han de hacer un esfuerzo por explicitar sus demandas en cuanto a las capacidades básicas que deben poseer los alumnos para poder seguir con éxito estudios superiores, y juntos deberían reflexionar sobre las aptitudes y conocimientos adecuados para cursar los distintos tipos de carreras» (Muñoz-Repiso y otros, 1997, p. 16).

Y en último término, ¿cómo conciliar el derecho a la educación, la igualdad de oportunidades, la necesidad de selección, la de exigencia académica y las necesidades de titulados superiores que, desde una perspectiva social, laboral y económica, requiere el país en las distintas ramas del saber?

Para la reflexión, quizás nos pueda servir también de referencia aproximarnos sucintamente a lo que sucede en otros países de nuestro entorno geográfico y sociopolítico más inmediato, preguntándonos cómo es el acceso a la Universidad desde la educación intermedia en la Unión Europea.

En su conjunto, existen en Europa diversos sistemas y procedimientos de acceso a la Universidad, "cada uno de los cuales - como señala Valle (2008, p. 129-130) - puede esconder detrás concepciones distintas de la cuestión de la selección y, por ende, formas diversas de entender la posición del acceso a la Universidad en el binomio "Derecho a la educación""Igualdad de oportunidades"».

El mismo autor, a renglón seguido, buscando encontrar, no obstante, elementos comunes, y considerando no únicamente países europeos, plantea, tres modelos generales de acceso:

- De «sistema abierto», caracterizado, entre otros aspectos, por permitir que todos cuantos estén capacitados para seguir una carrera universitaria la cursen, y por respetar, por tanto, la libertad individual de elegir libremente los estudios. Además del gasto educativo, uno de los problemas de este modelo deriva de poder encontrarse con un número excesivo de titulados respecto de las necesidades del sistema productivo.

- De «sistema cerrado», en el que no todos los que están capacitados para seguir estudios universitarios pueden hacerlo, debido a una selección rigurosa para fijar un número de aspirantes semejante al número de titulados requerido por el sistema productivo. Pese a las ventajas del «ajuste» y del ahorro, se duda de que este modelo respete el «derecho a la educación». 
- De «sistema entreabierto», que busca aprovechar las ventajas de los dos anteriores (derecho a la educación sin desajuste entre titulados y necesidades socio-laborales), y en el que el límite de entrada, planteado no sólo en función del sistema productivo, se lleva a cabo especialmente en aquellos estudios en los que existe una fuerte demanda o de los que la sociedad precisa un número pequeño de titulados.

En Europa, la mayoría de los países, al igual que ocurre también en gran parte de las naciones occidentales, opta preferentemente por el modelo mixto; bien es cierto que con diferencias significativas en diversos aspectos, tanto en lo que atañe a los procedimientos de acceso general como a los de selección para ingresar en una Universidad determinada o en un determinado centro.

Creemos que éste es también el modelo más acorde para conjugar en lo posible las variables más importantes que forman parte intrínseca del proceso mismo y a las que ya aludíamos líneas atrás: derecho a la educación, igualdad de oportunidades, necesidad de selección, exigencia académica, necesidad de titulados superiores, etc. Ahora bien, ¿cómo llevarla a cabo?

Si, como planteábamos con anterioridad, la única función que en verdad parece cumplir la prueba de acceso en nuestro país es la de seleccionar al alumnado para determinadas titulaciones, si todas las demás funciones pueden quedar claramente en entredicho, si el Bachillerato logra en realidad los objetivos y finalidades que se consideran, si con la nueva prueba de acceso el alumnado que no aspire a entrar en ciertos Grados con límite de plazas puede optar por examinarse sólo de la fase general, si ésta es en realidad escasamente exigente, escasamente discriminatoria y de poco valor académico, si... si... si..., ¿no sería preferible en todos los sentidos (académico, social, económico, incluso personal) inclinarse por hacer una prueba de acceso sólo para aquellos alumnos que se decidieran por una titulación con númerus clausus? Todo ello siempre y cuando, por una parte, se cumplieran realmente los objetivos y finalidades del Bachillerato (muy supeditado hoy en día su 2. ${ }^{\circ}$ curso en todos los órdenes por la propia prueba de acceso); hubiera, en consecuencia, por otra, una coordinación efectiva y provechosa entre el Bachillerato y la Universidad (a menudo dos cercanos desconocidos); y, finalmente, se establecieran con verdadero y justo criterio los «números clausus», uno de los tres condicionantes del itinerario de Secundaria a los que aludiremos brevemente a continuación para concluir con el paso desde el Bachillerato a los estudios universitarios.

Efectivamente, además de todo lo mencionado, entendemos que existen, asimismo, tres aspectos significativos que pueden influir en el alum- 
nado y condicionar su propio acceso a la Universidad. En primer lugar, la modalidad y materias de Bachillerato elegidas canalizan ya rígidamente a unos estudios determinados (Orden EDU/1434/2009). El problema surge por el coste que supone para un alumno el tránsito si, en $2 .^{\circ}$ de Bachillerato, decide cambiar de modalidad o de itinerario dentro de una misma modalidad. En el primer caso, habrá de cursar las asignaturas propias de $1 .^{\circ}$ de su nueva modalidad. En el segundo, si, por ejemplo, un estudiante del Bachillerato de Ciencia y Tecnología ha cursado Física, Matemáticas y Dibujo Técnico porque había decidido realizar alguna ingeniería y ahora desea inclinarse por el itinerario biosanitario, eligiendo, entre otras materias, Biología, habrá de cursar también Biología de 1. ${ }^{\circ}$, por ser de «contenido progresivo». Todo ello cuando muchos alumnos muestran un "sentimiento de incertidumbre» al tener que tomar una decisión que puede marcar el curso de sus vidas (Santana y Feliciano, 2009).

Otro condicionante, como hemos venido señalando, es el «númerus clausus» de algunos estudios, en los que quizás no sea admitido el alumno pese a haber cursado la modalidad y las materias adecuadas, y conseguido incluso buenas calificaciones en Bachillerato y en la prueba de acceso. Para justificar el límite de admisión, se suelen esgrimir tres razones: necesidad de planificación, necesidad de exigencia e imposibilidad de acoger más alumnos por determinadas carencias (infraestructura, alto coste...). Hoy en día, creemos que es esta última causa la única que se estima. Si no es así, ¿cómo se justifica que estudios de alta exigencia no tengan «númerus clausus»?

Finalmente, hemos de considerar cómo realizar una carrera universitaria, además de un bien de consumo, se concibe hoy en nuestra sociedad como un bien que ofrece ventajas en el devenir vital y laboral de las personas (Salas y Martín-Cobos, 2006), y así lo entiende gran parte de los padres y del alumnado; pero ¿realmente es siempre la Universidad la mejor opción para alcanzar una cualificación y un título profesional, y también para conseguir un buen empleo? ¿Cabe, y más en nuestros días, que muchos estudiantes puedan considerar en mayor medida la opción de la FP? De acuerdo con la $\operatorname{OCDE}(2009$, p. 17), entre 2001 y 2007, al tiempo que en nuestro país ha ido disminuyendo la tasa de ingreso en la Universidad, ha aumentado el número de quienes han optado por un CFGS (Ciclo Formativo de Grado Superior). A pesar de ello, quizás por el estigma social y académico que aún sufre en España la FP, la tasa de titulados superiores en cualquiera de sus ramas sigue siendo menor que en Europa, mientras que la de universitarios en muchos casos muestra incluso ventaja porcentual. Y aunque también es cierto que la opción universitaria parece tener mayor rendimiento salarial (Consejo Económico y Social, 2009, p. 261), quizás sería necesario potenciar más la FP superior entre el alumnado como una opción de gran valor; en 
mayor medida cuando, en la relación sistema educativo-sistema productivo, la FP superior »en nuestro país ha ofrecido en los últimos años resultados muy positivos en relación a las posibilidades de empleo para los que la han cursado con éxito « (FE de CCOO, 2009, 16), y cuando cada vez son más los estudios que, respecto de los titulados universitarios, aluden a la «sobrecualificación» o «sobreeducación» (Budría y Moro-Egido, 2009; Consejo Económico y Social, 2009; Gobernado, 2009; Rahona, 2008; Salas, 2004): al desempeño por parte de la población más cualificada de ocupaciones por debajo del nivel de formación adquirido.

Todo ello, considerando, asimismo, que aquellos estudiantes de un CFGS que estuvieran verdaderamente interesados en acceder luego a la Universidad podrían también hacerlo una vez concluidos sus estudios.

\section{Técnicos Superiores y acceso a la Universidad}

Efectivamente, según el RD de acceso de 2008, podrán también iniciar enseñanzas universitarias quienes hayan conseguido los títulos de Técnico Superior de Formación Profesional, Técnico Superior de Artes Plásticas y Diseño, y Técnico Deportivo Superior. En este RD de 2008, esta modalidad de ingreso conllevaba, en principio, cuatro características (alguna anulada o cambiada por el RD 558/2010, por el que se modifica el RD 1892/2008):

- No requerir prueba de acceso.

- Frente a la norma anterior, ser éste universal en estudios sin límite de admisión.

- En enseñanzas con "númerus clausus», poder ingresar sólo en algunas de las ramas de conocimiento de los estudios universitarios, acordes con el título y la modalidad poseídos (Orden EDU/1434/2009).

- En este supuesto, "competir» por el mismo «cupo» con el alumnado de Bachillerato que, además de la «fase general» de la prueba, haya superado la «específica». Todo ello considerando lo cursado y mediante la aplicación de una complicada fórmula.

Al hilo de esto, caben al menos dos preguntas:

- Al no existir ya un «cupo» predeterminado, en aquellos estudios con límite de plaza, de gran demanda y de difícil entrada, ¿puede esta modalidad plantearse como un camino de más largo recorrido, 
aunque con un título más entre medias, pero quizás de fin más cierto, para acceder a los estudios deseados?

- Por más que se apliquen fórmulas, por más que sus resultados se «expresen con dos cifras decimales, redondeadas a la centésima más próxima», por más que se "pondere», ¿podría realmente equipararse, homologarse, converger, la «nota de admisión» alcanzada por un alumno mediante la prueba de acceso (con su «fase específica») y el expediente de Bachillerato, con la conseguida por otro mediante la nota media del CFGS realizado y la consideración de dos calificaciones de materias cursadas, como se planteaba en el RD de 2008?

A la primera cuestión no sabríamos qué responder, aunque es muy posible que ahora puedan producirse más casos particulares. Respecto de la segunda, sin entrar en quiénes podrían beneficiarse mediante la fórmula, creemos que no era posible una equiparación: en el RD de 2008 se estaban estimando «cosas» diferentes, con lo que podría quedar resentida la «equidad» al determinar quiénes son admitidos o rechazados en esos estudios en particular; a la hora de "ordenar», por tanto, a alumnos con contextos académicos muy distintos.

Tanto es así, que el RD 558/2010 corrige ciertos «desajustes» apreciables en el acceso de esta modalidad y, manteniendo la nota media del CFGS, sustituye la estimación de dos de sus calificaciones por las dos mejores notas de admisión conseguidas en una prueba (ahora sí) específica de «un máximo de cuatro ejercicios a su elección», en la que "cada ejercicio estará relacionado con un tema del temario establecido a este efecto para cada una de las enseñanzas relativas a los títulos de Técnico Superior, Técnico Superior de Artes Plásticas y Diseño y Técnico Deportivo Superior». En todo caso, aunque mejore sin duda el procedimiento, entendemos que, habida cuenta de que se compite por el mismo "cupo», se siguen aún equiparando y estimando «situaciones diferentes».

\section{Mayores, experiencia laboral y acceso a la Universidad}

Sin duda, el acceso para «mayores» se encuadra dentro de la necesidad de incentivar la «formación permanente» $\mathrm{y}$ "a lo largo de toda la vida» que, entre diversas recomendaciones en nuestros días, busca impulsar, por ejemplo, la Comisión de las Comunidades Europeas (2001) o en 2007 recoge la Ley Orgánica 4/2007 por la que se modifica la Ley Orgánica 6/2001 de Universidades, cuando señala en su Preámbulo que las universidades «han de dar adecuada respuesta a las necesidades de formación a lo largo de toda 
la vida y abrirse a quienes, a cualquier edad, deseen acceder a su oferta cultural o educativa».

Tal empeño se traduce en España en la posibilidad de que los «mayores», mediante un porcentaje de reserva, puedan acceder gracias a tres modalidades:

- Mayores de 25 años. Mediante una prueba cuya fase específica consta de cinco opciones correspondientes a las ramas de conocimiento de los títulos de Grado. La opción da preferencia para ingresar en las enseñanzas vinculadas.

- Mayores de 40 años con experiencia laboral. Mediante la acreditación de experiencia laboral relacionada con unos estudios universitarios específicos.

- Mayores de 45 años. Mediante una sencilla prueba destinada a quienes no puedan acreditar experiencia profesional.

En estos dos últimos casos, se excluye a quienes posean una titulación que les permita acceder por otras vías. Asimismo, en ambos, puede realizarse para su acceso una entrevista personal con el candidato.

Más allá de los aspectos positivos (motivación, madurez) o negativos (carencias formativas, dificultades para el estudio, necesidad de mayor orientación, fracaso) respecto de los estudios universitarios de gran parte de este alumnado (Álvarez Rojo y otros, 2002; García Aretio, 1987; Rodríguez Gómez y Díaz, 2008), creemos que, en el contexto socioeconómico actual y próximo, su acceso se irá revalorizando progresivamente.

En todo caso, en esta vía, como hemos hecho, asimismo, en las otras dos, es posible plantearse al menos dos cuestiones en lo que a su adecuación atañe:

- En los casos de mayores de 40 y 45, ¿es equitativo dejar fuera a quienes tengan otra posibilidad de acceso por poseer un título - por ejemplo, de Bachillerato- conseguido quizás hace ya muchos años?

- ¿Puede realmente una entrevista condicionar el ingreso?

Sobre la primera cuestión, creemos que excluirlos supone discriminarlos respecto de los de su edad que no tengan título alguno que les permita incorporarse por otras vías. En relación con la segunda, depende en gran medida de en qué consista la entrevista y de cómo y de quiénes la 
hagan; de cualquier modo, con una valoración cargada siempre de humana subjetividad.

En suma, como el propio ámbito al que pertenece - la educación misma-, el acceso a la Universidad ha de estar también en crisis permanente, en su sentido prístino de cambio, de reflexión y revisión cuidadosas, con objeto siempre de ir mejorando el proceso, de ir siempre perfeccionándolo en sus varias, múltiples y diversas vertientes.

\section{LA ENTRADA DEL ESTUDIANTE EN EL ESCENARIO UNIVERSITARIO: APUNTANDO ALGUNOS REFERENTES PARA LA CONSISTENCIA FORMATIVA Y PARA LA INTEGRACIÓN AL NUEVO CONTEXTO}

La consecución de una educación de calidad pasa, a nuestro entender, por concebir los subsistemas que la conforman dentro de un sistema global e integrador que dé consistencia y sentido al proceso formativo mediante el que pretendemos educar al conjunto de ciudadanos de un determinado país.

Este presupuesto es enormemente importante incluso si lo analizamos desde el subsistema universitario. Así, como se recuerda en el informe Global University Network for Innovation (2008), la conferencia Mundial sobre la Educación Superior celebrada en París en 1998 en la que se gestó la Declaración Mundial sobre la Educación Superior en el siglo XXI propuso como una de las acciones prioritarias para la renovación y la revitalización de la educación superior la siguiente:

"La educación superior es un componente de un sistema educativo único que empieza con la educación para la primera infancia y la enseñanza primaria y continúa a lo largo de toda la vida. La contribución de la educación superior al desarrollo del conjunto del sistema educativo y a la nueva orientación de su vinculación con los demás niveles de enseñanza, y más concretamente con la enseñanza secundaria, ha de ser una prioridad.»

Obviamente, en el proceso de vertebración de ese sistema educativo global, el sistema universitario ha de prestar especial atención a la etapa de educación secundaria en cuanto que ésta se convierte en el sustrato y principal referencia a la hora de establecer los diferentes elementos conformadores de los marcos y modelos formativos universitarios. A nuestro entender, la educación secundaria y la universitaria han de verse no tanto como eslabones o componentes jerarquizados dentro de una cadena de carácter marcadamente lineal sino, fundamentalmente, como elementos que 
conforman un sistema formativo concéntrico-expansivo que requeriría, para su óptimo funcionamiento, la determinación de elementos comunes facilitadores de una necesaria continuidad formativa, no exenta de elementos de diferenciación contextual, entre los marcos institucionales en los que transitan los estudiantes.

En definitiva, las anteriores consideraciones se enmarcan dentro de una problemática de gran relevancia en el ámbito educativo como es la de la transición entre etapas educativas. Y, en concreto, la que se lleva a cabo entre el Bachillerato y la Universidad.

Para conseguir que este proceso de transición se produzca de forma armónica a la vez que consistente y fundamentada, necesitaríamos tomar en consideración algunos referentes de análisis que nos podrían ayudar a plantear focos de reflexión y de actuación a las personas e instituciones que conforman ambos subsistemas educativos.

Los dos referentes que a continuación contemplamos, aun perteneciendo a ámbitos que responden a cuestiones pedagógicas de diversa índole (una fundamentalmente teleológica y la otra de sustrato antropológico), tienen en común la globalidad o el holismo como principales elementos conformadores y que les otorgan relevancia y protagonismo. El primero de ellos serían las competencias a adquirir y/o desarrollar a lo largo del proceso formativo, mientras que el segundo tendría que ver con la perspectiva integral e integradora a adoptar en la forma de entender al estudiante universitario.

\section{Las competencias como principales referentes vertebradores entre los diferentes marcos educativos}

No deja de resultar paradójico que, moviéndonos en un contexto europeo y nacional en el que el concepto de competencia aparece como elemento supuestamente clarificador y de referencia común a la hora de establecer recomendaciones y diseños curriculares, en el caso de nuestro país, encontramos una cierta disfunción en la etapa del Bachillerato por la ausencia de alusión al aprendizaje por competencias.

Así, a diferencia de lo que ocurre tanto en la Educación Secundaria Obligatoria (RD 1631/2006), como en la Formación Profesional (RD 1538/2006) o en la Universidad (RD 1393/2007), en el RD 1467/2007, de 2 de noviembre por el que se establece la estructura del Bachillerato y se fijan sus enseñanzas mínimas, no encontramos referencia alguna a esta orientación de aprendizaje por competencias. 
Con independencia del tipo o carácter que ostenten las competencias referidas en las diferentes etapas educativas (bien sean básicas o bien vinculadas al desarrollo profesional y académico de cada ámbito de especialización universitario), parece obvia la necesidad de conformar planteamientos similares en la etapa de Bachillerato, más allá de la respuesta que en este sentido se haya podido dar desde alguna de nuestras comunidades autónomas.

Nos cuesta encontrar justificación al hecho de que, mientras que en el Decreto de enseñanzas mínimas de la ESO se entienda por currículum «el conjunto de objetivos, competencias básicas, contenidos, métodos pedagógicos y criterios de evaluación» (art. 6.1), en el art. 9 del Decreto de enseñanzas mínimas del Bachillerato se contemplen todos los elementos anteriores excepto el de las competencias.

Este «olvido» normativo, si no se subsana con desarrollos legislativos autonómicos posteriores y, fundamentalmente, con su concreción en las propuestas pedagógicas correspondientes, puede conllevar consecuencias muy negativas en el aprendizaje de los estudiantes, al generarles cierto desconcierto la alternancia de la "visibilidad» tanto textual como pragmático-funcional de los referentes competenciales en las diferentes etapas educativas por las que va transitando.

Sin la existencia de una continuidad en la orientación, enfoque o modelo por competencias a desarrollar entre esas diferentes etapas, difícilmente podremos armonizar y dar consistencia formativa a los procesos de aprendizaje de nuestros estudiantes. Un adecuado enfoque por competencias (sustentado en una interpretación abierta, integrada, holística y relacional del concepto) requeriría por parte de todas las instancias formativas implicadas una convicción asumida de los beneficios que puede comportar, más allá de miradas y planteamientos - tanto personales como institucionales- reduccionistas, desenfocados, ingenuos o interesados.

El contemplar las competencias como elementos de referencia importantes en el nuevo marco universitario demanda, necesariamente, establecer estructuras y estrategias de coordinación estables y estrechas con el nivel educativo precedente. Sólo desde una mínima definición o delimitación de una topología competencial común que ostente un marcado carácter transversal y que integre y dé sentido a la adquisición y desarrollo de otra serie de competencias más específicamente vinculadas a cada ámbito de conocimiento, será desde donde podamos construir puentes que armonicen y den consistencia a ese tránsito a la Universidad tan importante como complejo para el estudiante de nuevo acceso. 
Así, ámbitos competenciales como los relacionados con el tratamiento de la información y la competencia digital, la competencia para aprender a aprender, la competencia social y ciudadana y la vinculada con la autonomía e iniciativa personal pueden ser ejemplos de referentes de aprendizaje transversales a educar desde las primeras etapas educativas hasta la universidad y que, adecuadamente asumidas y desarrolladas por los estudiantes, otorgarán sentido y continuidad a las propuestas que en este último escenario se planteen.

Desde las anteriores constataciones se hace explícita una meta inexcusable a abordarse desde el contexto universitario: la concienciación de todas las personas e instituciones en él implicadas sobre el indudable valor que entraña un enfoque profundo de formación por competencias.

\section{La mirada global al estudiante universitario como prerrequisito para su adecuada formación}

Uno de los principios pedagógicos que ha ostentado un carácter relevante en la mayoría de los planteamientos y teorías educativas surgidas a lo largo de la historia es el que podríamos denominar de integralidad formativa. Así, desde diferentes posicionamientos y formatos pedagógicos y dando lugar a diversas acuñaciones terminológicas, este principio sostiene como axioma prioritario la necesidad de considerar a la persona, al educando, no sólo como referente primario de la educación sino, también, como alguien que conformado holísticamente requiere y demanda para su adecuada educación y desarrollo ser mirado y valorado como un ser global aglutinador de múltiples dimensiones (cognitivo-lingüística, social, motriz, efectiva, moral) que se despliegan de forma concomitante y, en muchos casos también, simultánea.

Pues bien, dicho principio tiende a desaparecer o, en el mejor de los casos, a desdibujarse, conforme nos vamos aproximando a los niveles universitarios. Así, sin excesiva dificultad podemos constatar una serie de hechos y de planteamientos pedagógicos que corroboran esta afirmación: los planteamientos integradores de diferente tipo (globalizados, interdisciplinares, transdisciplinares) van perdiendo peso; el acompañamiento tutorial se desvanece mucho más de lo que debiera como consecuencia de la madurez del alumnado; las concepciones y prácticas evaluadoras tienden a ser menos holísticas, configurándose como más parciales, superficiales, fragmentarias o especializadas... Estos ejemplos, junto con otros que podrían ubicarse en otras dimensiones curriculares, se convierten en indicadores tangibles de una tendencia que podríamos denominar fragmentadora. 
Del mismo modo que estamos asistiendo a un resurgimiento de la importancia que entraña el conjugar o integrar en la figura del docente universitario las dimensiones ontológica y epistemológica de cara a su desarrollo como formador (Dall'Alba, 2005), entendemos que también el estudiante, desde su ingreso en la institución universitaria, demanda ser mirado desde una perspectiva holística, integral y profunda que permita responder a exigencias que trasciendan a las meramente vinculadas con sus logros académicos. Ignorar y/o desvincular las esferas del conocer, actuar y ser supondría, para nosotros, simplificar la concepción de lo que tendríamos que entender por estudiante universitario y, en consecuencia, plantear modelos y estrategias formativas reduccionistas y superficiales vinculadas estrechamente con los planteamientos de carácter «tecnocrático» que, en ocasiones y por desgracia, han colonizado la formación universitaria.

Una vez que el estudiante accede al contexto universitario, necesita someterse a un proceso de aprendizaje conductual, cognitivo, y actitudinal, y para lograr una integración a ese nuevo contexto, se requiere de todo un proceso de adaptación creativa que comporta procesos de interpretación idiosincráticos de las reglas de juego definidas por la institución universitaria (Ariño y otros, 2008). Y será desde esa primera toma de contacto con este nuevo escenario cuando el «recién llegado» interprete las miradas y las expectativas que ese entorno y sus actores proyectan - manifiesta o latentemente- sobre él. Sólo cuando las expectativas y las demandas que las concretan atiendan a la perspectiva integral y profunda del estudiante será cuando estemos en disposición de abordar con ciertas dosis de éxito el desarrollo de su proceso formativo.

Y ese tipo de mirada exigente creemos que ha de suponer también la necesaria incorporación de un enfoque perspectivista que tome en consideración el punto de vista del estudiante como referente fundamental e irrenunciable de análisis, ya que, desde él, podremos acceder de forma directa y no mediada al conjunto de percepciones e interpretaciones que éste mantiene acerca del contexto universitario y de las propuestas e intercambios de todo tipo que en él se despliegan. Dentro de esta orientación metodológica encontramos diferentes trabajos empíricos que han abordando investigaciones de diverso alcance y amplitud de temáticas (Méndez, 2008; Wintre y Morgan, 2009), así como interesantes experiencias-piloto de modelos de orientación y mentoría universitaria (Manzano, Martín y Sánchez, 2012).

Hasta aquí hemos contemplado dos referentes importantes -axiomáticos, diríamos- a la hora de favorecer una adecuada transición entre el sistema universitario y las etapas educativas precedentes: las competencias en cuanto que potenciales bisagras armonizadoras de esa transición y los 
estudiantes concebidos como sujetos que requieren inexcusablemente considerarse desde la totalidad o integralidad formativa.

Ahora bien, ambas instancias o ámbitos referenciales nos han de llevar, por fuerza, a considerar y definir otros elementos no menos importantes, como los relativos a los nuevos roles a asumir por los docentes universitarios (Argos y Ezquerra, 2008) o como a todo lo relacionado con el ámbito metodológico y muy especialmente con la forma de entender el acompañamiento o la acción tutorial del estudiante.

\section{APUNTANDO ALGUNAS PROPUESTAS Y FUTURAS LÍNEAS DE ACTUACIÓN}

De las reflexiones y constataciones efectuadas a lo largo del presente trabajo, pueden desprenderse ciertas propuestas que ayuden a generar, favorecer y mejorar los procesos de acceso y de transición de los estudiantes a la etapa universitaria. Algunas de las que nos parecen más relevantes son las siguientes:

- El desarrollo de un proceso de transición armónico y fundamentado entre la Educación Secundaria y la Universidad requeriría, a nuestro entender, el establecimiento de estructuras, dinámicas y protocolos de coordinación (más allá de los meramente formales y burocráticos) que permitieran generar un marco consensuado común sobre ciertos elementos conformadores de los procesos formativos de los estudiantes.

- La dinámica a desarrollar por dichas estructuras (concretadas, por ejemplo, en grupos de trabajo o seminarios integrados por responsables y docentes de los dos ámbitos académicos) debería de ser expansiva, tratando de llegar a docentes y estudiantes, considerando sus «voces» y miradas en relación con el doble plano del ser y del deber ser de los procesos formativos en los que están inmersos.

Así, la bidireccionalidad entre el grupo de coordinación y los colectivos a los que pretenden servir, se convierte en un rasgo fundamental del proceso.

- Con independencia de lo anterior, sería positivo poder generar procesos formativos destinados a los docentes de ambas etapas, en los que se ahondara en el valor que supone un enfoque profundo en formación por competencias, y se pudiera determinar consensuada- 
mente una topología competencial común conformada por algunas competencias, ya apuntadas, de marcado carácter transversal.

- También, otra tarea que se nos antoja importante y que debería de ser objeto de diferentes dinámicas informativas y/o formativas a los docentes y estudiantes de ambas etapas sería la de valorar el principio que hemos denominado de integralidad formativa y que afecta no sólo a los estudiantes, sino también a las diferentes dimensiones (conocer, actuar, ser) a considerarse en los docentes.

\section{NOTAS}

1 Este trabajo es fruto de la Ponencia «Itinerarios de formación del estudiante universitario» presentada en el XXIX SITE celebrado en la Universidad Complutense, 2010. Disponible en http://pendientedemigracion.ucm.es/info/site/docu/29site/ponencia1.pdf. 


\section{REFERENCIAS BIBLIOGRÁFICAS}

Álvarez Rojo, V. y otros (2002). Evaluación del curso de orientación e iniciación a los estudios universitarios. Revista de Investigación Educativa, 20 (2), 411-429.

Argos, J. y Ezquerra, M.P. (2008). Los roles docentes en el nuevo escenario universitario: algunos referentes, cautelas y retos. En M. Hijano, (coord.) Las titulaciones de Educación ante el Espacio Europeo de Educación Superior. (pp. 89-102). Málaga: Aljibe.

Ariño, A. y otros (2008). El oficio de estudiar en la universidad: compromisos flexibles. Valencia: Universitat de València.

Boal, N. y otros (2008). Las habilidades matemáticas evaluadas en las pruebas de acceso a la Universidad. Un estudio en varias universidades públicas españolas. Revista de Investigación Educativa, 26 (1), 11-23.

Budría, S. y Moro-Egido, A. (2009). El fenómeno de la sobre-educación en Europa. Revista Internacional de Sociología, 67 (2), 329-345.

Comisión de las Comunidades Europeas (2001). Comunicación de la Comisión: Hacer realidad un espacio europeo del aprendizaje permanente. Bruselas: Comisión de las Comunidades Europeas.

Consejo Económico y Social de España (2009). Informe: sistema educativo $y$ capital humano. Madrid: Consejo Económico y Social de España.

Consejo Escolar del Estado (2009). Informe sobre el estado y situación del sistema educativo. Curso 2007-2008. Madrid: Ministerio de Educación.

Dall'Alba, G. (2005). Improving teaching: Enhancing ways of being university teachers. Higher Education Research \& Development, 24 (4), 361-372.
Escudero, T. (1997). Investigaciones sobre el procedimiento de selección de universitarios en España. Una revisión comentada. Revista de Educación, 314, 7-27.

FE de CCOO (2009). Los objetivos educativos 2010. Génesis, datos y valoración. La situación española. Madrid: FE de CCOO.

García Aretio, L. (1987). Rendimiento académico y abandono en la educación superior a distancia. Madrid: ICEUNED.

García Garrido, J.L. (2005). Sistemas educativos hoy. Madrid: Ediciones Académicas.

Gaviria, J.L. (2005). La equiparación del expediente de Bachillerato en el proceso de selección de alumnos para el acceso a la Universidad. Revista de Educación, 337, 351-387.

Global University Network for Innovation (2008). La Educación Superior en el mundo 3. Educación Superior: nuevos retos y roles emergentes para el desarrollo humano y social. Madrid: Mundi-Prensa.

Gobernado, R. (2009). Consecuencias sociales y culturales de la sobreeducación. Papers, 91, 81-102.

Manzano, N.; Martín, A. y Sánchez, M. (2012). El rol del mentor en un proceso de mentoría universitaria. Educación XX1, 15(2), 93-118.

Marcenaro, O. y Navarro, M. (2007). El éxito en la Universidad: una aproximación cuantílica. Revista de Economía Aplicada, 15 (44), 5-39.

Martínez Bisbal, J. y Guardiola, R. (2001). El acceso a la Universidad pública. Revista de Educación, 326, 195-224. 
Méndez, R. (2008). La universidad como agente socializador: un análisis desde las percepciones de los estudiantes. Cuadernos FHyCS-UN, 34, 151-169.

Muñoz-Repiso, M. y otros (1997). El sistema de acceso a la Universidad en España: tres estudios para aclarar el debate. Madrid: CIDE.

OCDE (2009). Panorama de la educación. Indicadores de la OCDE 2009. Informe español. Madrid: Ministerio de Educación.

Rahona, M. (2008). Un análisis del desajuste educativo en el primer empleo de los jóvenes. Principios. Estudios de Economía Política, 11, 45-67.

Rodríguez Gómez, J.M. y Díaz, J.M. (2008). Acceso a la Universidad después de los veinticinco años. Campo Abierto, 27 (2), 73-89.

Salaburu, P. (2007). La universidad en la encrucijada. Europa y EEUU. Madrid: Academia Europea de Ciencias y Artes.

Salas, M. (2004). La relación educacióneconomía: un estudio del desajuste educativo de los titulados universitarios. Revista de Educación, 334, 259-278.

Salas, M. y Martín-Cobos, M. (2006). La demanda de educación superior: un análisis macroeconómico con datos de corte transversal. Revista de Educación, 339, 637-660.

Santana, L. y Feliciano, L. (2009). Dificultades en el proceso de toma de decisiones académico-profesionales: el reto de repensar la orientación en $\mathrm{Ba}-$ chillerato. Revista de Educación, 350, 323-350.

Secretaría General de Universidades (2012). Datos básicos del sistema universitario español. Curso 2012-2013. Madrid: Ministerio de Educación, Cultura y Deporte.

Senado (1997). Texto del Informe de la Ponencia de estudio sobre la selectividad en el acceso a la Universidad, problemas actuales y propuestas de soluciones, aprobado por la Comisión de Educación y Cultura en su sesión del día 20 de noviembre de 1997, Boletín Oficial de las Cortes Generales. Senado, 347.

Valle, J.M. (2008). Hacia el pasaporte europeo universitario: armonización de los sistemas de acceso a la Universidad. En J.L. García Garrido, (ed.) Formar ciudadanos europeos. (pp. 99156). Madrid: Academia Europea de Ciencias y Artes.

Wintre, M. y Morgan, A. (2009). Transferring Post-Secondary Schools. Journal of Adolescent Research, 24 (6), 726-749. 


\section{PALABRAS CLAVE}

Universidad, acceso, competencias, estudiantes, educación secundaria

\section{KEYWORDS}

Higher Education, access, skills, college students, secondary education.

\section{PERFIL ACADÉMICO Y PROFESIONAL DE LOS AUTORES}

María del Mar Lorenzo Moledo, Profesora Titular de Universidad en la Facultad de Ciencias de la Educación de la Universidad de Santiago de Compostela. Sus líneas de investigación incluyen: Pedagogía de la Delincuencia, Educación Intercultural, y Pedagogía Familiar. Es miembro del Grupo de Investigación Esculca-USC y de la Red de Investigación RIES.

Javier Argos González, Profesor Titular de Teoría de la Educación de la Universidad de Cantabria. Ha sido decano de la Facultad de Educación y Vicepresidente del Consejo Escolar de Cantabria. Sus actuales líneas de investigación se relacionan con el estudio de los vínculos entre creencias y práctica pedagógica de los docentes y con el nuevo escenario universitario en el marco del EEES.

Jesús Hernández García, Licenciado en Pedagogía y en Filosofía y Letras. Doctor en CCEE y Profesor Titular de la Universidad de Oviedo. Entre sus ámbitos de trabajo e investigación, se encuentran la formación del profesorado, la política educativa o el pensamiento educativo del ilustrado mexicano Fernández de Lizardi; campos en los que ha publicado diversos libros y artículos.

Julio Vera Vila, Profesor Titular de Teoría de la Educación en la Facultad de Ciencias de la Educación de la Universidad de Málaga. Coordina un Máster oficial y un programa de doctorado sobre «Cambio social y profesiones educativas». Sus líneas de investigación incluyen el análisis de la función docente y la educación intercultural.

Dirección de los autores: María del Mar Lorenzo Moledo Facultad de Ciencias de la Educación

Campus Vida 15782 - Santiago de Compostela

E-mail: mdelmar.lorenzo@usc.es 
Javier Argos González

Departamento de Educación

Edificio Interfacultativo

Avda. Los Castros s/n, 39005, Santander

E-mail: argosj@unican.es

Jesús Hernández García

Facultad de Formación del Profesorado

y Educación

C/Aniceto Sela, s/n

33005, Oviedo.

E-mail: jhdzg@uniovi.es

Julio Vera Vila

Facultad de Ciencias de la Educación

Departamento de Teoría e Historia

de la Educación

Campus de Teatinos s/n. 29071 Málaga.

E-mail:juliovera@uma.es

Fecha Recepción del Artículo: 15. Abril. 2011

Fecha Modificación Artículo: 26. Septiembre. 2011

Fecha Aceptación del Artículo: 16. Noviembre. 2011

Fecha Revisión para publicación 24. Junio. 2013 


\title{
INVESTIGADORAS CON ÉXITO EN LA UNIVERSIDAD... ¿CÓMO LO HAN LOGRADO?
}

2

\section{(SUCCESSFUL WOMEN RESEARCHERS AT THE UNIVERSITY... HOW HAVE THEY COME TO ACHIEVE IT?)}

\author{
Mar Duran-Bellonch \\ Universidad Autónoma de Barcelona \\ Georgeta Ion \\ Universidad Autónoma de Barcelona
}

DOI: 10.5944/educxx1.17.1.10704

\section{Cómo referenciar este artículo/How to reference this article:}

Durán-Bellonch, M. e Ion, G. (2014). Investigadoras con éxito en la universidad... ¿Cómo lo han logrado? Educación XX1, 17 (1), 39-57. doi: 10.5944/educxx1.17.1.10704.

Durán-Bellonch, M. e Ion, G. (2014). Successful women researchers at the university... How have they done? Educación XX1, 17 (1), 39-57. doi:10.5944 /educxx1.17.1.10704.

\section{RESUMEN}

Presentamos los resultados de una investigación en la que nos preguntamos por las condiciones que influyen en el éxito de la actividad investigadora de las mujeres académicas en ciencias sociales. Consideramos que las mismas investigadoras pueden ofrecernos información valiosa al respecto, y por ello entrevistamos en profundidad a una muestra de académicas de una universidad pública catalana, todas ellas líderes de grupos de investigación reconocidos por la Generalitat de Catalunya en la actualidad. Partimos de un guión de entrevista compuesto por tres categorías teóricas: condicionantes para el éxito académico de carácter individual, condicionantes de tipo grupal y condicionantes institucionales. Los resultados validan las categorías teóricas y contribuyen a su enriquecimiento, en tanto que apuntan la existencia de una serie de subcategorías que pueden ser estudiadas en profundidad en futuras investigaciones. Destacan los siguientes factores individuales para el éxito en la carrera académica: «el amor por el saber» de quien investiga; su procedencia sociocultural; las estancias de investigación en el extranjero; la perseverancia y tenacidad; el apoyo de la familia; el respeto a los tiempos biológicos y la relación con un mentor o mentora. De entre los factores grupales aparecen: el equilibrio entre trabajo individual y grupal; la formación fruto del intercambio entre miembros del equipo de trabajo; la participación en equipo en proyectos competitivos y un estilo de liderazgo basado en la mediación y la delegación. Finalmente, de factores institucionales surgen con fuerza: la existencia de otros grupos de investigación con los que com- 
petir; la convergencia temática entre investigación y docencia; la dirección de trabajos de investigación y el soporte económico de órganos estatales y europeos.

\section{ABSTRACT}

We present the results of a research analysing the conditions that influence the successful research career of academic women in the field of the social sciences. In our research we used in-depth interview in a sample of academics pertaining to Catalan public universities, all of them leaders of research groups recognized by the Generalitat de Catalunya. The interviews were structured according to the following topics: individual conditions for academic success, group-type conditions and institutional factors.

The results validated the theoretical categories and contributed to their enrichment, while - nevertheless - pointing the existence of a number of subcategories that can be studied in depth in future research. Among the individual factors for success in academic careers participants mentioned: «the passion for knowing», the sociocultural factors, the research periods abroad, the perseverance and tenacity, the support of family, respect of biological time and the relationship with a mentor.

Among the factors linked to the group, we can highlight: the balance between individual and group work, the research experience exchange between team members, participation in competitive team projects and a leadership style based on mediation and delegation. Finally, the following institutional factors were also highlighted: the existence of other research groups with which they compete, the convergence between research and teaching activities, the coordination of research project and financial support from national and European bodies.

\section{INTRODUCCIÓN}

En las últimas décadas abundan los estudios dedicados al papel de la mujer en la universidad. Flecha (1999) expone los logros de las mujeres en Europa y España y los retos que entrando en el nuevo milenio todavía estaban por conseguir. Según la autora, los llamados «estudios de la mujer» contribuyen a repensar modelos que perpetúan la desigualdad de género en la educación superior. Aún con todo, «las mujeres no están representadas de manera igualitaria respecto a los hombres a lo largo de las categorías profesionales del sistema científico» (Bermúdez y otros, 2011, p. 17). Es la llamada segregación vertical. Los resultados obtenidos en el reciente estudio experimental de Milkman, Akinola y Chugh (2012) son sugerentes en tanto que descubren que una de las razones para dicha segregación es que los académicos tienen acceso a información que les permite planificar su carrera 
a largo plazo, mientras que las académicas y las personas pertenecientes a minorías étnicas, no tienen las mismas facilidades de acceso, lo que solamente les permite tomar decisiones sobre su carrera a corto y medio plazo.

Además, a pesar de que el número de académicas se ha venido incrementando con los años, la academia sigue considerándose elitista, masculina y patriarcal (Asmar, 1999; Pole Bornholt, y Summers, 1997; Marie y Moldovan, 2012; Seierstad, 2012; Brink y Benschop, 2012, entre otros), puesto que la asignación de funciones sigue perpetuando el modelo tradicional (Sagaria y Agans, 2006; Smeby y Try, 2005). Un ejemplo en este sentido es que las mujeres tienen más carga docente que los hombres y reciben encargos de gestión que conllevan mucho trabajo y poco poder (McLaughlin y Helsi, 2013). Ellos, en cambio, se dedican y destacan más por su actividad investigadora (Bagilhole y White, 2003) y de gestión asociada a puestos con poder (Bagilhole, 2007; Ruth, 2005; Tomàs, Duran, Guillamon y Lavié, 2008).

Guillamon (2011) estudia las condiciones que llevan a que las mujeres tengan menos productividad investigadora que los hombres. Como obstáculos indica que las mujeres tienen menos confianza en sus habilidades y menos acceso a las redes académicas (Britton, 1999; Doherty y Manfredi, 2005) y optan en mayor medida por las denominadas "ciencias blandas», como son las humanidades y las ciencias sociales. Mientras tanto, los hombres tienen más presencia en las áreas denominadas «duras» como las ciencias empíricas o las tecnológicas.

Mientras la investigación representa solo una de las facetas del trabajo académico (junto a la docencia y a las tareas de gestión), Hobson, Jones y Deane (2005) observan como en la universidad actual, la investigación se considera como el aspecto más importante. Es la época en la cual la atención se dirige hacia los indicadores de rendimiento del personal académico (Bruneau y Savage, 2002; Morley, 2003), medido sobre todo por aspectos como el número de publicaciones o el presupuesto de los proyectos, la investigación y sus resultados representan un indicador para la promoción a los niveles profesionales superiores o para obtener "ventajas» profesionales. Este criterio evaluativo resulta discriminatorio para las mujeres. Los resultados obtenidos por Metz y Harzing (2012) sobre la poca presencia de mujeres en los consejos editoriales de las llamadas revistas de prestigio, es un indicador claro del sesgo existente. También el trabajo de Duch y otros (2012), sugiere que existe correlación entre el hecho de que las mujeres publiquen menos en revistas de impacto con el hecho de que obtienen menos recursos para investigar. Teniendo en cuenta que la investigación permite la orientación de la universidad hacia el mercado y hacia la sociedad (Olssen y Peters, 2005), conseguir un nombre en un campo de investigación, se convierte en una necesidad para poder avanzar en la carrera académica. 
Los criterios de calidad aplicados para la evaluación de la trayectoria profesional responden a la lógica de las ciencias «duras» y no a la de las ciencias «blandas» (Arranz, 2004). La evaluación de la productividad en investigación y los criterios empleados se consideran otro obstáculo en el desarrollo exitoso de la carrera de las mujeres. Se añaden las exigencias derivadas de la tensión entre la vida personal y la profesional (Forster, 2000; Probert, 2005), el tiempo dedicado a la maternidad y a la familia (Donoso, 2011; Mervis, 2012; Rafnsdóttir y Heijstra; Resick, 2012; Foa, 2012) o la falta de redes de trabajo colaborativo, lo que hace que el acceso a la financiación sea difícil para las investigadoras (Brink y Benschop, 2012).

A pesar de las evidencias, la mayoría de profesoras universitarias aún tiene poca conciencia sobre las desigualdades existentes y, en consecuencia, poca motivación para procurar cumplir con los criterios establecidos para promocionar (Arranz, 2004).

Aunque pocas, también existen profesoras que han alcanzado cierto grado de reconocimiento como investigadoras en sus áreas de conocimiento. Es especialmente interesante estudiar qué condiciones se han dado para que las barreras anteriormente citadas hayan sido superadas en sus casos. Cabe mencionar que hay menos investigación dedicada al estudio de los factores de éxito que a los obstáculos en la carrera académica de las profesoras. Los que hay han servido como base para nuestro estudio, abordan: los programas de formación y la importancia que tienen en la construcción profesional y en la adquisición de capacidades investigadoras para las profesoras (Devos, 2000; Ginther y Kahn, 2006) y los programas de «mentoring» en los que las profesoras participan (Groombdridge y Worden, 2003, Higgs, 2003 y Guillarmon, 2011) Las conclusiones derivadas de la convención de la «Association for Behavioral and Cognitive Therapies», celebrada en Nueva York en 2009, recogen experiencias de mujeres que han conseguido romper el llamado «techo de cristal» existente en la institución universitaria (McGinn y Newman, 2012).

Siguiendo estos trabajos anteriormente citados, nuestro estudio ha sido diseñado para investigar los factores específicos, las estrategias, las culturas de trabajo y los condicionantes asociados al éxito profesional de las mujeres investigadoras. En este planteamiento nos hemos guiado por las observaciones de Fox y Colatrella (2006, p. 377) que apuntan:

"Women's participation, performance and advancement are not a simple function of their individual characteristics, such as prestige of doctoral origins, training or skills. Rather their participation and attainments also reflect and are affected by features of organizational contexts in which they work including work climates and cultures, work structures, evaluative practices and reward patterns, among other factors.» 
Este artículo ofrece un punto de partida para estudios posteriores que profundicen sobre los factores de éxito en las carreras académicas de profesoras universitarias y también puede servir como base para orientar las prácticas y las políticas en las instituciones de educación superior.

\section{METODOLOGÍA}

Hemos entrevistado a profesoras que lideran grupos de investigación consolidados en una universidad pública catalana. Todas las mujeres participantes son investigadoras reconocidas en su campo de conocimiento. Se ha adoptado el paradigma cualitativo, dado que el estudio se ha diseñado para proporcionar un acercamiento a las experiencias intelectuales y a la construcción de la carrera investigadora de las mujeres desde la percepción de las mismas protagonistas. Se pretende descubrir e interpretar sus vivencias personales. Se han entrevistado 7 académicas de diferentes campos disciplinares del área de las ciencias sociales. El grupo está formado por personas que tienen entre 30 y 60 años y son profesoras ayudantes doctoras (categoría denominada «lector/a» en Cataluña), titulares y catedráticas. La muestra elegida para este primer estudio exploratorio, aunque no es muy amplia, refleja la diversidad de experiencias y tipologías profesionales en las que se encuentran las profesoras con una trayectoria investigadora consolidada en general dentro de las Ciencias Sociales, el ámbito escogido como objeto de estudio en la investigación realizada.

Han servido de población de referencia los grupos de investigación reconocidos por la Generalitat de Catalunya en la convocatoria 2009-2013, denominados «Grups de Recerca de la Generalitat de Catalunya (SGR)». Se trata del máximo reconocimiento que los grupos de investigación de las universidades públicas y privadas de Cataluña pueden obtener y va asociado, frecuentemente, a cierta dotación económica destinada financiar proyectos de investigación del grupo.

La universidad estudiada cuenta con un número total de 69 grupos de investigación en ciencias sociales y jurídicas reconocidos por la Generalitat de Catalunya, de los cuales 45 son liderados por hombre y 24 por mujeres.

De estos 24 grupos liderados por mujeres: 6 son de Derecho; 1 de Pedagogía; 7 de diversas Didácticas, 2 de Antropología; 1 de Sociología; 2 de Psicología; 1 de Ciencias Económicas y 4 de Geografía.

De entre todos ellos, en una primera fase se seleccionaron 7 de las que accedieron a participar 4. En una segunda fase se amplió la muestra con 6 investigadoras más, 3 de las cuales pasaron a formar parte del estudio. Finalmente la muestra quedó compuesta por una investigadora de cada una 
de las siguientes disciplinas: Geografía, Antropología, Pedagogía, Sociología, Ciencias Económicas y dos investigadoras de distintas Didácticas. En el apartado dedicado a los resultados se reproducen citas textuales de las participantes en el estudio, por considerarse que ilustran la esencia de la categoría de contenido considerada. Se opta por no incluir ningún elemento identificativo a fin de preservar el anonimato, puesto que, como se decía más arriba, son todas profesoras de la misma universidad y son pocas, puesto que no hay muchas mujeres dirigiendo SGR en Ciencias Sociales.

Realizaron las entrevistas las mismas investigadoras durante el periodo comprendido entre diciembre del 2010 y febrero del 2011. Tuvieron una duración de entre 40 y 50 minutos. Se utilizó un guión de entrevista orientativo y abierto que se centraba en los siguientes tópicos de discusión:

- Los antecedentes y el contexto actual de la situación profesional de la investigadora.

- El papel de la investigación en relación a otras funciones propias de su perfil profesional.

- Los factores de éxito en la investigación según su propia percepción.

- Los factores organizativos y grupales.

- Los factores personales.

- Las dinámicas y culturas de trabajo.

- Otros tópicos.

Las entrevistas se transcribieron y fueron validadas por las mismas entrevistadas. Se realizó un análisis de contenido (Ruiz Olabuénaga, 2003) utilizando el programa de análisis de datos cualitativos MAXQDA 2007.

Se identificaron tres categorías de factores de éxito, cada una con una serie de subcategorías. En la tabla 1 se expone una síntesis de ellas:

\begin{tabular}{|l|l|}
\hline Categorías & Subcategorías \\
\hline Condicionantes personales & Vocación \\
del éxito & Pasión por el saber \\
& Dedicación al trabajo \\
& Sistema de acreditación y evaluación \\
& Conciliación de la vida profesional y la personal \\
\hline
\end{tabular}




\begin{tabular}{|l|l|}
\hline Categorías & Subcategorías \\
\hline $\begin{array}{l}\text { Condicionantes grupales } \\
\text { del éxito }\end{array}$ & $\begin{array}{l}\text { Estructura del grupo } \\
\text { Proceso de selección de los miembros } \\
\text { Estrategias de formación } \\
\text { Liderazgo ejercido en el grupo } \\
\text { Acciones de «mentoring» }\end{array}$ \\
\hline $\begin{array}{l}\text { Condicionantes institucionales } \\
\text { del éxito }\end{array}$ & $\begin{array}{l}\text { Relación docencia-investigación-gestión } \\
\text { Financiación } \\
\text { Gestión del tiempo } \\
\text { Soporte institucional } \\
\text { Autonomía }\end{array}$ \\
\hline $\begin{array}{l}\text { Ideas/recomendaciones para } \\
\text { que las investigadoras tengan } \\
\text { éxito }\end{array}$ & \\
\hline
\end{tabular}

Tabla 1. Categorías de análisis de las entrevistas y subcategorías surgidas

\section{RESULTADOS}

\section{Factores personales que contribuyen al éxito}

La construcción de la carrera investigadora empieza en el momento en que se finalizan los estudios doctorales o incluso antes, según nos confirma algunas de nuestra entrevistadas: "El tema de la investigación me ha gustado desde siempre». Esta etapa inicial en la cual la investigadora empieza a tener confianza en su capacidad, se caracteriza por «la perseverancia, la creatividad, la irregularidad, la ilusión y las ganas de mejora». Esta fase inicial es importante para entender las diferentes maneras de relacionarse con la investigación, el crecimiento y el desarrollo continuo desde ser una «aprendiz» hasta ser una investigadora de éxito (Akerlind, 2008).

En esta etapa de comienzo de la carrera investigadora, la formación postdoctoral, especialmente las estancias de investigación fuera del país, han sido mencionadas por todas las entrevistadas como factores determinantes: "Quizás hay una cosa importante, el haberme formado fuera y el dominar el inglés, esto para mi es fundamental, poder escribir los artículos directamente en inglés, poder publicar sistemáticamente fuera»; «abrir campos $y$ hacer contactos».

Ninguna de las entrevistadas ha desestimado el peso de la motivación, del trabajo duro, de la pasión por el campo de conocimiento, del interés temprano para la investigación y de la curiosidad por el saber. En este sentido nuestros resultados coinciden con estudios como el de Dever y Morri- 
son (2009) que apuntan hacia el papel fundamental de la motivación por encima de cualquier aspecto institucional o grupal en la construcción de las carreras investigadoras.

Una serie de características individuales completan el cuadro de condicionantes personales para el éxito investigador: la paciencia, el control de la ansiedad, la constancia en el trabajo "porque cuando investigas al inicio ves una lucecita a lo lejos y cuesta mucho"; "[es fundamental] ser muy perseverante, muy tenaz, muy segura de lo que tú quieres hacer, pero también muy abierta a mejorar».

A estos elementos se añaden aspectos que tienen que ver con el rol de la familia, con el apoyo que se recibe en los contextos externos a la universidad en los comienzos de la carrera académica. La mayoría de las expertas participantes proceden de familias con un nivel cultural alto, que las que han apoyado en su decisión de dedicarse a estudiar: "considero que un aspecto clave en mi trayectoria profesional ha sido mi familia. Mi padre es psiquiatra y profesor universitario...» El factor «procedencia social» ha sido clave para que algunas mujeres en la historia de la humanidad hayan podido dedicarse a la ciencia (Sánchez Prieto, 2010) y por lo que parece actualmente sigue siéndolo.

Una vez iniciada la carrera académica, se han de pasar una serie de evaluaciones externas sobre los propios méritos. Las llamadas acreditaciones se han convertido en una medida del éxito investigador y en un condicionante para poder seguir el desarrollo profesional en sus inicios. Las valoraciones de dichos procesos de acreditación por parte de las investigadoras participantes son desiguales. Aquellas que ya están consolidadas tienden a pensar que el nuevo modelo es un elemento motivador, que traza una dirección a seguir en la carrera profesional: «Yo digo que los jóvenes han entrado con estas reglas del juego, yo creo que sí que la gente se implicará mucho más en la investigación y no solo en ella, sino también en la difusión de los resultados de investigación. Nos ayudará a parecernos más a las titulaciones de ciencias». Las que están en vías de consolidación, por otra parte, comentan las dificultades debidas a la gestión de los tiempos: «Hay momentos vitales en que se hace imposible responder a ellos [a los sistemas de acreditación], tiene que revisarse como se reequilibran las dedicaciones y las tareas, si no, no funciona. Por tanto, que toda la evaluación del profesorado pivote en un porcentaje tan alto sobre los resultados de la investigación es terriblemente injusto».

Muchas de las entrevistadas muestran inquietud porque se sobrevaloran algunos aspectos de la producción científica, especialmente los artículos de impacto. En cambio, a otros productos como los informes o los 
libros no se les da mucha importancia en el sistema actual de evaluación: "que un artículo vaya a parar a una revista, yo sé que es importante, ipero que no se pueda valorar nada más que eso![…] yo he realizado informes para la comisión europea que nunca se han publicado, ni se publicaran nunca, que son verdaderas (iba a decir joyas) cosas muy interesantes y muy bien hechas... Bien, estos informes al no estar publicados en una revista con impacto, pues bien: ifuera!

¿Cómo se enfrentan las mujeres a estos retos profesionales y construyen una carrera exitosa? Como ya se ha visto, trabajando duro, mostrando pasión por la investigación y siendo competitivas. A esto se le añade la importancia de «los modelos», «la identificación con los mentores» $y$ «la acción colectiva». Nuestros resultados coinciden con los de Bagilhole (1994) que identifica diferentes estrategias que las mujeres utilizan para superar los obstáculos en la carrera investigadora, entre los cuales: la dedicación al trabajo y el apoyarse en las redes profesionales. En nuestro caso, las participantes reconocen que dedican al trabajo mucho esfuerzo y que invierten mucho tiempo: «siempre de vacaciones con la maleta llena de libros, no siempre encerrada en casa, también tenía la suerte de trabajar en otros sitios, cerca del mar, pero el trabajo siempre ha sido una constante»; "[para investigar] es necesaria una cierta continuidad diaria, no ocho horas diarias, que es muy difícil, pero sí un tiempo todos los días»., "despertarse temprano por la mañana» para poder tener la «tranquilidad para escribir» o «negociar las tareas domesticas», son otras de las referencias que las participantes hacen en relación al tiempo dedicado al trabajo.

A estos elementos se les añaden otros factores que favorecen el éxito, especialmente los que tienen que ver con tener modelos y con el mentoring. Las participantes describen a sus mentores/as como las personas que les han marcado el camino, dándoles las pautas necesarias y ofreciéndoles apoyo en los momentos difíciles: "Es muy importante, tener una pauta institucionalizada y una persona que es clave cuando tu eres joven para decirte: el camino es este, porque éste es el que yo he seguido, éste es el que me ha ido bien y éste es el que la academia reconoce, y por tanto el camino este». Nuestras entrevistadas señalan que la universidad es un lugar difícil para sobrevivir sin apoyo, en consonancia con los resultados de Caplan (1993) y de Toth (1997), entre otros. En este sentido una de las participantes añade, refiriéndose al papel del mentor: «debe haber una persona que sea capaz de decir: hay que ir por aquí, lo tenemos claro, vamos a ir por aquí, nos vamos a encontrar dificultades como nos pasa a lo largo de la vida, pero las vamos a superar, tú ves haciendo que yo te doy una mano para que tu vayas continuando».

Así, el mentor y la tarea que lleva a cabo son aspectos clave y tienen un papel importante (Acker y Armenti, 2004) en la construcción de una 
carrera exitosa. El poder de las redes y del grupo ha sido ampliamente debatido por autores como Davies (2003) o McLaren (2002) y nuestro estudio confirma sus resultados. "El grupo añade otra dimensión, el trabajar con mucha gente que te hacen ver desde perspectivas distintas, cosas que no se te habian ocurrido [...] son siempre un elemento de avance y de placer intelectual extraordinario».

Esto nos lleva a otro aspecto importante que contribuye al éxito profesional: el gusto por compartir, la cultura de la colaboración: «la red de ayuda siempre beneficia al grupo y si beneficia al grupo, beneficia a los individuos».

\section{Factores grupales que contribuyen al éxito}

El grupo de investigación puede convertirse en una de las estrategias más importantes para asegurar el éxito en la actividad investigadora. Las entrevistadas se sitúan en relación al tema entre dos polos: por un lado consideran la autonomía en el trabajo como un aspecto clave y muy importante para el éxito, asociado con la fase inicial de su trayectoria investigadora y por otro lado, destacan las potencialidades de la actividad en grupo, en fases posteriores, una vez probada su valía investigadora individual.

La autonomía se relaciona con la independencia en el trabajo: «Yo por lo menos, el entorno que tengo aquí de trabajo me permite hacer lo que quiera», «al principio yo trabajaba sola», "trabajo en casa por la mañana», aspectos debatidos en otros estudios (Lambright y Teich 1981). Se configura de esta manera la imagen del investigador como un científico libre y autónomo, a veces aislado (Travaille y Hendriks, 2010) y se considera que debe buscarse el equilibrio entre la internalización y la socialización en la producción del conocimiento puesto que los resultados demuestran la importancia de la socialización en una trayectoria investigadora de éxito. Así mismo, las participantes explican que tanto el proceso de redacción de artículos, el de ejecución de proyectos o la participación a las actividades formativas se hacen en grupo. Muchas apuntan entre los factores que están implicados en la creación de conocimiento, la colaboración con los demás miembros del grupo, "las reuniones de trabajo», "las interacciones con los especialistas" y la "participación en seminarios de intercambio». Así estos resultados concuerdan con los obtenidos por Grbich (1998).

Todos los grupos de las personas entrevistadas obtienen fondos económicos «modestos» para la investigación. Las investigadoras están convencidas de que un elemento importante para que sus proyectos ganen concursos es que solicitan poco dinero, además de saber avanzarse a las necesidades sociales en relación a la investigación: «tener olfato para el tema, es decir, 
haber sabido con tiempo qué temas serian interesantes de estudiar, ser pionero en un tema es fundamental».

La obtención de recursos compitiendo con otros grupos de investigación es un hecho que llena de orgullo a los miembros del equipo y, por tanto, además de ser un necesario el dinero para poder investigar, supone también reconocimiento y aumenta la moral del grupo: "hace dos años nos dieron un Exploratory Workshop, y casi estoy más orgullosa de eso que del SGR, ese es el resultado más visible del trabajo de investigación». Este resultado coincide con una de las conclusiones a la que llegan McLaughlin y Helsi (2013) en su estudio: a pesar de lo que comúnmente se cree, las mujeres hacen más solicitudes para recibir fondos para la investigación que los hombres.

También coinciden las participantes es destacar la importancia que dan a la formación dentro de sus grupos de trabajo: : "una de las cosas que hacemos es invitar algún experto o experta que está trabando en lo nuestro»; "una vez al mes nos reunimos todo el equipo y hacemos dos tareas: nos ponemos al día sobre cómo van los proyectos y demás y después hacemos alguna actividad formativa»; "la formación es fundamental para el desarrollo de los investigadores jóvenes "trabajar en equipo es clave para el éxito. Saber llevar un equipo que tenga buen clima, en el que haya cooperación, es fundamental. De hecho yo delego mucho. Hay investigadores que están suficientemente formados para dirigir sus propios proyectos», igual que la «generosidad» de los investigadores sénior en compartir el conocimiento: "porque mis conocimientos, que son un pequeño grano de arena en el proceso de avanzar la ciencia, quiero que esos conocimientos vayan a más gente, se difundan y lleguen a más gente».

Sobre el estilo de liderazgo ejercido, las participantes difieren poco. Parece que valoran el poder delegar responsabilidades y, cuando perciben que pueden, lo hacen. Otro aspecto común es que consideran que su tarea fundamental consiste en apoyar a las personas para que puedan desarrollar sus carreras profesionales individuales dentro del grupo, respetando los ritmos de trabajo individuales. Para ello ocasionalmente han de ejercer de mediadoras en los «pequeños» conflictos de intereses que pueden darse entre los miembros. También todas ellas consideran fundamental de su papel como líderes el velar para que el clima del grupo sea positivo, que ir a trabajar sea algo agradable.

Ninguna de las investigadoras se ha formado específicamente para el ejercicio del liderazgo aunque todas ellas mencionan las bondades que en su opinión tendría el hecho de participar en actividades de formación relacionadas con el tema: «no, no he hecho ningún tipo de formación específica para 
liderar, pero quizá debería de hacerla puesto que ahora en mis «vejeces» lo que más hago es liderar...»; "funciona un poco así intuitivamente...».

\section{Factores institucionales que contribuyen al éxito}

Aparte de los factores personales y de los grupales, los institucionales también influyen sobre el éxito profesional de quien investiga. El papel de los departamentos y de las facultades es decisivo.

El hecho de que haya otros grupos de investigación en la organización, en algunos casos se vive como un estímulo para la mejora continua. Una de las participantes, además, añade un concepto interesante en este punto: las redes de apoyo horizontales que puedan establecerse entre mujeres pertenecientes a diferentes núcleos dentro de la misma organización y hasta pertenecientes a otras organizaciones: «creo que especialmente para las mujeres es muy importe construirse redes horizontales dentro de los ámbitos académicos, tener no tanto el mecanismo vertical del mentor que te ayuda desde arriba, si no [...] el mecanismo horizontal de redes de mujeres que están haciendo lo mismo que nosotras en otros sitios, en otros departamentos, en otras universidades, dentro y fuera de España que pueden trabajar en lo mismo que nosotras o simplemente podemos tener los mismos problemas».

Otras participantes, sin embargo, afirman que no perciben influencia directa de la organización en el desarrollo de sus equipos de trabajo. Una de ellas afirma que las exigencias organizacionales condicionan negativamente el éxito de su equipo en tanto que consumen tiempo que debería poder destinarse a la investigación: "yo no tengo la sensación, y quizá sea injusta, de que la Universidad me haya dado apoyo con la investigación, no la tengo. Las ayudas económicas que he recibido han sido siempre muy pequeñas. El dinero que he conseguido ha sido de la Unión Europea».

La asignación de la docencia se realiza en las facultades y la relación entre docencia e investigación puede constituir un factor de éxito profesional. Los estudios que han analizado la relación entre la docencia y la productividad en investigación no indican una correlación directa (Hattie y Marsh, 1996). Sin embargo, autores como Griffiths (2004) insisten sobre el carácter complejo de las dos actividades que requieren de mucha dedicación. Nuestras participantes corroboran este resultado: «la docencia siempre quita mucho tiempo».

Si tenemos en cuenta que a las mujeres se las asocia más a la docencia que a la investigación (Poole, Bornholt y Summers, 1997), es una clara ventaja que los contenidos docentes coincidan con los de investigación: «lo 
más óptimo es que la docencia pueda estar relacionada con aquello que investigas de manera que puedas explicar en clase aquello que has investigado». El problema es que muchas veces la coincidencia no se da y se vive como un problema: "cuando esté en una posición consolidada, si lo consigo que espero que sí, podré escoger y para yo creo que es muy importante la vinculación entre docencia e investigación».

Por otro lado las entrevistadas identifican los beneficios que la dirección de trabajos de investigación y supervisión de tesis de doctorado tienen para su propia carrera investigadora: «la docencia en Máster y Doctorado, y tener alumnos y dirigir tesis doctorales, eso sí te compensa de muchas cosas», coincidiendo con las conclusiones de Dever y Morrison (2009).

En el caso de las actividades de gestión, las académicas consideran que «la gestión es brutal, nos toca hacer unas cosas alucinantes y tomar decisiones y saber de todo, contabilidad para hacer presupuestos y no sé cuantas cosas más» y es una responsabilidad que "quita mucho tiempo». Este resultado está en la misma línea que el obtenido por McLaughlin y Helsi (2013), mencionado en la introducción, según el cual a las mujeres se les pide que ejerzan cargos de gestión en mayor número que a los hombres y ellas tienden a acceder. Pero se trata de cargos que conllevan mucho trabajo y poco poder para tomar decisiones importantes.

El hecho de ser mujer ha sido más un obstáculo que una ventaja para construir una carrera académica brillante. Y lo sigue siendo si partimos de los estudios realizados en España (Guillamon, 2011), en otros países europeos (Seierstad y Healy, 2012; Macarie y Moldovan, 2012), en países norteamericanos (Duch y otros, 2012) y de las afirmaciones que hacen las profesoras entrevistadas en esta investigación: «es un campo en que a pesar de que hay muchas estudiantes, muchas doctoradas y muchas mujeres iniciando la carrera, tenemos sólo 4 catedráticas en toda España y están desesperadas con las oposiciones de cátedra porque tienen que estar recorriéndose toda España para los tribunales, estoy en un campo que no puedo decir que sea especialmente "friendly» para las mujeres».

Trabajos como los de Brink y Benschop (2012) ponen claramente en duda que «meritocracia» sea una vía objetiva para garantizar el acceso a la carrera académica y la promoción una vez en ella. Cuando las académicas toman conciencia sobre la desigualdad de género aun vigente, se movilizan en el sentido de que actúan para intentar la erradicación de la desigualdad: «son muy pocas [las mujeres que están], yo por ejemplo he estado dirigiendo una revista y he sido la única mujer del comité editorial durante muchos años, hasta que yo me he ido y he podido meter a otras dos [mujeres]». 


\section{CONCLUSIONES}

El concepto de «investigación de éxito» comprende la calidad y la cantidad de las producciones científicas, la reputación de quien investiga y su prestigio en el campo. Connota el reconocimiento de que se ha contribuido al desarrollo del campo de conocimiento y al desarrollo profesional y personal de los compañeros y supone una contribución social relevante.

El éxito también se relaciona con la organización en la que se trabaja y depende en gran medida del funcionamiento del grupo. El grupo es un factor de éxito si se procura el desarrollo individual de cada miembro. Liderar para compartir y acompañar es primordial para el buen rendimiento grupal. Un grupo es exitoso cuando tiene suficientes resultados (publicaciones, proyectos financiados conseguidos, formación), un buen clima de trabajo asociado con unas condiciones de infraestructura de financiación adecuadas y una buena reputación de la investigadora líder. El equipo es un motor necesario para llegar al éxito porqué sus resultados son más que la suma de los resultados individuales y dicha sinergia es imprescindible cuando la carrera académica cada vez es más competitiva.

Como cualidades personales para la investigación destacan: la pasión por la ciencia, combinada con la perseverancia, la curiosidad y la iniciativa, en un contexto en el cual se tiene suficiente autonomía.

A lo largo de este artículo hemos analizado la percepción sobre género e investigación de investigadoras que han conseguido tener un lugar destacado entre la comunidad científica, comprometidas con la producción de resultados de investigación y con el crecimiento de sus ámbitos de conocimiento, a pesar de no tener en muchas ocasiones, la infraestructura y el tiempo suficientes para ello. Son académicas que enfrentándose a las dificultades de formar parte de una cultura organizativa masculinizada, han decidido seguir trabajando y creer en la posibilidad de cambiar esta realidad. 


\section{REFERENCIAS BIBLIOGRÁFICAS}

Acker, S. y Armenti, C. (2004). Sleepless in academia. Gender and Education, $16,13-24$.

Akerlind, G.A. (2008). Growing and developing as a university researcher. Higher Education, 55, 241-254.

Amâncio, L. (2005). Reflections on science as a gendered Endeavour: changes and continuities. Social Science Information, 44 (1), 65-83.

Arranz L.F. (2004). Las mujeres y la universidad española: estructuras de dominación y disposiciones feminizadas en el profesorado universitario. Politica y Sociedad. 41 (2), 223-242.

Asmar, C. (1999). Is there a gendered agenda in academia? The research experience of female and male PhD graduates in Australian universities. Higher Education, 38 (3), 255-273.

Bagilhole, B. (1994). Being different is a very difficult row to hoe: survival strategies of women academics. En S. Davies; C. Lubelska y J. Quinn (eds.) Changing the subject: Women in higher education. (pp. 211-231). London: Taylor \& Francis.

Bagilhole, B. (2007). Challenging women in the male academy: think about draining the swamp. En P. Cotterill, S. Jackson y G. Letherby (eds) Chanllenges and negotiations for women in higher education. (pp. 21-32). Dordrecht: Springer.

Bagilhole, B. y White, K. (2003). Created in their image: An analysis of male cultural hegemony in higher education in Australian and the United Kingdom. En B. Groombridge y V. Mackie (eds.) Re-searching research agendas: women, research and publication in higher education. Proceedings of the Australian
Techology network-women's executive development (ATN-WEXDEV) 2003 Research Conference (1-12). Perth: Curtin University of Technology Learning Support Network.

Bermúdez, M.P.; Guillén-Riquelme, A.; Gómez-García, A.; Quevedo-Blasco, R.; Sierra, J.C. y Buela-Casal, G. (2011). Análisis del rendimiento en el doctorado en función del sexo. Educación XX1, 14 (1), 17-33.

Brink, M. y Benschop, Y. (2011). Salaying the Seven-Headed Dragon: The Quest for Gender Change in Anademia. Gender, Work and Organitzation, 19 (1), 71-92.

Brink, M. y Benschop, Y. (2012). Gender Practices in the construction of academic excellence: Sheep with five legs. Organitzation, 19 (4), 507-524.

Britton, C. (1999). Supporting women in research. En S. Hatt, J. Kent y C. Britton (eds.) Women, research and careers. (pp. 69-88). Houndsmills: Macmillan.

Bruneau, W.A., y Savage, D.C. (2002). Counting out the scholars: How performance indicators undermine universities and colleges (A CAUT Series Title) Toronto: James Lorimer.

Caplan, P. (1993). Lifting a ton of feathers: a woman's guide to surviving in the academic world. Toronto: University of Toronto Press.

Davis, B. (2003). Death to critique and dissent? The policies and practices of new managerialism and of «evidencebased practice», Gender and Education, 15 (1), 91-103.

Dean, E., Jonhson, L., Jones, G., y Lengkeek, N. (1996). Women, research and research productivity in the post-1987 universities: Opportunities and con- 
straints. University of Western Sydney, Nepean: Department of Employment, Education, Training and Youth Affairs, Evaluations and Investigations program, Higher education Division.

Dever, M. y Morrison, Z. (2009). Women, Research Performance and work Context. Tertiary Education and Management, 15 (1), 49-62.

Devos, A. (2000). Women Research21: Responding to the issue for beginning women academics. HERDSA News, 22 (2), 11-13.

Doherty, L., y Manfredi, S. (2005). Improving women's representation in senior positions in the higher education sector, stage findings. Oxford: Centre for Diversity Policy Research, Oxford Brookes University.

Donoso, T.; Figuera, P. y RodríguezMoreno, M.L. (2011). Barreras de género en el desarrollo profesional de la mujer universitaria. Revista de Educación, 355, 187-212.

Duch, J.; Zeng, X.; Sales-Pedro, M.; Radicchi, F.; Otis, S.; Woodruff, T.; y Amaral, L. (2012). The possible role of resource requirements and academia career-choice risk on gender differences in publication ate and impact. Plose One, 7 (12), e51332.

Flecha, C. (1999). Género y Ciencia. A propósito de los «estudios de la mujer» en las universidades. Educación $X X 1$, 2, 224-244.

Foa, E.B. (2012). How being female influenced my professional experiences and growth. Behavior Therapy, 43, 715-717.

Forster, N. (2000). A case study of women academics"views on equal opportunities, career prospects and work-family conflicts in a British univesrity. Women in management review, 15 (7), 316-330.
Fox, M.F. y Colatrella, C. (2006). Participation, performance and advancement of women in academic science and engineering. What is the issue and why. Journal of Technology Transfer, 31(3), 377-386.

Ginther, D. y Kahn, S. (2006). Women's Careers in Academic Social Science: Progress, Pitfalls, and Plateaus.

Ginther, D. (2003). Is MIT an Exception? Gender Pay Differences in Academic Science. Bulletin of Science Technology Society, 23, 21-26.

Godden, J. (1996). From new to successful researcher: Enhancing the research skills of academics. En J. Godden, A. Brew, y E. Roe (eds.) Learning research skills: Programs and issue: reports on the research skills development program for academic staff 1990-1995. (pp. 4-15). Sydney: University of Sydney Centre for Teaching and Learning.

Grbich, C. (1998). The academic researcher: Socialization in settings previously dominated by teaching. Higher Education, 36, 67-85.

Griffiths, R. (2004). Knowledge production and the research-teaching nexus in eight advanced-industrialized countries. Higher Education, 34 (3), 397420.

Groombridge, B., y Worden, S. (2003). Values, visions, strategies and goals: Is coaching a viable pathway? En B. Groombridge, y V. Mackie (eds.) Researching research agendas: Women, research and publication in higher education: Proceedings of the Australian Technology Network-Women's Executive Development (ATN-WEXDEV) 2003 Research Conference. (pp. 117185). Perth: Learning Support Network, Curtin University of Technology.

Guillamon, C. (2011). Los condicionantes de la carrera investigadora en la 
Universidad que encuentran las mujeres. En M. Tomàs (coord.) La Universidad vista desde una perspectiva de género. (pp. 77-112). Barcelona: Octaedro.

Hattie, J. y Marsh,H.W.(1996). The relationship between research and teaching: A meta-analysis. Review of Higher Education, 66, 507-542.

Higgs, J. (2003). Making a difference. En H. Edwards, D. Baume, y G. Webb (eds.), Staff and educational development: Case studies, experience and practice from higher education. (pp. 29-36). Sterling, VA/London: Kogan Page.

Hobson, J., Jones, G., y Deane, E. (2005). The research assistant: Silenced partner in Australia's knlowlegde production? Journal of Higher Education Policy and Mangement, 27 (3), 357-366.

Lambright, W. H., y Teich, A. H. (1981). The organizational context of scientific research. En P. C. Nystrom y W. H. Starbuck (eds.), Handbook of organizational design. (pp. 305-319). Oxford: Oxford University Press.

Macarie, F.C. y Moldovan, O. (2012). Are universities role models for communities? A gender perspective, Transylvanian Review of Administrative Sciences, 81-97.

McGinn, L.K. y Newman, M.G. (2012). Overcoming the glass ceiling. Lessons learned in looking back: Perspectives from trailblazers. Behavior Therapy, 43, 698-700.

McLaren, M. (2002). Feminism, Foucault and embodied subjectivity. Albany: State University of New York Press.

McLaughlin, S y Helsi, V.L. (2013). Women don't ask? Women don't say no? Bargaining and service in the political science profession. The Profes- sion, April, 355-369.

Mervis, J. (2012). Is Motherhood the biggest reason for academia's gender imbalance? Science, 335, 1030-1031.

Metz, I. y Harzing, A. (2012). An update of gender diversity in editorial boards: a longitudinal study of management journals. Personnel Review, 41 (3), 283-300.

Milkman, K.L.; Akinola, M. y Chugh, D. (2012). Temporal distance and discrimination: an audit study in academia. Psychological Science, XX (X), 1-8.

Morley, L. y Walsh, V. (eds.). (1995). Feminist academics: creative agents for change. London: Taylor \& Francis.

Morley, L. (2003). Quality and Power in higher education. Buckingham: Open University Press.

Olssen, M. y Peters, M. (2005). Neoloberalism, higher education and the knowledge economy. From the free market to knowledge capitalism. Journal of Education Policy, 20 (3), 313-345.

Poole, M., Bornholt, L. y Summers, F. (1997). An international study of the gendered nature of academic work: Some cross-cultural explorations. Higher Education, 34 (3), 373-396.

Poole, M., Bornholt, L. y Summers, F. (1997). An international study of the gendered nature of academic work: Some cross-cultural explorations. Higher Education, 34 (3), 373-396.

Probert, B. (2005). I just couldn't fit it in: Gender and unequal outcomes in academic careers. Gender, Work and Organization, 12(1), 50-72.

Rafnsdóttir, G.L. y Heijstra, T.M. (2013). Balancing work-family life in academia: The power of time. Gender, 
Work and Organization, 20 (3), 283-296.

Ramsden, P. (1999). Predicting instructional research performance from published indicators: A test of a classification of Australian university types. Higher Education, 37 (4), 341-358.

Resick, P.A. (2012). Getting out of our own way. Behavior Therapy, 43, 708-711.

Ruiz Olabuénaga, J.I. (2003). Metodología de la investigación cualitativa. Bilbao: Universidad de Deusto.

Sagaria, M. y Agans, L. (2006). Gender equality in US higher education: International framing and institutional realities. Higashi-Hiroshima City: research Institute for Higher Education, Hiroshima University.

Sánchez Prieto, A.B. (2010). La educación de la mujer antes del año 1000. ¿Es Dhoda un caso único? Educación XX1, 13 (2), 69-94.
Seierstad, C. y Healy, G. (2012). Women's equality in the Scandinavian academy: a distant dream? Work, Employment and Society, 26 (2), 296-313.

Smeby, S. y Try, S. (2005). Departmental contexts and faculty research activity in Norway. Research in Higher Education, 46 (6), 593-619.

Tomàs, M., Duran, MM, Guillamon, C. y Lavié, J.M. (2008). Profesoras universitarias y cargos de gestión. Contextos educativos, 11, 113-129.

Toth, E. (1997). Ms Mentor's impeccable advice for women in academia. Philadelphia: University of Pennsylvania Press.

Travaille E., y Hendriks, P. (2010). What keeps science spiralling? Unravelling the critical success factors of knowledge creation in university research. Higher Education, 59, 423-439. 


\section{PALABRAS CLAVE}

Género, Universidad, Carrera académica, Investigación.

\section{KEYWORDS}

Gender, Higher Education, Academic career, Research.

\section{PERFIL ACADÉMICO Y PROFESIONAL DE LAS AUTORAS}

Mar Duran-Bellonch, licenciada en Filosofía y Letras y doctora en Pedagogía. Es profesora del Departamento de Pedagogía Aplicada de la Universidad Autónoma de Barcelona y está especializada en el ámbito de la Dinámica de Grupos en organizaciones educativas. Además, investiga sobre género y carrera académica y sobre la evaluación de la formación en la empresa.

Georgeta Ion, licenciada en Psicología y Ciencias de la Educación y doctora en Ciencias de la Educación. Es profesora del Departamento de Pedagogía Aplicada de la Universidad Autónoma de Barcelona. Sus líneas de investigación se relacionan con la evaluación basada en competencias y el estudio de las instituciones de educación superior.

Dirección de las autoras: Departamento de Pedagogía Aplicada, G6, 255 y 248

Facultad de Ciencias de la Educación

Campus de Bellaterra 08913 - Cerdanyola del Vallès.

E-mail: mariadelmar.duran@uab.cat georgeta.ion@uab.cat

Fecha Recepción del Artículo: 01. Noviembre. 2011

Fecha Revisión del Artículo: 27. Febrero. 2012

Fecha Aceptación del Artículo: 27. Marzo. 2012

Fecha de Revisión para publicación: 24. Junio. 2013 


\title{
3 \\ VALORACIONES DE LOS ESTUDIANTES DE CIENCIAS DE LA EDUCACIÓN SOBRE LA CALIDAD DE LA DOCENCIA UNIVERSITARIA
}

\author{
(ASSESSMENT OF STUDENTS STUDYING EDUCATIONAL SCIENCES IN \\ RESPECT QUALITY OF UNIVERSITY TEACHING)
}

Ángel De-Juanas Oliva

Universidad Nacional de Educación a Distancia

Jesús A. Beltrán Llera

Universidad Complutense de Madrid

DOI: 10.5944/educxx1.17.1.10705

\section{Cómo referenciar este artículo/How to reference this article:}

De Juanas Oliva, Á. y Beltrán Llera, J.A. (2014). Valoraciones de los estudiantes de ciencias de la educación sobre la calidad de la docencia universitaria. Educación XX1, 17 (1), 59-82. doi: 10.5944/ educxx1.17.1.10705.

De Juanas Oliva, Á. y Beltrán Llera, J.A. (2014). Assessment of students studying educational sciences in respect quality of university teaching. Educación XX1, 17 (1), 59-82. doi: 10.5944/educxx1.17.1.10705

\section{RESUMEN}

El escenario social impulsó el proceso de cambio en el que se encuentra la Educación Superior europea tras la Declaración de Bolonia. El núcleo sustancial de la reforma universitaria es la inversión de prioridades que se ha producido en el proceso de enseñanza-aprendizaje. En la actualidad, la prioridad se sitúa en el estudiante y su aprendizaje más que en el profesorado y su enseñanza. En consecuencia, este nuevo modelo requiere una mayor aportación de los estudiantes en la vida universitaria. Dadas las circunstancias, la investigación sobre el profesorado desde el punto de vista de los estudiantes representa un potencial relevante para la comprensión del funcionamiento académico. En el presente trabajo se presenta un estudio descriptivo que se llevó a cabo con 1388 participantes de la Universidad Complutense de Madrid. Para esta investigación se utilizó el cuestionario CDUCA (Características de la Docencia Universitaria de Calidad desde el punto de vista de los Alumnos) que recoge las valoraciones de los estudiantes sobre el profesorado universitario en nueve dimensiones: identidad personal y planificación; mediación del aprendizaje; disposición favorable hacia los estudiantes; utilización de las nuevas tecnologías; orientación, autoevaluación y control propio del aprendizaje; aprendizaje experiencial; dominio académico en su área y pensamiento crítico. Los resultados del estudio confirman la importancia, percibida por parte de los distintos organismos que regulan el EEES, de fomentar la articulación de nuevas competencias docentes al objeto de me- 
jorar las capacidades socio-personales y profesionales. Del mismo modo, se comprobó que los docentes son valorados de diferente manera en función del género. Por último, los resultados confirman que los estudiantes de primer y segundo ciclo valoran de forma diferente las características de la docencia de calidad que muestran sus profesores. Siendo los estudiantes de primer ciclo los que valoran más positivamente a sus profesores.

\section{ABSTRACT}

The social scene propelled the process of change of the European Higher Education according to the Bologna Declaration. The substantial core of the university reform is the reordering of priorities that has occurred in the teaching-learning process. Currently, priority is placed on the students and their learning rather than in teachers being in the core of the process. Consequently, this new model requires greater input from students in university life. In these circumstances, research on teachers from the point of view of students has the potential relevant to the understanding of academic performance. This paper presents a descriptive study conducted with 1388 participants from the Universidad Complutense of Madrid. For this study, we used the questionnaire CDUCA (Characteristics of University Teaching Quality from the point of view of Students) which collects student ratings of university faculty in nine dimensions: personal identity and planning; mediation of learning readiness to students, use of new technologies, guidance and control self-assessment own learning, experiential learning, academic proficiency in their area and critical thinking. The study results confirm the importance, perceived by the various agencies that regulate the EHEA, of promoting the articulation of new teaching skills in order to improve sociopersonal skills and professional. Similarly, it was found that teachers are valued differently according to gender. Finally, the results confirm that students in first and second cycle were assessed differently according to the characteristics of quality teaching that show their teachers. Thus, as an example, undergraduate students are the ones that most positively value their teachers in relation to students in other academic levels.

\section{INTRODUCCIÓN}

La reforma actual de los sistemas educativos universitarios fue concebida, entre otras cuestiones, para asegurar la comparabilidad de las titulaciones en Europa. Como consecuencia, se adoptó un enfoque de competencias que se desarrolló a lo largo de los planes de estudio en todos los niveles educativos. Dada la situación de cambio estructural, se trató de contrarrestar la tendencia por la que las condiciones relativas a la docencia se habían deteriorado en las últimas décadas. Algo que parece complicado si se tiene en cuenta que la labor del profesorado universitario es compleja y se ubica en un contexto desafiante (Knight, 2006; Ruiz-Corbella, 2006; Galán y 
Rubalcaba, 2007; Rioja, 2007). Las palabras de Day (2006, p. 29) dan cuenta del cariz de la situación por la que atraviesa el profesorado:

"Se dice que en su trabajo, se enfrentan a una serie de imperativos externos que conducen a unas exigencias contradictorias: por una parte, se reconoce cada vez más la importancia del trajo en equipo y la cooperación, la tolerancia y la comprensión mutua para la economía, la educación permanente y la sociedad. Por otra, aumenta el distanciamiento de los alumnos de la escolarización formal, se insiste cada vez más en la competición y en los valores materiales y aumentan las desigualdades, se ahondan las diferencias sociales y se rompe la cohesión social».

La nueva realidad de cambio ha provocado que administraciones e instituciones universitarias se muestren más sensibles a las dificultades por las que atraviesa el profesorado, pese a que no se han concretado propuestas firmes y de consenso que den respuesta a las necesidades formativas de los docentes (Bolívar, 2007). A esta situación, se ha sumado el estado actual de crisis económica que, sin lugar a dudas, ha afectado directamente a la Universidad y, por supuesto, a la formación del profesorado.

A todo ello, habría que añadir la existencia de cierto grado de ignorancia por parte de los docentes acerca de los cambios en la educación superior europea. Tal y como corrobora el estudio de Fernández, Carballo y Galán (2010) en el que se pone de manifiesto la necesidad de una mayor orientación por parte de las universidades para poder integrar nuevos modelos de aprendizaje y estrategias adecuadas para la adaptación a los docentes a los nuevos requerimientos en educación superior.

Teniendo en cuenta estas premisas, la transformación más relevante para el profesorado es la modificación de las modalidades de acción docente trascendiendo la percepción tradicional del mismo. De forma que, a partir de la incorporación del Sistema Europeo de Transferencia de Créditos (ECTS), se está apostando por una formación centrada en el estudiante en la que prima un enfoque fundamentado en aprendizajes profundos orientados hacia el significado de lo que se desea aprender, en el que se relaciona el objeto de aprendizaje con los conocimientos previos y se integra la teoría con la práctica (Biggs, 2005; Biggs y Tang, 2007; Entwistle, 2007). Dicho enfoque aparece en contraste con los modelos reproductivos tradicionales donde los aprendizajes son más superficiales (Gibbs, 1994). Por tanto, si tenemos en cuenta estas premisas y consideramos que la buena enseñanza resulta ser la que promueve el aprendizaje de los estudiantes (Ramsdem, 1992), consecuentemente la calidad de la enseñanza dependerá de la medida en que se percibe la necesidad de que el profesorado se comprometa a desarrollar su profesión sobre la base de nuevos roles que inciden directamente en las 
demandas surgidas a raíz de estos nuevos planteamientos de aprendizaje. Estas demandas se concretan en la evaluación de aprendizajes, el desarrollo de nuevas herramientas para enseñar-aprender, la utilización de las nuevas tecnologías, la gestión de aprendizajes, la tutoría y la atención a la diversidad, entre otras (Haigh, 2010).

Precisamente, la propia condición del aprendizaje centrado en el estudiante ha sido tomada como referencia para la adaptación de los estudios a Bolonia desde el enfoque de las competencias y para la consideración de las profesiones como conglomerados de competencias (generales y específicas), tal y como se recogió en el Informe Dearing (1997), en el Informe Bricall (2000) o en los informes resultantes del Proyecto Tuning (González y Wagennar, 2003; 2006) para la convergencia de la educación superior en Europa.

Ciertamente, en el marco de las competencias, una de las preocupaciones que más incidencia tiene en educación superior es que el profesorado universitario requiere estar en posesión de aquel conjunto de competencias que permitirá desempeñar la función docente de un modo digno (Zabalza, 2011). Esencialmente, para poder delimitar ese conjunto de competencias se han de conformar previamente las dimensiones que caracterizan la docencia de calidad teniendo presente los nuevos roles del profesorado tras el Plan Bolonia. Desde este discurso, se entiende que es preciso ir a la base de la docencia de calidad, que en el caso de las competencias del profesorado no puede tener otro fundamento que la propia naturaleza de las dimensiones para la enseñanza en el contexto del EEES. Así pues, la docencia de calidad, en este caso, reside en las características que los profesores ponen en marcha en el contexto de enseñanza-aprendizaje. De tal modo, se toma el criterio de calidad docente desde un planteamiento que se sustenta sobre el proceso, entendido como acciones dirigidas a lograr la formación de los estudiantes para dar respuesta o prestar servicio al ciudadano, como cliente o estudiante beneficiario de este servicio (Cantón, Valle y Arias, 2008). Si bien, el presente trabajo considera el proceso desde la perspectiva de los estudiantes como sujetos que aprenden significativamente y se forman a partir del enfoque de las competencias.

Por todo ello, y teniendo presente que la calidad de la docencia tiene una íntima relación con la evaluación del profesorado por parte de los estudiantes, se hizo una revisión profunda sobre los estudios acerca del profesorado universitario con la finalidad última de aportar información suficiente a los interesados e identificar necesidades de formación y mejora de los docentes desde el punto de vista de los estudiantes.

En efecto, la literatura científica ha dado lugar a una proliferación de publicaciones en esta línea. De tal manera, Al-Issa y Sulieman (2007) halla- 
ron 2.988 artículos publicados, sobre la evaluación del profesorado por parte de los estudiantes, en revistas entre 1990 y 2005. Con la enorme cantidad de datos disponibles, es difícil que administradores de la Universidad e investigadores lleguen a un acuerdo sobre la utilidad y la eficacia de la evaluación del profesorado por parte de los estudiantes, así como de las dimensiones a estudiar. Ahora bien, al cotejar las fuentes analizadas (Ramsdem, 1991, 1992; Zabalza, 2003; Berliner, 2005; Bain, 2005; ANECA, 2007; Cano, 2007; Ginns, Prosser y Barrie, 2007; Valencic, 2007; Ginns, Prosser y Barrie, 2007; Ginns y Ellis, 2009; Webster, Chan, Prosser y Watkins, 2009; Duarte, 2013; entre otras) se desprende la idea de que las dimensiones y rasgos que caracterizan la docencia universitaria de calidad pueden agruparse en ciertos elementos comunes. De hecho, se observa cierta coincidencia en los nombres de las dimensiones encontradas tanto en el ámbito internacional como español, aunque a veces aparecen con nombres diferentes pero con el mismo significado.

Algo similar sucede con otros trabajos realizados en España en los que se ha tratado de identificar, definir, clasificar y estructurar las competencias de los docentes universitarios para desempeñar con éxito y calidad su rol profesional (Valcárcel, 2003; Zabalza, 2003; Tejedor y García-Valcárcel, 2010; Esteban y Menjívar, 2011).

El análisis de las diferentes propuestas sobre las competencias docentes y de la voluminosa literatura sobre el campo de investigación del profesorado universitario, permite afirmar que las dimensiones encontradas, en su mayoría, están representadas en el modelo del profesor universitario de Beltrán y Pérez (2005, p.112). La propuesta de estos autores integra y sintetiza las diferentes competencias para la docencia universitaria en cuatro funciones: 1) facilitador de aprendizajes; 2) mediador de aprendizajes; 3) mentor; y 4) experto en el conocimiento pedagógico y de contenidos.

La primera, atiende a la competencia académica, al dominio de la materia y a los principios de diseño e intervención del aprendizaje. El criterio del conocimiento de lo que se enseña, por sí solo no es garantía de éxito en la docencia pero junto con las habilidades que permiten construir aprendizajes constituye una condición para una enseñanza eficaz.

En este sentido, el rol del profesor es el de facilitador de aprendizajes. El empleo de esta dimensión es común en los diferentes instrumentos propuestos por investigadores, evaluadores y administradores universitarios. Los autores, desde una posición integradora basada en los presupuestos del nuevo paradigma educativo, presentan un modelo flexible que integra cinco ámbitos: 1) perspectivas y metas de los alumnos; 2) intervención educativa; 3) roles del profesor; 4) formación del profesor; y 5) evaluación del profesor. Si se atiende a las dimensiones de la evaluación del profesor, Beltrán y Pérez 
$(2005,86)$ semana las siguientes perspectivas: 1$)$ calidad docente, 2$)$ calidad pedagógica, 3) calidad personal, y 4) eficiencia personal.

La segunda, se refiere a la competencia pedagógica, al desarrollo del intelecto y del pensamiento crítico. Se asocia a la formación en valores y requiere de una capacidad didáctica general que permita el desarrollo de competencias y valores en los alumnos. Desde esta dimensión el rol del profesor sería el de mediador. Al igual que el anterior, se recoge en las investigaciones mostradas a lo largo del capítulo. También se puede integrar dentro de esta perspectiva la dimensión evaluación recogida en numerosos estudios puesto que la evaluación constituye una expresión de la competencia pedagógica.

La tercera hace alusión a la personalidad del profesor. Comprende su capacidad como mentor, su optimismo, entusiasmo y liderazgo pedagógico. En este sentido, la comunicación e interacción con los alumnos constituye la máxima expresión de la personalidad del docente. El rol del profesorado desde esta perspectiva es el de mentor. En las investigaciones estudiadas se hace alusión principalmente a comunicación e interacción con los alumnos, extroversión, solidaridad, etc.

Finalmente, la eficiencia personal a partir de la cual el profesorado permite a los alumnos solucionar problemas de manera creativa asumiendo el rol de experto. Dentro de esta perspectiva, se recoge la profesionalidad del docente como compromiso hacía su área de investigación y hacía su desempeño pedagógico. Así pues, la implicación con la organización educativa, con otros docentes y con su desarrollo profesional, constituyen elementos a tener en consideración.

En definitiva, la propuesta de los autores constituye un modelo de consenso que ha sido considerado como fuente de referencia sobre el que se fundamenta teóricamente el presente estudio. Sobre todo porque a pesar de que se ha investigado mucho sobre la figura del profesor universitario y se han desarrollado numerosos cuestionarios de evaluación de la docencia desde el punto de vista de los alumnos, no existen apenas referencias específicas acordes a instrumentos que contemplen los nuevos requerimientos del EEES y que midan mediante la opinión de los alumnos cómo los profesores universitarios logran poner en marcha los procesos de aprendizaje.

Desde esta posición, el estudio que se presenta tiene dos pretensiones. Por un lado, explorar las valoraciones de los estudiantes que cursan carreras relacionadas con la enseñanza y educación sobre el profesorado universitario en un momento de transición y establecer un perfil sobre la base de sus aportaciones. Por otro, analizar y describir las valoraciones de los estudiantes en relación a sus profesores a lo largo de su proceso de formación uni- 
versitaria teniendo en consideración el ciclo de estudio y el género. Ambas variables independientes asignadas fueron elegidas de un modo sistemático dado que responden a una observación deliberada para descubrir su posible relación con las características de la docencia universitaria de calidad en los centros seleccionados en los que se imparten estudios relacionados con las Ciencias de la Educación.

En el caso particular del sexo, entendemos que se trata de un elemento constitutivo de las relaciones sociales diferenciadas dentro de nuestro sistema de género social. Nuestro interés no va más allá de evitar someter el estudio al término "sujetos», lo que nos hubiera llevado a tener una visión reductiva del testimonio de los estudiantes.

\section{MÉTODO}

\section{Participantes}

Para la realización del estudio se llevó a cabo un muestreo no probabilístico en el que se seleccionó una muestra siguiendo criterios de disponibilidad, procurando que fuera lo más representativa posible.

La muestra estuvo formada por estudiantes de la Universidad Complutense de Madrid, pertenecientes a dos facultades o escuelas: Educación y Trabajo Social. Se eligió esta muestra dado que los contenidos curriculares de las titulaciones que se ofrecen en estos centros contienen una formación elevada en materia pedagógica. Ambos centros cuentan con una larga historia en común dado que tienen una amplia proyección social y académica. La formación en intervención educativa en contextos sociales es compartida en ambos centros y en el ámbito profesional se hace efectiva en los diferentes equipos multidisciplinares en los servicios psicopedagógicos escolares y en los servicios sociales.

Para la estimación inicial de una muestra representativa se tuvo en cuenta el número total de estudiantes matriculados en ambas facultades (N=7791). Según los procedimientos de muestreo aleatorio simple, la muestra necesaria debiera ser inicialmente de 366. Sin embargo, el procedimiento de muestro aleatorio no fue posible llevarlo a cabo dado que se requerían los listados de todos los alumnos matriculados para poder aplicar un muestreo totalmente aleatorizado. Por otro lado, aun teniendo dichos listados, hubiese sido muy complicado localizar a los alumnos. La solución a estas dificultades fue ampliar el tamaño de la muestra llevando a cabo un procedimiento de muestreo incidental que resultó satisfactorio dado que el número de participantes que colaboraron en el estudio alcanzó los 1388 sujetos. 
A continuación se presentan las características básicas de los participantes que colaboraron en la investigación. Estas características se muestran a partir de los resultados de un cuestionario inicial de presentación de la investigación y se corresponden con las variables sociodemográficas y otras variables descriptivas.

Sobre el total de participantes, 212 fueron hombres (15.3\%) y 1176 mujeres $(84.7 \%)$. La presencia mayoritaria de mujeres en el estudio se ve refrendada al analizar el porcentaje de mujeres y hombres en las diferentes titulaciones (once en total) que participan en el estudio. En titulaciones como Psicopedagogía, Magisterio especialidad Ed. Infantil, Magisterio especialidad Lengua Extranjera y Magisterio especialidad Ed. Especial el porcentaje de mujeres es superior al 90\%. Únicamente, en el caso de Educación Física, el porcentaje de varones (69\%) supera al de mujeres.

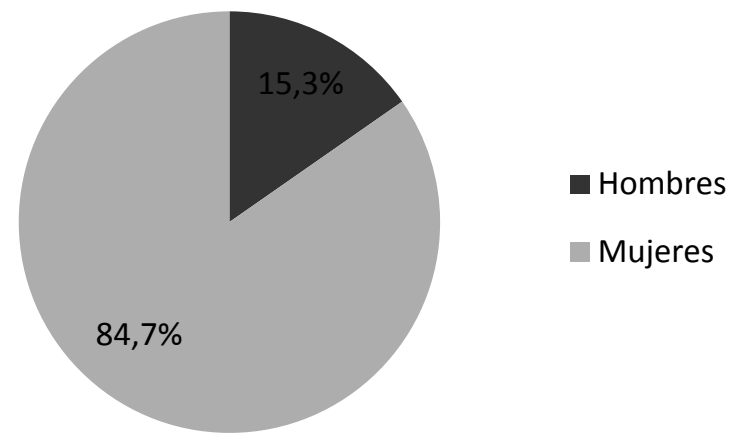

Figura 1. Distribución de los participantes por sexo

El estudio se llevó a cabo con estudiantes de titulaciones de primer y segundo ciclo universitarios (no doctorados) en el curso anterior a la implantación de los estudios de grado. La aplicación de las pruebas tuvo lugar a lo largo de los meses de abril y mayo de 2008. Se aprecia diferencia entre unas carreras y otras debido a la duración de los estudios. Siendo las de segundo ciclo y, por tanto, de mayor duración, las que se dan únicamente en la Facultad de Educación. En la siguiente tabla resumen aparecen los datos de la distribución de la muestra seleccionada para el estudio en función de los estudios que se encuentran realizando:

\begin{tabular}{|l|c|c|}
\hline & Frecuencia & Porcentaje \\
\hline Trabajo social & 159 & 11.5 \\
Magisterio Ed. Infantil & 215 & 15.5
\end{tabular}




\begin{tabular}{|l|c|c|}
\hline & Frecuencia & Porcentaje \\
\hline Magisterio Ed. Especial & 107 & 7.7 \\
Magisterio Ed. Musical & 74 & 5.3 \\
Magisterio Ed. Física & 84 & 6.1 \\
Magisterio Ed. Primaria & 194 & 14.0 \\
Audición y lenguaje & 88 & 6.3 \\
Pedagogía & 281 & 20.2 \\
Psicopedagogía & 89 & 6.4 \\
Educación Social & 40 & 2.9 \\
Magisterio Ed. Lengua Extranjera & 57 & 4.1 \\
\hline Total & $\mathbf{1 3 8 8}$ & $\mathbf{1 0 0 . 0}$ \\
\hline
\end{tabular}

Tabla 1. Distribución de participantes por titulaciones.

Como se puede apreciar, cerca de un $20 \%$ de los participantes son de Pedagogía, esto se explica porque se trata de una Licenciatura de cinco años de duración frente al resto que son diplomaturas planificadas en tres cursos de duración. En el estudio, los estudiantes de Pedagogía que participaron cursaban desde primero hasta quinto de carrera.

Las pruebas se aplicaron a un total de 30 grupos: nueve en primer curso, ocho en segundo curso, cuatro en tercer curso, seis en cuarto curso y tres en quinto cursos. La disminución de grupos en tercero y quinto se debe a la dificultad de acceso a la muestra, pues la mayoría de estos estudiantes se encontraban finalizando estudios. Por otro lado, en los estudios de segundo ciclo disminuye la muestra (225 sujetos frente a 1163), porque únicamente se dan en dos carreras de las once que participaron en el estudio.

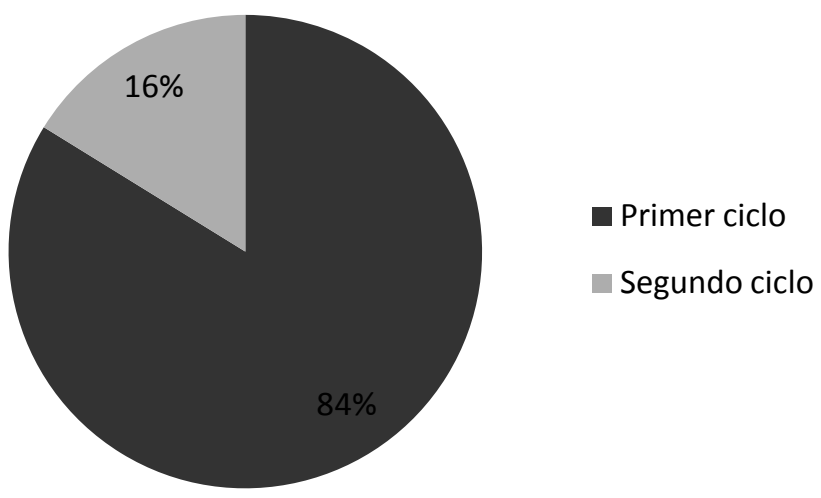

Figura 2. Distribución de participantes por ciclo 


\section{Procedimiento}

La recogida de la información tuvo lugar en el momento previo a la implantación de los estudios de Grado en ambas facultades. La aplicación de las pruebas se desarrolló dentro del aula y en horario académico de los estudiantes. Todos los participantes recibieron las instrucciones y el material necesario en el aula durante los instantes previos a la realización de la prueba. Se comentaron los propósitos del estudio haciendo hincapié en que no se trataba de una evaluación del profesorado. Por otro lado, todos los estudiantes que participaron en el estudio lo hicieron de manera voluntaria tras haberles solicitado su colaboración. Posteriormente, se procedió a la codificación, ordenación y grabación informática de las respuestas a los cuestionarios en una base de datos para su tratamiento estadístico.

\section{Instrumentos}

Para el estudio del punto de vista de los estudiantes sobre el profesorado se utilizó el cuestionario CDUCA (Características de la Docencia Universitaria de Calidad desde el punto de vista de los Alumnos) (De-Juanas, 2009). Este instrumento toma en consideración las siguientes aportaciones de manera prioritaria: los cambios y surgidos a partir del EEES, el modelo de competencias docentes de Beltrán y Pérez (2005) y los procesos de aprendizaje desde el nuevo paradigma educativo.

El CDUCA recoge las valoraciones de los estudiantes sobre el profesorado universitario. Se trata de una escala aditiva global tipo Likert de siete alternativas que presenta 57 ítems formulados en positivo. Cada puntuación expresa frecuencias en relación a cuántos profesores universitarios, de los que los estudiantes tienen y han tenido en su experiencia académica, se ajustan a los enunciados planteados en cada elemento del cuestionario. Puntuaciones altas en un factor reflejan que en opinión de los estudiantes muchos profesores concuerdan con los enunciados del cuestionario. De tal manera que 1 equivale a «ninguno», 2 a "pocos» (menos del 20\%), 3 a "algunos» (entre el 20\% y menos del 40\%), 4 a «bastantes» (entre el 40 y menos del 60\%), 5 a «muchos» (entre 60\% y menos del 80\%), 6 a «prácticamente todos» (entre el $80 \%$ y menos del total) y 7 a «todos».

El cuestionario se estructura en nueve dimensiones que se presentan a continuación: Identidad personal y planificación (PERSO); Mediación del aprendizaje (MEDIA); Disposición favorable hacia los estudiantes (DISPO); Utilización de las nuevas tecnologías (TIC); Orientación (ORIENTA); Autoevaluación (AUTOEV); Aprendizaje experiencial (AEXPER); Dominio académico (DOMINIO) y Pensamiento crítico (PENCRIT). 
Por último, se ha de señalar que el análisis de fiabilidad del instrumento presentó un coeficiente alfa de Cronbach de .966.

\section{Análisis}

Para la realización de los análisis estadísticos se utilizó el paquete estadístico SPSS 17.0. Mediante este software los datos fueron sometidos a diferentes tipos de análisis: Análisis descriptivos, análisis de contraste sobre medias y análisis de varianzas.

\section{Resultados}

Los resultados de la aplicación del cuestionario CDUCA permiten visualizar un perfil del profesorado universitario desde la percepción de los estudiantes. Igualmente, se describe y analiza la influencia del ciclo de estudio y del género sobre los resultados del CDUCA.

\section{Perfil del profesorado universitario desde el punto de vista de los alumnos}

Como primer resultado de la aplicación del CDUCA se presentan los datos correspondientes a las medias y desviación típica de sus respuestas para cada una de las dimensiones del instrumento (Tabla 2). Estos datos ponen de manifiesto un perfil estadístico descriptivo que caracteriza a los docentes percibidos por los estudiantes que cursan estudios universitarios relacionados con la educación y la formación del profesorado.

\begin{tabular}{|l|c|c|}
\hline & Media & Desv. Típ. \\
\hline F1. Identidad personal y planificación (PERSO) & 4.17 & .744 \\
F2. Mediación del aprendizaje (MEDIA) & 3.40 & .860 \\
F3. Disposición favorable hacia los estudiantes (DISPO) & 3.59 & .918 \\
F4. Utilización de las nuevas tecnologías (TIC) & 3.14 & .960 \\
F5. Orientación (ORIENTA) & 3.21 & .951 \\
F6. Autoevaluación y control propio del aprendizaje (AUTOEV) & 4.35 & 1.273 \\
F7 Aprendizaje experiencial (AEXPER) & 3.97 & .979 \\
F8. Dominio profesional académico en su área (DOMINIO) & 3.36 & 1.050 \\
F9. Pensamiento crítico (PENCRIT) & 3.19 & .919 \\
\hline
\end{tabular}

Tabla 2. Medias y desviaciones típicas para cada una de las dimensiones del CDUCA 


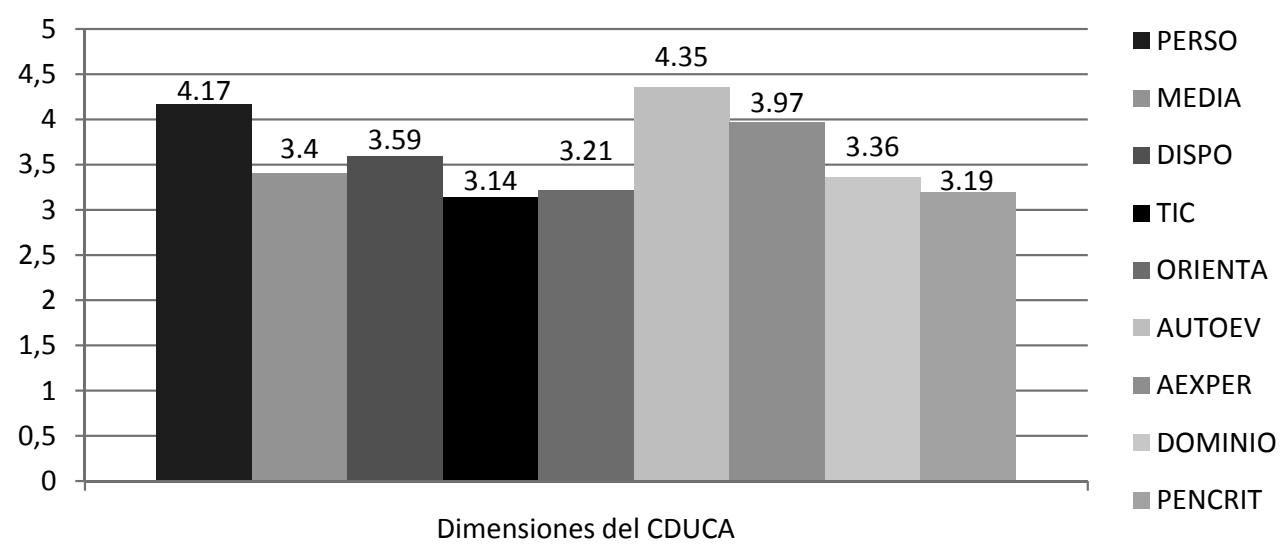

Figura 3. Medias para las dimensiones del cuestionario CDUCA

Las dimensiones que mayor valoración media obtuvieron en el estudio fueron (véase Figura 3) "Autoevaluación y control propio del aprendizaje» (4.35) e "Identidad personal y planificación» (4.17). Estos valores se corresponden con la respuesta «bastante» que en este caso, se puede atribuir a que, aproximadamente, la mitad de los profesores promueven la evaluación y control de los aprendizajes por parte de los propios alumnos, así como manifiestan rasgos de personalidad y habilidades interpersonales que favorecen el proceso de instrucción.

El resto de dimensiones obtuvieron una valoración media por encima de 3, pero que no alcanza a 4. En cuanto a las valoraciones medias más bajas, las dimensiones que menos puntuaron fueron "Utilización de las TIC» (3.14) y «Pensamiento crítico» (3.19).

Por otro lado, la desviación típica más alta se corresponde con la dimensión "Autoevaluación y control propio del aprendizaje» (1.273) y la más baja con la dimensión «Identidad personal y planificación»(0.744).

Por último, en cuanto a la puntuación media global del cuestionario CDUCA para el total de la muestra fue de 3.632, mientras que la desviación típica media fue de 0.745 .

\subsection{Influencia del sexo en las valoraciones de los estudiantes sobre el profesorado universitario}

Primeramente, se analizaron los estadísticos descriptivos sobre las puntuaciones del CDUCA para hombres (212) y mujeres (1176 participantes). 
Los resultados muestran que los hombres y mujeres puntuaron más alto en «Identidad personal y planificación» y «Autoevaluación y control del propio aprendizaje» (Tabla 3). A su vez, ambos grupos coincidieron en puntuar más bajo en «Utilización de las nuevas tecnologías» $\mathrm{y}$ «Pensamiento crítico».

\begin{tabular}{|l|c|c|c|c|c|c|c|c|}
\hline & $\begin{array}{c}\text { Media } \\
\text { hombres }\end{array}$ & $\begin{array}{c}\text { Desv. } \\
\text { Típica } \\
\text { hombres }\end{array}$ & $\begin{array}{c}\text { Media } \\
\text { mujeres }\end{array}$ & $\begin{array}{c}\text { Desv. } \\
\text { Típica } \\
\text { mujeres }\end{array}$ & $\begin{array}{c}\text { Prueba } \\
\text { de } \\
\text { Levene }\end{array}$ & Sig. & $\begin{array}{c}\text { Prueba } \\
\text { T }\end{array}$ & $\begin{array}{c}\text { Sig. } \\
\text { (bilateral) }\end{array}$ \\
\hline $\begin{array}{l}\text { Identidad } \\
\text { personal } \\
\text { y planificación } \\
\text { (PERSO) }\end{array}$ & 4.32 & .896 & 4.15 & .851 & .225 & .635 & .2619 & $.008^{*}$ \\
\hline $\begin{array}{l}\text { Mediación } \\
\text { del aprendizaje } \\
\text { (MEDIA) }\end{array}$ & 3.55 & .916 & 3.37 & .917 & .275 & .600 & 2.566 & $.010^{*}$ \\
\hline $\begin{array}{l}\text { Disposición } \\
\text { favorable } \\
\text { hacia los } \\
\text { estudiantes } \\
\text { (DISPO) }\end{array}$ & 3.71 & .912 & 3.57 & .918 & .221 & .639 & 1.953 & .051 \\
\hline $\begin{array}{l}\text { Utilización de } \\
\text { las nuevas tec- } \\
\text { nologías (TIC) }\end{array}$ & 3.31 & .987 & 3.11 & .952 & 1.248 & .264 & 2.790 & $.005^{*}$ \\
\hline $\begin{array}{l}\text { Orientación } \\
\text { (ORIENTA) }\end{array}$ & 3.43 & .947 & 3.18 & .947 & .038 & .845 & 3.602 & $.000^{*}$ \\
\hline $\begin{array}{l}\text { Autoevalua- } \\
\text { ción y control } \\
\text { propio del } \\
\text { aprendizaje } \\
\text { (AUTOEV) }\end{array}$ & 4.30 & 1.253 & 4.36 & 1.277 & .763 & .382 & -.610 & .542 \\
\hline $\begin{array}{l}\text { Aprendizaje } \\
\text { experiencial } \\
\text { (AEXPER) }\end{array}$ & 3.97 & .976 & 3.96 & .980 & .006 & .941 & .063 & .949 \\
\hline $\begin{array}{l}\text { Dominio } \\
\text { profesional } \\
\text { académico } \\
\text { en su área } \\
\text { (DOMINIO) }\end{array}$ & 3.48 & 1.045 & 3.34 & 1.053 & .025 & .875 & 1.824 & .068 \\
\hline $\begin{array}{l}\text { Pensamien- } \\
\text { to crítico } \\
\text { (PENCRIT) }\end{array}$ & 3.24 & .895 & 3.17 & .923 & .097 & .755 & .960 & .337 \\
\hline $\begin{array}{l}\text { Puntuación } \\
\text { global CDUCA }\end{array}$ & 3.75 & .752 & 3.61 & .741 & .095 & .757 & 2.619 & $.009^{*}$ \\
\hline
\end{tabular}

* La diferencia de medias es significativa a un nivel crítico de .05

Tabla 3. Descriptivos y comparación de medias. Dimensiones del CDUCA en función de la variable sexo 
Para analizar si existen diferencias estadísticamente significativas en las valoraciones dadas por hombres y mujeres se decidió utilizar el estadístico $t$ de Student adecuado para la comparación de medias de muestras independientes.

En primer lugar y atendiendo a los resultados proporcionados por la prueba $F$ de Levene, la probabilidad asociada a los valores de $F$ permite asumir la homogeneidad de varianza en todos los casos con un margen de confianza del 95\% (Tabla 3, véase la columna séptima).

A continuación, la probabilidad asociada a los valores de $t$ permite observar que existen diferencias estadísticamente significativas entre las puntuaciones medias obtenidas en el global del cuestionario por hombres y mujeres a un nivel de confianza del 95\%. Se puede afirmar que los hombres (media: 3.75), respecto a las mujeres (media: 3.61), consideran que un mayor número de profesores universitarios se ajustan al total de los enunciados de calidad del cuestionario CDUCA.

Un análisis posterior, indicó diferencias significativas en cuatro de las nueve dimensiones del cuestionario CDUCA (Tabla 3, véase columna novena). En concreto en: "Identidad personal y planificación»; "Mediación del aprendizaje»; "Utilización de las nuevas tecnologías» y "Orientación». En ocho de las nueve dimensiones, las valoraciones medias de los hombres fueron superiores a las de las mujeres. Únicamente, en la dimensión «Autoevaluación y control propio del aprendizaje», la media de las valoraciones de las mujeres es superior a la de los hombres.

\section{Influencia de los estudios de ciclo en la valoraciones de los estudiantes sobre el profesorado universitario}

A continuación, se muestran los resultados en el cuestionario CDUCA para los estudiantes que cursan estudios de primer ciclo (1163 participantes), respecto a los que cursan estudios de segundo ciclo (225 participantes).

\begin{tabular}{|l|c|c|c|c|c|c|c|c|}
\hline & $\begin{array}{c}\text { Media } \\
\text { Primer } \\
\text { ciclo }\end{array}$ & $\begin{array}{c}\text { Desv. } \\
\text { Típica } \\
\text { Primer } \\
\text { ciclo }\end{array}$ & $\begin{array}{c}\text { Media } \\
\text { Segundo } \\
\text { ciclo }\end{array}$ & $\begin{array}{c}\text { Desv. } \\
\text { Típica } \\
\text { Segundo } \\
\text { ciclo }\end{array}$ & $\begin{array}{c}\text { Prueba } \\
\text { de } \\
\text { Levene }\end{array}$ & Sig. & $\begin{array}{c}\text { Prueba } \\
\text { T }\end{array}$ & $\begin{array}{c}\text { Sig. } \\
\text { (bilateral) }\end{array}$ \\
\hline $\begin{array}{l}\text { Identidad } \\
\text { personaly } \\
\text { planificación } \\
(\text { PERSO })\end{array}$ & 4.22 & .865 & 3.92 & .789 & 2.648 & .104 & 4.738 & $.000^{*}$ \\
\hline
\end{tabular}




\begin{tabular}{|c|c|c|c|c|c|c|c|c|}
\hline & $\begin{array}{l}\text { Media } \\
\text { Primer } \\
\text { ciclo }\end{array}$ & $\begin{array}{l}\text { Desv. } \\
\text { Típica } \\
\text { Primer } \\
\text { ciclo }\end{array}$ & $\begin{array}{l}\text { Media } \\
\text { Segundo } \\
\text { ciclo }\end{array}$ & $\begin{array}{l}\text { Desv. } \\
\text { Típica } \\
\text { Segundo } \\
\text { ciclo }\end{array}$ & $\begin{array}{c}\text { Prueba } \\
\text { de } \\
\text { Levene }\end{array}$ & Sig. & $\begin{array}{c}\text { Prueba } \\
\mathrm{T}\end{array}$ & $\begin{array}{c}\text { Sig. } \\
\text { (bilateral) }\end{array}$ \\
\hline $\begin{array}{l}\text { Mediación del } \\
\text { aprendizaje } \\
(M E D I A)\end{array}$ & 3.44 & .931 & 3.16 & .813 & 4.894 & .027 & 4.245 & $.000 \%$ \\
\hline $\begin{array}{l}\text { Disposición fa- } \\
\text { vorable hacia } \\
\text { los estudiantes } \\
(D I S P O)\end{array}$ & 3.65 & .931 & 3.33 & .801 & 5.548 & .019 & 4.693 & $.000 \%$ \\
\hline $\begin{array}{l}\text { Utilización de } \\
\text { las nuevas tec- } \\
\text { nologias (TIC) }\end{array}$ & 3.17 & .977 & 2.97 & .844 & 9.377 & $.002 *$ & 2.939 & $.003 *$ \\
\hline $\begin{array}{l}\text { Orientación } \\
\text { (ORIENTA) }\end{array}$ & 3.28 & .974 & 2.88 & .736 & 19.343 & $.000 *$ & 5.863 & $.000 \%$ \\
\hline $\begin{array}{l}\text { Autoevalua- } \\
\text { ción y control } \\
\text { propio del } \\
\text { aprendizaje } \\
(\text { AUTOEV) }\end{array}$ & 4.37 & 1.302 & 4.22 & 1.107 & 12.987 & $.000 \%$ & 1.619 & .106 \\
\hline $\begin{array}{l}\text { Aprendizaje } \\
\text { experiencial } \\
(A E X P E R)\end{array}$ & 3.97 & .983 & 3.92 & .963 & .250 & .617 & .823 & .411 \\
\hline $\begin{array}{l}\text { Dominio } \\
\text { profesional } \\
\text { académico en } \\
\text { su área (DO- } \\
\text { MINIO) }\end{array}$ & 3.42 & 1.057 & 3.07 & .981 & 2.911 & .088 & 4.512 & $.000 \%$ \\
\hline $\begin{array}{l}\text { Pensamiento } \\
\text { crítico (PEN- } \\
\text { CRIT) }\end{array}$ & 3.21 & .924 & 3.03 & .878 & .886 & .347 & 2.721 & $.007 *$ \\
\hline $\begin{array}{l}\text { Puntuación } \\
\text { global CDUCA }\end{array}$ & 3.68 & .754 & 3.40 & .646 & 5.567 & .018 & 5.083 & $.000 \%$ \\
\hline
\end{tabular}

* La diferencia de medias es significativa al nivel .01

Tabla 4. Descriptivos y comparación de medias para dimensiones del CDUCA en función de la variable estudios de ciclo

Un análisis previo de los estadísticos descriptivos sobre las puntuaciones del CDUCA en función de la variable estudios de ciclo, mostró que, tanto en primer ciclo como en segundo ciclo, las dos dimensiones que puntúan más alto son «Autoevaluación y control del propio aprendizaje» e «Identidad personal y planificación»(Tabla 4). Respecto a las variables del CDUCA que se valoraron menos, en ambos ciclos se coincide en señalar «Utiliza- 
ción de nuevas tecnologías» como la dimensión que obtiene peor puntuación media. Si bien, en segundo lugar para los estudiantes de primer ciclo apareció como peor valorada la dimensión «Pensamiento crítico», mientras que para los estudiantes de segundo ciclo se indicó la variable «Orientación».

Para el análisis de las diferencias en las dimensiones del cuestionario CDUCA y la variable ciclo de estudio se llevó a cabo la prueba $t$ de Student de contraste de medias. Previamente, los resultados de la prueba $F$ de Levene no permitieron asumir varianzas iguales a un nivel de confianza del $99 \%$ en todas las variables salvo en las dimensiones: «Utilización de las nuevas tecnologías», "Orientación» y "Autoevaluación y control propio del aprendizaje» (Tabla 4, véase columna séptima). Por lo tanto, la generalización de los resultados en estos casos es cuestionable, pues estadísticamente se rechaza la hipótesis nula de igualdad de varianzas y puede concluirse que los datos muestrales no han podido ser extraídos de una población con media 100 (Pardo y Ruiz, 2005).

Los resultados del contraste de medias mostraron que existían diferencias estadísticamente significativas para un nivel crítico de 0.01 en la puntuación media de la escala global a favor de los estudiantes de primer ciclo (3.68) frente a los de segundo ciclo (3.40). De la misma forma, a nivel particular se encontraron diferencias significativas en siete de las nueve variables (Figura 8, véase columna novena). En todos los casos la diferencia de medias fue a favor de los estudiantes de primer ciclo. En las dimensiones "Aprendizaje experiencial» y "Autoevaluación y control del propio aprendizaje» las diferencias no resultaron estadísticamente significativas a un nivel de confianza del $99 \%$.

\section{Conclusiones}

Los propósitos de este estudio no se relacionan directamente con fines evaluadores. No obstante, las valoraciones recogidas por parte de los estudiantes permiten ofrecer información sobre el quehacer del profesorado de Ciencias de la Educación reflejado en sus respuestas en un periodo de transición hacía el EEES. En dicho momento, el profesorado ya era consciente de la existencia de un cambio de paradigma educativo en la enseñanza superior. Por aquel entonces, algunos docentes fueron introduciendo cambios en su docencia previa al EEES, se plantearon interrogantes y se prepararon. Otros muchos, se mantuvieron al margen de estas propuestas y esperaron a la implantación de los cambios en cursos posteriores. Así se manifiesta en las valoraciones medias del total de la muestra del estudio para cada una de las dimensiones del instrumento CDUCA. Los resultados presentados son relevantes y ofrecen un perfil del profesorado en el que los docentes destacan 
positivamente por promover la evaluación y el control de los aprendizajes por parte de los mismos estudiantes, así como por presentar rasgos de personalidad que favorecen el proceso de instrucción, así como habilidades interpersonales y de comunicación. Estos resultados coinciden con los resultados hallados en otros estudios, véanse por ejemplo los trabajos de Kember (1997), Prosser y Trigwell (2006), Ginns, et al (2007) y Webster, et al (2009), todos ellos en el contexto de la línea de investigación conocida como «Student Learning Research» que dieron origen al CEQ (Course Experience Questionnaire) elaborado por Ramsdem (1991). Este hallazgo corrobora que, sobre la base de las opiniones de los estudiantes, los profesores abordan su docencia centrándose en el aprendizaje, en su método de enseñanza y en el estudiante. Por otro lado, también es importante tener en consideración que estos resultados son coherentes con varios trabajos realizados en España sobre la evaluación de la calidad docente (Domenech, Jara y Rosel, 2004; Martínez-Gómez, 2005).

En contra, aparecen déficits sensibles en la utilización y promoción de las nuevas tecnologías. Asimismo, es importante mencionar que, a partir de los resultados del presente estudio también se encontraron puntuaciones bajas en los siguientes aspectos: el fomento del pensamiento crítico en los estudiantes ayudándoles a reflexionar acerca de sus convicciones, valorar fuentes de información diversas y ayudarles a tomar una posición personal ante los aprendizajes; así como, en la orientación socio-laboral, asistencia y ayuda que prestan a sus estudiantes.

En cuanto a la influencia del sexo en las valoraciones de los estudiantes sobre el profesorado, se puede concluir que los docentes son valorados de diferente manera por hombres y mujeres. En concreto, los resultados muestran una clara tendencia de las mujeres a valorar en menor medida el desempeño del profesorado universitario. Esta tendencia se confirma de manera estadísticamente significativa en las dimensiones «Identidad personal y planificación», "Mediación del aprendizaje» $\mathrm{y}$ "Utilización de las nuevas tecnologías». Estos resultados refuerzan el interés que han cobrado los estudios sobre efectividad docente y género. Según García-Garduño (2000), el grueso de la investigación sobre la evaluación del profesorado concluye que las valoraciones de los profesores por parte de los estudiantes se ven afectadas por el sexo de los estudiantes.

Respecto a la influencia de los ciclos de estudio en las opiniones de los estudiantes, se confirma que los estudiantes de primer y segundo ciclo valoran de forma diferente las características de la docencia de calidad que muestran sus profesores. Se aprecia que los estudiantes de primer ciclo tienden a valorar más positivamente a sus profesores. Asimismo, los resultados muestran diferencias estadísticamente significativas especialmente en los factores "identidad personal y planificación», "mediación del aprendi- 
zaje», «disposición favorable hacia los estudiantes», "dominio profesional y académico en su área» y "pensamiento crítico». Los hallazgos encontrados guardan relación con la aportación de Smith y Cranton (1992), estos autores señalan que existen diferencias significativas entre las opiniones de los estudiantes sobre la efectividad docente de acuerdo con el año en que los estudiantes se encuentran cursando los estudios universitarios.

Los resultados del presente trabajo permiten ofrecer un juicio de los estudiantes de Ciencias de la Educación sobre el perfil de sus docentes. No obstante, estas evidencias han de tomarse con precaución pues el presente trabajo muestra un diagnóstico sobre la calidad de la docencia únicamente desde la valoración de los estudiantes. Por tanto, la aproximación a la valoración de la calidad docente en este estudio debe considerarse necesariamente parcial. Asimismo, los resultados obtenidos corresponden a una muestra reducida en tamaño y con sesgo en la selección de la misma. En consecuencia, los resultados no pueden utilizarse para obtener conclusiones generalizables a todo el profesorado universitario. Sin embargo, los hallazgos de nuestro trabajo pueden servir para aproximarnos a una realidad latente en un momento de cambio producido por la entrada al EEES, en el que no se encuentran referencias en la literatura pese a la evidencia de la realización de múltiples y diversas encuestas de satisfacción al estudiantado en prácticamente la totalidad de los centros universitarios de nuestro país.

A sabiendas de que la reforma que hemos atravesado conlleva diferentes versiones, se ha de considerar que las opiniones de los estudiantes encuestados sobre el profesorado que se dedica a formar a los educadores del mañana, ofrecen una información puntual en un momento de transformación y podrían servir para ayudar a replantearse ciertas decisiones sobre la mejora de la calidad docente a sabiendas de que «hoy se aprecia un cierto consenso en la idea de que el fracaso o el éxito de todo un sistema educativo depende fundamentalmente del desempeño de sus docentes» (Tejedor y García-Valcarcel, 2010, p. 444). La cuestión es bastante polémica dado que los hallazgos nos llevan a la condición sine quanon de reajustar la formación docente por la necesidad que tienen los profesores de familiarizarse con las nuevas tecnologías, conocer herramientas necesarias para facilitar un aprendizaje mediado, lograr que sus estudiantes sean mejores pensadores críticos, conocer y organizar recursos para orientar a los estudiantes, etc. Todo ello, confirma la importancia percibida, por parte de los distintos organismos que regulan el EEES, de fomentar la articulación de nuevas competencias docentes al objeto de mejorar las capacidades socio-personales y profesionales demandadas por la sociedad actual (De-Juanas, 2010).

Evidentemente, para iniciar este paso se requiere un análisis más en profundidad de otros factores que puedan suponer una transformación ra- 
dical de la educación superior. Dado que, en la actualidad, la Educación Superior se encuentra a bastantes pasos por detrás de los cambios surgidos en nuestra sociedad (Arroyo, 2007). Asimismo, en opinión de Ramos (2008, p. 28):

"El EEES demanda un compromiso importante por parte de la Universidad y para que el proceso sea lo más adecuado posible debe involucrar a todos los estamentos de la misma, cada uno en su ámbito. Para que el cambio sea viable, requiere un esfuerzo económico importante, puesto que es necesario modificar el contexto de enseñanza-aprendizaje, y ello conlleva unas necesidades específicas (...) que si no se atienden adecuadamente pueden hacer fracasar todo el esfuerzo realizado hasta el momento».

En este sentido, el profesorado debe prepararse para cumplir nuevos roles que nada tienen que ver con los que desempeñaba en el pasado (Blanco, 2007). Como recogen en una frase reveladora Beltrán y Pérez (2005, p. 79): "Ni los alumnos son como los de la Edad Media, cuando se abrieron las universidades, ni los profesores pueden formar hoy a los profesionales del mañana con los métodos y sistemas del ayer».

Para que esta nueva redefinición del rol profesional del profesorado sea una realidad se requiere un replantear en la cultura docente en la Universidad, tanto en la configuración del currículum como en la incorporación de habilidades, competencias y compromisos cada vez más complejos que guardan una estrecha relación con la transmisión de valores en el quehacer docente (Buxarrais, 2006). Así mismo este cambio conceptual del perfil profesional del profesorado demanda, como señalábamos con anterioridad, un nuevo enfoque en la formación docente que permita tener un conocimiento amplio y profundo de su nuevo rol. 


\section{REFERENCIAS BIBLIOGRÁFICAS}

Al-Issa, A. y Sulieman, H. (2007). Student evaluations of teaching: perceptions and biasing factors. Quality Assurance in Education, 15 (3), 302317.

ANECA (2007). Informe ejecutivo. El profesional flexible en la Sociedad del Conocimiento. Madrid: ANECA. Recuperado de http://www.aneca.es/ estudios/docs/InformeejecutivoANECA_jornadasREFLEXV20.pdf

Arroyo, P. (2007). Aprendizaje, escuela y sociedad tecnológica. Recuperado de http://www.uned.es/ntedu/espanol/ master/primero/modulos/ teorias-delaprendizaje-y comunicacion-educativa/paloma2.htm

Bain, K. (2005). Lo que hacen los mejores profesores universitarios. Valencia: Servicio de Formación Permanente PUV.

Beltrán, J.A. y Pérez, L.F. (2005). El profesor universitario desde la perspectiva de los alumnos. Revista de Psicología y Educación, 1 (1), 79-114.

Berliner, D.C. (2005). The Near impossibility of Testing for Teacher Quality. Journal of Teacher Education, 56 (3), 205-213.

Biggs, J. (2005). Calidad del aprendizaje universitario. Madrid: Narcea.

Biggs, J. y Tang, C. (2007). Teaching for quality learning at university: what the student does (3nd ed.). Phildelphia, Pa.: Society for Research into Higher Education. Open University Press.

Blanco, F. (2007). El desarrollo de competencias docentes en la formación del profesorado. En A. López (Coord.), El desarrollo de Competencias docentes en la formación del profesorado. (pp. 6196). Madrid: MEC.
Bolívar, A. (2007). La formación del profesorado entre la posibilidad y la realidad. En J. Romero y A. Luis (Ed.), La formación del profesorado a la luz de una "profesionalidad democrática». (pp. 79-120). Cantabria: Consejería de educación de Cantabria.

Bricall, J.M. (2000). Informe Universidad 2000. Consultado el 22 de junio de 2007 en http://www.crue.org/informeuniv2000.htm

Buxarrais, M.R. (2006). La misión de la universidad en la construcción de la ciudadanía europea. En M. ${ }^{a}$ A. Murga y M.P. Quicios (Coords.), La reforma de la Universidad. Cambios exigidos por la nueva Europa. (pp.39-56). Madrid: Dykinson.

Cano, E. (2007). Las competencias de los docentes. En A. López (Coord.), El desarrollo de Competencias docentes en la formación del profesorado. (pp.33-60). Madrid: MEC.

Cantón, I., Valle, R.E. y Arias, A.R. (2008). Calidad de la docencia universitaria: procesos clave. Educatio Siglo $X X I, 26,121-160$.

Day, C. (2006). La pasión por enseñar: La identidad personal y profesional del docente y sus valores. Madrid: Narcea.

Dearing, R. (1997). Higher Education in the Learning Society. Consultado el 17 de marzo de 2009 en http://www.leeds. ac.uk/educol/ncihe

De-Juanas, A. (2009). Construcción del cuestionario Características de la Docencia de Calidad desde el punto de visa de los Alumnos. Revista de Psicología y Educación, 4 (1), 101-126.

De-Juanas, A. (2010). Contemplando Bolonia: una década de acontecimientos en la formación del Espacio Europeo 
de Educación Superior. Foro de Educación, 12, 69-91.

Doménech, F., Jara, P. y Rosel, J. (2004). Percepción del proceso de enseñanza/ aprendizaje desarrollado en Psicoestadística I y su incidencia en el rendimento. Psicothema, 16 (1), 32-38.

Duarte, F. (2013). Conceptions of Good Teaching by Good Teachers: case studies from an Australian University. Journal of University Teaching \& Learning Practice, 10(1), 1-17.

Entwistle, N. (2007). Research into student learning and university teaching. BJEP Monograph Series II, Student Learning and University Teaching, 1, 1-18.

Esteban, R.M. y Menjívar, S.V. (Coords.) (2011). Una mirada internacional a las competencias docentes universitarias. Barcelona: Octaedro.

Fernández-Díaz, M.J., Carballo, R. y Galán, A. (2010). Faculty Attitudes and Training Needs to Respond to the New European Higher Education Challenges. Higher Education: The International Journal of Higher Education and Educational Planning, 60 (1), 101-118.

Galán, A. y Rubalcaba, L. (2007). Fines, motivación y ámbito de trabajo en la universidad. En A. Galán (Ed.), El perfil del profesor universitario. Situación actual y retos de futuro (pp. 33-59). Madrid: Encuentro.

García-Garduño, J.M. (2000). ¿Qué factores extraclase o sesgos afectan ala evaluación docente en la Educación Superior? Revista Mexicana de Investigación Educativa, 5 (10) 303-325.

Gibbs, G. (Ed.) (1994). Improving Student Learning. Theory and Practice. Oxford: The Oxford Centre for Staff Development.

Ginns, P., Prosser, M. y Barrie, S. (2007). Student»s perceptions of teaching quality in higher education: the perspective of currently enrolled students. Studies in Higher Education, 32 (5), 603-615.

Ginns, P. y Ellis, R. A. (2009). Evaluating the quality of e-learning at the degree level in the student experience of blended learning. British Journal of Educational Technology, 40 (4), 652-663.

González, J. y Wagennar, R. (2003). Tuning. Estructuras educativas en Europa, Informe Final, Fase I. Deusto: Universidad de Deusto. Recuperado de http://www.relint.deusto.es/TUNINGProject/spanish/ doc2_fase1.asp

Haigh, A. (2010). Enseñar bien es un arte. Madrid: Narcea.

Knight, P.T. (2006). El profesorado de Educación Superior: Formación para la excelencia. Madrid: Narcea.

Martínez-Gómez, M. (2005). Estudio del cuestionario de Evaluación del profesorado de la UPV mediante la opinion de los estudiantes. Tratamiento estadístico. Valencia: UPV - Tesis doctoral.

Prosser, M. y Trigwell, K. (2006). Confirmatory factor analysis of the approaches to teaching inventory. British Journal of Educational Psychology, 76, 405-419.

Ramos, A. M. (2008). El Espacio Europeo de Educación Superior -EEES- y el sistema europeo de transferencia de créditos -ECTS-. En A. Rodríguez, M.J. Caurcel y A.M. Ramos (Coords.), Didáctica en el Espacio Europeo de Educación Superior: Guías de trabajo autónomo. (pp.11-46). Madrid: EOSEditorial.

Ramsden, P. (1991). A performance indicator of teaching quality in higher education: the "Course Experience Questionnaire». Studies in Higher Education, 16, 129-150. 
Ramsden, P. (1992). Learning to teach in higher education. London: Routledge.

Rioja, A. (2007). ¿Hacia qué modelo de Universidad converge Europa? Pedagogía Social. Revista Interuniversitaria 14, 53-62,

Ruiz-Corbella, M. (2006). La Universidad y el Mercado del aprendizaje. Claves para comprender el concepto de competencia. En M.A. Murga y M.P. Quicios (Coords.), La reforma de la Universidad. Cambios exigidos por la nueva Europa. (pp.93-114). Madrid: Dykinson.

Smith, R.A. y Cranton, P.A. (1992). Students, perceptions of teaching skills and overall effectiveness across instructional settings. Research in Higher Education, 33, 747-764.

Tejedor, F.J. y García-Valcárcel, A. (2010). Evaluación del desempeño docente. Revista Española de Pedagogía, 247, 439-460.

Valcárcel, M. (2003). La Preparación del Profesorado universitario Español para la Convergencia Europea en Educación
Superior. Informe de investigación. Recuperado de: http://www.etsit.upv.es/ paeees/pdf/PRY_MECD_PDI_EEES.pdf

Valencic, M. (2007). Student's conceptions of knowledge, the role of the teacher and learner as important factors in a didactic school reform. Educational Studies, 33 (1), 29-40.

Wanegaar, R. y González, J. (2006). Tuning Educational Structures in Europe. Informe del Proyecto Piloto. Fase II. La contribución de las universidades europeas al proceso de Bolonia. Bilbao: Universidad de Deusto. Recuperado de: http://www.tuning.unideusto.org/ tuningeu/index.php?option $=$ content $\&$ task $=$ view \&id $=155 \&$ Itemid $=182$

Zabalza, M.A. (2003). Las competencias docentes del profesorado universitario. Calidad y desarrollo profesional. Madrid: Narcea.

Zabalza M.A. (2011). Prólogo. En R.M. Esteban y S.V. Menjívar (Coords.), Una mirada internacional a las competencias docentes universitarias. (pp. 13-16). Barcelona: Octaedro. 


\section{PALABRAS CLAVE}

Educación superior; competencias docentes; desarrollo profesional; evaluación; estudiantes.

\section{KEYWORDS}

Higher education; teaching skills; professional development; assessment; students.

\section{PERFIL ACADÉMICO Y PROFESIONAL DE LOS AUTORES}

Ángel De-Juanas Oliva, Doctor en Psicología Evolutiva y de la Educación y Profesor Ayudante Doctor de la Universidad Nacional de Educación a Distancia. Autor de varios artículos en Revistas Científicas y comunicaciones en Congresos Nacionales e Internacionales sobre competencias del profesorado y las creencias epistemológicas de los estudiantes.

Jesús A. Beltrán Llera, Catedrático de Psicología Evolutiva y de la Educación de la Universidad Complutense de Madrid. Autor de diversos libros, artículos en Revistas Científicas y ponencias en Congresos Nacionales e Internacionales. Director de diversos Proyectos de Investigación autonómicos y nacionales sobre estrategias de aprendizaje, resolución de conflictos y enseñanza en educación superior.

Dirección de los autores: Ángel de Juanas Oliva

Facultad de Educación

Dpto. Teoría de la Educación y Pedagogía

Social

Universidad Nacional de Educación

a Distancia.

C/Juan del Rosal

28040 - Madrid

E-mail: adejuanas@edu.uned.es

Jesús A. Beltrán Llera

Facultad de Educación

Dpto. Psicología Evolutiva y de la Educación

Universidad Complutense de Madrid.

Rector Royo Villanova, s/n.

28040 - Madrid

E-mail: jbeltran@edu.ucm.es 
Fecha Recepción del Artículo: 27. Julio. 2011

Fecha Modificación del Artículo: 08. Abril. 2012

Fecha Aceptación del Artículo: 10. Abril. 2012

Fecha Revisión para publicación 24. Junio. 2013 


\title{
4 \\ APROXIMACIÓN A LAS REPRESENTACIONES Y CREENCIAS DEL ALUMNADO DE MAGISTERIO SOBRE LOS ESTILOS DE ENSEÑANZA
}

\author{
(APPROACH TO REPRESENTATIONS AND BELIEFS OF STUDENTS OF THE \\ TEACHER TRAINING DEGREE IN RELATION TO TEACHING STYLES)
}

\author{
Margarita González-Peiteado \\ Universidad Nacional de Educación a Distancia \\ Margarita Pino-Juste \\ Universidad de Vigo
}

DOI: 10.5944/educxx1.17.1.10706

\section{Cómo referenciar este artículo/How to reference this article:}

González Peiteado, M. y Pino Juste, M. (2014). Aproximación a las representaciones y creencias del alumnado de magisterio sobre los estilos de enseñanza. Educación XX1, 17 (1), 83-110. doi: 10.5944/educxx1.17.1.10706.

González Peiteado, M. y Pino Juste, M. (2014). Approach to representations and beliefs of students of the teacher training degree in relation to teaching styles. Educación XX1, 17 (1), 83-110. doi: 10.5944/educxx1.17.1.10706.

\section{RESUMEN}

El artículo presenta los resultados de una investigación desarrollada en las tres Universidades de Galicia con el propósito de descubrir los estilos de enseñanza preferidos por el alumnado de las distintas especialidades de Magisterio.

Se trata de un diseño de investigación no experimental de carácter transversal. Se utilizó la triangulación como recurso de investigación utilizando como instrumentos los grupos de discusión, la entrevista y una escala Likert.

Entre los resultados destaca que el estilo activo es el preferido por los estudiantes frente al estilo académico. Además hemos de señalar que los hombres en comparación con las mujeres, manifiestan una mayor tendencia hacia estilos tradicionales.

\section{ABSTRACT}

This paper presents the results of research conducted at the three Universities of Galicia in order to discover the teaching styles preferred by students pertaining to the Teacher Training Degree. 
This is a non-experimental crosscurricular research design. Triangulation was used as a research method with instruments like focus groups, interviews and a Likert scale.

The results show that the active style is preferred by students opposite to the traditional academic style. We have also noted that men compared to women, show a greater tendency towards traditional styles.

\section{MARCO TEÓRICO}

Los cambios generalizados y acelerados que diseñan el panorama actual en todos los ámbitos de la actividad humana han incidido notoriamente sobre el rol a desempeñar por el docente. Tras un largo recorrido trazado por distintos períodos históricos y concepciones pedagógicas, se perfila un nuevo escenario educativo en el que los cambios formativos no solo apuntan a las competencias técnicas y científicas, sino también a las competencias sociales necesarias para asumir nuevos retos, lo que les ha permitido a los futuros profesores el desarrollo de perfiles cada vez más profesionales. Desde este modelo, se considera que la eficacia profesional está vinculada con la calidad del trabajo que realizan, el compromiso que asumen en su trayectoria laboral, así como con el estilo de enseñanza que implementan en las aulas, entre otros aspectos.

Esta evolución en la percepción de la praxis educativa ha implicado necesariamente un rechazo de estilos tradicionales y un compromiso de coherencia con las demandas que plantea la sociedad, estableciendo estilos de enseñanza abiertos, innovadores, flexibles y comprensivos, venciendo la resistencia al cambio. Dimensiones, todas ellas, que deben ser atendidas desde la Formación Inicial del Profesorado (Blanco Felip, Jové Deltell y Reverter Masià, 2012; Feiman-Nemser, 2001; Marcelo, 2009).

Obviamente, lo asimilado a lo largo de la carrera no garantiza que los futuros docentes lo vayan a aplicar en las aulas; pero todos sabemos que lo que no se aprende, no se puede enseñar. El hecho de aproximarnos a distintos enfoques de la enseñanza nos ofrece la posibilidad de adaptarnos a las diversas necesidades e intereses del alumnado y abre la reflexión sobre la conveniencia de implantar un estilo u otro de enseñanza adaptándose a las circunstancias. Pero, ¿qué entendemos por estilo de enseñanza?

Considerando que las diferencias individuales son un fenómeno intrínseco y concomitante al desarrollo y evolución del ser humano, podemos afirmar que la realidad particular del ejercicio docente presenta como nota fundamental la variedad de constructos cognitivos, culturales y con- 
textuales. Todo ello como resultado de una historia personal, académica y profesional que va configurando consciente o inconscientemente un estilo preferido de dirigir la acción educativa. «La docencia es una creación científica y artística y por tanto, muy personal» (Nevot y Cuevas, 2009, p. 40).

Es desde la aceptación de esta diversidad como puede comprenderse que cada persona presente una determinada forma de enseñar y de aprender, manifestando una variedad de conductas y roles a lo largo del proceso educativo, contribuyendo a la conformación de un estilo determinado. Así lo suscribe Lozano (2004, p. 17) al proporcionarnos a partir de sus reflexiones un conjunto de rasgos que creemos importantes para poder establecer un perfil docente. "Si bien es cierto que un estilo implica preferencias, tendencias y disposiciones, también lo es el hecho de que existan patrones conductuales y fortalezas que distinguen a un sujeto de los demás en la manera en que se conduce, se viste, habla, piensa, aprende y enseña».

En cuanto a este aspecto, en el trabajo de Gonzaléz Peiteado (2010, p. 3) se resalta que en el comportamiento docente existe una implicación de multiplicidad de factores relacionados con una ideología o percepción de la realidad que asume el educador. Así, para esta autora, "Cuando se habla de estilos de enseñanza se alude al modo particular de enseñar, a la tendencia docente de adoptar un determinado modo de interactuar con el alumno en función de las demandas específicas de la tarea, de percibir las necesidades del educando, sus intereses, aptitudes, actitudes, de pensar acerca de la praxis educativa, pero también se refiere a comportamientos verbales y no verbales, producto de creencias, principios, autobiografía y teorías de la enseñanza que sustentan su actuación refrendado por una cierta regularidad en la forma de aplicar las distintas estrategias de enseñanza».

En efecto, los estilos de enseñanza vertebran dimensiones que tienen gran impacto en el ejercicio de la profesión, en la configuración pedagógica del quehacer educativo y en las relaciones interpersonales que se establecen dentro del aula (González-Peiteado, 2012). Se trata de una dimensión que constituye una articulación entre lo individual y lo social. Por tanto, entendemos que ambas dimensiones van asociados a características cognitivas, afectivas y procedimentales que sirven de indicadores relativamente estables de los roles, comportamientos y métodos preferidos por cada profesor. Así mismo, el estilo de enseñanza resalta la relación dinámica que existe entre las concepciones que tienen los profesores acerca de lo que debe ser la educación (concepción idealista de la práctica educativa) y lo que es (actuaciones educativas concretas).

A este respecto, señalamos la existencia histórica de dos grandes estilos: el estilo de enseñanza académico y el estilo de enseñanza activo que según el momento y el contexto fueron adoptando diferentes denominacio- 
nes. Así podemos señalar las experiencias realizadas por Anderson, 1945 y Flanders, 1984 y más recientemente las llevadas a cabo por Coldren y Hively, 2009; Hood, Poulson, Mason, Walker y Dixon, 2009; Gargallo, 2008; Michel, James y Varela, 2009 y Weltman y Whiteside, 2010.

Siguiendo este enfoque, Gargallo (2010) da cuenta de la existencia de diversas investigaciones que abordan los dos grandes componentes «el modelo de «transmisión del conocimiento» o «centrado en la enseñanza», también denominado «modelo centrado en el profesor», y el modelo de «facilitación del aprendizaje», o "centrado en el aprendizaje», que también llamado «modelo centrado en el alumno».

Como ya sabemos, la concepción académica o tradicional, está fundamentada en el discurso expositivo que transmite hechos y conceptos, vinculada a la capacidad de impartir una disciplina y lograr un clima de máximo rigor, rigidez y control. En este caso la enseñanza gira en torno a la figura del profesor (Delgado, 1991, 1994; Martín-Cuadrado, 2011; González-Peiteado, 2013).

Sin embargo, la concepción activa genera un estilo de enseñanza ligado a planteamientos que consideramos más innovadores y a expectativas de éxito y calidad respetando el ritmo de aprendizaje del alumno. Así mismo, se promueven actitudes de cooperación, tolerancia y se fomenta competencias vinculadas al aprender a aprender, a aprender a ser, aprender a hacer y aprender a convivir (Monereo y Pozo, 2003; Samuelowicz y Bain, 2002). A lo que añadimos la importancia de la «reflexión en la acción» hecho que abarca el «conocimiento en la acción» aquél que se revela en las acciones inteligentes, ya sean observables al exterior o que se den internamente en las personas. En ambos casos el conocimiento está en la acción, se evidencia a través de la ejecución espontánea y hábil» (Tejada Fernández, 2011, p. 23).

Para Ballesta, Izquierdo y Romero (2011, p. 358) «los resultados en la enseñanza son mucho más claros cuando los profesores, además de tener una concepción centrada en el aprendizaje, y de usar metodologías coherentes con ella, disponen de más habilidades docentes».

Evidentemente, en las aulas no se dan estos comportamientos en toda su amplitud, sino que el profesor se mueve dentro de un continuum, combinando rasgos de ambos estilos, aunque uno de ellos sea el predominante (González-Peiteado y Aznar, 2010).

Desde el estudio de las diferencias individuales y partiendo de un marco teórico multidimensional, nuestro objetivo es describir y analizar los estilos de enseñanza preferidos por los futuros maestros de la Comunidad de Galicia, identificando sus potencialidades y deficiencias. 


\section{MÉTODO}

Con la pretensión de conocer e interpretar una realidad y de abrir un debate sobre la optimización de la práctica docente y la mejora de los procesos formativos, hemos optado por un diseño no experimental de carácter transversal. Para tal fin, se emplea una muestra no probabilística de sujetos voluntarios, con garantías de aleatoriedad e independencia de los pares de sujetos. La recogida de información se solicitó a los estudiantes a través de un instrumento que incluye datos de identificación y una escala sobre estilos de enseñanza así como la realización de entrevistas semiestructuradas y grupos de discusión.

En esta investigación hemos rentabilizado los aportes de diferentes paradigmas (cualitativo y cuantitativo) a través de una visión plural que nos permite abordar la triangulación de técnicas y de fuentes de recogida de datos, de acuerdo con estudios similares (Pino, Domínguez y López, 2007), o lo referido por Rodríguez (2005) con la intención de conocer la propensión que manifiestan en relación a los estilos de enseñanza.

Con mucha frecuencia en la medición de una creencia o una actitud se comenten involuntariamente sesgos y errores. En consecuencia, con el propósito de evitar alteraciones en los resultados, hemos optado por la triangulación de datos ya que nos permite establecer comparaciones desde diferentes posiciones, precisar consonancias y disonancias, y determinar elementos que permitan decidir sobre la credibilidad de la información.

En última instancia, nuestro propósito radica en la evaluación de los estilos de enseñanza de los futuros docentes de la forma más objetiva posible. En cuanto al contenido, por razones obvias, en esta muestra evaluamos las intenciones u opiniones de los estudiantes en relación con el quehacer docente en lugar de prácticas concretas. Entendiendo por opinión, la postura más o menos constante en el tiempo y representativa de un posicionamiento coherente y una perspectiva consciente sobre cómo entiende la realidad educativa. Por tanto, somos conocedores de la existencia de una mayor implicación de un componente teórico-idealizador sobre el prácticorealista en la etapa de la formación inicial del profesorado que se ha tenido en cuenta en la construcción de la escala.

\section{Sujetos}

En la presente investigación, la población estudiada está constituida por 1314 estudiantes de tercer curso de Magisterio que realizan sus estudios en las tres universidades gallegas. De ellos, 464 pertenecen a Educación 
Infantil, 449 corresponden a Educación Primaria, 148 a Educación Física, 121 están en Educación Musical y 132 son alumnos de Lengua Extranjera.

Teniendo en cuenta el tamaño de la población, hemos obtenido un tamaño muestral aconsejable de $\mathrm{N}=492$ con la ayuda del programa Raossoft (Sample Size Calculator). Dado la cifra señalada, se confirma que la muestra del estudio $(\mathrm{N}=555)$ es suficientemente amplia.

Por tanto, la muestra queda compuesta por 555 estudiantes $(\mathrm{N}=555)$ de formación inicial del profesorado que cursan sus estudios en las tres universidades gallegas: Universidad de Vigo, Universidad de Santiago de Compostela y Universidad de A Coruña.

En función de la variable especialidad, el grupo investigado está compuesto en un 41,3\% por estudiantes de Educación Infantil, mientras que el 29,5\% pertenece a Educación Primaria. Con un porcentaje menor de estudiantes se encuentran las especialidades de Educación Física, 10,8\%; Educación Musical, 7,4\% y, finalmente, Lengua Extranjera con un 11,0\% del total de la muestra. En todo caso, se ha conseguido la existencia de representatividad en las tres Universidades gallegas.

En lo referente al sexo, existe una mayoría de mujeres $(81,4 \%)$ respecto a los hombres $(18,6 \%)$, que lejos de ser un sesgo en esta muestra, es coherente con los patrones ordinarios de presencia de hombres y mujeres en las aulas de Magisterio.

La distribución por edad es la siguiente: el 35,9\% de la muestra tiene menos de 20 años, el 45,9\% integra la franja de 21 a 23 años, mientras que el $18,2 \%$ posee más de 24 años. Este dato también coincide con los patrones tipo del estudiante de Magisterio en nuestro país.

\begin{tabular}{|l|l|l|l|l|}
\hline \multicolumn{1}{|c|}{ Datos } & Categorías & Dimensiones & Frecuencias & Porcentajes \\
\hline \multirow{4}{*}{$\begin{array}{l}\text { Datos } \\
\text { académicos }\end{array}$} & UNIVERSIDAD & U.Vigo & 332 & $59,8 \%$ \\
\cline { 3 - 5 } & & USC & 159 & $28,6 \%$ \\
\cline { 3 - 5 } & & U.Coruña & 64 & $11,5 \%$ \\
\cline { 3 - 5 } & Total & 555 & $100 \%$ \\
\cline { 2 - 5 } & ESPECIALIDAD & Ed. Infantil & 229 & $41,3 \%$ \\
\cline { 3 - 5 } & Ed. Primaria & 164 & $29,5 \%$ \\
\cline { 3 - 5 } & & Ed. Física & 60 & $10,8 \%$ \\
\cline { 3 - 5 } & Ed. Musical & 41 & $7,4 \%$ \\
\cline { 3 - 5 } & & L. Extranjera & 61 & $1,0 \%$ \\
\hline
\end{tabular}




\begin{tabular}{|c|l|l|l|l|}
\hline \multicolumn{1}{|c|}{ Datos } & \multicolumn{1}{|c|}{ Categorías } & Dimensiones & Frecuencias & Porcentajes \\
\hline \multirow{3}{*}{ Datos personales } & \multirow{2}{*}{ SEXO } & Hombre & 103 & $18,6 \%$ \\
\cline { 3 - 5 } & & Mujer & 452 & $81,4 \%$ \\
\cline { 2 - 5 } & \multirow{2}{*}{ EDAD } & Menos de 20 & 199 & $35,9 \%$ \\
\cline { 3 - 5 } & & $21-23$ & 255 & $45,9 \%$ \\
\cline { 3 - 5 } & & 24 o más & 101 & $18,2 \%$ \\
\hline
\end{tabular}

Tabla 1. Datos personales y académicos de la muestra

\section{Instrumentos}

Con la intención de contribuir al propósito de la investigación, se ha realizado una primera aproximación a las concepciones que el alumno manifiesta sobre los estilos de enseñanza, en el último año de carrera, a partir de los elementos simbólicos, ideas y representaciones asociadas a él y manifestadas en los grupos de discusión. Todo ello en línea con propuestas como la de Smith (1988) quien sugiere el uso de metodologías cualitativas para la medición de estilos de enseñanza. De esta forma, en primer lugar, hemos llevado a cabo un estudio exploratorio-descriptivo a través de la configuración de dos grupos de discusión integrados por cinco estudiantes cada uno. Situación que añade un elemento de intensidad y profundidad, para poder integrar sus argumentos posteriormente en un constructo global que permita un mejor conocimiento de lo que acontece. En consecuencia, algunos de los razonamientos realizados por los alumnos pasaron a completar la escala.

En efecto, en segundo término y dentro del espectro de instrumentos de signo cuantitativo empleado en la evaluación de preferencias en el estilo docente hemos elaborado una la escala (Likert, 1953) sobre estilos de enseñanza (ESEE). La finalidad es abarcar, con los 31 ítems que recoge la escala, las principales dimensiones del constructo que se quiere medir, recogiendo cuestiones de interés en la actuación educativa: comunicación, trabajo grupal, participación, atención individualizada, innovación y reflexión, entre otros aspectos. Es así como nos aproximamos al conocimiento del estilo de enseñanza preferido de la muestra estudiada. Con tal fin, hemos revisado los principales instrumentos elaborados por diversos autores a lo largo de los años para la medición de estilos de enseñanza (Delgado, 1991; DomenechBetoret, 2012). Cada enunciado ha sido presentado seguido de una escala de estimación que oscila desde el total acuerdo «siempre» al total desacuerdo «nunca» incluyendo estadios intermedios («frecuentemente», «raras veces») en relación con la proposición. 
En tercer lugar y teniendo en cuenta el criterio de saturación y representación de los diversos grupos estudiados, se han realizado cinco entrevistas a los alumnos de cada una de las especialidades de Magisterio de las tres Universidades $(\mathrm{N}=50)$. Ello ha servido para contrastar cuestiones que se trataban en los instrumentos complementarios (grupo de discusión y escala) con el fin de obtener resultados desde diversas perspectivas y de este modo saturar la información sobre los estilos de enseñanza.

En vista de las apreciaciones precedentes, las preguntas elaboradas dieron respuesta a los objetivos y cuestiones planteadas en la investigación, formuladas en un lenguaje claro, con la intención de conseguir información espontánea e interesante para el estudio. En este sentido, Stake (1998, p. 25) afirma que "Quizá la tarea más difícil del investigador es la de diseñar buenas preguntas, las preguntas de la investigación, que dirijan la atención y el pensamiento lo suficiente pero no en exceso».

En todo caso, se ha asegurado el tratamiento de los temas clave.

\section{Análisis realizados}

- En relación a los grupos de discusión.

Se han tenido presentes dos premisas esenciales: a) No sesgar el proceso comunicativo evitando influir en la línea discursiva, b) Crear un espacio de colaboración en el que los asistentes expresen sus opiniones libremente.

A partir de estos criterios, hemos formulado cinco cuestiones abiertas encaminadas a propiciar la interacción dialógica: ¿Qué entienden por estilo de enseñanza? ¿Consideran que el estilo de enseñanza puede incidir en el correcto aprendizaje del alumno? ¿Qué comportamientos del docente creen que son más eficaces para producir mejoras en los aprendizajes de los alumnos? Si un docente enseña bien ¿por qué hay niños que sin evidenciar trastornos de aprendizaje no aprenden? ¿Cómo caracterizaría su estilo de enseñanza?

En cuanto al análisis de contenido, lo llevamos a cabo en términos descriptivos, conduciendo a la elaboración de informes en los que el material recogido se estructura y sistematiza en torno a una serie de temas considerados relevantes para la elaboración de la escala. Hemos considerado todas las expresiones aportadas aprehendiendo las ideas claves del discurso en torno a dos grandes descriptores: a) La realidad de los estudiantes de Magisterio en torno a la construcción de su propio estilo, b) Concepciones en torno a la aplicación de los estilos de enseñanza en las aulas. 
- En relación a la escala.

La formulación de los elementos de la escala se ha llevado a cabo integrando las aportaciones de diversas fuentes literarias y las ideas expresadas en los grupos de discusión. Proceso que va a ser seguido de una selección de ítems y del estudio de las propiedades psicométricas (González-Peiteado, López-Castedo, Pino-Juste, 2013).

Inicialmente se procedió a la validación de la escala mediante un estudio analítico de dicho instrumento, con el fin de depurar su longitud, teniendo en cuenta los siguientes criterios (Cea, D’Ancona, 1999; Mc Millan y Schumacher, 2005): a) Se eliminan ítems redundantes, con doble sentido o compuestos, b) Es valorado por tres expertos universitarios.

En referencia a las características técnicas del cuestionario, y como paso previo a la selección del método de extracción, se han solicitado dos indicadores de adecuación muestral.

a) El test de Esfericidad de Barlett (TEB) con el fin de determinar si existen correlaciones significativas. El valor obtenido es de 2264,064 con un nivel de significación (p10,00), por tanto existe un nivel de correlación suficiente entre variables

b) El test Kaiser-Meyer-Olkin (KMO) que revela un valor de 0,862, lo que refleja una notable proporción de varianza común entre las variables.

Seguidamente, se ha llevado a cabo un análisis factorial de Componentes Principales con rotación Varimax, con el propósito de confirmar la existencia de las dimensiones fijadas a priori y así poder afirmar que se está midiendo lo que se ha querido medir. Dicho análisis factorial confirma la existencia de dos factores, que en su conjunto explican el 53,260\% de la varianza total de los resultados. Para facilitar su interpretación se recogen sólo las saturaciones superiores a 0.40. Ambas dimensiones se corresponden con el estilo de enseñanza activo o centrado en el alumno y el estilo de enseñanza académico o centrado en el profesor. A su vez, el estilo de enseñanza activo está integrado por cinco subdimensiones (reflexivo, cooperador, individualizado, innovador e indagador).

Así mismo, con el objetivo de valorar el grado de precisión de la medida, se calculó el coeficiente alfa de Cronbach, obteniendo una alta consistencia interna con un coeficiente de 0,886 para el conjunto de la escala. Con relación a cada uno de los factores, los resultados fueron los siguientes: estilo activo $(\alpha=0,894)$, estilo académico $(\alpha=0,791)$. 
- En relación a las entrevistas.

Con el fin de asegurar el tratamiento de los temas claves y saturar la información recibida, se ha elaborado un protocolo estructurado con preguntas amplias que facilitan que los estudiantes produzcan abundantes valoraciones sobre cada uno de los cuatro aspectos a tratar: ¿Cómo describiría su estilo de enseñanza? ¿Si pudiera diseñar un profesor ideal ¿Cómo sería? ¿Por qué? ¿Qué comportamientos docentes pueden derivar en fracaso escolar? ¿Qué comportamientos docentes estimulan el aprendizaje?

La fase de análisis de contenido consistió en la codificación a mano de palabras clave extraídas de las respuestas de cada sujeto. Hemos definido las actitudes que son relevantes para el estudio y que consideramos que deben ser categorizadas. En una siguiente fase se clasificó a los contenidos por asociación temática. Esto permitió agrupar en categorías las palabras con el mismo significado semántico, lo que llevó a la obtención de 14 indicadores para posteriormente establecer sus frecuencias (ver anexo 2).

\section{Procedimiento}

Como ya hemos mencionado, para alcanzar los objetivos del estudio y con el deseo de evitar sesgos y errores hemos optado por una triangulación de instrumentos. Con la intención básica de contribuir a este propósito, se ha realizado una primera aproximación a las representaciones y percepciones de los estudiantes de Magisterio sobre los estilos de enseñanza a través de la organización de dos grupos de discusión compuesto por cinco estudiantes.

A partir del análisis del contenido emergente en estas reuniones y del estudio intensivo de la bibliografía existente, hemos recogido contribuciones importantes para la elaboración de la escala ESEE, sometida al estudio de los datos obtenidos mediante el paquete estadístico SPSS 19.0. Así mismo, hemos querido ampliar el carácter informativo-descriptivo de esta parte de la investigación con el uso ulterior de la entrevista a alumnos de las distintas especialidades.

Todos los sujetos participaron de forma voluntaria y anónima en el estudio y se respetaron todos los procedimientos éticos para la recogida de datos.

\section{RESULTADOS}

Se han organizado los resultados obtenidos describiéndolos de forma sistemática en función de los dos factores (estilo de enseñanza académico 
y estilo de enseñanza activo) que han emergido de la estructura factorial de la escala en el estudio realizado previamente sobre sus propiedades psicométricas.

El análisis de los datos se ha efectuado en dos niveles. En primera instancia, se lleva a cabo un estudio descriptivo de las dimensiones objeto de estudio en función de tres variables: especialidad, sexo y edad. A continuación, se realiza un análisis inferencial con la intención de determinar si existen diferencias significativas entre las distintas categorías. Con tal propósito, hemos integrado todo el trabajo de campo en un todo coherente con el objetivo de obtener resultados veraces y contrastados a partir de la integración de instrumentos de corte cuantitativo (escala de estilos de enseñanza) y de signo cualitativo (entrevista y grupo de discusión).

\section{Análisis descriptivo}

En una primera aproximación a los resultados observamos que el estilo activo es el preferido por los estudiantes siendo la especialidad de Lengua Extranjera $(85.02 \%)$ y Educación Infantil (83.20\%) las que puntúan más alto en este estilo, mientras que la de Educación Física (74.62\%) es la que genera menos evaluaciones positivas en relación al estilo activo.

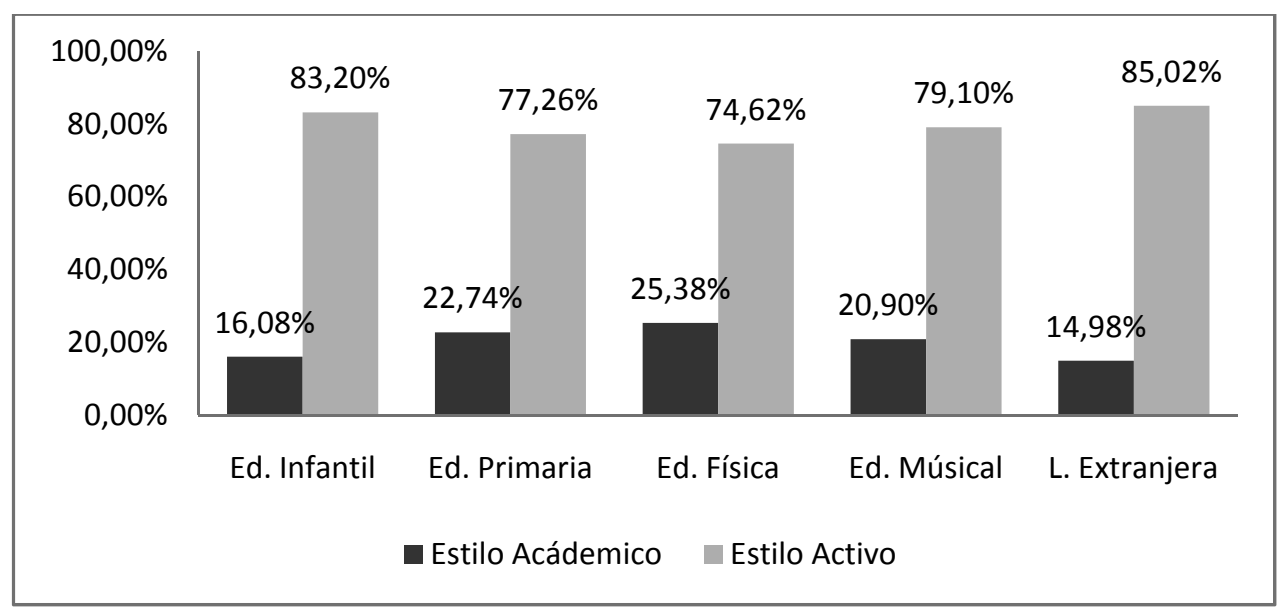

Gráfico 1. Estilos de enseñanza en función de la especialidad de la muestra

Del análisis efectuado a partir de los argumentos aportados en las entrevistas y grupos de discusión, hemos constatado claramente como los alumnos de Educación Física denotaban una mayor inclinación hacia el estilo académico en comparación con las creencias apuntadas por los in- 
tegrantes de las otras especialidades. Sin embargo, este apunte hacia un estilo académico, concretamente «mando directo», se combina con el uso de estilos activos como veremos a continuación en dos comentarios recogidos por ser especialmente ilustrativos:

«Creo que el estilo de enseñanza ideal es el que fusiona mando directo, autoaprendizaje y trabajo cooperativo» (Ed.Física1).

"Combinaría la asignación de tareas más mando directo, pero en general una mezcla de estilos para favorecer una mayor participación» (Ed.Física3).

Además hemos de señalar que las dos dimensiones descritas (enseñanza académica versus enseñanza activa) arrojaron diferencias con respecto al sexo. Así, los hombres en comparación con las mujeres, manifiestan una mayor tendencia hacia estilos tradicionales. Mientras que solamente el $18.20 \%$ de las mujeres presentan una tendencia hacia el estilo tradicional y un $81.80 \%$ hacia el estilo activo; el $26,18 \%$ de hombres se identifica con el estilo tradicional y el $73.82 \%$ lo hace con el estilo activo. Es decir, las futuras docentes que participaron en este estudio rechazan más que los hombres el estilo tradicional.

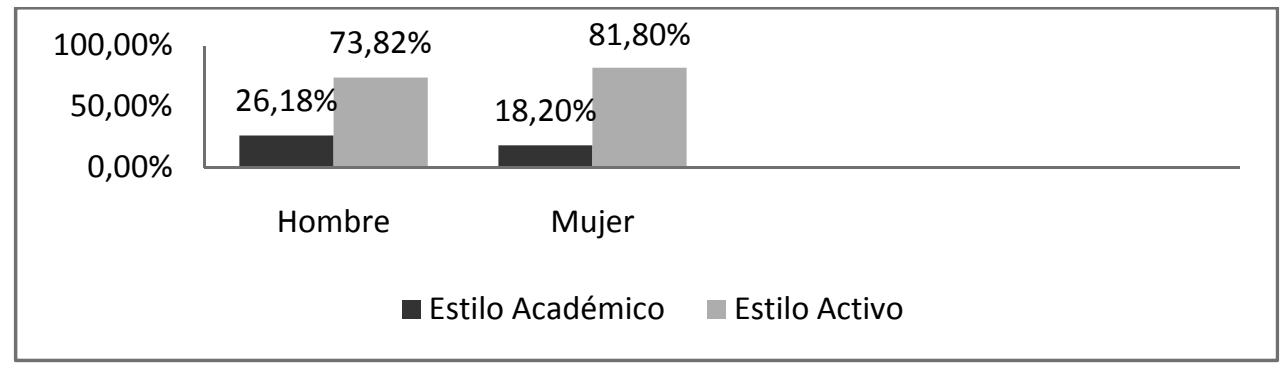

Gráfico 2. Estilos de enseñanza en función del sexo de la muestra

En relación a esta dimensión, en las entrevistas y grupos de discusión se pone de manifiesto una tendencia concordante con los datos aportados por la escala. Destacamos a modo de ejemplo algunos argumentos manifestados en los grupos de discusión:

"Es importante que sepa transmitir conocimientos y que sea disciplinado (...) Personalmente combinaría la asignación de tareas con el mando directo» (G2. Hombre, Ed Física). 
"Me identifico con un profesor que se interesa por su asignatura y en como transmitirla a los alumnos para que ellos adquieran conocimientos.»(G2. Hombre, L.Extranjera).

Las razones esgrimidas por estos estudiantes nos hacen retrotraernos hacia períodos históricos donde lo fundamental eran los «conocimientos» y su «correcta transmisión». Sin embargo, se hace preciso destacar que los comentarios relacionados con un estilo tradicional-academicista figuran con escasa frecuencia en los discursos, por lo menos en su vertiente más radical.

A continuación vemos como, en el transcurso de los argumentos aportados, se articulan ejes conceptuales y actitudes favorables a la incorporación de estilos de enseñanza activos que impliquen al alumno:

"Es importante favorecer el aprendizaje por descubrimiento por parte del alumno, creo que es necesario que descubran poco a poco los fines que buscamos para que aprendan a trabajar y buscar la información, pero también a trabajar en grupo y a valorar el esfuerzo personal. Aunque finalmente sea yo quien les dé la solución para que comparen lo real con lo que han hecho y corrijan sus errores (...) muchas veces el profesor desanima al alumno. Si el alumno no alcanza los conocimientos hay que ayudarle a conseguir los objetivos a través de distintos métodos que le ayuden»(G1.Mujer Ed.Infantil).

"A mí me gustaría que los alumnos comprendieran la importancia de descubrir cosas, mediante la motivación y las ganas de aprender. Para ello sería positivo que pudieran ayudarse unos a otros, participando en trabajos grupales que le sirvan para interiorizar mejor los conceptos (...) creo que eso se consigue mirando con esperanza a los alumnos, tratando de dar explicaciones claras y preocupándonos por poner en práctica la teoría todos los días y en la medida de lo posible.»(G2. Mujer. Ed.Primaria.).

En efecto, todas las argumentaciones expresadas han consolidado un mayor conocimiento acerca de las percepciones de los estudiantes sobre el hecho educativo. Sin embargo, en todo caso, hemos tenido en cuenta que el factor de deseabilidad social podría ocultar en ciertos momentos la expresión sincera de cuál sería su comportamiento real en el aula.

En relación con la edad, los resultados obtenidos en la escala confirman un patrón ascendente hacia los estilos de enseñanza activos. Es decir, cuanto mayor es la edad del alumnado mayor es la inclinación hacia estilos más activos. 


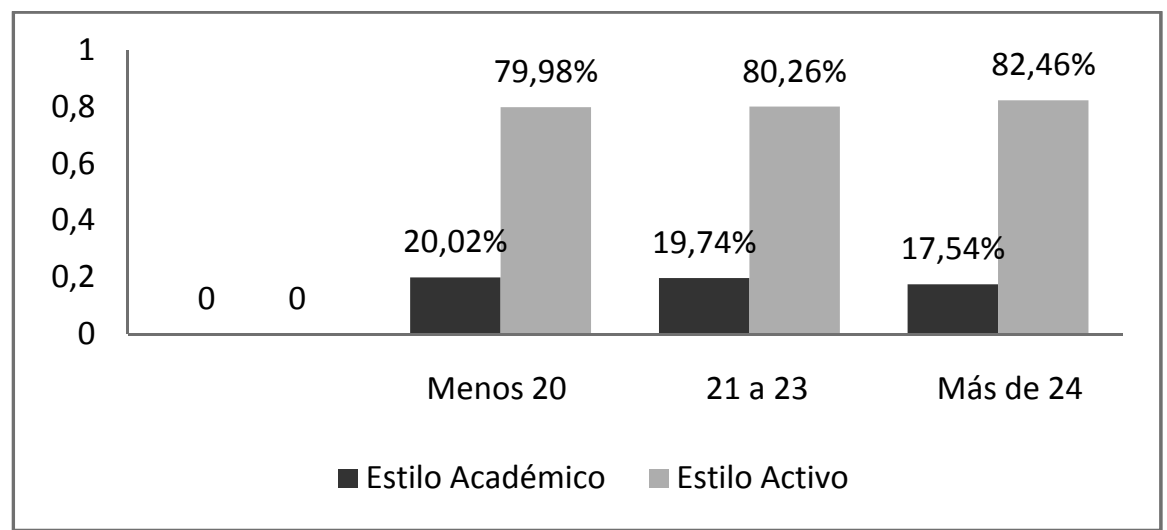

Gráfico 3. Estilos de enseñanza en función de la edad de la muestra

Esta tendencia no se ha podido constatar en el análisis de contenido de los textos fruto de los grupos de discusión o las entrevistas.

\section{Análisis inferencial}

El análisis inferencial se llevó a cabo bajo tres situaciones. Para las variables especialidad y edad se ha aplicado un diseño multigrupo con el propósito de verificar la relación funcional entre estas categorías y los estilos de enseñanza utilizando el análisis de varianza (ANOVA) de un factor. En la tabla 2 y 3 se recoge el análisis de varianza en función de la especialidad y la edad. Los resultados muestran que ambas dimensiones, son fuentes significativas de variación, por lo que se deriva la existencia de un estilo preferente en función de la especialidad que se curse.

Los resultados confirman que los integrantes de la muestra que cursan Educación Infantil poseen en mayor medida creencias coherentes con estilos de enseñanza activos, estableciendo diferencias significativas con los estudiantes de Educación Física y Educación Primaria. Le suceden los estudiantes de Lengua Extranjera, existiendo diferencias significativas con los alumnos de Educación Física, quienes en la muestra recogida son los que manifiestan una percepción menos proclive a estilos activos.

Atendiendo al estilo académico, observamos que los integrantes de la muestra de Educación Infantil se revelan como significativamente menos tradicionales en relación con los estudiantes de Educación Primaria y Educación Física. Seguido de los alumnos de Educación Musical y Lengua Extranjera. Siendo el alumnado de Educación Física el que presenta una mayor propensión hacia el estilo académico. 


\begin{tabular}{|c|c|c|c|c|}
\hline FACTORES & Media & $\mathrm{F}$ & Sig. & HSD de TUKEY Sig.* \\
\hline \multirow[t]{5}{*}{ Estilo Activo } & Ed. Infantil: 85,80 & \multirow[t]{5}{*}{12,00} & \multirow[t]{5}{*}{0,000} & \multirow{5}{*}{$\begin{array}{l}\text { Ed.Infantil-Ed.Primaria: } \\
\text { 0,000 } \\
\text { Ed.Infantil-Ed.Física:0,000 } \\
\text { Ed Física-L.Extranjera: } \\
\text { 0,006 }\end{array}$} \\
\hline & Ed. Primaria: 82,06 & & & \\
\hline & Ed. Física: 79,87 & & & \\
\hline & Ed. Musical: 83,35 & & & \\
\hline & Ed.Extranjera: 84,24 & & & \\
\hline \multirow{5}{*}{$\begin{array}{l}\text { Estilo Aca- } \\
\text { démico }\end{array}$} & Ed. Infantil:11,93 & \multirow[t]{5}{*}{10,30} & \multirow[t]{5}{*}{0,000} & \multirow{5}{*}{$\begin{array}{l}\text { Ed.Infantil-Ed.Primaria: } \\
\text { 0,000 } \\
\text { Ed.Infantil-Ed.Física: 0,000 } \\
\text { Ed.Física-Ed.Musical: 0,014 } \\
\text { Ed.Física-L.Extranjera: } \\
\text { 0,026 }\end{array}$} \\
\hline & Ed. Primaria:13,58 & & & \\
\hline & Ed. Física:14,38 & & & \\
\hline & Ed. Musical:12,30 & & & \\
\hline & Ed.Extranjera:12,62 & & & \\
\hline
\end{tabular}

* La diferencia de medias es significativa al nivel .005

Tabla 2. Análisis de varianza y HSD de Tukey por especialidad

$\mathrm{Al}$ analizar si la edad influye en la configuración de los estilos de enseñanza en la muestra estudiada, hemos concluido que efectivamente existen diferencias en torno al estilo activo entre los rangos comprendidos entre 21-23 años y más de 24 años. Siendo estos últimos los que evidencian una mayor inclinación hacia estilos activos.

\begin{tabular}{|c|c|c|c|c|}
\hline FACTORES & Media & $\mathrm{F}$ & Sig. & HSD de TUKEY Sig. \\
\hline \multirow[t]{3}{*}{ Estilo Activo } & 18-20 años: 83,73 & \multirow[t]{3}{*}{3,324} & \multirow[t]{3}{*}{0,037} & \multirow{3}{*}{$\begin{array}{c}\text { *Diferencias entre } 21-23 \text { y } \\
24 \text { o más = sig } 0,029\end{array}$} \\
\hline & 21-23 años: 83,06 & & & \\
\hline & 24 o más: 85,24 & & & \\
\hline \multirow[t]{3}{*}{ Estilo académico } & $18-20$ años: 12,88 & \multirow[t]{3}{*}{1,145} & \multirow[t]{3}{*}{0,319} & \\
\hline & 21-23 años: 12,89 & & & \\
\hline & 24 o más: 12,33 & & & \\
\hline
\end{tabular}

* La diferencia de medias es significativa al nivel .05

Tabla 3. Análisis de varianza y HSD de Tukey por edad

Para la variable sexo, hemos utilizado un diseño unifactorial intersujetos. En consecuencia, mediante la diferencia de medias (prueba t) interpretamos si las medias correspondientes a dos grupos difieren de manera significativa. De esta forma, hemos corroborado la existencia de diferencias significativas entre los sexos en las dos dimensiones estudiadas. En la Tabla 4 se muestran las medias, la prueba t y el nivel de significación, sobre cómo 
se comportan los estilos en función del sexo. En vista de los resultados se concluye que el sexo influye en la conformación de un estilo de enseñanza preferente.

\begin{tabular}{|l|l|c|c|}
\hline \multicolumn{1}{|c|}{ FACTORES } & \multicolumn{1}{|c|}{ Media } & T & Sig. \\
\hline \multirow{2}{*}{ Estilo Activo } & Hombre: 79,91 & $-6,028$ & 0,000 \\
\cline { 2 - 2 } & Mujer : 84,55 & & \\
\hline Estilo Académico & Hombre: 14,09 & \multirow{2}{*}{4,414} & 0,000 \\
\cline { 2 - 2 } & Mujer: 12,49 & & \\
\hline
\end{tabular}

Tabla 4. Prueba t de Student para el contraste de medias de muestras independientes

\section{CONCLUSIONES Y DISCUSIÓN}

Dada la escasez de investigaciones sobre las creencias y opiniones de los futuros maestros en torno al estilo de enseñanza a adoptar en su función docente, este estudio ha buscado la complementariedad entre los paradigmas cualitativo y cuantitativo, con el propósito de precisar, describir y comprender una realidad. Todo ello, a través de un marco metodológico que enriquece el estudio, capitalizando las contribuciones de diferentes técnicas y fuentes de recogida de datos, para así poder comparar y comprobar la exactitud de los aportes conseguidos.

La credibilidad de esta investigación se sustenta en el hecho de que el objeto de estudio, "conocer las representaciones y creencias que sobre los estilos de enseñanza tienen los alumnos del último curso de Magisterio en la Comunidad de Galicia», fue identificado y descrito a través de las propias manifestaciones y juicios críticos de los protagonistas de las tres universidades, y por tanto, los comportamientos descritos y analizados son los que realmente existen en los contextos señalados. Esta credibilidad también está reflejada en la triangulación de datos, de perspectivas, e instrumentos de recogida de información con la intención de conseguir la corroboración de testimonios y la coherencia estructural con respecto a las creencias del alumnado y realizando diferentes comprobaciones a lo largo del estudio.

Como principal conclusión podemos afirmar que existe un predominio, en el discurso de los futuros docentes, de un vocabulario ligado a concepciones activas y humanistas unidas al corpus defendido por los teóricos de la educación. A propósito de lo referido anteriormente, Delgado, Medina y Viciana (1996) han investigado sobre la preferencia de los estilos de enseñanza de los estudiantes de formación inicial del profesorado de la especia- 
lidad de Educación Física. Los resultados indican una clara tendencia hacia estilos activos y una valoración negativa hacia estilos tradicionales. En un estudio posterior, Delgado (1998) analiza los estilos de enseñanza en estudiantes en formación inicial de Educación Física y profesores en ejercicio de su profesión. En ambos casos hay un manifiesto predominio de los estilos activos frente a los estilos tradicionales.

Esta tendencia hacia estilos centrados en el alumno es más acusada entre los futuros profesores de Educación Infantil. Evidentemente, no podemos afirmar, a partir de los datos recogidos, que las creencias positivas hacia estilos activos signifique una apropiación sustantiva de este comportamiento en sus futuras prácticas educativas. Sin embargo, al no manifestarse contradicciones en el discurso de los estudiantes, podemos asegurar que, en su mayoría, han interiorizado la importancia de adoptar estilos de enseñanza activos, dinamizadores y coherentes con los principios de individualización, cooperación y enseñanza reflexiva, entre otros.

Por otro lado, la realidad nos muestra que los profesores de Educación Infantil han sido pioneros en el diseño de proyectos de innovación educativa y en la intervención educativa que realizan suelen utilizar técnicas y métodos activos de aprendizaje.

Convenimos en que en las exposiciones, los estudiantes no evidencian el agotamiento de un estilo de enseñanza academicista sustentado en la transmisión de conocimientos. Sin embargo, las características que configuran principalmente su representación de la práctica educativa se basa fundamentalmente en un estilo activo de la enseñanza. Podemos observar que, en modo alguno, el marco pedagógico de la formación docente mantiene configuraciones didácticas que repiten aspectos del modelo tradicional, que justamente se intentan transformar. Más bien descubrimos la existencia de una asunción de un estilo mixto de enseñanza, el cual consideran conveniente para atender las necesidades educativas del alumnado y los distintos ritmos y estilos de aprendizaje.

En consecuencia, el presente estudio nos ha brindado los soportes sustanciales para identificar las creencias y los núcleos teóricos en los que se apoyan las imágenes que poseen los estudiantes en formación acerca del acto educativo y sus vicisitudes, lo que tiene múltiples implicaciones teóricas, metodológicas y prácticas. Nuestro propósito es, a partir del análisis de la situación real en torno a la percepción de los propios estilos educativos, ayudar a los futuros docentes a realizar un análisis reflexivo y crítico sobre su forma de actuar y pensar en relación con el proceso educativo. Circunstancia que aporta información con alcance para la investigación, así como para los alumnos de Magisterio y profesionales de la educación. 
Dado que parece que los resultados muestran que los futuros profesores optan por estilos activos de enseñanza, futuras investigaciones deberían evaluar otras variables como la influencia de la organización del centro en la configuración de los estilos, los factores institucionales que inciden en la adquisición de una tendencia determinada: tamaño grupo-clase, recursos, legislación educativa, entre otros. En todo caso, confiamos en que los resultados encontrados hasta ahora y los futuros ayudarán a diseñar programas más eficaces de formación inicial del profesorado y una intervención educativa más precisa. Como apunta Martín-Cuadrado y Sánchez-Elvira (2010) las características individuales y el comportamiento humano no son rasgos inamovibles, por lo que se pueden modificar las actuaciones que resultan ineficientes y entrenar aquellas que son convenientes para el buen desempeño de la tarea educativa.

En última instancia y como síntesis de las ideas expuestas destacamos el pensamiento de Román (2008, p. 32): «si enseñar es ayudar a aprender, y para aprender hay que estar mentalmente activos, el maestro debe ayudar a aprender utilizando una serie de habilidades docentes básicas y motivadoras. Habilidades que concebimos como, todas aquellas acciones, conductas, actitudes y patrones de comportamiento implicados habitualmente en el aula, que se presentan íntimamente ligadas a las diferentes competencias, estilos de enseñanza-aprendizaje, y a las propias funciones y finalidades de la enseñanza».

De ahí la importancia de precisar cuáles son las razones por las cuáles los profesores manifiestan reiteradamente modelos tradicionales en el aula, si su pensamiento y actitudes están más dirigidas a modelos activos. 


\section{REFERENCIAS BIBLIOGRÁFICAS}

Anderson, H. H. (1945). Domination and social integration in the behavior of kindergarten children and teachers. Genetic psychological monographs, 21, 287-385.

Ballesta, F; Izquierdo, T y Romero, B. (2011). Percepción del alumnado de Pedagogía ante el uso de metodologías activas. Educatio Siglo XXI, 29 (2), 353-368.

Blanco Felip, F.; Jové Deltell, M.C. y Reverter Masià, J. (2012). Paradigma estratégico para el desarrollo de habilidades competenciales. Estudio descriptivo sobre la variabilidad en la percepción de habilidades competenciales de 40 alumnos de educación física en fase de formación inicial. Educación XX1, 15 (2), 231-248.

Coldren, J. y Hively, J. (2009). Interpersonal teaching style and student impression formation. College Teaching, 57 (2), 93-98.

Delgado, M.A. (1991). Los Estilos de Enseñanza en la Educación Física. Propuesta para una reforma de la enseñanza. Granada: Universidad de Granada.

Delgado, M. A. (1994). Intervención didáctica en Primaria. Implicaciones en la Formación del Maestro especialista. En S. Romero (Comps.). Didáctica de la E.F.: Diseños Curriculares en Primaria (pp. 111-117). Sevilla: Wanceulen.

Delgado, M.A. (1998). Comparación de la valoración de los Estilos de Enseñanza por los futuros profesores de Educación Física durante la Formación Inicial y Profesores de Educación Física en Formación. Lecturas de Educación Física. Recuperado de: http:// w.w.w.sir.ca/revista/
Delgado, M.A.; Medina, J. y Viciana, J. (1996). The Teaching Styles in the Preservice of Physical Education Teachers. International Seminar AIESEP. Lisbon.

Doménech Betoret, F. (2012). Análisis de los estilos de pensamiento que utilizan los profesores españoles en el aula. $R e$ vista de Educación. 358, 497-522.

Cea D'ancona, M. A. (1999). Métodos y Técnicas de Investigación Cuantitativa. Madrid: Editorial Síntesis.

Feiman-Nemser, S. (2001). From Preparation to Practice: Designing a Continuum to Strengthen and Sustain Teaching. Teachers College Record, 103(6), 1.013-1.055.

Flanders, N.A. (1984). Análisis de la interacción didáctica. Madrid: Anaya.

Gargallo, B. (2008). Estilos de docencia y evaluación de los profesores universitarios y su influencia sobre los modos de aprender de sus estudiantes. Revista Española de Pedagogía, 241, 425-446.

Gargallo, B.; Sánchez, F.; Ros, C. y Ferreras, A. (2010). Estilos docentes de los profesores universitarios. La percepción de los alumnos de los buenos profesores. Revista Iberoamericana de Educación, 51 (4), 1-16.

González Peiteado, M. (2010). Estilos de enseñanza: Un constructo nuclear de gran impacto en la praxis docente. $R e$ vista Educación y Futuro Digital. Recuperado de www.cesdonbosco.com/ revista/articulos2010/

González-Peiteado, M. (2013). Los estilos de enseñanza y aprendizaje como soporte de la actividad docente. Revista de estilos de aprendizaje 11, 51-70. Recuperado de http://www.uned.es/re- 
vistaestilosdeaprendizaje/numero_11/ lsr_11_abril_2013.pdf

González-Peiteado, M. y Aznar-Cuadrado, V. (2010) Aproximación al perfil de estilos de enseñanza en la formación inicial del profesorado de Educación Secundaria: nuevos canales, nuevos retos. Actas del I Congreso Internacional Reinventar la profesión docente. (pp. 348-356). Málaga.

González-Peiteado, M. (2012). Las representaciones sobre los estilos de enseñanza en la construcción del rol docente. Tesis doctoral inédita. Universidad de Vigo.

González-Peiteado, M.; Lopez-Castedo, A. y Pino-Juste, M. (2013). Análisis psicométrico de una Escala sobre Estilos de Enseñanza (ESEE). Revista Enseñanza \& Teaching, 31 (1) 181-198.

Hood, J., Poulson, R., Mason, S., Walker, T. y Dixon, J. (2009). An examination of traditional and nontraditional students» evaluations of professorial leardership styles: transformational versus transactional approach. Journal of the Scholarship of Teaching and Learning, 9 (1), 1-12.

Lickert, R. (1953). A technique for the measurement of attitudes. Archives of Psychology, 22 (140), 1-55.

Lozano Rodríguez, A (2004). Estilos de aprendizaje y enseñanza. Sevilla: MAD.

Marcelo García, C. (2009). Formalidad e Informalidad en el Proceso de Aprender a Enseñar. Revista de Educación, 350, 31-35.

Martín-Cuadrado, A.M. (2011). Competencias del estudiante autorregulado y los estilos de aprendizaje. Revista Estilos de Aprendizaje, 8 (8). Recuperado de www.uned.es/revistaestilosdeaprendizaje/...8/.../lsr_8_articulo_8.pdf
Martín-Cuadrado y Sánchez-Elvira, A. (2010). Ser estudiante a distancia, diferencias individuales y aprendizaje autónomo. En Sánchez García, M. ${ }^{a}$ F y otras (coords) Entrenamiento en competencias para el estudio autorregulado. Madrid: UNED.

McMillan, J. y Schumacher, S. (2005). Investigación Educativa. Madrid: Pearson Educación.

Michel, N., James, J. y Varela, O. (2009). Active versus passive teaching styles: an empirical study of student learning outcomes. Human Resource Development Quarterly, vol. 20 (4), 397-418.

Monereo, C. y Pozo, J. I. (2003). La universidad ante la nueva cultura educativa. Madrid: Síntesis.

Nevot Luna, A y Cuevas Cava, V. (2009). Los estilos de aprendizaje y el Espacio Europeo de Educación Superior. Un paseo por el aula de matemáticas. Revista de Estilos de Aprendizaje 3 (3) 38-56.

Pino, M.; Domínguez, J. y López, A. (2007). Evaluating appreciation of measures attending to pupil diversity (EMAD). Psychological Reports, 100, 783-786.

Rodríguez, O. (2005). La Triangulación como Estrategia de Investigación en Ciencias Sociales. Revista de Investigación en Gestión de la Innovación y Tecnología. 31. Recuperado de http:// www.madrimasd.org/revista/revista31/ tribuna/tribuna2.asp

Román, J. M. (2008). Psicología de la instrucción. Universidad de Valladolid: Departamento de Psicología. Documento mimeografiado.

Samuelowicz, K. y Bain, J.D (2002). Identifying academics» orientatios to assessment practice. Higher Education, 43, 173-201. 
Smith, R. M. (1988). Learning how to learn. Milton Keynes, UK: Open University Press.

Stake, R. E. (1998). Investigación con estudio de casos. Madrid: Ediciones Morata.

Tejada Fernández, J. (2011). La alternancia de contextos para la adquisición de competencias profesionales en escenarios complementarios de Educación
Superior: Marco y estrategia. Educación XX1. 15 (2), 17-40

Weltman, D. y Whiteside, M. (2010). Comparing the Effectiveness of Traditional and Active Learning Methods in Business Statistics: Convergence to the Mean. Journal of Statistics Education 18, 1. Recuperado de http://www. amstat.org/publications/jse/v18n1/weltman.pdf. 


\section{ANEXO 1}

Escala sobre Estilos de Enseñanza (ESEE)

\section{DATOS DE IDENTIFICACIÓN}

1. Universidad de

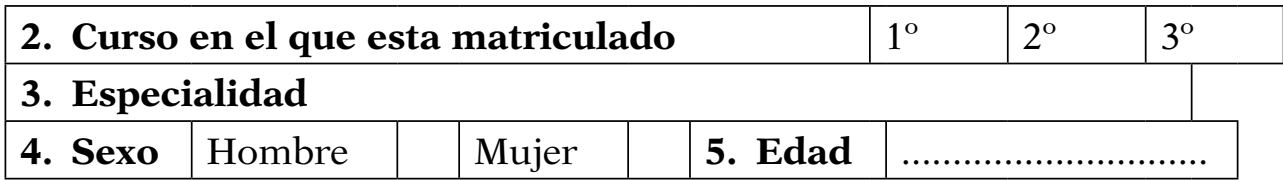

\begin{tabular}{|l|l|l|l|l|}
\hline \multicolumn{1}{|c|}{ Grado de pertinencia } & $\begin{array}{c}1 \\
\text { Nunca }\end{array}$ & $\begin{array}{c}2 \\
\text { Raras } \\
\text { veces }\end{array}$ & $\begin{array}{c}3 \\
\text { Frecuente }\end{array}$ & $\begin{array}{c}4 \\
\text { Siempre }\end{array}$ \\
\hline $\begin{array}{l}\text { 1. El verdadero aprendizaje es aquel } \\
\text { que se produce a través de un proce- } \\
\text { so de descubrimiento del alumno. }\end{array}$ & & & & \\
\hline $\begin{array}{l}\text { 2. Favorecer la adquisición de hábitos } \\
\text { de convivencia en grupo y de respeto } \\
\text { a los otros. }\end{array}$ & & & & \\
\hline $\begin{array}{l}\text { 3. Valorar positivamente las aportacio- } \\
\text { nes del alumnado. }\end{array}$ & & & \\
\hline $\begin{array}{l}\text { 4. Los niños llegarán a los conocimien- } \\
\text { tos a través de la experiencia, de la } \\
\text { búsqueda y el tanteo. }\end{array}$ & & & \\
\hline $\begin{array}{l}\text { 5. El principal fin de la evaluación es } \\
\text { calificar a los alumnos. }\end{array}$ & & & & \\
\hline $\begin{array}{l}\text { 6. Hay que fomentar actividades que re- } \\
\text { quieran cooperación y colaboración. }\end{array}$ & & & & \\
\hline $\begin{array}{l}\text { 7. El docente debe ser original e imagi- } \\
\text { nativo. }\end{array}$ & & & & \\
\hline $\begin{array}{l}\text { 8. Ofrecer a los estudiantes la oportuni- } \\
\text { dad de trabajar con diferentes mate- } \\
\text { riales y bajo diferentes condiciones. }\end{array}$ & & & & \\
\hline $\begin{array}{l}\text { 9. La enseñanza debe girar en torno al } \\
\text { profesor. }\end{array}$ & & & \\
\hline $\begin{array}{l}\text { 10. Importante potenciar la autode- } \\
\text { terminación y al autocontrol del } \\
\text { alumno. }\end{array}$ & & & & \\
\hline
\end{tabular}




\begin{tabular}{|c|c|c|c|c|}
\hline Grado de pertinencia & $\begin{array}{c}1 \\
\text { Nunca }\end{array}$ & $\begin{array}{c}2 \\
\text { Raras } \\
\text { veces }\end{array}$ & $\begin{array}{c}3 \\
\text { Frecuente }\end{array}$ & $\begin{array}{c}4 \\
\text { Siempre }\end{array}$ \\
\hline $\begin{array}{l}\text { 11. La evaluación es el único indicador } \\
\text { fiable de la calidad del aprendizaje. }\end{array}$ & & & & \\
\hline $\begin{array}{l}\text { 12. La relación alumnos-padres-profe- } \\
\text { sores deben regular la vida en las } \\
\text { aulas. }\end{array}$ & & & & \\
\hline $\begin{array}{l}\text { 13. Es importante que el educando } \\
\text { sienta como propias las metas pro- } \\
\text { puestas por el grupo. }\end{array}$ & & & & \\
\hline $\begin{array}{l}\text { 14. Hay que favorecer las relaciones in- } \\
\text { terpersonales de los alumnos }\end{array}$ & & & & \\
\hline $\begin{array}{l}\text { 15. Los padres deben participar en la } \\
\text { elaboración de los fines educativos } \\
\text { de la formación del alumno. }\end{array}$ & & & & \\
\hline $\begin{array}{l}\text { 16. Fomentar la aportación de ideas } \\
\text { nuevas }\end{array}$ & & & & \\
\hline $\begin{array}{l}\text { 17. Los objetivos deben tener en cuen- } \\
\text { ta las necesidades e intereses del } \\
\text { alumnado. }\end{array}$ & & & & \\
\hline $\begin{array}{l}\text { 18. La enseñanza debe ajustarse al rit- } \\
\text { mo que marque cada niño. }\end{array}$ & & & & \\
\hline $\begin{array}{l}\text { 19. La participación del alumno en el } \\
\text { proceso de enseñanza-aprendizaje } \\
\text { motiva al alumno a perseguir los } \\
\text { objetivos fijados. }\end{array}$ & & & & \\
\hline $\begin{array}{l}\text { 20. El profesor debe poner más énfasis } \\
\text { en el dominio de conocimientos que } \\
\text { en la adquisición de actitudes. }\end{array}$ & & & & \\
\hline $\begin{array}{l}\text { 21. Es mejor que los niños se agrupen } \\
\text { en sectores por su mayor o menor } \\
\text { aptitud. }\end{array}$ & & & & \\
\hline $\begin{array}{l}\text { 22. El trabajo en grupo provoca la dis- } \\
\text { persión en el alumno y por tanto el } \\
\text { aprendizaje superficial. }\end{array}$ & & & & \\
\hline $\begin{array}{l}\text { 23. Es fundamental estimular a los } \\
\text { alumnos para que aprendan por si } \\
\text { mismos. }\end{array}$ & & & & \\
\hline $\begin{array}{l}\text { 24. Hay que mantener niveles elevados } \\
\text { de rendimiento escolar y tener poca } \\
\text { tolerancia con aquellos que rinden } \\
\text { menos de lo esperado. }\end{array}$ & & & & \\
\hline
\end{tabular}




\begin{tabular}{|c|c|c|c|c|}
\hline Grado de pertinencia & $\begin{array}{c}1 \\
\text { Nunca }\end{array}$ & $\begin{array}{c}2 \\
\text { Raras } \\
\text { veces }\end{array}$ & $\begin{array}{c}3 \\
\text { Frecuente }\end{array}$ & $\begin{array}{c}4 \\
\text { Siempre }\end{array}$ \\
\hline $\begin{array}{l}\text { 25. Se deben relacionar los conoci- } \\
\text { mientos de unas materias con otras } \\
\text { cuantas veces sea posible. }\end{array}$ & & & & \\
\hline $\begin{array}{l}\text { 26. Cuando un discente fracasa en una } \\
\text { tarea es importante estimularle a } \\
\text { repensar la actividad y formular } \\
\text { nuevas alternativas de trabajo. }\end{array}$ & & & & \\
\hline $\begin{array}{l}\text { 27. Lo importante es que cada niño in- } \\
\text { tervenga en la búsqueda, discusión, } \\
\text { consulta, aunque esto conlleve más } \\
\text { tiempo. }\end{array}$ & & & & \\
\hline $\begin{array}{l}\text { 28. Es más importante la enseñanza de } \\
\text { técnicas de estudio y de investiga- } \\
\text { ción que la transmisión de un cuer- } \\
\text { po de conocimiento. }\end{array}$ & & & & \\
\hline $\begin{array}{l}\text { 29. Es importante utilizar los agrupa- } \\
\text { mientos de los alumnos como vía } \\
\text { para favorecer la participación en } \\
\text { procesos de aprendizaje. }\end{array}$ & & & & \\
\hline $\begin{array}{l}\text { 30. El docente debe provocar la re- } \\
\text { flexión. }\end{array}$ & & & & \\
\hline $\begin{array}{l}\text { 31. Es necesario motivar a los alumnos } \\
\text { a aprender de forma autónoma }\end{array}$ & & & & \\
\hline
\end{tabular}


ANEXO 2

Plantilla de categorización de la información de las entrevistas.

\begin{tabular}{|c|c|c|c|c|c|c|c|c|c|c|c|c|c|}
\hline \multirow[t]{2}{*}{ Dimensiones } & \multicolumn{6}{|c|}{ Especialidad } & \multicolumn{3}{|c|}{ Sexo } & \multicolumn{4}{|c|}{ Edad } \\
\hline & $\mathrm{I}$ & $\mathrm{P}$ & M & EF & LE & $\mathrm{T}$ & $\mathrm{H}$ & M & $\mathrm{T}$ & -20 & $\begin{array}{c}21- \\
23 \\
\end{array}$ & +20 & $\mathrm{~T}$ \\
\hline \multicolumn{14}{|l|}{ Estimula la reflexión } \\
\hline \multicolumn{14}{|l|}{ Motiva } \\
\hline \multicolumn{14}{|l|}{$\begin{array}{l}\text { Promueve la capacidad } \\
\text { crítica }\end{array}$} \\
\hline \multicolumn{14}{|c|}{ Fomenta la participación } \\
\hline \multicolumn{14}{|l|}{ Impulsa la socialización } \\
\hline \multicolumn{14}{|l|}{ Favorece la creatividad } \\
\hline \multicolumn{14}{|c|}{$\begin{array}{l}\text { Estimula el pensamiento } \\
\text { divergente }\end{array}$} \\
\hline \multicolumn{14}{|l|}{ Es divertido } \\
\hline \multicolumn{14}{|l|}{$\begin{array}{l}\text { Guía el proceso de } \\
\text { aprendizaje }\end{array}$} \\
\hline \multicolumn{14}{|l|}{\begin{tabular}{|l|} 
Transmisor \\
\end{tabular}} \\
\hline \multicolumn{14}{|l|}{$\begin{array}{l}\text { No favorece la } \\
\text { comunicación }\end{array}$} \\
\hline \multicolumn{14}{|l|}{ Excesiva rigidez } \\
\hline \multicolumn{14}{|l|}{$\begin{array}{l}\text { No individualiza la } \\
\text { enseñanza }\end{array}$} \\
\hline $\begin{array}{l}\text { Centrado en la } \\
\text { competencia acadé- } \\
\text { mica }\end{array}$ & & & & & & & & & & & & & \\
\hline
\end{tabular}




\section{PALABRAS CLAVE}

Estilos de enseñanza, investigación educativa, triangulación, creencias.

\section{KEY WORDS}

Teaching styles, educational research, triangulation, beliefs.

\section{PERFIL ACADÉMICO Y PROFESIONAL DE LAS AUTORAS}

Margarita González-Peiteado, Doctora en Ciencias de la Educación por la Universidad de Vigo. Licenciada en Ciencias de la Educación por la UNED.

Ha impartido docencia en la Universidad de Vigo y en la actualidad es profesora-tutora del Centro Asociado de la UNED en Pontevedra.

Sus líneas de investigación están centradas en la Formación Inicial del Profesorado y los Estilos Docentes. Ha participado en Congresos y ha realizado numerosas investigaciones y publicaciones en revistas del ámbito educativo indizadas en prestigiosas bases de datos y con elevado índice de impacto. Igualmente ha participado en varios proyectos sobre formación inicial del profesorado.

Margarita Pino-Juste, Doctora en Filosofía y Ciencias de la Educación por la Universidad de Santiago de Compostela. Profesora Titular del Departamento de Didáctica, Organización escolar y Métodos de Investigación. Facultad de Ciencias de la Educación y del Deporte. Pontevedra Sus líneas de investigación están centradas en el diseño y desarrollo de programas de educación para la salud y proyectos colaborativos en centros. Ha participado en varios congresos, así como en libros y revistas de impacto nacional e internacional.

Dirección postal de las autoras: Margarita Pino-Juste Universidad de Vigo Profesora Titular del Departamento de Didáctica, Organización Escolar y Métodos de Investigación.

Facultad de Ciencias de la Educación y del Deporte Pontevedra E-mail: mpino@uvigo.es Margarita González Peiteado UNED

E-mail: margonzalez@pontevedra. uned.es 
Fecha Recepción del Artículo: 15. Diciembre. 2011

Fecha Revisión del Artículo: 22. Abril. 2012

Fecha Aceptación del Artículo: 16. Agosto. 2012

Fecha de Revisión para publicación: 24. Junio. 2013 


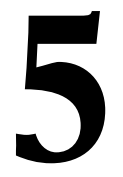

FORMACIÓN DEL PROFESORADO UNIVERSITARIO EN TIC. APLICACIÓN DEL MÉTODO DELPHI PARA LA SELECCIÓN DE LOS CONTENIDOS FORMATIVOS

\author{
(UNIVERSITY TEACHER TRAINING IN ICT. APPLICATION OF DELPHI \\ METHOD FOR THE SELECTION OF TRAINING CONTENT)
}

Julio Cabero Almenara

Universidad de Sevilla

DOI: 10.5944/educxx1.17.1.10707

Cómo referenciar este artículo/How to reference this article:

Cabero Almenara, J. (2014). Formación del profesorado universitario en TIC. Aplicación del método Delphi para la selección de los contenidos formativos. Educación XX1, 17 (1), 111-132. doi: 10.5944/educxx1.17.1.10707.

Cabero Almenara, J. (2014). University teacher training in ICT. Application of Delphi method for the selection of training content. Educación XX1, 17 (1), 111-132. doi: 10.5944/educxx1.17.1.10707

\title{
RESUMEN
}

Uno de los problemas con que nos encontramos para la incorporación de las Tecnologías de la Información y Comunicación (TIC) es la formación que el profesorado tenga para su utilización didáctica. Con objeto de formar los bloques de contenidos que deberían tener una futura acción formativa del profesorado universitario en TIC, se llevó a cabo un estudio Delphi parcialmente «modificado». Se presenta, cómo se llevó a cabo la aplicación del estudio Delphi, el proceso seguido para determinar la lista definitiva de contenidos, y las características de los participantes en el trabajo. El estudio demuestra la eficacia de esta metodología para la configuración de programas de capacitación, y de forma más concreta las posibles temáticas de formación del docente universitario en TIC. También se ofrecen los diferentes descriptores que podrían incluirse en las temáticas de formación. En las conclusiones se ofrecen elementos para la mejora de la aplicación del método Delphi.

\section{ABSTRACT}

One of the problems we find for the incorporation of Information Technology and Communication (ICT) is the training that teachers receive for the didactical application of such tools. With the aim of forming the blocks of content that should have a future training activity of university teachers in 
ICT, we conducted a Delphi study partially «modified». We analyse how the implementation of the Delphi study was carried out, the process used to determine the final list of contents, and the characteristics of the participants in the study. Our analysis demonstrates the effectiveness of this methodology for setting up training programs, and more specifically the possible topics of training of university teachers in ICT. We also offer different descriptors to be included in the thematic of training. The conclusions point out elements for improving the application of the Delphi method.

\section{INTRODUCCIÓN}

Actualmente nos encontramos con una fuerte paradoja, por una parte las Tecnologías de la Información y Comunicación (TIC) están adquiriendo un fuerte protagonismo para la capacitación de los alumnos en los nuevos contextos formativos; al mismo tiempo se están realizando amplios esfuerzos económicos y en recursos humanos para facilitar su penetración en la práctica educativa universitaria (Uceda y Barro, 2010); y también nos encontramos con que los profesores tienen actitudes positivas para su utilización e incorporación en los procesos de formación del EEES (Jimoyiannis y Komis, 2007; Banas, 2010; Alvarez y otros, 2011). Pero en contrapartida, nos encontramos con que su introducción es marginal, más centrado en usos tradicionales que socioconstructivistas del aprendizaje, poco frecuentes de utilización, de usos para actividades tradicionales, más incorporadas a la investigación que la docencia y de uso más frecuente fuera de las aulas (Balanskat y otros, 2006; European Commission, 2006; Becta, 2007; Teo y otros, 2008; Maroto, 2007; Mcvee y otros, 2008).

Y ante este escenario cabe hacernos una serie de preguntas: ¿por qué tal situación?, ¿por qué incluso en las instituciones educativas con presencia física, y presencia física de calidad y novedad, y fácil acceso el profesorado muestra reticencia a su utilización?, ¿y por qué dicha situación se mantiene incluso después de haberse realizado muchas horas de acciones formativas?

Las respuestas que podemos ofrecer, van desde las creencias que los profesores tengan respecto al papel que las TIC puedan desempeñar en la enseñanza (Chen 2008; Teo, 2008), la cultura organizativa de las instituciones y las facilidades que se le den a los profesores para su utilización a través de centros de apoyo (Cabero y otros, 2010), la falta de materiales educativos de calidad (Pls Ramboll, 2004), hasta la poca alfabetización digital del profesorado para su utilización técnico-didáctica. Siendo esto último, desde nuestro punto de vista, lo que dificulta más su utilización (Valdes y otros, 2010; Ballestero y otros, 2010). Hammond y otros (2009) nos llaman la atención como la formación que los profesores han recibido en preservicio se 
convierten en un elemento determinante para la utilización posterior que realicen de las TIC en su práctica de la enseñanza.

Desde nuestro punto de vista, otra de las razones de esta baja utilización es el tipo de acción formativa realizada, centrada exclusivamente en la capacitación para el manejo instrumental de las tecnologías. Valga como ejemplo de lo que decimos el dato obtenido en su investigación por Goktas, y otros (2008), que cuando le preguntaron a los profesores de pre-servicio de Turquía que habían recibido cursos en TIC, que los valoraran, uno de sus hallazgos fue que aún reconociendo su eficacia, señalaban que mayoritariamente deberían ser rediseñados para que fueran más beneficioso para la práctica educativa, pues tenían un excesivo carácter instrumental y tecnológico. Resultados muy similares obtuvieron Valerio y Paredes (2008) en México, y Ballestero y otros (2010) en España.

\section{LA FORMACIÓN DEL PROFESORADO EN TIC}

Ya hemos realizado diferentes trabajos donde ofrecíamos nuestras ideas sobre la formación y el perfeccionamiento del profesorado en TIC, y en las cuales recogíamos diferentes aspectos referidos tanto a cómo debe abordarse la misma, como a las dimensiones a contemplar para su formación (Llorente, 2008; Romero y otros, 2012), y de ellos obtenemos las siguientes conclusiones: 1) que no es suficiente con llevar a cabo acciones para la formación del profesorado en TIC, sino que la misma debe hacerse con principios diferentes a los que hasta la fecha usualmente se han realizado, es decir, desde una óptica meramente de capacitación instrumental; 2) que la capacitación del docente en TIC debe incorporar diferentes tipos de dimensiones como son: instrumental, semiológica/estética, curricular, pragmática, psicológica, productora/diseñadora, seleccionadora/evaluadora, crítica, organizadora, actitudinal, e investigadora; y 3) que para su puesta en acción debemos asumir una serie de principios: el valor de la práctica y la reflexión sobre la misma, contemplar problemas reales para los docentes no para los formadores o los técnicos, la participación del profesorado en su construcción y determinación, su diseño como producto no acabado, centrarse en los medios disponibles, situarse dentro de estrategias de formación más amplias que el mero audiovisualismo y el alcance en consecuencia de dimensiones más amplias como la planificación, diseño y evaluación, su desarrollo en contextos naturales de enseñanza, la utilización de la deconstrucción de mensajes mediados como principios para el aprendizaje de su realización, y la coproducción de materiales entre profesores y expertos.

En esta línea de propuestas de formación, Mishra y Koehler (2006) y Koehler y Mishra (2008) han propuesto un modelo de análisis del fun- 
cionamiento de las TICs en los procesos de enseñanza-aprendizaje que denominan TPCK («Technological Pedagogical Content Knowledge»), y con el que pretenden explicar el conocimiento que debe tener el profesor para la integración de las TIC. En él se indica que se necesita la capacitación en tres grandes componentes: disciplinar, pedagógico y tecnológico. Tales dimensiones deben percibirse no de forma aislada sino en interacción, lo que nos permite identificar diferentes dimensiones para la capacitación: CC: Conocimiento sobre el contenido de la materia; CP: Conocer los procesos y prácticas del método de enseñanza; CCP: Conocimiento Pedagógico del Contenido; CT: Conocimiento de las TIC estándar que se utilizan en la enseñanza; CPT: Conocimiento de la utilización de las TIC en los procesos de enseñanza; y CTPC: Conocimiento Tecnológico, pedagógico y de contenido.

Lo importante de esta propuesta estriba en la importancia que le conceden al componente didáctico, y su relación de la formación con otras variables curriculares, rechazando abiertamente que la capacitación se centre exclusivamente en elementos tecnológicos e instrumentales. Aspecto en el cual coinciden con Merma (2008) que nos habla que las competencias que deben poseer los profesores para la incorporación de las TIC son de tipo cognoscitiva (conocimiento de su disciplina), técnica (dominio de las TIC), de aplicaciones pedagógicas (conocimiento de las posibilidades que ofrecen como herramientas educativas), metodológicas (aplicación de procedimientos adecuados), de actitud positiva y crítica hacia ellas, facilitadora del proceso de enseñanza-aprendizaje, de habilidad para que sus alumnos las incorporen en su aprendizaje, de destreza para elegir adecuadamente los recursos tecnológicos, de formarse y capacitarse permanentemente en su uso, habilidad para trabajar cooperativamente en redes, y de ser un evaluador constante.

Una aportación que puede ser significativa es la ofrecida por Kirschner y Davis (2003, p. 145), que tras analizar 26 acciones formativas que podían considerarse de buenas prácticas, llegan a proponer seis grandes bloques que deberían poseer todas las acciones formativas que se desarrollen:

1. Competente para el uso personal de las TIC;

2. Competente para hacer uso de las TIC como herramientas de la mente («Mindtool»);

3. Dominio de una serie de paradigmas educativos que hacen uso de las TIC;

4. Competente para hacer uso de las TIC como una herramienta para la enseñanza; 
5. Maestro de una amplia gama de paradigmas de evaluación que hacen uso de las TIC;

6. Y comprender la dimensión política de la utilización de las TIC para la enseñanza y el aprendizaje.

Por su parte, Oliveira y otros (2010) nos llaman la atención respecto a que la formación y el perfeccionamiento del profesorado en TIC, debe perseguir cuatro grandes metas:

- Crear y/o utilizar tecnologías teniendo en cuenta diseños pedagógicos específicos.

- Identificar y seleccionar las tecnologías más apropiadas para un diseño pedagógico, teniendo en cuenta sus posibilidades y limitaciones, produciendo y permitiendo a los estudiantes producirlas.

- Usar y/o modificar herramientas tecnológicas, generalmente diseñadas para contextos empresariales o de entretenimiento, en contextos creativos y educacionales.

- Y entender y comprender qué cambia en educación cuando se utilizan nuevas tecnologías.

En nuestro contexto Prendes (2010) ha dirigido una de las investigaciones más rigurosa sobre las competencias que deberían tener los profesores universitarios para el dominio de las TIC, en concreto perseguía los siguientes objetivos: elaboración de un catálogo de indicadores referidos a las competencias TIC, y desarrollo de una propuesta formativa en función de los indicadores para mejorar las competencias TIC. También en su trabajo nos propone establecer tres niveles de acciones formativas: 1) Dominio de las bases fundamentales de la acción con TIC: 2) Diseño, implementación y evaluación de la acción educativa con TIC; y 3) Análisis, reflexión y difusión de la acción llevada a cabo con TIC (Prendes, 2010, pp. 169-173).

En esta línea, resaltamos también las propuestas de estándares de capacitación tecnológica y didáctica del profesorado en TIC, formuladas por el «National Council for Acceditation» (NCATE, 1997), por el Departamento de Educación de Australia (Pearson, 2003), por la «International Society for Technology in Education» (2008), o la del Ministerio de Educación de Chile (2008).

Si nos gustaría señalar que somos partidarios de que el profesorado reciba una capacitación conceptual respecto a cómo las TIC se comportan en 
los ambientes educativos, y permiten la transformación de los mismos. Tal capacitación transformarán las creencias que tengan respecto a las TIC, así como también les permitirá tomar decisiones para adaptar y buscar nuevas formas de utilización, y no ser meramente un reproductor de prácticas enseñanzas elaboradas por otros. Estamos de acuerdo con Resta (2004, p. 94) cuando señala: «Un aspecto importante del desarrollo profesional no sólo es propiciar que los educadores de docentes comprendan y utilicen las TICs en sus clases, sino también que puedan comprender cómo la tecnología, al integrarse a los nuevos enfoques educativos, puede enriquecer el aprendizaje de los alumnos. Sunkel (2006, p. 44), con otras palabras matiza lo que queremos venir a decir: «vencer la resistencia» de los docentes significa no solo que ellos/as aprendan a manejar los equipos sino muy especialmente que aprendan a utilizarlos con propósitos educativos, es decir, que puedan incorporar la tecnología al trabajo diario en el aula».

Por otra parte, estamos completamente de acuerdo con Prendes (2010, p. 165), cuando señala que «... la formación en TIC debe partir de la base de ofrecer al profesorado selecciones prácticas y hacer énfasis de las mejoras que ésta aportará al proceso de enseñanza-aprendizaje y no limitarse a dar a conocer herramientas y metodologías».

\section{EL MÉTODO DELPHI}

Dentro de las diferentes estrategias de investigación que existen para la identificación de preguntas y problemas de investigación, la selección de variables críticas de investigación, o la construcción y validación de instrumentos de recogida o análisis de información, nos encontramos con el «método Delphi». Método que ha sido utilizado en profundidad en el terreno de la Tecnología Educativa (Barroso y Cabero, 2011), donde nos encontramos aplicaciones para la construcción de sistema de categorías para el análisis informativo de la publicidad, de la calidad didáctica de los cursos universitarios virtuales, o construcción de un sistema categorial para el análisis de las investigaciones e-learning (Royo y Bigné, 2002; Aguaded y López, 2009; Cabero y otros, 2009).

A manera de síntesis consideramos que los investigadores podrían ayudarse de esta técnica para diferentes usos: identificar los tópicos a investigar, especificar las preguntas de la investigación, identificar una perspectiva teórica para la investigación, seleccionar las variables de interés y generar las proposiciones, identificar las relaciones causales entre factores, definir y validar los constructos, y crear un lenguaje común para la discusión y gestión del conocimiento. 
Para nosotros los tipos de estudios que se adaptan a su utilización son los que:

- No existe información disponible o con la que se cuenta es insuficiente, y lo utilizaremos para poder extraer la información que posean diferentes participantes.

- El problema no se presta para el uso de una técnica analítica precisa, pero si puede beneficiarse de juicios subjetivos sobre bases colectivas.

- Se necesitan más participantes expertos de los que pueden interactuar en forma eficiente en un intercambio cara a cara.

- Por problemas de costes y de tiempo de los participantes, no es posible llevar a cabo encuentros presenciales periódicos del grupo.

- Se desea mantener una cierta heterogeneidad de los participantes a fin de asegurar la validez de los resultados, por lo que es preferible este método a los encuentros cara a cara, porque así se evitan los efectos de dominación de grupos por personalidades.

- Y que la técnica es recomendable cuando los participantes expertos están físicamente dispersos y requieren el anonimato.

Utilizaciones como las apuntadas han llevado a autores tan significativos en la investigación educativa como Patton (1987), a señalar que es un método fuertemente consolidado dentro de la investigación educativa.

Para Luna y otros (2005, p. 95) «la técnica Delphi pretende obtener una visión de expertos sobre un tema a partir de rondas repetidas de preguntas, siendo un método capaz de obtener y depurar los juicios de grupo. La operativa del método Delphi consiste en el envío de encuestas sucesivas a un grupo de expertos previamente elegidos. El consenso se obtiene por un procedimiento matemático de agregación de juicios individuales». Por su parte León y Montero (2004, p. 178) la definen como: «Técnica de recogida de datos que se utiliza para poner de acuerdo a un grupo de expertos dispersos geográficamente- sobre un tema de interés para el investigador. Consiste en aplicar un cuestionario repetidamente, dando a conocer a todos los expertos las respuestas de los demás en las aplicaciones anteriores e invitándoles a buscar el máximo consenso entre ellos».

En resumen, la técnica Delphi pretende obtener una visión colectiva de expertos sobre un tema a partir de rondas repetidas de preguntas, siendo 
un método capaz de obtener y depurar los juicios de grupo. La operativa del método Delphi consiste en el envío de encuestas sucesivas a un grupo de expertos previamente elegidos. El consenso se obtiene por un procedimiento matemático de agregación de juicios individuales. En cada nueva vuelta se informa a los participantes los acuerdos y desacuerdos de las respuestas en la fase anterior, y se les pide que se ratifiquen o rectifiquen.

En su puesta en acción debemos prestarle especial atención a una serie de aspectos: garantizar el anonimato de los participantes y más concretamente de sus respuestas, llevar a cabo diferentes iteraciones, establecer el control del feed-back por parte del grupo coordinador, y la utilización de técnicas estadísticas en el análisis de la respuesta (Rowe y Wright, 1999). método:

Tres son las características básicas que podemos contemplar de este

- Anonimato: ningún miembro del grupo debe conocer las respuestas particulares que corresponden a cada uno de los otros participantes. En un sentido más estricto puede implicar incluso, según las características del estudio, que ni siquiera sepan quiénes son los otros expertos componentes del grupo.

- Iteración y realimentación controlada: la iteración se consigue al presentar varias veces el mismo cuestionario y así los expertos emiten su opinión en más de una ocasión.

- Respuesta del grupo en forma estadística: la información que se presenta a los expertos no es sólo el punto de vista de la mayoría, sino que se presentan todas las opiniones indicando el grado de acuerdo que se ha obtenido.

Antes de iniciar un Delphi, se deben realizar una serie de tareas previas entre las que podemos destacar:

- Delimitar el contexto y el horizonte temporal en el que se desea realizar la previsión sobre el tema en estudio.

- Seleccionar el panel de expertos y conseguir su compromiso de colaboración.

- Explicar a los expertos en qué consiste el método. Con esto se pretende conseguir la obtención de previsiones fiables. Estos deben conocer en todo momento cuál es el objetivo de cada una de las fases utilizadas en el estudio, así como los datos que vamos obteniendo. 
Como podemos imaginarnos la calidad de los resultados que alcancemos con el Delphi, va a depender de los expertos que utilicemos. Entre otros motivos porque el término experto es bastante polisémico; de ahí la precaución que debemos tener en su elección, y los criterios a movilizar para ello, siendo algunos de estos los siguientes: conocimiento y experiencia en la temática, voluntad de participar, disponer de tiempo, comprometerse a la participación en todas las rodas que se establezcan, y capacidad de comunicación efectiva.

Como podemos imaginarnos el método Delphi ha ido evolucionando desde su creación, encontrándonos en la actualidad, diferentes formas de aplicación y puesta en funcionamiento. En el terreno educativo va ganando terreno la utilización de la versión denominada como «Delphi modificada» (Murray y Hammons, 1995; Mengual, 2011) una de las que va ganando frecuencia de aplicación. En la versión original de la técnica Delphi se realizan tres o más rondas, en la denominada "Delphi modificado», en la cual se suelen realizar dos rondas, por una serie de motivos: a) el Delphi llevado a un extremo puede convertirse en una tarea larga y costosa para ambas partes (investigador y expertos); b) cada fase consume un tiempo extendido, haciendo que cada vez sea más difícil mantener una tasas de respuesta aceptable; c) con dos rondas se mantiene el interés de los panelistas de manera más fácil; d) en esta versión los expertos reaccionan ante un tema en vez de generarlo; y e) tiende no a la construcción sino a llegar acuerdos sobre la misma.

\section{LA INVESTIGACIÓN}

Digamos desde el principio que el trabajo que presentamos forma parte del proyecto de investigación financiado por el MEC denominado «Dipro 2.0» (EDU2009-08893), cuyo objetivo principal es la creación de un «Entorno Personal de Aprendizaje» (PLE) para la formación del profesorado universitario en la utilización de las TIC. Respecto al cual ya hemos ido presentando diferentes trabajos aproximativos en revistas y congresos (Barroso y otros, 2012; Cabero y Marín, 2012; Infante y otros, 2013).

\section{Objetivos del estudio}

Uno de los objetivos que se perseguían era: «Elaborar temáticas básicas de forma consensuadas entre diferentes profesionales del ámbito de la Tecnología Educativa (TE) sobre las áreas más significativas en las cuales debe capacitarse el profesorado universitario para el manejo didáctico de las TIC». Y para él realizamos un estudio Delphi «modificado». 
Al mismo tiempo nuestro trabajo perseguía el conocer la posible eficacia de dicha técnica para la construcción de temáticas de formación.

\section{Procedimiento de aplicación}

En su ejecución seguimos las fases siguientes:

1. Elaboración de una primera lista de temáticas, con los descriptores que se podrían incluir.

2. Realización primera vuelta del estudio Delphi.

3. Análisis de los resultados alcanzados y elaboración de una nueva lista.

4. Realización segunda vuelta del estudio Delphi.

5. Y análisis de los resultados alcanzados y elaboración de la lista definitiva de contenidos del plan de formación.

El número de expertos que participaron inicialmente en su puesta de acción fueron 68, dándose de baja tres en la segunda vuelta. El criterio que se utilizó para la selección de los expertos fue que estuvieran impartiendo asignaturas relacionadas con la Tecnología Educativa, las Nuevas Tecnologías aplicadas a la Educación, o TIC en Universidades españolas o latinoamericanas.

La base de datos de los expertos se construyó a partir de diferentes fuentes: contactos existentes de miembros del grupo de investigación, conocimiento de la biografía de determinados investigadores, y su pertenencia a la «Asociación Edutec». El procedimiento que seguimos consistió en enviarle por correo electrónico una carta explicándoles los objetivos y solicitando su participación, y una vez recibida su conformidad, remitirle la dirección donde se encontraba ubicada la primera versión del instrumento de recogida de información.

Para la ejecución del método Delphi se llevó a cabo mediante una versión electrónica creada «ad hoc» para nuestro trabajo. En esta versión los temas se articulaban alrededor de tres bloques y 18 propuestas temáticas, y respecto a los cuales se les pedía que los valoraran con una escala de estimación de 1 a 5, donde 1 equivalía a nada importante y 5 a muy importante; también se les ofreció la recomendación que utilizaran el 3 solamente en casos necesarios. También se les solicitó su opinión sobre una serie de aspectos: bloque de contenidos que eliminaría o incluiría, o si sugeriría eliminar incorporar dentro de los bloques de los contenidos propuestos. 


\section{Análisis de resultados}

Una vez realizada la primera vuelta del estudio Delphi, las puntuaciones medias y las desviaciones típicas alcanzadas las presentamos en la tabla n. ${ }^{\circ} 1$.

\begin{tabular}{|c|c|c|}
\hline \multicolumn{3}{|l|}{ ASPECTOS INTRODUCTORIOS } \\
\hline Línea temática & M & DT \\
\hline $\begin{array}{l}\text { 1. Modalidades de formación integrando tic: enseñanza pre- } \\
\text { sencial, e-learning, b-learning y m-learning. }\end{array}$ & 4,379 & 0,721 \\
\hline 2. ${ }^{\circ}$ Uso de las tecnologías en la enseñanza universitaria. & 4,574 & 0,633 \\
\hline $\begin{array}{l}\text { 3. Criterios generales para la integración, el diseño y la produc- } \\
\text { ción de las tic en la enseñanza universitaria. }\end{array}$ & 4,510 & 0,674 \\
\hline 4. ${ }^{\circ}$ Los alumnos y las tecnologías. & 2,931 & 0,973 \\
\hline \multicolumn{3}{|l|}{$\begin{array}{l}\text { HERRAMIENTAS SERVICIOS Y RECURSOS PARA LA } \\
\text { FORMACIÓN EN CONTEXTOS DE EDUCACIÓN SUPERIOR }\end{array}$} \\
\hline $\begin{array}{l}\text { 5. }^{\circ} \text { Recursos multimedia para la enseñanza universitaria (I): } \\
\text { pizarra digital y presentaciones colectivas informatizadas. }\end{array}$ & 4,086 & 0,803 \\
\hline $\begin{array}{l}\text { 6. } .^{\circ} \text { Recursos multimedia para la enseñanza universitaria (II): } \\
\text { los hipermedias y multimedias. }\end{array}$ & 3,959 & 0,966 \\
\hline 7. ${ }^{\circ}$ Recursos audiovisuales en la red & 4,245 & 0,751 \\
\hline 8. ${ }^{\circ}$ La videoconferencia como herramienta didáctica & 3,687 & 0,988 \\
\hline 9..$^{\circ}$ La radio en la universidad & 2,811 & 0,942 \\
\hline $10 .^{\circ}$ Herramientas telemáticas para la comunicación & 4,519 & 0,795 \\
\hline $\begin{array}{l}\text { 11. Entornos web 2.0. en la formación universitaria - herra- } \\
\text { mientas web 2.0 }\end{array}$ & 4,392 & 0,896 \\
\hline 12. ${ }^{\circ}$ Las redes sociales aplicadas a la formación universitaria & 2,903 & 0,972 \\
\hline 13..$^{\circ}$ Los entornos personales de formación & 2,528 & 1,030 \\
\hline \multicolumn{3}{|l|}{ ASPECTOS METODOLÓGICOS Y EVALUACIÓN } \\
\hline $\begin{array}{l}\text { 14. } .^{\circ} \text { Metodologías y estrategias didácticas centradas en el alum- } \\
\text { no para el aprendizaje en red individuales y grupales/cola- } \\
\text { borativas }\end{array}$ & 4,652 & 0,653 \\
\hline 15..$^{\circ}$ La tutoría virtual & 4,396 & 0,893 \\
\hline $16 .^{\circ}$ La Webquest & 3,700 & 1,216 \\
\hline $\begin{array}{l}\text { 17. } .^{\circ} \text { Bases generales para la evaluación de tic para la enseñanza } \\
\text { universitaria }\end{array}$ & 4,273 & 0,869 \\
\hline $\begin{array}{l}\text { 18. La utilización de las tic como instrumento de evaluación de } \\
\text { los estudiantes }\end{array}$ & 4,440 & 0,644 \\
\hline
\end{tabular}

Tabla n. ${ }^{\circ}$ 1. Primera lista de contenidos sometidas al «Delphi», y puntuaciones medias y desviaciones típicas alcanzadas tras su desarrollo 
Por lo que se refiera a la pregunta de si eliminaría algún bloque concreto, las respuestas que nos encontramos las presentamos en la tabla n. ${ }^{\circ} 2$.

\begin{tabular}{|c|c|c|c|c|}
\hline Línea temática & SI & $\%$ & NO & $\%$ \\
\hline $\begin{array}{l}\text { 1. Modalidades de formación integrando tic: en- } \\
\text { señanza presencial, e-learning, b-learning y m- } \\
\text { learning. }\end{array}$ & 8 & 11,76 & 60 & 88,24 \\
\hline $\begin{array}{l}\text { 2. Uso de las tecnologías en la enseñanza universi- } \\
\text { taria. }\end{array}$ & 2 & 2,94 & 66 & 97,06 \\
\hline $\begin{array}{l}\text { 3. Criterios generales para la integración, el diseño } \\
\text { y la producción de las tic en la enseñanza univer- } \\
\text { sitaria. }\end{array}$ & 1 & 1,47 & 67 & 98,53 \\
\hline 4. ${ }^{\circ}$ Los alumnos y las tecnologías. & 38 & 55,88 & 30 & 44,12 \\
\hline $\begin{array}{l}\text { 5. Recursos multimedia para la enseñanza universi- } \\
\text { taria (I): pizarra digital y presentaciones colecti- } \\
\text { vas informatizadas. }\end{array}$ & 9 & 13,24 & 59 & 13,24 \\
\hline $\begin{array}{l}\text { 6. }{ }^{\circ} \text { Recursos multimedia para la enseñanza universi- } \\
\text { taria (II): los hipermedias y multimedias. }\end{array}$ & 10 & 14,71 & 58 & 85,24 \\
\hline 7..$^{\circ}$ Recursos audiovisuales en la red & 4 & 5,88 & 64 & 94,12 \\
\hline 8. ${ }^{\circ}$ La videoconferencia como herramienta didáctica & 16 & 23,53 & 42 & 61,77 \\
\hline 9..$^{\circ}$ La radio en la universidad & 41 & 60,29 & 27 & 39,71 \\
\hline $10 .^{\circ}$ Herramientas telemáticas para la comunicación & 3 & 4,41 & 65 & 95,59 \\
\hline $\begin{array}{l}\text { 11. }{ }^{\circ} \text { Entornos web 2.0. en la formación universitaria - } \\
\text { herramientas web } 2.0\end{array}$ & 5 & 7,35 & 63 & 92,65 \\
\hline $\begin{array}{l}\text { 12. Las redes sociales aplicadas a la formación uni- } \\
\text { versitaria }\end{array}$ & 31 & 45,59 & 37 & 54,41 \\
\hline 13..$^{\circ}$ Los entornos personales de formación & 37 & 54,41 & 31 & 45,59 \\
\hline $\begin{array}{l}\text { 14. } .^{\circ} \text { Metodologías y estrategias didácticas centradas en } \\
\text { el alumno para el aprendizaje en red individuales } \\
\text { y grupales/colaborativas }\end{array}$ & 4 & 5,88 & 64 & 94,12 \\
\hline 15. ${ }^{\circ}$ La tutoría virtual & 6 & 8,82 & 62 & 91,18 \\
\hline $16 .^{\circ}$ La Webquest & 12 & 17,65 & 56 & 82,35 \\
\hline $\begin{array}{l}\text { 17. }{ }^{\circ} \text { Bases generales para la evaluación de tic para } \\
\text { la enseñanza universitaria }\end{array}$ & 6 & 8,82 & 62 & 91,18 \\
\hline $\begin{array}{l}\text { 18. } .^{\circ} \text { La utilización de las tic como instrumento de eva- } \\
\text { luación de los estudiantes }\end{array}$ & 4 & 5,88 & 64 & 94,12 \\
\hline
\end{tabular}

Tabla n. ${ }^{\circ}$ 2. Valoración de si eliminaría alguna línea temática 
Ya hemos señalado que también se les demandó una serie de valoraciones cualitativas respecto a la propuesta temática entregada. Y algunos de los comentarios fueron los siguientes:

- Eliminar la línea temática de las redes sociales, e incorporarla en temática de la web 2.0.

- Eliminar el bloque referido a la radio universitaria, e incorporarlo como un descriptor; y el de los alumnos y las tecnologías, e incorporarlo como descriptor en la línea temática 1.

- Incluir elementos de las TIC como elementos de innovación en la enseñanza universitaria.

- Reforzar la línea temática 3 de las bases pedagógicas.

- Ampliar los descriptores de la temática de la videoconferencia.

- Cambios en algunas líneas de bloque temático, como la de webquest, incorporando nuevos descriptores, como el referido a su diseño y construcción.

Las valoraciones realizadas por los expertos nos llevó a suprimir aquellas líneas temáticas donde se mostraban fuertemente de acuerdo en su eliminación, o cuyo valor medio alcanzado fuera inferior a «3»; en concreto las siguientes:

4. ${ }^{\circ} \quad$ Los alumnos y las tecnologías.

9. ${ }^{\circ} \quad$ La radio en la universidad.

12. ${ }^{\circ} \quad$ Las redes sociales aplicadas a la formación universitaria

13. ${ }^{\circ} \quad$ Los entornos personales de formación.

Tras esta primera elaboración se construyó la segunda lista, que fue sometida a la segunda vuelta del estudio Delphi y que ofrecemos en la tabla n. ${ }^{\circ}$ 3. Señalar que en este caso hemos incorporado los bloques de contenidos.

\begin{tabular}{|l|c|c|}
\hline ASPECTOS INTRODUCTORIOS & $\mathrm{M}$ & $\mathrm{DT}$ \\
\hline Línea temática & 4,472 & 0,631 \\
\hline $\begin{array}{l}\text { 1. } \\
\text { o Modalidades de formación integrando tic: enseñanza presen- } \\
\text { cial, e-learning, b-learning y m-learning. }\end{array}$ & $\begin{array}{l}\text { (Contenidos: Uso de las TIC en contextos de enseñanza presencial. Conceptua- } \\
\text { lización del eLearning, bLearning y mLearning. Principios y características del } \\
\text { eLearning, bLearning y mLearning,...) }\end{array}$ \\
\hline
\end{tabular}




\begin{tabular}{|c|c|c|}
\hline \multicolumn{3}{|l|}{ ASPECTOS INTRODUCTORIOS } \\
\hline 2. ${ }^{\circ}$ Uso & 3 & 5 \\
\hline \multicolumn{3}{|c|}{$\begin{array}{l}\text { (Contenidos: Determinación de los usos de los materiales TIC en la docencia uni- } \\
\text { versitaria. Campus Virtuales. Uso de las TIC en diversas modalidades de enseñan- } \\
\text { za. Aspectos pedagógicos del uso de las TIC. Las TIC como factor de innovación } \\
\text { en la enseñanza universitaria. Adaptación de las TIC como factor de innovación } \\
\text { en la enseñanza universitaria, Adaptación de las TIC a los nuevos perfiles de los } \\
\text { alumnos universitarios,....) }\end{array}$} \\
\hline - & 34 & 89 \\
\hline \multicolumn{3}{|c|}{$\begin{array}{l}\text { (Contenidos: Diseño de materiales TIC para la docencia. Producción de mate- } \\
\text { riales TIC. Programas de producción de materiales TIC para la docencia uni- } \\
\text { versitaria. Evaluación de materiales TIC destinados a la docencia universitaria. } \\
\text { Programas de diseño de materiales formativos para su implementación en la red. } \\
\text { Aspectos organizativos y de gestión en el uso de las TIC. Actitudes de los alum- } \\
\text { nos hacia las TIC,...). }\end{array}$} \\
\hline
\end{tabular}

\section{HERRAMIENTAS SERVICIOS Y RECURSOS PARA LA FORMACIÓN EN CONTEXTOS DE EDUCACIÓN SUPERIOR}

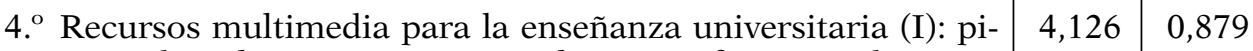
zarra digital y presentaciones colectivas informatizadas.

(Ejemplos y sugerencias de contenidos: Utilización didáctica de las presentaciones visuales informatizadas; Diseño didáctico de las presentaciones colectivas informatizadas-Conocimiento de programas para la realización de presentaciones colectivas informatizadas. Evaluación de las presentaciones colectivas generadas - la pizarra digital. Ventajas y desventajas de la utilización de la pizarra digital. Cómo elegir una pizarra digital,...).

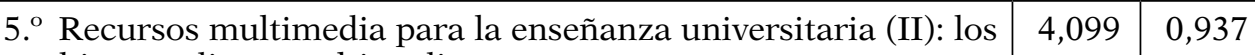
hipermedias y multimedias.

(Contenidos: Conocimiento del concepto multimedia educativo-Conocimiento del concepto hipermedia educativo-Posibilidades didácticas de los multimedia e hipermedia en la educación universitaria-Selección de software educativoEvaluación de software educativo-Diseño de actividades a realizar a través de multimedias educativos. Diseño de actividades a realizar a través de hipermedias educativos. Otros recursos multimedia; criterios de integración curricular de los recursos multimedia en la enseñanza superior; aplicaciones y servicios para el diseño de recurso multimedia,...).

\begin{tabular}{|c|c|c|}
\hline 6. $^{\circ}$ Recursos audiovisuales en la red & 4,127 & 0,934 \\
\hline
\end{tabular}

(Contenidos: Funciones del video en la docencia universitaria-Diseño de videos didácticos-Postproducción de videos didácticos-Conocimiento de programas de realización de videos-Implementación del video digital en la metodología de aulaDiseño de actividades cuyo recurso sea el video digital. La web audiovisual. Otros recursos audiovisuales: streaming, webcast, screencast, etc. Diseño de actividades con estos con recursos audiovisuales en la red. La televisión en red. La radio en la Universidad,,...). 


\section{HERRAMIENTAS SERVICIOS Y RECURSOS PARA LA FORMACIÓN EN CONTEXTOS DE EDUCACIÓN SUPERIOR}

\begin{tabular}{|c|c|c|}
\hline 7. ${ }^{\circ} \mathrm{La}$ & & \\
\hline \multicolumn{3}{|c|}{$\begin{array}{l}\text { (Contenidos: La videoconferencia definición y tipos. La videoconferencia como } \\
\text { herramientas comunicativa. La planificación de videoconferencias en acciones } \\
\text { formativas. El comportamiento del profesor en la videoconferencia,...). }\end{array}$} \\
\hline 8. $\mathrm{Her}$ & & 06 \\
\hline \multicolumn{3}{|c|}{$\begin{array}{l}\text { (Contenidos: Herramientas sincrónicas para la comunicación: mensajería instan- } \\
\text { tánea, pizarra compartida, chat,... }\end{array}$} \\
\hline 9. ${ }^{\circ}$ En & 81 & 0 \\
\hline \multicolumn{3}{|c|}{$\begin{array}{l}\text { (Contenidos: ¿Qué es la web } 2.0 \text { ? Herramientas de publicación, gestión } \\
\text { información- Aplicación on-line de la web } 2.0 \text {. Herramientas web } 2.0 \text { : D } \\
\text { de un blog, edublogs, creación y eliminación de blogs, generadores de blo } \\
\text { seño y elaboración de una wiki, las eduwikis. Webquest. Características d } \\
\text { contenidos 2.0. Las redes sociales y sus aportaciones al terreno educativo. E } \\
\text { nos personales de aprendizaje,...) }\end{array}$} \\
\hline
\end{tabular}

\section{ASPECTOS METODOLÓGICOS Y EVALUACIÓN}

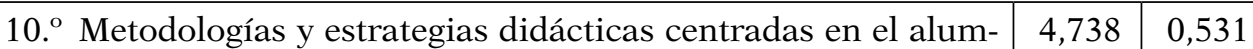
no para el aprendizaje en red individuales y grupales/colaborativas

(Contenidos: Conocimiento de metodologías didácticas en red centradas en el alumno. Diseño de metodologías didácticas apoyadas en la red. Conocimiento de estrategias didácticas en red centradas en el alumno. Diseño de estrategias didácticas apoyadas en la red. Implementación de metodologías didácticas en red. Implementación de estrategias didácticas en red. Conceptualización del término trabajo colaborativo en la red. Estrategias de trabajo colaborativo en red-Diseño de actividades de trabajo colaborativo en red,...).

\begin{tabular}{|l|l|l|}
\hline 11. $^{\circ}$ La tutoría virtual & 4,531 & 0,793 \\
\hline
\end{tabular}

(Contenidos: Bases generales de la tutoría virtual-Roles de tutor virtual-Funciones del tutor virtual-Estrategias didácticas para la tutoría virtual-Herramientas de comunicación para la tutorización virtual. Características del tutor telemático,...).

\begin{tabular}{|l|r|r|}
\hline $12 .^{\circ}$ La Webquest en la formación universitaria & 3,741 & 1,079 \\
\hline
\end{tabular}

(Contenidos: Diseño y construcción de webquest. Bloque, generadores de webquest-Herramientas de publicación de webquest. Conocimiento de la terminología de la Webquest. Utilidades de la Webquest).

\begin{tabular}{|l|l|c|}
\hline $\begin{array}{l}13 .^{\circ} \\
\text { Bases generales para la evaluación de tic para la enseñanza } \\
\text { universitaria }\end{array}$ & 4,189 & 0,812 \\
\hline
\end{tabular}

(Contenidos: Diseño de criterios de evaluación a través de TIC del trabajo del estudiante. Diseño de instrumentos de evaluación de/con TIC para la enseñanza universitaria. Implementar los instrumentos de evaluación. Indicadores de evaluación de TIC para la enseñanza universitaria. Competencias para el manejo de la información. Cómo enfrentarse a la búsqueda, selección y análisis de la información). 


\begin{tabular}{|l|l|l|}
\hline \multicolumn{4}{|l|}{ ASPECTOS METODOLÓGICOS Y EVALUACIÓN } \\
\hline \begin{tabular}{l} 
14. ${ }^{\circ} \begin{array}{l}\text { La utilización de las tic como instrumento de evaluación de } \\
\text { los estudiantes }\end{array}$ \\
\hline $\begin{array}{l}\text { (Contenidos: Las posibilidades de las TIC para la evaluación de los estudiantes. La } \\
\text { utilización de videoclip evaluativo. Las posibilidades evaluación de la informática } \\
\text { y las herramientas multimedias. El portafolio electrónico. Diseño de plantillas de } \\
\text { evaluación online. Programas de evaluación en red,...). }\end{array}$
\end{tabular} \\
\hline
\end{tabular}

Tabla n. ${ }^{\circ}$ 3. Segunda lista de contenidos sometidas al «Delphi», y puntuaciones medias y desviaciones típicas alcanzadas tras su desarrollo.

Preguntados también respecto a si eliminarían algún bloque de contenido, indicar que los resultados encontrados fueron en todos los casos, con un porcentaje del $60 \%$ o superior a que no.

Como podemos observar en las tablas anteriores, en este caso ninguna de las líneas temáticas apuntadas obtuvieron una puntuación media inferior a 3, ni un porcentaje de eliminación superior al 50\%. Hecho que nos llevó a tomar la decisión de convertirla en la lista definitiva sobre la que construiríamos nuestros materiales para la investigación.

Para concluir este apartado señalar que la versión final sobre la que se aplicó la segunda vuelta del Delphi puede observarse en la siguiente dirección web: http://tecnologiaedu.us.es/cuestionario/delphi/.

\section{CONCLUSIONES}

Los resultados alcanzados nos permiten señalar que se han alcanzado los dos objetivos del estudio, que hemos señalado anteriormente, referidos tanto a la configuración de la escala, como a la validez de la metodología Delphi para ello. Por lo que se refiere al segundo el apuntar con toda claridad la eficacia del método "Delphi modificado» para la determinación de los bloques de contenidos de un programa de formación del profesorado, tanto por su rapidez, facilidad de aplicación, reducción de costes, y eficacia de la información conseguida. Por otra parte el haber utilizado una versión electrónica del instrumento de recogida de información, nos ha facilitado el obtener información de profesionales de la enseñanza pertenecientes a diferentes Universidades tanto españolas como latinoamericanas.

Al mismo tiempo el método «Delphi modificado» se ha mostrado eficaz para llegar acuerdos pues ya en la segunda vuelta se establecieron los mismos, con unos mínimos desacuerdos entre los expertos. Hecho que no ocurrió en la versión primera propuesta. 
También creemos que permite la transferencia del procedimiento que hemos seguido para la selección de los expertos que han configurado nuestro grupo. De todas formas, de cara a una posterior aplicación, creemos que puede ser interesante el establecer una medida del nivel de competencia de los componentes del panel de expertos, y en este sentido puede ser de utilidad la obtención del coeficiente de competencia experto (Cabero y Barroso, 2013), y que viene expresado por la fórmula $\mathrm{K}=\mathrm{V} 2(\mathrm{kc}+\mathrm{ka})$. Donde kc - viene determinado por el «coeficiente de conocimiento» o información del propio experto sobre el problema planteado; propia autovaloración en una escala de cierre gráfico $(0-10)$ y multiplicado por 0.1 . El valor «0» representa el conocimiento nulo mientras que el «10» el pleno conocimiento de la problemática tratada. ka - es el «coeficiente de argumentación» o fundamentación de los criterios del experto, obtenido a partir de la suma de la puntuación alcanzada en una serie de parámetros. Una aplicación del mismo puede observarse en el trabajo de Mengual (2011).

Por lo que se refiere al primer objetivo, señalar que la aplicación de la metodología Delphi, nos ha permitido construir una lista de contenidos que recogen diferentes visiones y percepciones respecto a la capacitación del profesorado universitario en TIC. Lista que podría comprender un plan de formación del profesorado universitario en TIC, tanto en acciones de formación como de perfeccionamiento, en el que sobresaldrían una serie de contenidos de carácter general: introductorios sobre las posibilidades que las TIC en los contextos de formación universitaria; y el diseño y la producción de TIC; otros centrados en los audiovisuales y multimedia: la pizarra digital y las presentaciones colectivas informatizadas, los recursos multimedias, los audiovisuales en la red, y la videoconferencia; y un último grupo, donde sobresale todo lo referido a la formación virtual y a la implantación de las herramientas de la web 2.0. Señalar que la versión definitiva de los materiales que elaboramos a partir del trabajo que hemos presentado puede observarse en la siguiente dirección web: http://tecnologiaedu.us.es/dipro2/. 


\section{REFERENCIAS BIBLIOGRÁFICAS}

Aguaded, J. y López, E. (2009). La evaluación de la calidad didáctica de los cursos universitarios en red. Diseño e implementación de un instrumento. Enseñanza \& Teaching, 27 (1), 95-114.

Álvarez, S. y otros (2011). Actitudes de los profesores ante la información de las TIC en la práctica docente. Estudio de un grupo de la Universidad de Valladolid. Edutec, 35. Recuperado de http://edutec.rediris.es/revelec2/revelec35/

Balanskat, A y otros (2006). The ICT Impact Report. A review of studies of ICT impact on schools in Europe. European Schoolnet. Luxembourg: European Comission. Recuperado de http:// ec.europa.eu/education/doc/reports/ doc/ictimpact.pdf

Ballestero, C. y otros (2010). Usos del e-learning en las universidades andaluzas. Estado de la situación y análisis de buenas prácticas. Pixel-Bit. Revista de Medios y Educación, 37, 7-18.

Banas, J. (2010). Teachers' Attitudes toward Technology. Considerations. Community \& Junior College Libraries, 16(2), 114-127.

Barroso, J. y Cabero, J. (2010). La investigación educativa en TIC. Madrid: Síntesis.

Barroso, J. y otros (2012). Formación desde la perspectiva de los entornos personales de aprendizaje. Apertura. Revista de Innovación educativa, 4, 1.

Becta (2007). Harnessing Technology Review 2007: Progress and impact of technology in education. Recuperado de http://partners.becta.org.uk/uploaddir/ downloads/page_documents/research/ harnessing_technology_review07.pdf

Cabero, J. (Dir) (2010). Usos del e-learning en las universidades andaluzas. Sevilla: Grupo de Investigación Didáctica.

Cabero, J. y Marín, V. (2012). ICT training of university teachers in a Personal Learning Environment. Project DIPRO 2.0. New approaches in Educational Research, 1, 1, 2-6.

Cabero, J. y Barroso, J. (2013). La utilización del juicio de experto para la evaluación de TIC: el coeficiente de competencia experta. Bordón, 65, 2, 25-38.

Cabero, J. y otros (2009). La aplicación de la técnica Delphi, para la construcción de un instrumento de análisis categorial de investigaciones e-learning. Edutec, 28. Recuperado de http.// edutec.rediris.es/Revelec2/revelec28/ edutec28_aplicacion_delphi_analisis_ categorial.html

Chen, Ch. (2008). Why Do Teachers Not Practice What They Believe Regarding Technology Integration? Journal of Educational Research, 102.1, 65-75.

European Commision (2006). Benchmarking Access and Use of ICT in European Schools 2006. Final Report from Head Teacher and Classroom Teacher Surveys in 27 European Countries. Recuperado de http://ec.europa.eu/information_society/eeurope/i2010/docs/ studies/final_report_3.pdf

Goktas, Y. y otros (2008). A review of ICT related courses in pre-service teacher education programs. Asia Pacific Education Review, 9, 2, 168-179.

International Society for Technology in Education (2008). Estándares nacionales (EEUU) de Tecnologías de Información y Comunicación (TIC) para docentes. Recuperado de http.//www. eduteka.org/estandaresmaes.php3 
Jimoyiannis, A. y Komis, V. (2007). Examining teachers' beliefs about ICT in education. implications of a teacher preparation programme. Teacher Development, 11(2), 149-173.

Kirschner, P. y Davis, N. (2003). Pedagogic benchmarks for information and communications technology in teacher education. Technology, Pedagogy and Education, 12 (1), 125-147.

Koehler, J. y Mishra, P. (2008). Introducing Technological Pedagogical Knowledge. En AACTE (Eds.). The Handbook of Technological Pedagogical Content Knowledge for Educators. Routledge/Taylor \& Francis Group/ American Association of Colleges of Teacher Education.

León, G. y Montero, I. (2004). Métodos de investigación en Psicología y Educación. Madrid: McGraw-Hill.

Llorente, M.C. (2008). Aspectos fundamentales de la formación del profesorado en TIC. Pixel-Bit. Revista de Medios y Educación, 31, 121-130.

Luna, P. y otros (2005). Los Delphi como fundamento metodológico predictivo para la investigación en sistemas de información y tecnologías de la información. Pixel-Bit. Revista de Medios y Educación, 26, 89-112.

Hammond, M. (2009). What happens as student teachers who made very good use of ICT during pre-service training enter their first year of teaching? Teacher Development, 13, 2, 93-106.

Infante, A. y otros (2013). Los gadgests en las plataformas de teleformación: el caso del Proyecto Dipro 2.0. PixelBit. Revista de Medios y Educación, 42, 187-198.

Maroto, A. (2007). El uso de las nuevas tecnologías en el profesorado universitario. Pixel-Bit. Revista de Medios y
Educación, 39, 211-223.

Mcvee, M. y otros (2008). Teachers and teacher educators learning from new literacies and new technologies. Teaching Education, 19 (3), 197-210.

Mengual, S. (2011). La importancia percibida por el profesorado y el alumnado sobre la inclusión de la competencia digital en educación Superior. Alicante: Departamento de Didáctica General y Didácticas específicas de la Facultad de Alicante.

Merma, G. (2008). Competencias del profesorado para el uso de las tecnologías de la información y la comunicación en la enseñanza, en el marco del Espacio Europeo de Educación Superior. En R. Roig. (dir). Investigación e innovación en el conocimiento educativo actual, (pp. 317-326). Marfil: Alcoy.

Ministerio de Educación de Chile (2008). Estándares de competencias en TIC para docentes. Londres: UNESCO.

Mishra, P. y Koehler, J. (2006). Technological Pedagogical Content Knowledge. A new framework for teacher knowledge. Teachers College Record, 108 (6), 1017-1054.

Moreno, E. y otros (2002). La técnica «Delphi» en la evaluación de necesidades. Una aplicación al tratamiento del género en los centros escolares. Bordón, 54, 1, 83-94.

Murray, J. y Hammons, J. (1995). Delphi. A versatile methodology for conducting qualitative research. The Review of Higher Education, 18 (4), 423-436.

NCATE (1997). Technology and the new professional teacher. Preparing for 21st. Century classroom. Washington: NCATE.

Patton, MQ. (1987). Depth Interviewing. En M.Q. Patton, How to Use Qualita- 
tive Methods in evaluation. (pp. 108143). London: Sage Publications.

Pearson, J. (2003). Information and Communications Technologies and Teacher Education in Australia. Technology, Pedagogy and Education, 12 (1), 39-58.

Pls Ramboll (2004). Studies in the context of the e-learning initiative. Virtual models of European Universities (Lot1). Denmark: Pls-Ramboll.

Prendes, M.P. (Dir) (2010). Competencias TIC para la docencia en la Universidad Pública española. Indicadores y propuestas para la definición de buenas prácticas. Programa de estudio y Análisis. Recuperado de http.//www.um.es/ competenciastic.

Resta. P. (Coord.) (2004). Las tecnologías de la información y la comunicación. París: UNESCO.

Rohrbaugh, J. (1979). Improving the quality of group judgement. social judgement análysis and the delphi technique. Organizational Behaviour and Human Perfomance, 24 2), 73-92.

Romero, R. y otros (2012). La formación en TIC, enfocada en la enseñanza y el aprendizaje. Global, 48, 48-55.

Rowe, G. y Wright, G. (1999). The Delphi technique as a forecasting tool. Issues and analysis, International Journal of Forecasting, 15 (4), 353-375.

Royo, M. y Bigné, E. (2002). Una propuesta consensual de las categorías para el análisis informativo de la publicidad. Revista Europea de Dirección y Economía de la Empresa, 11(2), 95-118.

Sunkel, G. (2006). Las tecnologías de la información y la comunicación (TIC) en la educación en América Latina. Una exploración de indicadores. Santiago de Chile: CEPAL.

Teo, T. y otros (2008). Beliefs about teaching and uses of technology among preservice teaching. Asia-Pacific Journal of Teacher Education, 36 (2), 163-174.

Uceda, J. y Barro, S. (2010). Universitic 2010. Evolución de las TIC en el sistema universitario español 2006-2010. Madrid: CRUE.

Valdés, A. y otros (2010). Necesidades de capacitación de docentes de educación básica en el uso de las TIC. Pixel-Bit. Revista de Medios y Educación, 39, 211-223.

Valerio, C. y Paredes, J. (2008). Evaluación del uso y manejo de las tecnologías de información y comunicación en los docentes universitarios. Un caso mexicano. Revista Latinoamericana de Tecnología Educativa, 7(1), 13-32. 


\section{PALABRAS CLAVE}

Formación del Profesorado en TIC, método Delphi, investigación aplicación método Delphi, estándares formación profesorado en TIC.

\section{KEYWORDS}

Teacher training in ICT, Delphi method, Delphi method application research, standards teacher training in ICT.

\section{PERFIL ACADÉMICO Y PROFESIONAL DEL AUTOR}

Julio Cabero Almenara, Catedrático de Didáctica y Organización Escolar de la Universidad de Sevilla. Director del Secretariado de Recursos Audiovisuales y Nuevas Tecnologías de la Universidad de Sevilla. Ha publicado diferentes libros sobre Tecnología Educativa y la aplicación de las Tecnologías de la Información y Comunicación en diferentes editoriales como McGraw-Hill, Síntesis, Alianza, y Pirámide. Ha impartido conferencias y cursos sobre las TIC aplicadas a la educación en diferentes Universidades españolas y latinoamericanas.

Dirección del autor: Julio Cabero Almenara

Facultad de Ciencias de la Educación

C/Pirotecnia s/n

41013 Sevilla

E-mail: cabero@us.es

Fecha Recepción del Artículo: 18. Octubre. 2011

Fecha Revisión del Artículo: 16. Marzo. 2013

Fecha Aceptación del Artículo: 24. Marzo. 2013

Fecha de Revisión para publicación: 24. Junio. 2013 


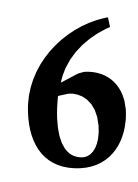

\title{
LA SOSTENIBILIDAD EN LA FORMACIÓN UNIVERSITARIA: DESAFÍOS Y OPORTUNIDADES ${ }^{1}$
}

\author{
(SUSTAINABILITY IN HIGHER EDUCATION: CHALLENGES AND \\ OPPORTUNITIES)
}

Aznar Minguet, Pilar, Ull, M. Angels, Piñero, Albert y Martínez-Agut, M. Pilar

Universitat de Valencia

DOI: $10.5944 / e d u c x x 1.17 .1 .10708$

\section{Cómo referenciar este artículo/How to reference this article:}

Aznar Minguet, P.; Ull, M.A.; Piñero, A. y Martínez Agut, M.P. (2014). La sostenibilidad en la formación universitaria: Desafíos y oportunidades. Educación XX1, 17 (1), 133-158. doi: 10.5944/ educxx1.17.1.10708.

Aznar Minguet, P.; Ull, M.A.; Piñero, A. y Martínez Agut, M.P. (2014). Sustainability in higher education: challenges and opportunities. Educación XX1, 17 (1), 133-158. doi: 10.5944/educxx1.17.1.10708.

\section{RESUMEN}

La finalidad del estudio se dirige a integrar la perspectiva de la sostenibilidad en las titulaciones de enseñanza superior a través de la incorporación de actividades en los procesos de enseñanza-aprendizaje, que faciliten el desarrollo de competencias transversales básicas relacionadas con la sostenibilidad. Se ha realizado un estudio empírico con una muestra representativa de profesorado de la Universidad de Valencia, que ostenta cargos académicos para analizar los desafíos y oportunidades que comporta la introducción de la sostenibilidad en la docencia universitaria, en los aspectos referidos en el documento «Bolonia sostenible» basado en la Carta Universitaria de Educación Superior para un desarrollo sostenible de la RED Copérnicus-Campus, constituida en el seno de la CRE (Conferencia Europea de Rectores).

La metodología utilizada conforma una estructura descriptivo-exploratoria y evaluativa basada en un análisis DAFO. Los datos obtenidos nos permiten describir la situación inicial de partida en relación a la introducción de la sostenibilidad en la docencia universitaria para generar diseños de diálogo disciplinar y facilitar la puesta en marcha del compromiso institucional reflejado en el Plan Estratégico «Campus sostenible | UV» que es el marco de actuaciones que definen la estrategia institucional de sostenibilidad de la Universitat de València. 


\section{ABSTRACT}

The purpose of the study is aimed at integrating the perspective of the sustainability in the qualifications of higher education through the incorporation of activities in the learning process, in order to facilitate the development of cross-cutting core competencies related to sustainability.

We conducted an empirical study with a cross-section of a Faculty of the University of Valencia, which boasts academic posts to analyze the challenges and opportunities that involve the introduction of sustainability in university teaching, on the aspects referred to in the document "Sustainable Bologna» based on the letter University of higher education for a sustainable development of the network Copérnicus-Campus constituted within the CRE (European Rectors Conference).

The methodology used is a descriptive-exploratory and evaluative structure based on a SWOT analysis. The data obtained allow us to describe the initial situation of heading in relation to the introduction of sustainability in university teaching to generate dialogue design discipline and facilitate the implementation of the institutional commitment reflected in the Strategic Plan "Campus sostenible|UV», the framework of actions that define the corporate strategy of sustainability of the Universitat de València.

\section{INTRODUCCIÓN}

En el estudio partimos de la idea de que la sostenibilidad es un concepto dinámico que incluye la búsqueda de la calidad ambiental, la justicia social y una economía viable y equitativa a largo plazo. El nuevo modelo de desarrollo ha de estar basado en una nueva ética cuyo pilar esencial sea el de la solidaridad entre todos los miembros de la especie humana (independientemente de la generación a la que pertenezcan) y entre éstos y todos los seres vivos. Desde esta óptica se empiezan a formular propuestas que incluyen los diferentes aspectos que conforman el desarrollo, y que desde el ámbito de la educación se concreta, coherentemente con su objeto formal, en la búsqueda de un desarrollo humano compatible con los valores de la sostenibilidad (Aznar, 2006; Aznar y Ull, 2009; 2013)².

La Universidad es una institución dedicada a la formación de futuros profesionales, a la investigación, a la divulgación del conocimiento, a la creación y el desarrollo de la cultura y a la generación de una conciencia crítica; esta institución, como generadora de conocimiento y como impulsora de modelos científicos, sociales y humanistas, se encuentra ante un nuevo desafío debido al papel clave que representa en la búsqueda de respuestas a uno de los más importantes retos sociales que se le plantean al nuevo siglo: el desarrollo humano ambiental y socialmente sostenible (Geli, 2002, p. 11). 
Desde esta óptica la institución universitaria no puede quedar al margen del camino hacia la sostenibilidad; lo que implica reorientar la gestión de recursos, la docencia, el aprendizaje, las interacciones entre los miembros de la comunidad universitaria y las relaciones entre la universidad y la sociedad con criterios de sostenibilidad (Wals y Jickling, 2002; Wrigth 2004; Velazquez et al, 2005; Adomssent y Michelsen, 2006; Wals y Corcoran, 2006; Adomssent et al., 2007; Axelsson et al., 2008; Junyent y Geli, 2008; FerrerBalas et al., 2008).

La proyección de la universidad no sólo no puede escapar a las presiones de la sociedad globalizada sino que tiene que anticipar respuestas a las nuevas demandas de una sociedad futura. Pero dado que la globalización es un fenómeno que acompaña al surgimiento de nuevas formas sociales y a la emergencia de nuevos paradigmas en la producción del conocimiento, es también un fenómeno que obliga a las instituciones de enseñanza superior a buscar nuevas formas de adaptación a través de cambios en la organización, en los procesos de enseñanza y aprendizaje, así como en los valores; cambios hacia una línea de progreso enraizada, tanto en la libertad de ideas, la solidaridad, la democracia interna y la autonomía, como en la responsabilidad social, la eficiencia y la rendición de cuentas, como ya expresó Michavila (2001, p. 85) y, el mantenimiento de una forma de vida ambientalmente sostenible.

\section{REFERENTES BÁSICOS}

Hay una serie de referentes básicos en relación a la formación universitaria, que han supuesto un punto de inflexión en la introducción formal de la sostenibilidad:

a) UNESCO (1998): Conferencia mundial sobre la educación superior (La educación superior en el siglo XXI. Visión y acción). En esta conferencia se apuntaba que cada vez más, las universidades están llamadas a desempeñar una función de liderazgo en el desarrollo de formas de educación interdisciplinarias, transdisciplinarias y éticamente orientadas, a fin de idear soluciones para los problemas vinculados al desarrollo sostenible; las universidades no se constituyen tan sólo en centros de generación de conocimiento, sino que a través de la formación de los estudiantes, la investigación y la promoción de una conciencia crítica, asume un rol de responsabilidad de difusión de conocimientos, valores, actitudes y comportamientos favorables hacia un desarrollo humano sostenible a aplicar por los nuevos titulados universitarios en el ejercicio de sus respectivas profesiones. 
b) UNESCO (2005): Declaración de la Década de la Educación para el Desarrollo Sostenible (2005-2014), cuya finalidad es la construcción de un mundo en el que todos tengan igualdad de acceso a la educación a través de la cual aprender los valores, comportamientos y estilos de vida coherentes para un futuro sostenible y para la transformación positiva de la sociedad. La sostenibilidad es un concepto que transciende al propio concepto de medio ambiente, ya que incluye no solamente la búsqueda de la calidad ambiental, sino también la equidad y la justicia social. Estas cuestiones aparecen reflejadas como prioridades en la planificación de los programas para conseguir los objetivos de la «Década de la Educación para el Desarrollo Sostenible», tales como: reducción de la pobreza, igualdad de sexos, promoción de la salud, protección del medio ambiente, transformación rural, derechos humanos, comprensión cultural y paz, producción y consumo responsables, respeto a la diversidad cultural y acceso igualitario a las TIC. Con la declaración de la Década, las Naciones Unidas ofrecen una gran oportunidad para reorientar las funciones de enseñanza e investigación, generar respuestas creativas a los problemas ambientales y educar para la sostenibilidad.

c) UNESCO (2009): VII Conferencia Mundial sobre la Educación Superior (La nueva dinámica de la Educación Superior y la investigación para el cambio social y el desarrollo). En esta conferencia se defendía que la educación superior debe no sólo proporcionar competencias sólidas para el mundo de hoy y de mañana, sino contribuir además a la formación de una ciudadanía comprometida con la construcción de la paz, la defensa de los derechos humanos, la protección del medio ambiente, y con los principios éticos coherentes con los valores de un desarrollo humano ambiental y socialmente sostenible.

d) COPERNICUS-Guidelines for sustainable development in the European Higher Education Area: How to incorporate the principles of sustainable development into the Bologna Process. La Guía ofrece orientaciones acerca de la incorporación de los principios del desarrollo sostenible en el proceso de adaptación de los nuevos planes a la convergencia europea incorporando contenidos innovadores y enfoques interdisciplinarios en la integración del desarrollo sostenible en los estudios existentes. Los planes de estudio y la metodología a aplicar deben orientarse a la formación de los alumnos en los tipos de pensamiento que conducen a la construcción de conocimiento, el desarrollo de habilidades críticas, la adquisición de la capacidad personal y social para participar en la sociedad como 
ciudadanos activos y la concienciación y disposición de apoyo al desarrollo sostenible.

e) CRUE: Directrices para la introducción de la sostenibilidad en la docencia. Documento aprobado por la Comisión Sectorial para la Calidad Ambiental y el Desarrollo Sostenible (CADEP) de la Conferencia de Rectores de las Universidades Españolas (CRUE) ${ }^{3}$. En el contexto del modelo de formación por competencias, desde la CRUE se impulsa la formación de profesionales que sean capaces de comprender cómo su actividad profesional interactúa con la sociedad y el medio ambiente para poder identificar posibles impactos, que sepan aplicar los conocimientos profesionales de acuerdo con principios deontológicos y valores éticos universales que protejan los derechos humanos, incluidos los de la tercera generación, o que sepan participar activamente en la discusión, definición y evaluación de políticas y acciones públicas y privadas, para ayudar a redirigir la sociedad hacia un desarrollo más sostenible.

f) La Ley Orgánica 4/2007 de Universidades de 12 de abril, sienta las bases para realizar una modernización de la Universidad española (Título VI) y, se desarrolla con el Real Decreto 1393/2007, de 29 de octubre, por el que se establece la ordenación de las enseñanzas universitarias oficiales. En el preámbulo de dicho R.D. se especifica que «se debe tener en cuenta que la formación en cualquier actividad profesional debe contribuir al conocimiento y desarrollo de los Derechos Humanos, los principios democráticos, los principios de igualdad entre mujeres y hombres, de solidaridad, de protección medioambiental, de accesibilidad universal y diseño para todos, y de fomento de la cultura de la paz. Estos principios están siendo recogidos en muchos de los nuevos planes de estudio dentro de las competencias generales de los mismos; y, en los planes de estudio con habilitación profesional, se indican mediante resoluciones, las condiciones a las que deberán adecuarse los planes de estudios conducentes a la obtención de títulos que habiliten para el ejercicio de la profesión regulada.

g) Estrategia Universidad 2015. La consideración de la sostenibilidad como responsabilidad social universitaria ha venido de la mano explícitamente de la Estrategia Universidad 2015, dirigida a la modernización de las universidades según propuesta de la Comisión Europea. En nuestro país la EU2015 ha sido aprobada por el Consejo de Ministros (Gobierno de España, 2008), impulsada inicialmente por el Ministerio de Ciencia e Innovación (MICINN), asumida por el Ministerio de Educación a través de la Secretaría General de Universidades y dirigida a la promoción de la excelencia 
en la formación e investigación, a la internacionalización del sistema universitario y a la implicación en el cambio socio-económico basado en el conocimiento y la innovación y su adecuación a las necesidades y demandas sociales. La universidad española se ha venido caracterizando por responder a un modelo dual e indisoluble entre la docencia y la investigación, con un carácter humanístico proyectado en el ámbito del doctorado. La EU2015 incorpora como elemento fundamental la tercera misión: la transferencia de conocimiento y tecnología y la responsabilidad social universitaria (RSU), en la que la promoción de la sostenibilidad a nivel de gestión, de docencia e investigación y a nivel de relaciones con el contexto social son cuestiones clave (Cohen, 2007; Vallaeys et al, 2009; Rodríguez, 2010; Gaete, 2011).

h) Proyecto «Campus sostenible|UV». Es el marco de actuaciones que define la estrategia institucional de sostenibilidad de la Universitat de València $y$, en este contexto, una política propia y unos principios de gestión coordinada para contribuir a la sostenibilidad desde todos los ámbitos que caracterizan a la institución: formación, investigación, gestión propia y relaciones con la sociedad. Aprobado en Consejo de Gobierno en septiembre de 2011, es un programa de acción con horizonte 2015. Campus sostenible persigue sensibilizar y formar a la comunidad universitaria en materia de sostenibilidad, contribuir al desarrollo sostenible de la sociedad, así como conseguir una administración universitaria y un campus más sostenible y saludable. Sirva esta referencia concreta de ejemplo, muy actualizado, de lo que cada universidad puede hacer en este tema.

Estos documentos coinciden en señalar que la educación superior es una herramienta clave para caminar hacia un desarrollo humano ambiental y socialmente sostenible; lo cual supone que la universidad debe formar a profesionales capaces de utilizar sus conocimientos, no sólo en un contexto científico, sino también para dar respuesta a los problema ambientales y a las necesidades sociales, tomando decisiones y realizando acciones coherentes con los valores de la sostenibilidad (Lozano, 2006; Novo, 2009).

Así, dentro de las líneas estratégicas de la Universitat de Valencia, el estudio realizado pretende conocer las percepciones de los cargos académicos hacia la introducción de competencias y contenidos relacionados con la sostenibilidad en las asignaturas de las diferentes titulaciones, en línea con otras investigaciones (Sibbel, 2009) y también aquellas centradas en conocer la opinión de los profesores sobre lo que representa la sostenibilidad en la educación superior en general (Cotton et al, 2007; Wrigth, 2010; Granados Sánchez et al, 2011). 


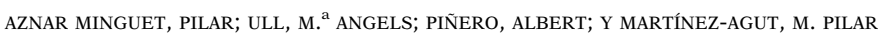

\section{METODOLOGÍA}

La metodología utilizada conforma una estructura descriptivo-exploratoria y evaluativa basada en un análisis DAFO. Tiene por objetivo la presentación sintética de los puntos fuertes y puntos débiles de la realidad estudiada desde una perspectiva sincrónica y de las oportunidades y amenazas que se presentan desde una visión diacrónica. Se trata de un instrumento de síntesis analítica de singular importancia ya que pone de relieve los distintos elementos del escenario de partida de una actuación o proyecto (Colás y de Pablo, 2005). Los datos obtenidos nos permiten describir la situación inicial de partida en relación con la introducción de la sostenibilidad en los currícula universitarios.

En el análisis actual de la realidad estudiada, se propone el estudio, por una parte, de las debilidades y fortalezas que pueden presentar con carácter propio la inclusión de competencias y contenidos relacionados con la sostenibilidad en las asignaturas de las diferentes titulaciones; mientras que su proyección a través de estrategias de intervención orientadas a dinamizar el cambio, y su posible integración en campos más amplios, definirán el marco de oportunidades y amenazas que, respectivamente, se dirigen a modificar la realidad actual en un sentido positivo o negativo a un plazo determinado. En este sentido, las categorías base, ordenadas en función de las siglas DAFO, asignadas al análisis son:

- Debilidades: aspectos que reducen o limitan la capacidad de aplicación de iniciativas relacionadas con la sostenibilidad en la docencia.

- Amenazas: aspectos o situaciones que incrementan dificultades o anticipan problemas para la inclusión de la sostenibilidad en la docencia si no varían las condiciones actuales.

- Fortalezas: capacidades, recursos o planteamientos que potencian la introducción de la sostenibilidad a través de la docencia en las asignaturas de los diferentes grados.

- Oportunidades: aspectos o situaciones que representan una ventaja para la consolidación de la introducción de la sostenibilidad en la docencia (siempre y cuando se superen las debilidades y se aprovechen debidamente las fortalezas).

Es importante tener en cuenta que el poder identificar a tiempo una amenaza puede llevar a reorientar el proyecto de integración de la sostenibilidad en los procesos de enseñanza y aprendizaje hacia una oportunidad futura; mientras que no identificar una fortaleza, puede suponer enfrentarse a una futura amenaza. 


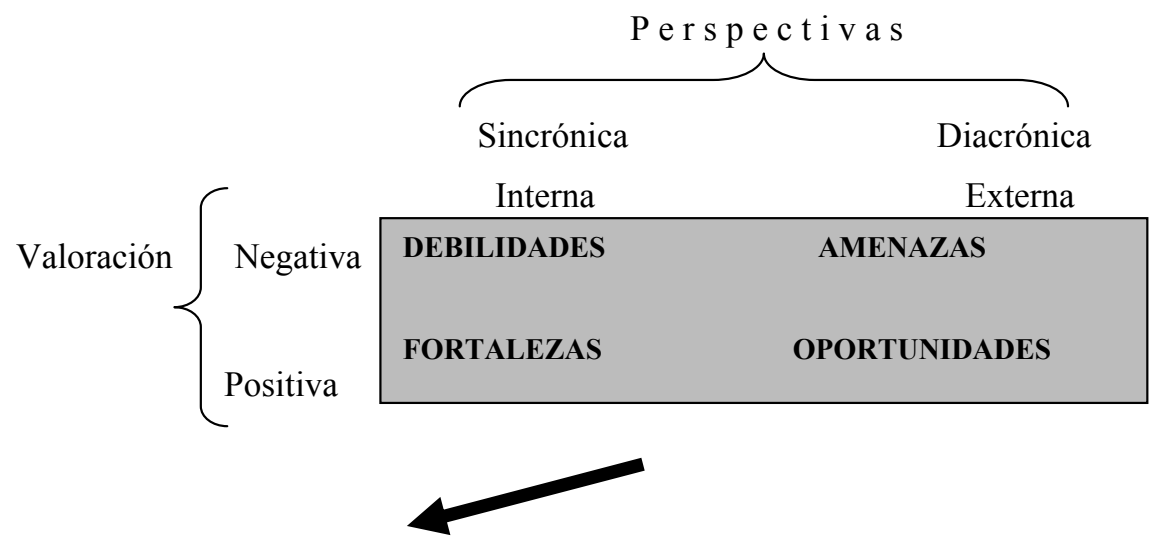

Obtención de una visión de conjunto de la sostenibilidad en la docencia

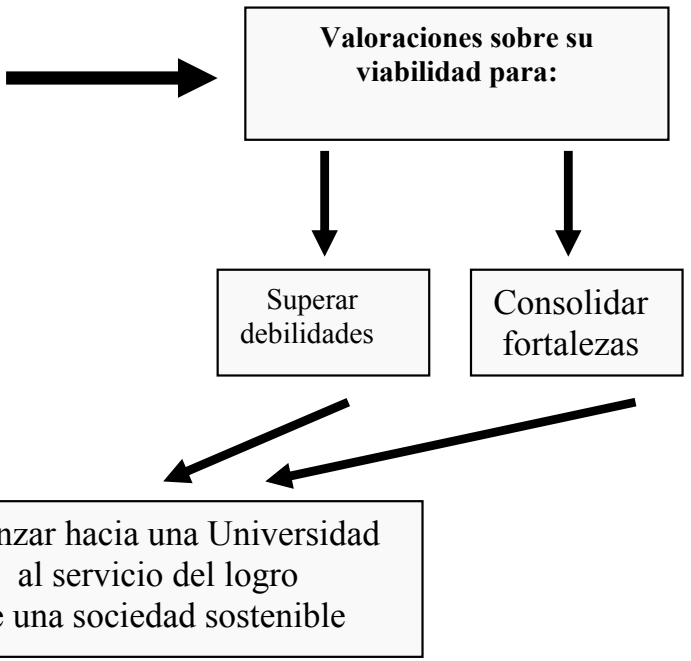

Figura 1. Análisis DAFO aplicado a la introducción de la sostenibilidad en la formación universitaria

El análisis DAFO es, por lo tanto, un instrumento metodológico que nos permite desarrollar una síntesis analítica y diagnóstica del escenario que constituye la introducción de la sostenibilidad en la docencia universitaria. El objetivo de su aplicación es la presentación sistémica de los puntos positivos (fortalezas, oportunidades) y negativos (amenazas, debilidades) presentes en los procesos de enseñanza-aprendizaje; teniendo en cuenta que las debilidades y fortalezas constituyen variables internas al desarrollo de la sostenibilidad en la docencia, y por tanto controlables y modificables; mientras que las oportunidades y amenazas constituyen variables externas, dependientes del contexto, no controlables ni modificables, pero que hay que conocer para tratar de prever, evaluar y actuar en consecuencia (Cutropia, 2003, p. 88). 


\section{La muestra}

Para el desarrollo del DAFO que hemos aplicado en la presente investigación, hemos utilizado la técnica cualitativa de informantes clave. La población objeto de análisis ha sido la totalidad de directores de Departamento de la Universidad de Valencia (90), así como los decanos de las diferentes Facultades. Para la selección de la muestra hemos constituido 4 grupos de informantes con una muestra de 30 entrevistados, correspondientes a las 4 grandes ramas generales del saber:

- Ciencias Sociales:

- 4 directores de los Departamentos de la Escuela Universitaria de Magisterio Ausiàs March (Didáctica de las Ciencias Experimentales y Sociales, Didáctica de la Matemática, Didáctica de la Lengua y la Literatura y Didáctica de la Expresión Musical, Plástica y Corporal).

- 2 directores de Departamento de la Facultad de Ciencias Económicas (Dirección de Empresas y Economía Financiera y Actuarial).

- 1 director de Departamento de la Facultad de Derecho(Derecho Penal).

- Decano de la Facultad de Derecho.

- Artes y Humanidades:

- 4 directores de Departamento de la Facultad de Filosofía y Ciencias de la Educación (Métodos de Investigación y Diagnóstico en Educación, Teoría de la Educación, Educación Comparada e Historia de la Educación y Didáctica de la Organización Escolar).

- 2 directores de Departamento de la Facultad de Geografía e Historia (Historia del Arte y Prehistoria y Arqueología).

- 1 directora de Departamento de la Facultad de Filología, Traducción y Comunicación (Filología Clásica).

- Decano de la Facultad de Filosofía y Ciencias de la Educación.

- Ciencias de la Salud:

- 4 directores de Departamentos de la Facultad de Medicina (Anatomía y Embriología; Cirugía; Medicina y Fisiología).

- 2 directores de Departamento de la Facultad de Farmacia (Farmacología, Parasitología).

- Decana de la Facultad de Farmacia. 
- Ciencias y Tecnología:

- 3 directores de Departamento de la Facultad de Ciencias Biológicas (Botánica, Zoología y Biología Funcional y Antropología Física).

- 1 director de Departamento de la Facultad de Química (Química Inorgánica).

- 1 director de Departamento de la Facultad de Matemáticas (Estadística).

- 1 director de Departamento de la Facultad de Física (Física Teórica).

- Decano de la Facultad de Ciencias Biológicas.

- Director de la Escuela Técnica Superior de Ingenierías.

\section{Análisis de datos}

El trabajo cualitativo desarrollado se ha basado en el análisis de contenido de las 30 entrevistas realizadas a informantes clave. El contenido de las mismas se transcribió, para ser sometido ulteriormente a un proceso de conceptualización. Llamamos tal a la selección de los conceptos tratados en las entrevistas. El proceso seguido consta de tres fases o niveles: a) categorización; b) conceptualización; c) teorización.

El número de categorías base iniciales para el análisis fue inicialmente de 4: debilidades, amenazas, fortalezas y oportunidades. Para agrupar, clasificar y analizar los datos recogidos se ha partido inicialmente de una codificación abierta para descubrir las sub-categorías de conceptos, en términos de sus propiedades y dimensiones; en este proceso las sub-categorías van emergiendo desde los datos. Posteriormente hemos aplicado una codificación axial, que es básica en la formación de conceptos, en la que hemos relacionado las categorías formando conceptos siguiendo la línea de sus propiedades y dimensiones para establecer los pertinentes vínculos (Coffey y Atkinson, 2003). En este proceso los conceptos se derivan de las relaciones pertinentes entre las categorías, ya que este nivel permite visualizar y descubrir patrones centrales (patrones conceptuales) en los datos, que traducen representaciones coherentes del conjunto sometido a análisis; las cuales constituyen un marco conceptual integrado desde el que producir teorizaciones contextualizadas.

El vaciado de las transcripciones, empleando estas categorías como unidades clasificatorias, se realizó mediante la construcción de una aplicación sobre Excel ${ }^{4}$, en la que se manejan 7 columnas: documento, página, párrafo, texto de referencia, interviniente, notas y observaciones. A partir de ese 
momento se ha tratado independientemente cada una de las sub-categorías con sus textos respectivos, buscando el sentido común de todos ellos, respetando las variaciones que cada uno de ellos representan en cuanto a contenidos y matices y elaborando como resultado los correspondientes resúmenes.

En suma, se ha desarrollado una aplicación propia al servicio del análisis cualitativo. Esta aplicación ha permitido tanto incorporar los contenidos de teoría desarrollados por los autores del estudio, como aprovechar los contenidos empíricos observados en la realidad vivida por los profesores que han integrado la muestra de estudio. Se ha conseguido así llevar adelante el empeño de utilizar, en una espiral enlazada, una metodología deductiva — de la teoría al análisis de la realidad—, con una metodología inductiva — de la realidad a inferir constantes observadas-, con la que reelaborar los contenidos teóricos.

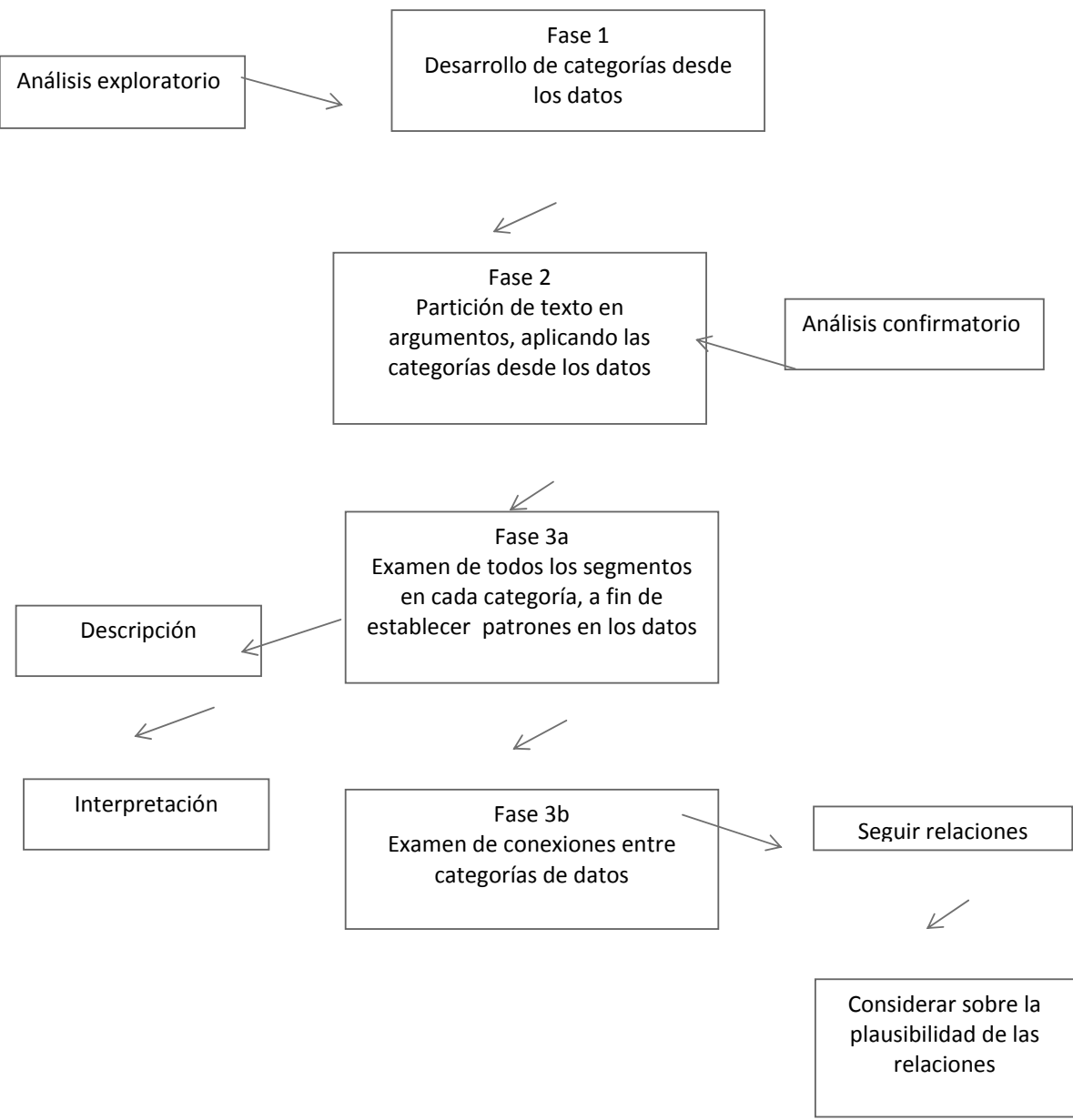

Figura 2. Proceso de Análisis Cualitativo (Pérez Serrano, 1994) 


\section{ANÁLISIS CONCEPTUAL: RESULTADOS}

Tras la codificación axial y la pertinente relación de subcategorías siguiendo la línea de sus propiedades y dimensiones hemos realizado la síntesis cruzada de las aportaciones provenientes de los diferentes sectores en los que hemos ubicado a los informantes clave y hemos establecido los vínculos que nos han permitido generar 11 patrones conceptuales; una evaluación de los análisis realizados por los distintos grupos de expertos nos lleva a seleccionar y particularizar la mirada en algunas consideraciones, dado que las valoraciones realizadas son numerosas, variadas y complejas, algunas de las cuales vienen a corroborar aspecto ya conocidos, aunque no siempre contrastados. Cabria reseñar como significativos los siguientes resultados del multi-análisis:

Las Debilidades: se refieren a cuestiones que obstaculizan la capacidad de aplicación de la sostenibilidad en la docencia, y como variables internas, requieren y pueden ser controladas y neutralizadas. El análisis realizado ha permitido generar tres patrones conceptuales que hacen referencia a: Política universitaria, Desarrollo de la función docente y Estructura de soporte a la actividad docente.

\begin{tabular}{|l|l|}
\hline Política universitaria & $\begin{array}{l}\text { - Ausencia de una política expresa de sostenibilidad. } \\
\text { - Incentivos ajenos a la sostenibilidad. } \\
\text { - Rechazo a normativas impuestas. } \\
\text { - Eslogan utilizado en política para decir sobre lo que } \\
\text { no se hace. }\end{array}$ \\
\hline $\begin{array}{l}\text { Desarrollo de la función } \\
\text { docente }\end{array}$ & $\begin{array}{l}\text { - Énfasis en la variable conocimiento. } \\
\text { - Desconocimiento del concepto de sostenibilidad; con- } \\
\text { cepto ambiguo no exento de interpretaciones. } \\
\text { - Actitudes reacias al concepto de competencia } \\
\text { - Carencia de métodos de evaluación de competencias. } \\
\text { - No inclusión de competencias para la sostenibilidad } \\
\text { en las Guías Docentes. }\end{array}$ \\
\hline $\begin{array}{l}\text { Estructura de soporte a } \\
\text { la actividad docente }\end{array}$ & $\begin{array}{l}\text { - Masificación en las clases. } \\
\text { - Materias distantes a aspectos socio-ambientales. } \\
\text { - Falta de medios y recursos técnicos. } \\
\text { - Dificultades para un trabajo en red. } \\
- \text { Ausencia de marcos y espacios de discusión. } \\
- \text { Ausencia de recursos centralizados. } \\
- \text { Problemas económicos y de equipamiento. }\end{array}$ \\
\hline
\end{tabular}

Tabla 1. Debilidades

Para controlar y neutralizar estas debilidades se ha constatado que «no hay una politica clara por parte de la institución (Universidad, Facultad, De- 
partamento) para implantar cuestiones relacionadas con la sostenibilidad en la docencia» (I.8); lo cual requiere una reorientación institucional ya en el Plan Estratégico General de la universidad, así como una comunicación eficaz respecto del contenido del mismo dirigida a toda la comunidad universitaria; «es una debilidad que la universidad haya presentado a nivel institucional un Proyecto estratégico de impulso de la excelencia en salud y sostenibilidad y, sin embargo, hasta ahora no haya implicado a sus centros en el objetivo explícito de incluir la sostenibilidad en todas las nuevas titulaciones universitarias; este proyecto debería llevar aparejado un conjunto de acciones en cada centro para orientar sobre la inclusión de la sostenibilidad en el currículum»(I.14).

Pero habría que tener en cuenta que "si el proyecto se presenta de forma autoritaria y politizada de manera que dé la impresión de ser una solución de pensamiento único a todos los problemas que actualmente tiene la humanidad puede provocar rechazo en los colectivos responsables de su implantación»(I.14). La imposición de proyectos y normativas con criterios de «arriba abajo», sin atender a las diferentes características y condiciones de cada ámbito de actuación (área de conocimiento, tamaño de los grupos...) incrementa en gran medida la probabilidad de fracaso o de resultados contrarios a los deseados.

De igual modo se ha visto necesario, en el análisis realizado, incentivar el desarrollo profesional de la carrera docente e investigadora del profesorado, desde objetivos coherentes con la sostenibilidad, ya que «la falta de tradición en la realización de enfoques interdisciplinares conlleva una gran dedicación y esfuerzo si se quieren llevar a cabo actividades transversales» (I.4).

En relación al desarrollo de la función docente se apunta como negativo la realización de actividades formativas más centradas en la variable cognitiva y escasamente en las variables relacionadas con las habilidades y las actitudes, tal y como también indica Orr (2010), y en las que «se prima el contenido específico de lo que se enseña antes que el contenido en su relación con el mundo en el que se vive» (1.28), debido a una cierta escasa conciencia del cambio metodológico esperado.

Se apunta también un desconocimiento generalizado de la filosofía y del propio concepto de sostenibilidad entre el profesorado por la ambigüedad que encierra "...no exenta de tantas interpretaciones como se le quieran dar» (1.28), cuestión ampliamente analizada por Wrigth (2010), y que «dificulta su percepción como concepto que compendia diversos valores inherentes a nuestro sistema constitucional» (1.11); lo que podría, en parte, explicar la consideración, encontrada en el análisis, de que ciertas asignaturas de diferentes grados estén «distantes» de planteamientos relacionados con la problemática socio-ambiental. 
Por otro lado, el nuevo modelo de formación por competencias, parece que "está suscitando ciertas prevenciones en una parte del profesorado que cuestiona el propio concepto de competencia, al que se le confieren significados difícilmente compatibles con procesos de formación» (1.24). A este condicionante habría que añadir la inexistencia de bancos de datos para facilitar la inclusión de competencias para la sostenibilidad en las actividades formativas, la dificultad para incluir en las Guías docentes contenidos promotores de competencias para la sostenibilidad, así como la carencia de métodos de evaluación por competencias según se desprende de las observaciones realizadas por diferentes informantes clave.

También se han podido constatar ciertas limitaciones por parte del profesorado en la comprensión y aplicación del enfoque constructivista y la dificultad de desarrollar meta-competencias, como las relacionadas con la inteligencia emocional; "el excesivo academicismo y unidireccionalidad en el cumplimiento de los objetivos profesionalizadores, con el evidente olvido de otras funciones de la universidad implica un alejamiento de estas cuestiones tan importantes para la formación de nuestros jóvenes» (I.7). Y no menos valoración tiene el esfuerzo adicional que supone la implantación de los nuevos grados y postgrados que hace que el profesorado esté saturado de trabajo y que, aun mostrando disponibilidad, no programe acciones favorables a la introducción de competencias transversales en sus clases.

En relación a la estructura de soporte de las actividades docentes, se señala como debilidad la masificación de alumnos tanto en las clases teóricas como en las clases prácticas, la falta de medios y recursos técnicos, el "excesivo individualismo del profesorado con las consecuentes dificultades para establecer un trabajo en red» (1.17) con las necesarias sinergias y canales comunicativos entre los diferentes actores relacionados con la sostenibilidad (rectorado, comisiones de grado, profesorado...); se destaca en el análisis una notable carencia en la oferta de cursos de concienciación y percepción social de la problemática socio-ambiental, así como la ausencia de marcos de discusión, debate y solución de conflictos y de recursos centralizados para facilitar la introducción de la sostenibilidad en los procesos de enseñanza-aprendizaje; y por otro lado se evidencian en determinados títulos "cuestiones relacionadas con problemas de equipamiento en aulas y laboratorios (falta de contenedores selectivos de reciclaje) o problemas económicos (disolventes menos contaminantes...)»(1.16).

Las Amenazas: están constituidas por variables externas provenientes del medio o entorno y que pueden impedir la implantación y realización de acciones tendentes a introducir la sostenibilidad en la docencia; al ser varia- 
bles externas es necesario proceder a su prevención, ya que es prácticamente imposible su control. Los resultados del análisis han generado dos patrones conceptuales: Barreras a la función docente y Barreras a la sostenibilidad.

\begin{tabular}{|l|l|}
\hline Barreras a la función & - Grupos de alumnos masificados. \\
docente & - Escasa cultura de sostenibilidad. \\
& - Carencia de interés y de motivación. \\
& - Posicionamientos ideológicos. \\
\hline Barreras a la sostenibilidad & - Dificultad presupuestaria para incrementar pro- \\
& fesorado. \\
& - Presión en la aplicación de los nuevos planes. \\
& - Menor concienciación hacia problemas sociales. \\
& - Escaso reconocimiento de las tareas docentes. \\
& - Deficiente información en la incorporación del \\
& profesorado novel. \\
& - Personal de administración poco formado en \\
& metodologías de gestión de recursos. \\
\hline
\end{tabular}

Tabla 2. Amenazas

Las amenazas encontradas en el análisis hacen referencia a la dificultad de incrementar los gastos en personal docente que implica disponer de grupos masificados y conlleva una reducción de la calidad ofrecida; "la ingente carga de trabajo que supone el desarrollo de los planes de estudio puede decantar la priorización de los esfuerzos institucionales hacia otros objetivos académicos menos difusos y mejor percibidos como tales por el profesorado, los estudiantes y la propia sociedad» (1.11). La existencia de un personal de la administración poco formado en las metodologías de gestión de recursos; el escaso desarrollo de la cultura de la sostenibilidad en la sociedad; la "presión excesiva en la aplicación de los nuevos planes y en la adaptación al EEES que incide en una menor atención a temas relacionados con el desarrollo sostenible a la hora de elaborar las guías docentes y planificar las asignaturas» (1.4); la falta de reconocimiento en las tareas académicas relacionadas con la sostenibilidad que incide en una "carencia de interés y motivación generalizada, sobre todo en lo referente a la incorporación de PDI novel formado en los departamentos que representaría la base futura para la generalización de la integración de la sostenibilidad en la docencia»(1.1); por otra parte también se ha detectado «algunos posicionamientos ideológicos condicionantes de la adhesión de algunos profesores y de su compromiso individual a la incorporación de la perspectiva de la sostenibilidad en su quehacer docente e investigador» (1.13).

Las Fortalezas: se refieren a aquellas cuestiones que actúan como ventajas en términos de recursos, enfoques, procedimientos relacionados con la introducción y desarrollo de competencias para la sostenibilidad en los 
procesos de enseñanza-aprendizaje; como variables internas pueden ser susceptibles de control para mejorar la introducción de la sostenibilidad en la docencia. El análisis realizado ha permitido generar tres patrones conceptuales que hacen referencia a: Capacitación del profesorado y personal técnico; Recursos científicos e Innovaciones docentes.

\begin{tabular}{|l|l|}
\hline $\begin{array}{l}\text { Capacitación } \\
\text { del profesorado } \\
\text { y personal técnico }\end{array}$ & - Alta capacidad intelectual. \\
& $\begin{array}{l}\text { - Estudios interdisciplinares con enfoques holísticos. } \\
\text { - Personal de laboratorio implicado. } \\
\text { - Existencia de clases prácticas. }\end{array}$ \\
\hline Recursos científicos & $\begin{array}{l}\text { - Existencia de redes de investigación. } \\
\text { - Nuevas metodologías didácticas. } \\
\text { - Incremento de formación a través de las TICs. }\end{array}$ \\
\hline Innovaciones docentes & $\begin{array}{l}\text { - Aumento de sensibilización. } \\
\text { - Coordinación docente. } \\
\text { - Reparto de responsabilidades. } \\
\text { - Tratamiento transversal de competencias generales y } \\
\text { específicas. }\end{array}$ \\
\hline
\end{tabular}

Tabla 3. Fortalezas

Las fortalezas encontradas en el análisis representan un importante punto de apoyo para la introducción de la sostenibilidad en la docencia; en relación a las fortalezas que hacen referencia a la capacitación del profesorado se indica "su alta capacidad intelectual y dedicación profesional» (1.1), que permite ser optimistas respecto al éxito de los proyectos innovadores como los relacionados con la sostenibilidad, teniendo en cuenta además, la existencia de estudios multidisciplinares que permiten enfocar la problemática socio-ambiental desde diferentes perspectivas. El análisis ha revelado la consideración de una creciente (aunque insuficiente) concienciación del profesorado hacia las cuestiones relacionadas con el desarrollo sostenible, cuestión ejemplificada en algunos casos, en «L'ús racional de les mostres biològiques... amb la máxima optimització posible, aprofitant al màxim cada animal d'estabulari $i$ cada mostra que utilitzem... i el rigurós maneig dels reactius d'elevada toxicitat d'acord amb la normativa vigent» (I.29) ${ }^{5}$, y en «... la sustitución de refrigerantes por recirculadores de agua...»(I.26); a lo que hay que sumar la existencia de un personal técnico de laboratorio implicado en la reducción de residuos en las prácticas docentes que parecen facilitar el desarrollo de actitudes y valores coherentes con los valores de la sostenibilidad.

En relación a los recursos científicos se ha constatado como altamente positivo la existencia de grupos y redes de investigación especializados en cuestiones relacionadas con la sostenibilidad, así como un progresivo au- 
mento de información a través del acceso a las nuevas tecnologías de la información y la comunicación, y de cursos de formación sobre sostenibilidad en la oferta no reglada para estudiantes y en la oferta de formación permanente para el profesorado. A destacar la aplicación de nuevas metodologías didácticas (juegos de simulación, ApS, portafolio...) que posibilitan la realización de actividades de enseñanza-aprendizaje no sólo centradas en el ámbito cognitivo, sino también en el procedimental y actitudinal; «con la implantación de los nuevos planes de estudios se han introducido nuevas metodologías de enseñanza-aprendizaje que favorecen, junto a un ahorro energético considerable, el tratamiento de cuestiones relacionadas con la sostenibilidad incluyendo junto a la variable de los conocimientos el desarrollo de procedimientos, actitudes y comportamientos acordes con los valores pertinentes para que los estudiantes adquieran una forma de trabajo en concordancia con el desarrollo sostenible»(1.13)

En el ámbito de la innovación docente se destaca «la posibilidad del profesorado de revisar los contenidos docentes de las asignaturas para adecuarlos al nuevo modelo de formación por competencias» (1.11), así como «el incremento de la coordinación docente en los nuevos planes de estudio abre posibilidades de reflexión colectiva acerca de la importancia de la formación en valores a integrar en las actividades didácticas, y de reparto de responsabilidades docentes de acuerdo a modelos educativos más dinámicos» (1.11); por otra parte, la inclusión de competencias generales en los nuevos planes de estudio posibilita un tratamiento transversal de cuestiones relacionadas con la sostenibilidad.

Las Oportunidades: tienen que ver con cuestiones o variables externas, no controlables que presenta la introducción de la sostenibilidad en la docencia y respecto a las cuales es necesario conocer y prevenir. En el presente estudio las oportunidades hacen referencia a: Situación del entorno socioeconómico; Desarrollo tecnológico y Marco jurídico normativo.

\begin{tabular}{|l|l|}
\hline $\begin{array}{l}\text { Situación del entorno } \\
\text { socio-económico }\end{array}$ & $\begin{array}{l}\text { Necesidad de crecer armónicamente con un desa- } \\
\text { rrollo sostenible. } \\
- \text { Crisis mundial: necesidad de egresados competen- } \\
\text { tes en sostenibilidad. } \\
- \text { Percepción social de la crisis socio-ambiental. } \\
- \text { Creciente «ola» de sentimientos pro-ambientales. }\end{array}$ \\
\hline Desarrollo tecnológico & $\begin{array}{l}\text { - Generalización del uso de las TICs. } \\
- \text { Modificación modos de trabajo, ocio y usos cotidia- } \\
\text { nos hacia criterios de sostenibilidad. }\end{array}$ \\
\hline
\end{tabular}




\begin{tabular}{|l|l|}
\hline Marco jurídico-normativo & $\begin{array}{l}\text { - Referencia a competencias generales y específicas } \\
\text { en los planes de estudio. } \\
\text { - Directrices europeas para ambientalizar los currícula. } \\
\text { - Declaración UNESCO: Década de la educación para } \\
\text { el desarrollo sostenible. }\end{array}$ \\
\hline
\end{tabular}

Tabla 4. Oportunidades

En relación a la situación del entorno socio-económico, las oportunidades encontradas en el análisis hacen referencia a que «la presión de la crisis económica actual hace que las empresas de ingeniería y el sector industrial sean cada vez más conscientes de la necesidad de "crecer» de manera sostenible por constituir un valor de negocio» (1.27). Esta situación de crisis generalizada por la que atraviesan las sociedades occidentales que configuran el denominado "mundo desarrollado» puede ser, a su vez, una fuente de oportunidades para apostar por proyectos educativos que aporten a la formación de los futuros gestores egresados, aspectos y criterios de sostenibilidad. Por otra parte se observa «una mayor percepción social sobre la crisis socio-ambiental, así como un crecimiento de la onda de sentimientos pro-sostenibilidad» (1.6), que afecta a la posible realización de acciones formativas.

Respecto al desarrollo tecnológico se han valorado en el análisis «los avances en la funcionalidad y uso de las tecnologías de la información y de la comunicación gracias al desarrollo de la ingeniería informática, electrónica y de telecomunicación, que permiten incrementar sustancialmente la disponibilidad de servicios avanzados inteligentes y así modificar hábitos de trabajo y ocio e incluso las actividades cotidianas de forma más acorde a criterios sostenibles» (1.27).

Y atendiendo al marco jurídico, la normativa ministerial que sirve de base para el desarrollo de los nuevos planes de estudio del Ministerio de Educación recoge en su articulado referencias expresas a la sostenibilidad en forma de competencias generales (y en algunas titulaciones en forma de competencias específicas), indica planteamientos claramente comprometidos con la sostenibilidad tanto en los aspectos ambientales como en los sociales (con clara influencia en los aspectos económicos) y sienta las bases para potenciarla a través de los planes de grado y postgrado. Esta coyuntura "supone, sin duda, un momento ideal de cambio para trabajar por incorporar contenidos transversales en los planes de estudio» (1.7). Por otra parte, se constata la existencia de orientaciones de la Conferencia de Rectores de las Universidades Europeas (CRE) a ambientalizar los currícula, así como las directrices de la Conferencia de Rectores de las Universidades Españolas sobre la introducción de la sostenibilidad en la docencia. No menos significativo es, a este respecto, la declaración de la UNESCO en la Década de la 
educación para el desarrollo sostenible sobre la necesidad de facilitar acciones de formación dirigidas a contribuir a la sostenibilidad del desarrollo.

\section{CONCLUSIONES Y PROPUESTAS}

Las conclusiones y propuestas han sido construidas a partir de la revisión bibliográfica realizada, el análisis de los datos obtenidos en la entrevista/encuesta aplicada a la muestra de estudio y la interpretación de los resultados de los Multi-Análisis DAFO aplicados a los informantes clave; muchas de ellas coinciden con la reciente revisión publicada por Granados et al (2011). Las hemos clasificado en tres apartados en función de los diferentes ámbitos en los cuales las propuestas pueden llevarse a cabo:

1. Ámbito institucional: Este ámbito involucra cuestiones políticoadministrativas y hace referencia a iniciativas provenientes de la propia institución universitaria; son aquí factores fundamentales: el apoyo institucional y el desarrollo de normativas orientadas a fomentar la educación para el desarrollo sostenible. En este ámbito ubicamos las siguientes conclusiones, ampliando las propuestas del artículo de Barrón et al (2010):

- La introducción de la sostenibilidad en la docencia necesita de una reflexión inicial por parte de la administración educativa competente que marque las líneas generales de acción.

- El éxito en la realización de actividades relacionadas con la sostenibilidad depende del posible acuerdo entre planteamientos específicos provenientes de normativa rectoral, y de la implicación del profesorado en su aplicación; estos acuerdos radican en la voluntad explícita de unos y otros de realizar acciones coherentes con los valores éticos y sociales relacionados con el desarrollo sostenible.

- Es pertinente una mayor divulgación del concepto de sostenibilidad a todos los niveles, para concienciar y sensibilizar a los profesores (Aznar et al, 2011), alumnos (Murga, 2008; Gomera, 2008) y personal de administración y servicios.

- Debería propiciarse un mayor apoyo institucional e implicación de las administraciones públicas en las iniciativas y desarrollo de acciones relacionadas con la introducción de la sostenibilidad en las instituciones educativas, puesto que ellas son las responsables del diseño, aplicación y desarrollo de competencias para la sostenibilidad. 
- Necesidad de establecer una base de datos de titulaciones y/o asignaturas en las que se trabaja la sostenibilidad en los procesos de enseñanza aprendizaje para canalizar la información y promover una red como referente para actuaciones más coordinadas.

- Creación de una instancia, a la que podría denominarse Observatorio de Sostenibilidad, para impulsar y coordinar las acciones a realizar y establecer y mantener las sinergias necesarias entre los actores de la misma.

2. Ámbito estratégico: el factor docente; hace referencia a la implicación de los equipos docentes en la especificación de competencias para la sostenibilidad en las asignaturas que imparten y el diseño y planificación de contenidos y actividades para desarrollarlas; requiere el compromiso y disponibilidad de los profesores; para cualquier innovación que se quiera introducir en la universidad, el profesor es el eje central del proceso; es el motor del cambio. Lo cual requiere facilitar su labor mediante la disponibilidad de tiempos y espacios para configurar los recursos y herramientas pertinentes para las materias especificas y propiciar el intercambio de experiencias. Sobre todo teniendo en cuenta que en este ámbito se otorga generalmente más relevancia a la actualización científica e investigadora que a la formación continua para la docencia (Tomás, 2001). En este ámbito aportamos las siguientes conclusiones y propuestas:

- Dado que los procesos de aprendizaje se basan en el logro de competencias, el logro de competencias clave para la sostenibilidad requiere un marco normativo que justifique la selección de las competencias a desarrollar; este marco normativo concretado en las resoluciones ministeriales propias de cada titulación, ha de especificarse en los planes de estudio, (ya que no todos lo contemplan: Martínez-Agut et al 2009), y en las Guías Docentes de cada materia.

- Es pertinente la realización de cursos de actualización profesional para especificar competencias básicas para la sostenibilidad en las diferentes asignaturas de los planes de estudio, su traducción en contenidos - conceptuales, procedimentales y actitudinales- en las Guías Docentes, y la utilización/aplicación de metodologías, técnicas y recursos pertinentes.

- Es pertinente potenciar en la docencia la inter-colaboración en el uso racional de recursos didácticos y una sólida base de participación colectiva, para la aplicación de criterios de sostenibilidad en los procesos de enseñanza-aprendizaje. Cabe aquí resaltar la oportunidad, ya reseñada en el análisis, que presenta la im- 
plantación de los grados, que está exigiendo al profesorado una mayor coordinación y trabajo en equipo.

- Es oportuno contemplar incentivos académicos para implicar a los profesores en acciones relacionadas con la sostenibilidad; por ej.: introduciendo ítems pertinentes en los cuestionarios de evaluación de los grados, de los posgrados y de la docencia.

3. Ámbito de interacción social: búsqueda de sinergias. La sostenibilidad es una responsabilidad compartida; su integración en los currícula universitarios puede verse mejorada por las sinergias que se pueden establecer en el contexto social; en este sentido encontramos como conclusiones del estudio:

- Necesidad de promover con las instituciones públicas y empresas privadas el desarrollo de proyectos conjuntos que potencien el papel de la universidad en la consecución de un desarrollo sostenible.

- Es necesario que las administraciones públicas establezcan líneas específicas de financiación, a través de convocatorias oficiales continuadas para la realización de proyectos concretos que incluyan, como acciones complementarias necesarias, procesos de formación para el desarrollo de competencias específicas en materia de sostenibilidad.

\section{NOTAS}

1 El presente estudio forma parte del Proyecto de Investigación EDU2010-21485: La sostenibilización curricular en los nuevos planes de grado: revisión de las Guías docentes desde la perspectiva de las competencias básicas para la sostenibilidad y propuestas para su desarrollo y evaluación. Proyecto financiado por el MICINN (2010-2013).

2 Página web del equipo investigador: Sostenibilidad y Educación Superior www.uv.es acuveg.

3 Acta reunión 18 de abril de 2005 (Valladolid), y asumido por la Asamblea General de la CRUE. Este documento ha sido actualizado en la reunión de la Comisión Sectorial (CADEP) en Sevilla (noviembre 2011).

4 La aplicación desarrollada sobre Excel es propia, y ha sido realizada por aproximación a los instrumentos de análisis cualitativo existentes en el mercado, muy especialmente de Atlas ti, pero con la ventaja de que las formas de manipulación de los datos se han adaptado al contenido y orientación de nuestro trabajo, de modo que no se ha producido una adaptación del trabajo al instrumento sino, muy al contrario, la de este instrumento a la naturaleza de nuestro trabajo.

5 «El uso racional de las muestras biológicas...con la máxima optimización posible, aprovechando al máximo cada animal de estabulario y cada muestra que utilizamos... y el riguroso manejo de los reactivos de elevada toxicidad de acuerdo con la normativa vigente» (I.29), (En valenciano en el original). 


\section{REFERENCIAS BIBLIOGRÁFICAS}

Adomssent, M., Godemann, J. y Michelsen, G. (2007). Transferability of approaches to sustainable development at universities as a challenge. International Journal of Sustainability in Higher Education 8 (4), 385-402.

Adomssent, M. y Michelsen, G. (2006). German academia heading for sustainability? Reflexions on policy and practice in teaching, research and institutional innovations. Environmental Education Research 12 (1), 85-99.

Axelsson, H., K. Sonesson, y P. Wickenberg (2008). Why and how do universities work for sustainability in higher education (HE)? International Journal of Sustainability in HigherEducation 9 (4), 469-78.

Aznar Minguet, P. (2006). El reto educativo de la sostenibilidad en el marco europeo de la educación superior. En A. Escolano Benito, Cambio educativo y cultura de la sostenibilidad. (pp. 167188). Madrid: Biblioteca Nueva.

Aznar Minguet, P y Ull, M. A. (2009). La formación de competencias básicas para el desarrollo sostenible: el papel de la Universidad. Revista de Educación, número extraordinario, 219-237.

Aznar Minguet, P y Ull, M. A. (2013). La responsabilidad por un mundo sostenible. Propuestas educativas a padres y profesores. Bilbao: Editorial Desclee de Brouwer.

Aznar Minguet, P.; Martínez-Agut, M. P.; Palacios, B.; Piñero, A. y Ull, M. A. (2011). Introducing sustainability into university curricula: an indicator and baseline survey of the views of university teachers at the University of Valencia. Environmental Education Research, 17 (2), 145-166.
Barrón, A., Navarrete, A. y Ferrer-Balas, D. (2010). Sostenibilización Curricular en las universidades españolas. ¿Ha llegado la hora de actuar? Revista Eureka sobre Enseñanza y Divulgación de las Ciencias, 7, n. $^{\circ}$ extraordinario, 388-399.

Coffey, A. y Atkinson, P. (2003). Encontrar el sentido de los datos cualitativos. Medellin: Universidad de Antioquía.

Cohen, D. (2007). Desafíos de la responsabilidad social universitaria. Revista electrónica Razón y Palabra; febreromarzo, 55. Recuperado de www.cem. itesm.mx/dacs/publicaciones/logos/ anteriores/n55/dcohen.html

Colás, P. y De Pablos, J. (2005). La formación del profesorado basada en redes de aprendizaje virtual: aplicación de la técnica DAFO. Teoría de la Educación. Revista interuniversitaria, 5, 1-8.

Copernicus Campus (2006). Copernicus guidelines for sustainable development in the European Higher Education Area: How to incorporate the principles of sustainable development into the Bologna Process. Recuperado de http:// www.aic.lv/bolona/Bologna/contrib/ Statem_oth/Copernicus-Campus.pdf

Cotton, D.R.E.; Warren, M. F. Maiboroda, O. and Bailey, I. (2007). Sustainable development, higher education and pedagogy: a study of lecturers' beliefs and attitudes. Environmental Education Research, 13 (5), 579-597.

Cutropía, C. (2003). El plan de marketing paso a paso. Madrid: ESIC.

Ferrer-Balas, D., J. Adachi, S., Banas, C. I., Davidson, A., Hoshikoshi, A., Mishra, Y., Motodoa, M., Onga y Ostwald, M. (2008). An international comparative analysis of sustainability trans- 
formation across seven universities. International Journal of Sustainability in Higher Education, 9 (3), 295-316.

Gaete Quezada, R. (2011). La responsabilidad social universitaria como desafío para la gestión estratégica de la Educación Superior: el caso de España. Revista de Educación, 109-133.

Geli de Ciurana, A. M. (2002). Universidad, sostenibilidad y ambientalización curricular. En E. Arbat y A. M. Geli de Ciurana (ed.) Ambientalización Curricular en los Estudios Superiores. Aspectos Ambientales de las Universidades, (pp. 11-14). Girona: Universitat de Girona y Red ACES.

Gobierno de España (2008). La Estrategia Universidad 2015 (EU 2015). Recuperado de: http://www.mecd.gob.es/ eu2015

Gomera Martínez, A (2008). La conciencia ambiental como herramienta para la Educación Ambiental. Conclusiones y reflexiones de un estudio en el ámbito universitario. Carpeta informativa del CENEAM, 7-14.

Granados Sánchez, J., Wals, A.E.J., Ferrer-Balás, D., Waas, T., Imaz, M., Nortier, S., Svanström, M., Van't Land, H. y Arriaga, G. (2011). Sustainability in Higher Education: moving from understanding to action: breaking barriers for transformation. En GUNI. Higher Education in the World 4. Series on the Social Commitment of universities 4, (pp.: 193-207). New York: Palmgrave Macmillan.

Junyent, M. y de Ciurana, A. M. (2008). Education for sustainability in university studies: a model for reorienting the curriculum. British Educational Research Journal, 34 (6), 763-782.

Lozano, R. (2006). Incorporating and institutionalization of sustainable development into universities: breaking through barriers to change. Journal of cleaner Production, 14 (9-11), 787-796.

Martínez-Agut, M. P., Ull Solís, A. y Aznar Minguet, P. (2009). Títulos que habilitan para el ejercicio de profesiones reguladas: análisis de las referencias a la sostenibilidad. En M. T. Tortosa; J. D. Álvarez y N. Pellín, VII Jornadas de Redes de Investigación en Docencia Universitaria. La calidad del proceso de enseñanzalaprendizaje universitario desde la perspectiva del cambio. (pp. 547-556). Alicante: Vicerrectorado de Planificación Estratégica y Calidad. Instituto de Ciencias de la Educación. Universidad de Alicante.

Michavila, F. (2001). La universidad española hacia Europa. Madrid: MundiPrensa Libros.

Murga Menoyo, A. (2008). Percepciones, valores y actitudes ante el desarrollo sostenible. Detección de necesidades educativas en estudiantes universitarios Revista Española de Pedagogía. 240, 307-344.

Novo, M. 2009. El desarrollo sostenible. Su dimensión ambiental y educativa. Madrid: Humanitas.

Orr, D. (2010). Para qué sirve ahora la educación superior. En The Worldwatch Institute. La situación del mundo 2010. Cambio cultural: del consumismo hacia la sostenibilidad. Icaria: Ciudad.

Pérez Serrano, G. (1994). Investigación cualitativa. Retos e interrogantes. Madrid: Editorial La Muralla.

Proyecto CAMPUS SOSTENIBLE (2011). Universitat de València. Recuperado de http://www.uv.es

Rodríguez, J.M. (2010). Responsabilidad social universitaria: del discurso simbólico a los desafíos reales. En M. De la Cuesta, C. De la Cruz, y J. 
M. Rodriguez, Responsabilidad social universitaria. (pp. 3-22). A Coruña: NetBiblo.

Sibbel, A. (2009). Pathways towards Sustainability through Higher Education. International Journal of Sustainability in higher Education 10 (1), 68-82.

Tomás, M. (2001). El cambio de cultura en las universidades del siglo XXI. Educar, 28, 147-62.

UNESCO (1998). La educación superior en el siglo XXI. Visión y acción. Conferencia Mundial sobre la Educación Superior. ED.98/CONF.202/7.2. París: UNESCO.

UNESCO (2005). Decenio de las Naciones Unidas de la Educación para el Desarrollo Sostenible 2005-2014: Plan de aplicación internacional. (ED/ DESD/2005/PI/01). Paris: UNESCO.

UNESCO (2009). La nueva dinámica de la Educación superior y la investigación para el cambio social y el desarrollo. VII Conferencia Mundial sobre la educación Superior. ED.2009/CONF.402/2. Paris: UNESCO.

Vallaeys, F; De la Cruz, C. y Sasia, P. (2009). Responsabilidad social uni- versitaria. Manual de primeros pasos. México D.F.: McGrawHill.

Velazquez, L., Munguía, N. y Sánchez, M. (2005). Deterring sustainability in higher education institutions: An appraisal of the factors which influence sustainability in higher education institutions, International Journal of Sustainability in Higher Education, 6 (4), 383-391.

Wals, A.E. J. y Jickling, B. (2002). Sustainability in higher education. International Journal of Sustainability in Higher Education, 3 (3), 221-232.

Wals, A. y Blaze Corcoran, P. (2006). Sustainability as an outcome of transformative learning. En J. Holmberg, y B. Samuelson (Ed.). Drivers and barriers for implementing sustainable development in higher education, (pp. 103-108). Paris: UNESCO. Recuperado de http://unesdoc.unesco.org/ images/0014/001484/148466E.pdf

Wrigth, T. (2010). University president's conceptualizations of Sustainability in Higher Education. International Journal of Sustainability in Higher Education 11 (1), 61-73. 


\section{PALABRAS CLAVE}

Sostenibilidad, educación superior, Análisis DAFO.

\section{KEYWORDS}

Sustainability, Higher Education, SWOT analysis.

\section{PERFIL ACADÉMICO Y PROFESIONAL DE LOS AUTORES}

Pilar Aznar Minguet es Catedrática de Teoría de la Educación adscrita al Dpto. de Teoría de la Educación de la Facultad de Filosofía y Ciencias de la Educación de la Universidad de Valencia. Dirige el Equipo de investigación sobre Sostenibilidad y Educación superior desde el año 2003 y al que pertenecen todos los autores de este artículo, Con más de 30 años de experiencia docente.

M. Àngels Ull es Profesora Titular de Bioquímica y Biología Molecular adscrita al Dpto. del mismo nombre de la Facultad de Ciencias Biológicas de la Universidad de Valencia y está adscrita a la Entidad de Investigación Interdisciplinar (ERI) de Estudios de Sostenibilidad. Con más de 30 años de experiencia docente.

Albert Piñero es Doctor en Sociología y Profesor contratado del Dpto. de Sociología y Antropología Social de la Universidad de Valencia y está adscrito a la Entidad de Investigación Interdisciplinar (ERI) de Estudios de Sostenibilidad.

M. Pilar Martínez-Agut es Doctora en Pedagogía y Profesora Asociada en el Dpto. de Teoría de la Educación de la Universidad de Valencia. Adscrita a la Entidad de Investigación Interdisciplinar (ERI) de Estudios de Sostenibilidad.

Dirección de los autores: Pilar Aznar Minguet

Dpto. Teoría de la Educación.

Fac. de Filosofía y CCEE

Universitat de Valencia

Avda. Blasco Ibáñez 30

46010, Valencia, España

E-mail: pilar.aznar@uv.es

Fecha Recepción del Artículo: 12. Diciembre. 2011

Fecha Revisión del Artículo: 17. Abril. 2012

Fecha Aceptación del Artículo: 07. Mayo. 2012

Fecha de Revisión para publicación: 24. Junio. 2013 


\title{
LAS OPORTUNIDADES DE LAS ACADÉMICAS EN EL DESARROLLO PROFESIONAL DOCENTE UNIVERSITARIO: UN ESTUDIO CUALITATIVO
}

\author{
(THE OPPORTUNITIES FOR WOMEN IN PROFESSIONAL ACADEMIC \\ DEVELOPMENT: A QUALITATIVE RESEARCH)
}

Inés Lozano Cabezas, Marcos Jesús Iglesias Martínez

y María Ángeles Martínez Ruiz

Universidad de Alicante

DOI: 10.5944/educxx1.17.1.10709

Cómo referenciar este artículo/How to reference this article:

Lozano Cabezas, I., Iglesias Martínez, M.J. y Martínez Ruiz, M.A. (2014). Las oportunidades de las académicas en el desarrollo profesional docente universitario: un estudio cualitativo. Educación XX1, 17(1), 159-182. doi: 10.5944/educxx1.17.1.10709.

Lozano Cabezas, I., Iglesias Martínez, M.J. y Martínez Ruiz, M.A. (2014). The opportunities for women in professional academic development: a qualitative research. Educación XX1, 17 (1), 159-182. doi: 10.5944/educxx1.17.1.10709.

\section{RESUMEN}

En la sociedad actual, caracterizada por la intensa conexión, existe un alto consenso científico en que el desarrollo profesional se beneficia de una auténtica participación e interacción en la comunidad de referencia. En este marco conceptual, el objetivo de esta investigación se ha centrado en indagar acerca de las percepciones profesionales de las mujeres académicas en la Universidad de Alicante, singularmente, en la expresión de sus visiones y experiencias acerca de las interrelaciones personales con sus mentores, así como su integración en las redes departamentales. La metodología utilizada ha articulado procesos de interpretación cualitativos y cuantitativos, tal como permite el software AQUAD Seis, programa que facilita la constitución de categorías y la presentación cuantificada de resultados. Los datos atestiguan que, a pesar de la preexistencia de diferencias evidentes de género en las instituciones universitarias, las académicas no propenden a culpabilizar a las instituciones en las que trabajan de estos diferenciales. No obstante, las profesoras universitarias no tienden a presentarse como víctimas, valoran que una estructura colaborativa en la comunidad universitaria podría proveer mejores oportunidades efectivas en su desarrollo profesional, beneficiando tanto la participación y la promoción equitativa, como un mejor aprovechamiento del capital de las académicas en los avances y progresos de la institución. 


\section{ABSTRACT}

In the current society of intense social connections, there is wide scientific consensus in relation to the issue advocating that professional development can benefit from true participation and interaction in the community of reference. Within this framework, the aim of this research has been to inquire about the perceptions of female academic professionals at the University of Alicante, and more specifically, to examine their opinions and personal experiences regarding professional interrelations with mentors and their integration in professional networks. The applied methodology has combined the processes of qualitative and quantitative interpretation supported by the AQUAD Six data processing program, which facilitates the presentation of results. The results show clear evidence in relation to the fact that, although the persistence of gender differentials in Higher Education Institutions is statistically evident, academic women do not blame institutions for discrimination nor do they feel like victims, but they would like a more collaborative structure in the university community which could provide effective opportunities in their professional development, and lead not only to equitable participation and promotion but also help the progress of the institution.

\section{INTRODUCCIÓN}

En la sociedad actual, caracterizada por la intensa conexión social (Christakis y Fowler, 2009), hay un alto consenso científico en que la identidad y el desarrollo profesional se benefician de una auténtica participación e interrelación en la comunidad de referencia (Cochran-Smith y Lytle, 1999). Coincidimos con Blickenstaff (2005) en que hay múltiples y muy complejos elementos de gran influencia en el contexto social en que se sitúa el desarrollo profesional. Singularmente, uno de los factores más relevantes en el aprendizaje profesional y en la forja de la identidad académica es la oportunidad de los actores de asumir responsabilidades, así como la posibilidad de que se preste atención a todas sus voces en la comunidad de trabajo.

Las conceptualizaciones del aprendizaje que enfatizan la dimensión social y situada del proceso educativo parecen idóneas para fundamentar un modelo en el ámbito del desarrollo profesional del personal académico. Entre estas, la perspectiva del aprendizaje como participación legítima periférica, propuesta por Lave y Wenger (1991), presenta el aprender como un hecho dilemático, comprometido y negociado. La perspectiva de los autores citados propone situar al aprendiz y al experto en un espacio de múltiples vías de progreso, en una red de interacciones dinámicas y complejas. En el campo del desarrollo profesional del profesorado, Cochran-Smith y Lytle (1999) enfatizan, en esta misma línea de pensamiento, que el conocimiento del aprendiz no depende únicamente de su conexión con el del experto, sino que emerge de la interacción con todos los pares. Las autoras argumentan que, en una comunidad de trabajo, novel y experto progresan conjuntamente a través de una mutua colaboración. Ambas perspectivas ofrecen una contribución relevante, por cuanto inspiran 
la creación de espacios participativos en los que puedan converger múltiples visiones de las prácticas profesorales. La acción colaborativa aúna y confronta reflexiones que favorecen la construcción de un conocimiento más distribuido en la comunidad de trabajo (Cochran-Smith y Zeichner, 2005). Si en la formación inicial universitaria ha sido canónico que el mentor supervise las creencias y prácticas de su aprendiz, la cultura de desarrollo profesional situado propone el diseño y creación de espacios compartidos donde las distancias se difuminen y las relaciones se acentúen (Johnson y Johnson, 2010).

En suma, las redes sociales y la participación en comunidades de aprendizaje son escenarios y condiciones inequívocamente requeridos para evitar el aislamiento, los temores y la inseguridad en el inicio del desarrollo profesional (Lieberman y Pointer-Mace, 2008; Lieberman y Pointer-Mace, 2010; Whitcomb, Borko y Liston, 2009). Adicionalmente, las oportunidades que la institución facilita al cuerpo académico son, las que contribuyen a generar mejores posibilidades en los aprendizajes de los estudiantes (Darling-Hammond, 1996).

En este marco, esta investigación pretende dilucidar en qué forma la cultura profesional de la institución universitaria procura a las académicas las oportunidades, los modelos y el apoyo para un desarrollo profesional adecuado y equitativo. La información necesaria para este fin se extrae de las propias voces de las académicas de la Universidad de Alicante.

Los diferenciales de género, en el caso de la Universidad Española, prosiguen evidenciando una divergencia a favor del conjunto de varones. Aunque el número de mujeres ha aumentado en la universidad, especialmente, en lo que se refiere al número de estudiantes que obtienen una titulación y el grado de doctora (Bermúdez et al., 2011), la evolución del porcentaje de profesoras va en declive según éstas van avanzando en su carrera profesional (véase Figura 1).

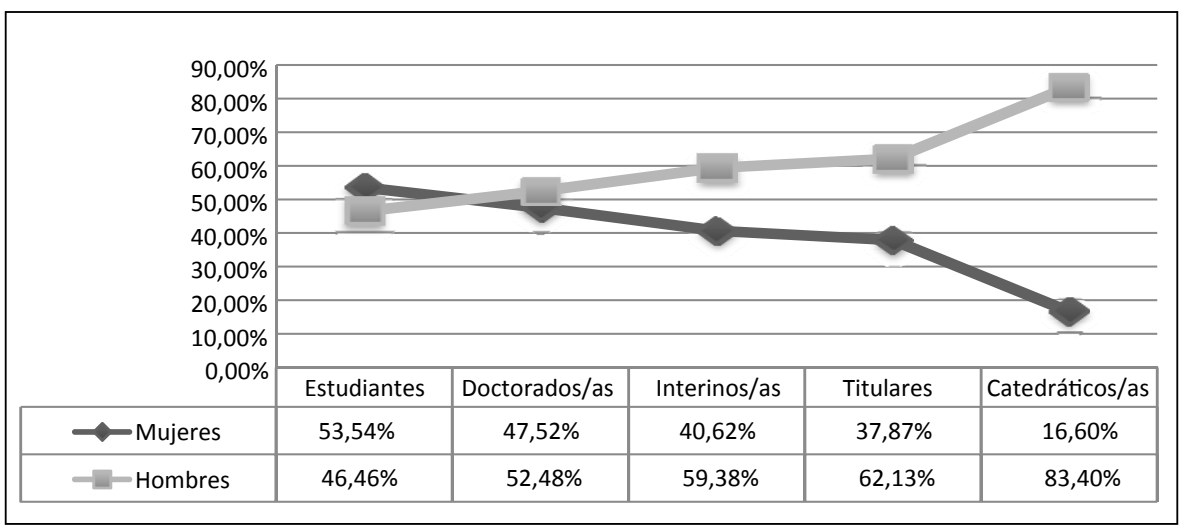

Figura 1. Distribución porcentual del alumnado y el profesorado en las universidades españolas Fuente: Redibujado a partir de los datos INEBASE (2010) 
Similares diferenciales de género estructuran a la Universidad de Alicante. Epítome de ello es que en esta institución de las 176 cátedras de universidad existentes únicamente 22 están ocupadas por mujeres. La presencia de las mujeres en el colectivo docente e investigador en la Universidad de Alicante supone únicamente un 33,7\% frente a un $66,3 \%$ en el caso de los hombres. Estos datos son coincidentes con las distribución de los puestos docentes a nivel nacional [académicos 65,5\%; académicas 34,5\%] (FECYT, 2007). Además, otros informes ministeriales, como el MEC-UMYC (2007), evidencian que la presencia de las mujeres en puestos de alta responsabilidad - decanato, dirección de institutos o departamentos- es muy limitada (Figura 2), principalmente, en lo que se refiere a los centros, institutos y departamentos de Ciencia y Tecnología.

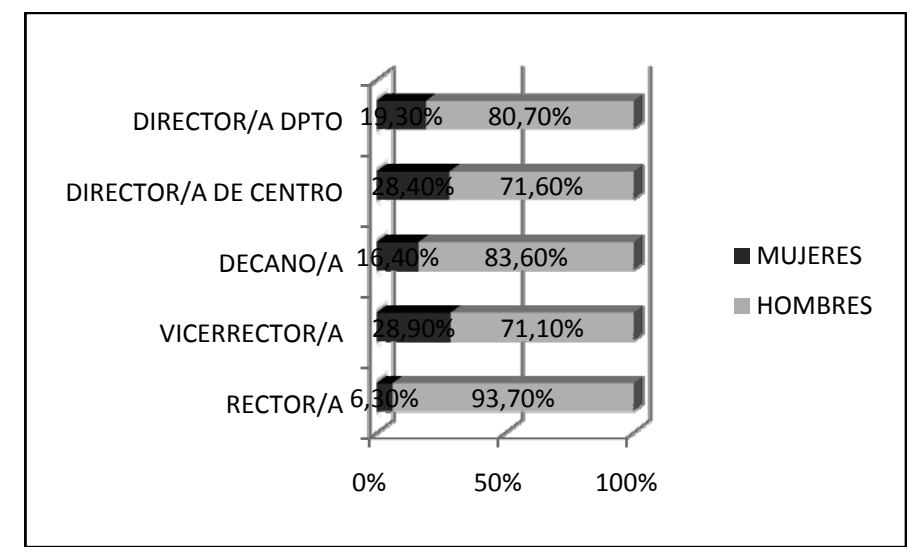

Figura 2. Mujeres y hombres en cargos unipersonales de las universidades públicas españolas (Redibujado a partir de MEC-UMYC (2007)

Entre las causas que motivan la desafección de las mujeres a la ciencia, el informe Mujer y Ciencia (FECYT, 2007), señala la ausencia de modelos que permitan a las mujeres verse representadas o imaginarse como científicas. Prácticamente, todos los datos, sea en investigación, docencia y liderazgo académico (Tomás, Castro y Durán, 2012), o en otros sectores profesionales, evidencian desigualdades. El citado documento reconoce que la «discriminación histórica» aún permanece pese a los esfuerzos legislativos y de concienciación social.

En el panorama internacional, numerosos estudios convergen en sus conclusiones con la situación española. Así, por ejemplo, en Europa las académicas representan un grupo minoritario (European Commission, 2009a, 2009b). Uno de los estudios norteamericanos más relevantes es el realizado por el Massachusetts Institute of Technology (1999), cuya aproximación al tema ha inspirado muchos estudios sobre académicas, espe- 
cialmente, en aquellas áreas de conocimiento donde el salario depende de la producción científica. Diversos estudios en universidades norteamericanas, destacan la escasa presencia de las académicas en los top post (Krefting, 2003), hecho que potencia la política masculina. Por otra parte, Acker y Dillabough (2007) han analizado, en las Facultades de Educación de la Universidad de Ontario (Canadá), entre los años 1960 y 1990, cómo los diferenciales de género han influido en la trayectoria laboral de las académicas. Las autoras se han centrado en la exposición de los vínculos entre el trabajo académico de las mujeres y los códigos de género que organizan la vida laboral en el contexto universitario, tanto ahora como en el pasado reciente, como una contribución a la sociología del trabajo de las mujeres (Acker y Armenti, 2004). Por otra parte, diversos estudios realizados en el Reino Unido consideran que las condiciones laborales todavía distan mucho de ser equilibradas prevaleciendo el modelo organizacional masculino (Bagilhole y Goode, 2001; Knights y Richards, 2003; Ledwith y Manfredi, 2000).

La emergencia de los estudios de género en el espacio académico responde a una demanda social a favor de una ciencia menos androcéntrica (Ballarín, 2005) y sus investigaciones y publicaciones permiten identificar qué barreras obstaculizan la promoción profesional de las mujeres en la academia (Alonso, 2002). En este sentido, los estudios de mujeres pueden animar a las investigadoras a participar activamente en la gestión universitaria y así convertir el, hasta ahora, monopolio de poder universitario en algo compartido por los hombres y las mujeres (Hemmings, 2006). Los hechos demuestran que las académicas no propenden a acceder a los puestos y funciones de responsabilidad (Tomás y Guillamón, 2009), y que sus aportaciones encuentran obstáculos para ser comunicadas a la comunidad científica. Esta divergencia en la participación merma las oportunidades de aprender de las mujeres teniendo que afrontar mayores dificultades que las que encuentran sus colegas académicos.

\section{DISEÑO METODOLÓGICO}

La investigación a partir de las voces de los participantes es lo que Clandinin y Connelly (2000) han denominado senda de la investigación narrativa. Esta metodología se fundamenta en la interpretación de los relatos y metáforas del conocimiento profesional, entretejido en la diversidad de historias de vida (Huber, Caine, Huber y Steeves, 2013), para extraer un conocimiento situado en lo social y en lo profesional. En concordancia con lo que antecede, el análisis de los discursos biográficos sobre la trayectoria profesional es, para Bourdieu (2003), la base para observar la estructura social, principalmente, la relación entre género y poder. En este 
sentido, Coffey y Delamont (2000) consideran que el discurso narrativo es una herramienta que da autoridad académica, mientras que, los distintos discursos sobre el género que proponen un proyecto feminista empírico son un factor que afecta a los esfuerzos hacia una mayor equidad. Las posturas expuestas justifican el que esta investigación se articule en base al análisis de las reflexiones de las académicas, por cuanto representan el pensamiento y la cultura de los centros en los diferentes contextos de la vida universitaria.

\section{Cuestiones de investigación}

Tres cuestiones de investigación son fundamentales en la trayectoria profesional pudiendo informar acerca de la posible existencia de una auténtica comunidad orientada hacia el proceso del desarrollo profesional, así como de los parámetros de igualdad existentes, singularmente en cuanto a género:

1. Cuáles son las valoraciones de las académicas sobre su relación con su mentor/a.

2. Qué diferencias de oportunidades, en cuanto a integración, promoción, distribución de responsabilidades, perciben las profesoras desde su condición de mujer a lo largo de su trayectoria profesional.

3. Cuáles son las valoraciones de las mujeres acerca de su relación con los colegas.

\section{Participantes}

La invitación a participar en esta investigación se extendió a la totalidad de académicas pertenecientes a las categorías de plazas que tienen más presencia en la estructura universitaria actual, lo que totalizó 638 académicas. El número de profesoras que voluntariamente respondieron, con total disponibilidad, ha sido de 89. Desde la asunción de que el porcentaje es limitado, el hecho de que las académicas participantes cubrieran todo el espectro de categorías y centros del campus permitía considerar que la muestra era suficientemente diversa y representativa dadas las características y la naturaleza de la investigación cualitativa. Las tablas 1 y 2 (datos demográficos) muestran la distribución de las participantes en las diferentes categorías de las plazas ocupadas. 


\begin{tabular}{|l|c|c|}
\hline $\begin{array}{c}\text { Categoría de plazas } \\
\text { seleccionadas }\end{array}$ & Total mujeres UA & $\begin{array}{c}\text { Porcentaje } \\
\text { de participantes }\end{array}$ \\
\hline Profesora asociada & 268 & $7,46 \%$ \\
\hline Ayudante & 75 & $16,00 \%$ \\
\hline Profesora Colaboradora & 27 & $11,11 \%$ \\
\hline Contratada Doctora & 52 & $11,54 \%$ \\
\hline Titular & 194 & $20,62 \%$ \\
\hline Catedrática & 22 & $36,36 \%$ \\
\hline Total & 638 & $13,95 \%$ \\
\hline
\end{tabular}

Tabla 1. Participantes de la investigación según categoría profesional

\begin{tabular}{|l|c|c|}
\hline \multicolumn{1}{|c|}{ Centros } & Total mujeres UA & \multicolumn{1}{c|}{$\begin{array}{c}\text { Porcentaje } \\
\text { participantes }\end{array}$} \\
\hline E. de Enfermería & 50 & $16,00 \%$ \\
\hline E. Politécnica Superior & 85 & $9,41 \%$ \\
\hline F. de Ciencias & 88 & $13,64 \%$ \\
\hline $\begin{array}{l}\text { F. de Ciencias Económicas } \\
\text { y Empresariales }\end{array}$ & 142 & $14,79 \%$ \\
\hline F. de Derecho & 87 & $9,20 \%$ \\
\hline F. de Educación & 63 & $19,05 \%$ \\
\hline F. de Filosofía y Letras & 123 & $16,26 \%$ \\
\hline TOTAL & 638 & $13,95 \%$ \\
\hline
\end{tabular}

Tabla 2. Participantes de la investigación por centros

\section{Recopilación y tratamiento de la información}

El proceso de recogida de datos se ha basado en una entrevista abierta (Denzin y Lincoln, 2000). La entrevista planteaba tres cuestiones claves para la reflexión (Tabla 3). Se les solicitaba una valoración de su experiencia y trayectoria profesional en la Universidad. Dos de los investigadores llevaron a cabo las entrevistas que fueron obtenidas en formato audio siendo transcritas posteriormente a formato escrito.

\section{ENTREVISTA}

1. ¿A quién consideras tu mentor/a? ¿Ves diferencias de trato con respecto a otros/as compañeros/as?

2. ¿Has percibido diferencias de oportunidades con tus compañeros/as respecto a la integración en el grupo? ¿La promoción? ¿La distribución de responsabilidades? ¿Otras diferencias?

3. ¿Cómo percibes tus relaciones personales y profesionales con tus compañeros/as? ¿Crees que vienen afectadas por el género o por otros factores?

Tabla 3. Entrevista 
La elección del software AQUAD Seis, desarrollado por Huber (2003), se fundamenta en el potencial de esta herramienta para hacer interactuar las categorías provenientes de las propias voces de las participantes con el proceso de conceptualización y estructuración que deben imprimir los investigadores. Mediante la codificación, pues, las categorías emergentes se interpretan y organizan en un proceso recursivo tal como aconsejan Miles y Huberman (1994). El programa Aquad permite este proceso flexible y revisable, de continuo diálogo, entre las categorías de análisis que emergen desde las propias voces de las participantes y el esfuerzo de estructuración y consistencia que el investigador ha de ir imprimiendo en la categorización basada en el marco conceptual. Los mapas de códigos resultantes han sido discutidos y validados a partir de las valoraciones de tres profesoras y tres profesores (en consecuencia, las perspectivas femenina y masculina ha atestiguado esta validación), quedando así una configuración definitiva para el análisis de esta investigación. El programa Aquad permite complementar el proceso cualitativo con una cuantificación, por lo que presentamos en las tablas de códigos la frecuencia absoluta (FA) y el porcentaje de la frecuencia absoluta (\%FA) de los códigos determinados.

\section{PRESENTACIÓN Y DISCUSIÓN DE LOS RESULTADOS}

Finalizado el proceso de constitución de categorías y codificación de las unidades de narrativa mediante la utilización del software Aquad Seis, obtenemos un resultado en forma de códigos, metacódigos y subcódigos con diferentes frecuencias de aparición.

\section{Primera cuestión de investigación}

La primera cuestión de investigación inquiere sobre la relevancia de la figura del mentor para una correcta inserción en la comunidad de práctica profesional (Lave y Wenger, 1991). El relevante rol de la mentoría es una variable de pleno reconocimiento en el acceso a todo tipo de oportunidades de aprendizaje profesional, como se señala en el estudio elaborado por The National Academies Press (NAP, 2009):

Aquellas profesoras ayudantes que tenían un mentor tuvieron mayor probabilidad de recibir más subvenciones que aquellas que no tuvieron mentor (p. 77).

En las narrativas emergen dos metacódigos básicos: el referido al sujeto de la mentoría y el que relata la vivencia de la relación. En el primer metacódigo surgen dos tipos de casuísticas: la identificación del mentor 
con una figura femenina o masculina y la carencia de mentoría y, por tanto, asumir ser mentoras de sí mismas (Tabla 4).

\begin{tabular}{|c|c|c|c|c|}
\hline \multicolumn{5}{|c|}{ Metacódigo 1. Mentoría } \\
\hline CÓDIGOS & SUBCÓDIGO & EJEMPLO & FA & $\% \mathrm{FA}$ \\
\hline \multirow[t]{2}{*}{$\begin{array}{l}1.1 \text { Identificación } \\
\text { de mentoría }\end{array}$} & 1.1.1 Varón & $\begin{array}{l}\text { Mi mentor mi director } \\
\text { de tesis. (Asociada010) }\end{array}$ & 61 & $54,46 \%$ \\
\hline & 1.1.2 Mujer & $\begin{array}{l}\text { Considero a mis mentoras } \\
\text { a mis directoras de tesis. } \\
\text { (Colaboradora001) }\end{array}$ & 21 & $18,75 \%$ \\
\hline \multicolumn{2}{|l|}{ 1.2 Sin Mentoría } & $\begin{array}{l}\text { No tengo mentor. } \\
\text { (Asociada019) }\end{array}$ & 30 & $26,79 \%$ \\
\hline \multicolumn{3}{|l|}{ TOTAL } & 112 & $100 \%$ \\
\hline \multicolumn{5}{|c|}{ Metacódigo 2. Igualdad de trato en la relación de mentoría } \\
\hline \multicolumn{2}{|c|}{ CÓDIGO } & EJEMPLO & FA & $\% \mathrm{FA}$ \\
\hline \multicolumn{2}{|l|}{2.1 Diferencia } & $\begin{array}{l}\text { Veo diferencias de trato de mi } \\
\text { mentora con respecto a mis } \\
\text { compañeros. (Titular013) }\end{array}$ & 6 & $12,77 \%$ \\
\hline \multicolumn{2}{|l|}{ 2.2 Igualdad } & $\begin{array}{l}\text { No he visto diferencias de } \\
\text { trato. (Titular003) }\end{array}$ & 41 & $87,23 \%$ \\
\hline \multicolumn{3}{|l|}{ TOTAL } & 47 & $100 \%$ \\
\hline
\end{tabular}

Tabla 4. Mentoría

En el código 1.1. Identificación de la mentoría, el subcódigo 1.1.1 Varón tiene una frecuencia más alta, resultado obvio derivado de que la presencia de los varones en las universidades españolas es superior al de las académicas. Las académicas identifican como mentores a sus directores de tesis, a los investigadores principales de proyectos de investigación, a los catedráticos del campo de conocimiento, a los directores o colegas de Departamento $\mathrm{y}$, en algunos casos, a sus parejas y familiares:

Respecto a mi investigación mi mentor es también mi marido (Asociada001).

Aún dada la alta frecuencia del anterior subcódigo, algunas de las narrativas hacen referencia a una mentoría femenina (subcódigo 1.1.2 Mujer), como directora de tesis, catedrática, etc.:

[T]engo también mentoras, en el ámbito político en el ámbito moral y ahora, también, en el intelectual (Titular034). 
Algunas participantes relatan no haber tenido mentor, por tanto, se consideran mentoras de sí mismas en su trayectoria profesional (subcódigo 1.1.2):

Considero que no tengo mentor/a, desgraciadamente no, y la verdad que sí que conozco gente que lo ha tenido y me parece envidiable (Titular036).

Mi consejera ha sido la experiencia y mi guía mi propia voluntad de superación personal y profesional (Titular006).

Profundizando en las vivencias de la mentoría, en el metacódigo 2, emergen los códigos 2.1 y 2.2 que respectivamente expresan la satisfacción o la insatisfacción con el mentor, básicamente, en lo referido a una igualdad de trato del mentor entre académicas y académicos. Como se puede apreciar en la Tabla 4, la mayoría de participantes (87.23\%) explicitan no haber percibido discriminación de género en sus relaciones con el mentor:

¿Sí veo diferencia en el trato hacia otros compañeros? La verdad es que no, yo veo que es una persona bastante comprometida con el desarrollo de los futuros académicos o de los becarios o incluso de los futuros profesionales en sí, es una persona bastante abierta y trata de apoyar al futuro profesional (Asociada002).

Otras participantes $(12.77 \%)$ constatan diferenciales de trato y la consiguiente frustración sentida ante una injusticia impropia de una institución a la que se le supone profundos valores éticos:

Mi mentor me decepcionó, por tanto, soy autodidacta. Me decepcionó porque cuando fui a pedir una beca pre-doctoral, me dijo, claramente, sin rodeos, que mientras que hubiera un hombre que pidiera esa beca, yo por muy buen expediente que tuviese, no tendría nada que hacer (Titular025).

En síntesis, aproximadamente la mitad de las académicas no considera haber disfrutado de la oportunidad de la mentoría, y cuando se ha dado el caso los mentores han sido fundamentalmente hombres. Los resultados indican que la figura del mentor, sea como apoyo o como modelo, no muestra una presencia suficientemente relevante y que las mentoras son una proporción insignificante. Los hallazgos concuerdan con el estudio FECYT (2007), en que la falta de modelo femenino en la academia dificulta que las mujeres puedan verse representadas o imaginarse como científicas, lo que a su vez incide, en gran medida, en que los potenciales de las académicas no encuentren una orientación y un apoyo para su desarrollo. 


\section{Segunda cuestión de investigación}

En esta cuestión de investigación han emergido tres categorías. Los códigos 3.1 y 3.2 se refieren a la percepción positiva o negativa de diferenciales de género en las oportunidades profesionales. Las participantes expresan claramente el no percibir diferencias de género. Adicionalmente, dado que en ambos códigos concretan los diferenciales alrededor de tres ámbitos de oportunidad académica: promoción, integración y cargos, se crearon subcódigos de análisis (tabla 5). El tercer código 3.3 identifica las vivencias de las participantes en su interrelación en el Departamento o unidad de investigación en el que laboran.

Metacódigo 3. Percepción de diferenciales de género

Código 3.1 Diferencias de oportunidades respecto al género

\begin{tabular}{|c|c|c|c|}
\hline SUBCÓDIGOS & EJEMPLO & FA & $\% \mathrm{FA}$ \\
\hline 3.1.1 En la promoción & $\begin{array}{l}\text { [E]n algún tribunal he visto que } \\
\text { hay diferencias de trato por el } \\
\text { simple hecho de ser hombre o } \\
\text { mujer. (Titular025) }\end{array}$ & 36 & 13,64 \\
\hline $\begin{array}{l}\text { 3.1.2 En la distribución de } \\
\text { responsabilidades e } \\
\text { integración }\end{array}$ & $\begin{array}{l}\text { En un colectivo del } 90 \% \text { de } \\
\text { mujeres siempre hay un hombre } \\
\text { en el mando del Departamento. } \\
\text { (Titular007) }\end{array}$ & 29 & 10,98 \\
\hline \multicolumn{2}{|l|}{ TOTAL } & 65 & 24,62 \\
\hline \multicolumn{4}{|c|}{ Código 3.2. Sin diferencias de oportunidades respecto al género } \\
\hline SUBCÓDIGOS & EJEMPLO & FA & $\% \mathrm{FA}$ \\
\hline 3.2.1 En la promoción & $\begin{array}{l}\text { Laborablemente no he } \\
\text { encontrado diferencias } \\
\text { de oportunidades con mis } \\
\text { compañeros. (Asociada005). }\end{array}$ & 50 & 18,94 \\
\hline $\begin{array}{l}\text { 3.2.2 En la distribución de } \\
\text { responsabilidades e } \\
\text { integración }\end{array}$ & $\begin{array}{l}\text { En gestión estamos todos por } \\
\text { igual. (Titular019) }\end{array}$ & 109 & 41,29 \\
\hline \multicolumn{2}{|l|}{ TOTAL } & 159 & 60,23 \\
\hline $\begin{array}{r}\text { Código 3.3 Otras diferencias } \\
\text { de oportunidades }\end{array}$ & $\begin{array}{l}\text { La universidad es muy clasista, } \\
\text { tu eres ayudante, eres doctora, } \\
\text { no doctora, pero no eres titular } \\
\text { ¿no? Yo creo que se hacen } \\
\text { muchos filtros (Ayu011) }\end{array}$ & 40 & 15,15 \\
\hline
\end{tabular}

Tabla 5. Diferencias de oportunidades

En el código 3.1, referido a la Percepción de diferenciales de género en las oportunidades profesionales tanto en la promoción, como en la integra- 
ción departamental o en la posibilidad de acceder a cargos y responsabilidades (Tabla 5), hemos constatado, al analizar el contexto de la Universidad de Alicante, que los datos estadísticos muestran diferencias (12,5\% son catedráticas). Lo mismo sucede en el resto de universidades españolas (35,50\% son catedráticas). Se concluye, pues, que los diferenciales de promoción existen y son una realidad constante en los contextos profesionales. Asimismo, son claramente patentes las diferencias en la distribución de cargos de responsabilidad (Figura 2). Puede suceder que la promoción de una persona con respecto a otra dependa de los vínculos relacionales. Esta situación ha estado relativamente presente en las universidades españolas. En qué forma, ha podido influir la cuestión de género es algo que los siguientes relatos apuntan:

Otra diferencia que se percibe bastante en el departamento que yo estoy es que el director suele promocionar antes a los chicos que a la otra chica que hay o a mí (Colaboradora002).

En cuanto a la promoción sí, cuando las cátedras eran a nivel nacional. Tuve un par de experiencias de misoginia claras (Catedrática006).

El subcódigo 3.1.2 emerge como una visión, no prominente pero clara, de percepción de diferenciales en la oportunidad de acceder a responsabilidades. Aunque las cifras constatan que actualmente, son pocas las mujeres que ocupan cargos de responsabilidad, las narrativas de las profesoras eluden declarar percepción de diferencias en la distribución de la responsabilidad, a excepción de una minoría que explicita las desigualdades:

Sí que he percibido diferencias, en cuanto a la distribución de responsabilidades, a mi directamente me mandaron a magisterio, y a la otra chica joven también, y los chicos se quedaron aquí (en la licenciatura) (Ayudante011).

Es patente que el conjunto de resultados concuerda con el análisis Mujer y Ciencia (2007) en cuanto los datos evidencian que a las élites femeninas no les gusta contemplarse como víctimas, y no suelen culpabilizar a sus propias instituciones de discriminación. El citado estudio argumenta la existencia de micro-desigualdades, la falta de oportunidades de inserción en comunidades de iniciados y de apoyo en mentores a las académicas. Las académicas rehúyen la crítica a la institución, de modo que sus narrativas contradicen los datos estadísticos. La evitación de la victimización es un fenómeno positivo, no obstante conviene considerar, como precisa el estudio NAP (2009), que en cualquier campo de conocimiento las candidatas a promoción representan un número menor que los candidatos; y que cuando 
una académica preside un comité de contratación supone un significativo efecto en el porcentaje de académicas contratadas.

\section{Tercera cuestión de investigación}

La tercera cuestión está vinculada con el metacódigo 4. Relaciones personales/profesionales, que aglutina las narrativas sobre los diferenciales de género entorno al tipo de relaciones percibidas con sus compañeros en los Departamentos. Este metacódigo se subdivide en cuatro códigos relativos a la vivencia de las relaciones por las participantes (Tabla 6).

\begin{tabular}{|l|l|c|c|}
\hline \multicolumn{1}{|c|}{ Metacódigo 4. Relaciones personales/profesionales } & \multicolumn{1}{|c|}{ EJEMPLO } & FA & $\%$ FA \\
\hline 4.1 Cordiales & $\begin{array}{l}\text { Mis relaciones personales } \\
\text { y profesionales con mis } \\
\text { compañeros en general son } \\
\text { buenas. (Catedrática006) }\end{array}$ & 60 & $46,51 \%$ \\
\hline 4.2 Colaborativas & $\begin{array}{l}\text { [D]e hecho siempre hemos } \\
\text { generado un buen equipo } \\
\text { y hemos trabajado siempre } \\
\text { junto. (Asociada011) }\end{array}$ & 13 & $10,08 \%$ \\
\hline 4.3 Afectadas por el género & $\begin{array}{l}\text { Hay bromas un poco sexistas } \\
\text { que no comparto [...] hay } \\
\text { cosas de comadreo masculino } \\
\text { en las que no voy a entrar } \\
\text { nunca. (Asociada011) }\end{array}$ & 21 & $16,28 \%$ \\
\hline 4.4 Afectadas por otros aspectos & $\begin{array}{l}\text { Desgraciadamente no } \\
\text { he tenido un grupo de } \\
\text { investigación donde } \\
\text { desarrollar una línea de } \\
\text { investigación. (Titular014) }\end{array}$ & 35 & $27,13 \%$ \\
\hline TOTAL &
\end{tabular}

Tabla 6. Percepción de las relaciones personales y profesionales con los colegas

El código que emerge como más preocupante para las académicas, derivado quizás por su motivación profesional inicial, es el centrado en la carencia de cooperación de los iguales y, en general, a nivel departamental (código 4.4):

La integración en el grupo ha sido difícil, porque mis compañeros cercanos en la edad, son todos hombres y tienen formas de trabajar diferentes (Titular012). 
Las relaciones profesionales son más difíciles de establecer por tres motivos: la forma que tienen de trabajar (de forma aislada), el «talante» de los que desean destacar (yo creo en el trabajo en equipo y no en trabajar para alguien) y que no existe un código ético claro compartido (Contratada Doctora004).

Estas percepciones coinciden con los estudios de Erixon-Arreman y Weiner (2007) que muestran cómo los colegas masculinos tienden a centrarse más en el conocimiento y en relaciones de poder en las académicas.

El código relaciones 4.3 "Afectadas por el género» hace referencia a aquellas relaciones personales y profesionales en las cuales su insatisfacción viene descrita por las actitudes machistas de otros compañeros, marcadas por los estereotipos propios de una cultura absolutamente inaceptable:

Lamentablemente, en esta sociedad sigue habiendo estereotipos y todavía sigue habiendo por parte de algunos hombres, independientemente, del nivel social, cultural y económico que tenga pues esa visión de mujer [...], desde mi experiencia, pues rubia, tal y tal, pues tienen, a lo mejor, una idea, [...] pues yo sí que me he encontrado con determinadas personas que en un principio antes de valorar otras cosas, pues tienen una percepción o una imagen distinta (Ayudante 008).

Las académicas describen también la defensa de sus derechos en este tipo de vivencias:

Sí suelo defender mis derechos cuando veo diferencias de género, lo he defendido, y desde luego eso me ha traído problemas y dificultades (Ayudante005).

En conjunto las autoras de las narrativas declaran no vivenciar discriminación, pero sí en algunos casos se sienten portadoras de una cierta invisibilidad:

A veces me he sentido discriminada por ser mujer, pero no que se me discrimine, sino que a lo mejor se me haría más caso si fuera un hombre, eso sí que lo he pensado (Asociada009).

La calidad e intensidad de las relaciones en las organizaciones de trabajo es una de las claves más relevantes para el aprendizaje y la constitución de la identidad profesional, por cuanto es en cada situación diaria y cotidiana donde se produce la auténtica integración y se explotan las oportunidades de aprendizaje genuinas. El estudio NAP (2009) explícita de forma 
incuestionable de qué modo la falta de un espacio de diálogo puede causar la mengua de las oportunidades:

El conjunto de mujeres que trabajan en las facultades informan de que ellas tienden a carecer de oportunidades de participar plenamente en las conversaciones con sus colegas, en un amplio rango de tópicos profesionales, que incluyen la investigación, el salario, o la gestión. Esta distancia puede bloquear a las mujeres el acceso a información relevante y puede determinar que ellas se sientan menos incluidas y más marginalizadas en sus vidas profesionales (p.74).

\section{CONCLUSIONES}

Urge un modelo educativo diseñando para atender la complejidad, diversidad e incertidumbre de la cultura propia del siglo XXI, por ello estamos obligados a iniciar la necesaria transformación social y educativa, y esta no será efectiva si no es a partir de un análisis profundo de las visiones y creencias de los profesores y profesoras (Welch, 2007). En este marco, los resultados de esta investigación aportan las perspectivas de las académicas. Aunque la limitación del estudio respecto al número de participantes, aconseja investigaciones complementarias, la voluntaria participación de genuinas voces merece ser valorada. Asimismo, existen diferenciales de participación que merecen una lectura. Un dato evidente es el bajo porcentaje de profesoras asociadas frente a la mayor voluntariedad de las titulares, hecho que podría ser indicio de un cierto temor a dejar oír sus voces dada su situación de mayor dependencia o también podría ser un indicador de una menor implicación con la institución. En cualquier caso, conviene considerar que en la investigación cualitativa la saturación se alcanza prontamente y, en muchos casos, la relevancia de los resultados no necesariamente se apoya en la frecuencia sino en el valor del significado.

En relación con la primera cuestión de investigación, la respuesta hallada es que un número relevante de las participantes no dispone de la ayuda de la mentoría, y las que manifiestan haberlo tenido se trata de un mentor masculino. En su conjunto, las evidencias atestiguan que ha habido una incorporación significativa de mujeres académicas en estos últimos años (Leemann, 2002; Raddon, 2002), aunque este hecho no ha mejorado la dificultad de las mujeres académicas en la inserción en las redes departamentales y de la mentoría. ¿Significa esto que sigue prevaleciendo en la academia una visión paternalista y patriarcal? Kurtz-Costes et al (2006) señalan la indispensabilidad de que los mentores actúen como auténticos modelos. En el caso de España, los datos de los estudios estadísticos (INEBASE, 2010) revelan que hay pocas académicas en las posiciones de mayor estatus y, por 
tanto, es difícil encontrar un modelo referente femenino en la universidad. Ante este obstáculo, sería conveniente sustituir el modelo individualizado de mentoría por modelos colaborativos de equipo en el sentido señalado por las conceptualizaciones sociales del aprendizaje.

En la segunda cuestión de investigación, las evidencias obtenidas en este estudio sugieren que las participantes no propenden a valorar que existan diferencias inequitativas acerca de las oportunidades de desarrollo profesional, no obstante, aparece una disonancia con esta convicción, cuando en sus narrativas las autoras indican que han sentido discriminación. En este sentido, las participantes no responsabilizan a la institución de los diferenciales en la promoción. En parte, valoran que el progreso puede verse dificultado por cuestiones personales y familiares, al tener que asumir la maternidad y las labores domésticas disminuyendo, de este modo, su tiempo dedicado a la profesión. Resulta de particular interés y relevancia examinar el análisis que las mujeres hacen de los hechos del género y de las relaciones de poder. Los datos sugieren que la gran mayoría de mujeres académicas muestran escasa disposición a explorar críticamente las relaciones entre poder y género.

Este hecho concuerda con las conclusiones del estudio de Maher y Tetreault (2011) que subrayan cómo las académicas a menudo no son sensibles a las frecuentes y sutiles desigualdades que regularmente causan un declinar en las oportunidades de inserción en comunidades formadas por iniciados. En adicción a lo que antecede, conviene tener presente como Acker y Dillabough (2007) sugieren que las académicas son vulnerables a formas de dominación simbólica inscritas en la cultura del puesto de trabajo. En conjunto las profesoras manifiestan una actitud más modesta, probablemente más insegura, acerca de sus propios méritos, fortalezas y capacidades profesionales en comparación a los colegas masculinos. En síntesis, las académicas y científicas aceptan, sin una suficiente y activa reacción crítica, prácticamente, cualquier situación profesional que la comunidad científica les ofrece.

Los hallazgos de la tercera cuestión de investigación, en forma significativa, inscriben una alta preocupación por un mayor espacio de colaboración y coordinación en el trabajo. Aunque un 46,51\% de las participantes indica valorar como cordiales las relaciones en los departamentos, pocas señalan lo que la realidad hace palpable: que los conflictos de relaciones en los departamentos son extremadamente frecuentes. Únicamente un 10,08\% explicita una positiva coordinación. Esta apreciación nos conduce al marco real existente de desarrollo profesional, anteriormente esbozado, en el sentido de la necesidad de aunar visiones en la construcción del conocimiento en los equipos y departamentos (Cochran-Smith y Zeichner, 2005). 
Los indicios de que prosigue prevaleciendo una visión masculina de la ciencia en muchas líneas de investigación y, en suma, falta una perspectiva femenina que interese a las académicas son evidentes (Harding, 1991). Blickenstaff (2005) propone que en el campo de la educación en ciencias se asegure a todos los estudiantes un igual acceso a la atención del profesor y a los recursos. Inequívocamente, en la universidad, los departamentos y unidades de investigación deben garantizar el acceso equitativo a la ciencia para todos. La patente infra-representación de las mujeres en la ciencia y en la tecnología hace necesario explicitar enfáticamente la producción científica femenina y su prestigio profesional. Fomentando la publicación de las científicas y su inserción en grupos de investigación de excelencia se podrá remontar la diferencia (Bank, 2007; Bank, 2011; Glazer-Raymo et al, 2000).

De las voces de las académicas participantes en este estudio, se aprecia, si bien en forma discreta, un pensamiento crítico con el sistema universitario, que rehúye toda forma de victimismo:

Decepcionada, por la universidad [...] lo que hacen es tratar de taparlo [el problema del género] (Catedrática003).

Nadie toma medidas para ayudarnos (Titular010).

Este pensamiento crítico incluye una valoración negativa del papel de algunas mujeres académicas:

El mayor obstáculo para la expresión y el desarrollo de un pensamiento crítico de las profesoras son las mujeres mismas, sobre todo en altos cargos (Titular026).

La auténtica profesionalización de la mujer no se va alcanzar con soluciones reduccionistas y acomodaticias más bien «through the painful struggle of constant reinvention ${ }^{1}$ (Walkerdine, Lucey y Melody, 2001, p. 182). Es necesario un mayor esfuerzo de auto-reflexión y autocrítica femenina en la búsqueda del reconocimiento y la visibilidad de las académicas. Será posible mediante un cambio de actitud personal, no sólo de los académicos, sino de muchas académicas que asumen un sistema que no les beneficia ni a ellas ni a la propia comunidad universitaria. Afortunadamente, los hallazgos han evidenciado que las participantes no tienden a buscar su autocomplacencia, sino que reclaman más responsabilidades e interacción como vías para avanzar hacia una identidad académica auténtica para todos.

Adicionalmente, la de los discursos de las participantes, aun en sus cuidadas y moderadas expresiones, permite afirmar que las universidades son fiel reflejo de las desigualdades de los contextos sociales y de las prácti- 
cas culturales. En consecuencia, las universidades, los departamentos y las unidades de investigación han de hacer un esfuerzo acelerado para instaurar una cultura más participativa y colaborativa que pueda redundar en un desarrollo profesional más auténtico para todos sus miembros.

Es de justicia finalizar esta investigación expresando y testimoniando nuestra gratitud más sincera y cordial a todas las académicas que generosamente han participado con sus activas aportaciones en este estudio. Esta valiosa participación es muy significativa porque una de las primeras premisas de la investigación cualitativa es la relevancia de crear relaciones interpersonales de calidad en el proceso de investigación y no únicamente el mero examen de objetos bajo estudio. Firmemente, queremos asegurar a todas las académicas que han contribuido en esta investigación que sus voces han representado para nosotros una gran motivación para proseguir ahondando en las vías más efectivas para avanzar hacia una mayor equidad en la comunidad universitaria.

\section{NOTAS}

1 «A través de la dolorosa lucha de la constante reinvención». 


\section{REFERENCIAS BIBLIOGRÁFICAS}

Alonso, M.J. (2002). Las académicas. Profesorado universitario y género. Revista de Educación, 328, 465-475.

Acker, S. y Armenti, C. (2004). Sleepless in academia. Gender and Education, 16 (1), 3-24

Acker, S. y Dillabough, J-A. (2007). Women "learning to labour» in the «male emporium»: exploring gendered work in teacher education. Gender and Education, 19 (3), 297-316.

Ballarín, P. (2005). Mujeres en el laberinto de cristal universitario. En I. Torres (coord.), Miradas desde la perspectiva de género. Estudios de las mujeres (pp. 183-194). Madrid: Narcea.

Bank, B.J. (2007). Gender and education. An encyclopedia. Vol. I y II. New York: Praeger.

Bank, B.J. (2011). Gender and Higher Education. Baltimore, MD: The Johns Hopkins University Press.

Bagilhole, B. y Goode, J. (2001). The contradiction of the myth of individual merit, and the reality of a patriarchal support system in academic careers: a feminist investigation. European Journal of Women's Studies, 8 (2), 161-180.

Bermúdez, M.P., Guillén-Riquelme, A., Gómez-García, A., Raúl QuevedoBlasco, R., Sierra, J.C. y Buela-Casal, G. (2011). Análisis del rendimiento en el doctorado en función del sexo. Educación XX1, 14(1), 17-33.

Blickenstaff, J. (2005). Women and science careers: leaky pipeline or gender filter? Gender and Education, 17 (4), 369-386.

Bourdieu, P. (2003). Las estructuras sociales de la economía. Barcelona: Anagrama.
Clandinin, D.J. y Connelly, F.M. (2000). Narrative inquiry: experience and story in qualitative research. San Francisco: The Jossey-Bass Education Series.

Coffey, A. y Delamont, S. (2000). Feminism and the classroom teacher. London: Routledge-Falmer.

Cochran-Smith, M. y Lytle, S.L. (1999). Relationships of knowledge and practice: teacher learning in communities. Review of Research in Education, 24, 249-306.

Cochran-Smith, M. y Zeichner, K. M. (Eds.) (2005). Studying teacher education: the report of the AREA panel on research and teacher education. Mahwah, New Jersey: AERA-Lawrence Erlbaum Associates.

Christakis, N. A. y Fowler, J.H. (2009). Connected: the surprising power of our social networks and how they shape our lives. New York: Little Brown and Company.

Darling-Hammond, L. (1996). The right to learn and the advancement of teaching: research, policy and practice for democratic educational. Educational Researcher, 6, 5-17.

Denzin, N.K. y Lincoln, Y. (Eds.). (2000). Handbook of qualitative research. London: Sage Publicacions, Inc.

Erixon-Arreman, I. y Weiner, G. (2007). Gender, research and change in teacher education: a Swedish dimension. Gender and Education, 19 (3), 317-337.

FECYT (2007). Mujer y Ciencia. La situación de las mujeres investigadoras en el sistema español de ciencia y tecnología. Madrid: Fundación Española para la Ciencia y la Tecnología.

European Commission (2009a). She figures 2009. Women and science sta- 
tistics and indicators. Luxembourg: Office for Official Publications of the European Communities. Recuperado de http://ec.europa.eu/research/ science-society/document_library/ pdf_06/she_figures_2009_en.pdf

European Commission (2009b). The gender challenge in research funding. Assessing the European national scenes. Luxembourg: Office for Official Publications of the European Communities. Recuperado de http://ec.europa.eu/ research/science-society/document_library/pdf_06/the-gender-challenge-inresearch-funding-report_en.pdf

Glazer-Raymo, J., Townsen, B. y RopersHuilman, B. (2000). Women in American Higher Education: A feminist Perspective. Second Edition. Nueva York: Pearson.

Harding, S. (1991). Whose science? Whose knowledge? Thinking from Women's lives. Milton Keynes: Open University Press.

Hemmings, C. (2006). Ready for Bologna? The impact of the Declaration on Women's and gender studies in the UK. European Journal of Women's Studies, 13 (4), 315-323.

Huber, G.L. (2003). AQUAD Six for WINDOWS. Tübingen: Ingeborg Huber Verlag.

Huber, J., Caine, V., Huber, M. y Steeves, P. (2013). Narrative Inquiry as Pedagogy in Education: the extraordinary potential of living, telling, retelling, and reliving stories of experience. $R e$ view of Research in Education, 37, 212 242.

INEBASE (2010). Instituto Nacional de Estadística. Recuperado de: http:// www.ine.es/inebmenu/indice.htm

Johnson, D.W. y Johnson, R.T. (2009). An educational psychology success story: interdependence theory and cooperative learning. Educational Researcher, 38 (5), 365-379.

Knights, D. y Richards, W. (2003). Sex discrimination in UK Academia. Gender, Work and Organization, 10 (2), 213-238.

Krefting, L.A. (2003). Intertwined discourses of merit and gender: evidence from academic employment in USA. Gender, Work and Organization, 2 (10), 260-278.

Kurtz-Costes, B., Andrews Helmke, L. y Ulku-Steiner, B. (2006). Gender and doctoral studies: the perceptions of Ph.D. students in an American university. Gender and Education, 18 (2), 137-155.

Lave, J. y Wenger, E. (1991). Situated learning: legitimate peripheral participation. New York: Cambridge University Press.

Ledwith, S. y Manfredi, S. (2000). Balancing gender in Higher Education: a study of the experience of senior women in a 'New» UK University. European Journal of Women's Studies, 7 (1), 7-33.

Leemann, R.J. (2002). Transitions into research careers in Switzerland. Education \& Training, 44, 146-198.

Lieberman, A. y Pointer-Mace, D.H. (2008). Teacher learning: the key to educational reform. Journal of Teacher Education, 59 (3), 226-234.

Lieberman, A. y Pointer-Mace, D.H. (2010). Making Practice Public: Teacher Learning in the 21st Century, Journal of Teacher Education, 61 (1-2), 77-88.

Maher, F. y Tetreault, M.K. (2011). Longterm transformations: excavating privileges and diversity in the academy. Gender and Education, 23(3), 281-297. 
Massachusetts Institute of Technology (1999). A study on the Status of Women Faculty in Science at MIT. Recuperado de http://web.mit.edu/fnl/women/ women.html\#The\%20Study

MEC-UMYC (2007). Académicas en cifras 2006-07. Ministerio de Educación y Ciencia: Unidad de Mujeres y Ciencia. Recuperado de http://genet.csic. es/biblioteca/mujeres\%20en $\% 20$ la $\% 20$ universidad\%20publica.pdf

Miles, B. M. y Huberman, A.M. (1994). Qualitative Data Analysis. London: SAGE Publications.

NAP-The National Academies Press. (2009). Gender differences at critical transitions in the careers of science, engineering and mathematics faculty. Washington, D.C.: The National Academies Press.

Raddon, A. (2002). Mothers in the academy: positioned and positioning within discourses of the "successful academic» and the "good mother».
Studies in Higher Education, 27, 387396.

Tomás, M. y Guillamón, C. (2009). Las barreras y los obstáculos en el acceso de las profesoras universitarias a los cargos de gestión académica. Revista de Educación, 350, 253-275.

Tomás, M., Castro, D. y Durán, M.M. (2012). Aproximación a un modelo de análisis de la visibilidad en la universidad desde la perspectiva de género. Bordón, 64(1), 141-155.

Walkerdine, V., Lucey, H. y Melody, J. (2001). Growing up girl: psychosocial explorations of gender and class. Basingstoke: Palgrave.

Welch, A. (Ed.). (2007). The professoriate. Profile of a profession. Dordrecht (The Netherlands): Springer.

Whitcomb, J., Borko, H. y Liston, D. (2009). Growing talent. Promising professional development models and practices. Journal of Teacher Education, 60 (3), 207-212. 


\section{PALABRAS CLAVE}

Género, educación superior, académicas, desarrollo profesional, AQUAD Seis.

\section{KEYWORDS}

Gender issues, higher education, professional development, AQUAD Six.

\section{PERFIL ACADÉMICO Y PROFESIONAL DE LOS AUTORES}

Inés Lozano Cabezas, doctora en Investigación Educativa, es profesora y secretaria del Departamento Didáctica General y Didácticas Específicas. Es miembro investigador del Grupo Interdisciplinar en Docencia Universitaria (GIDU) y Tecnologías Aplicadas a las Ciencias de la Educación (TACE). Sus líneas de investigación se centran los diseños de procesos educativos, formación profesional docente, género y diversidad, en ámbito universitario y en los niveles no universitarios.

Marcos Jesús Iglesias Martínez, doctor en Investigación Educativa por la Universidad de Alicante, con premio extraordinario de doctorado, y licenciado en Filosofía por la Universidad de Oviedo. Actualmente es profesor del Departamento Didáctica General y Didácticas Específicas. Es miembro investigador del Grupo Interdisciplinar en Docencia Universitaria (GIDU) y Tecnología Aplicadas a la Educación (TACE). Sus líneas de investigación se centran en el diseño de los procesos educativos y desarrollo profesional docente en distintos niveles educativos.

María Ángeles Martínez Ruiz, catedrática del área de Didáctica y Organización Escolar y Decana de la Facultad de Educación de la Universidad de Alicante. Ha sido Directora del Instituto de Ciencias de la Educación de la misma Universidad. Asimismo, es directora del Grupo Interdisciplinar en Docencia Universitaria (GIDU). Sus líneas de investigación se centran en el estudio de la educación superior y el desarrollo profesional docente en distintos niveles educativos.

Dirección de los autores: Universidad de Alicante

Facultad de Educación

Departamento de Didáctica General

y Didácticas Específicas

Carretera de San Vicente s/n

03080 Alicante

E-mail: ines.lozano@ua.es 
Fecha Recepción del Artículo: 18. Noviembre. 2011

Fecha Revisión del Artículo: 24. Abril. 2012

Fecha Aceptación del Artículo: 06. Junio. 2012

Fecha de Revisión para publicación: 24. Junio. 2013 

EVALUACIÓN: UNA ESTRATEGIA ADAPTADA AL ESPACIO EUROPEO DE EDUCACIÓN SUPERIOR

\author{
(ASSIGNMENT OF RESPONSIBILITY IN EVALUATION: \\ A STRATEGY ADAPTED TO THE EUROPEAN HIGHER \\ EDUCATION AREA)
}

Juan Antonio Moreno-Murcia, Adolfo Aracil y Raúl Reina

Universidad Miguel Hernández de Elche

DOI: $10.5944 / e d u c x x 1.17 .1 .10710$

\title{
Cómo referenciar este artículo/How to reference this article:
}

Moreno Murcia, J.A.; Aracil, A, y Reina, R. (2014). La cesión de responsabilidad en la evaluación: una estrategia adaptada al Espacio Europeo de Educación Superior. Educación XX1, 17 (1),183200. doi: 10.5944/educxx1.17.1.10710.

Moreno Murcia, J.A.; Aracil, A, y Reina, R. (2014). Assignment of responsibility in evaluation: a strategy adapted to the European Higher Education Area. Educación XX1, 17 (1),

183-200. doi: 10.5944/educxx1.17.1.10710.

\section{RESUMEN}

Este estudio prospectivo se centró en conocer la influencia que la cesión a los estudiantes de la responsabilidad sobre la evaluación tenía en la percepción de su propia autonomía, su motivación intrínseca, así como en la creencia del alumnado sobre el valor y el rol que debería tener la evaluación. 98 estudiantes universitarios de cuarto curso de la Licenciatura en Ciencias de la Actividad Física y del Deporte respondieron cuestionarios validados sobre el entrenamiento a favor de la autonomía, la autonomía percibida, la motivación intrínseca y la responsabilidad del alumnado en la evaluación. Y preguntas abiertas y cerradas relativas a la participación del alumnado en la evaluación en grupo, antes y después de una intervención didáctica de ocho meses de duración, basada en la cesión al alumnado de la responsabilidad en la evaluación. Tras un análisis descriptivo, de correlación y prueba t para muestras relacionadas, los resultados mostraron que este tipo de intervención incrementó la percepción de apoyo a la autonomía, la motivación intrínseca y el valor y rol concedido a la cesión de responsabilidad en la evaluación. Los participantes describieron este programa como un buen sistema de enseñanza-aprendizaje, novedoso y motivador. Estos resultados permiten apoyar el uso de programas de cesión de responsabilidad en la evaluación en la educación superior. 


\section{ABSTRACT}

In this study we undertake the prospective study of the impact of assignment of responsibility on evaluation to the students on their perception on its own autonomy, intrinsic motivation and their beliefs on the evaluation process. 98 undergraduate students at their fourth academic year of the Sports Sciences Degree participated in this study. Before and after a didactical intervention of 8 months of duration -in which responsibility on evaluation was partly assigned to the students-, participants responded a series of validated questionnaires on autonomy supportive coaching, autonomy self-perception, intrinsic motivation and on the role of students in the evaluation process, as well as several open questions on their beliefs on the participation of students in the evaluation process. Statistical differences were found between both time-points on the self perception of autonomy supportive coaching, intrinsic motivation and the role that assignment of responsibility should have in higher education. Participants described the intervention as a good learning strategy, new and motivating. These results support the use of strategies of assignment of responsibility on evaluation at higher education degrees.

\section{INTRODUCCIÓN}

En la esfera académica del estudiante, el concepto de «evaluación» suele estar fuertemente asociado al de «calificación», y ambos están estrechamente relacionados tanto con los productos de aprendizaje como con la satisfacción con los mismos (Özgüngör, 2009). Sin embargo, ambos hacen referencia a dos procesos diferenciados dentro de la enseñanza. Mientras la evaluación intenta establecer los criterios sobre los que juzgar la calidad del proceso de enseñanza-aprendizaje, la calificación se refiere a una parte incluida en la evaluación, que viene exigida administrativamente por el hecho de tener que colocar el profesorado, al final del periodo de enseñanza-aprendizaje, una puntuación a cada estudiante. Estamos, en ambos casos, ante una decisión compleja que suele ser una fuente constante de preocupaciones y dudas, tanto del discente como del docente. Por ello, encontrar una forma coherente de integrar la evaluación y la calificación (en lo que a veces representa finalidades opuestas), es una necesidad real del sistema educativo, aspecto éste que el Espacio Europeo de Educación Superior (EEES) contempla como uno de sus cambios. En el proceso de convergencia al EEES el cambio fundamental de la universidad europea lo va a ser en el aspecto conceptual: una nueva Universidad basada en la formación continuada de la persona que aprende a lo largo de toda su vida. Por ello, el trabajo académico deberá estar centrado en el estudiante, que pasa a ocupar un papel activo dentro del proceso educativo (Aracil, 2010), adoptando el docente un rol de «gestor» del proceso de aprendizaje del estudiante, garante de la calidad y significatividad del mismo. Más aún, en la evaluación de los aprendizajes de 
los universitarios se apuesta por permitir a los estudiantes a participar en su propia evaluación (Mateo y Martínez, 2005). Esta «nueva Universidad europea» deberá, pues, ajustar su organización, y sus estrategias metodológicas, incluyendo la evaluación, al nuevo marco en el que se encuadra.

La implementación de acciones educativas que conllevan un trabajo colaborativo, generalmente mediante proyectos o trabajo en grupo, ha sido una de las principales consecuencias de esta nueva realidad educativa (Elliott y Higgins, 2005). El aprendizaje colaborativo ha sido reportado como un medio de contrastada eficacia para la práctica profesional (Callaghan, Watts, McCullough, Moreau, Little, Gamroth y Durnford, 2009), aspecto éste fundamental en la educación superior. Sin embargo, determinadas variables interpersonales condicionan sobremanera dicho proceso, de manera que el modo en que se gestionen la responsabilidad otorgada en la calificación, puede determinar el éxito de la actividad formativa (van Genni, Segers y Tillema, 2009). Nos referimos a aspectos como la seguridad de la persona, la tolerancia a la diversidad de nivel entre miembros, el nivel de interdependencia entre los componentes del grupo, o el esfuerzo (van Genni, Segers y Tillema, 2010). Uno de los aspectos que más podría influir aquí es una falta de actitud positiva de alguno de los componentes para con el trabajo o bien del grupo. De acuerdo con Freeman y McKenzie (2002), los estudiantes no ven justo la valoración del trabajo realizado, si las aportaciones de los diferentes componentes no ha sido equitativa, pudiendo incluso a conllevar sentimientos de insatisfacción con el trabajo realizado (Toynbee-Wilson, 2001), sobre todo en aquellos compañeros que hubieren tenido un menor nivel de implicación.

El nivel de implicación, tanto de cada participante como de la propia dinámica grupal, condicionará el desarrollo y resultado del proceso de enseñanza-aprendizaje. Así, la determinación de la responsabilidad a través del compromiso del estudiante resulta a veces preocupante para el docente cuando al alumnado se le cede responsabilidades, de manera que los mecanismos para responsabilizarlos en la evaluación hacen referencia al interés en la organización e implicación de las tareas de aprendizaje (Moreno, Vera y Cervelló, 2009), por lo que resulta interesante inculcar en los estudiantes la capacidad de reflexionar críticamente sobre sus propias acciones y su aprendizaje (Del Valle, Ruiz, Vega, Velázquez y Díaz, 2005).

Así pues, el objetivo del presente estudio fue comprobar el efecto que un programa de trabajo basado en cesión de responsabilidad en la evaluación, a través del apoyo a la autonomía, tuvo en la creencia del propio alumnado sobre la misma, así como en la mejora de la percepción de autonomía, la motivación intrínseca, y el valor y rol de la evaluación. La hipótesis de trabajo se fundamenta en el modelo jerárquico de motivación intrínseca y extrinseca de Vallerand (Vallerand, 1997), que incluye entre sus elementos 
conceptuales la presencia de unos mediadores entre los desencadenantes y sus consecuencias. Se partió de la hipótesis de que un programa de cesión al estudiante universitario de la responsabilidad en la evaluación (como desencadenante) conseguiría aumentar su percepción de autonomía, y a través de ella (como mediador), su motivación intrínseca y el valor y rol que el alumnado atribuye a la evaluación (como consecuencias).

\section{MÉTODO}

\section{Participantes}

La muestra estuvo compuesta por 98 estudiantes (77 varones y $21 \mathrm{mu}$ jeres) universitarios de cuarto curso de la titulación de Ciencias de la Actividad Física y del Deporte de la Universidad Miguel Hernández de Elche, del curso académico 2008-09, con una edad media de 22.76 años $(D T=3.15)$.

\section{Instrumentos}

Cuestionario de percepción de soporte de la autonomía en el proceso de entrenamiento (ASCQ). Se empleó la traducción al castellano (Conde, SáenzLópez, Carmona, González-Cutre, Martínez Galindo, y Moreno, 2010) del Autonomy-Supportive Coaching Questionnaire de Conroy y Coatsworth (2007). Este cuestionario está compuesto por un total de nueve ítems agrupados en dos dimensiones: cinco ítems que miden el interés en la opinión del practicante (e.g. "Mi docente me permite elegir sobre lo que hacemos en clase») y cuatro ítems que evalúan la valoración del comportamiento autónomo (e.g. «Mi docente me valora por las cosas que elijo hacer en clase»). El cuestionario está encabezado por la frase «En mis prácticas...», respondiéndose mediante una escala de respuesta tipo Likert de 1 (totalmente en desacuerdo) a 7 (totalmente de acuerdo). Los alfas de Cronbach obtenidos fueron para la dimensión interés $\alpha$ pre $=.84$ y $\alpha$ post $=.93$, y para la dimensión valoración $\alpha$ pre $=.81$ y $\alpha$ post $=.91$.

Autonomía. Se utilizó el factor autonomía de la Escala de Mediadores Motivaciones en el Deporte (EMMD) de González-Cutre Coll, Martínez Galindo, Alonso, Cervelló, Conte y Moreno (2007). Estaba compuesta por ocho ítems (e.g. "Mi docente me valora por las decisiones que tomo»), precedidas de la frase «En mis clases...» y las respuestas fueron recogidas en una escala tipo Likert, donde 1 correspondía a totalmente en desacuerdo y 5 a totalmente de acuerdo. La consistencia interna obtenida fue de $\alpha$ pre $=.85$ y $\alpha$ post $=.93$.

Motivación intrínseca. Se empleó el factor motivación intrínseca de la Escala del Locus Percibido de Causalidad (PLOC Scale) de Goudas, Biddle y 
Fox (1994), validada al contexto español por Moreno, González-Cutre y Chillón (2009). Este factor, encabezado por el enunciado «Participo en esta clase de educación física...», está compuesto por cuatro ítems (e.g. «Porque disfruto aprendiendo nuevas habilidades») que se responden con una escala tipo Likert que va de 1 (totalmente en desacuerdo) a 7 (totalmente de acuerdo). La consistencia interna reveló un valor $\alpha$ de .89 para la toma pre y .93 para la toma post.

Escala de Responsabilidad del alumnado en la Evaluación en Educación Física (ERAEEF). La escala de Moreno, Vera y Cervelló (2006) pretende conocer la importancia que el alumnado le concede a la cesión de responsabilidad en la evaluación. Está compuesta de dos factores: el primero, formado por cinco ítems, hace referencia al valor que el alumnado le da a la cesión de responsabilidad que el docente le otorga para su participación en el resultado de la evaluación (e.g. "Los estudiantes deben interesarse por decidir la nota que se merecen en la asignatura»). El segundo factor, formado por seis ítems, se refiere al rol que juega el alumnado en la cesión de responsabilidad en el proceso de la evaluación (e.g. «En mi clase los estudiantes le decimos al docente la opinión que tenemos de nuestra habilidad físico-deportiva»), valora el grado de participación que el alumnado tiene en la evaluación de la asignatura, determinado por la percepción del papel participativo que tienen de su evaluación y la de sus compañeros. Las respuestas a dicho cuestionario son cerradas y responden a una escala tipo Likert cuyos rangos de puntuación oscilaban entre 0 , valor que corresponde a totalmente en desacuerdo, y 10, valor correspondiente a totalmente de acuerdo con lo que se le planteaba. Los alfas de Cronbach obtenidos fueron para la dimensión valor en la cesión $\alpha$ pre $=.83$ y $\alpha$ post $=.86$, y para la dimensión rol en la cesión $\alpha$ pre $=.81$ y $\alpha$ post $=.84$.

Preguntas sobre la participación en la evaluación. Estuvo compuesta por dos preguntas cerradas ( $\dot{E}$ En qué medida consideras que tu intervención en el diseño, exposición y defensa del proyecto contribuirá a la calificación final de tu grupo?, valorada en una escala Likert cuyos rangos de puntuación oscilaban entre 1, valor que corresponde a nada, y 5, valor correspondiente a imprescindible; ¿recomiendas este tipo de evaluación para el futuro?, donde únicamente existían dos posibilidades de respuesta «si-no») y cinco preguntas abiertas (¿qué ha supuesto para ti la evaluación en grupo?, ¿consideras que tus preguntas pueden influir en la evaluación del grupo?, ¿qué te ha parecido evaluar a otros compañeros?, ¿qué te ha parecido ser evaluado por otros compañeros?, y ¿por qué recomiendas este tipo de evaluación para el futuro?).

\section{Procedimiento y diseño de la investigación}

El estudio se desarrolló durante los meses de octubre de 2008 a mayo de 2009, en un único grupo de intervención en las asignaturas de actividad física 
para la salud, enseñanza de la actividad física y del deporte, entrenamiento deportivo, y deportes y recreación. En todas ellas se realizaron diferentes actividades (prácticas o teórico-prácticas) en las que se cedió la responsabilidad a los estudiantes en la evaluación de sus compañeros y en su auto-evaluación.

Todas las variables fueron medidas antes y después de la intervención. Una semana previa al inicio del programa, todos los estudiantes fueron informados de que formarían parte de un estudio que «buscaría un nuevo camino de evaluar la enseñanza en la actividad físico-deportiva», y completaron los instrumentos de medida. La duración para completar los cuestionarios fue de unos 15 minutos aproximadamente. Los estudiantes fueron informados de la importancia de su honestidad en la contestación y de que sus respuestas serían confidenciales. Al final de los ocho meses de intervención, todos los estudiantes completaron de nuevo los mismos instrumentos, además de las preguntas sobre la participación en la evaluación.

Programa de cesión de responsabilidad en la evaluación. Se intervino en un entorno ecológico de enseñanza universitaria, planteando diversas actividades en el aula a lo largo de los ocho meses: auto-evaluaciones de situaciones prácticas, evaluación a otros compañeros, toma de decisiones en equipo sobre trabajos presentados por otros compañeros, etc. Todos los estudiantes tuvieron la posibilidad de realizar las mismas actividades programadas. Se dividió cada asignatura en tres momentos diferenciados: una primera fase de experiencia dirigida por el docente, basada en la reproducción del conocimiento, y caracterizada por un sistema de organización masivo-consecutiva, donde las tareas se explicaban al conjunto de la clase y todos los estudiantes las realizaban al mismo tiempo. A mitad de las sesiones que conformaban el programa comenzaba una segunda fase donde se cedía responsabilidad al alumnado en la evaluación de las tareas, caracterizada por un sistema de organización donde la clase se dividía en varios subgrupos, de unos cinco participantes cada uno de ellos, en promedio. En la tercera fase se pedía al alumnado su colaboración en la evaluación del trabajo realizado. Para la participación en la evaluación se convocaban a los grupos donde uno de ellos exponía un trabajo relacionado con la materia y otro grupo lo evaluaba junto al docente. Dicha valoración formaba parte de la calificación final. El docente adoptaba un papel de guía después de la primera fase, utilizando estrategias en la cesión de responsabilidad encaminadas a orientar la enseñanza al desarrollo de la habilidad en la tarea, al interés por la construcción de las actividades y a la valoración del esfuerzo personal y colectivo en el desarrollo de la habilidad.

Para confirmar que esta intervención estaba teniendo un impacto real se recogieron las percepciones en la concesión de autonomía en el aula usando el subfactor autonomía de la escala de mediadores psicológicos 
(González-Cutre et al, 2007). Se midieron en una escala tipo Likert con un rango de puntuación que oscila de 1 (totalmente en desacuerdo) a 5 (totalmente de acuerdo). Tras la prueba t se comprobó el efecto de la intervención $\left(M_{\text {pre }}=3.62\right.$ y $\left.M_{\text {post }}=3.90, p<.01\right)$.

\section{Análisis de datos}

Se utilizó el a de Cronbach para comprobar la consistencia interna de los distintos factores. Fueron calculadas las correlaciones, medias y desviaciones estándares de todas las variables en las dos tomas. Para valorar los efectos del programa se utilizó una prueba t para muestras relacionadas. Para el análisis del contenido del texto el proceso que se siguió fue de tipo interpretativo, con un proceso de categorización del contenido expresado por los estudiantes, y con niveles de fiabilidad inter-observadores superior al 80\%. Las diferencias se consideraron estadísticamente significativas cuando $p<.05$. Para el tratamiento de los datos se usó el paquete estadístico SPSS 18.0.

\section{RESULTADOS}

\section{Efectos de la intervención}

La Tabla 1 muestra los resultados para cada una de las variables dependientes, antes y después de la intervención en el programa. La prueba t para muestras relacionadas reveló que el grupo incrementó significativamente en todas las variables en la toma post $(p<.01)$.

\begin{tabular}{|l|l|l|l|}
\hline \multicolumn{2}{|c|}{} & $M$ & $D T$ \\
\hline \multirow{2}{*}{ Interés } & Pre & $4.77^{*}$ & 1.00 \\
\cline { 2 - 4 } & Post & 5.10 & 1.26 \\
\hline Valoración & Pre & $5.0 *^{*}$ & 1.05 \\
\cline { 2 - 4 } & Post & 5.22 & 1.23 \\
\hline \multirow{2}{*}{ Motivación intrínseca } & Pre & $4.25^{*}$ & 1.11 \\
\cline { 2 - 4 } & Post & 5.23 & 1.22 \\
\hline Valor en la cesión & Pre & $6.31 * *$ & 1.71 \\
\cline { 2 - 4 } & Post & 7.43 & 1.60 \\
\hline Rol en la cesión & Pre & $5.10^{* * *}$ & 1.78 \\
\cline { 2 - 4 } & Post & 6.46 & 1.74 \\
\hline
\end{tabular}

$* \mathrm{p}<.01 ; * * \mathrm{p}<.001$

Tabla 1. Prueba t para muestras relacionadas $(M \pm D T)$ de las variables dependientes antes y después de la intervención 


\section{Análisis de contenido}

En un primer momento se realizó una lectura de las respuestas de los estudiantes sin anotaciones, se continuó familiarizándose con el texto trascribiendo a ordenador las respuestas que se contestaron a mano y, a continuación, se fueron describiendo los grandes campos temáticos a partir de la reducción de datos textuales propuesta por Gil Flores (1994). De este modo, el contenido de cada respuesta se fue dividiendo en unidades temáticas que expresaban la misma idea. Las transcripciones se convirtieron en múltiples unidades de secuencias textuales que se agrupaban en torno a una unidad temática. A cada una de estas unidades le fue asignado un código en función de su afinidad. De este modo, los investigadores expresaron sus ideas respecto a la constitución de categorías, utilizando para su creación el contraste entre dos compañeros del grupo de investigación, con el fin de buscar acuerdos sobre la visión particular en la existencia de una categoría. Las categorías estaban en constante modificación, redefiniéndose conforme aparecían otros indicadores que las confirmaban o las desautorizaban. Este proceso de acomodación de las categorías a partir de la recodificación permitió una definición más precisa. La interpretación del análisis del contenido del texto se agrupó en los siguientes apartados: contribución en la calificación final, importancia de la participación en la evaluación e implicaciones futuras.

\section{Contribución en la calificación final}

Tras la finalización de la intervención se les preguntó de forma cerrada a los estudiantes en qué medida su participación en la evaluación influiría en la calificación final (Figura 1), donde el 61\% (88) consideró que mucho, mientras que el 29\% (42) la consideraban imprescindible. Cabe destacar que ningún participante la consideró insignificante.

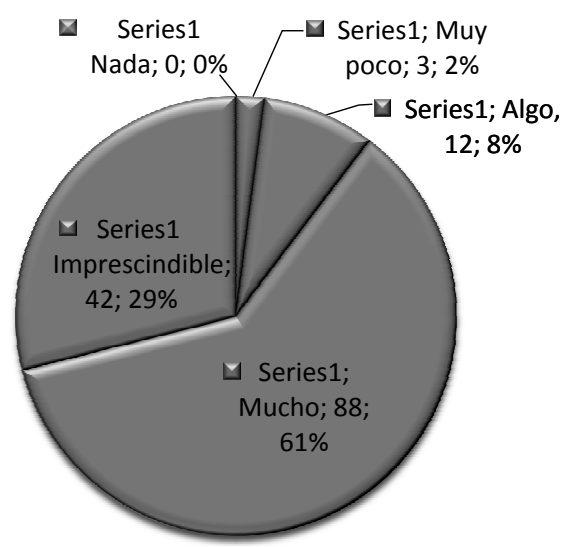

Figura 1. Distribución Porcentual de la Contribución del Estudiante en la Calificación final 
En un intento de profundizar en este orden de importancia, se les preguntó si consideraban que sus preguntas podían influir en la evaluación del grupo (Tabla 2), destacando, en orden de importancia, que dependía del tipo de respuestas que se realizaran, quedando ello reflejado en respuestas como: "Estas preguntas pueden servir para confirmar el buen trabajo del grupo contestando correctamente o certificando por el contrario el no tan buen trabajo del grupo a la hora de realizar su proyecto» (A1). Aunque otro bloque de estudiantes sí que consideraban que se podía influir, bien como apoyo o ayuda a complementar la información, por ejemplo: "Creo que sí que influyen, pero de manera positiva, ya que en principio las preguntas se realizan para que los compañeros puedan explicar mejor algún aspecto» (A61). Por otro lado, el hecho de que se realizaran un determinado tipo de preguntas fue considerado como importante en la influencia en la evaluación, a esta cuestión algunos estudiantes respondieron: "Sí, ya que el grado de dificultad de la pregunta puede poner en apuros al otro grupo» (A32).

\section{Importancia de la participación en la evaluación}

Como queda recogido en la Tabla 2, la evaluación en grupo supuso para el alumnado, principalmente, una aproximación a la realidad laboral, siendo algunos estudiantes sumamente explícitos para dicha cuestión: "Me ha dado la oportunidad de experimentar cómo se lleva a cabo un proyecto que podría ser viable en la realidad» (A37). También, aunque en un orden de importancia mucho menor, fue para ellos una experiencia novedosa, por ejemplo: "Es la primera vez que realizamos una evaluación final de esta forma» (A13), un trabajo en grupo positivo: "Supuso crear un buen ambiente de trabajo y de aportaciones de ideas conjuntas» (A33), lo que les ha llevado a valorarlo como un sistema de evaluación adecuado. Por el contrario, existió un determinado número de estudiantes que lo consideraron un esfuerzo extra y les sirvió para detectar la falta de compañerismo entre el alumnado.

Ante la pregunta de qué les había parecido evaluar a otros compañeros (Tabla 2), la respuesta de una posibilidad de contrastar información, obtener una visión crítica, tomar decisiones y asumir responsabilidades, fue en el recuento de las categorías recogidas la más reiterada en sus respuestas, muestra de ello podría ser: "Ha servido para comparar el estilo y la calidad de los escritos, así como las diferentes formas de interpretar los datos y plasmarlos en un documento» (B4). También lo consideraron como una experiencia positiva para futuras actuaciones profesionales, por ejemplo: "En un futuro no muy lejano nosotros tendremos que evaluar y nos sirve de práctica» (B18) y un trabajo innovador que permite experimentar el rol de evaluador: «Es una modalidad de evaluación de un carácter innovador»(B55). Por el contrario, 
también lo consideraron como problemático por la falta de conocimientos para evaluar y por la dificultad de obtener un consenso grupal: «Debes saber perfectamente la materia que estás evaluando (B67)». Al igual que en la pregunta anterior, el hecho de que se tuviera que dedicar mucho tiempo a dicha evaluación, fue considerado como un trabajo excesivo: «El evaluar los informes de otros compañeros y sus diversos casos lo considero como un trabajo extenso» (B33).

Preocupados por conocer qué les había parecido ser evaluados por otros compañeros (Tabla 2), la respuesta más repetida por el alumnado fue la de que la diversidad de feed-back recibido les permitió obtener una valoración objetiva de los trabajos realizados y, de esa forma, conocer sus propios errores de forma constructiva: «Es una experiencia enriquecedora, ya que te aportan un feed-back sobre el trabajo» (B40). No obstante, otro grupo importante de respuestas coincidieron en considerarlo como negativo, por la falta de conocimiento para la evaluación y la diversidad de criterios en la evaluación por parte del alumnado: "Sientes que no tienes la preparación que tiene el profesor y puede que no se interprete correctamente lo que quieres decir» (B29). Aunque también consideraron que el ser evaluado por compañeros de un mismo nivel era muy positivo: "Me parece bien que se nos dé la oportunidad de ser evaluados por gente cercana a nosotros» (B47). Ante esta diversidad de respuestas, surge la siguiente, que bajo nuestro criterio permitiría regular dicho sistema de participación en la evaluación, y es que por la exigencia del alumnado en la evaluación, ésta debería ser complementada por el docente.

\section{Implicaciones futuras}

El 96\% de los estudiantes recomendó este tipo de evaluación para el futuro, pues lo consideraban como un buen sistema de enseñanza-aprendizaje, novedoso y motivador (Tabla 2): "Pienso que la motivación es mayor» (A26) o "el aprendizaje mediante un trabajo de este tipo es muy significativo» (A40). También destacaban que ofrecía una buena experiencia para el mundo laboral: "Parece resultar útil de cara al futuro» (A18), fomentaba el compañerismo y trabajo en grupo, como por ejemplo: «A la hora de trabajar así se afianzan más las relaciones sociales entre los compañeros y nos da lugar a conocernos más por el tiempo que pasamos juntos» (A48), permitía mejorar la exposición en público, además de servir de control del trabajo realizado. No obstante, otra categoría en la que también insistían era que lo recomendarían siempre y cuando se mejoraran algunos aspectos de organización, como podría ser acortar el número de preguntas y tiempo de exposición, menos dedicación en tiempo, etc. 


\begin{tabular}{|c|c|}
\hline $\begin{array}{l}\text { ¿Consideras que tus preguntas pueden influir en la evaluación } \\
\text { del grupo? }\end{array}$ & Recuento \\
\hline Dependiendo de las respuestas & 44 \\
\hline Sí, como apoyo o ayuda a complementar información & 37 \\
\hline Dependiendo de las preguntas & 20 \\
\hline Sí, detectando errores & 13 \\
\hline No significativamente & 12 \\
\hline Sí, enriqueciendo activamente el proceso de enseñanza-aprendizaje & 11 \\
\hline Sí, más positivo cuantos más evaluadores & 7 \\
\hline Sí, igual de válidas que las de los profesores & 7 \\
\hline ¿Qué ha supuesto para ti la evaluación en grupo? & Recuento \\
\hline Aproximación a la realidad laboral & 84 \\
\hline Experiencia novedosa & 36 \\
\hline Trabajo en grupo positivo & 31 \\
\hline Sistema de evaluación adecuado & 27 \\
\hline Esfuerzo extra & 25 \\
\hline Muestra de falta de compañerismo & 13 \\
\hline Adquisición de conocimientos & 10 \\
\hline ¿Qué te ha parecido evaluar a otros compañeros? & Recuento \\
\hline $\begin{array}{l}\text { Posibilidad de contrastar información, obtener una visión crítica, } \\
\text { tomar decisiones y asumir responsabilidades }\end{array}$ & 86 \\
\hline Positivo como experiencia y para futuras actuaciones profesionales & 55 \\
\hline $\begin{array}{l}\text { Un trabajo innovador que permite experimentar un nuevo rol (eva- } \\
\text { luador) }\end{array}$ & 39 \\
\hline $\begin{array}{l}\text { Problemático, por la falta de conocimientos para evaluar y por la di- } \\
\text { ficultad de obtener un consenso grupal }\end{array}$ & 29 \\
\hline Trabajo excesivo (duradero) & 25 \\
\hline Muestra de carencias de los compañeros & 8 \\
\hline Positivo porque ha sido un proceso muy objetivo (anonimato) & 6 \\
\hline ¿Qué te ha parecido ser evaluado por otros compañeros? & Recuento \\
\hline $\begin{array}{l}\text { Con el feedback múltiple, he podido obtener una valoración objetiva } \\
\text { de los trabajos y conocer mis propios errores de modo constructivo }\end{array}$ & 83 \\
\hline $\begin{array}{l}\text { Negativo por la falta de conocimientos para evaluar y la existencia } \\
\text { de criterios diferentes de evaluación }\end{array}$ & 32 \\
\hline $\begin{array}{l}\text { Positivo por ser evaluado por compañeros con el mismo nivel de co- } \\
\text { nocimientos }\end{array}$ & 20 \\
\hline
\end{tabular}




\begin{tabular}{|l|c|} 
Por la exigencia de los compañeros la evaluación deber ser comple- & 16 \\
tada por el docente & 8 \\
Adquisición de experiencias para el futuro (ser evaluado) & 7 \\
Ha hecho que me esfuerce más (motivación) & 5 \\
Muestra de falta de objetividad del alumnado & Recuento \\
\hline ¿Por qué recomiendas este tipo de evaluación para el futuro? & 36 \\
\hline Buen sistema de enseñanza-aprendizaje, novedoso y motivador & 27 \\
Ofrece experiencia para el mundo laboral & 15 \\
Fomenta el compañerismo y trabajo en grupo & 15 \\
Mejorando aspectos de organización (Acotando el número de pre- \\
guntas y tiempo de exposición, con menos dedicación, adelanto de la & \\
fecha de exposición, aumento en el tiempo de exposición, etc.) & 14 \\
Mejora la exposición en público & 13 \\
Permite llevar un control de lo trabajado & 5 \\
Complementando con un examen teórico & 5 \\
Dependiendo de la asignatura & \\
\hline
\end{tabular}

Tabla 2. Distribución del recuento de las categorías obtenidas ante las preguntas

\section{DISCUSIÓN Y CONCLUSIONES}

El presente estudio se centró en conocer la influencia que un programa de trabajo de cesión de responsabilidad en la evaluación tenía en la creencia del alumnado sobre dicho programa y en la mejora de la percepción de autonomía, la motivación intrínseca, y el valor y rol de la evaluación. Tras el análisis de resultados se pudo aceptar la hipótesis de partida. Al respecto, numerosos estudios e investigaciones (Álvarez Méndez, 2007; Vera y Moreno, 2008) vienen profundizando en la necesidad de proponer estrategias diferentes en la evaluación del alumnado, argumentando, fundamentalmente, la utilización de una evaluación que puede incorporarse al proceso formativo desde el protagonismo del discente, abandonando las características de un modelo tradicional basado en la medición del rendimiento y facilitando oportunidades para valorar la comprensión de los contenidos y el esfuerzo empleado para su consecución. Esta circunstancia guarda cierto paralelismo con aquellas investigaciones (Moreno, Vera, y Del Villar, 2010; Prusak, Treasure, Darst y Pangrazi, 2004; Wallhead y Ntoumanis, 2004; Ward, 2006) que han subrayado la importancia de dirigir la enseñanza de la educación física y del deporte hacia un incremento de la autonomía, centrada en la toma de decisiones del alumnado, donde la cesión de responsabilidad ocupa un lugar destacado en el desarrollo de la autonomía responsable. 
Así pues, la autonomía juega un papel importante en el impacto que tiene sobre los factores situacionales que afectan a la motivación. Al respecto, algunas investigaciones (Moreno, Gómez y Cervelló, 2010; Vallerand y Rousseau, 2001) han informado de niveles más altos de motivación intrínseca en aquellos estudiantes a los que se les permitía elegir las tareas en el aula de educación física. Los datos obtenidos en nuestro estudio, nos permiten apoyar este tipo de observaciones también en el nivel universitario. Esta participación construida desde la autonomía de acción resulta necesaria si el aumento en la valoración de las clases se ha visto mejorado cuando el docente ha generado un clima motivacional que proporciona autonomía y responsabilidad al alumnado (Cervelló, Jiménez, Del Villar, Ramos y SantosRosa, 2004; Moreno et al, 2006). De este modo, las oportunidades de los estudiantes para participar en la evaluación han presentado efectos positivos en la motivación intrínseca cuando se han planteado desde estilos de enseñanza que suministran a los estudiantes la oportunidad de elegir y de tomar decisiones (Hassandra, Goudas y Chroni, 2003). Parece que la motivación es un factor que nos ayuda a comprender las diferentes percepciones individuales que tienen lugar en los estudiantes. De este modo, Li, Lee y Solmon (2005) indican que aquellos estudiantes que están más motivados se perciben más competentes.

El resultado del análisis del contenido del texto confirmó la importancia concedida por el alumnado a la participación en la evaluación de forma significativa. Además, en el caso de la intervención donde cada grupo tenía la oportunidad de repartir la calificación obtenida de forma dispar, este tipo de intervención contribuye a que afloren posibles conflictos dentro del grupo, a tenor del nivel de implicación de cada miembro en el desarrollo del trabajo. En este sentido, la construcción de las categorías de análisis pueden constituir temas que afronten la didáctica a partir de ofrecer al profesorado la posibilidad de plantear un debate con implicaciones prácticas y reflexivas acerca de cómo desarrollar estrategias de cesión de responsabilidad ante la evaluación del alumnado.

A tenor de los resultados obtenidos, consideramos que la cesión de responsabilidad al alumnado en el proceso de evaluación de parte de los productos de enseñanza-aprendizaje ha sido positiva. Por un lado, la preparación de un trabajo en grupo, para su posterior defensa, permite que el estudiante calibre el papel que desempeña dentro del grupo, haciendo palpable el hecho que de su implicación y rendimiento se verá afectada la evaluación, u posterior calificación, tanto suya como de sus compañeros. Además, la formulación de preguntas a otros grupos hace que el estudiante adopte un rol de evaluador, similar al que podría desempeñar en futuras tareas como egresado universitario o profesional. 
Estas situaciones de evaluación pueden ser de gran utilidad, no solo en el ámbito de la enseñanza universitaria, sino también en el de la educación física secundaria o la formación profesional (e.g. titulaciones profesionales o títulos federativos), así como otros niveles formativos como los de post-grado o master. No obstante, creemos que se hace preciso de un buen conocimiento de la dinámica de evaluación, del alcance de las decisiones adoptadas, y la repercusión que ello puede tener en una calificación ulterior. Se hace preciso crear un clima de aula adecuado, exento de situaciones donde el estudiante pueda utilizar esta responsabilidad para hacer "daño» a otros compañeros, es decir, no utilice su rol de forma constructiva. Así, también creemos que este tipo de estrategias evaluativas son de interés cuando el alumnado conoce el contenido que está evaluando, y por supuesto, el que está exponiendo. La calidad de sus intervenciones se torna en un indicativo que puede mostrar la claridad de los conceptos allí expuestos.

No obstante, creemos que este estudio presenta algunas limitaciones. Por ejemplo, la formación de los grupos se permitió que fuera a propuesta de los propios estudiantes, lo cual limita en cierto modo valorar la capacidad del mismo de acoplarse a diferentes dinámicas de trabajo. El resultado de ello, es que es posible que el alumnado «pacte» el nivel de implicación en el trabajo, y el reparto de la calificación posterior sea equitativo si se da una situación de mayoría, evitando así conflictos entre compañeros cuya percepción del esfuerzo sea dispar al de otros miembros del grupo. Por ello, recomendamos hacer futuras intervenciones con una formación de grupos azarosa, para lo cual se podría aplicar en grupos de cursos inferiores, donde las relaciones sociales no están tan arraigadas todavía. 


\section{REFERENCIAS BIBLIOGRÁFICAS}

Álvarez Méndez, J.M. (2007). La evaluación formativa. Cuadernos de Pedagogía, 364, 96-100.

Aracil, A. (2010). A new conception of knowledge, a new conception of learning: from Tetris to Rubick's cube. $\mathrm{Me}$ dical Education, 44 (2), 215.

Callaghan, D., Watts, W.E., McCullough, D.L., Moreau, J. T., Little, M.A., Gamroth, L.M. y Durnford, K.L. (2009). The experience of two practice education models: Collaborative learning unit and preceptorship. Nurse Education in Practice, 9 (4), 244-252.

Cervelló, E., Jiménez, R., Del Villar, F., Ramos, L. y Santos-Rosa, F. J. (2004). Goal orientations, motivational climate, equality, and discipline of Spanish physical education students. Perceptual and Motor Skills, 99, 271-283.

Conde, C. Sáenz-López, Carmona, J., González-Cutre, D., Martínez Galindo, C., y Moreno, J.A. (2010). Validación del Cuestionario de Percepción de Soporte de la Autonomía en el Proceso de Entrenamiento (ASCQ) en jóvenes deportistas españoles. Estudios de Psicología, 31 (2), 145-157.

Conroy, D. y Coatsworth, J. (2007). Assessing autonomy-supportive coaching strategies in youth sport. Psychology of Sport and Exercise, 8, 671-684.

Declaración de Bolonia (1999). Declaración conjunta de los Ministros Europeos de Educación. Bolonia. Recuperado de: www.universia.es/contenidos/universidades/documentos/ Universidades-documbolonia.htm

Declaración de Praga (2001). Hacia el Espacio Europeo de Educación Superior. Comunicado de la Conferencias de Ministros Europeos responsables de
Educación Superior. Recuperado de: www.crue.org/comcumbrepraga.htm

Del Valle, S., Ruiz, L.M., Velázquez, R. y Díaz, P. (2005). ¿Sabemos qué contenidos aprenden los escolares en educación física? European Journal of Human Movement, 13, 87-106.

Del Villar, F. (Ed.) (2006). Libro Blanco del título de grado en Ciencias de la Actividad Física y del Deporte. ANECA. Recuperado de: http://www.aneca.es/ activin/activin_conver_LLBB.asp

Elliott, N. y Higgins, A. (2005). Self and peer assessment: does it make a difference to student group work? Nurse Education in Practice, 5 (1), 40-48

Gil Flores, J. (1994). Análisis de datos cualitativos. Aplicaciones a la investigación educativa. Barcelona: PPU.

González-Cutre, D., Martínez Galindo, C., Alonso, N., Cervelló, E., Conte, L. y Moreno, J.A. (2007). Las creencias implícitas de habilidad y los mediadores psicológicos como variables predictoras de la motivación autodeterminada en deportistas adolescentes. En J. Castellano, y O. Usabiaga (Eds.), Investigación en la Actividad Física y el Deporte II (pp. 407-417). Vitoria: Universidad del País Vasco.

Goudas, M., Biddle, S.J.H. y Fox, K. (1994). Achievement goal orientations and intrinsic motivation in physical fitness testing with children. Pediatric Exercise Science, 6, 159-167.

Hassandra, M., Goudas, M. y Chroni, S. (2003). Examining factors associated with intrinsic motivation in physical education: a qualitative approach. Psychology of Sport and Exercise, 4, 211-223.

Li, W., Lee, A.M. y Solmon, M.A. (2005). Relationships among dispositional 
ability conceptions, intrinsic motivation, perceived competence, experience, persistence, and performance. Journal of Teaching in Physical Education, 24, 51-65.

Mateo, J. y Martínez, F. (2005). La evaluación alternativa de los aprendizajes. Barcelona: ICE de la Universidad de Barcelona.

Moreno, J.A., Gómez, A. y Cervelló, E. (2010). Un estudio del efecto de la cesión de autonomía en la motivación sobre las clases de educación física. Motricidad. European Journal of Human Movement, 24, 1-21.

Moreno, J. A., González-Cutre, D. y Chillón, M. (2009). Preliminary validation in Spanish of a scale designed to measure motivation in physical education classes: the Perceived Locus of Causality (PLOC) Scale. The Spanish Journal of Psychology, 12 (1), 327-337.

Moreno, J.A. y Vera, J.A. (2008). Un estudio experimental de las diferencias por género en la percepción de competencia a partir de la cesión de responsabilidad en las clases de educación física. Revista Iberoamericana de Educación, 46, 1-10.

Moreno, J.A., Vera, J.A. y Cervelló, E. (2006). Evaluación participativa y responsabilidad en educación física. $R e$ vista de Educación, 340, 731-754.

Moreno, J.A., Vera, J.A. y Cervelló, E. (2009). Efectos de la cesión de responsabilidad de la evaluación en la motivación y la competencia percibida en el aula de educación física. Revista de Educación, 348, 423-440.

Moreno, J.A., Vera, J.A. y Del Villar, F. (2010). Search for autonomy in motor task learning in physical education university students. European Journal of Psychology of Education, 25 (1), 37-47.
Özgüngör, S. (2009). The relationships between students' evaluations of teaching behaviors and self-efficacy beliefs. Procedia-Social and Behavioral Sciences, 1(1), 2687-2691.

Prusak, K.A., Treasure, D.C., Darst, P.W. y Pangrazi, R.P. (2004). The effects of choice on the motivation of adolescent girls in physical education. Journal of Teaching in Physical Education, 23, 19-29.

Vallerand, R.J. y Rousseau, F.L. (2001). Intrinsic and extrinsic motivation in sport and exercise: A review using the hierarchical model of intrinsic and extrinsic motivation. En R.N. Singer, H. A. Hausenblas y C.M. Janelle (Eds.), Handbook of Sport Psychology ( $2^{\mathrm{a}}$ ed., pp. 389-416). New York: John Wiley \& Sons.

van Genni, N.A.E., Segers, M.S.R. y Tillema, H.H. (2009). Peer assessment for learning from a social perspective: The influence of interpersonal variables and structural features. Educational Research Review, 4(1), 41-54

van Genni, N.A.E., Segers, M.S.R. y Tillema, H.H. (2010). Peer assessment as a collaborative learning activity: The role of interpersonal variables and conceptions. Learning and Instruction, 20(4), 280-290

Vera, J.A. y Moreno, J.A. (2008). La enseñanza de la responsabilidad en el aula de educación física escolar. $\mathrm{Habi}$ lidad Motriz, 32, 39-43.

Wallhead, T.L. y Ntoumanis, N. (2004). Effects of a sport education intervention on students' motivational responses in physical education. Journal of Teaching in Physical Education, 23, 4-18.

Ward, P. (2006). What we teach is as important as how we teach it. Journal of Physical Education, Recreation \& Dance, 77, 20-23. 


\section{PALABRAS CLAVE}

Autonomía; toma de decisiones; evaluación; educación física; educación superior; innovación docente.

\section{KEYWORDS}

Autonomy; decision-making; evaluation; physical education; higher education; teaching innovation.

\section{PERFIL ACADÉMICO Y PROFESIONAL DE LOS AUTORES}

Juan Antonio Moreno Murcia, Profesor en la Facultad de Ciencias Sociosanitarias de la Universidad Miguel Hernández de Elche. Docente de la asignatura "Enseñanza de la actividad física y del deporte», así mismo, también es investigador del Grupo de Investigación en Comportamiento Motor y sus líneas de investigación se centran en el estudio de los procesos de enseñanza-aprendizaje de las actividades físico-deportivas.

Adolfo Aracil Marco, Profesor en la Facultad de Ciencias Sociosanitarias de la Universidad Miguel Hernández de Elche. Docente de la asignatura «Bases biológicas del cuerpo humano», y miembro del Grupo de Investigación en Acondicionamiento Físico Saludable. Sus líneas de investigación se centran en el estudio de las variables biológicas del comportamiento humano en las actividades físico-deportivas.

Raúl Reina Vaillo, Profesor en la Facultad de Ciencias Sociosanitarias de la Universidad Miguel Hernández de Elche. Especialista en actividades físico-deportivas para personas con discapacidad. Miembro del Grupo de Investigación en Aprendizaje y Control Motor y su línea de investigación se centra en el estudio de la actividad física adaptada.

Dirección de los autores: Juan Antonio Moreno Murcia Universidad Miguel Hernández de Elche Centro de Investigación del Deporte Avenida de la Universidad, s/n. 03202 Elche (Alicante) E-mail: j.moreno@umh.es fito@umh.es rreina@umh.es

Fecha Recepción del Artículo: 11. Octubre. 2011

Fecha Revisión del Artículo: 24. Mayo. 2012

Fecha de Aceptación para publicación: 21. Junio. 2012

Fecha Revisión para publicación: 24. Junio. 2013 

DE INVESTIGACIÓN PARA CONSTRUIR CONTEXTOS DE APRENDIZAJE Y FOMENTAR PROCESOS PARTICIPATIVOS

\author{
(OBSERVATION AS A RESEARCH STRATEGY FOR BUILDING LEARNING \\ CONTEXT AND ENCOURAGING PARTICIPATORY PROCESSES)
}

Itziar Rekalde, Maria Teresa Vizcarra, Ana María Macazaga Universidad del País Vasco

DOI: 10.5944/educxx1.17.1.1074

Cómo referenciar este artículo/How to reference this article:

Rekalde, I.; Vizcarra, M.T. y Macazaga, A.M. (2014). La observación como estrategia de investigación para construir contextos de aprendizaje y fomentar procesos participativos. Educación XX1, 17 (1), 201-220. doi: 10.5944/educxx1.17.1.1074

Rekalde, I.; Vizcarra, M.T. y Macazaga, A.M. (2014). Observation as a research strategy for building learning context and encouraging participatory processes. Educación XX1, 17 (1), 201-220. doi: 10.5944/educxx1.17.1.1074

\title{
RESUMEN
}

Este artículo pone de relieve la importancia de la observación participante en los centros educativos. Se describe la utilización de esta estrategia para generar e impulsar procesos de participación e indagación en el ámbito del deporte escolar, y construir y conformar contextos de aprendizaje implicando a la comunidad educativa. En este sentido el objetivo del estudio se centra, por una parte, en describir la construcción de los contextos de aprendizaje que el uso de la estrategia ha fomentado y, por otra, en desvelar el desarrollo interno de la propia estrategia dando cuenta de las herramientas derivadas de ella.

La investigación se ha articulado a través de un planteamiento metodológico basado en la investigación-acción y dentro de éste, el diálogo ha constituido un aspecto clave en la construcción de conocimiento. En el mismo han participado familias, alumnado, profesorado, monitores y equipo directivo de los centros educativos de Bizkaia Resurrección M. ${ }^{a}$ de Azkue Ikastola (Lekeitio), Betiko Ikastola (Leioa) y Seber Altube Ikastola (Gernika).

Los resultados de la investigación ponen de manifiesto los procesos participativos en la utilización de la observación así como en las herramientas derivadas de ésta (notas de campo, sistema categorial, reconstrucción de los significados), y se concluye subrayando aquellos aspectos formativos (a nivel procedimental y a nivel afectivo-relacional) que la observación participante genera sobre las personas que intervienen en procesos de cambio y mejora educativa. 


\section{ABSTRACT}

This article highlights the importance of participant observation in schools. It describes the use of this strategy to generate and promote participation and inquiry processes in school sport, and build and shape learning contexts involving the educational community. In this respect, the objectives of the study are to describe the construction of learning environments that the use of the strategy has encouraged and, to reveal the internal development of the strategy itself and describing the tools derived from it.

The research has been articulated through a methodological approach based on action research and within this, the dialogue has been a key issue in the construction of knowledge. In the study families, students, teachers, trainers and management team of schools of Biscay have participated: Resurrección M. ${ }^{a}$ de Azkue Ikastola (Lekeitio), Betiko Ikastola (Leioa) and Seber Altube Ikastola (Gernika).

The results of the research show the participatory processes in the use of the observation and in the tools derived from this (field notes, categorical system, reconstruction of the meanings), and concludes emphasizing those aspects of learning (procedural level and affective-relational level) that participant observation generates about people involved in processes of change and educational improvement.

\section{INTRODUCCIÓN}

A lo largo de estas páginas damos a conocer nuestra opción metodológica, la investigación-acción, a través de la observación participante. Esta apuesta ha significado la implicación de un grupo de personas que han optado conscientemente por un cambio socio-educativo en el deporte escolar (DE) con el que estaban implicadas. El camino recorrido ha sido duro, pero se ha visto aliviado por la compañía de familias, alumnado, profesorado, monitores y equipos directivos de tres centros educativos de Bizkaia $R e$ surrección M. ${ }^{a}$ de Azkue Ikastola (Lekeitio), Betiko Ikastola (Leioa) y Seber Altube Ikastola (Gernika).

La dinámica ha exigido generar encuentros que favorecieran la comunicación y el diálogo, y que ayudaran a penetrar en el mundo de los significados y en el análisis que los participantes realizan de ellos. La estrategia que ha articulado este proceso a lo largo de cuatro años de investigación ha sido la observación participante.

Nuestro objetivo es, por una parte, describir la construcción de los contextos de aprendizaje que el uso de la estrategia ha fomentado y, por otra, desvelar el desarrollo interno de la propia estrategia dando cuenta de las herramientas derivadas de ella. 


\section{LA MIRADA METODOLÓGICA DESDE LA QUE SE HA ARTICULADO LA INVESTIGACIÓN}

El planteamiento metodológico intenta unir aspectos que hasta no hace muchos años estaban separados estructuralmente dentro de la investigación: teoría y práctica; investigadores e investigados, construcción de la teoría y aplicación de la teoría.

Como señala Pérez Serrano (2008), uno de los rasgos de esta metodología, la investigación-acción, es la unión de teoría y práctica. Cada vez se demanda con más énfasis una investigación más abierta, flexible, participativa, asequible a cualquier profesional y, sobre todo, comprometida en la resolución de problemas prácticos (Rekalde, Vizcarra y Macazaga, 2011). En este sentido, la teoría no se presenta como un elemento separado y regulador de la acción, sino como un elemento que ilumina, orienta y anima la práctica y la dinámica de la acción-reflexión (Woods, 1987). Dentro de este planteamiento, la comunicación y el diálogo constituye un aspecto clave para la construcción de conocimiento (Freire, 1997; Habermas, 1994).

La perspectiva dialógica (Aubert y otros, 2008; Gómez, Puigvert y Flecha, 2011) nos aporta un marco teórico de interpretación que nos conduce a utilizar los procesos dialógicos para comprender las interpretaciones de los otros y buscar argumentos para refutar, afirmar o replantear cada situación, y así, construir conocimiento y acción.

Entendemos que en el tema del DE, ha primado la tradición positivista, por lo que apremia la utilización de la investigación-acción como estrategia formativa que ayude a tomar conciencia de los cambios que se intentan promover (Kirk, 2009). Muchos investigan el DE con la intención de humanizarlo, no se dan cuenta de que están alimentando justo el propósito contrario del que persiguen. Es curioso, por ejemplo, observar que bajo claves de solidaridad y diálogo, se generan procesos verticales y exclusores, sin ser conscientes de esa contradicción (Rossi, Tinning y McCuaig, 2009). Podemos destacar algunos de los trabajos que se han centrado en impulsar procesos de participación en el ámbito del DE, tales como: Amenabar y Sistiaga, 2009; Gimeno, 2000; Orts, 2005; Macazaga, Rekalde y Vizcarra, 2013. Nuestra postura metodológica apunta a una vertiente de investigación centrada en la comprensión e interpretación de los hechos. Es decir, encaminada hacia el cambio y superación de situaciones que limitan la acción formativa orientada a la consecución de un DE, que al ser un fenómeno de tipo social, ha de ser descifrado en su propio contexto. Se han generado espacios de dialéctica permanente entre los participantes, espacios donde dar el paso desde el sentido común hasta el conocimiento científico, donde analizar, interpelar, interrogar, contrastar, redefinir y reconstruir las apor- 
taciones generadas sean un ejercicio continúo de reflexión colectiva. Son espacios simbólicos, donde la actividad investigadora y formativa supone la construcción de conocimiento, donde la formación, orientada a la comprensión sobre los procesos generados y su interiorización, crea niveles de autonomía y protagonismo real ante el DE (Prat y Soler, 2012; Vizcarra, Macazaga y Rekalde, 2013).

Esta manera de investigar y de participar en contextos de aprendizaje ha dado a los participantes la posibilidad de observarse y observar a los demás de forma sistemática, enfocando la atención en las situaciones problemáticas que protagonizan para, desde el darse cuenta de lo que hacen, estar en disposición de desarrollar destrezas ligadas a la observación, tales como, el registro, el análisis y la interpretación de la información observada. Los participantes se han encontrado en la necesidad de unir el conocimiento y la acción, como una constante del proceso de investigación (Carr y Kemmins, 1988).

\section{LA CONSTRUCCIÓN DE CONTEXTOS DE APRENDIZAJE}

A lo largo de la investigación se han construido contextos de intercambio, comunicación y aprendizaje, en los que han intervenido los participantes (Macazaga, Vizcarra y Rekalde, 2006). La observación participante ha sido la piedra angular sobre la que ha girado el proceso formativo en los diferentes contextos: Seminario, Grupos de centro y Grupos de familias, profesorado, escolares... En la figura 1, aparece representado cada uno de los contextos y la interacción entre ellos:

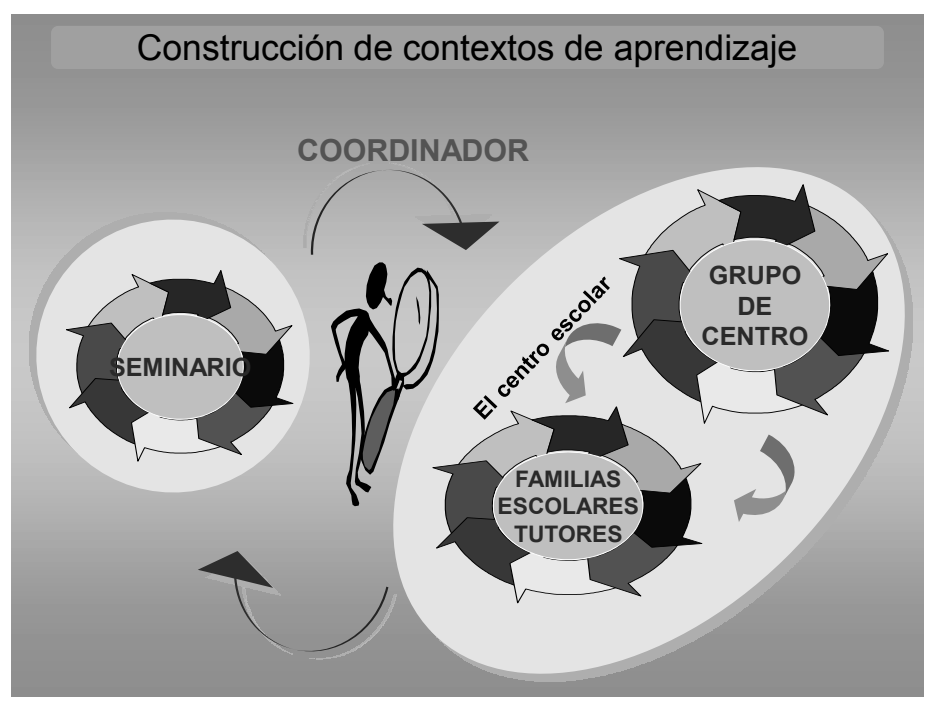

Figura 1. Los contextos de aprendizaje 
La participación por parte de los implicados en el DE en estos centros ha sido voluntaria. La difusión de la necesidad de la implicación de las familias, profesorado y alumnado se ha llevado a cabo a través de notas informativas, carteles y del boca a boca de unos a otros.

La necesidad de implicación no partió de las investigadoras sino de la propia federación de la que son miembros estos tres centros escolares (Federación de Ikastolas de Bizkaia). La escasa implicación de los escolares y sus familias en el DE el centro, activó en la directiva de la federación una preocupación por la que indagar y ofrecer una respuesta (Macazaga, Rekalde y Vizcarra, 2011).

\section{El contexto del Seminario}

En éste han participado durante cuatro cursos escolares: 3 facilitadoras universitarias (dos profesoras del área de didáctica de la expresión corporal y una de didáctica y organización escolar), 3 profesores de educación física (coordinadores de DE en sus centros) y representantes de BIE (Federación de Ikastolas de Bizkaia). Las profesoras universitarias han asumido el rol de facilitadoras acompañando a los participantes a través de las fases evolutivas que atraviesa todo grupo que se introduce en la investigaciónacción, y que van desde la fase de formación a la de realización, pasando por la de tempestad y normalización (Macazaga y Rekalde, 2005). Además, han rescatado como contenido esencial de trabajo la dimensión emocional de los participantes en su quehacer profesional, consciente de que no hay aprendizaje sin implicación emocional. Quienes han proporcionado el contenido específico sobre el que se ha trabajado en las sesiones, han sido los docentes de educación física, pues han expuesto sus opiniones, sentimientos, miedos, y tendencias en torno al DE, razonando de forma crítica sobre su experiencia. El contexto les ha dado la posibilidad de abrirse a los demás para derribar entre todos, el aislamiento, la soledad, la insatisfacción que sienten en ocasiones (Zeichner, 2010; Cochran-Smith y Zeichner, 2005). El seminario ha hecho visible el desafío que representa un cambio de hacer y de pensar el deporte escolar.

En el seminario ha reinado un ambiente de colegialidad y apoyo mutuo, debatiendo sobre cada problema detectado. Se han impulsado hábitos reflexivos al adoptar una actitud cuestionadora, retadora, problematizadora frente a las situaciones vividas en el DE, así como hábitos de búsqueda de soluciones inspiradas en el diálogo y consenso.

Se escogió esta modalidad docente por la estrecha vinculación con la formación práctica de los docente, por ser una estrategia coherente con el 
tipo de investigación, por estar fundamentada en el diálogo y la reflexión, y articulada a través de actividades de colaboración, porque podía suponer ser el observatorio de las acciones emprendidas en el resto de contextos, por ser el soporte para la construcción de conocimiento, desarrollando una formación en cascada, que llegaba desde el seminario hasta los grupos de centro y a los colectivos participantes (familias, profesorado, escolares, monitores,...). En este contexto las tareas de la observación, su registro y su análisis han sido realizadas por las docentes universitarias.

\section{El contexto de los Grupos de Centro (GC)}

En este contexto los participantes han sido aquellas personas representantes de todos los colectivos educativos implicados en el DE, alumnado $\left(5^{\circ}\right.$ y $6^{\circ}$ de Primaria), profesorado, familias, monitores de DE, equipos directivos, y cada representante del centro en el seminario. Los GC evidencian la necesidad de romper el aislamiento de las personas integrantes de la comunidad educativa para crear estructuras potenciadoras del diálogo, para compartir con otras personas intereses, preocupaciones, deseos y, en definitiva, su experiencia personal y profesional sobre el DE.

Es indiscutible que en todos los centros existen personas interesadas en la mejora de la escuela en su conjunto. A través de los GC, se ha dotado a las escuelas implicadas, de tiempos para compartir las reflexiones respecto al DE, ya que ha funcionado como motor para favorecer la construcción de los contextos conformados con los distintos colectivos. Se ha dotado a las familias, profesorado... de dinámicas de trabajo, para visibilizar la labor de estos grupos en el centro. El GC se ha considerado el artífice de los cambios y las mejoras introducidas en el DE, ha organizado y ha dotado de significado a las voces de todos los colectivos presentes, y ha desplegado y desarrollado los procesos formativos de los distintos colectivos.

En este contexto quienes han asumido la tarea de la observación, registro y análisis han sido los profesores de educación física, y coordinadores de DE, además de participante activo en el Seminario.

\section{Los contextos de los Grupos de familias, profesorado, escolares y monitores de DE}

Con este último nivel se llega al mayor despliegue en los procesos de participación generados en la investigación. De hecho se han conformado grupos de referencia con cada uno de los colectivos señalados y la técnica de generación de datos utilizada ha sido los grupos de discusión (Krueger, 
1991; Llopis, 2004), donde la observación participante ha tenido un gran peso al ser desarrollada por los miembros del GC de manera rotativa y articulada a través de las notas de campo (Vizcarra, Macazaga y Rekalde, 2006).

\section{LA OBSERVACIÓN PARTICIPATIVA COMO ESTRATEGIA DE INVESTIGACIÓN Y LAS HERRAMIENTAS DERIVADAS QUE HAN ARTICULADO LOS PROCESOS PARTICIPATIVOS}

En la investigación cualitativa las principales estrategias de generación de datos, son las interactivas, dentro de las cuales encontramos la observación participante, las entrevistas y las historias de vida, y las no interactivas entre las que podemos destacar los documentos oficiales - registros, estatutos, expedientes personales, etc.- y personales — diarios, cartas, autobiografías,... (Bolívar, de la Cruz y Domingo, 2001).

\section{La observación participante}

Centrándonos en los principios de la investigación-acción, y hemos hecho una apuesta por la observación participante en los diferentes contextos de aprendizaje construidos a lo largo de la investigación. También se han utilizado otras herramientas como: documentos oficiales, entrevistas, grupos de discusión... Pero la observación participante con sus consiguientes notas de campo, análisis, categorización y reconstrucción del proceso ha sido la constante a lo largo de los cuatro años de investigación y en los tres diferentes contextos. La observación participante es un método interactivo de recogida de información que requiere de la implicación del observador en los acontecimientos observados, ya que permite obtener percepciones de la realidad estudiada, que difícilmente podríamos lograr sin implicarnos de una manera afectiva (Rodríguez, Gil y García, 1996). En nuestra investigación se ha aportado una visión constructivista para elaborar o reelaborar el conocimiento práctico que fundamenta la profesión docente, trabajar distintos contenidos y procesos cognitivos inconscientes que guían la actuación, y acercarnos a los procesos de introspección que nos han llevado a clarificar los objetos de estudio en cada una de las fases de la investigación (Macazaga y Rekalde, 2005).

La observación participante ha dado inicio a la construcción de instrumentos que han facilitado la interpretación y comprensión de las situaciones analizadas. La observación se ha registrado a través de las notas de campo, de sistemas categoriales emergentes, y de la reconstrucción de la realidad, para comenzar nuevamente el ciclo con una nueva observación. Además de adquirir y desarrollar estas destrezas cognitivas-racionales, se ha intentado traspasar al plano de los aprendizajes de tipo emocional y personal. 


\section{Las notas de campo}

A través de las notas de campo se registra aquello que se está observando, mediante los datos que se recogen en el campo durante el transcurso del estudio. Dependiendo de cada contexto las notas de campo han sido construidas por los implicados en cada contexto. A continuación, se recoge parte de la explicación de una las facilitadoras en una de las sesiones de Seminario:

Las notas de campo no son similares a las actas de una reunión de vecinos en las que se reflejan los temas tratados y los acuerdos adoptados por votación, son un documento en el que se registra la información vertida, en este caso, en el seminario... Su lectura nos permite darnos cuenta de la distancia que hay entre lo que queremos decir y lo que decimos, así como el modo en que saltamos de un tema a otro.

Los coordinadores de centro, encargados de desplegar esta experiencia en sus respectivos centros escolares, entienden que se trata de una herramienta que les resulta desconocida, ante la que están algo recelosos:

... pues he escuchado, a gusto, pero, si digo la verdad, no sé cómo se hacen. Es decir, si tuviera que hacerlo, creo que no dominaríamos las notas de campo.

Las intervenciones de los coordinadores deja traslucir que escoger las herramientas antes de la selección del problema, y del objeto de estudio, no concuerda con los conocimientos que poseen sobre investigación. Por este motivo, se encuentran desorientados ante este hecho.

... yo estoy perdido en un sentido, como les pasa a los alumnos con nosotros en clase cuando empezamos una unidad didáctica. De dónde a dónde vamos. Es que la primera pregunta: ¿qué queremos? Es muy importante. Parece que aqui estamos sacando instrumentos sobre la mesa, pero sin saber para qué los sacamos. Esa es mi percepción. Si no tenemos claro para qué estamos aquí, y yo todavía no lo tengo claro.

Desde esta preocupación, se centran en la rentabilidad de este instrumento, en términos de eficacia, para el proceso de indagación.

Yo creo que el esfuerzo que requiere realizar las notas de campo y su reconstrucción, lo hemos de valorar para saber qué influencia va a tener... para valorar si el esfuerzo a realizar va a resultar eficaz para lo que nosotros queremos.

Este malestar que al principio del proceso pudo suscitar la construcción de notas de campo en el seno de los GC, fue transformándose hacia una actitud favorable y muy positiva, gracias a la labor de las facilitadoras, y a 
que fueron viendo que las reflexiones vertidas en las notas de campo relanzaba el proceso de indagación.

El objetivo de la reunión, a partir de que nos pongamos a trabajar con los interrogantes, es darles respuesta. En ese proceso saldrán muchas cuestiones que quedarán recogidas en las notas de campo, pero en la reconstrucción solo recogeremos aquellos contenidos directamente relacionados con los interrogantes. De esa reconstrucción saldrán, a su vez, otros interrogantes cuya función es hacer avanzar el proceso. De alguna manera, estos interrogantes podemos entenderlos como los puntos del orden del día, a los que hemos hecho referencia en la reunión de trabajo.

Tal fue la evolución, que en los coordinadores se desvelaba un cambio de actitud en las reuniones del GC. Adquirieron una serenidad en las interrelaciones con las familias y una capacidad de escucha que en un principio no mostraban y, junto a éstas, la capacidad de observar y registrar aquello que era significativo para impulsar el proceso formativo del GC, en el que se convertían en verdaderos facilitadores. La siguiente voz, nos acerca a la manera de operar de éstos:

Cuando entramos en el tema de la normativa no habia debate posible, nadie quería entrar "al trapo». Yo también comparto su opinión, cosa que antes no compartía, me dieron argumentos para que comparta esta manera de pensar. Me ha hecho cuestionarme lo que implicaría poner una normativa, si ayudaría o sería negativo para la dinámica y para la propia organización del deporte en la ikastola...Les propuse hacer una prueba para ver qué pasaba, pero no quisieron entrar ni para atrás [...].

En definitiva y resumiendo, las notas de campo nos han servido para ver similitudes y discrepancias entre los contextos de aprendizaje, y en los grupos sobre un tema determinado, para identificar el tema a estudiar, debatir, analizar, para establecer afirmaciones a considerar e interrogantes a despejar, para conocer las razones, motivaciones y expectativas de cada uno de los participantes en los grupos, para explicitar los interrogantes que cada cual se planteaba, para percibir los distintos significados que se atribuye a un mismo concepto, para llevar al plano explícito creencias y prejuicios, para establecer un lenguaje común entre los miembros de los grupos.

\section{El proceso de penetración en las notas de campo}

Para llevar a cabo el análisis de las notas de campo, las facilitadoras, hemos volcado en bruto la información recogida en audio al papel para tener por escrito todo lo que se dijo en la sesión (seminario, grupos de centro...); se ha realizado un primer análisis que ha consistido en la lectura detallada 
del documento, dejando que las voces de los participantes nos digan de qué están hablando en cada momento; se han escrito notas al margen de la hoja, la idea sobre la que se pronuncian los participantes. Y se han trasladado los temas que han ido surgiendo al margen de la hoja, o en otro documento aparte para que, conforme se vayan sucediendo las reuniones estos bloques temáticos se vayan expandiendo, dividiendo, fusionando,... de esta forma se ha ido construyendo la herramienta de análisis e interpretación de los datos a la que llamamos sistema categorial.

El análisis de los datos (Taylor y Bogdan, 1986; Pérez Serrano, 2008; Gil y Rodríguez, 2004) ha discurrido de modo simultáneo al desarrollo del trabajo de campo. Puesto que la recogida de datos y el análisis de la información han supuesto dos procesos complementarios e interactivos. El análisis de los datos se ha caracterizado por ser dinámico y creativo, por su desarrollo cíclico y sistemático, y por la implicación al seleccionar, categorizar, comparar, sintetizar e interpretar los datos para comprender lo que estudiamos y matizar mejor la interpretación. Las notas de campo han sido clave para construir el sistema categorial, pero también para ayudarnos a plantear la dinámica de las reuniones (seminario, grupos de centro, grupos de escolares,...).

\section{El sistema categorial emergente}

Cómo construir un sistema categorial emergente fue uno de los grandes retos de este trabajo. Seguimos un proceso analítico inductivo generando un sistema categorial emergente. La manera de justificar esta opción tiene que ver con nuestro deseo de integrar lo que acontece en la realidad. Se trata de huir de planteamientos predeterminados para mantener una actitud de escucha sobre lo que ocurre en el aquí y ahora. El resultado es un sistema categorial dinámico y flexible que responde a aquello que vamos observando y aprendiendo en el proceso de captación de la realidad a estudio. Procedimos de la siguiente forma:

Primero separamos el contenido de los textos en unidades significativas en relación al problema objeto de estudio y a cada unidad se le asignó un código que se refería a la categoría asignada.

En segundo lugar, agrupamos las unidades semánticas a las que se les asignó un código, que se refiere a una categoría, en orden a facilitar el proceso interpretativo.

En tercer lugar, clarificamos y definimos la categoría, como unidad, que hacía referencia a un constructo mental.

En cuarto lugar, respetamos los requisitos de exhaustividad, cualquier unidad debe poder ser ubicada en alguna de las categorías; exclusión mutua, 
cada unidad se incluye en una sola categoría; principio clasificatorio único, obedecen a un único criterio de ordenación y clasificación; objetividad, inteligibles para distintos codificadores; pertinencia, relevantes para los objetivos del estudio (Miles y Huberman, 1994; Fernández-Ballesteros, 1995).

En quinto y último lugar, teniendo las categorías definidas y con las voces de los participantes detrás, el sistema categorial se ha construido enlazando y secuenciando las categorías (ver tabla 1). Si bien existen diferentes programas informáticos para llevar a cabo un análisis de estas características, hemos optado por un procedimiento manual con el que nos hemos familiarizado a lo largo de nuestra trayectoria de investigación.

\begin{tabular}{|c|c|c|}
\hline \multirow{9}{*}{$\begin{array}{l}\text { Planificación de la in- } \\
\text { tervención hace alusión } \\
\text { a todo lo que se ha } \\
\text { planeado para hacer } \\
\text { de cara al siguiente pe- } \\
\text { ríodo: cómo hacer las } \\
\text { convocatorias y quiénes } \\
\text { pueden ser los partici- } \\
\text { pantes objeto de esta } \\
\text { intervención. }\end{array}$} & \multirow{2}{*}{$\begin{array}{l}\text { Adaptaciones en el cro- } \\
\text { nograma recoge todas } \\
\text { las modificaciones que } \\
\text { se hacen con respecto al } \\
\text { plan inicial }\end{array}$} & Ajustes \\
\hline & & Cambios \\
\hline & \multirow{2}{*}{$\begin{array}{l}\text { Nuevas propuestas: son } \\
\text { propuestas emergentes } \\
\text { vertidas por los partici- } \\
\text { pantes }\end{array}$} & $\begin{array}{l}\text { Paneles de dibujo: todos los } \\
\text { contactos realizados con el } \\
\text { de plástica }\end{array}$ \\
\hline & & Contacto familias \\
\hline & \multirow{5}{*}{$\begin{array}{l}\text { Grupos de discusión } \\
\text { todo lo relativo a cómo } \\
\text { proceder con los grupos } \\
\text { de discusión a que parti- } \\
\text { cipantes implicar, a que } \\
\text { información preguntar, y } \\
\text { cómo relanzar el debate } \\
\text { para ahondar más }\end{array}$} & $\begin{array}{l}\text { Elaboración de las pregun- } \\
\text { tas: se presenta el proceso } \\
\text { seguido por las investigado- } \\
\text { ras para elaborar los inte- } \\
\text { rrogantes que impulsan la } \\
\text { intervención }\end{array}$ \\
\hline & & $\begin{array}{l}\text { Contacto: Cómo se contac- } \\
\text { ta con el tutor }\end{array}$ \\
\hline & & $\begin{array}{l}\text { Proceder: Cómo se procede } \\
\text { con los grupos de discu- } \\
\text { sión, con el tutor con los } \\
\text { escolares, pautas a seguir }\end{array}$ \\
\hline & & $\begin{array}{l}\text { Interrogantes; dudas que se } \\
\text { les plantean a los coordina- } \\
\text { dores, con quién, cuándo, } \\
\text { cómo tomar las notas de } \\
\text { campo }\end{array}$ \\
\hline & & $\begin{array}{l}\text { Normativa: reticencias y } \\
\text { resistencias para su aplica- } \\
\text { ción }\end{array}$ \\
\hline
\end{tabular}

Tabla 1. Ejemplo de una parte del sistema categorial 
La construcción paulatina y progresiva del sistema categorial nos ha servido de marco de contenido para seleccionar las unidades de información que se recogen, a modo de voces, a lo largo del artículo.

Si tuviéramos que destacar aspectos que refuerzan la utilización de un sistema categorial emergente, diríamos que es un instrumento abierto a la modificación, inductivo y emergente. Una herramienta en vías de confección, cuyo contenido se va arrastrando de reunión en reunión. El sistema categorial emergente ha supuesto en nuestra investigación la hoja de ruta del camino seguido:

Tenemos el sistema categorial de la primera reunión, el de la segunda y el de la tercera. Esos documentos indican los temas que hemos trabajado en un comienzo, los que hemos ido abandonando y los que hemos colocado en el centro de nuestros debates y con ello, se va indicando cuál es el itinerario de trabajo que estamos siguiendo.

Nos da la posibilidad de ver la estructura del trabajo que se está abordando y los temas que emergen en las reuniones para decidir sobre qué centrar la futura tarea del grupo:

(...) claro, para considerarlo válido todos tenemos que ver que nuestras razones aparecen aquí reflejadas, y si no es así, éste es el momento para decirlo, porque ésta es nuestra estructura para trabajar, aquí están nuestros porqués. En cada reunión hay un nuevo sistema categorial surgido de notas de campo anteriores y trabajar con él, es muy costoso y lleva mucho tiempo, por eso, hemos de encontrar un procedimiento viable para trabajar con el sistema categorial.

Recoge los temas tratados y permite debatir sobre ellos y llegar a consensuar cuestiones que en un primer momento se consideran problemas, y si lo siguen siendo, cuál es el grado de importancia frente al resto:

(...) el primer punto versa sobre motivaciones que nos hacen ser miembros del seminario, o sea los porqués, las razones que tenemos para estar sentados aquí y discutir sobre el deporte que queremos nosotros y cómo lo tenemos que enfocar.(...) Entonces pienso que tenemos que ir debatiendo para decidir cuáles son realmente importantes y priorizarlas.

Supone un compromiso de intercambio y comunicación entre todos los participantes, y nos llevan a tomar las notas con precisión para que aparezcan en ellas, todas las maneras de sentir y pensar:

Hay una cuestión que creo que, en ocasiones anteriores, ya se ha comentado, y sin embargo, no la veo reflejada en este punto. En torno 
al deporte hay dos aspectos, uno es el aspecto ideológico que responde a para qué hacer deporte, en un sentido amplio y otro es el de los servicios. Para mí, son dos ámbitos bien diferenciados y en mi opinión no sé si aquí están recogidos.

El compromiso de intercambio y comunicación, se refleja en el análisis de las notas de campo y la construcción del sistema categorial, ya que se pedía a todos los participantes que las leyeran, realizaran modificaciones, y enviaran sus aportaciones a través de la red. Subrayando lo importante e imprescindible que resultaba que sus pensamientos estuvieran reflejados en el contenido de esas notas, porque la información no debía aparecer distorsionada o manipulada.

\section{La reconstrucción de los significados}

Como escribió Dewey hace ya años, en su libro Democracia y Educación (1916, p. 74) «La educación es aquella reconstrucción o reorganización de la experiencia que da sentido a la experiencia, y que aumenta la capacidad para dirigir el curso de la experiencia subsiguiente». Aprender es una reconstrucción continua de la experiencia en la que, se incrementa la percepción de la actividad a que estamos dedicados, al tiempo que se dirigen y controlan las experiencias subsiguientes, y donde el último resultado revela el sentido de las anteriores. La reconstrucción dentro de un proceso de investigaciónacción implica, por una parte, resituar-revisar los modos anteriores de ver y hacer, para generar desde un presente nuevas apreciaciones en los modos de comprender y hacer, que puedan transformar las prácticas futuras. Hemos de tener en cuenta que en las investigaciones cualitativas la reconstrucción es una fase de la investigación (Bolívar, 2010) y que seguimos investigando en la medida en que continuamos organizando la información (Denzin y Lincoln, 1994).

Las perspectivas son el objeto de la reconstrucción. Para que pueda darse una reflexión sobre la práctica se tiene que ver el propio hacer en términos de situarse en otro lugar. Tomamos así posición sobre nuestro pensamiento en acciones pasadas y, al apreciarlos desde otra perspectiva, se genera su transformación mediante nuevas imágenes y configuraciones de la práctica. El puente espacial y temporal que une cognitivamente, los tres momentos es la clave del proceso reconstructivo; el cambio se genera mediante 
una combinación y contextualización de las perspectivas. A continuación recogemos, a modo de ejemplo, el índice de una de las reconstrucciones:

\section{ÍNDICE}

- Mirando al pasado

- ¿En qué situación se encuentra el proyecto? ¿Qué estamos haciendo? ¿Qué vamos a hacer?

- ¿Cómo nos hemos organizado en el seminario esta vez?

- ¿Qué ha ocurrido en la segunda sesión formativa con familias?

- ¿Cuál ha sido la labor desarrollada por los Grupos de Centro durante este mes?

- ¿Qué y cómo vamos a trabajar con las familias en la tercera sesión formativa?

- Mirando al futuro

Ejemplo de un índice de una de las reconstrucciones

En nuestro caso, las reconstrucciones las hemos hilado a través de los interrogantes que emergían del sistema y que han vertebrado la narrativa del documento, lo que ha supuesto un gran esfuerzo para quienes asumían esta tarea, porque requería una dedicación diaria al trabajo para llegar a consensos. Las reconstrucciones han provocado en los implicados una comprensión nueva de la práctica, de las situaciones de enseñanza y de las propias asunciones implícitas en los contextos formativos generados. La claridad que nos han ofrecido las reconstrucciones sobre el proceso que estábamos siguiendo compensaba los esfuerzos y las limitaciones con las que nos hemos ido encontrando.

\section{A MODO DE CONCLUSIÓN}

La observación participante, como estrategia de investigación, y las herramientas derivadas de ella (notas de campo, sistema categorial y reconstrucción), nos desvelan las siguientes apreciaciones:

- Que las notas de campo permiten a los participantes en distintos contextos, revivir situaciones de un pasado inmediato, releer 
las aportaciones del resto de compañeros/as y reparar en los matices que se pierden en los debates aunque seamos participantes directos.

- Que las notas de campo ayudan a repensar los recursos dialécticos que se ponen en marcha en cada contexto de aprendizaje, al poder analizar con detenimiento cada recurso. A todos los colectivos les resulta más fácil entrar en una dinámica de diálogo si las preguntas que se lanzan en las sesiones de trabajo son directas y concretas, si les sitúa ante un problema... Del mismo modo, se ha comprobado a través de las notas de campo que la participación y argumentación es mayor si las actividades que se plantean son orales y no escritas.

- Que las notas de campo orientan respecto a las tareas que se realizan en cada contexto. Las tareas de reflexión enviadas para casa han favorecido el nivel de argumentación de los participantes, su implicación en el tema problemático y, sobre todo, subrayan haber disfrutado con la tarea.

- Que el sistema categorial emergente es una herramienta sujeta al debate, contraste, discusión y al consenso.

- Que el sistema categorial permite visualizar lo priorizado por los participantes, al fusionarse la razón (lo que se dice) con el corazón (cómo y por qué se dice).

- Que el intercambio de información con los participantes provoca remodelaciones en las reconstrucciones. Esto no ha de ser entendido como simple triangulación del contenido, sino como una pretensión de que los participantes sientan poder controlar la investigación y ser conscientes de que son dueños y/o esclavos de sus palabras y actos.

Los participantes en los distintos contextos de aprendizaje han desvelado que trabajar con la observación participante y las herramientas de análisis derivadas de ella, les ha propiciado aprendizajes emocionales y personales.

Destacan como uno de los puntos de interés haber aprendido a dinamizar y gestionar los grupos de trabajo, y haberlo hecho adoptando una postura relajada y tranquila, de escucha y diálogo, al haber tenido como respaldo la lectura de las notas de campo a modo de cuaderno de bitácora. 
Los participantes se han sentido cómodos en el manejo de la observación participante, y de la información: notas de campo, contraste, categorización, interpretación,... como una tarea cuyo objetivo era conocer para reconocerse, para cambiar e impulsar un proyecto común.

La observación participante les ha servido para implicarse en la necesidad de dar respuesta a un problema que sentían como suyo. Consideramos que este proceso formativo les ha dado mayor sensibilidad para ver lo que a simple vista no habían visto, es decir, lo que se les ocultaba detrás de lo aparente. Han sentido la necesidad de implicarse para cambiar, y esa necesidad se ha creado, se ha aprendido. El hecho de implicar conlleva comprometerse y sentirse partícipe de un proyecto colectivo.

Todo lo desconocido, lo novedoso provoca inseguridad, desconfianza y miedo. Aprender a vencer los miedos iniciales con una actitud positiva como producto de la reflexión, es otro de los aprendizajes subrayados.

Releer las notas de campo da la posibilidad de calzarse los mocasines del otro y darse cuenta de cosas en las que se había reparado, generando empatía que también se aprende.

Quizá lo que más nos guste subrayar sea que en toda la investigación se ha hecho hincapié en que todos y todas aprendemos a sentir. Los encuentros siempre han comenzado con una pregunta ritual ¿cómo nos sentimos? que ha ayudado a crear un espacio de comunicación y escucha en el que cualquiera podía expresar cómo se sentía en el grupo, cómo se veía, qué necesitaba, qué echaba de menos,... Este es el mundo oculto que preside los procesos de investigación, y es también, el que ha fundamentado los nuestros, y así se recoge en las notas de campo generadas a partir de la observación participante. 


\section{REFERENCIAS BIBLIOGRÁFICAS}

Amenabar, B. y Sistiaga, J.J. (2009). Perspectivas de las y los agentes implicados en el deporte escolar. Libro Blanco del deporte escolar. Vitoria-Gasteiz: Gobierno Vasco.

Aubert, A., Flecha, A., García, C., Flecha, R. y Racionero, S. (2008). Aprendizaje dialógico en la Sociedad de la Información. Barcelona: Hipatia.

Bolívar, A., de la Cruz, J.M. y Domingo, J. (2001). La investigación biográficonarrativa en educación: enfoque y metodología. Madrid: La Muralla.

Bolívar, A. (2010). La lógica del compromiso del profesorado y la responsabilidad del centro escolar. Una revisión de la investigación. Revista Iberoamericana sobre Calidad, Eficacia y Cambio en Educación, 8 (2), 10-33.

Carr, W. y Kemmis, S. (1988). Teoría crítica de la enseñanza. Barcelona: Martínez Roca.

Cochran-Smith, M. y Zeichner, K. (2005). Studying teacher education. New York: Routledge.

Denzin, N. K. y Lincoln, Y. (1994). Handbook of Qualitative Research. New York: Sage Publications.

Dewey, J. (2004). Democracia y educación. Una introducción a la filosofía de la educación. Madrid: Morata.

Fernández-Ballesteros, R. (1995). Evaluación de programas. Una guía práctica en ámbitos sociales, educativos y de salud. Madrid: Síntesis.

Freire, P. (1997). Pedagogía de la esperanza. Un reencuentro con la Pedagogía del oprimido. Madrid: Siglo XXI.

Gil, J. y Rodríguez, J. (2004). Análisis de datos en la Investigación Educativa. Sevilla: Edición Digital@Tres.
Gimeno, F. (2000). Entrenando a padres y madres.... Zaragoza: Gobierno de Aragón.

Gómez, A., Puigvert, L. y Flecha, R. (2011). Metodología comunicativa crítica: Informar a la transformación social real a través de la investigación. Investigación Cualitativa, 17 (3), 235245.

Habermas, J. (1994). Teoría de la acción comunicativa. Madrid: Cátedra.

Kirk, D. (2009). The idea of the idea of physical education: Between essentialism and relativism in studying the social construction of physical education. Journal de la Recherche sur l'Intervention en Éducation Physique et Sport, 18, 24-40.

Krueger, R. A. (1991). El grupo de discusión. Guía práctica par la investigación aplicada. Madrid: Pirámide.

Llopis, R. (2004). Grupos de discusión. Madrid: ESIC Editorial.

Macazaga, A. y Rekalde, I. (2005). El proceso de formación a través de la investigación participativa: una experiencia en torno al deporte escolar. Guiniguada, 14, 141-156.

Macazaga, A.M., Vizcarra, M.T. y Rekalde, I. (2006). Estudio del proceso formativo que siguen un grupo de docentes para realizar un diagnóstico de necesidades en deporte escolar. Revista de Psicodidáctica, 11 (2), 207-226.

Macazaga, A.M., Rekalde, I. y Vizcarra, M.T. (2011). Pedagogía del deporte escolar y valores educativos. Reflexiones sobre una experiencia. En E. Isidori, y A. Fraile. La pedagogía del deporte hoy. Escenarios y desafíos. (pp. 251-300). Roma: Edizioni Nuova Cultura. 
Macazaga, A.M., Rekalde, I. y Vizcarra, M.T. (2013). ¿Cómo encauzar la agresividad? Una propuesta de intervención a través de los juegos y los deportes. Revista Española de Pedagogía, 255, 263-276.

Miles, M.B. y Huberman, A.M. (1994). Qualitative Data Analysis. London: Sage Publications.

Orts, F. (2005). La promoción del deporte de base en Valencia. Los programas deportivos municipales. Aula de Innovación Educativa, 91, 24-27.

Pérez Serrano, G. (2008). La educación como respuesta a los retos que plantea la escuela. Bordón, 60, 15-30.

Prat, M. y Soler, S. (2012). De las palabras a los hechos: un proyecto para promover la participación femenina en el deporte universitario. El caso de la Universitat Autònoma de Barcelona. Ágora para la Educación Física y el deporte, 14 (3), 283-302.

Rekalde, I., Vizcarra, M.T. y Macazaga, A.M. (2011). La aventura de investigar. Una experiencia de investigaciónacción participativa. Aula Abierta, 39 (1), 93-104.

Rodríguez, G., Gil, J. y García, E. (1996). Metodología de la Investigación Cualitativa. Málaga: Ediciones Aljibe.
Rossi, T., Tinning, R. y McCuaig, L. (2009). With the Best of Intentions: A Critical Discourse Analysis of Physical Education Curriculum Materials. Journal of teaching in physical education, 28 (1), 75-89.

Taylor, S.J. y Bogdan, R. (1996). Introducción a los métodos cualitativos de investigación. Barcelona: Paidós.

Vizcarra, M.T., Macazaga, A. M. y Rekalde, I. (2006). ¿Con qué deporte escolar sueñan las familias? Apunts. Educación Física y Deportes, 86, 97107.

Vizcarra, M.T.; Macazaga, A. M. y Rekalde, I. (2013). El proceso de acompañamiento en la construcción participativa de una normativa. Revista Española de Orientación y Psicopedagogía, 24 (1), 110-120.

Woods, P. (1987). La escuela por dentro: La etnografía en la investigación educativa. Barcelona: Paidós/MEC.

Zeichner, K. (2010). Nuevas epistemologías en formación del profesorado. Repensando las conexiones entre las asignaturas del campus y las experiencias de prácticas en la formación del profesorado en la universidad. Revista Interuniversitaria de Formación del Profesorado, 68, 123-150. 


\section{PALABRAS CLAVE}

Observación, Participación, Investigación, Escuela, Deporte escolar.

\section{KEYWORDS}

Observation, Participation, Research, School, Scholar Sport.

\section{PERFIL ACADÉMICO Y PROFESIONAL DE LAS AUTORAS}

Itziar Rekalde Rodríguez, pertenece al Departamento de Didáctica y Organización Escolar, en la Facultad de Filosofía y Ciencias de la Educación, de la Universidad del País Vasco/Euskal-Herriko Unibertsitatea (UPV/ EHU).

Sus aportaciones más significativas giran en torno al acompañamiento en procesos formativos que se desarrollan en áreas curriculares diversas, como es el caso de la salud o el del deporte escolar, y en niveles educativos diferentes como la educación primaria y la superior. En todos los estudios el principal objetivo es construir contextos de participación que fomenten la comunicación y reflexión.

Estas autoras han investigado en torno al tema del deporte escolar y de la coordinación de éste respecto a la educación física que se desarrolla en los diferentes niveles educativos.

Asimismo, las tres son autoras de trabajos derivados de las investigaciones llevadas a cabo en la Federación de Ikastolas (País Vasco), así como en Comunidades de Aprendizaje en colaboración con la Universidad de Barcelona (Proyecto Juega, dialoga y resuelve: la superación de conflictos en Educación Física mediante el modelo comunitario. Diseño de un programa específico para Comunidades de Aprendizaje. Plan Nacional I+D+I. Programa Nacional de Ciencias Sociales, Económicas y Jurídicas. 2007- 2010).

Maria Teresa Vizcarra Morales y Ana María Macazaga López pertenecen al Departamento de la Expresión Musical, Plástica y Corporal, de la Universidad del País Vasco/Euskal-Herriko Unibertsitatea (UPV/EHU).

Dirección de los autores: Itziar Rekalde Rodríguez

Departamento de Didáctica y Organización

Escolar

Facultad de Filosofía y Ciencias de la Educación 
Universidad del País Vasco/Euskal-Herriko Unibertsitatea (UPV/EHU)

Av. Tolosa, n. ${ }^{\circ}$ 70, 20018 Donostia.

E-mail: itziar.rekalde@ehu.es

Maria Teresa Vizcarra y Ana María Macazaga Departamento de la Expresión Musical, Plástica y Corporal Universidad del País Vasco/Euskal-Herriko Unibertsitatea (UPV/EHU).

E-mail: mariate.bizkarra@ehu.es ana.makazaga@ehu.es

Fecha Recepción del Artículo: 07. Diciembre. 2011

Fecha modificación Artículo: 12. Abril. 2012

Fecha Aceptación del Artículo: 15. Mayo. 2012

Fecha de Revisión para publicación: 24. Junio. 2013 


\title{
COACHING EDUCATIVO: MODELO PARA EL DESARROLLO DE COMPETENCIAS INTRA E INTERPERSONALES
}

\author{
(EDUCATIONAL COACHING: A MODEL FOR THE DEVELOPMENT OF INTRA \\ AND INTERPERSONAL SKILLS)
}

Beatriz Sánchez Mirón y Julia Boronat Mundina

Universidad de Valladolid

DOI: $10.5944 / e d u c x x 1.17 .1 .1072$

\section{Cómo referenciar este artículo/How to reference this article:}

Sánchez Mirón, B. y Boronat Mundina, J. (2014). Coaching Educativo: Modelo para el desarrollo de competencias intra e interpersonales. Educación XX1, 17 (1), 221-242. doi: 10.5944/ educxx1.17.1.1072

Sánchez Mirón, B. y Boronat Mundina, J. (2014). Educational Coaching: A model for the development of intra and interpersonal skills. Educación XX1, 17 (1), 221-242. doi: 10.5944/educxx1.17.1.1072

\section{RESUMEN}

En la actual sociedad del conocimiento, en constante cambio y vertiginosa evolución, se necesitan hombres y mujeres con iniciativa para tomar decisiones y ser capaces de adaptarse a un mundo incierto e imprevisible.

Para lograr este objetivo, en el contexto de la enseñanza universitaria, seleccionamos el coaching, como la técnica metodológica que favorece el desarrollo del potencial humano y ayuda a los estudiantes a progresar, de donde están hoy hacia donde pretenden llegar mañana. Esta metodología se basa en el establecimiento de metas personales y en la ejecución de una serie de acciones planificadas que permiten al sujeto poner en práctica determinadas formas de ser y de actuar.

El primer paso ha consistido en profundizar en el coaching: orígenes, delimitación conceptual, características y funciones que asumen los sujetos implicados, información que nos ayuda a avanzar un modelo que hemos aplicado en nuestra realidad docente: la formación inicial de maestros.

En la metodología se han seguido diversas fases: previa, como punto de partida, y de desarrollo, cuyo hilo conductor ha girado en torno al desarrollo de las competencias inter e intrapersonales. La aplicación del DAFO nos ha permitido realizar una valoración del proceso seguido y avanzar unas propuestas tendentes a consolidar este modelo en un futuro, ya que permite que el estudiante pueda adquirir las competencias clave para su reafirmación como persona y representa un acicate para su futura inserción socio-laboral. 


\section{ABSTRACT}

In today's knowledge-based society, in constant change and vertiginous evolution, we need men and women able to take decisions and to adapt themselves to an uncertain and unpredictable world.

To achieve this goal in higher education context, we have chosen coaching as a methodological technique which encourages the development of human potential and helps the students to progress from where they are today to where they intend to get tomorrow. This methodology is based on setting personal goals and on the implementation of a series of planned actions that allow the subject to carry out certain ways of being and acting.

The first step consisted in deepening in coaching programs: origins, conceptual definition, characteristics and functions of the subjects involved, information that allowed us to present a model we have implemented in teachers former education.

Several phases have been followed in methodology implementation: a preliminary phase as a starting point to implement the model; the development phase, centred on the development of inter and intrapersonal competences. SWOT analysis made possible an assessment of the process and the putting forwards of some proposals in order to consolidate this model in the future, model which makes possible the acquisition of key competences for self-assertiveness and supposes a stimulus for a future incorporation into the work force.

\section{INTRODUCCIÓN}

En la época actual, la sociedad globalizada avanza de forma vertiginosa y se rige por una alta competitividad y una compleja tecnología, aspectos en constante transformación. En este contexto, no es extraño que el éxito esté condicionado por la calidad del producto o servicio, por el talento de las personas, por la habilidad de interrelación con el entorno, y por la capacidad de innovación y creatividad de los individuos y empresas.

En tales circunstancias, resulta fundamental entender que «el conocimiento ya no es, sino que deviene» (Sancho y Correa, 2010, p. 18). El conocimiento ha dejado de ser propiedad exclusiva de la institución escolar y de los docentes, para convertirse en un proceso que el individuo gestiona autónomamente a lo largo de su vida. En consecuencia, se hace necesario preparar a las nuevas generaciones para gestionar tales cambios, dotándoles de una serie de competencias.

En el ámbito universitario, para posibilitar que los estudiantes puedan gestionar su vida de forma autónoma y responsable, hemos seleccionado el coaching, modalidad de asesoramiento que proviene de la evolución del coun- 
seling. De esta corriente emerge el modelo de programas y la consultoría, relacionados con la tutoría, mentoring y asesoramiento» (Bisquerra, 2008, p. 165).

A lo largo de su trayectoria, el coaching se ha convertido en una herramienta clave y exitosa en el management empresarial y su influencia se ha extendido a diversos ámbitos. Nuestra propuesta pretende transferir sus fortalezas al educativo, considerando que, con la adecuada aplicación de esta técnica en las aulas universitarias, los alumnos aprenderán más y mejor, y estarán mejor preparados para enfrentarse de forma proactiva a su futuro.

En esta publicación presentamos, de forma sucinta, el origen, fundamentos, significado y modelos de coaching. Todo ello nos va a permitir el avance de un modelo aplicable en la enseñanza universitaria.

La elección de esta técnica no ha sido fortuita, puesto que sus principios coinciden, en gran medida, con la filosofía que preside el proceso de Bolonia (Obiols y Giner, 2011). En ambos enfoques se promueve la autonomía del estudiante, su autoaprendizaje y el desarrollo de competencias, a partir de su compromiso durante el proceso de aprender.

\section{ORÍGENES, FUNDAMENTOS Y SIGNIFICADO DE COACHING}

Debido a la amplia divulgación que existe actualmente del término coaching, estimamos conveniente delimitar su origen, fundamentos y enfoques que han permitido que adquiera cada vez mayor relevancia y entidad.

Las primeras referencias sobre apelativo coach se encuentran en el argot universitario inglés del siglo XVIII, aludiendo al profesor particular que ayudaba a un estudiante a prepararse, rápida y eficientemente para los exámenes. Este sentido prevalece en la actualidad, "porque se entiende que la aplicación del coaching transporta a las personas, desde donde se encuentran hoy, hacia donde les gustaría estar mañana, siendo el coach el facilitador de este viaje» (Bayón et al, 2006, p. 7). En nuestro caso, existe cierto paralelismo con nuestros alumnos, que hoy se están preparando para ser los docentes del futuro, como profesionales eficaces, resilientes y promotores del cambio.

El coaching, como ámbito de estudio, surge en Estados Unidos y Canadá, a finales del siglo XX, de la mano de John Whitmore, considerado su precursor en el campo empresarial, donde ha tenido una considerable incidencia y aceptación. Desde los años setenta, revistas científicas, como Training \& Development Journal, o asociaciones, como The American Counseling Association (ACA), han promovido una aproximación entre el coaching, counseling y consulting (Sperry, 1993). En nuestro país, una de las primeras 
publicaciones sobre coaching aplicado a la educación, aparece en la Revista de Orientación y Psicopedagogía (Bisquerra, 2008), como técnica digna de tener en cuenta en el campo de la orientación.

Si bien sus primeros pasos se desarrollan en el ámbito empresarial, sus fundamentos se enmarcan en distintos campos de las ciencias humanas y sociales (filosofía, psicología, orientación, sociología...), pero también derivan de los avances de la programación neurolingüística. Nos vamos a referir brevemente a estas corrientes.

Entre los fundamentos filosóficos cabe destacar la mayéutica socrática y el existencialismo. En realidad, la base subyacente del coaching se apoya en el método socrático, que permite, a base de preguntas, que el alumno vaya resolviendo sus problemas de forma autónoma, llegando a descubrir su verdadero potencial.

Un concepto nuclear del existencialismo (Kierkegaard, Heidegger, Sartre) es el de libertad, que indudablemente se otorga a los estudiantes en nuestra propuesta. Una persona es libre cuando tiene la posibilidad de elegir, equivocarse y decidir a lo largo de su trayectoria vital.

Por otra parte, son varias las corrientes psicológicas que han influido en el desarrollo del coaching como técnica. Según la psicología humanista, el individuo percibe el mundo que le rodea de un modo singular y único; tal percepción constituye su peculiar realidad y determina su comportamiento. Asimismo, el constructivismo, como corriente psicológica actual, ha propiciado su desarrollo. Mantiene que la persona (cognitiva, social y afectivamente) es el resultado de la construcción producida por la interacción entre el ambiente y el individuo. Las construcciones se producen cuando el sujeto interactúa con el objeto del conocimiento (Piaget), cuando tal interacción se realiza con los otros (Vigotsky), y cuando es significativa para el sujeto (Ausubel).

Pero el enfoque que más ha incidido en la aplicación del coaching ha sido el counseling, En sus primeros tiempos, las aportaciones más notables provienen de Williamson, quien, desde un enfoque directivo, incide en la preparación y experiencia del orientador para ayudar al sujeto. Posteriormente, desde un enfoque no directivo, cabe destacar a Carl Rogers, quien promovió una nueva forma de relaciones humanas, basada en la confianza en la persona libre y autónoma. Según este autor, a lo largo de la vida, y en función de las vivencias y los efectos positivos o negativos que el sujeto tiene, se va configurando el autoconcepto. Su teoría se caracteriza por incidir en los procesos dinámicos y de cambio, al igual que sucede en el coaching.

Entre las teorías sociológicas cabe destacar el estudio de las competencias en el ámbito empresarial, que data de 1973, cuando David McClelland 
fue encargado de detectar las características personales que predecían el éxito laboral de los miembros del Departamento de Estado Norteamericano. Asimismo, es digna de mención la teoría del empowerment, que se remonta a 1988, bajo la influencia de Kenneth Blanchard y Paul Hersey, enfoque que trabaja en la delegación de responsabilidades, mediante la liberación del potencial disponible en las personas (Ramírez y Vivas, 2005).

Desde una perspectiva complementaria, la programación neurolingüística (PNL) del lingüista Grinder y del matemático Bandler representa una de las bases teóricas más sólidas, aceptadas y utilizadas en el proceso de coaching, considerando el lenguaje como un valor esencial del mismo. «La programación neurolingüística se centra en el análisis de la comunicación y de los procesos de cambio, estudiando la estructura de la experiencia subjetiva» (Launer, 2007, p. 122).

En síntesis, la profundización sobre sus fundamentos nos ha permitido constatar que, si bien el coaching deriva de diversas corrientes científicas, si queremos aplicar esta técnica en el campo de la educación, indudablemente el counseling, por su influencia, adquiere un protagonismo notorio.

En base a sus fundamentos, estimamos que el coaching se sustenta en una serie de principios, presentes en los enfoques originarios, destacando: a) la importancia de la autonomía del sujeto y del autoaprendizaje; b) la conducta está condicionada por la peculiar visión del mundo que el sujeto se forma a lo largo de su vida; c) la necesidad de que coexista una alta motivación, responsabilidad hacia el cambio y deseo de transformación; d) y la relevancia del proceso comunicativo, pues, a través del lenguaje, de la verbalización de metas y del uso de preguntas poderosas, el individuo se descubre a sí mismo y tiende a actuar.

Por último, el rastreo realizado sobre diversos autores (Bayón, 2006; Bisquerra, 2008; Cantera, 2003; Gordillo, 2008; Haneberg, 2006; Launer, 2007; Whitmore, 2003, etc.) nos permite aportar una definición, contextualizada en nuestro ámbito de intervención: el coaching es un proceso interactivo y sistemático de aprendizaje y descubrimiento del potencial individual, centrado en el presente y orientado al cambio y la excelencia. Pretende desarrollar la autonomía del alumno, siendo éste el protagonista de los pasos a seguir y de los resultados obtenidos.

\section{MODELOS DE COACHING}

No parece existir unanimidad entre quienes estudian el coaching, al delimitar sus modelos y tampoco es nuestra intención reflejar las posibles 
clasificaciones. Según Banner, citado por Gordillo (2008), los enfoques teóricos más generales son: el psicodinámico, conductista, centrado en la persona, cognitivo y sistémico. Cada uno presenta un foco de atención diferente, a los que nos vamos a referir, de forma sucinta.

Modelo psicodinámico o clínico. Se centra en las fases de toma de conciencia (precontemplación, reflexión y descubrimiento), siendo su objetivo fundamental que el cliente logre una mayor autocomprensión de sí mismo $\mathrm{y}$, de este modo, consiga realizar los cambios necesarios en su manera de actuar. Para que este modelo resulte eficaz, se precisa que el coach tenga una buena formación psicológica, que le permita llevar a cabo inferencias acertadas y actuar, de forma objetiva, sobre el sujeto orientado.

Modelo conductual. Este modelo centra la atención, casi exclusivamente, en las conductas específicas, considerando que los cambios solamente pueden darse si el sujeto comprende el impacto de sus conductas en sí mismo y en los otros, y actúa en consecuencia.

Modelo centrado en la persona. Focaliza la atención en el proceso de interrelación que ayuda al cliente a llegar a sí mismo, lo que implica una profunda experiencia de elección personal. El sujeto espera mantener una conducta consistente, de acuerdo con su autoconcepto, conducta que se dirige hacia la autorrealización, es decir al proceso de convertirse en persona.

Modelo cognitivo social. En este caso, el lenguaje es determinante y, por tanto, el foco de atención. Lo que decimos sirve para dar sentido y reconstruir nuestra historia personal, dentro de un marco de referencia concreto; en el caso del universitario, se va configurando a partir de determinadas experiencias de vida. Su mayor inconveniente es que el coach realice interpretaciones subjetivas, en base a su historia personal, en vez de a la historia del sujeto, que es la que debe primar.

Modelo sistémico. Este modelo, aplicado a diversos campos del conocimiento, parte de la premisa de que las personas son parte del sistema en donde se hallan inmersas; por tanto, cambiar sus conductas implica modificar el sistema. Este modelo trata de conseguir la implicación de los sujetos, equipos y organizaciones en la construcción del conocimiento, con el fin de actuar eficazmente ante los desafíos que plantea el entorno. Entiende que el ser humano es el principal activo de una organización y, por tanto, el impulsor del aprendizaje y del cambio.

La amplia difusión del coaching, en distintos ámbitos, ha promovido la aparición de modelos específicos, que, si bien coinciden en muchos de sus principios con los anteriormente descritos, acotan su intervención a campos y situaciones concretas. Cabe citar el modelo G.R.O.W. (Whitmore, 2003), 
que centra su atención en el establecimiento de metas y creación de planes de acción estructurados; el modelo de Seligman, que enfatiza en la resiliencia, como premisa de actuación ante el fracaso; el modelo CoachVille, centrado en la necesidad de percibir la distancia entre el estado presente y el estado deseado para que exista desarrollo; el modelo DBM (Development Behaviour Modeling), que tiene su origen en la programación neurolingüística, orientado al desarrollo humano, mediante la aplicación de técnicas de modificación de conducta; y el modelo de López y Key, citado por Bisquerra (2008), que integra el coaching en el counseling.

Ninguno de los modelos citados debe entenderse como un modelo estándar, puesto que las posibilidades de aplicación son muy variadas. De hecho, el coaching opera en todas las dimensiones del ser humano: en el ámbito personal (desarrollo de competencias y capacidades), profesional (desarrollo de la carrera), social (adaptación al medio, supervivencia) y educativo (aprendizaje y preparación para la capacitación).

\section{AGENTES IMPLICADOS EN EL COACHING}

Muy en consonancia con las premisas de los modelos mencionados, el coaching, desde su vertiente educativa, encaja perfectamente con los nuevos roles de los agentes implicados en el proceso de enseñanza-aprendizaje, considerando al profesor (coach), como «facilitador», y al alumno (coachee), como «generador de su propio conocimiento».

Según Bayón et al. (2006, p. 47), «el coach puede desempeñar siete roles distintos en la relación con el pupilo: maestro, socio, investigador, espejo, profesor, guía y notario».

- Como maestro, el coach coordina, modela, encauza y analiza. Además, mantiene una escucha activa, promueve la reflexión, demuestra interés y respeto por el aprendiz.

- Como socio, comparte responsabilidades, define estrategias, negocia, se involucra. Además, se compromete con la confidencialidad y la transparencia.

- Como investigador, asume una función indagadora; pregunta, descubre necesidades, muestra curiosidad, pero, a la vez, lo hace con rigor.

- Como espejo, refleja una imagen veraz del aprendiz, no sesgada, es honesto, directo y procura hacer ver al pupilo sus fortalezas y potencial. 
- Como profesor, mediante la función docente, dota de herramientas, reta y estimula el pensamiento, ofrece estrategias y opciones de respuesta.

- Como guía, orienta, anima, sugiere y encamina, pero siempre con la libertad suficiente como para que el aprendiz sea quién vaya tomando las decisiones.

- Como notario, ejerce la función normativa, comprueba los avances producidos, establece acuerdos, resuelve dudas, realiza el seguimiento y ayuda al aprendiz a reevaluar su progreso.

Si a nivel teórico resulta fácil delimitar estos roles, en la práctica la separación es más compleja, llegando a coincidir varios roles en quién asume el papel de coach. Si tenemos en cuenta la variedad de roles y funciones que pueden aplicarse durante el proceso, resulta conveniente que el coach cuente con una amplia gama de competencias para ejercer con éxito su cometido. Las competencias giran en torno a estas cuatro dimensiones: aptitudinales: referidas a conocimientos, procedimientos y habilidades; intrapersonales o de personalidad: proactividad, intuición, coherencia, entusiasmo, sensibilidad, humildad, optimismo, integridad, sinceridad, paciencia, etc.; interpersonales o de relación con los demás: escucha activa, empatía, receptividad, sutileza, asertividad, adaptación, participación, compromiso e inteligencia emocional; y técnicas, como saber preguntar, reconducir la situación y manejar diversos instrumentos.

Para Haneberg (2006, p. 3), «un gran coach habla poco, escucha mucho y facilita el proceso de pensamiento del cliente» En nuestro caso, se convierte en un guía que focaliza su atención en los deseos y expectativas del estudiante y procura que éste descubra por sí mismo y desarrolle su autonomía durante el proceso formativo, en base a sus propias creencias y valores.

En correspondencia con el coach, se encuentra el coachee o aprendiz, en este caso, el estudiante universitario. Aquello que define inicialmente a un buen coachee, más que su pericia en habilidades, es su actitud hacia el cambio, que puede lograr mediante la adquisición paulatina de una serie competencias, tanto interpersonales (receptividad, comunicación, escucha activa, inteligencia emocional...), como intrapersonales (motivación, autonomía, responsabilidad, reflexividad, persistencia, iniciativa, autoconocimiento y autocrítica).

En definitiva, los agentes del proceso de coaching deben compartir diversos valores básicos, sintetizados en estas competencias: de aceptación 
(de los objetivos y deseos del cliente), acción (para salir de la zona de confort), autenticidad (para generar confianza mutua), coraje (para asumir los riesgos del proceso), desapego (para mantener la objetividad), efectividad (para conseguir realmente resultados), aprendizaje (para afianzar la autonomía), respeto (para que realmente exista libertad) y orientación al logro (para mantenerse motivados).

\section{APROXIMACIÓN A UN MODELO EDUCATIVO DE COACHING}

Si hasta aquí hemos abordado la perspectiva teórica de coaching, estimamos conveniente dar un paso más y presentar su vertiente operativa, que permite aplicarlo en una situación determinada. Bisquerra (2008) admite que el coaching ha tenido escasa proyección en el ámbito educativo al afirmar que «los pedagogos, psicopedagogos y orientadores se dedican muy poco al coaching y son escasos los trabajos científicos sobre su aplicación a la enseñanza u orientación. Sin embargo, en los últimos cinco años la situación ha cambiado y encontramos trabajos e investigaciones sobre la aplicación del coaching al campo educativo (Obiols y Giner, 2011; Rodríguez Marcos, 2011, Saphier y West, 2010). Así pues, en la actualidad, asistimos a un renacimiento del coaching, como estrategia formativa, como una aproximación estratégica y sistemática, situada en el contexto profesional, orientada al profesorado, basada en la escuela, colaborativa y centrada en el aprendizaje del alumnado» (Teeman, Wink y Tyra, 2011). De ahí nuestro afán de incorporarlo, como una experiencia piloto en la formación de los futuros docentes, en la realidad de las aulas universitarias.

Para ello, nos apoyamos en los modelos procesuales de Bayón et al (2006) y de Carril (2008), dada la proyección que puede tener en el ámbito educativo universitario. Según Carril, los principios o pilares que constituyen la esencia del proceso de coaching, son: a) tomar conciencia de nosotros y aceptar lo que somos; b) salir de la zona de confort y marcarse metas motivadoras; c) dar pasos pequeños y constantes, seguir la intuición y ser dueños de nuestro tiempo; d) reflexionar para reconducirnos y avanzar. Para Bayón, estos pilares condicionan las fases del modelo de coaching: a) precontemplación (toma de conciencia de una necesidad de cambio); b) reflexión (autoanálisis sobre las carencias, ordenación de ideas y planificación); c) descubrimiento (detección de las creencias, nivel de compromiso); d) plan de acción (compromiso, objetivos concretos, realistas, estimulantes y personales); y e) hábito (transferencia de los aprendizajes, ejecución de forma autónoma).

En base a estos principios, nuestro modelo se basa en la creación del conocimiento por parte del alumno (autoaprendizaje), y en la consideración de la figura del profesor como guía del proceso de aprendizaje y facilitador 
del descubrimiento (orientador). Todo ello, en línea con la filosofía que subyace en el proceso de Bolonia, de corte constructivista. Estimamos que con su puesta en práctica, no sólo los estudiantes pueden lograr mayor éxito en la adquisición de conocimientos, sino que puede acrecentarse su motivación, que afecta positivamente a su actitud ante el estudio.

La presentación de nuestro modelo no resulta baladí, dado el momento que vive la universidad, donde el proceso de Bolonia devuelve a los estudiantes el poder de aprender (Cajina, 2011; Obiols y Giner, 2011). El modelo apuesta para que los jóvenes lleguen a ser inconscientemente competentes en la resolución de problemas, dado que no hay una solución preestablecida en los libros (Bayon, 2006).

Indudablemente, este modelo está en línea con los enfoques subyacentes sobre el desarrollo de competencias, que remite a un tratamiento metodológico particular y propio de la sociedad del conocimiento, orienta la enseñanza al desarrollo de habilidades complejas, donde lo que importa es, más que la adquisición de datos, la movilización del conocimiento para resolver situaciones. El sustrato de las habilidades puestas en juego se sintetiza en el principio de aprender a aprender, base del aprendizaje a lo largo de la vida. Ello implica querer aprender, ser consciente de cómo se aprende y cómo se continúa aprendiendo durante todo el ciclo vital, poniendo en juego estrategias metacognitivas diversas, es decir, autorregulando el propio proceso de aprendizaje (Díaz, 2009).

\section{Interrogantes y fases del modelo}

Con la intención de constatar la proyección del coaching en las aulas universitarias, nuestro modelo parte de los siguientes interrogantes: ¿cuáles son sus fundamentos?; ¿qué se pretende conseguir? ¿quiénes intervienen durante el proceso?, ¿cuándo y cómo se aplica? ¿cuáles son los resultados obtenidos? El modelo se ha aplicado como estudio piloto en la formación inicial del profesorado, el cual tiene visos de traducirse, en un futuro próximo, en un modelo de coaching más consolidado y abierto a la comunidad universitaria.

\section{¿Cuáles son los fundamentos?}

En el siguiente cuadro, ubicamos en la primera columna las corrientes que han sido nuestro referente, de las que derivan tres elementos sustantivos del modelo: idea básica, técnicas y aplicación en el aula, y competencias desarrolladas, extraídas de los autores manejados y acomodadas a las com- 
petencias que aparecen en las guías docentes de las asignaturas del título de maestro: Diseño Curricular y Métodos de Investigación (Educación Infantil) y Tecnologías en Educación (Educación Física). La siguiente tabla delimita la relación entre los elementos del modelo.

\begin{tabular}{|c|c|c|c|c|}
\hline \multicolumn{2}{|c|}{ FUNDAMENTOS } & \multirow{2}{*}{\begin{tabular}{l}
\multicolumn{1}{|c|}{ IDEA BÁSICA } \\
$\begin{array}{l}\text { Diálogo y pre- } \\
\text { guntas podero- } \\
\text { sas. }\end{array}$
\end{tabular}} & \multirow{2}{*}{\begin{tabular}{l}
\multicolumn{1}{c}{ TÉCNICAS } \\
Seminarios (lec- \\
turas comenta- \\
das, preguntas \\
y comunicación \\
dialógica)
\end{tabular}} & \multirow{2}{*}{$\begin{array}{l}\text { COMPETENCIAS } \\
\text { DESARROLLADAS } \\
\text { Autonomía, resolu- } \\
\text { ción de problemas, } \\
\text { análisis-síntesis, co- } \\
\text { municación. }\end{array}$} \\
\hline 告 & Mayéutica & & & \\
\hline 是 & Existencialismo & $\begin{array}{l}\text { Yo soy responsa- } \\
\text { ble de mis actos. }\end{array}$ & $\begin{array}{l}\text { Compromiso ini- } \\
\text { cial (contrato), } \\
\text { autoevaluación. }\end{array}$ & $\begin{array}{l}\text { Responsabilidad, vo- } \\
\text { luntad, compromiso, } \\
\text { autodeterminación. }\end{array}$ \\
\hline \multirow{3}{*}{$\begin{array}{l}0 \\
0 \\
0 \\
0 \\
0 \\
0 \\
0 \\
0 \\
0 \\
0\end{array}$} & $\begin{array}{l}\text { Psicología } \\
\text { humanista }\end{array}$ & $\begin{array}{l}\text { Interpretación } \\
\text { de la realidad, } \\
\text { en función de } \\
\text { las vivencias } \\
\text { previas. }\end{array}$ & $\begin{array}{l}\text { Debates, con- } \\
\text { traste de opinio- } \\
\text { nes, resolución } \\
\text { de casos. }\end{array}$ & $\begin{array}{l}\text { Respeto, adapta- } \\
\text { ción, cooperación, } \\
\text { trabajo en equipo, } \\
\text { creatividad. }\end{array}$ \\
\hline & Constructivismo & $\begin{array}{l}\text { Conexión de } \\
\text { aprendizajes y } \\
\text { reestructuración } \\
\text { del conocimien- } \\
\text { to. }\end{array}$ & $\begin{array}{l}\text { Portfolios, ma- } \\
\text { pas conceptua- } \\
\text { les, líneas de } \\
\text { tiempo. }\end{array}$ & $\begin{array}{l}\text { Organización } \\
\text { y planificación, } \\
\text { análisis - síntesis, } \\
\text { autonomía, } \\
\text { creatividad. }\end{array}$ \\
\hline & Counseling & $\begin{array}{l}\text { Persona libre y } \\
\text { autónoma. }\end{array}$ & $\begin{array}{l}\text { Metáforas, en- } \\
\text { trevista no di- } \\
\text { rectiva, relación } \\
\text { empática. }\end{array}$ & $\begin{array}{l}\text { Diálogo, escucha } \\
\text { activa, iniciativa, } \\
\text { aprender a aprender, } \\
\text { toma de decisiones. }\end{array}$ \\
\hline \multirow{3}{*}{ ס } & Competencias & $\begin{array}{l}\text { Potencial in- } \\
\text { terno, único y } \\
\text { personal por de- } \\
\text { sarrollar. }\end{array}$ & $\begin{array}{l}\text { Seminarios } \\
\text { (evaluación por } \\
\text { pares), agrupa- } \\
\text { mientos flexi- } \\
\text { bles. }\end{array}$ & $\begin{array}{l}\text { Autoconocimiento, } \\
\text { análisis-síntesis, tra- } \\
\text { bajo en equipo. }\end{array}$ \\
\hline & Empowerment & $\begin{array}{l}\text { Sentirse parte } \\
\text { de un sistema } \\
\text { grupal. }\end{array}$ & $\begin{array}{l}\text { Normas basadas } \\
\text { en respeto, no } \\
\text { en imposición. } \\
\text { Negociación de } \\
\text { tareas. }\end{array}$ & $\begin{array}{l}\text { Toma de decisiones, } \\
\text { responsabilidad, } \\
\text { compromiso. }\end{array}$ \\
\hline & PNL & $\begin{array}{l}\text { Creencias poten- } \\
\text { ciadoras y limi- } \\
\text { tantes. }\end{array}$ & $\begin{array}{l}\text { Tutoría indivi- } \\
\text { dual y grupal. }\end{array}$ & $\begin{array}{l}\text { Autoestima, autoco- } \\
\text { nocimiento, volun- } \\
\text { tad, energía y afán } \\
\text { de superación. }\end{array}$ \\
\hline
\end{tabular}

Tabla 1. Elementos del Modelo de coaching aplicado en la universidad 
¿Qué se pretende conseguir?

En nuestro caso, nos planteamos articular la docencia en torno al aprendizaje del estudiante universitario, delimitando qué competencias inter e intrapersonales van a presidir el desarrollo de la enseñanza universitaria, de forma más eficaz y significativa. Se trata de lograr la interiorización de determinadas competencias, con objeto de que constituyan una forma habitual de operar y puedan ser aplicadas de manera autónoma (competencia inconsciente) en diferentes situaciones vitales del estudiante. En concreto, los objetivos a conseguir, por parte de los estudiantes, son: promover la adquisición de competencias y hábitos de trabajo, y favorecer la transferencia y generalización de los aprendizajes a diversas situaciones personales y académicas; por parte del profesorado se trata de aplicar las funciones del coach en diversas situaciones docentes, y propiciar el trabajo colaborativo entre el profesorado implicado.

En definitiva, a partir del modelo de Bayón et al (2006), se pretende que el proceso de coaching haga evolucionar al sujeto desde la dimensión inconscientemente incompetente hacia la inconscientemente competente. En este sentido, si durante el proceso de enseñanza-aprendizaje, si el docente se implica en que los alumnos lleguen a ser, por ejemplo, inconscientemente organizados, van a poder aplicar esta competencia en su vida personal, profesional, social..., y lo harán sin esfuerzo, pues no necesitarán pararse a pensar en los pasos a seguir, ya que llegarán a actuar por inercia.

\section{¿Quiénes han intervenido?}

En nuestro caso, la experiencia ha sido implementada por dos profesoras universitarias, autoras del artículo. El proyecto piloto, orientado a la formación en competencias, ha representado la situación propicia para su aplicación en la docencia universitaria, muy vinculada a la tutoría. Nuestra dilatada experiencia y trayectoria investigadora en el campo de la orientación universitaria y laboral nos ha permitido identificar las funciones del coach que debían presidir esta experiencia, fundamentalmente las de: maestro, socio, profesor, y guía, descritas anteriormente y aplicarlas en el día a día.

En este sentido, conocedoras de los beneficios que aporta la incorporación de la orientación en el ámbito universitario, nos propusimos ayudar al estudiante a descubrir «dónde está», cuestionando las creencias limitadoras $\mathrm{y}$ fomentando las potenciadoras, mediante el uso acertado de preguntas poderosas, motivándole para que fuera el protagonista del sus respuestas y toma de decisiones. 
En relación al coachee o alumnado, la selección del grupo nos vino dada por circunstancias profesionales. Docencia en dos asignaturas impartidas en tercer curso a estudiantes de las especialidades de Maestro de Educación Infantil (64 alumnos) y Educación Física (78 alumnos). La situación era la idónea, pues eran alumnos del último curso de la Diplomatura de Maestro, en el que, a pesar de no haber iniciado el grado, se trabajaba en un proyecto piloto sobre desarrollo de competencias. Por ello, nos planteamos vincular las contempladas en las guías docentes de las mencionadas asignaturas con las que se pretenden lograr que el coachee llegue a ser un estudiante autónomo, que actúe como sujeto activo de su propio aprendizaje, se formule metas, organice el conocimiento, construya significados, utilice estrategias adecuadas y elija los momentos para adquirir, desarrollar y generalizar lo aprendido. El proceso ha estado presidido por un compromiso bidireccional entre las profesoras y el alumnado.

\section{¿Dónde y cuándo se ha aplicado?}

La experiencia se ha desarrollado en un Centro de Formación del Profesorado, la Escuela Universitaria de Educación de Palencia, que cuenta con una amplia trayectoria en proyectos de investigación, orientados a la innovación y calidad docente, orientación y tutoría universitaria. Se ha implementado durante el curso 2010-11, con 142 alumnos de tercer curso, de las especialidades de maestro de Educación Infantil y Educación Física.

\section{¿Cómo se ha aplicado?}

- Fase previa. La revisión teórica sobre coaching ha permitido constatar su aplicabilidad en la docencia universitaria. El punto de partida ha sido la observación y, fundamentalmente, cuatro preguntas abiertas que debían responder en una sesión de clase: ¿qué competencias crees tener como estudiante?, ¿y para desenvolverte en la sociedad?, ¿qué competencias estimas que más demanda la sociedad actual?, ¿y tu ámbito laboral?. Las cuestiones han sido respondidas por el $85 \%$ de la muestra, ya que en torno al $15 \%$ no acuden habitualmente a clase. Los estudiantes se encuentran identificados, por este orden, respecto a las competencias académicas: trabajo en equipo $(65 \%)$ y autoestima (61\%), situando la comunicación oral y escrita $(35 \%)$ y la creatividad o capacidad de aportar ideas innovadoras $(28 \%)$ en la posición más baja. Resaltan que creen tener capacidad de trabajo (78\%), responsabilidad (68\%), amabilidad (63\%) y sinceridad (52\%) para desenvolverse en la sociedad. Respecto a las que demanda la sociedad, la capacidad de trabajo en equipo (87\%) 
sigue siendo la más valorada, seguida de la apariencia física (72\%), sociabilidad y responsabilidad (62\% en ambas). A partir de estos resultados, consideramos que el profesor puede ayudar a desarrollar tanto las competencias que han verbalizado como aquellas que conviene incorporar.

- Fase de desarrollo: Si como hemos visto, las competencias personales del coach son de gran importancia para lograr el éxito en la aplicación del coaching, no lo son menos las técnicas y herramientas utilizadas (Cantera, 2003). En esta experiencia subyace una pluralidad metodológica que prevé diversas situaciones de enseñanzaaprendizaje, diversas formas de agrupamiento y estrategias, que han permitido la coexistencia de distintos formatos de actuación docente, de actividades grupales e individuales, teóricas y prácticas. Entre las estrategias y técnicas aplicadas destacamos las siguientes:

- Las preguntas, por su carácter polifacético, permiten explorar lo que realmente importa al otro y le ayudan a resolver los interrogantes. Las preguntas poderosas permiten conocerse mejor, profundizar en creencias, limitaciones, potencialidades, e impulsan la toma de decisiones. El arte de preguntar implica poner en juego la participación, la opinión, la duda, el intercambio y la multiplicidad de alternativas (Cantera, 2003).

- Lecturas comentadas, aluden a reflexiones de teóricos o expertos en la materia, que son analizadas conjuntamente por el maestro y aprendiz, las cuales promueven la reflexión, el análisis y la discusión.

- Ejemplificaciones de casos reales, son situaciones educativas que ofrecen posibles soluciones ante un determinado hecho, cercano a la realidad; favorecen la retención, disparan la consciencia, posibilitan plantear alternativas diversas, fomentan la creatividad ante determinados problemas o situaciones.

- Las metáforas, integradas en los ejemplos, cuya idoneidad radica en su capacidad para actuar sobre el subconsciente, al incorporar sutilmente la comparación y permitir que el sujeto extraiga la parte con la que se encuentra más identificado.

- Líneas de tiempo, esta herramienta es muy útil, una vez se ha tomado conciencia de la necesidad de cambio. Fomenta la planificación, promueve la priorización de la acción y la satisfacción de ir avanzando, aspectos que demandan una continua retroalimentación. 
- Los mapas conceptuales, que permiten al estudiante organizar ideas, estructurar su pensamiento, acomodarlo a su peculiar modo de ver los contenidos y, de ese modo, fijar los aprendizajes y transferirlos a otros contextos y situaciones, consiguiendo así a comprender realmente y aprender significativamente.

El diseño y las técnicas utilizadas van en sintonía con la propuesta de Batt (2010), para quien el coaching atiende a un proceso diseñado y estructurado de aprendizaje apoyado en cuatro constructos básicos: conversaciones reflexivas, feedback positivo, proceso co-constructivo y apoyo emocional.

Queremos resaltar que la aplicación de las técnicas se ha realizado a la par que el desarrollo de la docencia, aprovechando las diversas situaciones de aprendizaje: lección magistral participativa, seminarios, sesiones prácticas y, fundamentalmente, la tutoría grupal.

\section{Valoración del proceso}

La aplicación de la técnica DAFO nos ha proporcionado un análisis estratégico de carácter cualitativo, que permite constatar las debilidades y amenazas, así como las fortalezas y oportunidades en los diferentes momentos del proceso.

Las Fortalezas detectadas son las siguientes:

- Se ha contado con la disponibilidad, motivación e interacción de las dos profesoras implicadas en este proyecto, a pesar de las dudas e interrogantes que han ido surgiendo, recogidas en un cuaderno de campo. La puesta en común de ideas y opiniones ha permitido reconducir las funciones asumidas, más orientadas a la docencia en los primeros momentos y más equilibradas con la función de ayuda, en la fase posterior (así lo manifiestan el 68\% de los alumnos).

- Las profesoras han logrado una mayor sintonía, a la hora de planificar actuaciones y llegar a acuerdos concretos con los estudiantes, reflejado en el cronograma consensuado. El 80\% de los estudiantes han elaborado el cuaderno de campo, incluso alumnos que no han asistido a las sesiones programadas.

- Los seminarios y tutorías grupales han tenido un peso significativo en el desarrollo del modelo. La asistencia y participación de los estudiantes ha sido mayor en los alumnos de Educación Infantil 
(92\%) que en los de Educación Física (63\%). Sin embargo, el nivel de autonomía e independencia de los segundos supera en un $20 \%$ al mostrado por los primeros.

Las Oportunidades están referidas a:

- La profundización sobre el tema y contraste de pareceres de las profesoras implicadas, les ha permitido conocer y situarse mejor en el coaching, como campo de estudio e investigación.

- El proceso seguido en esta experiencia ha supuesto una oportunidad para repensar el papel de la docencia y orientación universitaria y vincular el aprendizaje del alumno a las competencias contempladas en las guías docentes.

- Se ha posibilitado la realización de clases más atractivas. Un 90\% del alumnado ha reconocido, en la valoración final del proceso (mediante preguntas abiertas y tormenta de ideas), que la incitación a la verbalización y reflexión, así como la utilización de estrategias y recursos diferentes han alimentado su motivación hacia el aprendizaje (78\%), su autoconocimiento y autoestima (65\%) y preparación para su futuro profesional (61\%).

- En general, la aplicación del coaching ha supuesto una mayor implicación y responsabilidad de los estudiantes en el aprendizaje, ya así lo manifiestan dos tercios de los mismos.

Las Debilidades encontradas hacen alusión a:

- Falta y necesidad de coordinación con los profesores que imparten docencia con los mismos grupos, ya que actuaciones de esta índole requieren de un trabajo interdisciplinar y al unísono, a favor del desarrollo de competencias.

- No contar, en la mitad de las sesiones, con los espacios adecuados (bancadas fijas, dimensiones reducidas...), y en las clases presenciales con una franja horaria más amplia (horas seguidas), ha supuesto una limitación.

- Necesidad de elaborar y validar un instrumento que nos permita constatar la situación de partida con mayor profundidad y objetividad. Considerar los indicadores de la situación de llegada, con mayor precisión. Aspecto en el que actualmente estamos trabajando. 
- Respecto a los estudiantes, los resultados, a nivel de rendimiento, no se han podido constatar de forma objetiva, ya que es la primera vez que se aplica esta técnica. En un futuro, se prevé controlar, con mayor precisión, las variables que intervienen en la evaluación continua y en la calificación final.

- Resulta significativo que un tercio de los alumnos se haya pronunciado en contra de este modelo, ya que les resulta más cómodo seguir una enseñanza tradicional que asumir la responsabilidad y autonomía que conlleva este enfoque de aprendizaje (asistencia a seminarios y tutorías, realización de lecturas, participación...).

Las Amenazas percibidas aluden a:

- La principal resistencia proviene de las dudas que esta propuesta suscita, dado que todavía no es un modelo consistente y necesita de posteriores aplicaciones para lograr un mayor afianzamiento.

- En lo sucesivo, la resistencia puede venir de otros profesores, al negarse a participar en esta experiencia. El escaso reconocimiento que este tipo de acciones tiene en la Universidad hace que el profesorado se sienta reticente a incorporarse a las mismas.

- Dificultad de ajustar el cronograma al tiempo real. La diagramación de las actividades y el ajuste de los tiempos representa un problema complejo, debido a los imponderables que surgen durante el curso (reuniones, puentes, exámenes, etc.)

- El cambio de roles y el trabajo añadido que la aplicación de este modelo supone para el profesorado implicado, ya que los seminarios y tutorías (20 horas de seminarios, 6 horas por cada tutoría grupal y 12 grupos) se han realizado fuera del período lectivo.

\section{A MODO DE CONCLUSIÓN}

Avanzamos en este apartado una serie de conclusiones, como síntesis de las valoraciones presentadas en el epígrafe anterior.

A nivel general, cuando en la enseñanza universitaria se promueve en las jóvenes generaciones una predisposición positiva hacia el cambio, y paralelamente se aborda con los estudiantes el desarrollo de modelos innovadores, se consigue una mejor adaptación a tales cambios. 
La aplicación de este modelo piloto de coaching, por las dos profesoras implicadas ha resultado muy positivo, dado que los estudiantes han podido desarrollar y, al mismo tiempo, autoevaluar sus propias competencias. Se ha apreciado una mejora de 0,8 puntos (media actual $=7,1$ ), respecto a las calificaciones obtenidas en esta asignatura durante el curso pasado, pero al ser momentos y grupos distintos, resulta arriesgado generalizar que la mejora se deba a la aplicación del programa. Por parte de los estudiantes, un $74 \%$ reconocen que les ayudado a mejorar los resultados académicos.

Se ha conseguido estudiantes con un apreciable nivel de autoestima en ambos grupos (65\%), motivados e implicados en el proceso (78\%). Más de la mitad reconocen ser más eficaces en la resolución de problemas y en la toma de decisiones. Su modelo asertivo ha evolucionado al tener que intercambiar ideas y buscar soluciones conjuntas y cooperar con sus compañeros. En definitiva, estimamos que se ha contribuido al desarrollo de personas más competentes y mejor capacitadas para superar los obstáculos que van a encontrar a lo largo de su ciclo vital.

Se puede augurar que los estudiantes formados con este enfoque metodológico, no sólo serán capaces de asumir retos y solucionarlos, sino también de crear otros nuevos que generen posibilidades, iniciativas y les hagan crecer, seguir adelante y continuar aprendiendo durante toda su vida.

Pero la aplicación del coaching no ha resultado una tarea fácil. El proceso de implantación en las aulas universitarias requiere, entre otras cosas, que el profesorado tome conciencia de su transcendencia en el momento actual y se apoye en estos criterios: a) que el profesor cause impacto en el alumnado, no sólo por lo que sabe, sino porque es coherente, entusiasta, respetuoso y sabe escuchar; b) que utilice preguntas poderosas y potenciadoras que lleven al alumno a la búsqueda de soluciones, a reflexionar, contrastar opiniones y expresar emociones, favoreciendo su crecimiento personal y el afianzamiento de la autonomía y la capacidad de análisis; c) que evite los juicios de valor y analice las situaciones siempre en positivo y orientadas al futuro, desechando la profecía de autocumplimiento; d) que mantenga una escucha activa ante todas las aportaciones del alumnado, manifestando interés y reforzándole de forma verbal y no verbal; e) que promueva el diálogo y la libre participación del alumno en la generación de soluciones creativas, asumiendo los errores como una poderosa herramienta de aprendizaje.

Tanto el diseño como la aplicación del modelo ha propiciado interesantes debates entre las profesoras implicadas, no exentos de reflexiones y disquisiciones, con puntos de encuentro y desencuentro sobre el significado atribuido al coaching en el marco concreto de actuación. En este sentido, se 
estima que la apertura de este modelo a otros compañeros puede favorecer un cambio significativo e interdisciplinar en la tarea docente.

Tales reflexiones nos animan a profundizar más en el proceso de coaching, manejar nuevas publicaciones, al respecto, y conocer otras experiencias desarrolladas en contextos educativos. La realización de un estudio más exhaustivo que se pretende iniciar el curso próximo, con profesores y estudiantes de Grado, nos va a permitir diseñar una sólida metodología que promueva el desarrollo de competencias intra e interpersonales en las nuevas generaciones de maestros.

En suma, consideramos que el mundo universitario está viviendo un significativo cambio, y, como profesoras, no queremos vivirlo como meras espectadoras, sino como profesionales que apuestan por la mejora de la enseñanza superior, en general, y por la mejora de la acción docente en la actividad cotidiana del aula. La puesta en marcha de este modelo se ha debido a la voluntad y actitud favorable de las profesoras que han confiado en el potencial de sus estudiantes. El proyecto trata de responder a las nuevas exigencias del emergente Espacio Europeo de Educación Superior, fundamentalmente en el desarrollo competencias. Pero, desde nuestra perspectiva, tiene un mayor alcance; pretende formar a buenos profesionales de la docencia y ciudadanos que sean capaces de responder a las nuevas exigencias y demandas de la sociedad del siglo XXI. 


\section{REFERENCIAS BIBLIOGRÁFICAS}

Batt, E.G. (2010). Cognitive coaching: A critical phase in professional development to implement sheltered instruction. Teaching and Teacher Education, 26, 997-1005.

Bayón, F.; Cubeiro, J.C.; Romo, M.; Sainz, J.A. (2006). Coaching realmente. Madrid: Pearson Prentice Hall.

Bisquerra, R. (2008). Coaching. Un reto para los orientadores. Revista de Orientación Psicopedagógica, 19 (2), 163-170. .

Cajina, G. (2011). Coaching educativo: El salto de la enseñanza al aprendizaje. Recuperado de: http://www.educaweb. com/noticia/2011/03/14/coachingeducativo-salto-ensenanza-aprendizaje-14660.html

Cantera, J. (Coord.) (2003). Coaching. Mitos y realidades. Madrid: Pearson Prentice Hall.

Carril, J. (2008). Zen coaching: un nuevo método que funde la cultura oriental y occidental para potenciar al máximo tu vida profesional y personal. Madrid: Díaz de Santos.

Díaz, F. et al (2009). Aprender a aprender. México: Ángeles Editores.

Gordillo, M.V. (2008). Nuevas perspectivas en orientación: del counseling al coaching. Revista digital Orientación y sociedad. Recuperado de: http://www. scielo.org.ar/scielo.php?pid=S1851$88932008000100006 \&$ script $=$ sci_arttext

Haneberg, L. (2006). Fundamentos del coaching. Colección Formación y Desarrollo Barcelona: Gestión 2000.
Launer, V. (2007). Coaching: un camino hacia nuestros éxitos. Madrid: Pirámide.

Obiols, M. y Giner, A. (2011). El modelo educativo de Bolonia y competencias docentes. Aportaciones desde el coaching educativo. Univest. Recuperado de: http://dugi-doc.udg.edu/ bitstream/handle/10256/3726/321. pdf? sequence $=1$

Ramírez, M. y Vivas, D. (2005). Empowerment. Recuperado de: http:// www.monografias.com/trabajos21/empowerment/empowerment.shtml

Rodríguez Marcos, A. et al. (2011). Coaching reflexivo entre iguales en el Prácticum de la formación de maestros. Revista de Educación, 355, 355-379.

Saphier, J. y West L. (2010). How coaches can maximize student learning. Phi Delta Kappan, 91 (4), 46-50.

Sancho, J.M. y Correa, J.M. (2010). Cambio y continuidad en sistemas educativos en transformación. Revista de Educación, 352, 17-21.

Sperry, L. (1993). Working with Executives: Consulting, Counseling and Coaching. Individual Psychology, 49 (3), 257-267.

Teemant, A.; Wink,J. y Tira, S. (2010). Effects of coaching on teacher use of sociocultural instructional practices. Teaching and Teacher Education, 27, 683-693.

Whitmore, J. (2003). Coaching: El método para mejorar el rendimiento de las personas. Barcelona: Paidós. 


\section{PALABRAS CLAVE}

Coaching, competencias, orientación profesional, enseñanza superior, formación y desarrollo personal.

\section{KEYWORDS}

Coaching, skills, career counseling, higher education, training and personal development.

\section{PERFIL ACADÉMICO Y PROFESIONAL DE LOS AUTORES}

Beatriz Sánchez Mirón, Licenciada en Psicopedagogía, Maestra de Educación Infantil, Máster de Investigación en Educación, Máster en Recursos Humanos. Académico: Profesora Asociada del Departamento de Pedagogía de la Universidad de Valladolid. Escuela Universitaria de Educación de Palencia, trabajo que compagina como orientadora laboral. Líneas de investigación: métodos de innovación educativa, Prácticum, coaching, orientación y desarrollo personal.

Julia Boronat Mundina, Doctora en Ciencias de la Educación, Licenciada en Filosofía y Letras (Pedagogía) y Licenciada en Psicología. Profesora titular del Departamento de Pedagogía. Escuela Universitaria de Educación de Palencia. Subdirectora de prácticas y RR.HH. Profesora tutora de la UNED. Docencia en Maestro-Grado de Educación Infantil y Educación Primaria. Líneas de Investigación: docencia y orientación universitaria, Educación Infantil, Prácticum, investigación en el aula.

Dirección de los autores: Universidad de Valladolid Departamento de Pedagogía Escuela Universitaria de Educación. Palencia Avda./Madrid n. ${ }^{\circ}$ 44. C.P. 34004. Palencia E-mail: beasmir@pdg.uva.es jboronat@pdg.uva.es

Fecha Recepción del Artículo: 07. Julio. 2011

Fecha modificación Artículo: 24. Abril. 2012

Fecha Aceptación del Artículo: 05. Junio. 2012

Fecha de Revisión para publicación: 24. Junio. 2013 


\title{
LA ESCUELA 2.0: LA PERCEPCIÓN DEL DOCENTE EN TORNO A SU EFICACIA EN LOS CENTROS EDUCATIVOS DE LA RIOJA
}

\section{(SCHOOL 2.0: TEACHERS' PERCEPTION TOWARDS ITS EFFICACY IN LA RIOJAS' SCHOOLS)}

\author{
Raúl Santiago Campión y Fermín Navaridas Nalda \\ Universidad de La Rioja \\ Charo Reparaz Abaitua \\ Universidad de Navarra
}

DOI: 10.5944/educxx1.17.1.10713

\section{Cómo referenciar este artículo/How to reference this article: \\ Santiago Campion, R.; Navaridas Nalda, F. y Repáraz Abaitua, R. (2014). La escuela 2.0: La per- cepción del docente en torno a su eficacia en los centros educativos de La Rioja. Educación XX1, 17 (1), 243-270. doi: 10.5944/educxx1.17.1.10713}

Santiago Campion, R.; Navaridas Nalda, F. y Repáraz Abaitua, R. (2014). School 2.0: Teachers' perception towards its efficacy in La Riojas' schools. Educación XX1, 17(1), 243-270. doi: 10.5944/ educxx1.17.1.10713

\section{RESUMEN}

En este artículo se presentan los resultados más relevantes de una investigación centrada en el análisis del Programa Escuela 2.0 en los centros educativos de La Rioja. Entre otros objetivos, se pretende conocer qué recursos de la Escuela 2.0 se utilizan con mayor frecuencia en la realidad educativa investigada, cual es su sentido en los procesos de enseñanza y aprendizaje, la percepción docente con relación a su eficacia en los procesos educativos del centro, así como la opinión del profesorado sobre su propia formación docente para una integración curricular efectiva de estos recursos en los centros donde desarrollan su práctica educativa.

Para llevar a cabo la investigación se ha considerado conveniente adoptar un enfoque metodológico de carácter cuantitativo, desarrollado mediante un procedimiento de encuesta online dirigido a todo el profesorado de enseñanza no universitaria de La Rioja.

A grandes rasgos, los resultados vienen a confirmar los datos obtenidos por otros autores en investigaciones similares realizadas en otros contextos educativos. En este sentido, cabría destacar la necesidad formativa sentida por el profesorado investigado con relación a los aspectos pedagógicos de las tec- 
nologías de la información y la comunicación (en adelante TIC). No obstante, como reflexión final y prospectiva del estudio, nos inclinamos a pensar que la eficacia de los recursos de la Escuela 2.0 en los procesos educativos del centro no puede quedar supeditada simplemente a la competencia y actuación del profesor, sino también a la situación y al contexto singular donde se desarrolla la acción didáctica, así como al conocimiento y la competencia tecnológica de los propios estudiantes. Desde esta perspectiva, se abren nuevos campos de estudio que complementen, amplíen y enriquezcan este trabajo.

\section{ABSTRACT}

This article presents the most relevant results of a study, which analyzes the results of the Program 2.0 School in La Rioja's Educational Institutions. Among other relevant aims, we wanted to know which ICT resources are most used, which purpose teachers follow when they use them in the context of the teaching-learning process, teacher's perception about their effectiveness and also their opinions about their own training.

In order to carry on this research we decided to adopt a quantitative methodological framework, developed through an online survey, which was sent to all non-university teachers of La Rioja Autonomus Region.

In general terms, obtained results confirm other author's conclusions in similar studies developed in other educational contexts. Regarding this point, we should mention the need of an effective training declared by the teachers, especially related with the pedagogical aspects. We should also stress that the effectiveness of the Programs 2.0 School cannot simply depend on the teacher's competence and intervention, but also both the singular educational context and the didactical action, should be taken into account. From this point of view, new study fields, which complement, expand and enrich this study, are opened.

\section{INTRODUCCIÓN}

Son muchos los trabajos e investigaciones en materia educativa (UNESCO, 1998, 2004, 2008; Instituto de Evaluación, 2009, 2010; Duart y Repáraz, 2011) donde se pone de relieve el gran potencial didáctico de las TIC para promover la innovación y mejora continua de la educación en general. En el caso concreto de nuestro Sistema Educativo, para que los centros pudieran explotar al máximo los beneficios de las TIC a favor de la calidad de los procesos de enseñanza y aprendizaje, el MEC puso en marcha de forma coordinada con los diferentes gobiernos autonómicos el Programa Escuela 2.0 ${ }^{1}$. Entre sus principales objetivos se encuentra el de garantizar a los estudiantes y profesores de la educación básica el suficiente acceso a las tecnologías digitales, así como la conectividad a Internet y la 
interconectividad dentro del aula. Objetivo fundamental éste para conseguir que los principios y fines de la educación en nuestro país se conviertan en una realidad: en síntesis, que todos los estudiantes alcancen los máximos niveles de desarrollo y aprendizaje posible en todas sus dimensiones (LOE, arts. 1 y 2) ${ }^{2}$. En este sentido, es conveniente recordar que la Ley concibe la Competencia de Tratamiento de la Información y Competencia Digital como un aprendizaje básico para que los estudiantes al finalizar la enseñanza obligatoria puedan «ejercer la ciudadanía activa, incorporarse a la vida adulta de manera satisfactoria y ser capaces de desarrollar un aprendizaje permanente a lo largo de su vida» ${ }^{3}$.

La integración curricular de algunas de esas tecnologías denominadas por Cabero (2009) como educación 2.0 (hablamos, por ejemplo, de wikis, redes sociales, podcast, blogs, YouTube, Picasa) supone necesariamente la adopción de un nuevo enfoque en el modo de organizar y gestionar la actividad didáctica en el aula. Desde esta nueva perspectiva, se tiene la convicción fundamentada de que los estudiantes no son meros receptores pasivos de información, sino que son protagonistas activos en la construcción de su conocimiento (elaboran, organizan, transforman, evalúan e interpretan el material de aprendizaje). La enseñanza en este caso es cooperación e intercomunicación, supone creatividad y flexibilidad, ofrece perspectivas distintas, proporciona ayuda y herramientas para la indagación, el descubrimiento, el aprendizaje cooperativo, autónomo y permanente a lo largo de toda la vida (Navaridas, 2004).

En este escenario el profesor adquiere un papel de suma relevancia e importancia. Él es el agente responsable de hacer efectiva la integración curricular de estas tecnologías, de dar respuesta a las nuevas exigencias y necesidades sociales en materia de aprendizaje, de contribuir desde la propia acción al cambio y la mejora continua del proceso educativo. Por eso, parece lógico que el Programa Escuela 2.0 contemple entre sus directrices principales de intervención la formación del profesorado tanto en los aspectos tecnológicos como en los aspectos metodológicos y sociales de la integración de estos recursos en su práctica docente cotidiana.

Sin embargo, y a pesar de los esfuerzos realizados por la Administración educativa en esta dirección, se platean muchas dudas sobre la pertinencia y la eficacia de la formación del profesorado en TIC. Y se tiene la sensación fundamentada (Sigalés, Mominó, Meneses y Badia, 2008) de que no existen los recursos, los mecanismos de control y el apoyo suficiente para hacer efectivo el proceso de cambio educativo sobre la base de las nuevas herramientas tecnológicas. Desde este planteamiento, cabría preguntarse por la situación actual de las TIC en los centros educativos de nuestro entorno más cercano: ¿Cuáles son los recursos tecnológicos más frecuentes 
en nuestros centros educativos? ¿Para qué los utilizan los profesores? ¿Qué opinión tiene este colectivo profesional con relación a su propia formación en TIC? ¿De las necesidades y modelos formativos? ¿Y de la eficacia de las TIC en la mejora de los procesos educativos del centro?

En términos generales, estas cuestiones constituyen el problema objeto de este estudio. Nos parece interesante aproximarnos al conocimiento de nuestra realidad educativa desde el punto de vista de los profesores que la protagonizan, con el ánimo final de poder establecer propuestas de mejora. Para ello, hemos adoptado un enfoque de investigación descriptiva mediante el procedimiento de encuesta al profesorado. En este sentido, cabría destacar que el interés del trabajo no se queda en la mera descripción de los recursos tecnológicos utilizados en la realidad educativa analizada, sino que el cuestionario administrado aborda aspectos más complejos como las necesidades y la autoeficacia percibida de las TIC en relación con los procesos educativos del centro donde desarrolla su trabajo docente.

\section{ANTECEDENTES Y ESTADO ACTUAL DE LA CUESTIÓN: LA ESCUELA 2.0}

Desde los años 80 tanto el Gobierno central de nuestro país como las distintas administraciones de las CCAA han ido implementando diferentes programas, iniciativas y leyes en relación con la incorporación de las TIC a las aulas escolares (Martín, 2011). Es incuestionable el interés de los gobiernos por atender a esta demanda de la sociedad de la información y la comunicación; ahora bien lo que no está tan claro es que estas medidas hayan ido suficientemente acompañadas de medidas específicas de formación del profesorado. El último de dichos programas es el denominado Proyecto Escuela 2.0, enmarcado dentro del concepto más global la denominada «Web 2.0»(Santiago y Navaridas, 2012).

El Programa Escuela 2.0 es un proyecto de integración de las Tecnologías de la Información y de la Comunicación en los centros educativos, que contempla el uso personalizado de un ordenador portátil por parte de cada alumno. El objetivo supone poner en marcha las aulas digitales del siglo XXI, aulas dotadas de infraestructura tecnológica y de conectividad.

El programa Escuela 2.0 se basa en los siguientes ejes de intervención (Pérez, 2011):

- Aulas digitales. Dotar de recursos TIC a los alumnos y a los centros: ordenadores portátiles para alumnado y profesorado y aulas digitales con dotación eficaz estandarizada. 
- Garantizar la conectividad a Internet y la interconectividad dentro del aula para todos los equipos. Posibilidad de acceso a Internet en los domicilios de los alumnos en horarios especiales.

- Promover la formación del profesorado tanto en los aspectos tecnológicos como en los aspectos metodológicos y sociales de la integración de estos recursos en su práctica docente cotidiana.

- Generar y facilitar el acceso a materiales digitales educativos ajustados a los diseños curriculares tanto para profesores y profesoras como para el alumnado y sus familias.

- Implicar al alumnado y a las familias en la adquisición, custodia y uso de estos recursos.

Este proyecto, que inició el Ministerio de Educación en colaboración con las diferentes Comunidades Autónomas en 2009, entre otras La Rioja, sostiene que en la actualidad ya son casi 500.000 los alumnos que disponen de un ordenador portátil, cerca de 20.000 las aulas dotadas con tecnología digital y alrededor de 1.000.000 los profesores que han recibido la formación especializada para adaptar su labor docente al uso didáctico de las TIC (MEC, noviembre de 2010). El objetivo del Programa (2009-2013) es transformar las aulas convencionales de educación primaria y secundaria, públicas y concertadas, en aulas digitales.

Un aula digital, en principio, debería permitir al profesor:

- Atender individualmente al alumno en sus dificultades concretas al tiempo que el resto de la clase trabaja;

- Compaginar la clase magistral con una dinámica más centrada en el trabajo del alumno y en la adquisición de competencias;

- Completar el estudio y aprendizaje individual de los alumnos con el trabajo en equipo, es decir, con formas de aprender colaborativamente;

- Conseguir una mayor participación de los alumnos en clase, unos alumnos más activos aprendiendo;

- Mejorar el control del rendimiento de cada alumno, de su ritmo de aprendizaje y de sus dificultades y con ello una evaluación más objetiva; 
- Aumentar la implicación de los padres en los aprendizajes de los hijos al facilitarles los procesos de comunicación;

- Atender a la diversidad de alumnos con distintos niveles de capacidad intelectual, de intereses y motivaciones que conforman un aula.

En definitiva, centrar más el proceso de enseñanza en el aprendizaje del alumno; más que en lo que el profesor sabe, en lo que el alumno necesita aprender.

Sin embargo, como se pone de relieve en algunas investigaciones llevadas a cabo bajo esta perspectiva educativa (Reparaz, Sobrino, Molinos, Carceller, Baraibar y Lara, 2003; Valverde, Garrido, y Sosa, 2010, Santiago y Andía, 2012), parece necesario potenciar la formación didáctica del profesorado en TIC para hacer efectivo este cambio (Domingo y Marqués, 2013). En esta misma línea de trabajo, una investigación realizada en centros de primaria y secundaria de distintas comunidades autónomas españolas sobre cómo incorporan las TIC los distintos agentes educativos y qué hacen con ellas (Sigalés, Mominó, Meneses y Badia, 2008 y en la misma línea, mas recientemente, Hramiak y Boulton, 2013), corroboran esta necesidad formativa en el profesorado mediante resultados como los que siguen:

- Las competencias del profesorado en el uso específico de las TIC en los procesos de enseñanza y aprendizaje presentan un nivel de desarrollo sensiblemente menor que en gestión o apoyo y preparación de las clases.

- Menos de la mitad del profesorado (el 43,7\%) cree que sus competencias docentes con las TIC le permiten aprovechar en alto grado el potencial educativo de estas tecnologías.

- Si bien una gran mayoría (82\%) se considera muy capacitada para localizar en internet recursos para preparar sus clases, solamente un 61,4\% sabría identificar cuáles son las situaciones de enseñanza y aprendizaje más apropiadas para utilizar las TIC.

- La capacidad para desarrollar proyectos multimedia con los alumnos, para supervisar grupos de trabajo en línea o para crear recursos digitales que sean útiles para la asignatura sólo está al alcance de una minoría.

- Sólo un tercio de ellos las percibe como un instrumento para la innovación didáctica y metodológica. 
- Solamente un 36,8\% del profesorado cree que las características funcionales de las TIC, y el tipo de actividades que potencialmente pueden fomentar, se adaptan bien a las prioridades curriculares y educativas establecidas en su centro docente.

- Además, una gran parte de la comunidad escolar no cree que la utilización de las TIC como herramientas para el estudio y el aprendizaje mejore los resultados escolares.

En este mismo sentido De Pablos, Colás y González (2010), opinan que si bien es cierto que las políticas educativas emprendidas para potenciar las TIC en los centros educativos están incrementando el uso efectivo de las TIC en el currículo escolar, las innovaciones pedagógicas que se desarrollan con ellas no se han generalizado. Al analizar los factores que los centros innovadores reconocen que favorecen y condicionan un uso innovador de las TIC, señalan que tanto la disponibilidad de recursos como la actitud positiva de los docentes y el equipo directivo son los factores más relevantes.

Los resultados obtenidos por Area (2010) en un estudio sobre centros de educación infantil, primaria y secundaria de Canarias, en líneas generales, son similares a estudios realizados en otros contextos internacionales. Las conclusiones según el autor indican que si bien las TIC incorporan algunos cambios organizativos en el centro y en el aula, no se da necesariamente una innovación pedagógica en las prácticas docentes. Las TIC se siguen incorporando a las aulas en unos contextos de enseñanza-aprendizaje convencionales.

García-Valcárcel y Tejedor (2010), también reconocen que la mera dotación de infraestructuras y recursos informáticos en los centros no es suficiente para que se produzca una verdadera integración de las TIC en la práctica escolar y proponen como pautas para mejorar los procesos de integración de las TIC en la acción docente, desde cuestiones tan concretas como el implicar al mayor número de profesores del centro en los proyectos de innovación o facilitar el trabajo entre profesores de diferentes centros, hasta el esforzarse colectivamente por analizar la repercusión que el uso de las TIC puede suponer en la mejora del rendimiento, o el asumir la integración de las TIC como una oportunidad para replantearse la práctica docente en la búsqueda de una enseñanza más acorde con los tiempos.

Por su parte Marqués (2010) aporta algunos datos relevantes sobre el uso de las TIC por el profesorado no universitario; así afirma que en general el profesorado tiene acceso a ordenadores e Internet en el centro y en casa $(92 \%)$ y los usa con frecuencia para tareas personales y profesionales 
( $81 \%$ en casa y $66 \%$ en el centro - alrededor de un $45 \%$ lo usa cada día-). El $62 \%$ de los profesores afirman tener una cierta formación TIC y que el $27 \%$ ha participado en cursos online. La formación básicamente es ofimática $(81 \%)$ y metodología didáctica (56\%) pero en ambos casos solo un $20 \%$ se siente seguro; por ello un $84 \%$ pide más formación metodológica y alrededor de un 65\% técnica (multimedia, telemática, ofimática...)».

Una reciente investigación con profesores implicados en el Proyecto Escuela 2.0 (25 maestros de quinto y sexto de Primaria) de diferentes centros escolares de Sevilla (Rodríguez Vega, Thuiller, Suárez y Carmona, 2010), aporta los siguientes resultados:

1. Un $12 \%$ de los profesores en la actualidad no conocen el proyecto Escuela 2.0, y un 8\% no está implicado en el mismo.

2. Más de la mitad de los encuestados afirman no haber recibido formación específica sobre el proyecto, además el 44\% opinan que no existe un nivel de competencia adecuado para llevar a cabo el proyecto.

3. Los profesores utilizan las TIC para: búsquedas en internet el 48\%; power-point el 52\%; programas/juegos educativos el 56\%; procesador de textos el 76\%; cálculos matemáticos el $40 \%$ y un $8 \%$ no contesta.

En el informe realizado por la consultora McKinsey \& Company «Cómo hicieron los sistemas educativos con mejor desempeño del mundo para alcanzar sus objetivos» (Barber y Mourshed, 2007) se planteaba el porqué algunos sistemas educativos tienen un mejor desempeño y mejoran con más rapidez que otros. Para ello estudiaron 25 sistemas educativos de todo el mundo, después de conocerse los resultados de la tercera versión de las prueba PISA, incluidos diez de los sistemas con mejor rendimiento. Analizaron qué tienen en común estos sistemas y cuáles son las herramientas que emplean para mejorar los resultados de sus alumnos. Los resultados ponen de manifiesto que los sistemas educativos más exitosos resaltan la importancia de tres aspectos: 1) conseguir a las personas más aptas para ejercer la docencia, 2) desarrollarlas hasta convertirlas en instructores eficientes, y 3) garantizar que el sistema sea capaz de proporcionar la mejor instrucción posible a todos los niños.

Estos resultados nos tienen que hacer reflexionar muy seriamente sobre la naturaleza de la formación inicial y permanente del profesorado en relación con una integración curricular eficaz de las TIC en las aulas, que sigue siendo la piedra angular de toda reforma educativa. 


\section{FINALIDAD Y OBJETIVOS DE LA INVESTIGACIÓN}

Con esta investigación pretendemos aproximarnos al conocimiento de la situación actual de la llamada Escuela 2.0 en la Comunidad Autónoma de La Rioja, tratando de descubrir claves a partir de las cuales mejorar su integración curricular en la realidad educativa investigada. De modo más concreto, nos proponemos:

1. Definir el perfil general del profesorado que utiliza con mayor frecuencia los recursos de la Escuela 2.0 (edad, género, ámbito de conocimiento, etc.).

2. Identificar las TIC disponibles en los centros educativos y la frecuencia con que las utilizan, así como las posibles relaciones existentes en función de las variables relativas al perfil general del profesorado y del contexto educativo investigado (tipo de centro, titularidad, enseñanzas ofertadas, etc.).

3. Conocer para qué tareas docentes utilizan los profesores las TIC, así como las creencias de su eficacia en el desarrollo de los procesos educativos.

4. Conocer la percepción que tiene el profesorado con relación a su capacitación para el uso didáctico-educativo de las TIC.

5. Valorar la opinión del profesorado acerca de sus necesidades formativas para una integración curricular efectiva de las TIC en sus centros educativos.

6. Conocer los modelos de formación docente que los propios profesores perciben como más eficaces para la integración curricular de las TIC en los centros educativos.

\section{DISEÑO Y METODOLOGÍA}

\section{Diseño de la investigación}

El diseño metodológico adoptado para llevar a cabo el estudio se aproxima a planteamientos interpretativos en investigación educativa, preocupados por conocer la realidad desde el punto de vista de los sujetos que la protagonizan. De acuerdo con el modelo propuesto por algunos de los autores que más han trabajado este enfoque metodológico (Biggs, 1978; Entwistle, 1981), el esquema básico de estudio contiene tres dimensiones relacionadas 
(entrada, proceso, producto) que incluyen a su vez las variables más relevantes y significativas de acuerdo con los propósitos de la investigación señalados.

El estudio empírico se basó en una metodología de encuesta. Por ello y para dar respuesta a los mencionados objetivos, se diseñó y distribuyó un cuestionario online entre los centros de infantil, primaria y secundaria públicos y concertados de la comunidad autónoma de La Rioja.

El proceso de muestreo fue el siguiente: Se invitó a participar a todos los centros educativos de la Rioja a partir del listado de centros que aparece públicamente recogido en la siguiente web: http://www.educarioja.org/educarioja/index.jsp?tab $=$ ifg \&acc $=$ cen

Esta constituyó la población objeto de estudio. Se puede comprobar que aunque son 186 los centros de la comunidad autónoma de la Rioja, se contó con 132 puesto que el resto de centros no disponía, en ese momento, de una dirección de correo electrónico. Por tanto, en este estudio se puede considerar que la población y la muestra son coincidentes y que la muestra final fue una muestra incidental, es decir, una muestra a la que se tuvo acceso.

A partir de aquí, se optó por enviar un correo electrónico a los directores de los centros (132 centros educativos) solicitándoles que lo remitiesen a la persona encargada de las TIC en el centro (generalmente al coordinador TIC). En total, se remitieron 132 correos electrónicos, de los cuales el servidor rechazó 4 por errores en la dirección de la cuenta.

La encuesta estuvo online durante casi dos meses (principios noviembrefinales diciembre 2011) y a lo largo de este periodo de tiempo se recogieron un total de 106 respuestas, es decir un 82,81\% del total de correos enviados, lo que supone casi el $83 \%$ de participación de la población objeto de estudio.

El cuestionario se diseñó y distribuyó mediante un sistema online de creación de encuestas ${ }^{4}$.

\section{El instrumento}

El cuestionario estaba constituido por 13 items con distintos tipos de preguntas, la mayor parte de ellas de valoración a través de una escala tipo Likert. Además, el cuestionario estaba estructurado en torno a 3 grandes dimensiones:

- Personales y contextuales (6 items): Variables genéricas como la edad, género, nivel educativo en el que se imparte docencia, materia, tipo de centro... 
- Procesales (4 items): Variables relacionadas fundamentalmente con el equipamiento disponible, los recursos utilizados y el grado de utilización de los mismos. La variable relativa al equipamiento fue, a su vez, desglosada en un listado de posibles recursos TIC. En este sentido, distinguimos tres grupos:

- Por un lado, los «recursos tradicionales», que quizá no podemos catalogar como de «nuevos», entre los que incluiríamos los paquetes ofimáticos, la navegación por la red, las aplicaciones para el tratamiento de recursos (imagen, sonido, video...), los sistemas operativos y las herramientas de autor (aplicaciones que permiten la creación de materiales didácticos digitales).

- Por otro lado podemos hablar de los «recursos basados en hardware», como las Pizarras Digitales Interactivas, los dispositivos móviles (Tabletpcs, mini-ordenadores, iPads...)

- Finalmente, podemos mencionar los denominados «recursos basados en la WEB 2.0» como los blogs, wikis, podcast y la utilización de plataformas tipo LMS como Moodle. Una visión más amplia de este descriptivo lo podemos apreciar más claramente en la figura 1.

En esta misma dimensión, también se incluía un ítem relacionado con el nivel de competencia percibido en cada uno de los recursos TIC mencionados.

- Resultantes (3 items): En lo relativo a las dimensiones resultantes, abordamos dos temas: por un lado, incluimos un ítem sobre la finalidad pedagógica en la utilización de las TIC en la educación, siendo éste uno de los temas más recurrentes en la investigación sobre la integración curricular de estas tecnologías (Balanskat, Blamire y Kefala, 2006; Condie y Munro, 2007; Wong, Li, Chol y Lee, 2008). No es objetivo de este estudio entrar a detallar las múltiples posibilidades didácticas de cada uno de los recursos TIC habituales en las aulas, pero puede ser interesante desglosar, a grandes rasgos, cuáles son las finalidades genéricas que los docentes persiguen al utilizar las TIC en el aula. Estas finalidades las hemos englobado en cinco grandes grupos: a) La motivación de los estudiantes, b) El aprendizaje individualizado y la atención a la diversidad, c) El aprendizaje autónomo: aprender a aprender, d) El aprendizaje social: colaborativo/cooperativo y e) La participación de las familias.

Por otro lado, otro factor determinante a la hora de lograr una adecuada integración curricular de las TIC es el relativo a la formación docente. 
En este sentido, preguntamos a los profesores participantes en el estudio que valorasen los tres factores que constituyen las bases de la formación en este área, como son la capacitación técnica, la capacitación didáctica y la relacionada con la gestión y organización de los recursos:

- Aspectos Técnicos: funcionamiento de los dispositivos y redes, configuración, conectividad, compatibilidad...

- Aspectos pedagógicos: integración curricular y coherencia con los objetivos conceptuales, procedimentales, actitudinales. Potencial didáctico de programas y herramientas...

- Aspectos organizativos: disposición de los recursos en el aula o fuera de ella, gestión de los sistemas (por ejemplo, los 2.0, Moodle)...

El cuestionario finalizaba con un ítem sobre el modelo formativo más adecuado a juicio de los docentes: online, presencial o mixto.

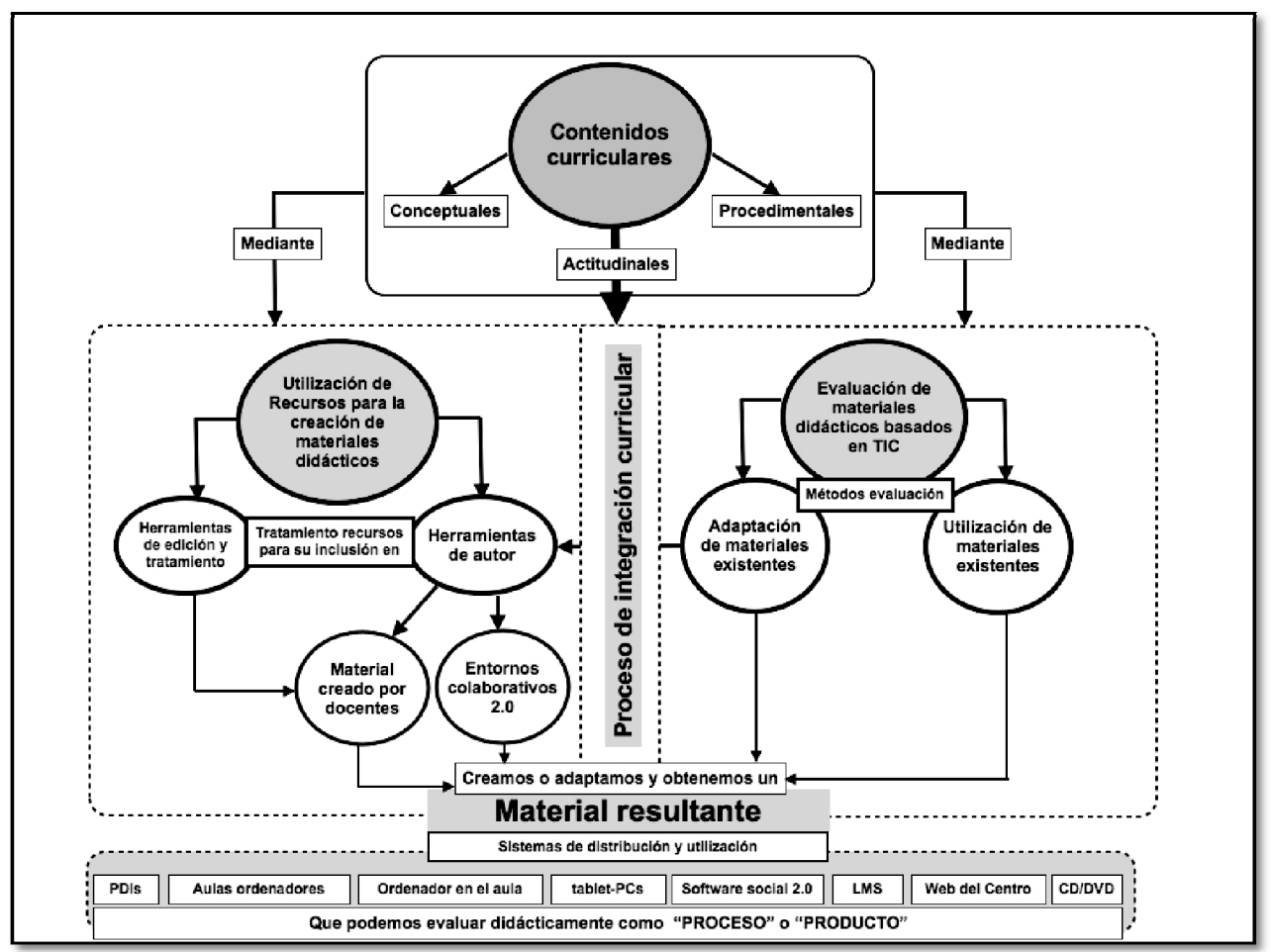

Figura 1. Recursos TIC en las escuelas (elaboración propia) 


\section{La muestra}

A continuación pasamos a describir la muestra definitiva del estudio que nos permite valorar el perfil del profesor.

Como hemos apuntado, la muestra participante en este estudio estuvo constituida por 106 docentes. Por sexo, respondió al cuestionario un 63\% de mujeres frente a un $37 \%$ de hombres.

En cuanto a la variable «edad», se observa que el número de docentes que participaron en el estudio aumenta cuanto menor es la edad de los profesores.

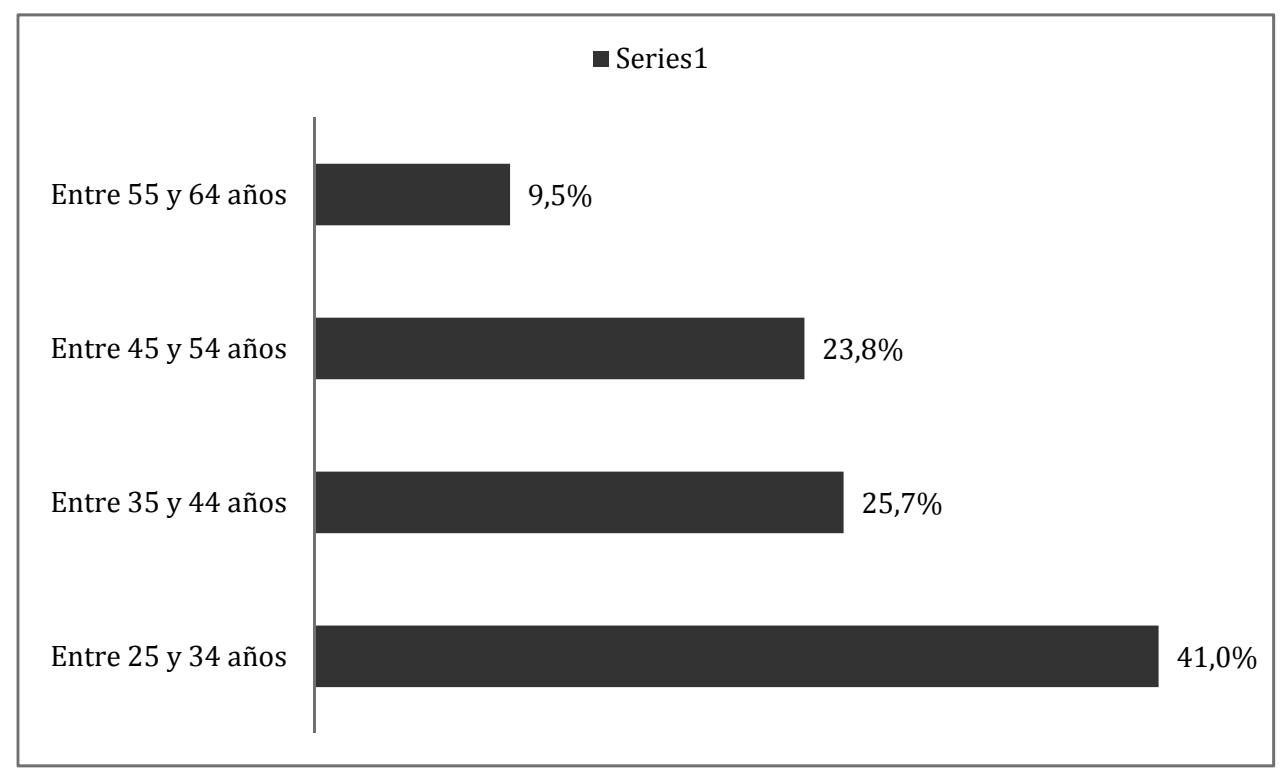

Gráfico 1. Composición de los participantes en el estudio por edad

En lo relativo al tipo de centro y su ubicación, la muestra se ha repartido casi al 50\%. Por su naturaleza: público el 51,4\% de la muestra y privado/ concertado el $48,6 \%$. Y por su ubicación: urbano el $57,7 \%$ de los centros y un $42,3 \%$ rural. Nos interesaba contar con una muestra amplia de centros con objeto de conocer si específicamente alguno de ellos mostraba particularidades en torno a la utilización de las TIC y de los recursos 2.0.

Por otro lado, hemos comprobado que también casi al 50\% se distribuyen entre profesores que pertenecen a centros en los que se desarrolla algún proyecto de innovación (53\%) frente a los que no lo hacen (47\%).

En el siguiente gráfico podemos apreciar la distribución de los participantes por el nivel educativo en el que desarrollan su actividad docente. 
En este sentido, los dos principales grupos han sido los docentes de Educación Primaria y los de Educación Secundaria Obligatoria (casi un 67\% entre ambos). Estos resultados son coherentes con la propia composición de centros y docentes en la estructura educativa de la Comunidad Autónoma de La Rioja.

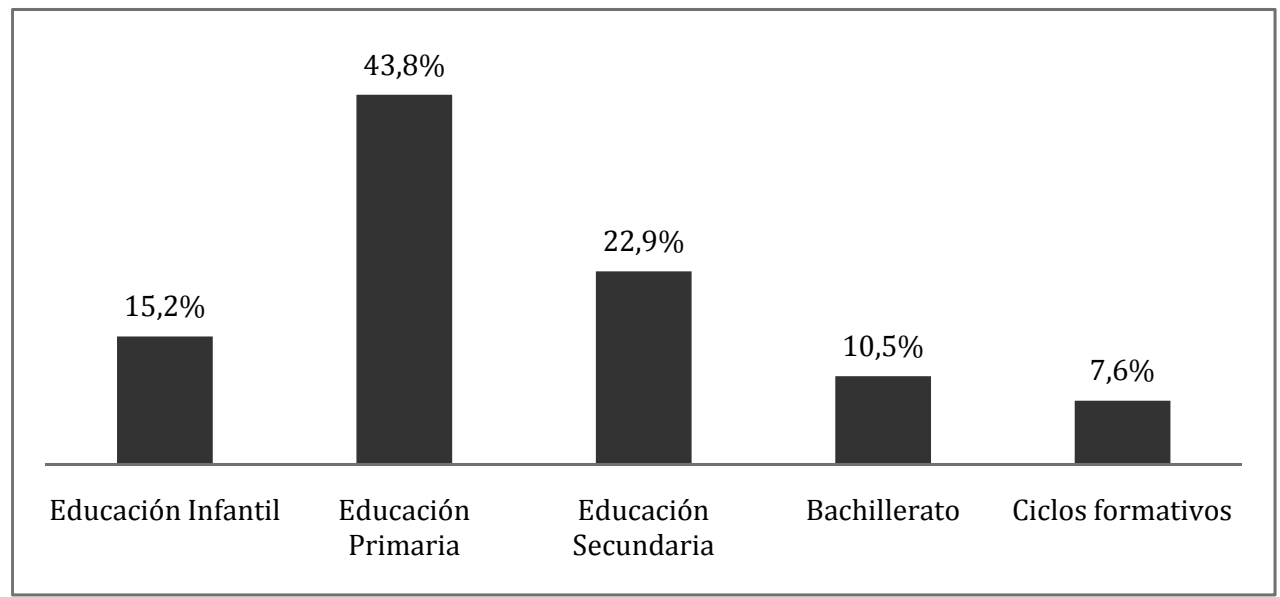

Gráfico 2. Distribución de la muestra por etapas educativas

Un último dato que nos interesa conocer es el tipo de materia o ámbito de conocimiento de los participantes en el estudio. Hay que dejar constancia de que en Educación Infantil y Primaria pueden convivir docentes generalistas y especialistas y en Educación Secundaria, Bachillerato y Ciclos Formativos solo existen especialistas. Aun así, creemos que este análisis también nos puede proporcionar datos relevantes sobre la utilización que se hace de los recursos TIC.

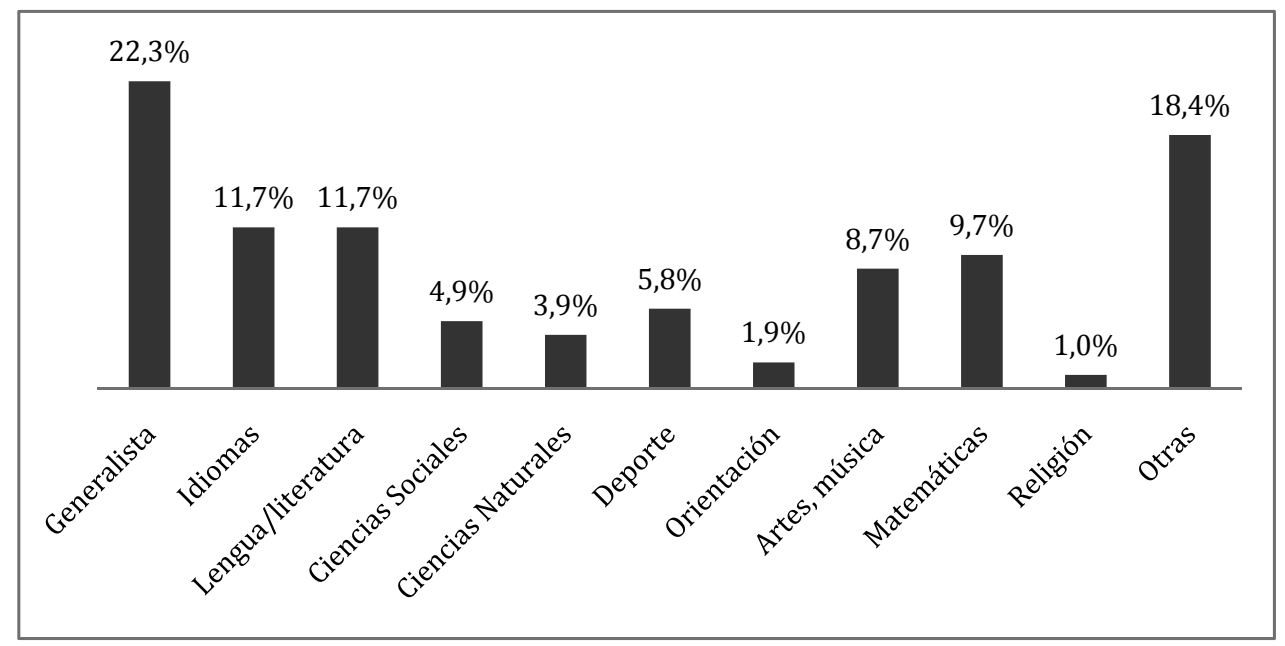

Gráfico 3. Distribución de la muestra por ámbito de conocimiento 


\section{ANÁLISIS DE LOS RESULTADOS}

\section{Ámbito y nivel de utilización de los recursos basados en TIC}

El primer objetivo del estudio consistía en conocer en cuál de los diferentes ámbitos de conocimiento se utilizan las TIC con mayor frecuencia. En este sentido, obviando la opción "generalista», parece ser que las materias donde más utilización se hace son: Idiomas (12,9\%), C. Sociales $(10,9 \%)$, Matemáticas (9,9\%), C. Naturales (8,9\%) y Artes/Música (7,9\%). Si adicionalmente, analizamos los usos que hacen los profesores de las TIC por materia y nivel o etapa educativa, nos encontramos con unos datos más precisos (gráfico 8): mientras que para Primaria son los Idiomas, las Ciencias Naturales y las Matemáticas, en Secundaria lo son la Lengua/Literatura, el Arte/Música y las Matemáticas y es llamativo el caso de Bachillerato, en el que solo se han seleccionado tres materias: las Ciencias Sociales, las Matemáticas y las Ciencias Naturales.

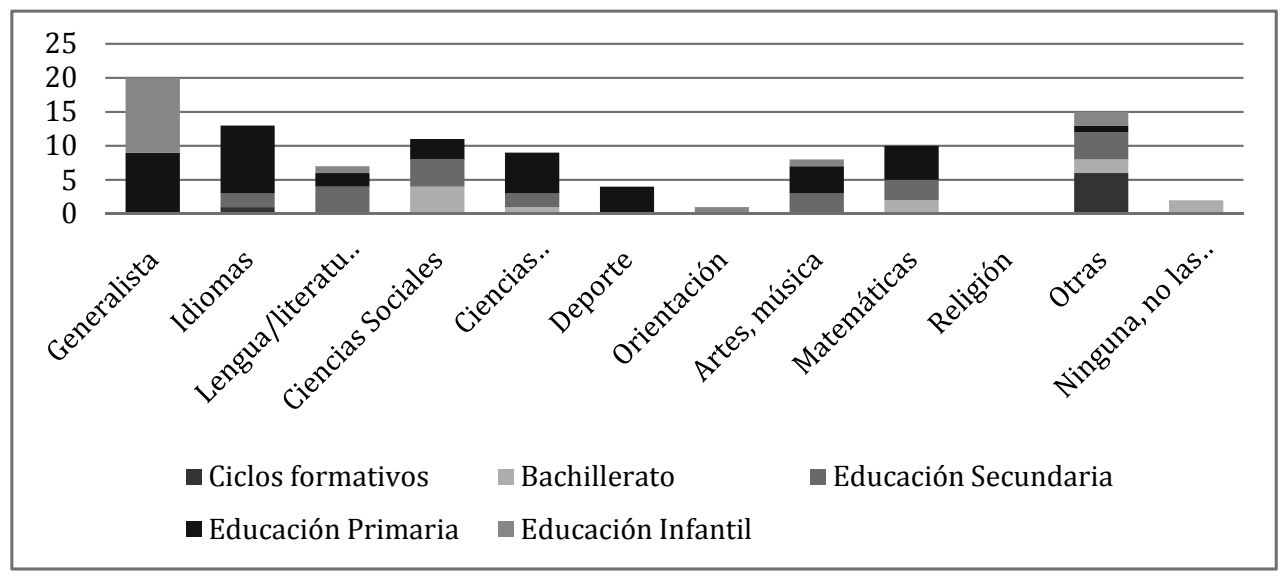

Gráfico 4. El uso de las TIC según la materia/ nivel educativo que se imparte

Otra información relevante a la hora de integrar las TIC es analizar si el hecho de pertenecer a un grupo de innovación educativa (por ejemplo, cualquiera de las iniciativas desarrolladas por las consejerías de educación de las comunidades autónomas), o el hecho de recibir algún tipo de ayuda por la adquisición de equipamiento, puede influir de alguna manera en su utilización. Para ello, preguntamos a los profesores del estudio si participaban en alguno de estos proyectos, para después, analizar la información en relación con las materias donde se utilizaban las TIC y también con el nivel educativo donde se imparte. En lo referido a esta segunda cuestión, los datos se equilibran casi al $50 \%$ ya que las diferencias entre los que utilizan las TIC, no varían sustancialmente por el hecho de pertenecer a un pro- 
yecto de innovación en ninguno de los niveles educativos analizados. Este argumento es igualmente válido en lo relativo al tipo de centro: público o privado.

En lo concerniente a la posible variabilidad por materias, serían los Idiomas y las Matemáticas las áreas curriculares potencialmente influenciadas por el hecho de pertenecer a un grupo de innovación. Por el contrario, las Ciencias Sociales y los docentes generalistas, serían los ámbitos curriculares en los que el uso de las TIC parece completamente ajeno a la pertenencia a un grupo de innovación.

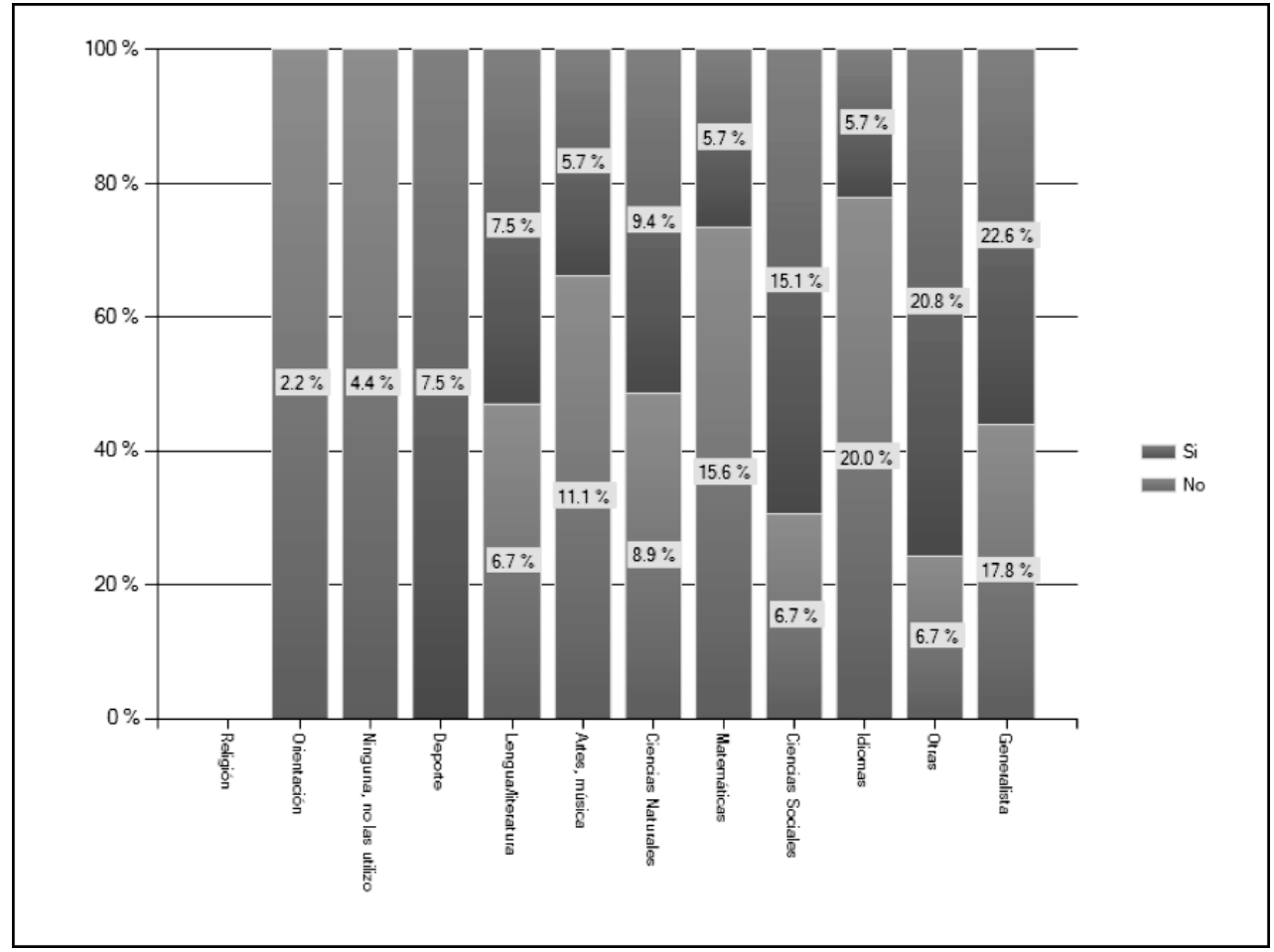

Gráfico 5. Uso de las TIC según materia y pertenencia a grupo de innovación

\section{Frecuencia en la utilización de los recursos TIC}

El segundo objetivo que nos planteamos tenía relación con el grado de utilización de los recursos TIC con objeto de conocer cuáles son los más demandados y cómo se utilizan. Para ello, hemos realizado una selección de los normalmente más utilizados en los centros educativos (Figura 1) mediante una escala Likert de 5 niveles (nada-todo) y un valor adicional «no se cuenta con ese recurso». 
Comenzaremos por analizar los recursos no disponibles en los centros: entre ellos se destacan estos cuatro recursos que están cercanos al 20\% en todos los casos: a) Dispositivos de aprendizaje móvil, como tabletas, minipcs, iPad... (26,3\%), b) Proyectos de Radio y TV 2.0 (podcast, videocast, con un $24,2 \%)$, c) Pizarras Digitales Interactivas $(22,2 \%)$ y finalmente, d) Sistemas de aprendizaje online-LMS tipo Moodle $(18,4 \%)$. Estos mismos cuatro recursos son además, los menos utilizados, aun cuando se pueda disponer de ellos en los centros escolares, destacando los de radio y tv 2.0 y $L M S$, ambos cercanos al 50\% de nula utilización.

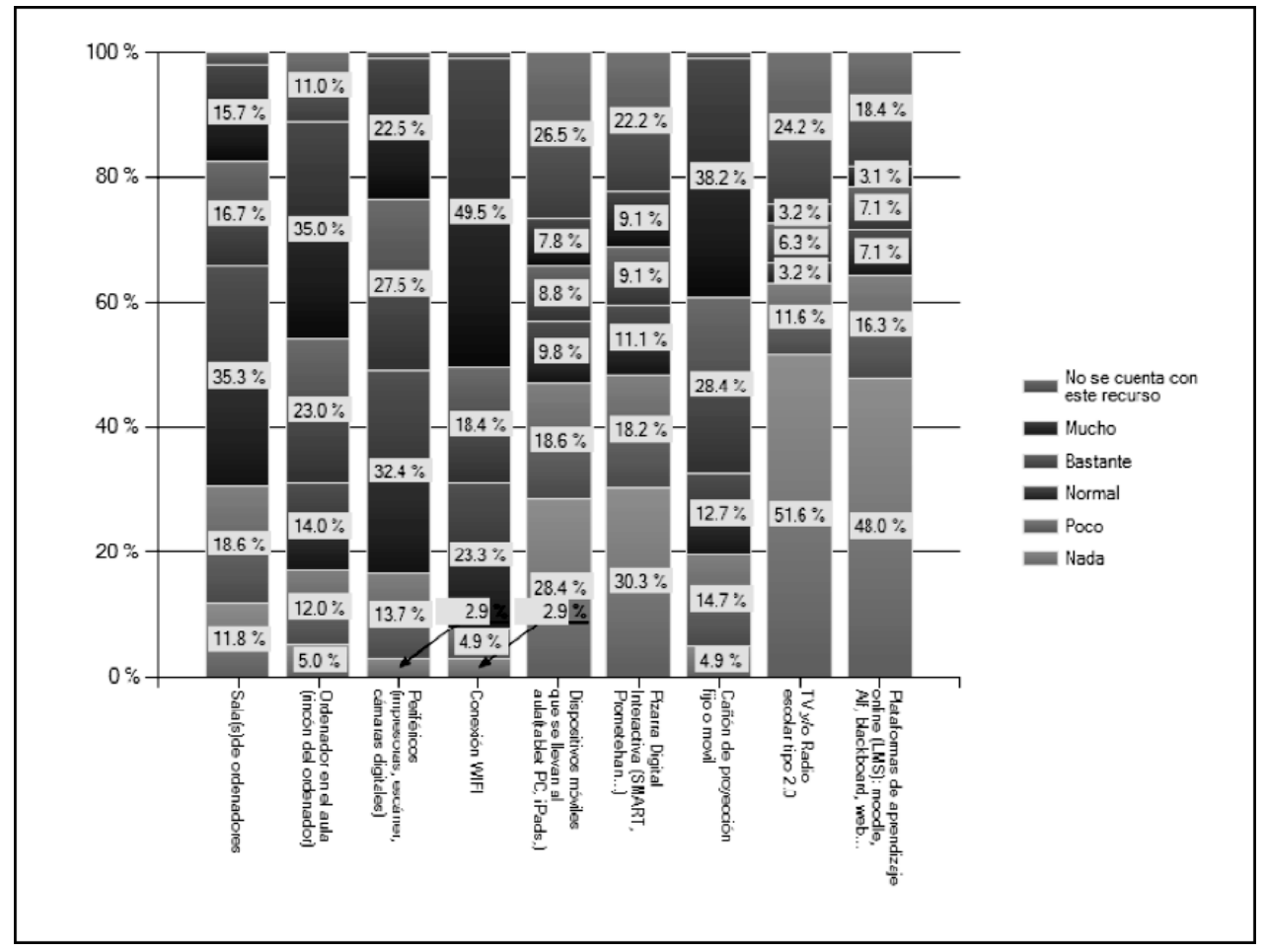

Gráfico 6. Disponibilidad y grado de utilización de los recursos TIC

En el polo opuesto, nos encontramos con aquellos recursos más empleados por los docentes. Entre ellos destacamos la utilización de la conexión WIFI (cercana al 50\%). Es preciso señalar que este tipo de conectividad no tiene necesariamente que ver con la acción didáctica en el aula, sino que en muchos casos se emplea para solucionar temas administrativos y de gestión: acceso a bases de datos de información genérica, documentación, servicios web del centro, etc. 
El segundo de los recursos más usados es el cañón de proyección $(38,2 \%)$, que puede constituir, por sí solo, un recurso tecnológico al servicio de la didáctica, pero que mejora sus prestaciones si se conecta a una PDI.

En tercer lugar nos encontramos con el «rincón del ordenador», es decir, un equipo que se ubica de modo permanente en el aula y que suele ser frecuente en las aulas de Infantil. Por último, con un 22,5\% encontramos la utilización de distintos periféricos (escáner, cámaras) que suelen ser utilizados como sistemas de captación, tratamiento o almacenamiento de diferentes tipos de recursos multimedia.

\section{Grado de utilización de los recursos TIC por nivel docente}

Creemos que puede ser interesante conocer los recursos más utilizados en cada contexto académico. Para ello, hemos cruzado ambas variables: tipo de recursos y nivel docente. En la gráfica de más abajo podremos analizar los datos en detalle, pero para una mayor claridad expositiva, los sintetizamos mediante una selección de los dos más utilizados en cada caso:

- Educación Infantil: Sala de ordenadores y rincón del ordenador (ordenador en el aula). Ambos cercanos al valor «4»

- Educación Primaria: Sala de ordenadores, rincón del ordenador y cañón de proyección. Se da por sabido que el equipamiento de esta etapa incorpora conjuntamente los dos últimos elementos mencionados (a ambos se les otorga un valor de 3,2 )

- Educación Secundaria: Sala de ordenadores, rincón del ordenador y cañón de proyección. Con un valor de 3,8 en el primer caso y 3,6 y 3,3 respectivamente en los dos siguientes.

- Bachillerato: Solo mencionaremos la sala de ordenadores que obtiene un valor de 3,6, mientras que el resto de recursos TIC no alcanza en ningún caso el «3». De hecho es el nivel educativo en el que los docentes manifiestan una menor utilización de las TIC en el aula.

- Ciclos formativos: Sala de ordenadores, ordenador en el aula y cañón de proyección. Es en los ciclos formativos donde más se integran las TIC, con niveles superiores incluso a los de Educación Infantil. 


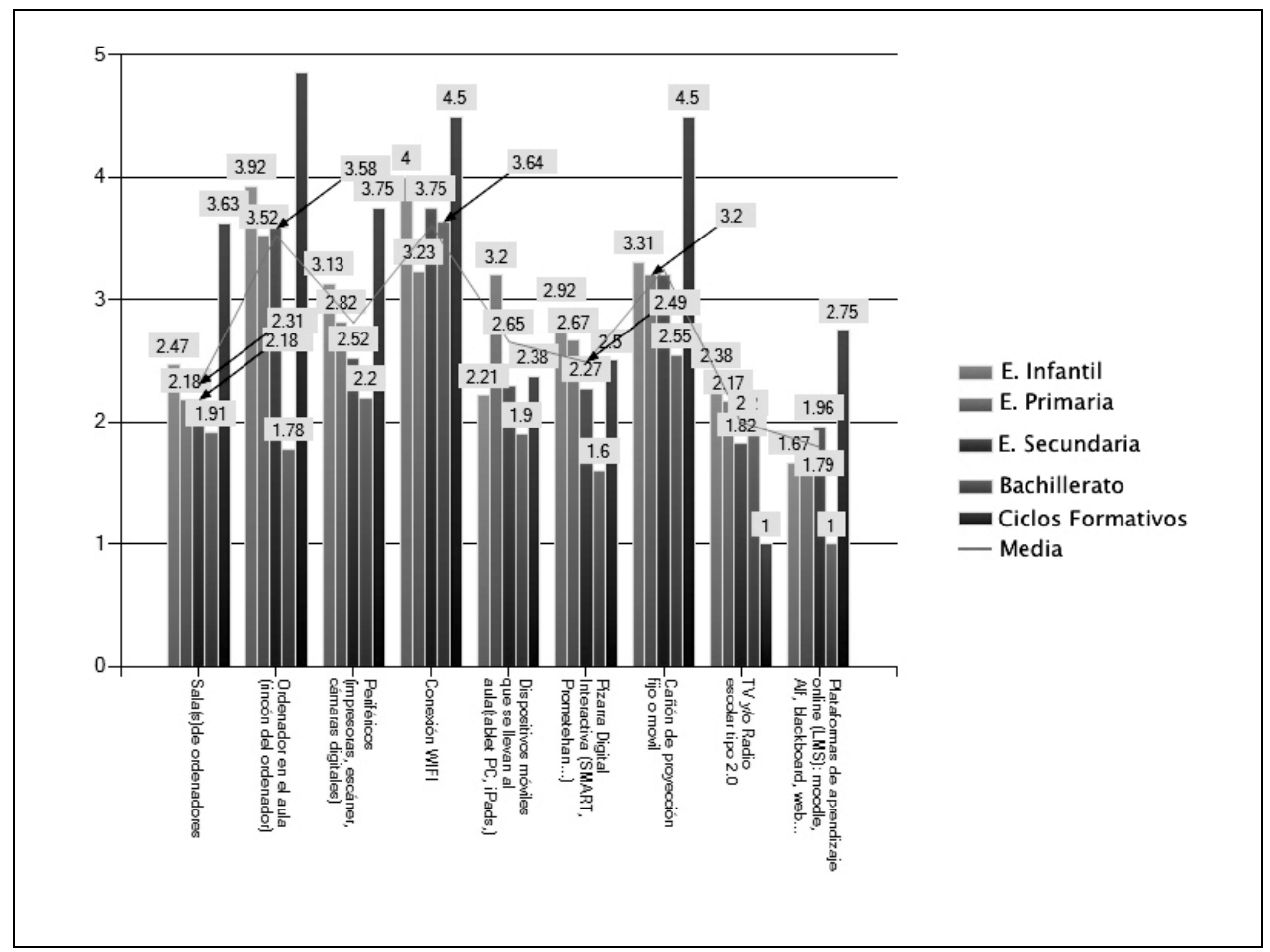

Gráfico 7. Utilización de recursos TIC y nivel escolar

\section{Finalidad en la utilización de los recursos TIC}

Abordemos ahora el tema de la finalidad en el uso de las TIC (objetivo 3 de la investigación). El análisis de los datos obtenidos nos muestra que es el incremento de la motivación de los estudiantes el proceso educativo más favorecido por uso de las TIC según los profesores. El fomento de la autonomía en el alumno $(2,7)$ y la atención a la diversidad $(2,6)$ son los dos siguientes procesos más desarrollados. Resulta un tanto sorprendente que el ítem propuesto "aprendizaje social, colaborativo-cooperativo» sea tan solo valorado con 2,1 puntos, cuando este tipo de proceso educativo es la finalidad sustancial de la Escuela 2.0 (recursos multimedia, podcast, blogs, wikis, plataformas como Moodle, etc.).

$\mathrm{Al}$ analizar estas finalidades perseguidas en función de los niveles educativos, observamos dos detalles significativos: por un lado, que no existen diferencias en función del nivel educativo según la finalidad en el uso de las TIC, es decir que para los profesores de las diferentes etapas educativas el uso de las TIC favorece los mismos procesos de aprendizaje. Por otro, que los docentes de los ciclos formativos son los que peor valoran los cinco 
procesos educativos propuestos. Por ejemplo, el objetivo de la «mejora de la motivación» lo valoran con una media de 2,5 frente al 3,1 de la muestra, o en el caso de la «atención a la diversidad» con un 1,6 frente al 2,6 de valor medio de la muestra. Hay que recordar que el volumen de profesores de este nivel participantes en el estudio era el menos numeroso.

(5)La participación con las familias

(4)El aprendizaje social: colaborativo/cooperativo

(3)El aprendizaje autónomo:aprender a aprender

(2)El aprendizaje individualizado: atención a la diversidad

(1)La motivación de los estudiantes

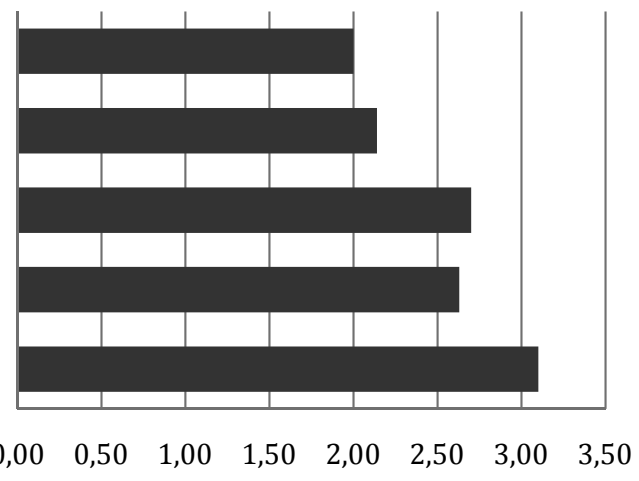

Gráfico 8. Finalidad en el uso educativo de las TIC

\section{Autovaloración del nivel de conocimiento de los recursos TIC}

El cuarto de los objetivos que queríamos abordar es el relacionado con el dominio que el propio docente manifiesta tener sobre los diferentes recursos TIC, lo que se traduce en las propias creencias del profesorado a la hora de integrar la tecnología en el aula.

En el gráfico 9 se puede apreciar con claridad cuál es la valoración que el docente hace del nivel de competencia que se atribuye a cada uno de los 3 grupos de recursos propuestos.

Los recursos «tradicionales», constituyen el grupo de recursos en los que los docentes manifiestan tener un mayor dominio: 54\% y 51\% respectivamente para el caso de ofimática e Internet. Sin embargo, tan solo un 10,5\% manifiesta dominar las herramientas de autor, aplicaciones que consideramos imprescindibles para cualquier docente que quiera integrar las TIC.

En el segundo de los casos nos referimos a dispositivos que están llegando a las aulas a través de los programas Escuela 2.0. Resulta sorprendente que a pesar de los recursos empleados, tanto en infraestructuras y formación, el $63 \%$ manifiesta un nivel de conocimiento catalogado como 
«poco» o «nada». Aún más bajas son las valoraciones obtenidas para el caso de los recursos basados en la web 2.0, siendo éste, no solo un conjunto de herramientas con un alto potencial didáctico, sino también un entorno habitual de relación y comunicación entre las generaciones de estudiantes del siglo XXI.

En este sentido, podemos catalogar los datos como de muy pobres: si tomamos como referencia los valores «poco»o «nada», nos encontramos que casi un 47\% valora en esos rangos su nivel de conocimiento-competencia en cuanto a las redes sociales, un 52\% para el caso de la web 2.0 (podcast, blogs, wikis...) y un $81 \%$ para el caso de plataformas tipo LMS como Moodle.

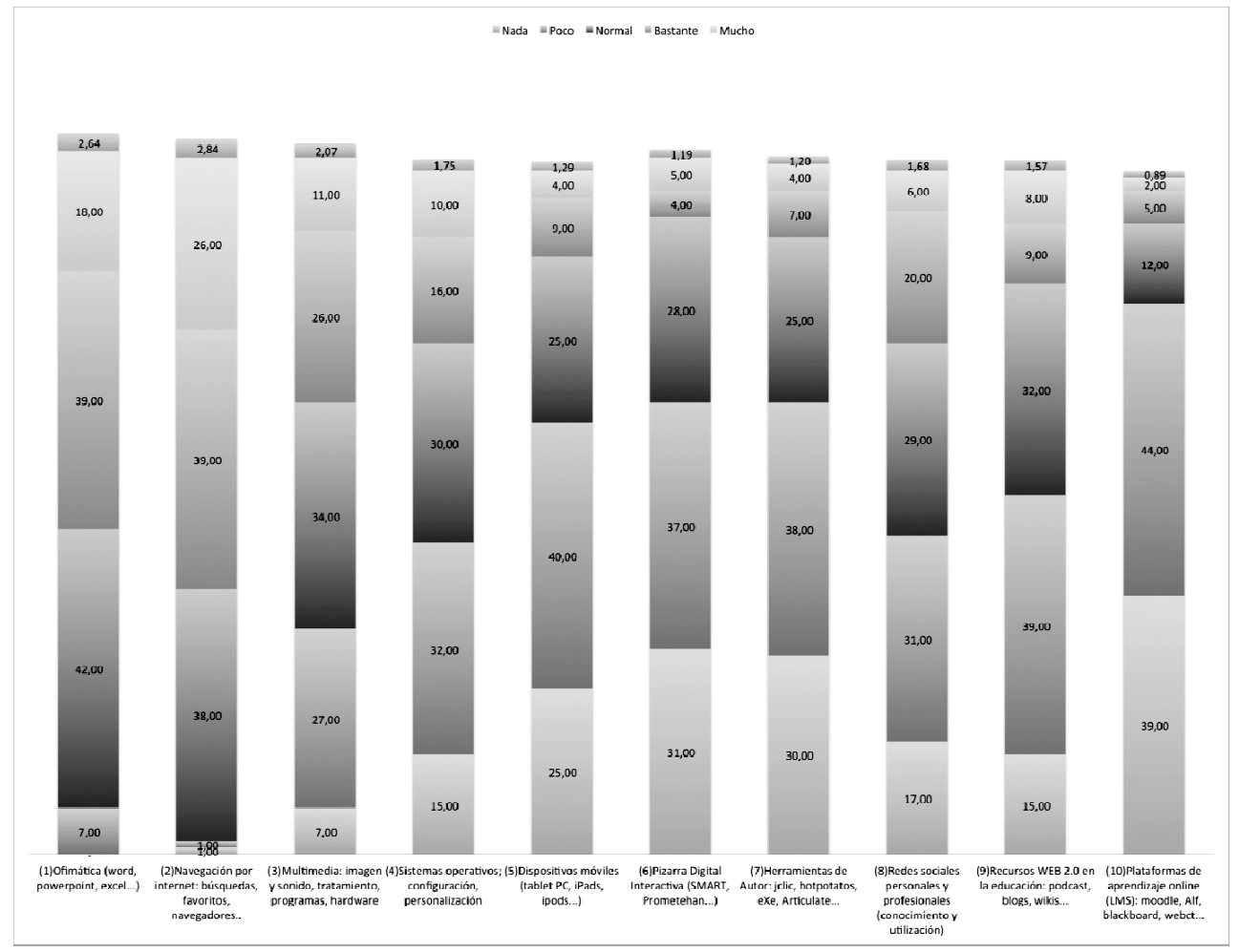

Gráfico 9. Auto-valoración sobre el conocimiento de los recursos TIC

\section{Formación del profesorado en la integración curricular de las TIC}

Esta cuestión nos debe dar respuesta al quinto y último objetivo que nos planteamos. En función de los datos obtenidos, se podría afirmar que los docentes son partidarios de una formación que se centre en aspectos didácticos, frente a los técnicos y los organizativos. 


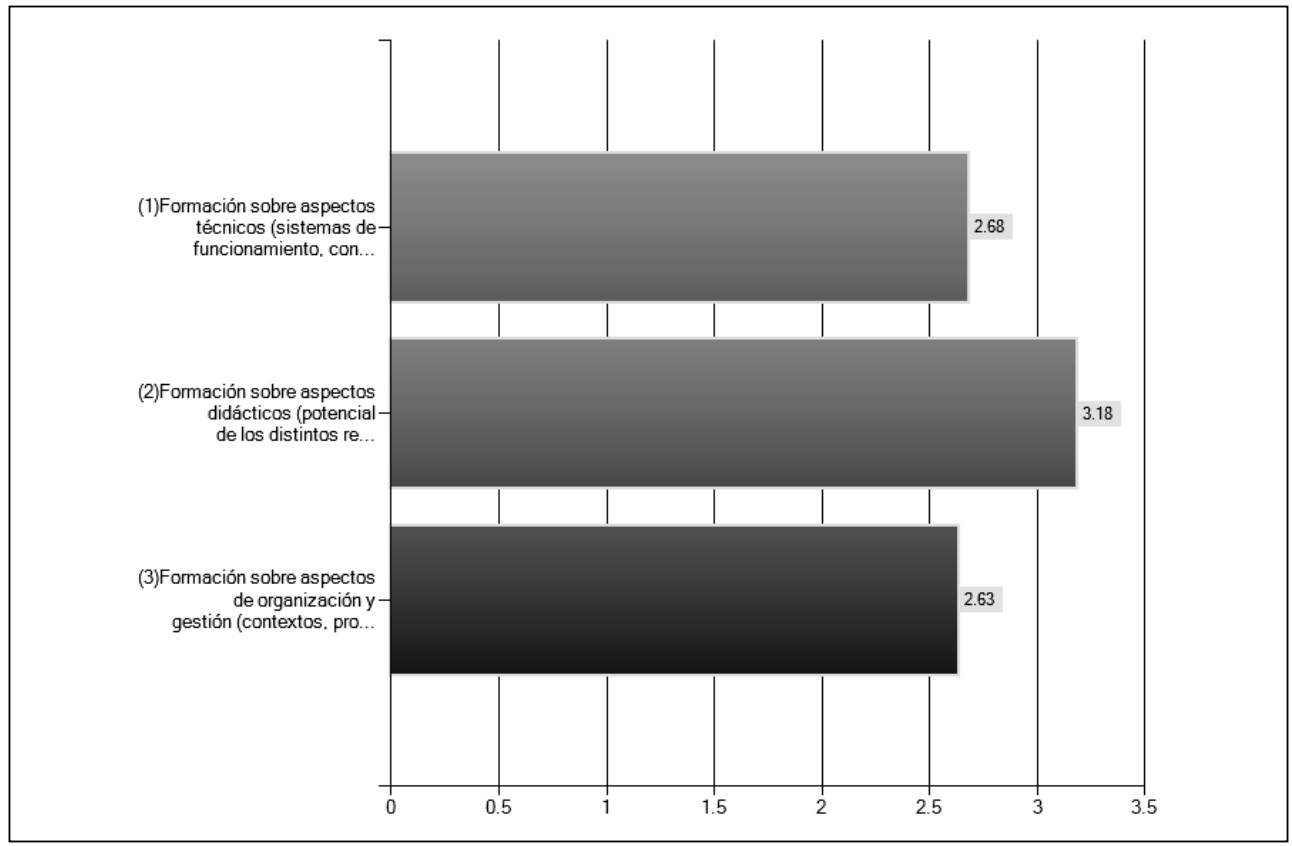

Gráfico 10. Factores relativos a la formación del profesorado en TIC

En cuanto a la preferencia por un tipo de modelo formativo, el profesorado se decanta por un modelo mixto presencial/online. También merece destacarse la baja aceptación de los modelos completamente online ( el 55\% lo considera «malo» $\mathrm{o}$ «regular»).

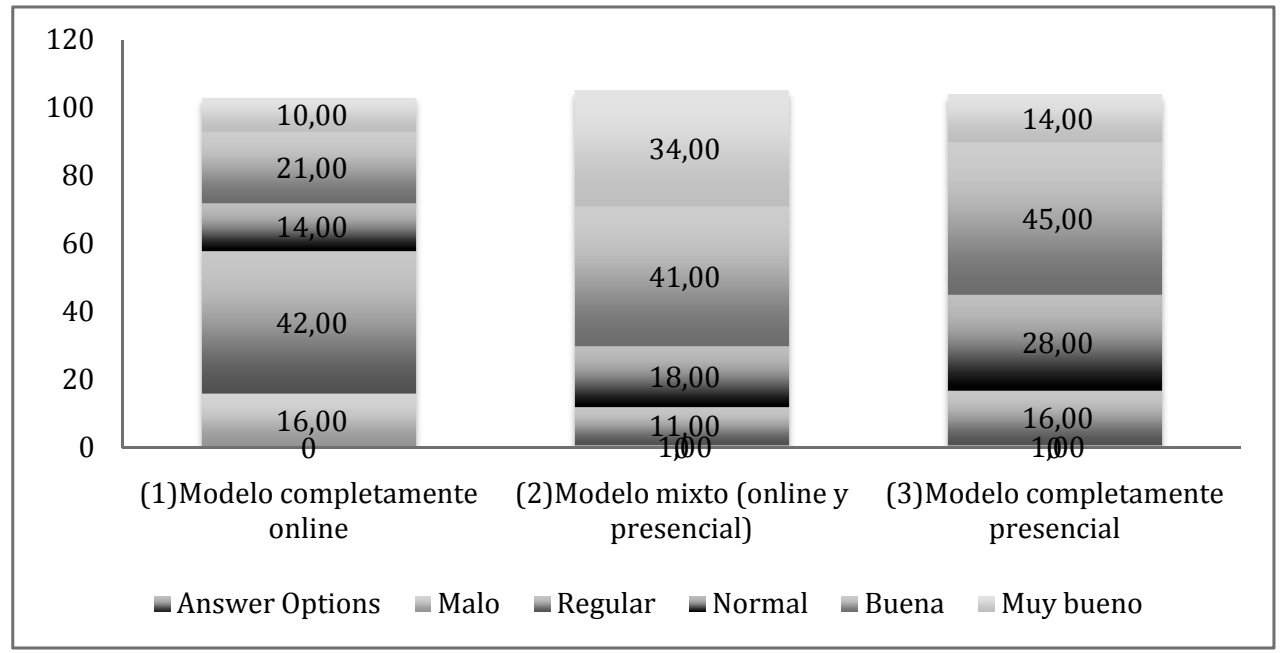

Gráfico 11. Preferencia de un tipo de modelo para la formación del profesorado en TIC 


\section{CONCLUSIONES}

De acuerdo con los resultados obtenidos, nos parece oportuno destacar las siguientes conclusiones del trabajo realizado:

1. En términos generales, el perfil del profesorado investigado que utiliza con mayor frecuencia los recursos de la Escuela 2.0 se corresponde con una maestra, relativamente joven (entre 25 y 34 años de edad), que desarrolla su actividad docente en un centro urbano de Educación Infantil y Primaria. Las áreas de conocimiento donde utiliza con mayor frecuencia los recursos analizados tienen que ver con el idioma, las ciencias naturales y las matemáticas.

2. En cuanto a los recursos más utilizados, los datos obtenidos nos permiten señalar los siguientes con una mayor presencia en el ámbito de la Educación Primaria: sala de ordenadores, rincón del ordenador, conexión WIFI y cañón de proyección (considerados en el estudio dentro de la categoría de «tradicionales»). Si junto a estos datos tenemos presentes aquellos otros que nos indican el poco dominio o bajo nivel de competencia que el propio docente manifiesta tener con relación al uso específico de las herramientas de autor o de la web 2.0, así como las finalidades que los mismos profesores se plantean al utilizar los recursos tecnológicos en los procesos educativos del centro, podemos presumir que la implantación del Programa Escuela 2.0 en el contexto educativo investigado no ha tenido todavía los efectos didácticos deseados en el modo de organizar y gestionar los procesos de enseñanza-aprendizaje.

3. Por último y en estrecha relación con todo lo anterior, nos parece importante destacar la necesidad formativa que reconocen los docentes investigados respecto a cuestiones de carácter pedagógicodidáctico de las TIC, frente a otros aspectos técnicos u organizativos también indicados en el cuestionario administrado. Como estrategia más adecuada para satisfacer dicha necesidad docente, los profesores prefieren que se adopten modelos mixtos de formación del profesorado online y presencial. Tales manifestaciones nos llevan a considerar la formación didáctica del profesorado en el uso de las TIC como clave fundamental para una integración efectiva de los recursos de la Escuela 2.0 en los centros educativos analizados.

\section{REFLEXIÓN FINAL Y PROSPECTIVA}

Como reflexión final y prospectiva del estudio, nos inclinamos a pensar que la eficacia de los recursos de la Escuela 2.0 en los procesos educativos 
del centro no puede quedar supeditada simplemente a la competencia y actuación del profesor, sino también a la situación y al contexto singular donde se desarrolla la acción didáctica, así como al conocimiento y la competencia tecnológica de los propios estudiantes desde la dinámica del proceso de enseñanza-aprendizaje. Desde esta perspectiva, somos totalmente conscientes de las limitaciones de nuestra investigación y nos planteamos nuevos campos de estudio que complementen, amplíen y enriquezcan este trabajo.

\section{NOTAS}

1 Resolución de 3 de agosto de 2009, de la Secretaría General Técnica, por la que se publica el Acuerdo del Consejo de Ministros de 31 de julio de 2009, por el que se formalizan los criterios de distribución, así como la distribución resultante, para el año 2009, de los créditos presupuestarios para la aplicación del Programa Escuela 2.0, aprobados por la Conferencia Sectorial de Educación.

2 Ley Orgánica 2/2006, de 3 de mayo, de Educación (BOE 4-5-2006).

3 Véase a este respecto el Real Decreto 1631/2006, de 29 de diciembre, por el que se establecen las enseñanzas mínimas correspondientes a la Educación Secundaria (Anexo I).

4 Disponible en: http://www.surveymonkey.com/s/encuestatic_centros 


\section{REFERENCIAS BIBLIOGRÁFICAS}

Area Moreira, M. (2010). El proceso de integración y uso pedagógico de las TIC en los centros educativos. Un estudio de casos. Revista de Educación, 352, 77-97

Balanskat, A.; BlaMIre, R. y Kefala, S. (2006). The ICT Impact Report. A review of studies of ICT impact on schools in Europe. Recuperado de http://ec.europa.eu/education/doc/reports/doc/ictimpact.pdf

Barber, M. y Mourshed, M. (2007). How the best performing school systems come out on top. London: McKinsey \& Company.

Biggs, J. (1978). Individual and group differences in study processes. British Journal of Educational Psychology, 48, 266-279.

Cabero, J. (2009). Educación 2.0. ¿Marca, moda o nueva visión de la educación?, en C. Castaño (coord.). Web 2.0. El uso de la web en la sociedad del conocimiento. Investigaciones e implicaciones educativas.Venezuela: Universidad Metropolitana, 9-30.

Condie, R. y Munro, B. (2007). The impact of ICT in schools - a landscape review. Recuperado de http://strathprints.strath.ac.uk/8685/

De Pablos Pons, J; Colás P. y González, T. (2010). Factores facilitadores de la innovación con TIC en los centros escolares. Un análisis comparativo entre diferentes políticas educativas autonómicas. Recuperado de http://www.revistaeducacion.mec.es/re352/re352_02.pdf

Domingo Coscollola, M. y Marqués Graells, P. (2013). Práctica docente en aulas 2.0 de centros de educación primaria y secundaria de España. PíxelBit. Revista de Medios y Educación, 42,

\section{5-128.}

Duart, J.M. y Reparaz, Ch. (2011). Enseñar y aprender con las TIC. Estudios sobre Educación, 20, 9-19.

Entwistle, N. (1981). Styles of learning and teaching. An integrated outline of educational psychology for students, teachers and lecturers. New York: John Wiley.

García-Valcárcel, A. y Tejedor, F.J. (2010). Evaluación de procesos de innovación escolar basados en el uso de las TIC desarrollados en la Comunidad de Castilla y León. Revista de Educación, 352, 125-148 (2013).

Hramiak, A. y Boulton, H. (2013).Escalating the use of Web 2.0 Technology in Secondary Schools in the United King: dom: Barriers and Enablers Beyond Teacher Training. The Electronic Journal of e-Learning, 11 (2), 91-100.

Instituto de Evaluación (2009). TALIS (OCDE). Estudio Internacional sobre la Enseñanza y el Aprendizaje. Informe español 2009. Madrid: Ministerio de Educación.

Instituto de Evaluación (2010). Sistema estatal de indicadores de la educación. Madrid: Ministerio de Educación.

Marqués, P. (2010). Datos sobre la informática educativa en España, Europa y el mundo. Recuperado de http://www. peremarques.net/dadainfo.htm

Martín Hernández, S. (2011). Escuela 2.0: panorama actual de la situación del programa. Recuperado de http:// scopeo.usal.es/images/documentoscopeo/Escuela2.0_ponencia.pdf

Navaridas, F. (2004). Estrategias didácticas en el aula universitaria. Logroño: Universidad de La Rioja. 
Pérez, A. (2011). Escuela 2.0. ¿Por qué en este momento? Recuperado de http:// www.ite.educacion.es/es/escuela-20

Reparaz, Ch., Sobrino, A., Molinos, C., Carceller, E., Baraibar, A. y Lara S. (2003). Programa de formación del profesorado en NTIC: diagnóstico de necesidades, desarrollo y evaluación. Observatorio de la Sociedad de la Información en Navarra. Recuperado de http://www.cfnavarra.es/ObservatorioSi/informes.htm

Rodríguez Vega, A.; Thuiller, L.; Suárez, M. y Carmona, M. (2010). La formación del profesorado implicado en el Proyecto Escuela 2.0. Recuperado de http://www.gabinetecomunicacionyeducacion.com/files/adjuntos/La\%20 formaci $\% \mathrm{C} 3 \% \mathrm{~B} 3 \mathrm{n} \% 20 \mathrm{del} \% 20$ profesorado $\% 20 \mathrm{implicado} \% 20 \mathrm{en} \% 20 \mathrm{el} \% 20$ proyecto $\% 20$ escuela $\% 2020$.pdf

Santiago Campión, R. y Navaridas Nalda, F. (2012). La WEB 2.0 en escena. Píxel-Bit. Revista de Medios y Educación, 41, 19-30.

Santiago Campión, R. y Andía Celaya, L.A. (2012). Creando y compartiendo conocimiento con herramientas 2.0: una experiencia sobre las prácticas del grado en educación infantil en entornos de aprendizaje colaborativo. Contextos Educativos, Revista de Educación, 15, 171-182.
Sigalés, C; Mominó, J.M.; Meneses, J. y Badia, A. (2008). La integración de internet en la educación escolar española: Situación actual y perspectivas de futuro. Barcelona: UCO - Fundación Telefónica.

UNESCO (1998). Declaración Mundial sobre la Educación Superior en el Siglo XXI: Visión y acción. París: UNESCO.

UNESCO (2004). Una Educación de Calidad para todos los jóvenes: desafíos, tendencias y prioridades. Conferencia Internacional de Educación, 47 ${ }^{\mathrm{a}}$ Reunión. Suiza: Ginebra.

UNESCO (2008). La Educación Inclusiva. El camino hacia el futuro. Conferencia Internacional de Educación, $48^{\text {a }}$ Reunión. Suiza: Ginebra.

Valverde, J.; Garrido, M.C. y Sosa, M. (2010). Políticas educativas para la integración de las TIC en Extremadura y sus efectos sobre la innovación didáctica y el proceso enseñanza-aprendizaje: la percepción del profesorado. Revista de educación, 352, 99-124.

Wong, E.M.L.; Li, S.S.C.; Choi, T-H y Lee, T.N. (2008). Insights into Innovative Classroom Practices with ICT. Identifying the Impetus for Change. Educational Technology \& Society, 11 (1), 248-265. 


\section{PALABRAS CLAVE}

Innovación educativa, Influencia de la tecnología, Mejora instruccional, Integración de la tecnología, Tendencias educativas.

\section{KEYWORDS}

Educational innovation, Influence of technology, Instructional improvement, technology integration, Educational Trends.

\section{PERFIL ACADÉMICO Y PROFESIONAL DE LOS AUTORES}

Raúl Santiago Campión, Doctor en Filosofía y Ciencias de la Educación por la Universidad de Navarra. Profesor del Área de Didáctica y Organización Escolar en la UR. Ha sido Director del Area de Recursos Multimedia de la Fundación de la UR y director del Centro Superior de Idiomas de la UPNA. Ha participado como asesor en proyectos nacionales y europeos sobre aplicaciones de las TIC en la educación. (raul.santiago@unirioja.es)

Fermin Navaridas Nalda, Doctor en Filosofía y Ciencias de la Educación. Premio Extraordinario de Doctorado. Profesor del Área de Didáctica y Organización Escolar en el Departamento de Ciencias de la Educación de la Universidad de La Rioja. Vicedecano de Educación en la Facultad de Letras y de la Educación de la citada universidad. Sus trabajos giran en torno a los procesos de innovación y mejora continua en las instituciones educativas. (fermin.navaridas@unirioja.es).

Charo Repáraz Abaitua, Doctora en Filosofía y Ciencias de la Educación. Premio extraordinario de licenciatura y doctorado. Profesora titular de Métodos de Investigación y Diagnóstico en Educación en la Universidad de Navarra. Directora del Departamento de Educación de la Universidad de Navarra. Ha publicado diferentes libros y artículos sobre el uso didáctico de las TIC. Dirige e imparte cursos de formación del profesorado en el ámbito de la tecnología educativa y ha participado en diferentes proyectos de investigación en el ámbito nacional e internacional.

Dirección de los Autores: Raúl Santiago Campión y Fermín Navaridas Nalda

Dpto de Ciencias de la Educación-Universidad de La Rioja

Edificio Vives c/Luis de Ulloa s/n-26004 Logroño 
La Rioja, España

E-mail: raul.santiago@unirioja.es

fermin.navaridas@unirioja.es

Charo Reparaz Abaitua

Universidad de Navarra

31080 - Pamplona (Spain)

E-mail: creparaz@unav.es

Fecha Recepción del Artículo: 30. Septiembre. 2011

Fecha modificación Artículo: 02. Abril. 2012

Fecha Aceptación del Artículo: 23. Mayo. 2012

Fecha de Revisión para publicación: 24. Junio. 2013 


\title{
ANÁLISIS DEL USO DE CUESTIONARIOS EN CONTABILIDAD FINANCIERA
}

\author{
(USING QUESTIONNAIRES IN FINANCIAL ACCOUNTING)
}

\author{
Carmen Pilar Martí Ballester \\ Universitat Autònoma de Barcelona \\ Neus Orgaz Guerrero \\ Universitat Autònoma de Barcelona
}

DOI: 10.5944/educxx1.17.1.10714

\section{Cómo referenciar este artículo/How to reference this article:}

Martí Ballester, C.P. y Orgaz Guerrero, N. (2014). Análisis del uso de cuestionarios en contabilidad financiera. Educación XX1, 17 (1), 271-290. doi: 10.5944/educxx1.17.1.10714

Martí Ballester, C.P. y Orgaz Guerrero, N. (2014). Using questionnaires in Financial Accounting. Educación XX1, 17 (1), 271-290. doi: 10.5944/educxx1.17.1.10714

\section{RESUMEN}

La implantación del Espacio Europeo de Educación Superior (EEES) supone un cambio de paradigma respecto al proceso de enseñanza-aprendizaje, en el que el estudiante adquiere un papel activo en su proceso formativo ayudado por el profesor que deja de ser un mero transmisor de conocimiento. Esto requiere una reformulación de las metodologías docentes que favorezcan la participación activa del estudiante. Entre los recursos para implantar una metodología docente activa el profesor cuenta con los cuestionarios que podrían resultar útiles para mejorar la capacidad de aprendizaje autónomo del estudiante de la asignatura de contabilidad financiera, y por tanto su rendimiento académico. Para demostrar si esto es así, proponemos el siguiente trabajo cuyo objetivo es analizar la incidencia del uso de cuestionarios formativos sobre los rendimientos obtenidos por los estudiantes de la asignatura de Contabilidad Financiera impartida en la Universidad Autónoma de Barcelona (UAB). Para ello disponemos de datos pertenecientes a 543 estudiantes relativos a grupo en el que se han matriculado, estudios que cursan, nota de acceso a la universidad, número de veces matriculado en la asignatura, notas parciales y finales de la parte de teoría, y a la realización de los cuestionarios interactivos. Sobre dichos datos se han aplicado diferentes análisis de covarianza (ANCOVA), teniendo en cuenta que las pendientes del modelo considerado pueden ser homogéneas o heterogéneas. Los resultados obtenidos aportan evidencia de diferencias significativas en el rendimiento medio obtenido por los diferentes grupos de la asignatura. Por lo que podemos concluir que la incorporación de cuestionarios en la estrategia de enseñanza-aprendizaje contribuye a mejorar los resultados promedio obtenidos por los estudiantes 
en asignaturas de carácter introductorio y en materia contable. Los cuestionarios formativos permiten al estudiante controlar su progreso en el proceso de aprendizaje, lo que podría favorecer su motivación hacia la asignatura.

\section{ABSTRACT}

The implementation of the European Higher Education Area (EHEA) requires a paradigm shift with respect to the teaching-learning process, in which students now take an active role in their formative learning process, helped by instructors who are no longer transmitters of knowledge but instead facilitators of student learning. In order to make this change, instructors have to adopt new teaching/learning methodologies that encourage active student involvement in learning. Questionnaires are among those resources that are available to instructors seeking to implement active methodologies that allow students to improve their academic outcomes. To assess this, our study aims to analyze the impact of using formative questionnaires on student performance in Financial Accounting, a subject taught at the Universitat Autònoma de Barcelona (UAB). The sample consists of data pertaining to 543 students, forming 7 groups. These data refer to the groups in which students are enrolled; university-access grades; the number of times a student is enrolled; partial and final grades; and the realization of interactive questionnaires. Different analyses of covariance (ANCOVA) - assuming homogeneous and heterogeneous regression slopes between groups - was applied to the sample data in order to examine group-factor effect and consequently the use of questionnaires, on student performance in accounting, isolating the effect of individual students' initial ability. The findings provide evidence for significant differences in the different subject groups' average performance. We conclude that the incorporation of questionnaires as a teaching-learning strategy helps to improve the average results obtained by students in introductory subjects and in accounting.

\section{INTRODUCCIÓN}

La Universidad, desde la aplicación del Espacio Europeo de Educación Superior, se ha visto inmersa en un proceso de cambios tanto en la metodología de enseñanza como en su estructura organizativa tal y como señala Bache (2006). Se ha pasado de un método docente tradicional, donde el profesor era la figura fundamental, a un método docente centrado en el estudiante que participa activamente en su propio proceso de aprendizaje, ayudado por el profesor. Este último, para orientar al estudiante, debe diseñar situaciones de aprendizaje, que estimulen y animen al estudiante a adquirir las competencias necesarias para desarrollar una actividad profesional en el mercado de trabajo (Lim, 2004), pudiendo utilizar las oportunidades que ofrecen las Tecnologías de la Información y Comunicación (TIC) como indican Garrison y Anderson (2003). 
Para ello, el profesor debe formarse en nuevas metodologías activas, siendo en muchas ocasiones recomendable el uso de las TIC para facilitar y agilizar su implantación. Esto ha provocado reacciones opuestas entre los profesores, pues algunos de ellos han encontrado dificultades a la hora de realizar cambios metodológicos, como señalan Alba y Carballo (2005) y Price y Kinkwood (2013), lo que podría haber motivado que parte del profesorado se muestre reacio a su aplicación, como indican Rientes et al (2013).

Por otra parte, la implantación de estas nuevas metodologías propicia que el estudiante adquiera un rol más activo, responsabilizándose de su propio aprendizaje. Esto favorece que el estudiante esté más motivado y aumente su interés en la asignatura (Alba, 2005). En este sentido, GarcíaValcárcel y Tejedor (2011) concluyen que la introducción de nuevas metodologías basadas en el uso de las TIC en las aulas han resultado útiles en el proceso de aprendizaje del estudiante, que se ha mostrado muy satisfecho con el uso de las mismas, ya que les ayudan a superar dificultades de aprendizaje a la vez que permiten solucionar problemas de absentismo o de desmotivaciones hacia el aprendizaje (Fombona y Pascual, 2011). Similar conclusión alcanzan Leemkuil y De Jong (2012) al analizar el efecto que ejerce el uso de wikis sobre los resultados obtenidos por estudiantes de postgrado de una Escuela de Negocios.

De este modo, el uso de las TIC está permitiendo la adopción de un modelo mixto o semipresencial de docencia. Una de las herramientas TIC más utilizadas en la adopción del mencionado modelo son las plataformas e-learning, que permiten planificar el aprendizaje virtual de tal forma que los estudiantes encuentran en ellas todos los recursos y actividades necesarias para desarrollar su aprendizaje, mientras el profesor dispone de lo necesario para evaluar todo el proceso formativo del estudiante. Dichos modelos han sido implantados con éxito en estudios de educación superior (Price y Kinkwood, 2013), teniendo una acogida satisfactoria por parte de los estudiantes que han recibido apoyo continuado a través de la plataforma digital Moodle (Area et al, 2008), lo que podría favorecer el alto grado de participación y seguimiento del estudiante en la asignatura evidenciado en los trabajos de Mora y Mérida (2010) y Seluakumaran et al (2011).

Esta innovación docente comporta también un nuevo marco conceptual en la relación aprendizaje-evaluación (Mateo y Vlachopoulos, 2013). El Espacio Europeo de Educación Superior ha optado por seguir una evaluación formativa donde no solo se evalúa el dominio de los contenidos de un programa docente por parte del estudiante, sino que además, ha de evaluar y garantizar la aplicación práctica de todo lo que ha aprendido el estudiante. Benito y Cruz (2005) y Ruiz (2005) exponen que los criterios de evaluación deben ser públicos y que la evaluación debe ser formativa, de manera que 
proporcione feedback al estudiante y al profesor. Dicha afirmación es congruente con la evidencia aportada por Buscà et al (2010) al encontrar que la evaluación formativa y participativa son efectivas para adoptar los principios pedagógicos que emergen del Espacio Europeo de Educación Superior (EEES).

Por ello, el objetivo de este trabajo es analizar la incidencia del uso de cuestionarios formativos en soporte digital e interactivo sobre los rendimientos académicos alcanzados por los estudiantes en la parte teórica de la asignatura de contabilidad financiera impartida en la Universidad Autónoma de Barcelona (UAB). Los mencionados cuestionarios se diseñaron utilizando la plataforma digital educativa Moodle que dispone la misma universidad, como apoyo a la docencia presencial realizada en la asignatura.

De este modo, este trabajo se enmarca en la línea de investigación desarrollada por Huon et al (2007), Balter et al (2013) y García y García (2013). Así, Huon et al (2007) aportan evidencia empírica del efecto positivo y significativo que ejerce el uso de cuestionarios online sobre los resultados académicos obtenidos por estudiantes de primer curso de la licenciatura de Psicología. Similar conclusión alcanzan García y García (2013) y Balter et al (2013) al implantar el mencionado recurso docente en diversas asignaturas del área de ciencias (microbiología industrial, métodos de programación, ciencias informáticas, arquitectura e ingeniería industrial y gestión) lo que podría justificar la aceptación favorable que muestran los estudiantes hacia los cuestionarios (Pat-el et al, 2013).

En el área de contabilidad, Martí y Orgaz (2011) también encuentran que el uso de cuestionarios ejerce un efecto positivo en los rendimientos académicos obtenidos en la asignatura de contabilidad financiera. Sin embargo, dicho trabajo presenta diferentes problemas metodológicos. Así, en el modelo propuesto en el mencionado trabajo, los autores no tienen en cuenta la habilidad individual previa del estudiante que, según Huon et al (2007), Elias y MacDonald (2007), Marcenaro y Navarro (2007) y Chamorro et al (2009), es uno de los factores que mejor explican el rendimiento académico que alcanza el estudiante en la universidad, lo que podría generar sesgos en los resultados obtenidos. A su vez, los autores eliminan de la muestra objeto de estudio los estudiantes matriculados en más de una ocasión en la asignatura de contabilidad financiera, lo que introduce sesgos al analizar el efecto grupo, pues en algunos grupos la tasa de repetidores alcanza aproximadamente el $19 \%$, el $35 \%$ y el $57 \%$ de los estudiantes matriculados, lo que es bastante probable que repercuta al analizar el efecto de la calidad del grupo sobre el resultado académico obtenido por el estudiante, como se deduce de Ding y Lehrer (2007). 
Tratando de solventar los mencionados problemas metodológicos, se propone el siguiente trabajo que se estructura como sigue: tras esta introducción, explicaremos el método utilizado para estudiar el efecto que ejerce el uso de cuestionarios por parte del estudiante sobre su rendimiento académico. Posteriormente, describiremos los resultados obtenidos. Finalmente, expondremos las conclusiones alcanzadas así como las implicaciones.

\section{MÉTODO}

Teniendo en cuenta las reflexiones anteriores, en el presente trabajo nos planteamos el estudio de la incidencia del uso de cuestionarios por parte de los estudiantes sobre su rendimiento académico en el área contable, planteando la siguiente hipótesis:

Hipótesis: Los estudiantes que realizan cuestionarios online formativos a lo largo del curso obtienen rendimientos académicos más elevados que aquellos que no los utilizan.

Para contrastar dicha hipótesis se desarrolla una investigación de carácter experimental en que la intervienen distintos estudiantes.

\section{Participantes}

La muestra está compuesta por 543 estudiantes, de los que 447 han desarrollado su proceso de aprendizaje siguiendo la metodología tradicional, mientras 96 estudiantes han utilizado también el cuestionario como herramienta de aprendizaje. Sobre dichos estudiantes se ha recopilado información relativa a: estudios que cursan (Licenciatura en Económicas, Licenciatura en Administración y Dirección de Empresas y doble Licenciatura de Administración y Dirección de Empresas más Derecho), grupo matriculado (7 grupos diferentes), número de veces matriculado en la asignatura y nota de acceso a la universidad facilitados por los servicios centrales de la Universitat Autònoma de Barcelona y nota final de la parte de teoría de la asignatura, obtenida a partir de la media aritmética de la nota alcanzada por los estudiantes en los cuatro parciales de teoría realizados en noviembre, enero, abril y mayo del curso 2009/2010, facilitados por los compañeros de la asignatura. Así mismo, disponemos de datos relativos a la realización de cuestionarios interactivos proporcionados por la profesora que los ha implantado en el grupo donde imparte docencia. 


\section{Unidades de análisis}

La unidad de análisis en el presente estudio la constituye el estudiante matriculado en la asignatura de contabilidad financiera y analítica en la Universitat Autònoma de Barcelona.

\section{Materiales} cuenta:

A la hora de elaborar las preguntas del cuestionario, tenemos en

1. Los conocimientos que debe adquirir el estudiante en temas contables.

2. Las competencias que debe conseguir al finalizar la asignatura, entre ellas: capacidad de organización, autonomía y planificación del trabajo.

Para poder evaluar y autoevaluar estas habilidades en diferentes niveles, siguiendo la taxonomía de Bloom (1956), elaboramos una base de preguntas de los 12 temas en los que se divide la asignatura de Contabilidad Financiera y Analítica. Esta base está formada por 600 preguntas: un 75\% de las preguntas son de respuestas múltiples, un 1,5\% de preguntas son con respuesta verdadero/falso, un 5,5\% de preguntas con respuestas calculadas, un $2 \%$ de preguntas con emparejamiento y un $16 \%$ de preguntas con respuesta breve.

La plataforma aula Moodle nos permite clasificar las preguntas en doce categorías que corresponden a cada uno de los temas de la asignatura. La clasificación del tipo de preguntas lo podemos ver en la tabla 1.

\begin{tabular}{|l|r|r|r|r|r|r|}
\hline \multicolumn{1}{|c|}{} & \multicolumn{7}{|c|}{ Tipo de preguntas } \\
\hline Tema & $\begin{array}{c}\text { Número } \\
\text { preguntas }\end{array}$ & $\begin{array}{c}\text { Elección } \\
\text { múltiple }\end{array}$ & Calculadas & Emparejamiento & $\begin{array}{c}\text { Respuesta } \\
\text { Breve }\end{array}$ & $\begin{array}{c}\text { Verdadero/ } \\
\text { Falso }\end{array}$ \\
\hline Tema 1 & 24 & 14 & 8 & 2 & & \\
\hline Tema 2 & 46 & 35 & 9 & 2 & & \\
\hline Tema 3 & 109 & 31 & & 2 & 73 & 3 \\
\hline Tema 4 & 54 & 44 & 9 & 1 & & \\
\hline Tema 5 & 90 & 87 & 3 & & & \\
\hline Tema 6 & 10 & 9 & & 1 & & \\
\hline Tema 7 & 78 & 62 & 1 & 1 & 14 & \\
\hline Tema 8 & 67 & 57 & & 1 & 9 & \\
\hline Tema 9 & 45 & 43 & 1 & 1 & & \\
\hline
\end{tabular}




\begin{tabular}{|l|r|r|r|r|r|r|}
\hline \multicolumn{2}{|c|}{} & \multicolumn{7}{|c|}{ Tipo de preguntas } \\
\hline Tema & $\begin{array}{c}\text { Número } \\
\text { preguntas }\end{array}$ & $\begin{array}{c}\text { Elección } \\
\text { múltiple }\end{array}$ & Calculadas & Emparejamiento & $\begin{array}{c}\text { Respuesta } \\
\text { Breve }\end{array}$ & $\begin{array}{c}\text { Verdadero/ } \\
\text { Falso }\end{array}$ \\
\hline Tema 10 & 30 & 23 & 2 & & & 5 \\
\hline Tema 11 & 27 & 26 & & & & 1 \\
\hline Tema 12 & 20 & 19 & & & 12 & 96 \\
\hline Total & 600 & 450 & 33 & & & 9 \\
\hline
\end{tabular}

Tabla 1. Clasificación del tipo de preguntas del cuestionario

Las características de los cuestionarios son las siguientes:

a) El cuestionario está compuesto por 10 preguntas

b) El tiempo de realización para el estudiante: 40 minutos

c) Las preguntas y respuestas están mezcladas, con lo que cada cuestionario será diferente.

d) El cuestionario se activa al finalizar cada tema de la asignatura.

e) El cuestionario está activado durante aproximadamente una semana.

f) El estudiante dispone de intentos ilimitados y se tiene en cuenta la nota más alta obtenida.

g) Existencia de feedback para el estudiante; respuestas correctas, puntuación y errores cometidos.

Con la implantación de los cuestionarios al final de cada tema de la asignatura, se pretende que el estudiante deba estudiar el tema correspondiente, por lo que se consigue que los temas posteriores se entiendan mejor, es decir, el estudiante sigue un aprendizaje progresivo. Además de conseguir las competencias mencionadas anteriormente, los estudiantes adquieren un hábito de estudio y están más motivados, lo que podría tener una repercusión positiva en la nota final.

\section{Diseño}

Con la finalidad de analizar el efecto del uso de cuestionarios formativos sobre los rendimientos obtenidos por los estudiantes, hemos diseñado 
una investigación de carácter descriptivo, basado en medidas de tendencia central, que nos permitirá identificar posibles errores, valores extremos, variabilidad no esperada y la forma de los datos recopilados, así como de carácter experimental, donde los investigadores modificamos las condiciones bajo las cuales se desarrolla el proceso de aprendizaje de un grupo (grupo experimental) introduciendo una nueva herramienta docente, el cuestionario, comparando el rendimiento académico promedio de dicho grupo con el obtenido por otros grupos (grupos de control) que emplean la metodología de aprendizaje tradicional. Esto nos permitirá demostrar si la introducción del cuestionario en la metodología docente produce un cambio en el rendimiento obtenido por el estudiante.

\section{Procedimiento}

Para desarrollar el experimento seleccionamos uno de los siete grupos en los que se imparte docencia en la asignatura de contabilidad financiera y analítica en la Universitat Autònoma de Barcelona. En dicho grupo se implantan los cuestionarios interactivos, que el estudiante debe completar en horario fuera de clase.

De este modo, los estudiantes tienen que responder los cuestionarios correspondientes a cada tema durante la semana posterior a la finalización de la lección magistral y ejercicios de las diferentes secciones de que consta la asignatura. Para completar los cuestionarios, los estudiantes disponen de 40 minutos e intentos ilimitados, obteniendo feedback instantáneo de la plataforma de aprendizaje moodle al finalizar cada uno de los cuestionarios, que incluye la nota alcanzada por el estudiante, así como las respuestas correctas de cada una de las diez preguntas seleccionadas aleatoriamente por la mencionada plataforma de aprendizaje. De las notas obtenidas en los diferentes cuestionarios realizados para cada tema se tiene en cuenta la nota más alta.

Tras impartir el contenido correspondiente a los tres primeros temas propuestos en la guía docente de la asignatura, los estudiantes realizan el primer examen tipo test coincidiendo en todos los grupos en contenido, día y hora. Transcurrida una semana se pide a los profesores de la asignatura los resultados obtenidos por los estudiantes matriculados en los grupos en los que imparten docencia. Este mismo procedimiento se sigue tras finalizar el contenido de los temas 6, 9 y 12. La nota final alcanzada por el estudiante en la parte de teoría se obtiene a partir de la media aritmética de los cuatro parciales. 
Tras realizar todos los exámenes parciales de la asignatura se ha procedido a solicitar a los servicios centrales de la Universitat Autònoma de Barcelona, información relativa a la licenciatura que están cursando, nota de acceso a la universidad y número de veces que se han matriculado los estudiantes en la asignatura de contabilidad financiera y analítica.

Una vez obtenidos todos los datos requeridos se ha procedido a realizar un análisis estadístico de los datos que integran la muestra y un análisis de covarianza para determinar el efecto que ejerce el uso de cuestionarios sobre el rendimiento académico de los estudiantes eliminando el efecto atribuible a la habilidad del estudiante, al no estar sometida a control experimental.

\section{RESULTADOS}

A continuación se realiza un análisis estadístico de los datos que componen la muestra del estudio. En la tabla 2 se observa que los estudiantes matriculados en la asignatura de Contabilidad Financiera y Analítica se distribuyen en 7 grupos de diferente tamaño, integrando entre 70 y 100 estudiantes. Cada uno de estos grupos integra estudiantes con diferentes características académicas. En este sentido, la mayoría de los estudiantes adscritos a los grupos 1, 2, 3 y 4 son estudiantes de nuevo ingreso en la universidad, mientras los grupos 5, 6 y 7 presentan una tasa de repetición del $34,57 \%, 57,69 \%$ y $18,57 \%$, respectivamente.

A su vez, la nota media de acceso de los estudiantes que integran los grupos 2, 4 y 7 es, en promedio, aproximadamente un notable, mientras los grupos 1, 3, 5 y 6 han accedido a la universidad con una nota de aprobado, en promedio. Esto podría condicionar el rendimiento académico obtenido por el estudiante en la universidad, pues como se puede observar en la tabla 2 , son los grupos con una nota promedio de acceso a la universidad más elevada los que consiguen alcanzar, en promedio, un mejor rendimiento académico en la parte teórica de la asignatura durante el curso 2009/10.

\begin{tabular}{|l|c|c|c|c|c|c|c|}
\hline & $\begin{array}{c}\text { Grupo } \\
1\end{array}$ & $\begin{array}{c}\text { Grupo } \\
2\end{array}$ & $\begin{array}{c}\text { Grupo } \\
3\end{array}$ & $\begin{array}{c}\text { Grupo } \\
4\end{array}$ & $\begin{array}{c}\text { Grupo } \\
5\end{array}$ & $\begin{array}{c}\text { Grupo } \\
6\end{array}$ & $\begin{array}{c}\text { Grupo } \\
7\end{array}$ \\
\hline $\begin{array}{l}\text { N. }{ }^{\circ} \text { estudiantes } \\
\text { matriculados }\end{array}$ & 86 & 88 & 90 & 100 & 81 & 78 & 70 \\
\hline $\begin{array}{l}\text { N. }{ }^{\circ} \text { estudiantes } \\
\text { presentados }\end{array}$ & 85 & 85 & 84 & 96 & 59 & 67 & 67 \\
\hline Repetidores & 5 & 2 & 2 & 1 & 28 & 45 & 13 \\
\hline
\end{tabular}




\begin{tabular}{|l|c|c|c|c|c|c|c|}
\hline & $\begin{array}{c}\text { Grupo } \\
1\end{array}$ & $\begin{array}{c}\text { Grupo } \\
2\end{array}$ & $\begin{array}{c}\text { Grupo } \\
3\end{array}$ & $\begin{array}{c}\text { Grupo } \\
4\end{array}$ & $\begin{array}{c}\text { Grupo } \\
5\end{array}$ & $\begin{array}{c}\text { Grupo } \\
6\end{array}$ & $\begin{array}{c}\text { Grupo } \\
7\end{array}$ \\
\hline $\begin{array}{l}\text { Nota media de } \\
\text { acceso: }\end{array}$ & & & & & & & \\
\hline - Media & 6,23 & 7,08 & 5,92 & 6,99 & 5,85 & 6,42 & 7,46 \\
\hline - Mediana & 6,06 & 6,87 & 5,75 & 6,80 & 5,73 & 6,26 & 7,35 \\
\hline - Desviación típica & 0,71 & 0,68 & 0,66 & 0,70 & 0,60 & 0,68 & 0,68 \\
\hline - Mínimo & 5,30 & 6,20 & 5,00 & 5,70 & 5,00 & 5,00 & 6,20 \\
\hline - Máximo & 9,1 & 8,80 & 8,70 & 9,00 & 7,50 & 8,30 & 9,30 \\
\hline $\begin{array}{l}\text { Nota contabilidad } \\
\text { teoría: }\end{array}$ & & & & & & & \\
\hline - Media & 4,22 & 5,97 & 5,03 & 6,5 & 4,00 & 4,75 & 6,41 \\
\hline - Mediana & 4,13 & 6,46 & 5,50 & 6,90 & 4,48 & 5,08 & 6,78 \\
\hline - Desviación típica & 2,22 & 2,07 & 1,89 & 2,09 & 1,95 & 1,80 & 1,90 \\
\hline - Mínimo & 0,20 & 0,40 & 0,50 & 0,7 & 0,10 & 0,20 & 1,00 \\
\hline - Máximo & 9,00 & 9,50 & 8,90 & 9,50 & 7,80 & 7,90 & 9,30 \\
\hline
\end{tabular}

Tabla 2. Estadísticos descriptivos

\section{Efecto del factor GRUPO sobre el rendimiento académico utilizando un análisis de covarianza}

Tras el análisis estadístico realizado, analizaremos si la utilización de cuestionarios online contribuye a mejorar el rendimiento académico de los estudiantes al igual que ocurre en otras áreas como ciencias (Balter et al, 2013) o psicología (Huon et al, 2007).

Para ello, dado que diversos autores, Elias y MacDonald (2007), Marcenaro y Navarro (2007), Chamorro et al (2009) y Martí (2012) aportan evidencia de que la nota de acceso a la universidad obtenida por el estudiante es uno de los factores que mejor explican el rendimiento académico alcanzado por el estudiante en la universidad, incluiremos en nuestro modelo la variable NOTACESO para controlar el efecto de la habilidad previa del estudiante sobre la nota obtenida en la parte teórica de la asignatura de contabilidad financiera y analítica.

Otro factor que puede influir en el rendimiento académico del estudiante es la calidad académica del grupo al que está adscrito. En este sentido, De Paola y Scoppa (2010) señalan que el grupo al que está adscrito un estudiante puede influir en su rendimiento académico por diversos motivos: (1) la interacción de los estudiantes durante su proceso de aprendizaje, (2) la 
formación de valores y aspiraciones y (3) el planteamiento de dudas y cuestiones en clase, que puede fomentar que el profesor desarrolle más un tema. De este modo, los estudiantes tienden a obtener significativamente mejores rendimientos académicos cuando la calidad del grupo al que están adscritos es más elevada, tal y como demuestran Ding y Lehrer (2007) y Seethamraju y Borman (2009). Por ello, analizaremos el efecto del factor grupo sobre el rendimiento obtenido por el estudiante incorporando la variable GRUPO en nuestro modelo.

La estrategia docente implantada en cada uno de los siete grupos es idéntica, basándose en la recomendación de un manual de contabilidad como bibliografía básica, la distribución de las diapositivas que se explican en clase así como de un cuadernillo con enunciados de ejercicios que se corrigen en clase. El mencionado material es el mismo en todos los grupos. Sin embargo, en el grupo 4 además de este material se han facilitado a los estudiantes cuestionarios interactivos que realizan en horario distinto al de clase.

De este modo, el modelo analizado es el siguiente:

$$
\text { NOTACONTA }_{i j}=\mu+\alpha_{j}+\beta\left(\text { NOTACESO }_{i j} \text {-NOTACESO }\right)+\varepsilon_{i j}^{\prime}
$$

Donde NOTACONTA indica el rendimiento obtenido por el estudiante $\mathrm{i}(\mathrm{i}=1$ a 543) del grupo $\mathrm{j}(\mathrm{j}=1,2, \ldots 7)$ en la parte teórica de la asignatura de contabilidad financiera y analítica cuyo valor oscila entre 0 y 10 puntos, $\mu$ es la media total, $\alpha_{j}$ mide el efecto del grupo $\mathrm{j}(\mathrm{j}=1,2, \ldots 7), \beta$ es el coeficiente de la regresión lineal intra-grupo de la variable notaconta sobre la variable notaceso, NOTACESO muestra la nota de acceso a la universidad del estudiante $\mathrm{i}(\mathrm{i}=1$ a 543$)$ del grupo $\mathrm{j}(\mathrm{j}=1,2, \ldots 7)$ cuyo valor oscila entre 5 y 10 , NOTACESO es la media total de la nota de acceso a la universidad y $\varepsilon_{\mathrm{ij}}$ es el error de la medida.

Sobre dicho modelo se aplica el análisis de covarianza (ANCOVA) que nos permite examinar el efecto del factor GRUPO sobre el rendimiento académico en contabilidad financiera controlando el efecto de la nota de acceso a la universidad que covaría con la variable dependiente.

\begin{tabular}{|l|r|c|c|c|r|}
\hline & $\begin{array}{c}\text { Suma de } \\
\text { cuadrados }\end{array}$ & $\begin{array}{c}\text { Grados de } \\
\text { libertad }\end{array}$ & $\begin{array}{c}\text { Media } \\
\text { cuadrática }\end{array}$ & Estadístico F & p-value \\
\hline Modelo corregido & $780,682^{\mathrm{a}}$ & 7 & 111,526 & 32,007 & 0,000 \\
\hline Intersección & 21,316 & 1 & 21,316 & 6,117 & 0,014 \\
\hline Notaaceso & 296,325 & 1 & 296,325 & 85,042 & 0,000 \\
\hline Grupo & 128,621 & 6 & 21,437 & 6,152 & 0,000 \\
\hline
\end{tabular}




\begin{tabular}{|l|r|c|c|l|l|}
\hline & $\begin{array}{c}\text { Suma de } \\
\text { cuadrados }\end{array}$ & $\begin{array}{c}\text { Grados de } \\
\text { libertad }\end{array}$ & $\begin{array}{c}\text { Media } \\
\text { cuadrática }\end{array}$ & Estadístico F & p-value \\
\hline Error & $1.864,178$ & 535 & 3,484 & & \\
\hline Total & $18.097,751$ & 543 & & & \\
\hline Total corregida & $2.644,859$ & 542 & & & \\
\hline R cuadrado: 0.295 & & & & & \\
\hline
\end{tabular}

Tabla 3. Análisis de los rendimientos de los estudiantes de contabilidad considerando pendientes homogéneas

La tabla 3 muestra los resultados obtenidos indicando, a través del estadístico F del modelo corregido, que el modelo propuesto explica una parte significativa de la variación observada en el rendimiento del estudiante de contabilidad financiera. Congruente con esto, el valor de $\mathrm{R}^{2}$ muestra que los efectos considerados en el modelo explican el 29,5 por cien de la varianza del rendimiento de la asignatura de contabilidad. Respecto a las variables consideradas en el modelo, encontramos que la habilidad previa del estudiante medido a través de la nota de acceso se encuentra linealmente correlacionada con la variable dependiente NOTACONTA. Controlando este efecto, hallamos diferencias significativas en los rendimientos medios obtenidos por los estudiantes adscritos a los siete grupos considerados en el presente trabajo. A este respecto, el análisis de regresión de los parámetros, cuyos resultados se indican en la tabla 4, muestra que el grupo 4 ha alcanzado rendimientos medios en contabilidad financiera significativamente mejores, mientras el grupo 1 ha obtenido un rendimiento medio en contabilidad significativamente más bajo con respecto al resto de grupos.

\begin{tabular}{|l|c|c|c|c|}
\hline \multicolumn{1}{|c|}{ Variable } & $\mathrm{B}$ & Error tip. & Estadístico t & $\mathrm{p}$-value \\
\hline Intersección & $-1,797$ & 0,918 & $-1,956$ & 0,051 \\
\hline Notaceso & 1,099 & 0,119 & 9,222 & 0,000 \\
\hline Grupo 1 & $-0,826$ & 0,339 & $-2,439$ & 0,015 \\
\hline Grupo 2 & $-0,011$ & 0,308 & $-0,035$ & 0,972 \\
\hline Grupo 3 & 0,323 & 0,357 & 0,904 & 0,366 \\
\hline Grupo 4 & 0,617 & 0,302 & 2,040 & 0,042 \\
\hline Grupo 5 & $-0,633$ & 0,385 & $-1,644$ & 0,101 \\
\hline Grupo 6 & $-0,509$ & 0,346 & $-1,470$ & 0,142 \\
\hline Grupo 7 & $0^{\mathrm{a}}$ & & & \\
\hline
\end{tabular}

a al parámetro se la asigna valor 0 para evitar problemas de multicolinealidad.

Tabla 4. Estimaciones de los parámetros considerando pendientes homogéneas 
No obstante, cabe destacar que los resultados anteriormente comentados podrían ser poco robustos si no se cumple el supuesto de homogeneidad de las pendientes de las ecuaciones de regresión. Por ello a continuación procederemos a contrastar la hipótesis nula de pendientes homogéneas incorporando en el modelo la intersección entre el factor GRUPO y la covariable NOTACESO. Los resultados obtenidos se presentan en la tabla 5, mostrando evidencia de que las pendientes de los distintos grupos considerados no son iguales.

\begin{tabular}{|c|c|c|c|c|c|}
\hline & $\begin{array}{c}\text { Suma de } \\
\text { cuadrados }\end{array}$ & $\begin{array}{c}\text { Grados } \\
\text { de libertad }\end{array}$ & $\begin{array}{c}\text { Media } \\
\text { cuadrática }\end{array}$ & Estadístico F & $\mathrm{p}$-value \\
\hline $\begin{array}{l}\text { Modelo } \\
\text { corregido }\end{array}$ & $824,942^{\mathrm{a}}$ & 13 & 63,457 & 18,445 & 0,000 \\
\hline Intersección & 15,087 & 1 & 15,087 & 4,385 & 0,037 \\
\hline Grupo & 38,316 & 6 & 6,386 & 1,856 & 0,086 \\
\hline Notaceso & 256,455 & 1 & 256,455 & 74,544 & 0,000 \\
\hline $\begin{array}{l}\text { Grupo* } \\
\text { Notaceso }\end{array}$ & 44,261 & 6 & 7,377 & 2,144 & 0,047 \\
\hline Error & $1.819,917$ & 529 & 3,440 & & \\
\hline Total & $18.097,751$ & 543 & & & \\
\hline $\begin{array}{l}\text { R cuadrado: } \\
0.312\end{array}$ & & & & & \\
\hline
\end{tabular}

Tabla 5. Análisis de homogeneidad de las pendientes

\section{Efecto del factor GRUPO sobre el rendimiento académico utilizando el análisis de regresión con pendientes heterogéneas}

Para solventar dicho inconveniente proponemos la siguiente modificación del modelo [1]:

$$
\text { NOTACONTA }_{i j}=\alpha_{j}+\beta_{j}\left(\text { NOTACESO }_{i j}-\underline{N O T A C E S O}\right)+\varepsilon_{i j}^{\prime}
$$

Donde NOTACONTA indica el rendimiento obtenido por el estudiante $\mathrm{i}(\mathrm{i}=1$ a 543$)$ del grupo $\mathrm{j}(\mathrm{j}=1,2, \ldots 7)$ en la parte teórica de la asignatura de contabilidad financiera y analítica cuyo valor oscila entre 0 y 10 puntos, $\alpha_{j}$ mide el efecto del grupo $\mathrm{j}(\mathrm{j}=1,2, \ldots 7), \beta_{\mathrm{j}}$ es el coeficiente de la regresión lineal intra-grupo de la variable notaconta sobre la variable notaceso para cada grupo $\mathrm{j}(\mathrm{j}=1,2, \ldots 7)$, NOTACESO muestra la nota de acceso a la universidad del estudiante $\mathrm{i}(\mathrm{i}=1$ a 543$)$ del grupo $\mathrm{j}(\mathrm{j}=1,2, \ldots 7)$ cuyo valor oscila entre 5 y 10, NOTACESO es la media total de la nota de acceso a la universidad y $\varepsilon_{\mathrm{ij}}^{\prime}$ es el error de la medida. 


\begin{tabular}{|l|r|r|r|r|r|}
\hline & $\begin{array}{c}\text { Suma de } \\
\text { cuadrados }\end{array}$ & $\begin{array}{c}\text { Grados } \\
\text { de libertad }\end{array}$ & $\begin{array}{c}\text { Media } \\
\text { cuadrática }\end{array}$ & Estadístico F & p-value \\
\hline Modelo & $16.277,835^{\mathrm{a}}$ & 14 & $1.162,702$ & 337,966 & 0,000 \\
\hline Grupo & 58,809 & 7 & 8,401 & 2,442 & 0,018 \\
\hline $\begin{array}{l}\text { Grupo * } \\
\text { Notaceso }\end{array}$ & 340,586 & 7 & 48,655 & 14,143 & 0,000 \\
\hline Error & $1.819,917$ & 529 & 3,440 & & \\
\hline Total & $18.097,751$ & 543 & & & \\
\hline $\begin{array}{l}\text { R cuadrado: } \\
0.833\end{array}$ & & & & & \\
\hline
\end{tabular}

Tabla 6. Análisis de los rendimientos de los estudiantes de contabilidad considerando pendientes heterogéneas

Los resultados obtenidos se presentan en la tabla 6. En este sentido, el valor $\mathrm{R}^{2}$ indica que los efectos considerados en el modelo explican el 89,9 por cien de la varianza del rendimiento de la asignatura de contabilidad. Respecto al factor, encontramos evidencia de diferencias significativas entre los rendimientos medios obtenidos por los estudiantes adscritos a los siete grupos considerados.

\begin{tabular}{|l|c|c|c|c|}
\hline \multicolumn{1}{|c|}{ Variable } & $\mathrm{B}$ & Error tip. & Estadístico t & $\mathrm{p}$-value \\
\hline Intersección & & & & \\
\hline - Grupo 1 & $-3,508$ & 1,792 & $-1,958$ & 0,051 \\
\hline - Grupo 2 & $-3,040$ & 2,118 & $-1,436$ & 0,152 \\
\hline - Grupo 3 & $-2,663$ & 1,841 & $-1,446$ & 0,149 \\
\hline - Grupo 4 & $-3,341$ & 1,908 & $-1,751$ & 0,080 \\
\hline - Grupo 5 & $-2,271$ & 2,378 & $-0,955$ & 0,340 \\
\hline - Grupo 6 & 4,715 & 2,173 & 2,170 & 0,030 \\
\hline - Grupo 7 & $-1,638$ & 2,520 & $-0,650$ & 0,516 \\
\hline Grupo 1*notaceso & 1,241 & 0,286 & 4,342 & 0,000 \\
\hline Grupo 2*notaceso & 1,273 & 0,298 & 4,275 & 0,000 \\
\hline Grupo 3*notaceso & 1,300 & 0,309 & 4,206 & 0,000 \\
\hline Grupo 4*notaceso & 1,408 & 0,272 & 5,186 & 0,000 \\
\hline Grupo 5*notaceso & 1,072 & 0,405 & 2,648 & 0,008 \\
\hline Grupo 6*notaceso & 0,005 & 0,337 & 0,015 & 0,988 \\
\hline Grupo 7*notaceso & 1,078 & 0,336 & 3,205 & 0,001 \\
\hline
\end{tabular}

Tabla 7. Estimaciones de los parámetros considerando pendientes heterogéneas 
Concretamente, según se observa en la tabla 7, los estudiantes del grupo 4 muestran significativamente mejores resultados en la asignatura de contabilidad sobre el resto de grupos, pues el coeficiente correspondiente al grupo 4 indica que una variación de un punto en la nota de acceso a la universidad supone un incremento del rendimiento promedio en la asignatura de contabilidad de 1,4 puntos, mientras en los grupos 5 y 7 esta relación prácticamente es proporcional como muestra la figura 1.

En el grupo 6 parece no existir una relación significativa entre el rendimiento obtenido por el estudiante en la asignatura de contabilidad financiera y la nota de acceso del estudiante a la universidad, lo que podría deberse a una falta de motivación por parte de los estudiantes que son en gran parte repetidores.

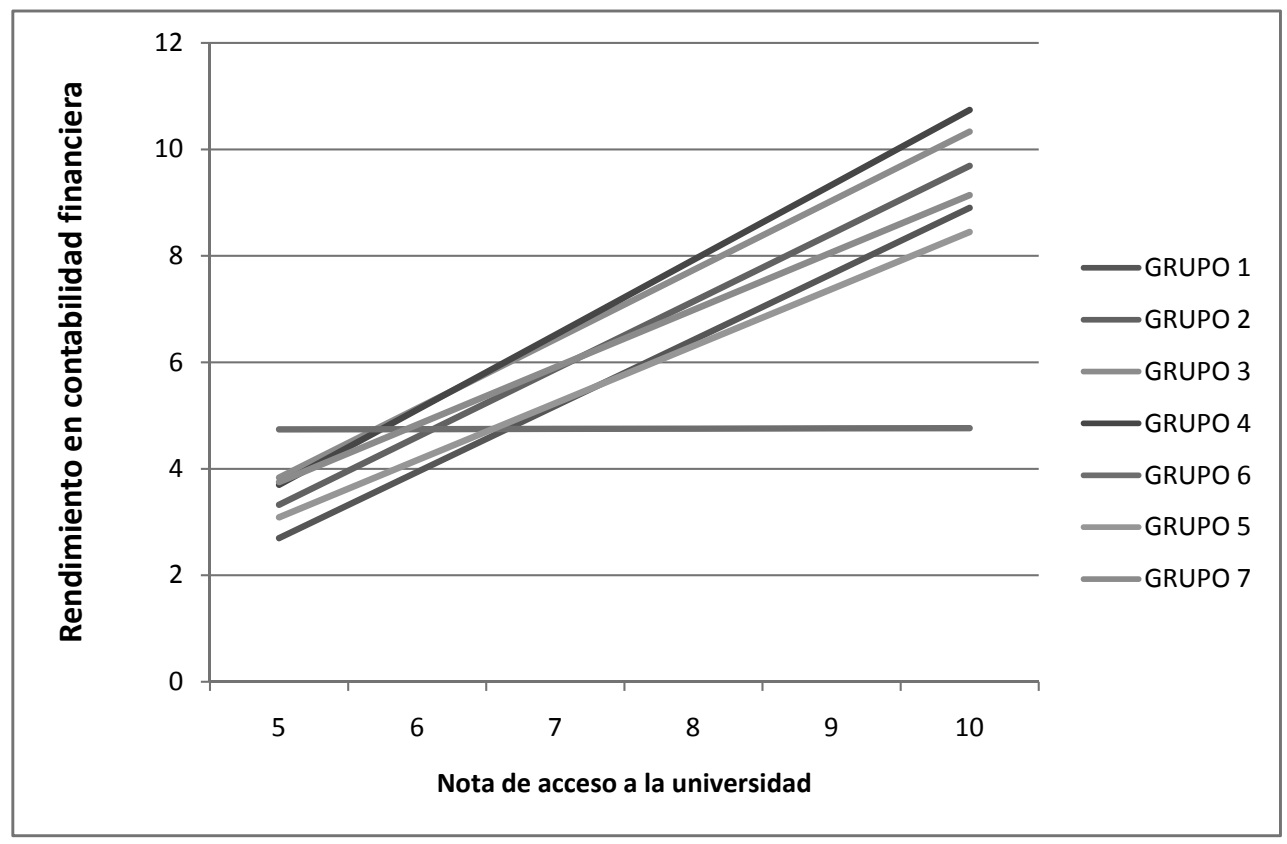

Figura 1. Representación gráfica del rendimiento en contabilidad financiera en función de la nota de acceso

En resumen, la implantación de los cuestionarios en la estrategia de enseñanza-aprendizaje permite mejorar, en promedio, el rendimiento académico alcanzado por los estudiantes en el área contable. Esto puede deberse a que el estudiante puede: evaluar su progreso en el proceso de aprendizaje, asegurarse de que ha adquirido los conocimientos que se exigen en el programa de la asignatura, diagnosticar dificultades en su proceso de aprendizaje, modificar su hábito de estudio para mejorar la adquisición de 
competencias en el área contable, y sentirse más motivado hacia la asignatura pues al dedicar su tiempo y esfuerzo a la elaboración de los cuestionarios de la asignatura de contabilidad financiera y analítica está sacrificando o renunciando al disfrute actividades de ocio, de trabajo remunerado y/o de tiempo de estudio en otra asignatura, lo que supone un incremento del coste de oportunidad para el estudiante, que podría repercutir en un menor incentivo para abandonar la asignatura.

\section{CONCLUSIONES E IMPLICACIONES}

La creación del Espacio Europeo de Educación Superior ha supuesto un cambio de paradigma en el proceso de enseñanza-aprendizaje, en el que el estudiante participa de forma activa en su proceso de aprendizaje ayudado por el profesor que actúa como orientador. Esto implica que el profesor debe diseñar situaciones de aprendizaje que estimulen y animen al estudiante a adquirir las competencias necesarias para desarrollar una actividad profesional en el mercado de trabajo.

Entre los recursos que tiene el profesor para guiar al estudiante en su proceso de aprendizaje, se encuentran los cuestionarios online. Dicha herramienta ha sido utilizada por Balter et al (2013) y Huon et al (2007), quienes han demostrado que en áreas como la psicología o la ingeniería los estudiantes que los han empleado han conseguido significativamente mejores resultados que aquellos que no los han utilizado. Por ello, el objetivo del presente trabajo se ha centrado en analizar el efecto que ejerce el uso de cuestionarios sobre los resultados obtenidos por los estudiantes en la asignatura de contabilidad financiera y analítica impartida en la Universitat Autònoma de Barcelona.

Para ello, se ha dispuesto de datos correspondientes a 543 estudiantes relativos a: nota de acceso a la universidad, rendimientos obtenidos por los estudiantes en la parte teórica de la asignatura, número de veces que se han matriculado en la asignatura, identidad de los estudiantes y si tienen acceso a cuestionarios interactivos. Sobre dichos datos se han aplicado distintos análisis de covarianza que nos han permitido analizar la incidencia del factor grupo y consecuentemente del uso de cuestionarios, sobre el rendimiento obtenido por el estudiante en contabilidad, aislando el efecto de la habilidad inicial del estudiante. Los resultados obtenidos han demostrado la existencia de diferencias significativas en el rendimiento medio alcanzado por los siete grupos constituidos en la $\mathrm{UAB}$, obteniendo mejores resultados los estudiantes que han utilizado los cuestionarios interactivos. De este modo, la incorporación del cuestionario en la estrategia docente se configura como una herramienta efectiva para la adquisición de competencias por parte del estudiante de la asignatura de contabilidad financiera y analítica. 
Por ello, se recomienda la integración de los cuestionarios, como recurso docente de la asignatura de contabilidad financiera, en la guía docente de los nuevos grados ofertados por la Universitat Autònoma de Barcelona al objeto de que puedan ser utilizados por todos los estudiantes matriculados en la mencionada asignatura. Sin embargo, también deben tenerse en cuenta las implicaciones que provoca establecer la herramienta del cuestionario en la docencia. Implicaciones que afectan a los profesores que imparten la asignatura, a los estudiantes matriculados y a la facultad.

A los profesores que imparten la asignatura les implica una inversión de su tiempo en formación y preparación del diseño de los cuestionarios, siendo ésta la principal limitación que encontramos. Si bien, dicho esfuerzo inicial se ve compensado en años posteriores en los que se puede aprovechar y completar el material elaborado. Para reducir la carga de trabajo inicial, la facultad podría proporcionar personal de apoyo a la docencia para la ayuda en la implantación del cuestionario. Para el estudiante implica organizar su tiempo en horario no lectivo para elaborar el cuestionario propuesto por el profesor y poder seguir con su proceso de aprendizaje. Además, la facultad debe proporcionar una sala de ordenadores con conexión a internet y personal cualificado para facilitar a los estudiantes poder realizar los cuestionarios, ya sean los encargados por el profesor para hacerlos en horario fuera de clase, o para el caso que el profesor quiera hacer algún cuestionario en horario de clase. 


\section{REFERENCIAS BIBLIOGRÁFICAS}

Alba Pastor, C. (2005). El profesorado y las tecnologías de la información y la comunicación en el proceso de convergencia al Espacio Europeo de Educación Superior. Revista de Educación, 337,13-36.

Alba Pastor, C. y Carballo Santaolalla, R. (2005). Viabilidad de las propuestas metodológicas para la aplicación del crédito europeo por parte del profesorado de las universidades españolas, vinculadas a la utilización de las TIC en la docencia y en la investigación. Revista de Educación, 337, 71-97.

Area, M.; Sanabria A.L. y González, M. (2008). Análisis de una experiencia de docencia universitaria semipresencial desde la perspectiva del alumnado. RIED-Revista Iberoamericana de Educación a Distancia, 11 (1), 231-254.

Balter, O.; Enstrom, E. y Klingenberg, B. (2013). The effect of short formative diagnostic web quizzes with minimal feedback. Computers and Education, 60 (1), 234-242.

Bache, I. (2006). The Europeanization of higher education: markets, politics or learning? Journal of Common Market Studies, 44 (2), 231-248.

Benito, A. y Cruz, A. (2005). Nuevas claves para la Docencia Universitaria. Madrid: Narcea.

Bloom, B.; Englehart, M.; Furst, E.; Hill, W. y Krathwohl, D. (1956). Taxonomy of Educational objectives: the classification of educational goals. Handbook I. Cognitive Domain. London: Longman.

Buscà, F.; Pintor, P.; Martínez, L. y Peire, T. ( 2010). Sistemas y Procedimientos de Evaluación Formativa en docencia universitaria: resultados de 34 casos aplicados durante el curso académico
2007-2008 . ESE-Estudios Sobre Educación, 18, 255-276.

Chamorro-Premuzic, T.; Quiroga, M.A. y Colom, R. (2009). Intellectual competence and academic performance: a Spanish study. Learning and Individual Differences, 19 (4), 486-491.

De Paola, M. y Scoppa, V. (2010). Peer group effects on the academic performance of Italian students. Applied Economics, 42 (17), 2203-2215.

Ding, W. y Lehrer, S.F. (2007). Do peers affect student achievement in China's secondary schools? The Review of Economics and Statistics, 89 (2), 300312.

Elias, S.M. y MacDonald, S. (2007). Using past performance, proxy efficacy and academic self-efficacy to predict college performance. Journal of Applied Social Psychology, 37 (11): 2518-2531.

Fombona, J. y Pascual, M.A. (2011). Las tecnologías de la información y la comunicación en la docencia universitaria. Estudio de casos en la Universidad Nacional Autónoma de México (UNAM). Educación XX1 14.2, 79-110.

García, T. y García, J.C. (2013). Aplicación de cuestionarios online sobre el rendimiento académico. Revista de Informática Educativa y Medios Audiovisuales, 10 (17), 1-7.

García-Valcárcel, A. y Tejedor F.J. (2011). Variables TIC vinculadas a la generación de nuevos escenarios de aprendizaje en la Enseñanza Universitaria. Aportes de las Curvas ROC para el análisis de diferencias. Educación XX1, 14 (2), 43-78.

Garrison, D.R. y Anderson, T. (2003). E-learning in the 21st Century: A Fra- 
mework for Research and Practice. London: Routledge/Falmer.

Huon, G.; Spehar, B.; Adam, P. y Rifkin, W. (2007). Resource use and academic performance among first year psychology students. Higher Education, 53 (1), 1-27.

Leemkuil, H. y De Jong, T. (2012). Adaptive advice in learning with a computer based strategy game. Academy of management Learning and education, 11 (4), 653-685.

Lim, B.R. (2004). Challenges and issues in designing inquiry on the web. British Journal of Educational Technology 35 (5), 627-643.

Marcenaro-Gutiérrez, O.D. y NavarroGómez, M.L. (2007). El éxito en la universidad: una aproximación cuantílica. Revista de Economía Aplicada, 15 (44), 5-39.

Martí-Ballester, C.P. (2012). Análisis de los factores que influyen en el desempeño académico de los alumnos de contabilidad financiera a través de modelos de elección binaria. $R B G N-R e$ vista Brasileira de Gestão de Negócios, 14 (45), 379-399.

Martí Ballester, C.P. y Orgaz Guerrero, N. (2011). El cuestionario como herramienta de autoevaluación en el proceso de aprendizaje de la asignatura Contabilidad Financiera y Analítica. EDUCADE- Revista de Educación en Contabilidad, Finanzas y Administración de Empresas, 2, 51-66.

Mateo, J. y Vlachopoulos, D. (2013). Reflexiones en torno al aprendizaje y a la evaluación en la Universidad en el contexto de un nuevo paradigma para la educación superior. Educación XX1, 16 (2), 183-208.
Mora, A. y Mérida E. (2010). MetNum: Una experiencia de utilización de nuevas tecnologías y herramientas, para la mejora en los procesos de aprendizaje. Píxel-Bit. Revista de Medios y Educación, 38, 201-214.

Pat-el, J.R.; Tillema, H.; Segers, M. y Vedder, P. (2011). Validation of Assessement for Learning Questionnaires for teachers and students. British Journal of Educational Psychology, 83, 98-113.

Price, L. y Kinkwood, A. (2013). Using technology for teaching and learning in higher education: A critical review of the role of evidence in informing practice. Higher Education Research and Development (in press).

Rientes, B.; Brouwer, N. y Lygo-Baker, S. (2013). The effects of online professional development on higher education teachers' beliefs and intentions towards learning facilitation and technology. Teaching and Teacher Education, 29, 122-131.

Ruiz Carrascosa, J. (2005). La evaluación de la docencia en los planes de mejora de la Universidad. Educación $X X 1,8,87-102$.

Seethamraju, R. y Borman, M. (2009). Influence of group formation choices on academic performance. Assessment and Evaluation in Higher Education, 34 (1), 31-40.

Seluakumaran, K.; Fedelis F.; Rosnah, J y Husain, R, (2011). Integrating an open-source course management system (Moodle) into the teaching of a first-year medical physiology course: a case study. Advances in Physiology Education, 35, 369-377. 


\section{PALABRAS CLAVE}

Cuestionario, autoevaluación, proceso de aprendizaje, contabilidad financiera, ANCOVA.

\section{KEYWORDS}

Questionnaire, Self-evaluation, learning process, financial accounting, ANCOVA.

\section{PERFIL ACADÉMICO Y PROFESIONAL DE LAS AUTORAS}

Carmen Pilar Martí Ballester, profesora del Departamento de Economía de la Empresa e investigadora del Centro de Estudios e Investigación de Humanidades en la Universitat Autònoma de Barcelona. Su especialización se centra en el ámbito de la innovación educativa y la economía de la educación aplicada al área de contabilidad y finanzas, así como en la evaluación de la gestión de carteras y el comportamiento del inversor de instituciones de inversión colectiva. Participa como evaluadora en diferentes revistas y congresos.

Neus Orgaz Guerrero es profesora post-doc en la Universitat Autònoma de Barcelona. Su línea de investigación principal es la conexión entre el riesgo de mercado y la información contable publicada por la empresa. Paralelamente, lleva a cabo otra línea de investigación en innovación docente en el área de contabilidad y finanzas.

Dirección de las autoras: Departamento de Economía de la Empresa Campus B

Universitat Autònoma de Barcelona 08193 Bellaterra (Barcelona)

E-mail: Neus.Orgaz@uab.cat

Fecha Recepción del Artículo: 23. Junio. 2011

Fecha modificación Artículo: 13. Febrero. 2012

Fecha Aceptación del Artículo: 06. Junio. 2012

Fecha de Revisión para publicación: 24. Junio. 2013 


\title{
LA RELACIÓN EDUCATIVA CON MUJERES EN CONTEXTOS DE PROSTITUCIÓN: LA DIMENSIÓN PEDAGÓGICA DE LA INTERVENCIÓN
}

\author{
(THE EDUCATIONAL RELATIONSHIP WITH WOMEN IN PROSTITUTION \\ CONTEXTS: THE PEDAGOGICAL DIMENSION OF THE INTERVENTION)
}

\author{
Ana Ayuste González y Montserrat Payá Sánchez \\ Universidad de Barcelona
}

DOI: 10.5944/educxx1.17.1.10715

\section{Cómo referenciar este artículo/How to reference this article:}

Ayuste González, A. y Payá Sánchez, M. (2014). La relación educativa con mujeres en contextos de prostitución: la dimensión pedagógica de la intervención. Educación XX1, 17 (1), 291-308. doi: 10.5944/educxx1.17.1.10715.

Ayuste González, A. y Payá Sánchez, M. (2014). Tthe educational relationship with women in prostitution contexts: the pedagogical dimension of the intervention. Educación XX1, 17 (1), 291-308. doi: 10.5944/educxx1.17.1.10715.

\section{RESUMEN}

El objetivo de este artículo es dar a conocer la intervención socioeducativa con mujeres en contextos de prostitución desde la acepción de educación como relación. Deriva de una investigación ya concluida de tipo cualitativo, etnográfico y socio-crítico en la que se han recogido las voces de mujeres inmigrantes que están en contextos de prostitución, profesionales de la intervención y especialistas teóricas en el tema.

Este nivel micro, interpersonal, de la acción educativa — recogido como relación «cara a cara» o relación de proximidad- está presente, aunque bajo formas e intensidades diferentes-, en todos y cada uno de los ámbitos y tipologías de la intervención: la ya citada relación "cara a cara», de grupo, el trabajo de y en equipo, con la comunidad y con las administraciones. A partir de esta relación de proximidad se producen las condiciones necesarias para que se vivencie el reconocimiento posibilitador de logros en lo que respecta a autonomía, responsabilidad, toma de conciencia y autoestima de las mujeres en contextos de prostitución.

\section{ABSTRACT}

The purpose of this article is to grasp the socio-educational intervention with women in prostitution contexts from the meaning of education as a relationship. It leads from a concluded qualitative, ethnographic and social- 
critical investigation in which they have gathered the voices of migrant women who are in situations of prostitution, intervention professionals and specialists in the field theory.

This micro level, interpersonal, of educational action — collected as «face to face» relationship or close relationship_-, are present, although in ways and different intensities, in each and every one of the areas and types of intervention: already mentioned relationship «face to face», of group, team work, community and government. This close relationship will produce the conditions for recognition that makes achievement in regard to autonomy, responsibility, awareness and self-esteem of women in situations of prostitution.

\section{INTRODUCCIÓN}

El movimiento de personas de los países pobres a los países ricos en busca de trabajo no es nuevo. Sin embargo, la velocidad y el alcance que han adquirido las migraciones femeninas desde los años 80 no tienen precedente. La masculinización de la riqueza, el progresivo empobrecimiento de las zonas más necesitadas del mundo, y el incremento de ofertas laborales relacionadas con la industria del cuidado en los países receptores de la inmigración (Hochschild, 2008), están provocando que muchas mujeres con escasas posibilidades de subsistencia o expectativas de futuro abandonen sus países en busca de mejores oportunidades. Pero son muchos los obstáculos y barreras con los que se encuentran en el país de llegada, agravados por el contexto económico actual, y que les impiden consolidar su proyecto migratorio y su plena participación en el mercado laboral y la sociedad en general (Ayuste y Payá, 2010). En este contexto, la prostitución supone para algunas de estas mujeres una vía para adquirir los recursos económicos que consideran necesarios.

El perfil de las mujeres inmigrantes que ejercen la prostitución es enormemente diverso. Éste varía en función de la edad, el lugar de procedencia, el nivel de instrucción, la extracción social, las expectativas, la vivencia subjetiva y los recursos personales. Sin embargo, hay dos factores que tienden a coincidir en la mayoría de los casos. El primero de ellos tiene que ver con la necesidad económica como principal motivo para acercarse al mundo de la prostitución. La industria del sexo es más rentable económicamente que otros espacios laborales como el trabajo doméstico al que tradicionalmente tienen acceso buena parte de las mujeres inmigrantes. Esta es una de las razones por las que muchas mujeres, después de una valoración de sus propias opciones, optan por la prostitución como actividad principal o se refugian en ella en momentos puntuales en los que necesitan obtener algunos ingresos (Holgado, 2008).

El segundo factor coincidente está relacionado con la vivencia personal del estigma. En general, uno de los factores que más acusan las mujeres que se dedican a la prostitución, y de manera más acentuada las que ejercen 
en la calle, son las miradas de reprobación y las descalificaciones que tienen que soportar día tras día. Miradas y mensajes que tienden a dañar su propia imagen y las obliga a desarrollar estrategias para encubrir su propio yo. Las mujeres se ven empujadas así a separar radicalmente entre lo que consideran su propia identidad - la real — y la que representan socialmente —identidad social- (Goffman, 1970; 2003). De ahí que la percepción subjetiva del estigma, y determinadas políticas y comportamientos sociales que se derivan del imaginario social de la prostitución, tienden a reducir las oportunidades y la calidad de vida de estas mujeres (Pheterson, 2000; Juliano, 2002; Osborne, 2004).

Con este artículo queremos visibilizar y reconocer el trabajo educativo orientado a ampliar las oportunidades de las mujeres que están desarrollando entidades y profesionales que intervienen en este ámbito. Desde esta perspectiva, nuestra mirada sobre la prostitución trata de captar la dimensión pedagógica de esta realidad y hacer emerger el conocimiento práctico de las profesionales. Para ello, nos referiremos a algunos de los resultados que hemos obtenido a través de la investigación que hemos realizado bajo el título «Mujer, inmigración y prostitución: elementos para la intervención socioeducativa». Esta investigación se inscribe dentro del Programa de Acciones Complementarias del VI Plan Nacional de Investigación Científica del Ministerio de Ciencia e Innovación y se ha realizado durante el período comprendido entre el 2009 y el 2011. En el equipo estaban representadas las universidades de Barcelona, Gijón y Las Palmas de Gran Canaria; el Instituto Universitario de Desarrollo y Cooperación, de la Universidad Complutense de Madrid; la fundación Sicar-Cat. (Adoratrices) y el servicio Abits (Agencia para el Abordaje Integral del Trabajo Sexual) del Ayuntamiento de Barcelona.

\section{ESTADO DE LA CUESTIÓN Y DEBATE FEMINISTA}

Tanto a nivel nacional como internacional, la mayor parte de estudios y análisis que se han realizado sobre la realidad de la prostitución provienen de disciplinas como la sociología, la antropología, la medicina, la psicología y el derecho (Delacoste y Alexander, 1987; Llim, 1998). Aunque en un primero momento han abundado los trabajos especialmente descriptivos y de ámbito local, desde hace unos años se vienen realizando estudios con un enfoque global y centrados en la comprensión de los factores que atraviesan el ejercicio de la prostitución (v. p.e. Juliano, 2002; Agustín, 2004). Desde la perspectiva educativa y dentro de nuestro estado, el tema se ha estudiado más recientemente y con una dimensión especialmente práctica orientada a la presentación de programas y propuestas de intervención socioeducativa (v. p.e., Meneses, 2000; Barahona y García, 2004; Ballester, Orte y Perelló, 2004).

El movimiento feminista, por su parte, se divide entre dos perspectivas diferentes y enfrentadas (Ordóñez, 2006). Por un lado, la postura abolicio- 
nista, que considera la prostitución como un acto de violencia contra las mujeres que debe ser erradicado (Barahona y García, 2004), y, por otro, la perspectiva pro-derechos, que entiende la regulación de la prostitución como la mejor vía para garantizar la calidad de vida de las mujeres que la ejercen (Briz y Garaizábal, 2007).

En este contexto, la postura abolicionista considera que la prostitución no puede ser considerada como una actividad económica más puesto que cosifica el cuerpo de la mujer, convirtiéndolo en una simple mercancía de consumo. Por otra parte, sostiene que la mayoría de las mujeres que se dedican al comercio sexual no lo hacen libremente. Son las condiciones de pobreza en sus países, la falta de derechos y oportunidades y, en ocasiones, los malos tratos a los que se ven sometidas, lo que empuja a estas mujeres al ejercicio de la prostitución. Esto, y concebir la prostitución como una forma de violencia, es lo que convierte a las mujeres que se ven abocadas al ejercicio de la prostitución en víctimas potenciales (Barry, 1988). De ahí que no establezcan ninguna separación entre lo que podría denominarse como trabajo sexual acordado, aquél que las mujeres realizan libremente a cambio de una gratificación económica, y el sexo coercitivo.

Desde la perspectiva que defiende los derechos laborales de las mujeres que se ocupan en prostitución, ésta se ha de considerar un trabajo para quienes recurren a esta actividad como vía para obtener recursos económicos. Ello daría la oportunidad a las mujeres inmigrantes en situación de irregularidad administrativa de salvar los obstáculos para legalizar su residencia en el país y acogerse a los derechos sociales y ciudadanos a los que no tienen acceso. De ahí que, a diferencia de la postura anterior, cree conveniente separar entre prostitución forzada y libre, y no asimilar la prostitución a la violencia de género. De lo contrario, se corre el riesgo de silenciar la voz de las mujeres que afirman que la prostitución es una estrategia económica más, y el hecho de que la falta de reconocimiento de esta actividad las obliga a permanecer en los márgenes de la sociedad y a enfrentarse, en muchas ocasiones, a situaciones todavía más peligrosas (Juliano, 2002; Osborne, 2004). Cabe considerar que en España la prostitución no está regulada ni penalizada, aunque sí están penalizados el proxenetismo y la trata de personas con fines de explotación sexual (Art. 188.1 ${ }^{\circ}$ del Código penal; Protocolo para prevenir y reprimir y sancionar la trata de personas, especialmente, mujeres y niños —Palermo, 13 de diciembre de 2000—).

Ambos enfoques, sin embargo, coinciden en abordar este fenómeno desde la óptica de los Derechos Humanos, aunque, lógicamente, el análisis y el contenido de las propuestas difieren notablemente. Para la perspectiva abolicionista la prostitución constituye un ataque contra los derechos humanos, dado que la considera una actividad altamente perjudicial para las 
mujeres a nivel físico, psicológico, afectivo y social. Entiende, además, que, en muchas ocasiones, la mujer no es plenamente consciente de esa situación por lo que se refiere a éstas como «mujeres prostituidas». Las acciones que este modelo realiza se centran en la abolición de la prostitución mediante el desarrollo de medidas legislativas y de políticas públicas adecuadas, entre las que se encuentra el penalizar al "prostituidor», y en conseguir una vida digna o normalizada para estas mujeres. Por su parte, el enfoque pro-derechos otorga a la mujer un papel activo, considerándola sujeto y agente, siempre en el caso de que sea ésta quien voluntariamente opta por ejercer la prostitución. El trabajo por los Derechos Humanos se enmarca, entonces, desde la desigualdad económica y la justicia social. Simultáneamente, enfocan también el debate desde los derechos laborales, procurando que las mujeres que se ocupan en prostitución pueden ejercer esa actividad en condiciones de trabajo igual de dignas que cualquier otro empleo. Así, mientras para la primera postura la prostitución ha de erradicarse e impedir la demanda de sexo, para la segunda hay que reconocer dicha actividad a fin de evitar situaciones de abuso, exclusión y estigmatización.

\section{DESARROLLO METODOLÓGICO}

La investigación que presentamos en este artículo se propuso recoger y sistematizar las necesidades de las mujeres inmigrantes en contextos de prostitución, preferentemente las que ejercen en medio abierto — calle-, el conocimiento pedagógico explícito y tácito de profesionales y entidades que trabajan con ellas, así como las prácticas educativas que la intervención en este ámbito comporta. Para ello debíamos acercarnos a la realidad y recoger la máxima pluralidad de voces. Por ese motivo optamos por un enfoque metodológico de carácter cualitativo desde una perspectiva socio-crítica y etnográfica.

A través de la metodología cualitativa se enfatiza la comprensión de las realidades por encima del establecimiento de relaciones causales o de la evaluación de determinadas teorías, conceptos o prácticas. En este sentido, pretendimos acercarnos al objeto de estudio desde los supuestos de complejidad, heterogeneidad y pluralidad dado que son los que mejor interactúan con el ámbito de la prostitución femenina, siguiendo las aportaciones teóricas consultadas al respecto (Arella, Fernández, Nicolás y Vartabedián, 2007). Ello implicó acercarnos al entorno natural en que se produce la realidad a investigar (profesionales, mujeres, entidades, medio abierto...). Por su parte, la perspectiva socio-crítica y la metodología etnográfica, orientadas también a la comprensión de la realidad, priman la voz de los agentes como fuente privilegiada de información, confiando en sus capacidades de interpretación y de transformación de la realidad. En este sentido, las aportaciones desde las ciencias sociales de autores como Giddens (1995) y Habermas 
(1987) nos fueron especialmente útiles para desarrollar la investigación a partir de las interpretaciones y reflexiones de las mujeres y las aportaciones generadas desde ámbitos profesionales y académicos.

Desde este enfoque metodológico, la muestra se configuró a partir de tres perfiles de informantes clave. Un primer grupo de personas expertas, entendidas como aquéllas que por su trayectoria académica o política se consideran referentes en la temática —con responsabilidad política en los temas de mujer e igualdad; vinculadas a la academia; y representantes de movimientos sociales y organizaciones no gubernamentales; asegurando la presencia de las dos perspectivas feministas sobre prostitución-. Un segundo grupo con profesionales de instituciones o entidades que trabajan directamente con las mujeres. En este caso, se tuvo en cuenta recoger la diversidad de centros —vinculados con la Administración, de carácter religioso y ONG's- y de perfiles profesionales diferentes. Finalmente, un tercer grupo formado por mujeres inmigrantes que se ocupan en prostitución, a las que tuvimos acceso gracias a la colaboración de los centros que participaron en el curso de la investigación. En este sentido cabe destacar la participación como miembros del equipo de investigación, de dos profesionales vinculadas directamente a la práctica. El siguiente cuadro sintetiza el trabajo de campo realizado:

\begin{tabular}{|c|c|c|}
\hline Objetivos & Sujetos participantes & $\begin{array}{c}\text { Instrumentos de recogida } \\
\text { de información }\end{array}$ \\
\hline \multirow[t]{3}{*}{$\begin{array}{l}\text { 1. Conocer las nece- } \\
\text { sidades y expectati- } \\
\text { vas educativas de las } \\
\text { mujeres inmigrantes } \\
\text { que ejercen la prosti- } \\
\text { tución. }\end{array}$} & $\begin{array}{l}6 \text { personas especialistas en } \\
\text { la temática de los ámbitos } \\
\text { político; universitario y } \\
\text { ONGs y movimientos so- } \\
\text { ciales (una de las personas } \\
\text { entrevistadas trabaja en pro- } \\
\text { yectos internacionales). }\end{array}$ & $\begin{array}{l}6 \text { entrevistas semiestructu- } \\
\text { radas. }\end{array}$ \\
\hline & $\begin{array}{l}6 \text { mujeres inmigrantes } \\
\text { que se habían ocupado en } \\
\text { prostitución y que en el mo- } \\
\text { mento de la investigación } \\
\text { asistían a un programa de } \\
\text { recolocación laboral. } \\
3 \text { mujeres inmigrantes víc- } \\
\text { timas de trata con fines de } \\
\text { explotación sexual. }\end{array}$ & $\begin{array}{l}1 \text { grupos de discusión. } \\
1 \text { grupo de discusión. }\end{array}$ \\
\hline & $\begin{array}{l}10 \text { profesionales de la inter- } \\
\text { vención en el ámbito con di- } \\
\text { ferentes perfiles formativos } \\
\text { (trabajo social, psicología, } \\
\text { educación social, media- } \\
\text { ción, medicina). }\end{array}$ & 2 grupos de discusión. \\
\hline
\end{tabular}




\begin{tabular}{|c|c|c|}
\hline Objetivos & Sujetos participantes & $\begin{array}{c}\text { Instrumentos de recogida } \\
\text { de información }\end{array}$ \\
\hline \multirow{3}{*}{$\begin{array}{l}\text { 2. Analizar la dimen- } \\
\text { sión educativa de las } \\
\text { acciones que reali- } \\
\text { zan las entidades que } \\
\text { trabajan con mujeres } \\
\text { en contextos de pros- } \\
\text { titución y recoger } \\
\text { buenas prácticas. }\end{array}$} & $\begin{array}{l}11 \text { profesionales con más de } \\
\text { tres años de experiencia en } \\
\text { el ámbito y con perfiles for- } \\
\text { mativos diversos (psicología, } \\
\text { abogacía, educación social, } \\
\text { trabajo social, sociología). } \\
\end{array}$ & $\begin{array}{l}7 \text { entrevistas semiestructu- } \\
\text { radas (una de ellas colec- } \\
\text { tiva a todo el equipo de la } \\
\text { entidad participante). }\end{array}$ \\
\hline & $\begin{array}{l}8 \text { profesionales de diversos } \\
\text { perfiles formativos y perte- } \\
\text { necientes a } 7 \text { entidades. } \\
7 \text { profesionales de diversos } \\
\text { perfiles formativos y perte- } \\
\text { necientes a } 5 \text { entidades. }\end{array}$ & $\begin{array}{l}2 \text { grupos de discusión. } \\
2 \text { grupos de discusión. }\end{array}$ \\
\hline & $\begin{array}{l}2 \text { profesionales y mujeres } \\
\text { inmigrantes que se ocupan } \\
\text { en prostitución. }\end{array}$ & $\begin{array}{l}6 \text { observaciones partici- } \\
\text { pantes. }\end{array}$ \\
\hline $\begin{array}{l}\text { 3. Recoger la voz de } \\
\text { las mujeres inmi- } \\
\text { grantes que ejercen } \\
\text { la prostitución y exa- } \\
\text { minar las vías que fa- } \\
\text { vorecen la inclusión. }\end{array}$ & $\begin{array}{l}7 \text { mujeres inmigrantes que } \\
\text { ejercen la prostitución en la } \\
\text { calle y } 1 \text { mujer víctima de } \\
\text { trata con fines de explota- } \\
\text { ción sexual (diversos países } \\
\text { de procedencia; más de año } \\
\text { y medio de permanencia en } \\
\text { nuestro estado y de ocupa- } \\
\text { ción en prostitución; entre } \\
19 \text { y } 40 \text { años; diversos ni- } \\
\text { veles de instrucción: de sin } \\
\text { estudios a con estudios su- } \\
\text { periores no concluidos; con } \\
\text { y sin permiso de residencia). }\end{array}$ & 8 relatos de vida. \\
\hline
\end{tabular}

En total configuraron la muestra 59 personas (omitimos del cómputo las dos profesionales que nos facilitaron las observaciones participantes, así como las mujeres con quienes establecimos contacto durante las mismas). Las profesionales y especialistas participantes en la investigación pertenecen a las Comunidades Autónomas de Cataluña, Asturias, Madrid, Canarias y Galicia. Una de las personas especialistas es de Brasil. Los países de procedencia de las mujeres en contextos de prostitución que participaron como informantes son: Brasil, Colombia, Ecuador, Uruguay, Rumanía, Argelia y Nigeria.

La técnica utilizada para el análisis de la información fue el método de análisis de contenido sin soporte informático, con un enfoque holístico y procediendo de forma molar. Las categorías se elaboraron inductivamente tras la lectura de diversas transcripciones y con acuerdo entre investigadoras. El rigor y la coherencia interna de la investigación fueron trabajados desde 
los supuestos teóricos asumidos por el equipo investigador y desde la triangulación de: fuentes de información; teorías e investigadoras e instrumentos de recogida de información.

\section{COMUNICACIÓN DE RESULTADOS}

A continuación presentamos los principales resultados elaborados a partir de las aportaciones y reflexiones que expertas, profesionales y mujeres que han participado en esta investigación, han compartido con nosotras, y que sacan a la luz la dimensión pedagógica de la intervención en este ámbito. En su sistematización hallamos que los conceptos de «relación educativa» $\mathrm{y}$ "acción comunicativa» se adaptaban totalmente a las prácticas que realizan y el sentido que otorgan a las mismas, y pudimos conocer los objetivos y principios que guían el trabajo pedagógico de las profesionales.

\section{La acción socioeducativa con mujeres en contextos de prostitución}

Se caracteriza por la proximidad entre mujer y profesional, por ser sumamente personalizada, por una gran obertura y flexibilidad y por servirse especialmente del diálogo. Es por ello que la conceptualizamos como relación educativa y acción comunicativa. Entender la educación como relación supone definirla desde la interacción entre dos elementos - personapersona y persona-medio- que se influyen mutuamente (Sanvisens, 1984; Freire, 1997; Morin, 2001). Por otra parte, la educación es una de las formas que puede adoptar la acción comunicativa entre seres humanos: así, los procesos educativos son procesos relacionales y comunicativos que tienden al entendimiento y al cambio (Habermas, 1987; Rogers, 1987).

Cinco son los ámbitos o dimensiones de intervención: la relación «cara a cara», de cercanía o proximidad -mujer-profesional—; la relación de grupo - mujeres-profesional—; el trabajo de y en equipo — entre profesionales de una misma entidad y entre profesionales de diferentes entidades-; la relación con el entorno - vecindario, comunidad-; y la relación con las Administraciones. En estos cinco ámbitos es común encontrar manifestaciones y ejemplos de ambos conceptos: cuando la profesional conversa con la mujer y se interesa por su estado de salud o le cuestiona una parte de su realidad; cuando realizan una salida recreativa en grupo o la profesional aprovecha situaciones espontáneas para que aprendan unas de otras; cuando, en el seno de la entidad, los miembros del equipo supervisan conjuntamente los casos o analizan el riesgo de ciertos automatismos en su práctica; cuando las profesionales suman esfuerzos entre ellas para conseguir determinado recurso que la mujer necesita o derivan la demanda a la entidad que está 
en mejor situación para darle respuesta; cuando las educadoras agradecen gestos espontáneos de solidaridad con las mujeres de algún vecino/a o reivindican algún derecho de las mujeres que no es respetado; cuando profesionales y entidades colaboran con iniciativas de las Administraciones o exigen el cumplimiento de lo acordado en otras ocasiones...

El sentido y finalidad de la intervención es el segundo gran núcleo de contenido que permite caracterizar la acción de las profesionales del ámbito. Así, en primer lugar, es interesante destacar cómo se puede perfilar una propuesta de objetivos, principios y prácticas de la intervención socioeducativa compartida por las entidades y las profesionales con las que hemos tenido la oportunidad de entrevistarnos. Incluso desde la pluralidad y diversidad ideológica y respetando, asimismo, los diferentes estilos personales de cada profesional, se puede hablar de un sentido y propósito de la intervención comunes y que se dirige, como expresa la siguiente profesional, a «desarrollar la autonomía de la mujer, su capacidad de decisión, de marcar objetivos y llegar a ellos» (entrevista a profesionales, I., pág. 15). Así, los objetivos de autonomía, responsabilización, toma de conciencia y autoestima, especialmente, han sido mencionados en todas las entrevistas y grupos de discusión realizados. Igualmente, lo han sido los principios de partir de la realidad; poner a la mujer en el centro de la intervención; dirigirse a la mujer en su totalidad y no desde la actividad que realiza; acompañamiento; escucha y la idea de proceso. Por otra parte, cabe también subrayar la elevada coherencia observada entre objetivos y principios de la intervención socioeducativa. En el apartado siguiente intentaremos ejemplificar esta coherencia mediante la presentación y el análisis de algunas de las prácticas más comunes de los equipos de profesionales en el ámbito que nos ocupa.

En tercer término, cabría mencionar como otro rasgo distintivo común la elevada flexibilidad con que proceden profesionales y entidades: personalizando cada intervención al máximo, concediendo total protagonismo a la mujer, rentabilizando y hasta exprimiendo los recursos disponibles. Por último, en cuarto lugar, pero no menos significativo, queremos recoger otro aspecto que imprime sello a la relación educativa en este contexto: la necesidad y la actitud expresada por todas las profesionales con quienes hemos tenido la suerte de entrevistarnos, de tomar distancia, alejarse de lo inmediato, de la acción, para pensar su práctica, reflexionarla y analizarla.

\section{Objetivos y principios de la relación educativa con mujeres en contextos de prostitución}

Las entidades con quienes nos entrevistamos comparten un objetivo global de la intervención, con una clara dimensión socio-política: que las 
mujeres accedan a sus derechos como ciudadanas y tengan oportunidades. Bajo este objetivo caben al menos dos planteamientos. Por una parte, se trata de dar a conocer a las mujeres sus derechos como ciudadanas, de facilitarles al acceso a los recursos y servicios, y de traspasarles la información necesaria para un ejercicio seguro de la prostitución. Es en este caso cuando las diferencias entre las perspectivas pro-derechos y la abolicionista se hacen más presentes. Mientras para las primeras, el objetivo fundamental consiste en que «las trabajadoras del sexo puedan constituirse como sujetos sociales. Es decir, que pasen de individualidades con sus problemas específicos a construir un sujeto social que pueda reivindicar derechos en una sociedad que las invisibiliza y victimiza» (entrevista a expertas, C.G., pág. 6). Para las segundas, las abolicionistas, el empoderamiento pasa por «visibilizar las consecuencias que tiene el ejercicio de la prostitución y el mal que la acompaña, (...) las consecuencias que tiene para la salud tanto física como mental y las consecuencias sociales» (entrevista a expertas, A.B., pág. 7).

Sin embargo, tanto para unas como para otras, se trata de ampliar sus horizontes y acompañarlas en el proceso de cambio o formación que ellas deseen iniciar hasta que ya no necesitan apoyos. Así, no se trata sólo de reducir la situación de vulnerabilidad social, sino de ofrecer herramientas para que puedan ampliar sus horizontes a nivel personal, relacional, formativo o laboral. El plan de trabajo individual o el itinerario personal que mujer y profesional acuerdan es el reflejo donde se puede observar el trabajo que los equipos de profesionales realizan sobre este particular. Con las mujeres que así lo desean, las profesionales ofrecen la posibilidad de seguir ese proceso. El plan de trabajo individual se elabora conjuntamente, mujer y profesional, con lo que se puede considerar una evidencia concreta de corresponsabilidad, pero es la mujer quien marca los contenidos - formativos, laborales, personales- y establece las metas. La profesional le presta apoyo preparando momentos de encuentro para conversar con tranquilidad y en profundidad acerca de los contenidos o temas elegidos. Durante estos encuentros la profesional acompaña la reflexión que acerca del tema la mujer va realizando, y el proceso de toma de decisiones - presentación de todas las alternativas posibles, previsión de sus consecuencias, valoración de cada alternativa-, pero es la mujer quien decide - elegir el curso formativo que prefiere y para el que se siente mejor preparada; buscar ofertas laborales en función de su formación y sus capacidades; cuidar más su salud y bienestar-.

Este seguimiento tan personalizado y la enorme disponibilidad de las profesionales son aspectos muy valorados por parte de las mujeres puesto que les hace sentirse acompañadas y aceptar nuevos retos con mayor seguridad, como leemos a continuación: «El lunes empecé a hacer unos cursillos, pues si Marta no me llamó cuatro o cinco veces, no me llamó ninguna (...). O sea, ves esa preocupación, entonces tú también te sientes más satisfecha 
contigo misma. (...). Aparte, cuando fui, ella me acompañó el primer día también. Estuvo conmigo hasta el último momento y eso a ti te hace sentir más segura. Es decir: "No estoy sola"». (grupo de discusión mujeres, S1, pág. 8).

Un segundo gran objetivo que se plantean las entidades y los equipos de profesionales es el de luchar contra el estigma y el estereotipo. En él se refleja claramente la labor de sensibilización social y, con ella, de formación de la ciudadanía que realizan en relación a la realidad de las mujeres. Las profesionales lo llevan a cabo de múltiples maneras: participando en todos aquellos espacios, mesas, foros... que las administraciones proponen, llevando a ellos la realidad de las mujeres en prostitución, sus necesidades y también sus deseos y expectativas, es decir, amplificando la voz de las mujeres; explicando a los/las profesionales del sistema público sanitario algunas de las necesidades específicas de las mujeres en contextos de prostitución; desmontando estereotipos sobre ellas —-son limpias, son educadas-; y, en algunos casos, alentándolas a manifestarse públicamente en contra de algunas medidas sancionadoras contra ellas y los clientes o censurando la publicidad de servicios sexuales en algunos medios de comunicación.

Por otra parte, no se limitan sólo a este tipo de acciones más formales o institucionalizadas, sino que las profesionales trabajan por la superación del estereotipo y del estigma mediante intervenciones más informales o espontáneas. Así, conversan con los vecinos y vecinas, dueños/as de locales del barrio donde ejercen las mujeres para que tengan en consideración y respeten ciertos condicionantes o necesidades derivadas de su ocupación - poder refugiarse del frío; poder contar con el apoyo del dueño de un bar cercano para guardar allá algunas pertenencias-. Al respecto, se podría decir que suelen realzar las muestras de solidaridad espontánea de la gente de la calle, las ponen como modelo a seguir por otras personas.

En relación a esta mirada social estereotipada sobre la prostitución, las mujeres reclaman mayor respeto y comprensión como muestran las siguientes reflexiones: "Que se escuche antes de juzgar porque somos todos personas y nadie es mejor que otro (...). Todos tenemos algo bueno o malo que decir». (grupo de discusión mujeres, S2, pág. 20). «Por desgracia siempre va a haber prostitución. Siempre va a haber mujeres. Es un trabajo muy antiguo. Y si yo tuviera que decir algo a la gente le diría que no se metan en mi vida. ¿Qué te pareció un trabajo fácil? Pues ¡hazlo!, ¡hazlo tú!» (grupo de discusión, S1, pp. 15-16). En este sentido, la clave para evitar conflictos con el vecindario en zonas donde se concentra la prostitución es el respeto: «Depende de cómo tú respetas a los vecinos para que te respeten ellos a ti también» (grupo de discusión, S1, pág. 16). Un ejemplo de la manifestación de respeto lo expresa esta participante: «Que todas las mujeres fueran más 
o menos decentes por la calle, ¿no? Por el día. Por la noche es otra cosa (...). ¡Claro! Lo ven los niños. No puede ser". (relatos de vida, R1, pág. 33).

Hasta aquí hemos planteado objetivos de carácter más social e incluso político, algunos de los cuales no tenían a las mujeres en contextos de prostitución como únicas protagonistas. Ahora vamos a presentar otros objetivos de carácter más personal centrados totalmente en la mujer y de clara dimensión educativa. Es en este segundo bloque de objetivos donde las acepciones de educación como relación y acción comunicativa se hacen aún más manifiestas, abarcando todas y cada una de las formas de la intervención. Se observará también cómo esos objetivos devienen principios y prácticas educativas.

En primer lugar las entidades destacan como objetivo de la intervención contribuir al desarrollo de la autonomía de las mujeres en los diferentes ámbitos de la vida. Este objetivo a conseguir orienta la práctica educativa a partir de situaciones en las que sea preciso que la mujer actúe y tome la iniciativa: ir a una visita ginecológica, valorar las posibilidades de cambiar de ocupación, inscribirse en un curso formativo, introducir cambios en la relación de pareja, solicitar la reagrupación familiar, etc. Para ello, se facilitan procesos de reflexión, de análisis de alternativas y de autovaloración de las propias capacidades. Son situaciones en las que pueden sentirse acompañadas y ganar confianza en sus propias posibilidades mediante el refuerzo y la interacción positiva con las profesionales y también entre ellas. Se trata, en definitiva, de tejer relaciones de solidaridad y de cuidado que les permita ganar confianza en sí mismas y una progresiva autonomía relacional. De ahí que una concepción cercana a la pedagogía del cuidado, como la ha denominado Vázquez (2010), esté tan presente en este tipo de relación educativa.

La toma de responsabilidades o responsabilización es otro de los objetivos personales más significativos de la intervención con mujeres en contextos de prostitución. Como consecuencia de la actividad que ejercen, a muchas mujeres les cuesta ajustarse a un horario, especialmente si ello implica madrugar o perder horas de sueño. Poco a poco, las profesionales intentan que sean conscientes de que concertar una visita, médica por ejemplo, supone la obligación de acudir el día y a la hora pactados. Se trata también de que paralelamente a la asunción de las consecuencias de los propios actos —en el caso anterior, cumplimiento o no de la cita médica-, la mujer vaya siendo consciente de que hay unos límites que marca la misma realidad, y de que todas las personas debemos ajustar nuestro proceder a esos márgenes de acción que la realidad nos permite. Por eso, ajustarse a los horarios y las pautas o normas de las instituciones o de los procedimientos, así como mantener los acuerdos - acudir a las citas con la educadora, asistir al curso formativo regularmente, cumplir con las tareas asignadas-, es otro 
importante medio a través del cual ir desarrollando la toma de responsabilidades y también la autonomía.

El tercer gran objetivo de la intervención en su dimensión personal es el que se refiere justamente a la toma de confianza y autoestima. Sin confiar en el medio social, difícilmente una persona se atreverá a salir al mundo de fuera; sin confiar en las propias capacidades, difícilmente una persona puede ser autónoma. Nuevamente, las profesionales lo trabajan de manera gradual, como proceso, partiendo de las posibilidades que al respecto ofrece la vida cotidiana y comunicando su creencia en las posibilidades de la mujer. Para ello, las educadoras procuran que las mujeres construyan un buen concepto y una estima ajustada de sí mismas, destacando sus cualidades a nivel personal, familiar, doméstico, educativo, profesional y aquellas que se derivan de su ocupación en prostitución - capacidad para negociar, poner límites, escuchar (Agustín, 2004) —. Cuando la profesional las pone en evidencia y subraya lo positivo de una capacidad determinada, les da valor y la mujer, al reconocerse en ellas, les da también más valor al tiempo que pueden orientarla en el proceso de toma de decisiones, como puede verse reflejado en la siguiente reflexión de una mujer que participaba en un curso formativo de estas características: «Muchas competencias las tenemos, pero yo creo no las llamamos así, las llamamos de ninguna manera (...). Y cuando te las exponen, cuando hacen que las observes, entonces... y sobre todo, cuando haces que te las valores, te das cuenta de que tienes un montón». (grupo de discusión mujeres, S1, pág. 5).

La apuesta por la autonomía de la mujer, su responsabilización y toma de confianza y autoestima, se manifiestan también claramente en el momento de dar por concluido el proceso - en el caso de que la mujer haya seguido un plan de trabajo individual- . Nuevamente la decisión corresponde a la mujer, es ella quien considera si ha alcanzado los objetivos propuestos y no necesita del apoyo o referente cercano de la profesional. Aunque las entidades no cierran nunca la puerta ante un posible retorno de la mujer motivado por alguna circunstancia o necesidad específica.

Hasta aquí hemos presentado y desarrollado brevemente los objetivos de la intervención socioeducativa con mujeres en contextos de prostitución. Los principios educativos que se hallan en la base de esta forma de relación educativa, se desprenden fácilmente de lo ya relatado y a su presentación nos dedicaremos ahora, si bien brevemente. Así, como ya hemos anticipado, se trata de una relación educativa sumamente individualizada y personalizada, lo que implica partir de la mujer como protagonista, situarla en el centro de la intervención e individualizar al máximo cada relación educativa y cada acción dentro de ella, como decía una profesional, «es una respuesta muy abierta, construida con ella, respetando sus posibilidades 
y los momentos en la vida de la mujer» (entrevista a profesionales, Ab., pág. 13). En este sentido, es interesante hacer notar cómo los equipos de profesionales se mantienen alertas frente al riesgo de automatismos en la intervención: la reflexión sobre la propia práctica, el trabajo en equipo, la supervisión de los casos y el cambio de referente o educadora, algunas ya citadas, son las vías que utilizan para garantizar que cada relación educativa se viva como única.

Un segundo gran principio que la fundamenta es el de partir de la realidad: las entidades están presentes en el medio físico donde trabaja la mujer, muchas de ellas suelen hacer recorridos o trayectos por las calles donde están las mujeres, ofreciéndoles sus servicios, charlando amigablemente con ellas, y también observando si los derechos de las mujeres son respetados o no. Este principio se concatena con otros dos: el de cercanía y proximidad, por un lado, y el de escucha, por otro. Ello les permite, como se pone de manifiesto en la siguiente aportación, «partir de sus propios discursos y experiencias tratando de rehuir de aquellos estereotipos (...) para intentar delimitar el nivel de estigmatización del colectivo y, por consiguiente, hacerles más fácil la vida» (entrevista a expertas, D. J., pág.2).

La relación educativa con mujeres en contextos de prostitución se caracteriza también por ser sumamente cercana. La comunicación y el contacto directo facilitan el conocimiento mutuo y, como expresa la siguiente participante, «Nos conocen a todas, "de pe a pa". Saben cómo darnos la vuelta, saben cómo enfocarnos las cosas... Eso significa que nos estudian (...). Saben lo que necesitamos» (grupo de discusión, S1, pág. 8). En este contexto, la escucha es un eje central sobre el que gira la relación y que permite a la profesional mostrar las actitudes de comprensión empática y apoyo incondicional (Rogers, 1987). Las profesionales desarrollan una escucha activa cuando parten de la mujer como persona y no de la actividad que desempeñan y cuando se sitúan en el universo de experiencias compartido - en tanto mujeres, madres, compañeras-. Mediante la escucha activa ofrecen apoyo emocional a la mujer para que sea ella misma la que siga sus procesos y tome sus decisiones, para que se conozca mejor y tome también más consciencia de las circunstancias que la rodean y de sus posibilidades de actuación y de cambio.

Aunque esta relación educativa tiende y se basa a la vez en la reciprocidad y la sinceridad, los equipos de profesionales tienen muy presente el riesgo, por ambas partes, de instrumentalización de la relación o de acción dramatúrgica, que intentan contrarrestar en sus actuaciones mostrando de todas las maneras posibles que aceptan a las mujeres tal como son. Todo ello supone un trabajo constante para controlar los prejuicios y los estereotipos. 
Es, por consiguiente, una relación educativa basada en el principio de acompañamiento que consiste, como expresa la siguiente profesional, en «escuchar más que hablar. En preguntar, más que ir suponiendo cosas y en no juzgar». (grupo de discusión profesionales, pág. 27). Las profesionales acompañan a la mujer durante todo su recorrido, en cada decisión, apoyando los procesos de deliberación y evaluación de alternativas. Muestran así otro principio educativo, el de respeto: respeto a la mujer y a sus decisiones; no pretenden convencer ni imponer su juicio. En el mismo sentido, es una relación que respeta los tiempos y ritmos de cada proceso, sin pretender acelerar. Por ello y todo lo anterior, es que la relación educativa resultante es cálida y afectiva.

\section{A MODO DE CONCLUSIÓN}

A lo largo de la investigación que hemos realizado y de aquellos aspectos de la misma que hemos tratado de comunicar en este artículo, se ponen de relieve la centralidad y el sentido de la tarea educativa que realizan las profesionales que trabajan con mujeres en contextos de prostitución. La mirada sobre la prostitución, habitualmente distorsionada como consecuencia del estigma y de una percepción social fuertemente estereotipada, oculta la labor educativa que entidades y profesionales están desarrollando día tras día en muchos espacios de nuestras ciudades. Reconocer y visibilizar esta labor nos permite conocer otras maneras de relacionarse con esta realidad y revelar un ámbito de intervención que consideramos muy adecuado al perfil profesional de la educación social. Para seguir avanzando en este contexto, es preciso que las y los profesionales reflexionen sobre su propia práctica en clave educativa y adquieran las herramientas teóricas y conceptuales para elaborar conocimiento pedagógico. De la misma manera, parece necesario que las instituciones de educación superior se impliquen en la formación de estos profesionales incluyendo la realidad de la prostitución como un ámbito más de la educación social.

En relación a los objetivos, se observa cómo autonomía, responsabilidad y confianza son centrales en la acción educativa con mujeres en contextos de prostitución. Estos objetivos, generalmente comunes en todos los ámbitos de la educación y en todas las etapas del ciclo vital, se contextualizan en este caso mediatizados por la multiplicidad de historias de vida y, no lo olvidemos, por el peso del estigma social que recae sobre el mundo de la prostitución. Así, la heterogeneidad en el perfil de las mujeres que se ocupan en la industria del sexo - origen, edad, condiciones de vida, proyecto migratorio, dominio del idioma de la sociedad de llegada, nivel formativo- y las condiciones en las que se desarrolla la intervención - mayormente en medio abierto-, hacen que la labor de las profesionales se adapte a cada 
circunstancia y sea flexible al máximo, para facilitar el desarrollo de todos aquellos procesos educativos que pretenden que las mujeres ganen autonomía en relación a diferentes parcelas de su vida - acceso a los servicios sociales, cuidado de su propia salud, defensa de sus derechos, búsqueda de recursos- . Para ello, las profesionales ponen especial atención en trazar con cada una de ellas proyectos e itinerarios personales que les permitan tomar conciencia de sus propias potencialidades y responsabilizarse del camino que recorren para alcanzar sus propios objetivos. Otros principios, además de la educación personalizada, son la aproximación a la realidad como fuente de conocimiento y experiencia a través del contacto directo con el contexto de la prostitución; la escucha activa y el cuidado de la relación a través de la comprensión empática y el apoyo incondicional vacío de prejuicios y estereotipos.

Acercarnos al mundo de la prostitución nos ha permitido reconocer otra realidad educativa. Una realidad que no siempre se expresa desde este prisma, pero cuya presencia se percibe en el cuidado que profesionales y mujeres prestan a la relación, la riqueza pedagógica del acompañamiento y en los gestos y mensajes de reconocimiento hacia las mujeres. En este sentido, pensamos que el estudio del fenómeno de la prostitución y el abordaje que se está haciendo del mismo, no se agota en el análisis de cuestiones sanitarias, legales ni sociológicas. La mirada educativa tiene también un gran valor. Un valor que viene dado tanto porque supone un compromiso con un colectivo de la sociedad muy vulnerable y frecuentemente olvidado, como por el hecho de que se trata de una fuente de aprendizaje indiscutible. Un aprendizaje que, desde nuestro punto de vista, no se circunscribe sólo a una mayor comprensión de la realidad de la prostitución, sino a un mayor conocimiento de las relaciones educativas y humanas en general. Y ello no hubiera sido posible sin los encuentros con profesionales y mujeres que generosamente han compartido con nosotras sus saberes y experiencias. 


\section{REFERENCIAS BIBLIOGRÁFICAS}

Agustín, L. (2004). Trabajar en la industria del sexo y otros tópicos migratorios. San Sebastián: Gakpa Liburuak.

Arella, C.; Fernández, C.; Nicolás, G. y Vartabedián, J. (2007). Los pasos (in) visibles de la prostitución. Barcelona: Virus.

Ayuste, A. y Payá, M. (2010). Prácticas cooperativas y redes de relación de las mujeres migrantes. Bordón, 62 (4), 37-49.

Ballester, L.; Orte, C. y Perelló, J. (2004). Programa de apoyo socioeducativo para mujeres jóvenes dedicadas a prostitución. Educació i Cultura, 16, 105-112.

Barahona, M.J. y García, L.M. (2004). Manual de intervención social con mujeres prostituidas. Madrid: Dirección General de Atención de la Mujer.

Barry, K. (1988). Esclavitud sexual de la mujer. Barcelona: LaSal.

Briz, M. y Garaizábal, C. (2007). La prostitución a debate. Por los derechos de las prostitutas. Madrid: Talasa.

Delacoste, F. y Alexander, P. (Eds.). (1987). Sex work: writtings by women in the sex industry. San Francisco: Celis Press.

Freire, P. (1997). Pedagogía de la autonomía. Saberes necesarios para la práctica educativa. México: Siglo XXI.

Giddens, A. (1995). La Constitución de la sociedad: bases para la teoría de la estructuración. Buenos Aires: Amorrortu.

Goffman, E. (1970; 2003). Estigma: la identidad deterioriada. Buenos Aires: Amorrortu.

Habermas, J. (1987). Teoría de la acción comunicativa. Vol. I. Racionalidad de la acción y racionalización social. Madrid: Taurus.

Hochschild, A.R. (2008). La mercantilización de la vida intima. Apuntes de la casa y el trabajo. Madrid: Katz.

Holgado, I. (ed.). (2008). Prostituciones. Diálogo sobre sexo de pago. Barcelona: Icaria-Antrazyt.

Juliano, D. (2002). La prostitución, el espejo oscuro. Barcelona: Icaria.

Llim, Ll. (Ed.) (1998). The sex sector. Ginebra: OIT.

Mead, G. (1999). Espíritu, persona y sociedad: desde el punto de vista del conductismo social. Barcelona: Paidós.

Meneses, C. (2000). Trabajo social con prostitutas, en M. J. Martínez Para el trabajo social: aportaciones teóricas y prácticas. Granada: Maristain, 449-470.

Morin, E. (2001). Los siete saberes necesarios para la educación del futuro. Barcelona: Paidós.

Ordóñez, A.L. (2006). Feminismo y prostitución: Fundamentos del debate actual en España. Oviedo: Trabe.

Osborne, R.(2004).Trabajador@s del sexo. Derechos, migraciones y tráfico en el siglo XXI. Barcelona: Bellaterra.

Pheterson, G. (2000). El prisma de la prostitución. Madrid: Talasa.

Rogers, C. (1987). El camino del ser. Barcelona: Kairós.

Sanvisens, A. (dtor.) (1984). Introducción a la Pedagogía. Barcelona: Barcanova.

Vázquez, V. (2010). La perspectiva de la ética del cuidado: una forma diferente de hacer educación. Educación XX1, 13 (1), 177-197. 


\section{PALABRAS CLAVE} social.

Relación educativa; prostitución femenina; mujer migrante; educación

\section{KEYWORDS}

Educational relationship; female prostitution; migrant women; social education.

\section{PERFIL ACADÉMICO Y PROFESIONAL DE LAS AUTORAS}

Ana Ayuste González, Profesora titular del área de Teoría de la Educación. Miembro del Grupo Consolidado de Investigación en Educación Moral (G.R.E.M.) y del Grupo Consolidado de Innovación Docente «Innova-the», de la Universidad de Barcelona. Co-coordinadora del Máster en Educación de Personas Adultas. Áreas de investigación: Teoría de la Educación, Educación de Personas Adultas y Mujer e Inclusión Social.

Montserrat Payá Sánchez, Profesora titular del área de Teoría de la Educación. Miembro del Grupo Consolidado de Investigación en Educación Moral (G.R.E.M.) y Coordinadora del Grupo Consolidado de Innovación Docente «Innova-the», de la Universidad de Barcelona. Áreas de investigación: Teoría de la Educación, Educación y Valores y Mujer e Inclusión Social.

Dirección de las autoras: Campus Valle de Hebrón. P. ${ }^{\circ}$ Valle de Hebrón, 171 08035 Barcelona.

E-mail: anaayuste@ub.edu mpaya@ub.edu

Fecha Recepción del Artículo: 11. Noviembre. 2011

Fecha modificación Artículo: 18. Abril. 2012

Fecha Aceptación del Artículo: 23. Mayo. 2012

Fecha de Revisión para publicación: 24. Junio. 2013 


\title{
EL PROCESO DE COMPRENSIÓN EN UNA LENGUA EXTRANJERA: UNA PROPUESTA PARA EVALUAR ESTRATEGIAS DE LECTURA
}

\section{(THE READING COMPREHENSION PROCESS IN A FOREIGN LANGUAGE: A PROPOSAL TO EVALUATE READING STRATEGIES)}

\author{
Eugenio Hidalgo Díez
}

Universidad de Granada, España

Mirtha Manzano Díaz

Universidad de Ciego de Ávila, Cuba

DOI: 10.5944/educxx1.17.1.10716

Cómo referenciar este artículo/How to reference this article:

Hidalgo Díez, E. y Manzano Díaz, M. (2014). El proceso de comprensión en una lengua extranjera: Una propuesta para evaluar estrategias de lectura. Educación XX1, 17 (1), 309-326. doi: 10.5944/educxx1.17.1.10716.

Hidalgo Díez, E. y Manzano Díaz, M. (2014). The reading comprehension process in a foreign language: a proposal to evaluate reading strategies. Educación XX1, 17 (1), 309-326. doi: 10.5944/educxx1.17.1.10716.

\section{RESUMEN}

Consideramos que las estrategias para el aprendizaje de la lectura, no son directamente observables pero si detectables y medibles. La evaluación es un proceso que está siendo estudiado desde nuevas perspectivas mucho más conscientes, centradas en el individuo que aprende a aprender. Para evaluar el uso de estrategias durante la comprensión lectora hemos elaborado un cuestionario que analiza los procesos cognitivos y afectivos en relación con este proceso en una lengua extranjera. El procesamiento de la información escrita incluye una lista de destrezas que involucran no solo la decodificación del texto, sino también la aplicación y extensión de la información a otros contextos, y con ello la construcción de nuevos significados y sentidos - la creación de nuevos textos. Por tal motivo en su construcción, hemos tenido en cuenta las siguientes dimensiones: Conocimiento previo, nivel de traducción, nivel de interpretación y nivel de extrapolación. Se establecieron las características técnicas del instrumento por medio de los estadísticos Alpha de Crombach para la fiabilidad y juicio de expertos y análisis factorial para la validez, que vinieron a corroborar la bondad del cuestionario, lo que nos permite evaluar y autoevaluar el uso de estrategias de lectura en el proceso de enseñanzaaprendizaje en una lengua extranjera. 


\section{ABSTRACT}

We understand that learning strategies in the reading comprehension process are not directly observed, but they may be detectable and measurable. The evaluation is a process that is being studied from new angles more consciously focused on the person who learns how to learn. To assess the use of strategies during reading we have elaborated an instrument - a questionnaire aimed at evaluating the students' own cognitive and affective procedures through the reading comprehension process in a foreign language. The process of the information includes a list of skills which contains not only decoding, but also applying and extending the interpretation of the written text to other contexts, and the construction of new meaning and senses i. e. the creation of new texts. Therefore, after an exhaustive bibliographical review, four categories with their corresponding items were established: previous knowledge, translation level, interpretation level, and extrapolation level. Finally, we set up the technical characteristics of the questionnaire through statistic methods such as: Alpha of Crombach to validate its reliability, the criterion of experts and factorial analysis which confirmed its validity to evaluate the use of reading strategies in the teaching learning process of a foreign language.

\section{INTRODUCCIÓN}

Aunque los profesores de lengua, generalmente, hablamos en términos de habilidades lingüísticas o comunicativas (expresión oral y escrita y comprensión auditiva y de lectura), la realidad es que no siempre somos conscientes de que a través de ellas se desarrollan otras habilidades intelectuales y científicas y de que se establecen valores necesarios para el graduado de cualquier campo del saber, por eso, actualmente, se incluyen en los planes de estudio como competencias que se precisan para la formación de un profesional. Estas competencias determinan el verdadero propósito de la comunicación y la actividad cognoscitiva (Hidalgo, 2007). Nuestra investigación está dirigida a la comprensión de la lectura, pero sustentada sobre la base de que forma parte de la lengua como una entidad, pues el lenguaje, aunque metodológicamente lo separemos para su estudio, no es solo palabra unida, el lenguaje es sentido e intención y tiene, además de su carácter universal, su propia identidad,por lo tanto, también es contexto.

Nuestro estudio asume una posición compleja y sistémica del proceso de enseñanza aprendizaje de una lengua extranjera, por lo que entendemos que las limitaciones que confrontamos en la propia concepción de la enseñanza-aprendizaje de la lengua como un todo, son aplicables, también, al desarrollo de la competencia de lectura como parte esencial de la competencia comunicativa. En este sentido, consideramos que la lectura, además 
de objetivo y contenido, es medio, método y evaluación en el proceso de enseñanza-aprendizaje.

Igualmente, consideramos que la concepción de la lectura como instrumento didáctico de los aspectos lingüísticos, y no como herramienta que desarrolla la formación en la sistematización de los contenidos y en la adquisición de una cultura integral, es la que ha frenado la formación adecuada en la competencia comunicativa a nuestros futuros profesionales, dando lugar a que solo aquellos con una elevada motivación e independencia cognoscitiva alcancen los mejores resultados en la formación académica en una lengua extranjera (Manzano, 2009).

El artículo presenta el proceso seguido en la elaboración y validación de un cuestionario de evaluación-autoevaluación de estrategias de lectura. Se parte desde una posición epistemológica que revela la significación que adquiere la evaluación en este proceso, y se concluye con la dinámica que promueve este instrumento como medio y método de enseñanza-aprendizaje, durante el proceso de comprensión en una lengua extranjera.

\section{LA EVALUACIÓN DE LAS ESTRATEGIAS COMO COMPONENTE ESENCIAL DE LA ACTIVIDAD COGNOSCITIVA}

Cuando hablamos del proceso de enseñanza-aprendizaje de una lengua extranjera nos estamos refiriendo a la actividad cognoscitiva. Cuando nos referimos a las habilidades de la actividad verbal (lingüísticas), estamos haciendo referencia a la expresión y comprensión oral y escrita, a las que también denominamos destrezas comunicativas. Si vamos a la esencia de esas acciones (destrezas o habilidades), no podemos obviar los procesos mentales que durante las mismas ocurren, ni obviar operaciones o estrategias que el ser humano necesita para lograr el objetivo de determinada tarea.

Para desarrollar una actividad cognoscitiva, se precisa desplegar todo un sistema de acciones y operaciones dirigidas a un objetivo, en condiciones tanto internas como externas, en las que intervienen las esferas motivacional-afectiva y cognitivo-instrumental.

Las estrategias forman parte de la actividad cognoscitiva como método, ya que entran dentro del sistema de acciones de las habilidades a desarrollar en el proceso de enseñanza-aprendizaje. Igualmente, las estrategias son las operaciones que se realizan para lograr la acción o tarea a realizar durante la actividad. 
Es la propia vorágine del desarrollo científico-técnico en la actualidad, la que ha llevado a las ciencias de la educación a que tomemos conciencia de la necesidad del dominio de herramientas que permitan al profesional gestionar el conocimiento de forma autónoma, así como a desarrollar estudios que den respuesta a esta problemática.

En este sentido, la nueva universidad no puede transmitir todo el conocimiento desarrollado por la humanidad, por lo que se necesitan estrategias para poder interactuar con el conocimiento de manera independiente; por ello, los nuevos modelos profesionales exigen el manejo y dominio consciente de determinadas competencias que consoliden la integración de conocimientos, habilidades, actitudes y cualidades personales (Hidalgo et al, 2007; Lara y Rivas, 2009).

Las estrategias de aprendizaje como procesos mentales no son directamente observables, sin embargo, si pueden ser detectables. La elaboración y usos de cuestionarios en este sentido son de mucha utilidad, como en nuestro caso, para la autoevaluación de los propios procesos cognitivos y afectivos en relación con la comprensión lectora.

La evaluación-autoevaluación es condición esencial en el aprendizaje. La misma regularmente se asume como un elemento externo que influye desde la visión y posición del profesor como director del proceso, pero es un error soslayar sus potencialidades como condición interna. La evaluaciónautoevaluación es motor que activa de forma consciente el aprendizaje, ya que ella, como función de la dirección del proceso, constituye un elemento importante, pues está llamada a potenciar la autovaloración del estudiante durante el aprendizaje, sus fortalezas y debilidades, sus preferencias y expectativas, los procedimientos empleados, el autocontrol de lo aprendido y la regulación de la actividad. Ésta será cualitativamente superior en tanto esté concebida de tal forma que contribuya a la autonomía del alumnado y a que valore cómo aprender (Gil y Padilla, 2009; Milán et al, 2009).

La evaluación educativa o formativa, según González (2009), es aquella que contribuye al desarrollo del estudiante en correspondencia con los rasgos fundamentales del proceso de formación del futuro profesional y con los objetivos sociales que plantea esa formación en nuestra sociedad. El cuestionario que presentamos tiene este carácter por cuanto con el mismo se persigue que:

- Actúe como orientador y regulador del proceso de comprensión o competencia lectora.

- Diagnostique y valore los estados y progresos del alumnado con respecto al uso de estrategias de lectura a diferentes niveles. 
- Constituya un instrumento de evaluación individual del proceso de lectura no solo para el estudiante, sino también para el profesorado y sirva para la reflexión del progreso colectivo en esta variable en el grupo.

- Constituya un objeto de aprendizaje, por cuanto el estudiante lo utiliza como instrumento de autovaloración y autorregulación.

- Explore las vías que permitan valorar integralmente el proceso de comprensión del alumnado.

- Cumpla las condiciones (relativas a finalidades, tipo de exigencias, formas de realización) que favorezcan el desarrollo de valores esenciales como la honestidad, la responsabilidad y el colectivismo.

- Regule y oriente al estudiante hacia la profundización en el estudio mediante el desarrollo de su motivación, la conciencia de su importancia personal y social y la formación de estrategias de aprendizaje. (González, 2009, p. 6).

Fitzpatrick (2006), Brodie e Irving (2007) y Gil y Padilla (2009) indican que la participación del alumnado en el proceso evaluativo es imprescindible, ya que desarrolla el pensamiento analítico, el espíritu crítico, la emisión de juicios y criterios y la autodeterminación. Así pues, la evaluación se convierte en un elemento fundamental e inseparable de la práctica educativa, y permite dar al estudiante y profesorado la información de cada momento y realizar los juicios de valor necesarios para la orientación y toma de decisiones respecto al proceso de enseñanza-aprendizaje. Estas habilidades están en congruencia con el propio desarrollo de las estrategias de lectura, ya que forman parte de los indicadores seleccionados en el cuestionario de evaluación.

El estudio de las variables objeto de investigación, nos posibilitó presentar un instrumento dirigido a evaluar las estrategias del alumnado durante el procesamiento de información que respondiera a las exigencias de los planes de estudios en el nivel universitario y que evaluara, principalmente, sus resultados en términos cualitativos y cuantitativos, aunque tanto los números como las palabras no pueden describir ni interpretar y mucho menos medir con precisión toda la subjetividad humana.

Al seleccionar el cuestionario como instrumento para evaluar el uso de estrategias de lectura, se hace necesario fundamentar teóricamente las dimensiones e indicadores asumidos en su elaboración, lo que vendrá a fortalecer, con elementos teóricos sustanciales, su validez y fiabilidad. 


\section{DESCRIPCIÓN DE LOS PROCEDIMIENTOS EN LA ELABORACIÓN DEL CUESTIONARIO DE EVALUACIÓN DE LAS ESTRATEGIAS DE LECTURA}

El cuestionario de evaluación-autoevaluación de estrategias de lectura constituye una nueva aportación en este campo. Para su elaboración se siguió el siguiente proceso:

1. Se delimitó como campo de estudio el proceso de lectura y dentro de su complejidad se seleccionaron diferentes acciones y operaciones o estrategias a niveles de traducción, interpretación y extrapolación que respondieran a los propósitos esenciales de nuestros programas y planes de estudio. También se seleccionaron operaciones dirigidas a establecer los metaconocimientos de los procesos mentales del individuo.

2. Se realizó una lista de indicadores y categorías que cubrieran la esencia de las estrategias de lectura.

3. Se seleccionaron para cada uno de los indicadores tres ítems o más que respondieran a lo que se proponía medir utilizando una escala Lickert con seis opciones, quedando de esta forma conformado el cuerpo esencial del instrumento. También se definió la forma de evaluación para facilitarle los resultados al propio alumnado.

4. Se aplicaron métodos empíricos y estadísticos para establecer las características técnicas de fiabilidad y validez de contenido y de constructo del cuestionario de evaluación de las estrategias de lectura.

\begin{tabular}{|l|l|c|}
\hline \multicolumn{1}{|c|}{ DIMENSIONES } & \multicolumn{1}{|c|}{ INDICADORES } & ITEMS \\
\hline $\begin{array}{l}\text { A. CONOCIMIENTO } \\
\text { PREVIO }\end{array}$ & $\begin{array}{l}\text { - Trazarse un propósito para la lectura. } \\
\text { - Activar los conocimientos previos. } \\
\text { - Tener conciencia de los propios procesos } \\
\text { de pensamiento. }\end{array}$ & $1-13$ \\
\hline $\begin{array}{l}\text { B. NIVEL DE } \\
\text { TRADUCCIÓN }\end{array}$ & $\begin{array}{l}\text { - Comprender globalmente. } \\
\text { - Reconocer significados: explícitos, implícitos } \\
\text { - y complementarios. }\end{array}$ & $14-39$ \\
$\begin{array}{l}\text { - Reconocer la estructura textual. } \\
\text { - Organizar, identificar y jerarquizar ideas. }\end{array}$ & \\
\hline $\begin{array}{l}\text { C. NIVEL DE } \\
\text { INTERPRETACIÓN }\end{array}$ & $\begin{array}{l}\text { - Inferir información implícita. } \\
\text { - Valorar la información. } \\
\text { - Emitir juicios y criterios. }\end{array}$ & $40-52$ \\
\hline
\end{tabular}




\begin{tabular}{|l|l|c|}
\hline \multicolumn{1}{|c|}{ DIMENSIONES } & \multicolumn{1}{|c|}{ INDICADORES } & ITEMS \\
\hline $\begin{array}{l}\text { D. NIVEL DE } \\
\text { EXTRAPOLACIÓN }\end{array}$ & $\begin{array}{l}\text { - Extender la información. } \\
\text { - Analizar situaciones similares. } \\
\text { - Resolver problemas. }\end{array}$ & $52-66$ \\
\hline
\end{tabular}

Tabla 1. Resumen de las dimensiones e indicadores seleccionados

Una vez establecidas las dimensiones y los indicadores correspondientes, se procedió a la definición de los diferentes ítems que iban a configurar el cuestionario que se puede observar a continuación:

\section{CUESTIONARIO DE EVALUACIÓN DE ESTRATEGIAS UTILIZADAS DURANTE LA COMPRENSIÓN DE LECTURA EN UNA LENGUA EXTRANJERA}

Durante el proceso de lectura en una lengua extranjera, el ser humano pone en funcionamiento una serie de estrategias de aprendizaje, tales como: estrategias metacognitivas o procedimentales, estrategias cognitivas o conceptuales de varios tipos, así como estrategias de interacción social, que les van a servir para una mejor compresión de lo que está leyendo. Con este cuestionario tratamos de que reflexiones sobre lo que te proponemos y nos contestes en qué medida tú lo haces.

En los apartados (A -B -C -D) que se incluyen a continuación, están recogidas las diversas estrategias que pueden ser utilizadas en el proceso de comprensión de una lectura. Léelas cuidadosamente y valóralas de 1 a 6 , según los siguientes parámetros:

1. No lo hago nunca.

2. Lo hago muy pocas veces.

3. Lo hago algunas veces.

4. Lo hago bastantes veces.

5. Lo hago muchas veces.

6. Lo hago siempre.

Elige la puntuación, marcando con una $\mathrm{X}$, la que corresponde a lo que tú haces realmente y no a lo qué piensas que deberías hacer o a lo que hacen los demás.

Por favor no dejes ninguna respuesta en blanco. 


\section{A. CONOCIMIENTO PREVIO}

Cuando leo un texto en idioma inglés:

\begin{tabular}{|c|c|c|c|c|c|c|}
\hline Ítems & 1 & 2 & 3 & 4 & 5 & 6 \\
\hline 1. Tengo definido el propósito de mi lectura. & & & & & & \\
\hline 2. Sé qué voy a leer y para qué voy a leerlo. & & & & & & \\
\hline 3. Leo con un objetivo determinado. & & & & & & \\
\hline $\begin{array}{l}\text { 4. Pienso que tengo los conocimientos previos necesa- } \\
\text { rios para enfrentar un texto, (conocimientos tanto } \\
\text { lingúísticos, del tema, como generales del mundo). }\end{array}$ & & & & & & \\
\hline $\begin{array}{l}\text { 5. Creo que domino el vocabulario necesario relaciona- } \\
\text { do con el tema del texto. }\end{array}$ & & & & & & \\
\hline $\begin{array}{l}\text { 6. Creo que domino las estructuras lingüísticas elemen- } \\
\text { tales del idioma inglés para enfrentar la lectura. }\end{array}$ & & & & & & \\
\hline $\begin{array}{l}\text { 7. Creo tener suficientes conocimientos generales para } \\
\text { entender información complementaria. }\end{array}$ & & & & & & \\
\hline $\begin{array}{l}\text { 8. Utilizo conscientemente mis propios pasos o procedi- } \\
\text { mientos para procesar la información de un texto. }\end{array}$ & & & & & & \\
\hline $\begin{array}{l}\text { 9. Pienso en cómo procesar la información, trazo } \\
\text { acciones a seguir. }\end{array}$ & & & & & & \\
\hline 10. Proceso la información sin ayuda. & & & & & & \\
\hline $\begin{array}{l}\text { 11. Proceso la información siguiendo una secuencia } \\
\text { lógica. }\end{array}$ & & & & & & \\
\hline $\begin{array}{l}\text { 12. Proceso la información con destreza (independencia, } \\
\text { rapidez, calidad). }\end{array}$ & & & & & & \\
\hline $\begin{array}{l}\text { 13. Rectifico mis pasos o procedimientos cuando algo no } \\
\text { sale bien. }\end{array}$ & & & & & & \\
\hline
\end{tabular}

\section{B. NIVEL DE TRADUCCIÓN}

Cuando realizo una lectura exploratoria o global:

\begin{tabular}{|l|l|l|l|l|l|l|}
\hline \multicolumn{1}{|c|}{ Ítems } & 1 & 2 & 3 & 4 & 5 & 6 \\
\hline 14. Anticipo el contenido del texto por su título. & & & & & & \\
\hline $\begin{array}{l}\text { 15. Determino la información general contenida en el } \\
\text { texto al leer el primer párrafo y/o el último. }\end{array}$ & & & & & & \\
\hline $\begin{array}{l}\text { 16. Determino la información general contenida en el } \\
\text { texto al pasar la vista rápidamente por el texto. }\end{array}$ & & & & & & \\
\hline
\end{tabular}




\begin{tabular}{|c|c|c|c|c|c|c|}
\hline Ítems & 1 & 2 & 3 & 4 & 5 & 6 \\
\hline $\begin{array}{l}\text { 17. Pienso en el mensaje o significado que transmite el } \\
\text { título. }\end{array}$ & & & & & & \\
\hline 18. Reconozco la información explícitamente expresada. & & & & & & \\
\hline 19. Infiero la información que intenta transmitir el autor. & & & & & & \\
\hline 20. Relaciono e integro ideas. & & & & & & \\
\hline 21. Reconozco las características del texto. & & & & & & \\
\hline $\begin{array}{l}\text { 22. Reconozco la función comunicativa del texto, su } \\
\text { estructura textual. }\end{array}$ & & & & & & \\
\hline $\begin{array}{l}\text { 23. Reconozco los conectores o palabras relacionantes en } \\
\text { un texto. }\end{array}$ & & & & & & \\
\hline 24. Reconozco la relación que expresan. & & & & & & \\
\hline 25. Reconozco la estructura de los párrafos. & & & & & & \\
\hline $\begin{array}{l}\text { 26. Reconozco la estructura textual del texto como con- } \\
\text { junto. }\end{array}$ & & & & & & \\
\hline $\begin{array}{l}\text { 27. Encuentro información relacionada a una idea que } \\
\text { está esparcida dentro del texto. }\end{array}$ & & & & & & \\
\hline $\begin{array}{l}\text { 28. Reconozco la posición de las ideas de un texto } \\
\text { tradicional. }\end{array}$ & & & & & & \\
\hline $\begin{array}{l}\text { 29. Identifico ideas principales, ideas secundarias y } \\
\text { detalles. }\end{array}$ & & & & & & \\
\hline $\begin{array}{l}\text { 30. Reconozco cuándo una idea está contenida dentro de } \\
\text { otra. }\end{array}$ & & & & & & \\
\hline $\begin{array}{l}\text { 31. Reconozco cuándo una idea generaliza o incluye } \\
\text { otras ideas. }\end{array}$ & & & & & & \\
\hline $\begin{array}{l}\text { 32. Identifico un grupo de ideas que están relacionadas } \\
\text { con otra más general. }\end{array}$ & & & & & & \\
\hline 33. Identifico los detalles de una idea. & & & & & & \\
\hline 34. Jerarquizo las ideas y las sintetizo. & & & & & & \\
\hline 35. Organizo correctamente las ideas en el resumen. & & & & & & \\
\hline 36. Suprimo la información que no es importante. & & & & & & \\
\hline $\begin{array}{l}\text { 37. Integro ideas fundamentales comunes en una más } \\
\text { amplia. }\end{array}$ & & & & & & \\
\hline 38. Selecciono solo lo esencial. & & & & & & \\
\hline 39. Redacto la información sintetizada. & & & & & & \\
\hline
\end{tabular}




\section{NIVEL DE INTERPRETACIÓN}

Cuando valoro críticamente la información leída:

\begin{tabular}{|c|c|c|c|c|c|c|}
\hline Ítems & 1 & 2 & 3 & 4 & 5 & 6 \\
\hline 40. Capto información implícita. & & & & & & \\
\hline 41. Infiero el tono, la atmósfera del texto. & & & & & & \\
\hline 42. Reconozco lo que el escritor intenta transmitir. & & & & & & \\
\hline $\begin{array}{l}\text { 43. Reconozco cuándo el emisor se basa en sus propios } \\
\text { juicios. }\end{array}$ & & & & & & \\
\hline 44. Reconozco cuándo el autor se basa en hechos. & & & & & & \\
\hline $\begin{array}{l}\text { 45. Valoro mis conocimientos sobre el tema durante la } \\
\text { lectura. }\end{array}$ & & & & & & \\
\hline 46. Extraigo conclusiones de mis inferencias. & & & & & & \\
\hline 47. Comparo esa información con otras fuentes. & & & & & & \\
\hline $\begin{array}{l}\text { 48. Determino cuándo el autor aporta nuevos elementos } \\
\text { sobre lo que sé del tema. }\end{array}$ & & & & & & \\
\hline $\begin{array}{l}\text { 49. Reconozco cuándo el autor ofrece una fundamenta- } \\
\text { ción convincente. }\end{array}$ & & & & & & \\
\hline 50. Establezco y emito mis propios puntos de vista. & & & & & & \\
\hline 51. Emito mis puntos de vistas y los argumento. & & & & & & \\
\hline
\end{tabular}

\section{NIVEL DE EXTRAPOLACIÓN}

Cuando aplico información leída:

\begin{tabular}{|c|c|c|c|c|c|c|}
\hline Ítems & 1 & 2 & 3 & 4 & 5 & 6 \\
\hline $\begin{array}{l}\text { 52. Integro información del texto a mis conocimientos } \\
\text { previos sobre el tema. }\end{array}$ & & & & & & \\
\hline $\begin{array}{l}\text { 53. Aplico la información leída a otros contextos de la } \\
\text { vida. }\end{array}$ & & & & & & \\
\hline $\begin{array}{l}\text { 54. Identifico los nexos y relaciones entre la información } \\
\text { contenida en el texto y lo que conozco del tema. }\end{array}$ & & & & & & \\
\hline $\begin{array}{l}\text { 55. Reconozco rasgos comunes de la situación dada con } \\
\text { situaciones similares de la realidad. }\end{array}$ & & & & & & \\
\hline $\begin{array}{l}\text { 56. Encuentro nexos y relaciones entre la información } \\
\text { leída y otros contextos. }\end{array}$ & & & & & & \\
\hline $\begin{array}{l}\text { 57. Determino el futuro de situaciones similares de la } \\
\text { realidad de no dársele solución inmediata. }\end{array}$ & & & & & & \\
\hline
\end{tabular}




\begin{tabular}{|l|l|l|l|l|l|}
\hline 58. Formulo problemas. & & & & & \\
\hline $\begin{array}{l}\text { 59. Doy sugerencias de solución a problemas similares de } \\
\text { la realidad. }\end{array}$ & & & & & \\
\hline $\begin{array}{l}\text { 60. Reconozco cuándo existen condiciones objetivas para } \\
\text { transformar la realidad a través de la solución que } \\
\text { propongo. }\end{array}$ & & & & & \\
\hline 61. Doy posibles sugerencias de solución a un problema. & & & & & \\
\hline 62. Argumento las soluciones. & & & & & \\
\hline 63. Actúo sobre la realidad y la transformo. & & & & & \\
\hline 64. Doy soluciones que son efectivas. & & & & & \\
\hline 65. Obtengo resultados satisfactorios. & & & & & \\
\hline
\end{tabular}

\section{PUNTUACIÓN}

\begin{tabular}{|c|l|}
\hline$\bullet$ & Pon tu puntuación en la casilla que hay al lado de cada número. \\
\hline$\bullet$ & $\begin{array}{l}\text { Suma la puntuación de cada apartado y divide el total obtenido por el } \\
\text { número de items: obtendrás así tu media personal para cada apartado. }\end{array}$ \\
\hline$\bullet$ & $\begin{array}{l}\text { Cada apartado corresponde a un grupo de estrategias. Lee el resumen } \\
\text { y compara tus medias personales con la clave para saber qué grupo de } \\
\text { estrategias sueles utilizar con más frecuencia. }\end{array}$ \\
\hline
\end{tabular}

\section{Clave de valoración de las estrategias utilizadas}

\begin{tabular}{|l|l|}
\hline Uso muy frecuente & 4,5 a 5,0 (lo hago siempre o casi siempre) \\
\hline Uso frecuente & 3,5 a 4,4 (lo hago a menudo) \\
\hline Uso moderado & 2,5 a 3,4 (lo hago a veces) \\
\hline Uso limitado & 1,5 a 2,4 (generalmente no lo hago) \\
\hline Uso muy limitado & 1,0 a 1,4 (no lo hago casi nunca / nunca) \\
\hline
\end{tabular}

Evaluar el uso de tus estrategias de lectura te ha permitido descubrir cuáles utilizas con mayor frecuencia para leer en una lengua extranjera. También te ha permitido darte cuenta de que durante el proceso de comprensión en una lengua extranjera, recurres a procedimientos que manejas cuando lees en la lengua materna y que la lectura en lengua extranjera va más allá de la simple decodificación de un texto. Conjuntamente, el conocimiento personal del uso de las estrategias de lectura, te facilita conocer tus potencialidades y debilidades durante el procesamiento de la información de un texto escrito y como consecuencia de ello, perfeccionar las limitaciones. 
Por último, ten presente también que una buena utilización de las estrategias de comprensión depende de varios factores: edad, personalidad, nivel de conocimientos alcanzados en la lengua extranjera, objetivos y necesidades de aprendizaje, experiencias anteriores, etc. Sin embargo, en la lista hay seguramente estrategias que tú no has utilizado hasta ahora y que te pueden ser de mucha utilidad.

\section{CARACTERÍSTICAS TÉCNICAS DEL CUESTIONARIO \\ DE ESTRATEGIAS DE LECTURA: SU FIABILIDAD Y VALIDEZ}

La validez y la fiabilidad son constantes que deben estar siempre presentes en el proceso de elaboración de un cuestionario sobre todo, como en nuestro caso, cuando se miden operaciones que el individuo realiza generalmente de forma inconsciente, como las estrategias de aprendizaje. Por todo ello, se hace necesario ser cuidadoso y riguroso en el proceso de elaboración y de validación.

\section{Análisis y estudio de la validez de contenido}

En principio se distribuyó el cuestionario preparado para facilitar su análisis a los jueces que actuaron como expertos entre los que figuraban: Profesorado del Departamento de Métodos de Investigación y Diagnóstico en Educación, del Departamento de Lengua Extrajera y Literatura y del Departamento de Psicología Evolutiva y de la Educación, así como personas de otros estamentos tales como: Asesores de los Centros de Profesorado e Inspectores de los Servicios Técnicos de Inspección. Los jueces debían seleccionar de entre una escala de 4 opciones: $1=\mathrm{Nada}$; $2=$ Poco; $3=$ Bastante; $4=$ Totalmente. Valorando con ello el grado de relación entre los ítems y las dimensiones establecidas.

La valoración dada por los diez jueces expertos quedó reflejada entre los rangos: bastante y totalmente. Con respecto a su univocidad y pertinencia todos estuvieron de acuerdo en que los ítems eran claros, concisos, concretos, se entendían bien y eran pertinentes para el estudio.

Estos resultados finalmente, confirman que los expertos concuerdan en que las preguntas contenidas dentro del cuestionario diseñado, corresponden al objetivo esencial de nuestro instrumento y de nuestro estudio, lo que permite corroborar su validez de contenido.

\section{Análisis y estudio de la validez de constructo}

El análisis factorial es aconsejable para estudiar la estructura de los cuestionarios de manera que podamos afirmar que determinados ítems se 
explican mejor desde una dimensión que desde otra, incluso nos sugiere aquellos ítems que puedan ser eliminados por escasa consistencia interna en correspondencia con otros de las diferentes dimensiones seleccionadas (Hidalgo, 2003). tados:

Por ello aplicamos análisis factorial, obteniendo los siguientes resul-

- Matriz de correlaciones. Los determinantes de la matriz fueron bajos, lo que confirmó que las correlaciones no son debidas al azar, demostrando así la intercorrelación entre las dimensiones del instrumento.

- La prueba de esfericidad de Bartlett. Probó la no significatividad de la hipótesis nula de que la matriz de correlaciones era una matriz de identidad y que, por lo tanto, tiene sentido aplicar el análisis factorial.

- La medida de adecuación de muestreo KMO (Kaiser-Meyer-Olkin). En nuestro caso, la medida de adecuación de muestreo KMO estuvo entre los coeficientes 1 y 0,8 catalogados como "maravillosos", y "meritorios" respectivamente. Esto implica que las correlaciones entre pares de variables pueden explicarse por otras variables y que, por lo tanto, resulta adecuada la aplicación del análisis factorial.

- Determinación de las comunalidades: Los valores que aparecen en la columna de extracción se alejan de cero, lo que nos indicó que la variable quedaba totalmente explicada por su componente al acercarse a un valor de uno.

- Método de extracción: Para cada una de las cuatro dimensiones se aplicó: Varianza total, Gráfico de Sedimentación y la Matriz de Componentes, a través de los cuales se corroboró que los ítems de cada apartado se podían resumir, o sea, se podían agrupar en componentes que explicaran la mayoría de la varianza observada en las respuestas ofrecidas por los encuestados, lo que implica que todas las variables estarían representadas de forma coherente.

- Método de rotación: El procedimiento utilizado fue una rotación ortogonal Varimax para cada una de las dimensiones. Al tener estas un índice de correlación interfactores bajo, queda claro que los componentes están relacionados entre sí. 
Estos resultados nos permitieron realizar un estudio confirmatorio para cada dimensión y establecer que los ítems se ajustan a cada uno de los indicadores, lo que demuestra que existe consistencia interna entre los ítems del instrumento.

\section{Fiabilidad del instrumento}

Para obtener la fiabilidad de nuestro instrumento se aplicó el Alpha de Crombach, tanto para el cuestionario completo como para cada una de las dimensiones establecidas para conformar el mismo. Se administró el cuestionario a 119 estudiantes de segundo año, los cuales culminan la asignatura Inglés IV en el segundo semestre de este curso académico (Manzano, 2007).

Como se puede observar en la tabla, los resultados obtenidos muestran un coeficiente de Alpha de Crombach de altísima fiabilidad.

\begin{tabular}{|c|}
\hline $\mathrm{N}$ of Cases $=119,0 \quad \mathrm{~N}$ of Items $=65$ \\
\hline Alpha $=0,9688$ \\
\hline
\end{tabular}

Tabla 2. Fiabilidad por Alpha de Crombach

\section{A MODO DE REFLEXIÓN}

La lectura es esencial durante el proceso de enseñanza-aprendizaje porque en ella intervienen procesos mentales de alto nivel, desarrolla destrezas y capacidades y posee potencialidades para ser explorada desde diferentes direcciones, sobre todo por parte de los educadores de las diferentes ramas del saber, pues debemos tener conciencia de que la lectura está presente cotidianamente en la docencia y que por lo tanto, es un problema que urge a todos perfeccionar desde nuestras propias perspectivas y posibilidades. De ahí que un trabajo consciente, interdisciplinar, sistemático, cohesionado y armónico con la comprensión, permitiría que el alumnado se apropie de algoritmos imprescindibles para el procesamiento de la información, como vía de solución para contribuir a la independencia cognoscitiva.

El dominio de destrezas y desarrollo de capacidades en la lectura, contribuye al logro de la autonomía del estudiante durante la adquisición de los conocimientos en una lengua extranjera. Para lograr esas destrezas y capacidades es necesario un trabajo consciente por parte del aprendiz y también, la reflexión colectiva en el avance personal de las estrategias a diferentes niveles de comprensión para que estas se desarrollen de manera integral. 
El instrumento que se presenta permite su utilización por apartados en correspondencia con los objetivos que persigamos en nuestra práctica pedagógica. Posibilita, además, que los sujetos del proceso de enseñanzaaprendizaje intercambien ideas, utilicen el proceso de lectura como medio y método de enseñanza y aprendizaje de forma eficaz y eficiente, lo que implica construir significados y aplicarlos sistemáticamente para adquirir rapidez e independencia en el manejo de la información.

«Los medios pueden favorecer la actividad sujeto-sujeto y la interacción sujeto-sujeto, cuando representan un eslabón de enlace con el acervo cultural con el que el proceso de enseñanza-aprendizaje ha de pertrechar a los estudiantes» (Zilberstein y Collazo, 2009, p. 338). El cuestionario de evaluación de lectura está en función de dicha actividad cognoscitiva y afectiva ,por lo que cumple varias funciones:

- Instructiva: Promueve la apropiación de los conocimientos, el desarrollo de habilidades y permite estudiar los objetos, fenómenos o procesos lo más objetivamente posible.

- Cibernética: Influye en las respuestas del estudiante, regula el proceso de enseñanza-aprendizaje, permite conocer las preferencias del estudiante, su motivación, manera de actuar.

- Formativa: Influye en su formación, convicciones y valores. Eleva su cultura, su cosmovisión y conocimiento de sí mismo.

- Recreativa: Favorece la distracción, permite el cambio de actividad, favorece la utilización de juegos.

- Desarrolladora: Favorece la integralidad de la personalidad del estudiante.

- De control: Propicia la observación, el autocontrol y la valoración del aprendizaje.

- Motivadora, innovadora y creadora: Motiva y entusiasma por la apropiación del contenido y despierta intereses e inclinaciones hacia la actividad creadora.

Desde el punto de vista práctico-metodológico, el cuestionario presentado propone estrategias que pueden ser objetivos que propicien tareas o actividades relacionadas con los textos que se imparten durante la enseñanza y el aprendizaje de la lengua. Estas actividades posibilitan la construcción de significados y sentidos, el desarrollo crítico y creativo del pensamiento a 
través del procesamiento de la información y alejan al proceso enseñanzaaprendizaje de actividades mecánicas y reproductivas, al permitir al estudiante que:

- Activen sus conocimientos previos sobre el tema.

- Tengan conciencia del objetivo de la lectura y la tarea que van a realizar.

- Trabajen los tres significados que aporta un texto: el literal o explícito, el intencional o implícito y el cultural o complementario.

- Desarrollen procesos de análisis - síntesis.

- Reflexionen sobre sus propias respuestas para que conozcan sus procesos mentales y puedan utilizar estrategias de autocorrección.

- Tengan en cuenta sus opiniones.

- Reconozcan la utilidad de lo leído.

- Reflexionen sobre situaciones problemáticas relacionadas con el tema.

- Se motiven por la lectura de otros textos escritos sobre el tema.

- Tomen conciencia de los niveles de ayuda que necesitan. 


\section{REFERENCIAS BIBLIOGRÁFICAS}

Brodie, P. e Irving, K. (2007). Assessment in work-based learning: investigating a pedagogical approach to enhance student learning.Assessment \& Evaluation in Higher education, 32 (1), 11-19.

Farías, P.L. (2008). El uso del cuestionario como instrumento de enseñanza de la comprensión de textos en la escuela media.Revista Iberoamericana de Educación, 45 (5). Recuperado de http:// www.rieoie.org/boletin45_5.htm

Fitzpatrick, D. (2006). An evaluative case study of the dilemmas experienced in designing a self-assessment strategy for Community Nursing students. Assessment \& Evaluation in Higher Education, 31 (1), 37-53.

Fernández, A. M. (2009). La Comunicación y su importancia en la educación. Estilos de comunicación. En AAVV. fundamentos didácticos de la educación superior cubana. Selección de lecturas. La Habana: Félix Varela.

Freire, P. (2010). Pedagogía de la autonomía y otros textos. La Habana: Caminos.

Gil, J. y Padilla, M.T. (2009). La participación del alumnado universitario en la evaluación del aprendizaje. Educación XX1,12, 43-65.

González, M. (2000). Evaluación del aprendizaje en la enseñanza universitaria. Revista Pedagogía Universitaria. 5 (2) 1-121. Recuperado de http:// www.uclm.es/profesorado/ricardo/ docencia_e_investigacion/4/evaluacion_halcones.doc
González, M. (2009). La Evaluación del Aprendizaje, en AAVV. Preparación pedagógica para profesores de la Nueva Universidad Cubana. La Habana: Félix Varela.

Hidalgo, E. et al. (2007). Formación en Competencias de Ciudadanía Europea. Granada: Método.

Hidalgo, V. (2003). La mejora de un centro multicultural: de la ciudad autónoma de Ceuta. Tesis doctoral. Granada: Universidad de Granada.

Lara, S. y Rivas, S. (2009). Aprendizaje autorregulado y fomento de competencias en dos asignaturas de master a través del empleo de plantillas de evaluación, método del caso, role-playing y video digital. Revista Educación XX1, 12, 67-96.

Manzano, M. (2007). Estilos de aprendizaje, Estrategias de lectura y su relación con el rendimiento académico del inglés como lengua extranjera. Tesis del programa de Doctorado “Aportaciones Educativas en Ciencias Sociales y Humanas". Universidad de Granada-Universidad de Ciego de Ávila.

Milán, R.; Fuentes, H.C. y De la Peña, R. (2009). La Evaluación como un proceso participativo, en AAVV. Fundamentos didácticos de la educación superior cubana. Selección de lecturas. La Habana: Félix Varela.

Zilberstein, J. y Collazo, R. (2009). Los medios de enseñanza-aprendizaje, en AAVV. Fundamentos didácticos de la educación superior cubana. Selección de lecturas. La Habana: Félix Varela. 


\section{PALABRAS CLAVE}

Comprensión de lectura, estrategias de lectura, evaluación.

\section{KEYWORDS}

Reading comprehension, reading strategies, evaluation.

\section{PERFIL ACADÉMICO Y PROFESIONAL DE LOS AUTORES}

Eugenio Hidalgo Diez, Profesor Titular de Métodos de Investigación y Diagnóstico en Educación, Facultad de Ciencias de la Educación de la Universidad de Granada, donde imparte docencia. Vicedecano de Grado, Garantía de la Calidad y Acción Tutorial. Líneas de investigación: Evaluación de los procesos de enseñanza-aprendizaje y de las competencias. Gestión y evaluación de la Calidad en centros educativos. Análisis y Estudio de Políticas Educativas y de Calidad en contextos rurales.

Mirtha Manzano Díaz, Profesora Titular del Departamento de Idiomas de la Facultad de Ciencias Sociales y Humanísticas de la Universidad de Ciego de Ávila, Cuba. Vicedecana de Investigación y Postgrado. Imparte docencia e investiga en áreas del conocimiento relacionadas con la didáctica de las lenguas extranjeras, comprensión de lectura, competencia comunicativa y estrategias de aprendizaje. Dirige un proyecto de servicios y asesoría de traducción e interpretación.

Dirección de los Autores: Eugenio Hidalgo Díez

Campus La Cartuja s/n

18071 - Granada (ESPAÑA).

E-mail: eugenio@ugr.es

Mirtha Manzano Díaz

Pasaje B N. ${ }^{\circ}$ : 254 Entre: 2da y 3ra Reparto:

Ortiz,

Ciego de Ávila

CP: 65200 - Cuba

E-mail: mansano@humanidades.unica.cu alebroc@ciego.cult.cu.

Fecha Recepción del Artículo: 28. Agosto. 2011

Fecha modificación Artículo: 11. Abril. 2012

Fecha Aceptación del Artículo: 06. Junio. 2012

Fecha de Revisión para publicación: 24. Junio. 2013 
LOS PROGRAMAS DE ENSEÑANZA PRIMARIA DE 1938. UN CURRÍCULO (INÉDITO) PARA LA ESCUELA DEL NUEVO ESTADO

\author{
(1938 PRIMARY EDUCATION PROGRAMS. \\ José Ramón López Bausela \\ Universidad de Cantabria
} AN (UNPUBLISHED) CURRICULUM FOR THE NEW STATE SCHOOL)

DOI: 10.5944/educxx1.17.1.10717

\title{
Cómo referenciar este artículo/How to reference this article:
}

López Bausela, J. R. (2014). Los programas de enseñanza primaria de 1938. Un currículo (inédito) para la escuela del Nuevo Estado. Educación XX1, 17 (1), 327-344. doi: 10.5944/educxx1.17.1.10717.

López Bausela, J. R. (2014). 1938 Primary Education Programs. An (unpublished) curriculum for the New State school. Educación XX1, 17 (1), 327-344. doi: 10.5944/educxx1.17.1.10717.

\section{RESUMEN}

El estudio que presentamos tiene por objeto analizar los rasgos más característicos de los programas de enseñanza primaria de 1938, elaborados durante el ministerio de Pedro Sainz Rodríguez, sacándolos del olvido archivístico en que se encontraban. Para ello se hace, en primer lugar, un recorrido histórico de los diferentes intentos dirigidos a proporcionar un currículo prescriptivo a la enseñanza primaria, destacando los programas sancionados por Jesús Hernández, ministro de Instrucción Pública durante la Segunda República. Se procede, en segundo lugar, a examinar las características más sobresalientes de los mencionados programas de 1938. Finalmente, las conclusiones subrayan, por un lado, la necesidad de abordar el estudio del contenido de estos programas desde distintas perspectivas, a fin de poder interpretar el cúmulo de circunstancias que coadyuvaron a la decisión de mantenerlos inéditos a pesar de haber sido aprobados oficialmente y, por otro, aunque la comisión presentó al ministro diseños independientes para los distintos tipos de escuela, se mantiene que todo el currículo de la enseñanza primaria responde a una única y exclusiva finalidad: ponerlo al servicio de los fines políticos del Nuevo Estado.

\section{ABSTRACT}

The aim of the study we are actually presenting is to analyze the main features of the Primary Teaching Programs developed in 1938, exactly during Pe- 
dro Sainz Rodriguez's ministry, removing them from the archivistic isolation. In order to do that, first of all, we should look at the historical background of the different ways of making a prescriptive curriculum in Primary Education, highlighting those programs which were penalized by Jesús Hernández, government minister for Public Instruction during the Spanish Second Republic. After that, we proceed to study thoroughly the main characteristics of the abovementioned programs developed during 1938. Finally, the conclusions found highlight, on one hand, the necessity of tackling these programs content from different perspectives in order to interpret the host of circumstances which contribute to decide to keep them unpublished in spite of being officially approved. On the other hand, whereas the commission presented to the government minister independent designs for the different types of School, they maintained the idea of the Primary Education Curriculum as an answer to only one purpose: to put it at the service of the politic targets of the New State.

\section{INTRODUCCIÓN}

Aunque un número importante de investigaciones enmarcadas en el ámbito de la Historia de la Educación ha puesto de relieve la ausencia en nuestro país, hasta el año 1953, de un currículo prescrito para la enseñanza primaria, son muy pocas las que, ahondando en este período, estudian las posibles causas que han originado tan dilatado vacío legislativo. Algunos trabajos, tras constatar esta realidad mediante análisis pormenorizados de nuestra normativa más relevante, señalan la inexistencia de una infraestructura educativa consolidada y la lucha ideológica presente en España desde los albores del siglo XIX como dos de las variables que contribuyen a clarificar, desde una perspectiva histórica, la escasa atención que ha despertado en nuestros gobernantes la regulación del currículo oficial para este nivel de enseñanza (López del Castillo, 1982).

Por otro lado, aunque algunas publicaciones sobre los orígenes del sistema educativo del primer franquismo dedican algún epígrafe y en algunos casos, capítulos enteros a los programas de enseñanza primaria de 1938, al carácter de los trabajos llevados a cabo por la comisión que los redactó o a distintos temas relacionados con los libros de texto, así como al contenido y la metodología de algunas asignaturas, no contamos con investigaciones que profundicen en los motivos que indujeron al ministro Pedro Sainz Rodríguez a mantener inédito su contenido.

\section{ESPAÑA EN GUERRA}

Otra cuestión importante, que no debemos obviar, es que a pesar de que los primeros ensayos legislativos sobre algo parecido a un plan de es- 
tudios para la enseñanza elemental afloran ya en el siglo XIX, y aunque la ley Moyano anunció en 1857 que el Gobierno tenía previsto publicar "programas generales para todas las asignaturas correspondientes a las diversas enseñanzas» (MEC, 1985, pp. 263-264), habrá que esperar hasta la Guerra Civil para que, en pleno conflicto bélico, tan anunciado proyecto esté más cerca de ser una realidad ${ }^{1}$.

Todo parece indicar que la certidumbre de que en el campo de batalla se dirimía algo más que la aniquilación física del enemigo fue el acicate para que los políticos de ambos bandos asumieran, tras más de un siglo de vacilaciones e intentos postergados, el reto que representaba la regulación de un currículo prescrito para la enseñanza primaria. Y aunque republicanos y sublevados consideraron que el anacronismo legislativo que atenazaba el desarrollo de esta etapa educativa era una de las causas generadoras de sus respectivas propuestas, lo cierto es que la finalidad con que ambas fueron concebidas fue diametralmente opuesta.

En la España gubernamental, el ministro Jesús Hernández presentaba en 1937 su plan de estudios, asumiendo que la carencia de una organización sistemática de la escuela española se debía a que los esfuerzos del ministerio se habían dirigido principalmente a potenciar la infraestructura del sistema educativo — «creación de millares de escuelas, construcción de edificios, mejora del sueldo de los maestros, campaña contra el analfabetismo»-, empresa que, según afirmaba, no debía abandonarse pero que, por otro lado, era imprescindible compaginar con «la reforma interior de la escuela nacional», identificando la base de esta reforma con «la publicación del nuevo plan de estudios primarios ${ }^{2}$.

Pocos meses después, el Ministerio de Educación Nacional de la España sublevada, con Pedro Sainz Rodríguez como máximo representante, encomendaba a una comisión de técnicos la elaboración de los programas que deberían «regir en las escuelas nacionales de Primera enseñanza, excepto los de materia religiosa y de formación cívica que serán objeto de otra disposición especial» ${ }^{3}$, subrayando que aunque a partir de la Ley Moyano se había anunciado en varias ocasiones la publicación de programas para la primera enseñanza, este propósito nunca se había hecho realidad.

Pero, como ya hemos indicado, a pesar de que ambos ministros coincidían en la evidencia representada por la ausencia histórica de estos programas, se distanciaban en lo fundamental, es decir, en la finalidad con que planteaban sus respectivos diseños curriculares.

La España republicana y democrática aseguraba que en la elaboración de su propuesta se contemplaban «las debidas garantías para que responda 
a las posibilidades de trabajo de la escuela española, asegure una cultura básica a nuestras generaciones juveniles y sirva para la rápida transformación de los antiguos métodos de enseñanza», triple perspectiva que configuraba el nuevo plan de enseñanza primaria como «la base e iniciación de toda la reforma posterior de nuestro sistema escolar que el Ministerio de Instrucción Pública y Sanidad se propone llevar a la práctica a fin de establecer una íntima relación entre los distintos grados de la enseñanza», además de «facilitar la adquisición de una sólida cultura elemental a todo el pueblo y permitir a los más aptos una formación científica de acuerdo con su capacidad, sea cualquiera la posición económica o social de los padres» ${ }^{4}$.

En el otro extremo, Sainz Rodríguez consideraba que la publicación de programas para la enseñanza primaria «en los momentos actuales en que prevalecen las ideas de unidad y disciplina es ya inexcusable», matizando a renglón seguido que tanto su elaboración como su puesta en práctica en la escuela no debían ser «simple y formularia aplicación de un precepto legal, sino producto de un estudio serio en que se tengan en cuenta los designios del nuevo Estado, nuestras realidades escolares, los caracteres genuinos de nuestra cultura y los progresos realizados hasta el día en materia pedagógica ${ }^{5}$.

Es evidente, por tanto, incluso antes de abordar siquiera el análisis de su contenido, que nos encontramos ante dos diseños curriculares de factura diametralmente opuesta. Pero no es esta la cuestión de la que nos ocuparemos en este artículo.

Los programas renovadores y modernos que Jesús Hernández sancionó en 1937 apenas pudieron ser aplicados en el territorio cada vez más mermado de la España republicana y la derrota final impidió para siempre la posibilidad de una reforma que perseguía, entre otros ambiciosos fines, el viejo y acariciado anhelo de unificar los distintos grados de enseñanza.

Todo apuntaba, pues, a que los programas elaborados por la comisión de técnicos designados por Sainz Rodríguez serían los que finalmente iban a regir en la escuela primaria de la nueva España.

\section{LLOVÍA SOBRE MOJADO}

No fue este, sin embargo, el primer intento que surgió desde el bando sublevado con el objetivo de fijar un programa oficial para la enseñanza primaria. Ya en 1936 diferentes colectivos profesionales del ámbito del magisterio manifestaban su inquietud por la ausencia de un currículo que cohesionara la labor docente de los maestros en la escuela de la nueva Es- 
paña ${ }^{6}$. Contamos con pruebas documentales que avalan la existencia de una propuesta elaborada en el seno de la Comisión de Cultura y Enseñanza de la Junta Técnica de Estado que, previamente a la redacción de unos programas que nunca se publicaron, planteó a modo de preámbulo diez principios en los que debía sustentarse la futura educación nacional. El primero de ellos — «la enseñanza primaria en España debe ser Católica, patriótica y esencialmente formativa» (Alted Vigil, 372) — había sido anunciado ya por el general Mola prácticamente al inicio de la sublevación — «organizaremos escuelas donde los maestros enseñen a amar a Dios y a la Patria» ${ }^{7}$ - y en él confluyen las coordenadas que acotarían durante decenios el espacio curricular de la enseñanza primaria española.

Así lo entendió también Sainz Rodríguez quien, a los pocos meses de hacerse cargo del ministerio, sancionó una circular de la Jefatura del Servicio Nacional de Primera Enseñanza en la que Romualdo de Toledo «dirigirá a los inspectores y maestros nacionales, municipales y privados de la España nacional la primera sistematización que recoge de forma oficial el corpus ideológico -Patria y Dios- a impartir por la escuela del Nuevo Estado» ${ }^{8}$ (López Bausela, 165), con el objetivo de «homogeneizar y sistematizar la acción de los docentes en un claro afán por potenciar la efectividad de su labor indoctrinadora, dictando para lograrlo instrucciones relativas a cuatro ámbitos curriculares concretos: educación religiosa, educación patriótica, educación cívica y educación física» (López Bausela, ib.).

La circular de 5 de marzo ${ }^{9}$ acotó definitivamente, incluso antes de iniciarse el procedimiento normativo de elaboración de unos programas oficiales para la enseñanza primaria, el espacio curricular reservado a los maestros.

Por otro lado, contamos también con diferentes propuestas remitidas en su día al ministro en las que además de plantear la estructura y contenido de los futuros programas de enseñanza primaria se señalaban diferentes ámbitos que debían ser objeto de especial consideración en el delicado proceso de construcción de la nueva escuela española. Alguna de estas aportaciones parte de una descripción del perfil psicológico del niño español al que se define en posesión de una "gran viveza, extraordinaria movilidad, adivinación rápida y fácil memoria. Y como cualidades negativas, falta de constancia, propensión a la indisciplina mental e inercia para la reflexión serena», indicando la conveniencia de educarle "activando sus facultades intuitivas y sucesivamente su potencia reflexiva, disciplinando su mentalidad dispersa, formando su voluntad y carácter y fomentando sus sentimientos morales», todo lo cual debía complementarse con «una fuerte educación religiosa, patriótica y física» ${ }^{10}$. 
Tanto la circular de 5 de marzo, que fue dictada con la finalidad de «dar orientación fija y uniforme a todos los maestros de España», como el contenido de las distintas propuestas planteadas con carácter previo a la redacción de los programas de enseñanza primaria corroboran que el contenido del currículo de esta etapa educativa estaba ya prefijado y, por tanto, el trabajo de la comisión técnica sería meramente testimonial, limitándose a desempeñar el rol de testaferro ideológico del Antiguo Régimen para quien, como sabemos, la escuela primaria representó siempre poco más que una institución de beneficencia abandonada al control de la Iglesia católica.

Esto explica, en buena medida, los escasos cincuenta días que la España tradicional, católica y nacionalista de Sainz Rodríguez dio de plazo a la comisión técnica para consumar una empresa que los distintos ministros del Ramo llevaron en sus carteras durante algo más de un siglo.

\section{UNA SUTIL ESTRATEGIA}

Simultáneamente al nombramiento de la comisión especial de técnicos encargada de redactar los programas escolares, el ministro Sainz Rodríguez encomendó al Instituto de España «la redacción y edición de textos destinados a la enseñanza primaria en sus distintos grados» ${ }^{11}$ que, según indicaba la orden, serían impuestos con carácter obligatorio tanto en las escuelas públicas como en las privadas de toda España, además de estar disponibles para su adquisición en el mes de octubre.

Si nos fijamos en los plazos otorgados tanto a la comisión como al Instituto de España para realizar sus respectivos trabajos, este último dispuso de un margen de cuatro meses para adecuar el contenido de los manuales escolares a los programas que la comisión debía tener redactados, según lo ordenado, antes del uno de junio. Y es precisamente aquí, como apuntamos en un trabajo monográfico publicado recientemente dedicado íntegramente a estos programas ${ }^{12}$, donde toma cuerpo la hipótesis de que su carácter inédito está relacionado con el preceptivo ajuste del contenido de los manuales al diseño curricular prescrito, lo que en plena contienda era un lastre considerable para las editoriales designadas por el Instituto de España para imprimir, en el plazo estipulado, los textos escolares.

Otro dato que apunta en idéntica dirección es que, aunque ambas órdenes fueron firmadas en la misma fecha, aparecen publicadas en el B.O.E. con dos días de diferencia, en lo que aparenta ser un intento de presentar separados ambos procesos: por un lado los programas y por otro la producción de manuales, estrategia que el propio ministro reforzará al afirmar que el contenido de los textos redactados por el Instituto «deberá conformarse 
con los planes y programas escolares que el Ministerio de Educación Nacional ordene» ${ }^{13}$, omitiendo cualquier referencia a los que él había ordenado elaborar ese mismo día.

En este sentido, el contenido de alguna de las reuniones de la mesa del Instituto de España es bastante clarificador. En una de ellas Sainz Rodríguez, que ejerció desde el primer momento la presidencia debido a la negativa de Manuel de Falla a desempeñar el cargo, comunicó a los presentes que, nada más publicar la orden que encomendaba al Instituto la redacción y edición de textos destinados a la enseñanza primaria, había dispuesto, como ministro de Educación, la celebración de una reunión de la comisión nombrada para redactar los programas a fin de coordinar los planes del Instituto y de los autores de los manuales con las previsiones que en materia de programas escolares se dictaran desde el ministerio.

El hecho de que, desde el inicio de esta sesión, Sainz Rodríguez marcara la diferencia entre sus decisiones como ministro y como presidente del Instituto de España es algo verdaderamente significativo y, como veremos seguidamente, este proceder del ministro constituye uno de los indicadores más relevantes de que nos encontramos, más que ante una circunstancia derivada del desempeño simultáneo de dos cargos oficiales, ante una calculada estrategia.

En esta misma sesión Eugenio D'Ors, secretario perpetuo del Instituto, informó a la mesa de los acuerdos adoptados en la ya citada reunión de la comisión de técnicos encargada de redactar los programas. Y lo verdaderamente sorprendente es que con el poco tiempo de que disponían para llevar a cabo su labor optaran por dejar "para días sucesivos y para el acuerdo de subcomisiones especiales el detalle de los temas, enunciados y condiciones en que hayan de redactarse dichos programas», llegando, sin embargo, de forma rápida y unánime «a un acuerdo expreso sobre las condiciones generales que deban proponerse al Instituto, a fin de que pueda éste empezar la tarea urgente de la redacción de dichos textos y del establecimiento de las bases en que la edición de los mismos deba realizarse o convenirse con quien de ello se encargue». Además, y esto es lo auténticamente revelador, uno de los acuerdos adoptados sobre la edición de los manuales, autorizaba al presidente del Instituto, al secretario perpetuo y al secretario de publicaciones a llevarla a cabo «bien en forma de gestión directa, bien mediante convenios con terceras personas» ${ }^{14}$, convenios que podían ser suscritos para la totalidad de los textos previstos, para una determinada sección o incluso para algún volumen en particular.

Este conjunto de declaraciones refuerzan la hipótesis de que no estamos frente a una mera casualidad fruto de las especiales circunstancias 
del momento sino ante un plan premeditado. Viene a confirmarlo el hecho de que unos meses más tarde, debido a las presiones recibidas desde varios frentes - no pedagógicos, precisamente- Sainz Rodríguez se vio obligado a suavizar de facto el monopolio de edición de libros de texto para la enseñanza primaria concedido al Instituto de España ${ }^{15}$, eludiendo de nuevo cualquier referencia a los programas, que para entonces debían estar ya redactados, como referente básico para que los manuales presentados a examen fueran aprobados.

No acaba aquí, sin embargo, el cúmulo de evidencias que apuntan en la dirección señalada.

Un par de meses después de asumir implícitamente que el intento de libro de texto único para la enseñanza primaria había fracasado, el ministro creó otra comisión, encargada, por un lado, de examinar los libros de texto presentados a examen y, por otro, de autorizar la publicación de nuevos manuales. En esta ocasión, además de perfilar el doble objetivo de la comisión, Sainz Rodríguez dejará patente no sólo la necesidad ineludible de «encauzar adecuadamente» la influencia del libro escolar dentro de la orientación cultural de la enseñanza primaria, sino que dará un paso más, poniendo de manifiesto que la finalidad de fijar esta orientación consistía en «dar a la Escuela, al maestro y a los niños aquella sana doctrina, saturada de espíritu religioso y patriótico, que constituye la esencia de nuestro Movimiento Nacional» ${ }^{16}$.

Esta vez el ministro no se limita tan sólo a evitar cualquier alusión explícita a los programas sino que hace públicos los criterios de evaluación que la comisión iba a tomar como referente para aprobar o no los textos presentados a examen: «contenido religioso, moral, patriótico, pedagógico, científico, literario, tipográfico y precio de venta», nombrando como vocales a cuatro catedráticos de instituto, síntoma inequívoco de su poca fe en el magisterio.

Pero la prueba más patente de que los programas no verían la luz, al menos durante el curso 1938/39, es la circular de la Jefatura del Servicio Nacional de $1^{\text {a }}$ Enseñanza que, pocos días antes del inicio de la actividad docente «recuerda a los señores Inspectores y Maestros nacionales el más exacto cumplimiento de las normas que sobre educación religiosa, patriótica, cívica y física contiene la Circular del 5 de marzo», al mismo tiempo que ordena a los inspectores jefes de cada provincia que pongan «en conocimiento de los Maestros nacionales que no deben adquirir libros escolares hasta que la Comisión dictaminadora de los mismos termine su labor sobre los libros admitidos, que serán los únicos que podrán utilizarse en la Escuela nacional» ${ }^{17}$. 
La ausencia reiterada, de cualquier referencia a los programas de enseñanza primaria en la legislación sobre los libros de texto, posterior a la orden de constitución de la comisión técnica, constituye un claro indicador de que en el ánimo del ministro jamás anidó intención alguna de publicar oficialmente un currículo que condicionara el espacio curricular reservado en exclusividad a Dios y la Patria. Con razón confesó Sainz Rodríguez desde la cima de su carrera ministerial que todo aquel que quisiera conocer sus orientaciones y su labor comprara un periódico llamado Boletín Oficial, ya que en él figuraban sus declaraciones o, lo que era igual: sus decretos (Fernández Flórez, 4).

El resto es historia conocida. Sainz Rodríguez abandonó el ministerio nada más terminar la guerra con el curso escolar aún sin concluir, dejando aprobados unos programas ${ }^{18}$ de los que tan sólo se publicó su preámbulo ${ }^{19}$.

\section{LA NATURALEZA DE LOS PROGRAMAS}

Como ya hemos indicado en la introducción de este artículo, el estado de la cuestión arroja un saldo negativo sobre el número de investigaciones que se ocupan del contenido de los programas escolares de enseñanza primaria de 1938 y las posibles causas que subyacen a su no publicación, si bien es cierto que muchos de los trabajos centrados en el estudio de los orígenes del sistema educativo franquista durante la guerra civil española ponen de manifiesto su extrañeza ante el hecho de que, a pesar de estar oficialmente aprobados y autorizada su publicación jamás llegaron a ser una realidad.

Por otro lado, el consenso entre los historiadores es unánime a la hora de calificar de excusa la versión oficial de la escasez de papel como la causa que originó que los programas no fueran distribuidos entre los maestros. Y aunque algunos han hecho referencia también a la precipitada salida del ministerio de Pedro Sainz Rodríguez junto con la prioridad que su sucesor en el cargo - Ibáñez Martín- concedió a la elaboración de una ley para la enseñanza primaria como dos factores más que contribuyeron a mantener inéditos los programas, lo cierto es que todavía hoy no se ha dado una explicación satisfactoria a este episodio singular de la Historia de la Educación en nuestro país durante el franquismo de guerra.

Contamos con una investigación sobre el magisterio en España durante el período 1936-1945 que dedica un capítulo a los programas, aventurando entre las posibles hipótesis que explican su carácter inédito la presencia de supuestas disonancias de carácter ideológico en su contenido, atribuyendo las mismas a la formación que durante la etapa republicana 
recibieron varios de los integrantes de la comisión de técnicos, alguno de los cuales fue becado en su día por la Junta de Ampliación de Estudios para completar su formación en el extranjero. Esta particularidad explicaría, en buena medida, según se afirma en dicha investigación, el contenido de «un documento que, por su carácter abierto e innovador, desde el punto de vista pedagógico, sorprende si se compara con otras disposiciones del momento» (Peralta Ortiz, 148).

$\mathrm{Y}$ es precisamente el contenido de los programas escolares de la enseñanza primaria de 1938 la cuestión fundamental en la que futuras investigaciones tendrán que incidir para dilucidar las verdaderas causas que motivaron que nunca llegaran a imprimirse, aunque si quieren llegar al fondo de la cuestión tendrán que atender a una triple perspectiva. En primer lugar, clarificar su proximidad o lejanía respecto del contenido de los manuales que en su momento la comisión dictaminadora de libros de texto autorizó a publicar; en segundo, determinar la existencia o no de paralelismos con el espíritu curricular recogido en la ley de enseñanza primaria de 1945 que regiría en nuestro país durante un cuarto de siglo y, finalmente, analizar su proyección en el currículo que definitivamente, y por segunda vez, vería la luz en nuestro país, en el año 1953, durante el ministerio de Joaquín Ruiz Giménez ${ }^{20}$.

\section{Un preámbulo para la posteridad}

Razones evidentes de espacio impiden que analicemos pormenorizadamente en este artículo los programas escolares de 1938, de los que se conserva una copia en el archivo personal que Sainz Rodríguez legó a su muerte a la Fundación Universitaria Española ${ }^{21}$; sin embargo, vamos a incidir en algunos aspectos de su contenido que pueden ayudarnos a entender mejor las posibles causas que indujeron al ministro a mantenerlos inéditos.

La comisión encargada de su redacción trabajó en la línea perfilada por Sainz Rodríguez en la orden de 11 de abril, tomando como referencia para llevar a cabo su estudio «nuestras realidades escolares y los caracteres genuinos de nuestra cultura, sin perder de vista los progresos realizados y los que conviene realizar en materia pedagógica», presentando, además, el resultado de su trabajo no como algo definitivo, «sino sólo a título de ensayo pedagógico, que habrá de completarse en la realidad viviente de los grupos y de todos los demás organismos y células escolares del país» ${ }^{22}$, punto de partida que no debemos perder de vista ya que constituye el referente para poder entender la dinámica desarrollada por la comisión en la elaboración de los programas, una dinámica que trasluce, además de las pautas ministeriales, el espíritu latente en los pedagogos adscritos ideológicamente a la 
España sublevada y su plasmación en la organización y orientación de la escuela primaria.

Por otro lado, una de las notas más peculiares de los programas escolares de 1938, es la propuesta de algunas metodologías verdaderamente novedosas procedentes de las corrientes pedagógicas europeas más reputadas en aquellos días como, por ejemplo, los centros de interés, el método cíclico, las concentraciones de conocimientos o el principio de actividad, pero la finalidad principal de los programas era trasladar al alumnado contenidos claramente indoctrinadores en clave de la más pura y genuina tradición española. Esta circunstancia ha llevado a numerosos investigadores a ver en estos planteamientos metodológicos una nota de modernidad que podría justificar, incluso, la no publicación de los programas, cuando, en realidad, nos encontramos ante una estrategia diseñada para optimizar la transmisión de determinados contenidos al alumnado, estrategia que tiene su origen en el conocimiento que varios miembros de la comisión poseían sobre esas metodologías por haberlas visto en funcionamiento fuera de nuestras fronteras, donde habían cosechado un éxito notable de la mano de importantes educadores de renombre. Además, la comisión llevó a cabo una exhaustiva y minuciosa clasificación de los diferentes tipos de escuela — párvulos, ambulantes y de temporada, rurales, de orientación marítima, urbanas y maternales-, elaborando para cada una de ellas su correspondiente programa, en un claro y manifiesto intento de controlar hasta el último de los valores y contenidos que los maestros debían trasladar al alumnado en su práctica diaria en la escuela.

Pero este control no terminaba con la prescripción de programas diferenciados para cada escuela en particular; además, la comisión encomendó a la «Inspección Profesional que, a manera de ramificación nerviosa del organismo nacional lleva a las Escuelas las inspiraciones del Estado en la enseñanza primaria», la labor de recoger «los resultados del trabajo escolar, las necesidades de la enseñanza y la propuesta de medios para mejorar la obra educativa de la Nueva España», evidentemente tan solo una excusa que, amparada en el anunciado carácter de ensayo pedagógico con que fueron presentados los programas, no perseguía otro objetivo que controlar estrechamente la labor de un colectivo sujeto además, en muchos casos, a la presión del dictamen de un expediente de depuración que, no obstante, tardaría años en conocer.

La comisión presentó al ministro un currículo para la escuela primaria concebido con espíritu de trascendencia, «mirando más a la España futura que al punto de partida», por lo que los contenidos de carácter bélico perdían protagonismo frente a los considerados imprescindibles para formar a las nuevas generaciones surgidas del conflicto. La victoria militar estaba 
cada día más cercana — «nuestros soldados avanzan y todas las actividades nacionales se intensifican»- por lo que el magisterio estaba obligado a unir su "entusiasta dinamismo al común esfuerzo», lo que suponía dirigir el diseño curricular de la escuela del Nuevo Estado hacia la consecución de una victoria ideológica que contribuyera a extender un manto de legitimidad sobre la obtenida en el campo de batalla mediante el recurso a las armas y a la rebelión militar: «La unidad nacional y el interés de la Patria exigen la cooperación armónica de todos los españoles e incumbe a los Maestros incorporar al Movimiento nacional, bien preparados para la noble empresa imperial de España, a los futuros ciudadanos».

A pesar del anuncio de la puesta en marcha de un abanico de propuestas que abarcaban desde la organización de cursos de perfeccionamiento profesional a la creación de bibliotecas de cultura pedagógica, junto con la afirmación de que «los métodos que en estos programas se desarrollan, para orientar y encauzar el trabajo de los educadores, dejan a salvo sus incitativas», lo cierto es que la senda metodológica que los programas escolares trazaron para ser transitada por los maestros de la nueva España estaba impregnada por la vieja pedagogía de personajes como San José de Calasanz, Andrés Manjón, San Ignacio de Loyola o Fray Pedro Ponce de León, sin olvidar la piadosa y preceptiva mención a la encíclica Divini illius magistri, sobre la educación cristiana de la juventud del Papa Pío XI. Por si quedaba alguna sombra de duda sobre esta cuestión, la comisión aludía especialmente, por un lado, a la eficacia de los métodos «que formaron a nuestros compatriotas de la época imperial por medio de las llamadas 'Escuelas de Gramática' » y, por otro, al «sistema de repetición para obtener la mayor fijeza y solidez de los conocimientos», al que no dudaba en calificar como un "clásico en la tradición [pedagógica] española», insistiendo en que era preferible que los conocimientos fueran «firmes y permanentes, aunque pocos, a que sean muchos y deleznables».

Como complemento a estas metodologías, se recomendaba a los maestros la lectura y reflexión sobre el contenido de dos obras «admirables y además españolísimas»: El Criterio, de Balmes y El Maestro mirando hacia dentro, de Andrés Manjón, aduciendo que «estos libros y aquellos métodos y doctrinas [...] les servirán de apoyo para formar y robustecer la conciencia católica de los niños» que, junto con el amor a la patria, era, como hemos visto, la razón de ser de la escuela del Nuevo Estado.

Otra cuestión importante es la presentación de las materias de estudio como «concentraciones» de conocimientos en lugar de adoptar la clásica forma de asignaturas, estrategia que permitió a la comisión, a pesar de estar exonerada de la obligación de redactar los programas especiales de materia religiosa y formación cívica, "saturar de espíritu religioso y patriótico su 
labor». Esta presentación de las materias de estudio por concentraciones de conocimientos en lugar de asignaturas otorgaba también un importante margen de maniobra al diseño del libro de texto único para la escuela primaria, el otro gran proyecto que Sainz Rodríguez puso en marcha oficialmente a la par que los programas ${ }^{23}$, y que originó numerosos problemas y enfrentamientos entre los distintos sectores implicados en su desarrollo.

\section{Todas las escuelas convergiendo a idéntico fin}

La comisión encargada de elaborar los programas presentó al ministro en el plazo convenido un plan pormenorizado para cada una de las escuelas que, según contempla el preámbulo, conforman el panorama de la enseñanza primaria española, minuciosidad que respondió, como ya hemos dicho, a la preocupación del Nuevo Estado por fiscalizar hasta el mínimo detalle el currículo que los maestros debían desarrollar en el ejercicio diario de su labor profesional. Esta diversificación de los programas que responde, en buena medida, a la existencia de distintos entornos físicos y edades para su aplicación, no debe hacernos perder la visión de conjunto sobre un proyecto curricular que persigue para la totalidad de la escuela primaria española un objetivo común y único, eje rector sobre el que gira el grueso del contenido de los programas escolares de 1938, acatando así el llamamiento a la unidad y la disciplina llevado a cabo por Sainz Rodríguez en la orden de 11 de abril.

Así, la finalidad fundamentalmente adoctrinadora de la escuela del Nuevo Estado afloró desde la escuela de párvulos, concebida en los programas como «un hogar alegre con una madre buena, cristiana y española», sin olvidar aquellos niños que, por cualquier circunstancia, accedieran directamente a la escuela primaria, para los que se prescribía que toda enseñanza debía girar «alrededor de un eje cuyos polos serán Religión y Patria. Fuerza impulsora: el amor a Dios, a la Patria y al Jefe del Estado", o las escuelas ambulantes y de temporada donde el maestro debía inculcar a sus alumnos "que el trabajo que se va a hacer es un acto de servicio por la Patria y para Dios», de donde emanaba "la seriedad con que se ha de hacer y la atención que exige, aunque cueste esfuerzo», recomendación presente también en las prescripciones generales que se elaboraron para todos los programas relativos a las escuelas rurales y de orientación marítima.

Para las escuelas urbanas unitarias y graduadas, tanto de niños como de niñas, esta finalidad se instrumentó a través del estudio de la lengua, ya que su enseñanza constituía, según la comisión, «una base de concentración en torno de la cual giren todas las demás materias», proponiendo para ello desde la observación de cuadros y láminas con contenidos eminentemente religiosos y patrióticos, como la adoración de los reyes magos, la huída a 
Egipto, la rendición de Granada, el testamento de Isabel la Católica o el escudo de España, hasta la propuesta de dictados de «intención formativa moral con base religiosa» $\mathrm{y}$ «de intención formativa patriótica».

Por otro lado, el conjunto de concentraciones de conocimientos propuesto por la comisión para la escuela del Nuevo Estado constituye, en esencia, una red de valores y contenidos cuya trabazón lógica se teje con el hilo de una única y exclusiva finalidad: educar al alumnado en el amor a Dios y a la patria, principio rector al que se subordinó la totalidad del proyecto curricular recogido en los programas y que se erigió en protagonista de las prescripciones de carácter general, mezcla de orientaciones metodológicas y pautas de intervención en el aula, que la comisión elaboró para los distintos tipos de escuela.

\section{CONCLUSIONES}

El contenido de los programas escolares de 1938 se amolda con total fidelidad a los dictados de Sainz Rodríguez y a su particular concepción de una escuela primaria universal, obligatoria y gratuita. La uniformidad de contenidos curriculares para todo el territorio nacional fue consustancial a un momento histórico, caracterizado por las ideas de unidad y de disciplina, hegemónicas no sólo en nuestro país, sino también en un entorno europeo sacudido hasta sus cimientos por el fenómeno político y social de los fascismos en alza. Además, la comisión encargada de su redacción trabajó con el punto de mira puesto en la España futura por lo que el currículo de la escuela primaria fue diseñado para cimentar el Nuevo Estado: el abanico de contenidos planteado para las distintas escuelas se nutrió así del fermento representado por un acervo de valores y actitudes que la España católica y tradicional consideraba primordiales para la formación de las generaciones surgidas del conflicto.

Tanto el ministro como los miembros de la comisión sabían que, aunque los maestros carecían de todo tipo de capacidad decisoria sobre el currículo, eran, sin embargo, los encargados de gestionarlo, siendo precisamente esta facultad la que les confería un rol de primera magnitud dentro del proceso de reelaboración que se originaba como consecuencia de su trabajo diario en la escuela. Presentar a los maestros un programa oficial, aunque fuera a título de ensayo pedagógico, era arrebatarles el único espacio de libertad que tradicionalmente habían tenido, consistente en programar itinerarios didácticos a partir de diferentes cuestiones. Se aseguraba de este modo la restauración de la escuela tradicional española sobre cimientos católicos y patrióticos, culminando así un proceso histórico que abocó en el nacional catolicismo. 
En realidad, el hecho de que los programas permanecieran inéditos es prácticamente irrelevante desde un punto de vista pedagógico, ya que la circular de 5 de marzo de 1938 determinó con nitidez el marco curricular para la escuela del Nuevo Estado, la inspección de primera enseñanza veló para que los maestros no se apartaran ni un milímetro de las orientaciones recogidas en ella asegurándose de esta manera una acción homogénea y sistemática en todo el territorio nacional. Los programas buscaron únicamente afinar esta estrategia, proponiendo unos contenidos mínimos y obligatorios que los maestros debían utilizar como punto de partida para alcanzar el fin perseguido. Esta es la diferencia fundamental entre la circular y los programas. La primera perfila únicamente los fines, los programas escolares de 1938 hacen una propuesta de contenidos curriculares que los maestros debían utilizar como punto de partida y fuerza impulsora para alcanzarlos.

Por otro lado, la urdimbre de la propuesta curricular presente en los programas es de tal naturaleza que incluso en el caso de aquellos maestros que, por su preparación, no fueran capaces de desarrollar la habilidad necesaria para conducir a sus alumnos hacia los fines señalados desde cualquiera de las concentraciones de conocimientos sugeridas, bastaba con que trabajaran a un nivel puramente mecánico los contenidos obligatorios del programa, ya que éstos estaban seleccionados de tal manera por la comisión que no representaban peligro alguno de alejamiento del fin último perseguido por la escuela del Nuevo Estado. Además, todos los alumnos completaban su formación con las materias específicas de religión y formación del espíritu nacional, con lo cual era imposible librarse del adoctrinamiento prescrito.

En definitiva, solo un análisis profundo del contenido de los programas y de su relación con los manuales escolares autorizados para la publicación, puede arrojar luz sobre uno de los múltiples enigmas que la estela del ministerio de Pedro Sainz Rodríguez dejó tras sí al abandonar el ministerio antes de que terminara el curso escolar 1938/39.

\section{NOTAS}

1 Otra norma legal importante que preveía la publicación de programas fue el real decreto de 26 de octubre de 1901, siendo ministro de Instrucción pública el conde de Romanones. El documento puede consultarse en el tercer volumen de la obra citada, pp. 157-169.

2 Decreto de 28-X-1937, Gaceta de la República de 31-X-1937, n. ${ }^{\circ}$ 304, p. 402.

3 Orden de 11-IV-1938, Boletín Oficial del Estado de 13-IV-1938, n. ${ }^{\circ}$ 539, p. 6764. Destacaba de entre todas ellas el ya citado real decreto de 26 de octubre de 1901.

4 Decreto de 28-X-1937, Gaceta de la República de 31-X-1937, n. ${ }^{\circ}$ 304, p. 402. 
5 Orden de 11-IV-1938, Boletín Oficial del Estado de 13-IV-1938, n. ${ }^{\circ}$ 539, p. 6764.

6 Algunos ecos de esta preocupación pueden verse en los números 64 y 69 de la revista Atenas.

7 Palabras del discurso del general Mola pronunciado en Radio Nacional el 28-I-1937. La Gaceta Regional, Salamanca, 29-I-1937.

8 Cursiva en el original.

9 Boletín Oficial del Estado de 8-III-1938, n. ${ }^{\circ}$ 503, pp. 6154-6156.

10 «Informe sobre programas en la Nueva Escuela Primaria Española», AFUEPSR, caja 89/28.

11 Orden de 11-IV-1938, Boletín Oficial del Estado de 15-IV-1938, n. ${ }^{\circ}$ 541, p. 6795.

12 López Bausela, J.R. (2012). Los programas escolares inéditos de 1938 en la España de Franco. El cerco pedagógico a la modernidad. Madrid: UNED-PubliCan. En este trabajo, además de llevar a cabo un estudio preliminar sobre los programas, reproducimos íntegramente su contenido.

13 Orden de 11-IV-1938, Boletín Oficial del Estado de 15-IV-1938, n. ${ }^{\circ}$ 541, p. 6795.

14 Instituto de España (1938): Actas de la Mesa del Instituto de España. Sexta Sesión, Mayo, San Sebastián.

15 Orden de 28-VI-1938, Boletín Oficial del Estado de 5-VII-1938, n. ${ }^{\circ}$ 5, p. 57.

16 Orden de 20-VIII-1938, Boletín Oficial del Estado de 25-VIII-1938, n. ${ }^{\circ}$ 56, p. 897.

17 Administración Central. Ministerio de Educación Nacional. Jefatura del Servicio Nacional de Primera Enseñanza, 30-VIII-1938, Boletín Oficial del Estado de 7-IX-1938, n. ${ }^{\circ}$ 69, p. 1135.

18 Orden de 16-XII-1938, Boletín Oficial del Estado de 19-XII-1938, n. ${ }^{\circ} 172$, p. 3028.

19 Administración Central. Ministerio de Educación Nacional. Jefatura del Servicio Nacional de Primera Enseñanza, 15-XII-1938, Boletín Oficial del Estado de 19-XII-1938, n. ${ }^{\circ} 172$, pp. 3035-3036.

20 Como ya hemos indicado los primeros que vieron la luz en la España oficial, gubernamental y democrática fueron los que en octubre de 1937 sancionó el ministro Jesús Hernández.

21 Archivo Fundación Universitaria Española Pedro Sainz Rodríguez (AFUEPSR): «Programas que han de regir en las escuelas nacionales de primera enseñanza. 1938», caja 3/8.

22 Salvo precisión en contra, todas las citas relativas al preámbulo proceden de: AFUEPSR: «Programas que han de regir en las escuelas nacionales de primera enseñanza. 1938», caja $3 / 8$, y pueden ser consultadas también en la circular de la Jefatura del Servicio Nacional de Primera Enseñanza de 15-XII-1938, B.O.E. de 19-XII-1938, n. ${ }^{\circ} 172$, pp. 3035-3036, que recoge íntegramente, salvo ligeros matices, el texto elaborado por la comisión.

23 Orden de 11 de abril de 1938, Boletín Oficial del Estado de 15-IV-1938, p. 6795.

24 AFUEPSR: «Programas que han de regir en las escuelas nacionales de primera enseñanza. 1938", caja 3/8. Salvo indicación en contra, todas las citas relativas al contenido de los programas proceden de esta fuente documental. 


\section{REFERENCIAS BIBLIOGRÁFICAS}

Alted Vigil, A. (1984). Política del nuevo Estado sobre el patrimonio cultural y la educación durante la Guerra Civil española. Madrid: Ministerio de Cultura.

Fernández Flórez, W. (1938). Una interviú con el ministro de Educación Nacional. Cómo se forma la nueva España. La reforma universitaria, $A B C$, 7-XI, 3-4.

López Bausela, J.R. (2006). Exequias en Pamplona del magisterio republicano: Los orígenes del sistema educativo franquista. Huarte de San Juan, 13, 311-338.

López Bausela, J.R. (2007). Exequias en Pamplona del magisterio republicano: Los orígenes del sistema educativo franquista (II). Huarte de San Juan, 14, 153-233.

López Bausela, J.R. (2011). La contrarrevolución pedagógica en el franquismo de guerra. El proyecto político de Pedro
Sainz Rodríguez. Madrid: Biblioteca Nueva.

López Bausela, J.R. (2012). Los programas escolares inéditos de 1938 en la España de Franco. El cerco pedagógico a la modernidad. Madrid: UNED-Publican.

López del Castillo, M.T. (1982). Planes y programas escolares en la legislación española. Bordón, 242-243, 127-202.

MEC (1985). Historia de la Educación en España II. De las Cortes de Cádiz a la Revolución de 1868. Madrid: Servicio de Publicaciones.

MEN (1938). Curso de Orientaciones $\mathrm{Na}$ cionales de la Enseñanza Primaria. Burgos: Hijos de Santiago Rodríguez.

Peralta Ortiz, M.D. (2012). La escuela primaria y el magisterio en los comienzos del franquismo. Madrid: Universidad Pontificia Comillas. 


\section{PALABRAS CLAVE}

Escuela primaria, programas escolares, curriculum, franquismo.

\section{KEYWORDS}

Primary education, school programs, curriculum, Francos' regime.

\section{PERFIL ACADÉMICO Y PROFESIONAL DEL AUTOR}

José Ramón López Bausela es doctor en Ciencias de la Educación por la U.N.E.D. Profesor del Área de Teoría e Historia en la Facultad de Educación de la Universidad de Cantabria e investigador del Centro MANES de la U.N.E.D., dirige en la actualidad el C.E.I.P. «María Blanchard» de Santander. Sus líneas de investigación se centran en la génesis del sistema educativo en el franquismo de guerra y los manuales escolares de esta época histórica.

Dirección del autor: Universidad de Cantabria

Facultad de Educación (despacho 205)

Avda. de los Castros s/n

39005 - Santander (Cantabria)

E-mail: joseramon.lopez@unican.es

Fecha Recepción del Artículo: 22. Diciembre. 2011

Fecha Modificación del Artículo: 19. Abril. 2012

Fecha Aceptación del Artículo: 06. Junio. 2012

Fecha de Revisión antes de la publicación: 24. Junio. 2013 

CORDOBÉS EN EL PRIMER TERCIO DEL SIGLO XX. INVESTIGACIÓN BASADA EN UNA METODOLOGÍA CUANTITATIVA

\author{
(THE EVALUATION OF THE TEACHER TRAINING SCHOOLS STUDENTS \\ OF CORDOBA IN THE FIRST THIRD OF THE XXTH CENTURY. RESEARCH \\ BASED ON A QUANTITATIVE METHODOLOGY)
}

Antonia Ramírez García
Universidad de Córdoba

DOI: 10.5944/educxx1.17.1.10718

\title{
Cómo referenciar este artículo/How to reference this article:
}

Ramírez García, A. (2014). La evaluación del alumnado normalista cordobés en el primer tercio del siglo XX. Investigación basada en una metodología cuantitativa. Educación XX1, 17 (1), 345-366. doi: 10.5944/educxx1.17.1.10718.

Ramírez García, A. (2014). The evaluation of the teacher training schools students of Cordoba in the first third of the xxth century. Research based on a quantitative methodology. Educación XX1, 17 (1), 345-366. doi: 10.5944/educxx1.17.1.10718.

\section{RESUMEN}

Este trabajo ofrece los resultados de la evaluación del alumnado de las Escuelas Normales de Córdoba durante los tres planes de estudio existentes en el primer tercio del siglo XX en función del sexo, plan de estudios cursado, procedencia geográfica, extracción social y modalidad de enseñanza cursada. La metodología seguida ha sido predominantemente cuantitativa, los datos se han obtenido de una muestra estratificada de 618 sujetos y para el análisis de los mismos se ha recurrido a la estadística descriptiva e inferencial. Los resultados muestran que la evaluación del alumnado estuvo condicionada por el plan de estudios, el sexo y la modalidad de estudios cursada. No obstante, la procedencia geográfica y la extracción social del alumnado no determinaron los resultados alcanzados por estos alumnos. La evaluación del alumnado encuentra en la Historia un referente para evitar errores del pasado o para incorporar aspectos positivos a los actuales planes de estudio.

\section{ABSTRACT}

This paper offers the results of the evaluation of the Teacher Training Schools Students' of Cordoba during three plans of study that existed in the first third of the twentieth century, according to the experienced plan, sex, 
geographical origin, social extraction and type of studies. The methodology has been quantitative, the information has been obtained of a stratified sample of 618 subjects and for the analysis of the same ones has been used the descriptive and inferencial statistics. The results show that the evaluation of the students was determined by the curriculum, the sex and the type of studies. However, the geographical origin and the social extraction of the students didn't determine the results reached by these students. The evaluation of the students finds in History the regarding one to avoid errors of the past or to incorporate positive aspects into current plans of study.

\section{INTRODUCCIÓN}

El objetivo que nos planteamos en este trabajo se centra en abordar de forma diferente el análisis e interpretación de hechos y procesos históricos; en este caso, centrados en el ámbito educativo, concretamente en la evaluación del alumnado que durante el primer tercio del siglo XX estudió la carrera de magisterio en las Escuelas Normales de Córdoba y fue evaluado de manera integral durante el periodo de vigencia de tres planes de estudio concretos, el Plan de 1903, el Plan Bergamín (1914) y el Plan Profesional (1931). Este trabajo plantea tres aspectos fundamentales de la evaluación del alumnado normalista cordobés. En primer lugar, el marco histórico-conceptual en el que se sitúa la evaluación educativa de estos años; en segundo lugar, la aplicación de una metodología cuantitativa a un problema histórico a través del establecimiento de una serie de hipótesis susceptibles de ser verificadas en la medida que los datos obtenidos lo permiten y, en tercer lugar, la interpretación de los resultados alcanzados por los alumnos y alumnas normalistas al finalizar la totalidad del conjunto de los cursos que integraban cada uno de los planes de estudio mencionados y determinar si este rendimiento académico puede verse alterado por factores personales, educativos y sociodemográficos.

El estudio de las trayectorias académicas del alumnado, señalan Zaldívar, Mendoza y Nava (2009), permite conocer las dimensiones, tiempo, rendimiento y eficiencia escolar, al objeto de modificar las políticas educativas al respecto de un plan de estudios determinado, modalidad de enseñanza o evaluación llevada a cabo con el alumnado. No obstante, aunque esta investigación se retrotrae a los cuarenta primeros años del siglo XX, los errores y aciertos que se cometieron en la aplicación de dichas políticas pueden ser un buen referente para el momento actual.

\section{MARCO HISTÓRICO-CONCEPTUAL DE LA EVALUACIÓN}

Los cambios producidos en la esfera política, nacional e internacional, a lo largo del siglo XIX originaron la aparición en nuestro país de un sistema 
nacional de educación que exigía la titulación de sus alumnos y alumnas acorde con la profesión que posteriormente ejercerían. De acuerdo con Max Weber (Barbier, 1993) se genera un sistema de exámenes que busca la comprobación de una preparación específica, con el fin de dar cumplimiento a una nueva sociedad más jerárquica y burocratizada.

La evaluación encuentra en el examen su instrumento más efectivo de control, una construcción histórica que Mainer (2002) identifica como un instrumento pedagógico de singular importancia en la gestación de los sistemas educativos de la era capitalista, éste trae consigo todo un ritual que se inicia con la configuración de unos tribunales, la estructuración de la forma de examinar — tipos de exámenes - y la fijación de un período de tiempo durante el que se desarrollarán los diferentes tipos de exámenes.

Por su parte, Batanaz Palomares (2003, p. 324) establece que la evaluación ha sido definida "como un examen cuidadoso, realizado con rigor, de un currículum educativo, de un programa, de una institución, de una variable organizativa o de una política educativa». Esta definición implicaría, por un lado, que la evaluación pretende alcanzar «el conocimiento de la realidad estudiada para mejorar su proceso de realización (evaluación formativa)» y, por otro, que la evaluación busca «juzgar resultados alcanzados (evaluación sumativa)». De este modo, los resultados de cualquier proceso que se ponga en marcha constituyen datos relevantes sobre el éxito o fracaso del mismo. En este sentido, la evaluación ejercida sobre los alumnos y alumnas de las Escuelas Normales conforma un índice significativo de la valoración de un determinado plan educativo y/o período histórico.

Asimismo, De la Orden (1990) ha considerado la evaluación en educación como un conjunto de procesos sistemáticos de recogida, análisis e interpretación de información relevante para medir o describir cualquier faceta de la realidad educativa y sobre esta descripción formular un juicio de valor por su comparación con un criterio o patrón, todo ello como base para tomar decisiones. Por tanto, la evaluación, implica la asignación de una calificación a un determinado alumno o alumna, que lo identifica y categoriza respecto a sus compañeros o compañeras. En esta idea insiste López Pastor (2009, p. 51), quien manifiesta que «el principal problema de la evaluación (...) es que no se suele interpretar en su sentido más amplio y abierto, sino como un mero sinónimo reduccionista de «calificación»». Al mismo tiempo, la evaluación supone un mecanismo de control por parte del profesorado sobre el alumnado, una forma de premiar los esfuerzos o castigar la falta de trabajo de aquél, configurando en todo momento una jerarquía en la que el profesor domina la situación e integra al alumno en una determinada posición dentro de la pirámide académica que se pudiera establecer en un aula, en cuya cúspide se encontraría el profesor dirigiendo 
el proceso de clasificación y en sucesivos peldaños inferiores la élite académica, la medianía y un sector menos considerado.

El momento en el que se produce la valoración de estos resultados nos lleva a considerar un tipo de evaluación diferenciado, aunque con una misma función: la catalogación del alumno. Así cuando el alumno solicita ingresar en la Escuela Normal se ve sometido a una evaluación inicial con el fin de comprobar si los conocimientos que posee son suficientes para comenzar a estudiar la carrera de magisterio. Durante su estancia en la Escuela Normal, a lo largo de cada curso académico verá cómo de forma trimestral es evaluado de forma continua en un deseo del profesorado de cerciorarse sobre la adquisición o no de los conocimientos expresados de manera diaria en clase. Al finalizar sus estudios, el alumno resulta de nuevo valorado en una evaluación final en forma de reválida o examen de conjunto que le posibilita el acceso al título académico, que le faculta para ejercer la profesión y, al tiempo, reproducir el sistema evaluador en la enseñanza primaria, como se ha constatado en los rituales evaluativos llevados a cabo en las propias escuelas graduadas anejas a las Normales cordobesas. En estas páginas nos centraremos en los resultados alcanzados por el alumnado normalista evaluado de manera continua en los diferentes cursos que integraban el plan de estudios cursado.

La actividad evaluativa, pues, que se aplicó durante el primer tercio del siglo XX en las Escuelas Normales de Córdoba siguió un modelo conductista-eficientista (Castillo y Gento, 1995), al tiempo que se vio influida por diversos factores como:

1. El florecimiento de las corrientes filosóficas positivistas y empíricas, que se sustentaban en la observación, la experimentación, los datos y los hechos como fuentes del conocimiento verdadero. En este sentido, se potenciarán las pruebas escritas como fórmula para eliminar la subjetividad de los exámenes orales (Ahman y Cook, 1967). En las Escuelas Normales cordobesas se puede apreciar en la aplicación de los distintos Reglamentos y normas legales relativos a los exámenes que se publicaron a lo largo del periodo analizado.

2. La influencia de las teorías evolucionistas, junto con los trabajos de Darwin, Galton y Cattel, apoyaban la medición de las características de los sujetos y las diferencias entre ellos y así determinar la posición relativa del sujeto dentro de la norma grupal (Fernández Ballesteros, 1981; Escudero Escorza, 2003). En el caso que estamos estudiando queda reflejado en las listas de mérito relativo que se generaban tras la realización de los exámenes. 
3. La evolución de una sociedad industrial que buscaba mecanismos de selección de los alumnos y alumnas según sus conocimientos.

Estos mecanismos de selección encuentran en la normativa que se publicará al efecto su referente inmediato. Así, los dirigentes del Ministerio de Instrucción Pública debían estar seriamente preocupados por el tema de los exámenes, pues fue exhaustiva la legislación publicada a principios del siglo XX respecto a ello, muestra de este interés podemos destacar el Real Decreto de 12 de abril de 1901, la Real Orden de 20 de abril de 1901 y el Reglamento de 10 de mayo de 1901, que diferenciaba el tipo de examen que debía sufrir el alumnado en función del tipo de enseñanza cursada —oficial o no oficial-.

No será hasta el Reglamento de Escuelas Normales de 1933 cuando encontremos innovaciones de importancia respecto al procedimiento de evaluación. De acuerdo con Holgado Barroso (2000), se observa, en primer lugar, un intento por finiquitar una práctica docente centrada en el examen tradicional sobre el programa oficial, eje y pilar de la actividad educativa, proponiendo como alternativa el hecho de que la función docente y educadora se realizara, según su artículo $17^{\circ}$, en todos y cada uno de los momentos de la vida escolar y otorgando al alumno un papel más activo en su propia formación, orientándoles su trabajo con el fin de que pudieran intensificarlo en una dirección acorde con su particular disposición. En segundo lugar, y continuando con esta línea reformadora, se propiciaba el desarrollar un trabajo docente en equipo, de manera que los profesores de diferentes disciplinas de un mismo curso, independientemente de las valoraciones personales acerca de sus asignaturas, realizaran sesiones conjuntas para calificar a los estudiantes.

\section{METODOLOGÍA}

La metodología seguida en este estudio o la «lógica de la investigación» a la que aludían Arnal, Del Rincón y Latorre (1992, p.82) se soporta en el convencimiento de que el pluralismo metodológico constituye la base de la investigación en el contexto educativo, aunque éste se localice en el pasado. Por tanto, en esta investigación se han seguidos dos métodos; por un lado, el método inductivo en el aspecto cualitativo (histórico) de la misma y, por otro, el método deductivo en lo que concierne al elemento cuantitativo de ésta. El proceso investigador se inició con una reflexión sobre la oportunidad de la temática y las posibilidades que ofrecía el estudio. La siguiente fase emprendida fue la consulta de diferentes archivos de Córdoba, Sevilla, Alcalá de Henares y Madrid, al objeto de determinar la existencia de fuentes documentales que pudieran permitir el inicio y la continuidad del trabajo. 
Tras esta comprobación, se procedió a establecer una serie de hipótesis de investigación relacionadas con la evaluación del alumnado que cursó sus estudios en las Escuelas Normales de Córdoba durante el primer tercio del siglo XX. Para González-Montesinos y Backhoff (2010) no sólo puede evaluarse el aprendizaje del alumnado, sino que es necesario identificar las condiciones contextuales en que éste ocurre, para así obtener información sobre variables que se asocien al mismo y posibiliten explicar los resultados alcanzados en una evaluación. En este caso, consideramos que la evaluación de las diferentes asignaturas a lo largo de todos los cursos que componían la carrera de magisterio recogida en el expediente académico del alumnado se encontraba determinada por el sexo, el plan de estudios cursado, la procedencia geográfica y social, así como por la modalidad de enseñanza seguida en los estudios de Magisterio. En la Tabla 1 se pueden apreciar las variables que formaban parte de esta hipótesis.

\begin{tabular}{|l|l|}
\hline \multicolumn{1}{|c|}{ Variables } & \multicolumn{1}{c|}{ Categorías } \\
\hline Sexo & 1. Hombre. 2. Mujer \\
\hline Plan de estudios & 1. Plan de 1903. 2. Plan de 1914. 3. Plan de 1931. \\
\hline Procedencia geográfica & $\begin{array}{l}\text { 1. Córdoba capital. 2. Campiña alta. 3. Campiña baja. } \\
\text { 4. Valle de los Pedroches. 5. Zona de la Sierra. }\end{array}$ \\
\hline Extracción social & $\begin{array}{l}\text { 1. Clases medias y profesiones liberales. 2. Clases in- } \\
\text { termedias bajas. 3. Clase obrera. }\end{array}$ \\
\hline $\begin{array}{l}\text { Modalidad de enseñan- } \\
\text { za }\end{array}$ & $\begin{array}{l}\text { 1. Oficial. 2. Empieza oficial y continúa como no ofi- } \\
\text { cial. 3. Empieza no oficial y continúa oficial. 4. No } \\
\text { oficial. 5. Desconocido / no continúa. }\end{array}$ \\
\hline $\begin{array}{l}\text { Evaluación del alum- } \\
\text { nado }\end{array}$ & $\begin{array}{l}\text { 1. Suspenso. 2. Aprobado. 3. Notable. 4. Sobresalien- } \\
\text { te. 5. Matrícula de honor. }\end{array}$ \\
\hline
\end{tabular}

Tabla 1. Identificación de las variables y sus categorías.

Fuente: Elaboración propia. Archivo de la Facultad de Ciencias de la Educación de Córdoba. Sección I y II. Expedientes personales de alumnos y alumnas.

Posteriormente, se analizaron diferentes herramientas que permitieran extraer la información procedente de los expedientes del alumnado, que constituirían la base documental de la investigación, y se optó por la confección de una plantilla de recogida de datos diseñada especialmente para este trabajo. Este instrumento fue ampliándose a lo largo de todo el proceso de análisis de los expedientes, en función de los datos que iban surgiendo, aunque siempre manteniendo su estructura inicial.

Finalmente, tuvo lugar la fase de recogida de datos a través del análisis de los expedientes del alumnado. Entre el inicio del Plan de 1903 y la 
finalización de la Guerra Civil (1939) se contabilizaron 3399 expedientes. Para la selección de la muestra se consideraron las aportaciones de Arkin y Colton (1962) y las orientaciones de Rodríguez Osuna (1991), lo que supuso seleccionar 618 expedientes y fijar un error muestral máximo de un $\pm 3 \%$. La elección de los expedientes se realizó de forma estratificada de acuerdo a los tres planes de estudios: Plan de 1903 (12,30\% de hombres y 10,68\% de mujeres), Plan de 1914 (33,82\% de hombres y 30,58\% de mujeres) y Plan de 1931 ( $8,41 \%$ de hombres y $4,21 \%$ de mujeres).

En este momento también hay que destacar la importancia que tuvo la consulta de diferentes archivos parroquiales de la provincia y el censo custodiado en el Archivo de la Excma. Diputación de Córdoba para completar la información de los expedientes relativa a la extracción social del alumnado, considerando como referente la profesión del padre.

Asimismo, cabe señalar que para establecer una calificación global del alumnado se consideraron las calificaciones numéricas obtenidas en todas las asignaturas y cursos que definían los distintos planes de estudio. En este proceso se eliminaron los expedientes que no contaban con la evaluación completa del alumnado, es decir, aquellos en los que el alumnado no había finalizado todos los cursos de cada plan de estudios (estos constituían el $5,2 \%$ del total).

Tras la obtención de los datos y la cumplimentación de las correspondientes plantillas, se procedió al diseño de una base de datos en la que se volcaron los mismos con el fin de realizar su análisis estadístico posterior a través del SPSS v.16.

\section{RESULTADOS}

Los resultados que se presentan a continuación ofrecen, en primer lugar, una descripción del alumnado normalista cordobés que fue evaluado de manera integral durante el periodo de tiempo analizado en esta investigación, es decir, que concluyeron todos los cursos que debían cursar en cada plan de estudio; y, en segundo lugar, la posible relación entre las distintas variables ya mencionadas anteriormente.

\section{Características identificativas del alumnado}

Respecto al sexo del alumnado evaluado, la revisión de los expedientes arrojó un $51,8 \%$ de hombres y un $48,2 \%$ de mujeres. 
Si hallamos los porcentajes en cada plan de estudio - 1903, 1914 y 1931- obtenemos resultados prácticamente idénticos. Así, durante el periodo de vigencia del Plan de 1903 el alumnado evaluado constituía una proporción semejante a la media global, es decir, un 52,8 por ciento los varones y un 47,2 por ciento las mujeres. Por su parte, en el tiempo de vida del Plan de 1914 el porcentaje de los hombres se redujo hasta el 50,3 por ciento y el de las mujeres ascendió al 49,7 por ciento. El Plan de 1931 rompió con la tónica iniciada en el plan anterior, así los varones calificados aumentaron hasta el 54,9 por ciento, mientras que las mujeres descendieron al 45,1 por ciento, alcanzando los porcentajes máximos y mínimos respectivamente de los planes de estudio analizados.

La ampliación de los años de estudio que supuso el Plan de 1914 equiparó los porcentajes de hombres y mujeres evaluados al finalizar sus estudios, la ampliación a cuatro años de la carrera docente pudo provocar que el alumnado masculino para «ganarse la vida» dedicara su tiempo a otros menesteres que no le supusiera tan larga inversión de tiempo y, por tanto, abandonase la carrera antes de alcanzar su titulación.

Por otro lado, como afirma Rivas Sánchez (1998), analizar los distintos planes de formación es indagar en la trayectoria educativa de un pueblo que se plantea su futuro desde las materias que configuran un determinado plan de estudio. En este sentido, podemos apuntar que la historia de los planes de estudio para la formación del maestro y la maestra constituye el paso de lo cultural a lo profesional, expresado en la pérdida o ganancia de la formación cultural o de la formación profesional a lo largo de diferentes momentos históricos. Así, pues, resulta ilustrador recurrir a la denominación empleada por Ávila y Holgado (2008) para definir, desde la legislación educativa, los periodos de tiempo que abarca esta investigación. De este modo, el marco temporal comprendido entre 1900 y 1931 es calificado como de «instrucción sólida y educación elevada», mientras que el establecido entre 1931 y 1939 es denominado como el de «la formación del sacerdote laico». Estos términos aclaran perfectamente cuál fue la filosofía que inspiró la configuración de los planes de estudio de 1903, 1914 (Plan Bergamín) y 1931 (Plan Profesional) y las asignaturas que quedaron integradas en cada uno de ellos.

La distribución del alumnado normalista cordobés que fue evaluado a lo largo de los tres planes de estudio analizados es la siguiente: el $23,14 \%$ durante el Plan de 1903, el 64,24\% en el periodo de vigencia del Plan Bergamín y el 12,62\% en la corta vida que tuvo el Plan Profesional.

En cuanto a la procedencia geográfica, de manera tradicional, la imagen del maestro y la maestra, así como los estudios de magisterio, 
han estado vinculados al ámbito rural. El docente suponía un referente cultural urbano dentro de la sociedad agraria y los estudios permitían una salida a las escasas posibilidades del campo. No obstante, esta vinculación no puede simplificar una relación mucho más compleja, la realidad cordobesa mostrará unos datos que ahondarán en estos conceptos. Al mismo tiempo, la procedencia social del alumnado puede configurarse como un nexo de unión entre el campo y la ciudad, ya que independientemente del origen geográfico, su extracción social le une al destinatario de sus enseñanzas, las clases más desfavorecidas de la sociedad (Gil de Zárate, 1995, p. 283).

Durante el primer tercio del siglo XX en la provincia de Córdoba se constata esta tendencia hacia la procedencia rural del alumnado que recibió una evaluación completa a lo largo de los tres planes de estudio. De este modo, Córdoba capital contaría con un 32,8 por ciento de alumnado y la provincia con un 67,2 por ciento, distribuido este porcentaje del siguiente modo: la Campiña alta, con un 11,4 por ciento; la Campiña baja, con un 18,3 por ciento; el Valle de los Pedroches, con un 21 por ciento y la Zona de la Sierra, con un 14,1 por ciento. Cabe señalar que el partido judicial de Córdoba capital integraba algunas zonas rurales circundantes como Obejo, localidad que contribuyó con un 2,4 al total de los porcentajes.

Respecto a la extracción social, hay que señalar que, a pesar de los esfuerzos realizados no se han podido obtener esta información en el 28,6 por ciento de los expedientes que contenían la evaluación completa del alumnado para el conjunto de los tres planes de estudio. Sin embargo, el resto ha quedado perfectamente categorizado en tres grupos sociales:

1. Clases medias y profesiones liberales con un 23,8 por ciento.

2. Clases intermedias bajas con un 33,8 por ciento.

3. Clase obrera con un 13,8 por ciento.

Esta categorización se ha obtenido a partir del nivel social de las profesiones de los padres y de la función ocupacional de la misma. En la primera categoría quedan incluidos los que tenían funciones de producción y reproducción, así como un conjunto social en el que se agrupaba la pequeña burguesía con profesiones liberales que contaban con un sueldo elevado y una función en la organización del trabajo que no era enteramente subalterna a la que habían accedido por poseer una formación académica superior, lo que les situaba en un nivel sociocultural más alto. La segunda se encontraba constituida por un sector de grupos poseedores de medios de producción en 
pequeña escala, lo que les posibilitaba utilizar fuerza de trabajo ajena (artesanos, labradores, etc.), además la integraban miembros con una formación académica media o profesional como los maestros y obreros especializados y un tercer grupo compuesto por miembros del ejército, de las fuerzas de seguridad y el funcionariado. Finalmente, la tercera se componía por unos grupos sociales que ocupaban la posición social, laboral y educativa más baja, la inmensa mayoría caracterizados por el analfabetismo (Holgado Barroso, 2000).

Con el fin de conocer la modalidad o el tipo de enseñanza que cursaron los alumnos y alumnas de las Escuelas Normales de Córdoba que fueron evaluados durante las cuatro primeras décadas del siglo XX se establecieron varias categorías en las que encuadrarlos, dos de ellas son puras - comienza sus estudios de una forma y los concluyen de la misma manera: la enseñanza oficial y la no oficial-. Sin embargo, no todo el alumnado seguirá estos cauces, sus circunstancias personales, económicas o académicas les obligará a tomar decisiones que les llevará a mezclar el tipo de enseñanza recibida, la oficial con la no oficial.

Aunque la formación de los maestros y maestras abogaba por un tipo de enseñanza oficial, bien es cierto, que en determinados momentos históricos, fruto de la legislación del momento, se propiciará el incremento de la enseñanza libre. No obstante, esta modalidad de enseñanza no se verá exenta de críticas en la Revista de Escuelas Normales (1925, p. 201), puesto que no se correspondía con el espíritu que debía inspirar la formación del maestro o la maestra.

Los resultados obtenidos de forma general para los tres planes de estudio nos indican que el 51,8 por ciento del alumnado evaluado siguió una enseñanza oficial; el 0,6 por ciento comenzó sus estudios siendo alumno oficial y los concluyó de manera no oficial; el 5,3 por ciento inició los estudios con una modalidad no oficial y los finalizó dentro del régimen oficial. Por su parte, el 21 por ciento cursó los estudios de manera no oficial y del 21,3 por ciento restante se desconoce su adscripción a una u otra modalidad.

En la Tabla 2 la tasa más alta de alumnado evaluado que cursó estudios de manera oficial corresponde al Plan de 1931, consecuencia de la profesionalidad del plan. Las cifras de oficialidad se reducen en el Plan de 1914 respecto al de 1903, fruto posiblemente de la ampliación de los estudios a cuatro años y de las dificultades económicas para que el alumnado pudiera costearse la estancia en la capital durante ese tiempo. El porcentaje de alumnos que empezaron su enseñanza de forma oficial y la concluyeron en la modalidad de «no oficial» aumentó desde el Plan de 1903 al de 1914, bien por cuestiones económicas, bien por asuntos personales. Sin embargo, 
los porcentajes del alumnado que estudió la carrera de manera «no oficial» se redujo en el Plan de 1914 respecto al de 1903, lo que indicaría que un mayor número y complejidad de las asignaturas exigiría la asistencia a clase para poder superarlas sin dificultad. Esta explicación también corroboraría el aumento del porcentaje de alumnado evaluado que inició sus estudios de forma «no oficial» y los concluyó dentro de la oficialidad.

\begin{tabular}{|l|c|c|c|}
\hline \multicolumn{1}{|c|}{ Enseñanza } & $\begin{array}{c}\text { Plan de 1903 } \\
\text { (por ciento) }\end{array}$ & $\begin{array}{c}\text { Plan de 1914 } \\
\text { (por ciento) }\end{array}$ & $\begin{array}{c}\text { Plan de 1931 } \\
\text { (por ciento) }\end{array}$ \\
\hline Oficial & 48,7 & 44 & 73,2 \\
\hline Oficial a no oficial & 0,6 & 1 & - \\
\hline No oficial a oficial & 4,4 & 7,7 & - \\
\hline No oficial & 37,1 & 28,9 & - \\
\hline Desconocido & 9,2 & 18,4 & 26,8 \\
\hline
\end{tabular}

Tabla 2. Modalidad de enseñanza del alumnado normalista cordobés. 1903-1931

Fuente: Elaboración propia. A.F.C.E.C. Sección I y II. Expedientes personales de alumnos y alumnas.

Aunque el porcentaje que arroja el Plan de 1931 respecto a este concepto resulta el más elevado de los tres planes de estudio, no implica duda alguna sobre el carácter de la enseñanza de los estudios puestos en marcha durante el período republicano, el Plan profesional se aseguraba la asistencia a clase de todo el alumnado. De acuerdo con las palabras de Holgado Barroso (2000, p. 81), los tipos de enseñanza —oficial y libre (no oficial)— conforman auténticos identificadores de la consideración socioeducativa de la formación del docente, pues, mientras que la profesionalización y el prestigio de los estudios, como se constata para el plan de 1931, potenciarán la matrícula oficial, «la miseria pedagógica y material de las Normales incitan al aumento de la enseñanza libre».

\section{La evaluación y el alumnado normalista cordobés}

La evaluación y el sexo

La hipótesis de partida consideraba que las mujeres evaluadas obtendrían mejores resultados que los hombres en las notas obtenidas a lo largo de los tres planes de estudio analizados. De este modo, el Análisis de Varianza realizado confirmaba esta hipótesis, asimismo las medias obtenidas de las asignaturas de los tres planes de estudio resultan elocuentes, tal y como la figura 1 lo ilustra. 


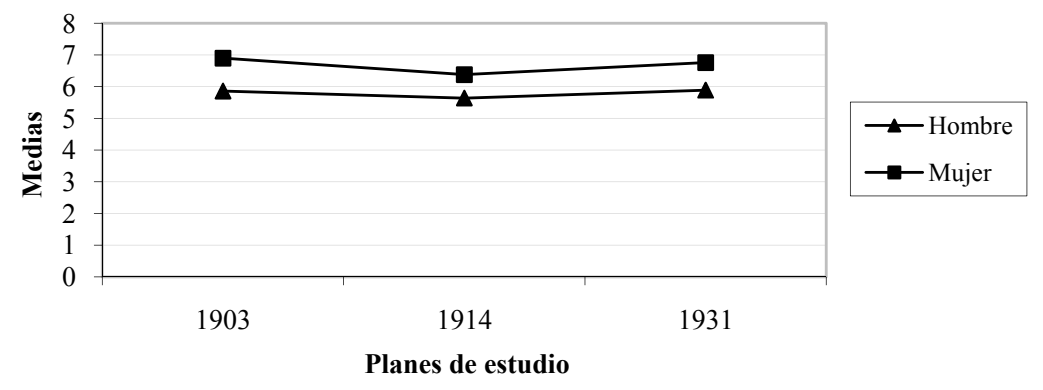

Figura 1. Medias alcanzadas por el alumnado en función del sexo

Fuente: Elaboración propia. A.F.C.E.C. Secciones I y II. Expedientes personales del alumnado.

La figura 1 muestra la primacía del sexo femenino sobre el masculino en cuanto a resultados académicos, además del punto de inflexión que supuso el Plan de 1914 en los expedientes académicos de los alumnos y alumnas evaluados. Si las notas alcanzadas por alumnos y alumnas las analizamos por grupos de asignaturas, los resultados son idénticos, las mujeres superan a los hombres, incluido el grupo de «ciencias», tradicionalmente vinculado a los hombres. Asimismo, se destaca esta diferencia en grado sumo, como se observa en la tabla 3, en el grupo de asignaturas que integraban la «Religión».

\begin{tabular}{|l|l|r|r|r|r|}
\hline \multicolumn{1}{c}{$\begin{array}{c}\text { Grupos de } \\
\text { asignaturas }\end{array}$} & \multicolumn{1}{c|}{ Género } & \multicolumn{1}{c|}{$\begin{array}{c}\text { Plan de } \\
1903\end{array}$} & $\begin{array}{c}\text { Plan de } \\
1914\end{array}$ & \multicolumn{1}{c|}{$\begin{array}{c}\text { Plan de } \\
1931\end{array}$} & \multicolumn{1}{c|}{ Total } \\
\hline \multirow{2}{*}{ Letras } & Hombres & 6,77 & 5,71 & 6,17 & 6,11 \\
\cline { 2 - 6 } & Mujeres & 7,05 & 6,34 & 6,79 & 6,59 \\
\hline \multirow{2}{*}{ Ciencias } & Hombres & 6,32 & 5,57 & 5,30 & 5,79 \\
\cline { 2 - 6 } & Mujeres & 6,61 & 5,90 & 5,99 & 6,11 \\
\hline \multirow{2}{*}{ Pedagogía } & Hombres & 5,41 & 5,36 & 5,35 & 5,38 \\
\cline { 2 - 6 } & Mujeres & 6,56 & 5,59 & 5,79 & 5,88 \\
\hline \multirow{2}{*}{ Religión } & Hombres & 5,63 & 5,85 & - & 5,74 \\
\cline { 2 - 6 } & Mujeres & 7,62 & 7,72 & - & 7,67 \\
\hline \multirow{2}{*}{ Otras } & Hombres & 5,15 & 5,69 & 6,44 & 5,59 \\
\cline { 2 - 6 } & Mujeres & 6,68 & 6,34 & 7,01 & 6,51 \\
\hline
\end{tabular}

Tabla 3. Medias obtenidas en los distintos grupos de asignaturas en función del sexo

Fuente: Elaboración propia. A.F.C.E.C. Secciones I y II. Expedientes personales del alumnado.

Ante estos resultados debemos detenernos un momento y pensar en ciertas afirmaciones que se han constatado referidas a que el plan de estu- 
dios de unas y otros difería considerablemente por la amplia dedicación de las féminas a las asignaturas "propias de su sexo». Esta consideración bien pudiera hacernos pensar que las alumnas recibían un trato de favor por parte del profesorado a la hora de emitir un juicio valorativo y cuantitativo de su rendimiento académico, máxime cuando los evaluadores eran diferentes, es decir, a los alumnos los evaluaban sus profesores en la Normal de Maestros y a las alumnas sus profesoras en la Escuela de Maestras. No obstante, esta idea quedaría desechada cuando el Plan de 1931 hizo coincidir en las aulas a alumnos y alumnas, evaluados todos ellos por profesores y profesoras de forma conjunta, lo que nos lleva a pensar que realmente el alumnado femenino superó con creces al masculino en todos los grupos de asignaturas que constituían la carrera de magisterio en los planes de estudio de 1903,1914 y 1931.

\section{La evaluación y el plan de estudios}

Con el fin de conocer qué plan de estudios obtuvo mejores resultados académicos entre el alumnado de las Normales cordobesas se han realizado Análisis de Varianza y pruebas de comparación de medias. En este sentido, se han detectado ciertas diferencias significativas entre estos planes de forma general, puesto que $\mathrm{F}_{(2,536)}=9,33 ; \mathrm{p}<.001$. De este modo, el alumnado que cursó el Plan de 1914 obtuvo peores resultados que el que siguió los Planes de 1903 y 1931. Por el contrario, el Plan de 1931 fue el que posibilitó que el alumnado consiguiese mejores resultados. La Figura 2 muestra las diferencias de las medias de los tres planes de estudio.

Figura 2.

Diferencia de las medias de las distintas alcanzadas por el alumnado en los planes de estudio de 1903, 1914 y 1931

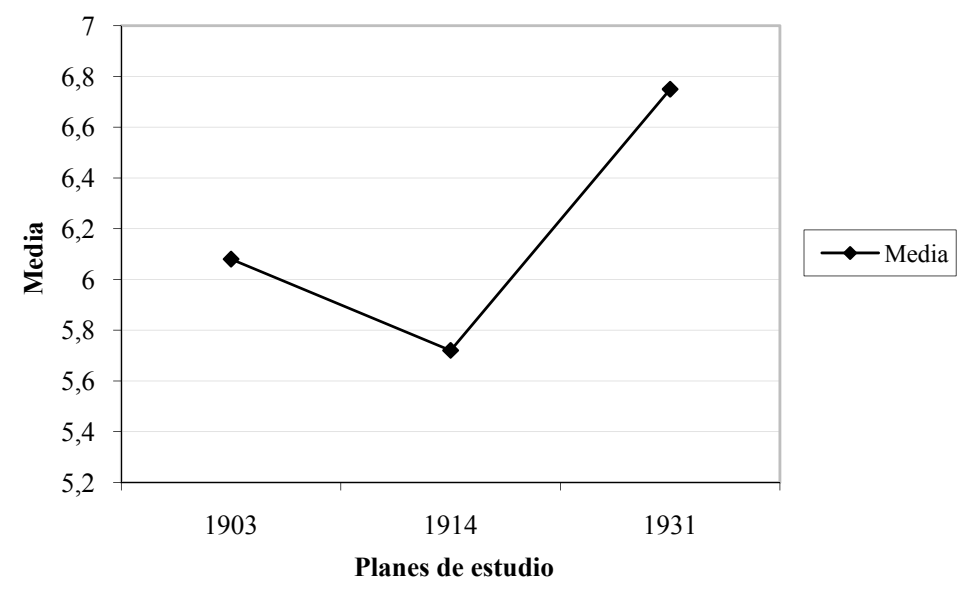


La figura 2 evidencia claramente el mejor rendimiento académico de los alumnos y alumnas del Plan de 1931 (Plan profesional) que el alcanzado por el alumnado evaluado en otros planes de estudio. Asimismo, una constante que se repetirá en los distintos grupos de asignaturas será la peor calificación de los alumnos y alumnas evaluados durante la vigencia del Plan Bergamín (1914) (ver Figura 3). Una explicación a esta diferencia de las medias podría encontrarse en que el Plan Bergamín inició por primera vez en España una remodelación de los estudios de magisterio sin precedente en el sistema educativo: la unificación de los diferentes títulos —elemental y superior-en uno solo tras haber cursado cuatro años de estudio. Esto era demasiado tiempo para los alumnos y alumnas que optaban por la docencia como vía rápida para ejercer una profesión y conseguir subsistir económicamente, al tiempo que el carácter impreso a las disciplinas, más culturales, bien pudo influenciar la actividad académica del alumnado. Por el contrario, la exigencia del Bachillerato para poder cursar los estudios de magisterio puestos en marcha con el Plan Profesional aumentó los conocimientos científicos y culturales de un alumnado con mayor preparación que el de años anteriores. Del mismo modo, el sistema de ingreso en el escalafón de maestros al concluir los estudios también pudo incrementar el deseo del alumnado por conseguir mejores notas, es decir, cuando el alumno o alumna del Plan Profesional accedía a la carrera, lo hacía con la certeza de conseguir una plaza en propiedad, pero desconocía la localización de la misma, un óptimo expediente académico le posibilitaría un destino mejor, con lo que, es de suponer, que el alumnado se esmeraría más en aumentar las notas de su expediente personal.

Figura 3.

Diferencia de las medias de los distintos grupos de asignaturas que integraron los Planes de 1903, 1914 y 1931

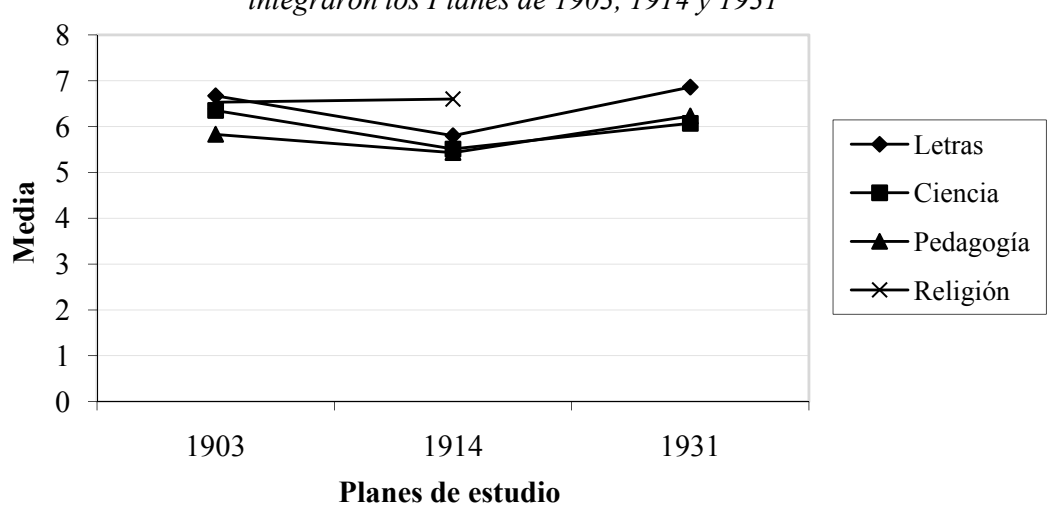

Fuente: Elaboración propia. A.F.C.E.C. Secciones I y II. Expedientes personales del alumnado.

En cuanto a los diversos grupos de asignaturas, el Análisis de Varianza vuelve a manifestar la existencia de diferencias significativas en el grupo 
de «Letras» $\left(\mathrm{F}_{(2,475)}=12,81 ; \mathrm{p}<.001\right)$, en el grupo de «Ciencias» $\left(\mathrm{F}_{(2,464)}=7,16\right.$; $\mathrm{p}<.001)$ y en el de «Pedagogía» $\left(\mathrm{F}_{(2,475)}=6,02 ; \mathrm{p}<.003\right)$. Tan sólo en las asignaturas que conformaban el grupo de Religión no se hacía presente esta significatividad $\left(\mathrm{F}_{(2,506)}=8,97 ;\right.$ n.s). Para confirmar la afirmación anterior sobre el peor rendimiento académico del alumnado evaluado en los años de pervivencia del Plan de 1914 y las diferencias entre los diferentes grupos de asignaturas a lo largo de los tres planes de estudio se realizaron las correspondientes pruebas "post hoc» (Scheffé), que han mostrado las diferencias significativas existentes en los diferentes grupos de asignaturas de los tres planes de estudio y el saldo negativo de los expedientes del alumnado de 1914 al compararlos tanto con el plan de estudios precedente como con el posterior. De este modo, la afirmación es concluyente.

\section{La evaluación y la procedencia geográfica y social}

Una capital de provincia, por muy pequeña que sea, normalmente, dispone de mayores ventajas a nivel educativo y cultural que las localidades rurales, por ello pensábamos que el alumnado —-femenino y masculinooriundo de la capital cordobesa conseguiría mejores notas que el vinculado al mundo rural. Sin embargo, el Análisis de Varianza llevado a cabo ha señalado que no existen diferencias significativas entre la procedencia geográfica y los resultados académicos de los alumnos y alumnas, tan sólo unas diferencias marginales $\left(\mathrm{F}_{(1,235)}=2,94 ; \mathrm{p}<.09\right)$ que permiten manifestar que la hipótesis expresada no es cierta. Estas diferencias marginales pueden establecerse porque sí existen diferencias significativas en cuanto al grupo de asignaturas denominado «Otras» $\left(\mathrm{F}_{(1,235)}=7,30 ; \mathrm{p}<.01\right)$, en el que quedarían integradas asignaturas como Música o Labores, pero nada que ver con el grueso de asignaturas que conformarían los restantes grupos y que llevarían el peso de la carrera de magisterio.

Respecto a la influencia de la procedencia social del alumnado en las notas obtenidas durante el tiempo de duración de la carrera de magisterio considerábamos que el alumnado procedente de clases sociales medias alcanzó mejores resultados académicos que los integrantes de clases sociales intermedias y obrera. De nuevo, el Análisis de Varianza nos ha llevado a concluir que la hipótesis no se confirma, puesto que no se establecen diferencias significativas entre los resultados académicos del alumnado evaluado en el transcurso de los tres planes de estudio analizados y la extracción social del mismo.

\section{La evaluación y la modalidad de enseñanza cursada}

En lo que respecta a la relación existente entre la evaluación alcanzada por el alumnado normalista cordobés y la modalidad de enseñanza cursada, 
pensábamos que los alumnos y alumnas que cursaron una modalidad de estudios «oficial» consiguieron un mejor expediente académico que el que siguió un tipo de enseñanza «no oficial».

En esta ocasión, la ANOVA confirmaba la hipótesis al establecerse diferencias significativas en la nota media de los diferentes planes de estudio $\left(\mathrm{F}_{(1,314)}=43,57 ; \mathrm{p}<.001\right)$ y en cada grupo de asignaturas: "Letras» $\left(\mathrm{F}_{(1,314)}=20,36 ; \mathrm{p}<.001\right)$, «Ciencias» $\left(\mathrm{F}_{(1,314)}=16,06 ; \mathrm{p}<.001\right)$, «Pedagogía» $\left(\mathrm{F}_{(1,314)}=20,48 ; \mathrm{p}<.001\right)$, «Religión» $\left(\mathrm{F}_{(1,314)}=31,61 ; \mathrm{p}<.001\right)$ y «Otras» $\left(F_{(1,314)}=52,83 ; p<.001\right)$. En este sentido, los alumnos y alumnas evaluados que optaron por una enseñanza de tipo «no oficial» obtuvieron peores resultados que los que decidieron hacer sus estudios de forma «oficial». En la figura 4 y en la tabla 4 se muestran respectivamente las medias de los diferentes planes de estudio según la modalidad de enseñanza seguida y las medias de los distintos grupos de asignaturas de los tres planes de estudio en función del tipo de enseñanza cursada.

Figura 4.

Diferencia de medias en los Planes de estudio de 1903, 1914 y 1931

en función de la modalidad de enseñanza

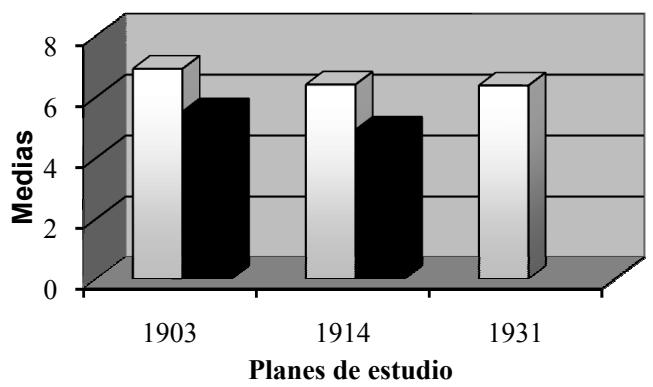

口Oficial

No oficial

Fuente: Elaboración propia. A.F.C.E.C. Secciones I y II. Expedientes personales del alumnado.

\begin{tabular}{|l|l|c|c|c|c|}
\hline \multicolumn{1}{|c}{$\begin{array}{c}\text { Grupos de } \\
\text { asignaturas }\end{array}$} & $\begin{array}{l}\text { Modalidad } \\
\text { enseñanza }\end{array}$ & $\begin{array}{c}\text { Plan de } \\
1903\end{array}$ & $\begin{array}{c}\text { Plan de } \\
1914\end{array}$ & $\begin{array}{c}\text { Plan de } \\
1931\end{array}$ & Total \\
\hline \multirow{2}{*}{ Letras } & Oficial & 7,26 & 6,40 & 6,52 & 6,66 \\
\cline { 2 - 6 } & No oficial & 6,31 & 4,95 & & 5,57 \\
\hline \multirow{2}{*}{ Ciencias } & Oficial & 6,90 & 6,03 & 5,69 & 6,21 \\
\cline { 2 - 6 } & No oficial & 5,90 & 4,83 & & 5,32 \\
\hline \multirow{2}{*}{ Pedagogía } & Oficial & 6,52 & 5,72 & 5,60 & 5,92 \\
\cline { 2 - 6 } & No oficial & 5,10 & 4,57 & & 4,81 \\
\hline \multirow{2}{*}{ Religión } & Oficial & 7,32 & 7,42 & & 7,37 \\
\cline { 2 - 6 } & No oficial & 5,63 & 5,55 & & 5,58 \\
\hline
\end{tabular}




\begin{tabular}{|l|l|c|c|c|c|}
\hline \multicolumn{1}{|c|}{$\begin{array}{c}\text { Grupos de } \\
\text { asignaturas }\end{array}$} & \multicolumn{1}{|c|}{$\begin{array}{c}\text { Modalidad } \\
\text { enseñanza }\end{array}$} & $\begin{array}{c}\text { Plan de } \\
1903\end{array}$ & $\begin{array}{c}\text { Plan de } \\
1914\end{array}$ & $\begin{array}{c}\text { Plan de } \\
1931\end{array}$ & Total \\
\hline \multirow{2}{*}{ Otras } & Oficial & 6,67 & 6,48 & 6,76 & 6,57 \\
\cline { 2 - 6 } & No oficial & 4,71 & 4,75 & & 4,73 \\
\hline
\end{tabular}

Tabla 4. Medias obtenidas en los distintos grupos de asignaturas en función de la modalidad de enseñanza

Fuente: Elaboración propia. A.F.C.E.C. Secciones I y II. Expedientes personales del alumnado

\section{DISCUTIENDO Y CONCLUYENDO}

A lo largo de estas páginas hemos podido comprobar la importancia que durante muchos años se dio a la evaluación del alumnado normalista desde la normativa legal, publicando y resaltando los resultados del estudiantado normalista en el ámbito estatal a través de los boletines de la Dirección General de Instrucción Pública. En este sentido, coincidimos con Bixio (2007, p.77), quien afirma que «el valor o la importancia de la evaluación, en sus orígenes, no es de índole pedagógica, sino social e institucional», ya se trate de una evaluación realizada hace casi cien años o en la actualidad, «los propios requisitos del sistema educativo y las demandas sociales» son los que hacen de la evaluación una práctica ineludible en las instituciones educativas. En la actualidad las pruebas de evaluación vuelven a resurgir con fuerza tanto en el panorama internacional (baste citar los Informes PISA, PIRLS o TIMMS), como en el nacional a través de las pruebas de evaluación de diagnóstico, para comprobar «el estado de salud» de los sistemas educativos respecto a sus enseñanzas básicas. En el ámbito universitario la evaluación se convierte en otra constante para responder a las demandas del Espacio Europeo de Educación Superior (Sánchez González, 2010). Pasado y presente, pues, se vuelven a encontrar alrededor de una preocupación común, la demanda social e institucional de la evaluación del alumnado.

Por otra parte, es el examen tradicional escrito el que ha predominado en la evaluación del alumnado normalista cordobés durante el periodo de tiempo analizado (1903-1939), convirtiéndose en la herramienta privilegiada y de más peso en la evaluación, de tal forma que, según Moreno Olivos (2009) llega hasta nuestros días convertida en la mayor preocupación de alumnado y profesorado. La actual convergencia europea hacia nuevas formas de aprender y evaluar está protagonizando que, cien años después, el examen escrito vaya perdiendo fuerza y cediendo su lugar predominante a otros modelos, técnicas e instrumentos evaluativos, más acordes a la sociedad del siglo XXI. 
Algunas conclusiones que podríamos reseñar en cuanto a la metodología empleada en esta investigación hacen referencia a que los hechos y procesos de la Historia en bastantes ocasiones se han estudiado de forma tradicional a través del método inductivo y de un tipo de investigación cualitativa, por lo que nuestra propuesta ha ido dirigida a comprobar que es posible «hacer historia» de otro modo, a través de una aproximación a la investigación cuantitativa, y comprobar cómo una serie de conjeturas pueden ser confirmadas o rechazadas a pesar de que encuentren su punto de origen hace cien años.

En este sentido, podemos afirmar que la evaluación a la que se sometió el alumnado normalista cordobés a lo largo de un periodo de tiempo comprendido entre 1903 y 1939 se vio condicionada por el sexo del alumnado, por el plan de estudios cursado, así como por la modalidad de estudios seleccionada. No obstante, la procedencia geográfica y la extracción social de dicho alumnado cordobés no determinaron los resultados alcanzados por los alumnos y alumnas que fueron evaluados durante el periodo de vigencia de los tres planes de estudio analizados.

Los mejores resultados obtenidos por el alumnado evaluado se concentran en el sexo femenino en cualquiera de los planes de estudio y en los diferentes grupos de asignaturas que se han establecido dentro de los mismos. El incremento a partir de la década de los cuarenta del número de alumnas en la enseñanza primaria, secundaria y universitaria, así como de profesoras en las Escuelas Normales, es un dato que también ponen de manifiesto Bermúdez et al (2011) y que podría justificarse, en parte, como consecuencia de estos mejores resultados académicos y la influencia que ellos podrían ejercer en el futuro profesional de las mujeres.

En cuanto al plan de estudios, cabría destacar los mejores resultados obtenidos por el alumnado que cursó el Plan de 1931 frente a los dos planes precedentes. En este sentido, a pesar de todos los problemas que generó su implantación, sus aportaciones a la formación del maestro y la maestra fueron importantes y redundaron en unos óptimos resultados académicos: la nueva consideración económica del maestro, que se sitúa en el sentido de su dignificación social y el establecimiento de un año de prácticas representaba una absoluta novedad con respecto a la situación precedente. Respecto a la mayoría de las críticas que se suelen realizar a los planes de estudio, ya nos encontremos en la década de los treinta del siglo XX, como en el segundo decenio de un nuevo milenio, es su alejada conexión con la realidad. En este sentido, el Plan de 1914 se distinguía por su falta absoluta de relación con la realidad escolar, el estudiante de magisterio aprendía lo que era una escuela una vez terminados sus estudios y después de haber superado una oposición y adquirido un empleo. El Plan Profesional, por el contrario, pre- 
tendía: 1) crear maestros y maestras plenamente conocedores de la realidad de la escuela, de aquí que el año de prácticas en la escuela pública se convirtiera en elemento esencial de la nueva estructuración y ordenación de los estudios de Magisterio, pues no se entendía bajo el prisma republicano que un maestro pudiera recibir su título, si previamente no había sido capaz de demostrar en la escuela, ante la realidad de su función, su capacidad para hacerla progresar; y 2) reestructurar las asignaturas cursadas para ceñirse a lo que el futuro maestro debía conocer y serle útil en su práctica cotidiana, eliminando, de este modo, el concepto de que los estudios de Magisterio eran una continuación de la educación secundaria.

El diseño de los nuevos títulos de Grado de Maestro en Educación Infantil y Educación Primaria ha recogido la vieja aspiración republicana de ampliar los estudios de magisterio, de dotarlos de un mayor componente práctico y profesional, así como de proporcionarles la dignificación que desde el siglo XIX se ha solicitado.

Asimismo, la formación pedagógica y profesional requería la máxima implicación del alumnado, con una asistencia continuada a las clases, su participación en seminarios o grupos de trabajo especializado, las prácticas escolares, en definitiva, una implicación activa en el proceso educativo. Esto va a suponer que el alumnado evaluado que cursó una modalidad de enseñanza oficial consiguiera mejores resultados en su expediente académico que el que cursó la enseñanza libre o no oficial.

El contexto, pues, como señalábamos al principio de estas páginas y coincidiendo con González-Montesinos y Backhoff (2010), ha condicionado en determinados aspectos los resultados académicos del alumnado normalista cordobés.

En definitiva, la Historia puede interpretarse desde otro prisma, el que aquí hemos intentado ofrecer; al tiempo que el sistema educativo actual en cualquiera de sus dimensiones, como es la evaluación del alumnado, puede encontrar en la Historia un referente que no puede ignorar para evitar que se cometan los errores del pasado o para incorporar aquellos aspectos positivos que hicieron triunfar — aunque con matices - un plan de estudios determinado, la elección de una modalidad de enseñanza concreta o cualquier otro elemento que se haya contrastado de manera científica. 


\section{REFERENCIAS BIBLIOGRÁFICAS}

Ahman, S.J. y Cook, M.D. (1967). Evaluating Pupil Growth. Principles of Tests Measure-ment. Boston, Ma: Allyn and Bacon.

Arkin, H. y Colton, R. (1962). Tables for staticians. Nueva York: Barnes y Noble.

Arnal, J.; Del Rincón, D. y Latorre, A. (1992). La investigación educativa. Fundamentos y metodología. Barcelona: Labor.

Ávila Fernández, A. y Holgado Barroso, J.A. (2008). Formación del magisterio en España. La legislación normalista como instrumento de poder y control (1834-2007). Madrid: MEPSYD.

Barbier, J. M. (1993). La evaluación en los procesos de formación. Barcelona: Paidós.

Batanaz Palomares, L. (2003). Organización escolar. Bases científicas para el desarrollo de las instituciones educativas. Córdoba: Servicio de Publicaciones de la Universidad de Córdoba.

Bermúdez, M.P.; Guillén Riquelme, A.; Gómez García, A.; Quevedo Blasco, R.; Sierra, J.C. y Buela Casal, G. (2011). Análisis del rendimiento en el doctorado en función del sexo. Educación $X X 1,14,(1), 17-33$.

Bixio, C. (2007). Cómo planificar y evaluar en el aula. Propuestas y ejemplos. Sevilla: Eduforma.

Castillo, S. y Gento, S. (1995). Modelos de evaluación de programas educativos, en Medina, A. y Willar, L. M. (Coord.). Evaluación de programas educativos, centros y profesores. Madrid: Editorial Universitas, S. A., 25-69.

[Editorial]. (1925). La enseñanza libre. Revista de Escuelas Normales, 26, 201.
Escudero Escorza, T. (2003). Desde los tests hasta la investigación evaluativo actual. Un siglo, el XX, de intenso desarrollo de la evaluación en educación. RELIEVE 9 (1), 11-43. Recuperado de http://www.uv.es/RELIEVEv9n1_1. htm

Fernández Ballesteros, R. (1981). Perspectivas históricas de la evaluación conductual, en Fernández, R. y Carrobles, J.A.I. (ed.). Evaluación conductual. Madrid: Ediciones Pirámide, 33-64.

Gil de Zárate, A. (1995). De la Instrucción Pública en España. Oviedo: Pentalfa Ediciones.

González-Montesinos, M.J. y Backhoff, E. (2010). Validación de un cuestionario de contexto para evaluar sistemas educativos con Modelos de Ecuaciones Estructurales. RELIEVE, 16 (2), 1-17. Recuperado de http://www.uv.es/ RELIEVE/v16n2/RELIEVEv16n2_1. htm

Holgado Barroso, J. (2000). Las Escuelas Normales de Sevilla durante el siglo XX (1900-1970). Tradición y renovación en la formación del magisterio primario. Sevilla: Universidad de Sevilla, Servicio de Publicaciones.

López Pastor, V.M. (2009). Fundamentación teórica y revisión del estado de la cuestión, en López Pastor, V.M. (coord.). Evaluación formativa $y$ compartida en Educación Superior. Propuestas, técnicas, instrumentos y experiencia. Madrid: Narcea, 45-64.

Orden, A. de la (1990). Evaluación de los programas de intervención. Revista de Investigación Educativa, 8, 61-76.

Mainer Baqué, J. (2002). Pensar históricamente el examen para proble- 
matizar su presente. Notas para una sociogénesis del examen. Boletín del Instituto Jerónimo de Uztáriz, 17-18, 107-135.

Moreno Olivos, T. (2009). La evaluación del aprendizaje en la universidad: tensiones, contradicciones y desafíos. Revista mexicana de investigación educativa, 14 (41), 563-591.

Rivas Sánchez, M.R. (1998). Desarrollo histórico de los planes de formación de maestros (1900-1990). Contenidos y prácticas. Aula. Revista de Enseñanza e Investigación Educativa, 10, 253-264.
Rodríguez Osuna, J. (1991). Métodos de muestreo. Madrid: Centro de Investigaciones Sociológicas.

Sánchez González, M.P. (coord.). (2010). Técnicas docentes y sistemas de evaluación en Educación Superior. Madrid: Narcea.

Zaldívar Colado, A.; Mendoza Zatarain, R. y Nava Pérez, L. (2009). Predicción de éxito académico basado en estudio de trayectorias escolares aplicando análisis de datos multivariados. XIV Congreso Nacional de Modelos de Investigación Educativa. Educación, investigación y desarrollo social. Huelva. 


\section{PALABRAS CLAVE}

Historia de la educación, rendimiento académico, evaluación, Escuelas Normales, estudios de Magisterio.

\section{KEYWORDS}

History of education, academic achievement, evaluation, teacher training schools, teacher training degreee.

\section{PERFIL ACADÉMICO Y PROFESIONAL DE LA AUTORA}

Antonia Ramírez García, Doctora (2006), Licenciada en Psicopedagogía (2003) y en Geografía e Historia (1995). Maestra de educación primaria por oposición hasta 2012, fecha en que aprobó una plaza de Profesora Contratada Doctora en el área MIDE de la Universidad de Córdoba. Ha sido coordinadora de la Titulación de Psicopedagogía. Las líneas de investigación se centran en la innovación educativa, especialmente en lo referente al desarrollo de competencias básicas, la convivencia escolar y la evaluación educativa.

Dirección de la Autora: Área MIDE, Facultad de Ciencias de la Educación

Universidad de Córdoba. Córdoba.

Avda. San Alberto Magno s/n. 14004. Córdoba

E-mail: ed1ragaa@uco.es

Fecha Recepción del Artículo: 04. Enero. 2011

Fecha modificación Artículo: 17. Agosto. 2011

Fecha Aceptación del Artículo: 17. Agosto. 2011

Fecha Revisión antes publicación: 24. Junio. 2012 


\section{Recensiones}


VÁZQUEZ VERDERA, V.; ESCÁMEZ, J. Y GARCÍA LÓPEZ, R. (2012).

Educación para el cuidado. Hacia una nueva pedagogía.

Valencia: Editorial Brief, 119 pp.

La obra que comentamos, publicada en la colección Observatorio Pedagógico de la editorial Brief, es fruto del trabajo de un grupo de profesores de la Universidad de Valencia expertos en temas de Educación Moral, Teoría y Filosofía de la Educación. Más concretamente, la autora principal es especialista en el pensamiento de Nel Noddings, aspecto esencial que se pone de manifiesto a lo largo de la obra, porque en ella se elabora y propone una nueva pedagogía «que tiene sus raíces en la vulnerabilidad de las personas, que necesitan el cuidado de los demás, desde su nacimiento hasta su muerte, y a las que se demanda, a su vez, que se hagan responsables de las otras personas, de los demás seres vivos, de la naturaleza y del maravilloso mundo de los productos humanos, materiales e inmateriales» (p. 9).

El libro está compuesto por 5 capítulos y un epílogo, en los que se exponen los conceptos fundamentales (capítulo 1) y los principales ámbitos de desarrollo (capítulos 2 a 5 ) de la visión pedagógica que proponen los autores.

El primer capítulo, titulado «Qué se entiende por educación para el cuidado" es fundamental, y en él los autores desgranan el significado y alcance de los conceptos fundamentales que constituyen esta pedagogía. El «cuidado" se vincula a las realidades a las que se dirige la atención y el esfuerzo, y así «se plantea como el conjunto de actividades sociales e individuales que contribuyen al bien público y a la sostenibilidad de la vida» (p. 11). De acuerdo con esto, «la educación para el cuidado tendrá por objeto el desarrollo de competencias para la vida en todas sus dimensiones: personal, laboral, comunitaria, técnica, cultural, doméstica, recreativa y espiritual» (p. 11).

Sobre estos principios, los autores dedican el resto del capítulo a desgranar y profundizar en temas tales como los orígenes de la educación para el cuidado, la filosofía práctica desde la que se construye, quiénes pueden llevar a cabo esta tarea, y las implicaciones éticas y relacionales de la educación para el cuidado. Como núcleo central y resumen del capítulo se sostiene que «educar para el cuidado implica desarrollar identidades éticas que reconozcan la vulnerabilidad propia y ajena, y también facilitar que las personas se involucren en el cuidado [de manera que] las relaciones educativas conlleven una transformación de lo que merece la pena ser enseñado y aprendido (...). Las actividades que no sólo tienen reconocimiento monetario, sino también los bienes y servicios que se producen a través del trabajo no mercantilizado y la creación de relaciones humanas de cooperación (p. 19).

En los capítulos siguientes se presenta la idea de la educación para el cuidado en distintos escenarios. Concretamente, los autores estudian los ámbitos educativos tradicionales y hacen propuestas acerca del modo en que podría desarrollarse la educación para el cuidado en cada uno de ellos. Y así, se considera el ámbito familiar como primer y principal contexto educativo; el currículum y su relación con las dimensiones cognitiva y afectiva del aprendizaje; el perfil y la función del profesorado implicado en una educación para el cuidado; y la dimensión social de la educación para el cuidado, como agente de convivencia pacífica.

Se trata de una obra sugestiva, clara y de lectura agradable, lo que no va en detrimento de su interés, que aporta elementos valiosos para la reflexión 
sobre el papel de la educación en la sociedad actual. Pero si hay un punto que es discutible en este trabajo que se propone "ofrecer al lector [una] nueva pedagogía que alumbra una práctica educativa distinta a la que se ha hecho hasta el momento presente» (p. 9), es precisamente que los autores fundamentan la «novedad» de su propuesta presentándola como una «educación para el cuidado [que] está basada en la consideración de la relación educativa como relación ética y, en segundo lugar, que la autonomía no implica la consideración del individuo como un ser aislado, sino que la autonomía es relacional» (p.11). En mi opinión, estas dos consideraciones no constituyen una especial «novedad» en el ámbito educativo, porque remiten a dimensiones que, ya desde Sócrates y Platón, han sido consideradas propias y esenciales de la tarea educativa en cuanto tal. A mi modo de ver, la «novedad» a la que se refieren los autores se encuentra principalmente en la integración del pensamiento pedagógico de $\mathrm{Nel}$ Noddings con la tradición humanística multisecular y la lógica del sentido común, tan poco común en nuestros días.

Por eso es importante que los autores recuerden esas dos dimensiones en una época en la que, en muchos casos, la educación se ejerce de manera poco educativa, por entenderse como un proceso de naturaleza supuestamente neutral, orientado a fomentar la efectividad, eficacia y competitividad de los alumnos.

María García Amilburu UNED
PÉREZ, C. (COORD); ESCÁMEZ, J.; GARCÍA, R.; SANZ, R. Y LÓPEZ, I. (2012). La acción educativa social: Nuevos planteamientos.

Bilbao: Desclée de Brower, 277 pp.

En el ámbito de la Pedagogía Social $y$, en particular, de la intervención socioeducativa va cobrando importancia la educación en contextos no formales e informales, sin restar importancia a otros contextos como son la familia y el sistema educativo. Los distintos cambios y las nuevas situaciones a las que nos vamos enfrentando en los últimos tiempos, han contribuido a generar demandas y necesidades que anteriormente no tenían relevancia y que, ahora, aparecen debido también a las nuevas sociedades plurales y complejizadas.

En esta obra, los autores abordan los temas clave de la actual Pedagogía Social con el objetivo de poder ofrecer estrategias, herramientas y reflexiones científicas y teóricas a los profesionales que intervienen en toda acción socioeducativa. Para ello, en el primer capítulo, exponen un análisis de los distintos escenarios sociales actuales que generan exclusión social desde una visión más general y contextualizadora de las distintas temáticas que abordan a lo largo de la obra, sin olvidar la dimensión ética, fundamental en todo desempeño profesional. A este capítulo le sigue una descripción de las principales aportaciones de expertos que 
presentan una trayectoria relevante en relación a la intervención con los colectivos más desfavorecidos.

El siguiente capítulo trata la intervención educativa en los distintos escenarios sociales en su sentido más amplio, destacando cómo deben ser los proyectos socioeducativos, su organización, planificación, ejecución, etc. El cuarto capítulo se centra en la exclusión social, donde se describe el fenómeno, sus principales características y factores, sus consecuencias, con el objetivo de ofrecer propuestas generales nacionales y europeas de intervención socioeducativa para luchar contra la exclusión social.

La educación a lo largo de la vida es el tema tratado en el quinto capítulo y los autores de la obra la definen «como un proceso que es necesario para un desempeño profesional actualizado y adaptado a la evolución del conocimiento, pero también como una formación para la realización personal y la participación activa en la sociedad». Para abordar este tema, analizan otros conceptos como Educación de Adultos, Educación Permanente y Educación de las Personas Mayores, con las peculiaridades que se destacan y diferencian de cada una.

A continuación, pasan a desarrollar el capítulo sobre la educación para el ocio y el tiempo libre, ámbito que según los autores presenta más posibilidades de intervención socioeducativa. Para ello, parten de la aclaración de los conceptos de ocio y tiempo libre para analizar las distintas dimensiones que los forman y proponen alternativas educativas que respondan a las necesidades que se plantean en esta temática en la actualidad.

En el séptimo capítulo se centran en la educación intercultural y la figura del mediador intercultural, ámbito que responde a la complejidad de la sociedad actual y a los retos educativos que esta diversidad plantea. La principal propuesta que se realiza desde esta parte del libro es el desarrollo de un modelo de ciudadanía diferenciada e intercultural basado en un «marco común» que sea compartido por todos los miembros de la sociedad. Este modelo se plasma en la presentación de unas directrices pedagógicas que permitan a los ciudadanos lograr la «integración y participación de todos los grupos culturales». Para poner en marcha esta propuesta, se trata la figura del mediador intercultural como "comunicador, gestor y regulador de conflictos» entre los distintos grupos culturales que conviven en las sociedades democráticas y plurales en las que nos encontramos.

Al tratar la intervención socioeducativa, hoy en día resulta imposible no abordar la temática de la educación para la igualdad y la prevención de la violencia de género, el cual tratan en el capítulo octavo. Para exponer este tema, parten del análisis desde distintos ámbitos, comenzando por la situación actual de la igualdad efectiva entre hombres y mujeres, pasando por el estudio del concepto de "género", al entender que es el aspecto fundamental en la construcción de la identidad del hombre y de la mujer. Y, finalmente, analizan el principio de igualdad como cuestión propia de la ciudadanía.

En último término, este libro trata el tema de las adicciones producidas por el consumismo que domina a la sociedad: drogodependencias, ludopatías, compras, internet, videojuegos... La propuesta que se propone en este tema se relaciona con el aprendizaje de valores, actitudes, dominio de técnicas para la toma de decisiones, así como la adquisición de competencias para la interacción social, cuyo fin último es el trabajo de la prevención y el tratamiento de este tipo de adicciones.

Como podemos ver, los autores tratan en esta obra la temática fundamental relacionada con la intervención 
educativa y social. Destacamos el rigor científico y la claridad expositiva con la que plantean los distintos temas y tipos de intervención/acción socio-educativa. Se trata de una obra de referencia práctica para todos los profesionales que trabajan por erradicar la exclusión social y la igualdad de oportunidades en la sociedad.

Miriam García Blanco UNED

IRANZO GARCÍA, P. (2012). Asesoramiento pedagógico al profesorado. Madrid: Síntesis, 350 pp.

La Pedagogía puede conceptuarse como la ciencia del cambio educativo para la formación y la mejora social. Es intrínsecamente compleja y profundamente teleológica. En un país en que la Pedagogía no se reconoce ni tanto ni tan bien como en otros con mayor desarrollo educativo, la función asesora de carácter pedagógico emerge, cada vez más claramente, como una necesidad que necesita ser cubierta por profesionales pertinentes (pedagogos o psicopedagogos) y con una formación adecuada. La creciente e irreversible complejidad asociada a los procesos educativos reclaman una formación y unos profesionales del asesoramiento pedagógico capacitados para el desarrollo de una actuación orientadora científicamente fundada, que sirva como referente o guía facilitadora de múltiples procesos de cambio, tanto individuales como colectivos, tanto personales como profesionales e institucionales, tanto didácticos como organizativos.
El libro objeto de comentario se detiene en las claves acerca del qué, el para qué y el cómo del asesoramiento pedagógico. Su campo es la mejora escolar, percibida desde el acompañamiento asesor al profesorado en los procesos de cambio. Su contenido se aborda desde una perspectiva a la vez reflexiva, reconstructiva, cooperativa, evaluativa y práctica. En sus páginas se estudian los cambios en las prácticas escolares -de dentro y de fuera del aulapara el éxito educativo.

Su contenido se distribuye en dos bloques principales. La primera parte se ocupa de «definir y contextualizar el asesoramiento pedagógico» desde los diferentes ángulos asociados a la ayuda pedagógica al profesorado, para generar mejoras. Destaca en ella el análisis de la constitución histórico-profesional de la función asesora - tanto desde la mirada pedagógica y psicopedagógica-, la sistematización de algunos parámetros clasificatorios del asesoramiento, los tipos y modelos de asesoramiento, la normativa legal de referencia. Dentro de esta primera parte, la autora analiza los marcos sociológico, psicológico y pedagógico en los que inscribir el asesoramiento pedagógico y la contribución del asesoramiento al desarrollo profesional docente desde una formación permanente emancipadora.

La segunda parte se dedica a «las claves prácticas del asesoramiento para innovar». Dentro de ella se abordan cuestiones fundamentales con una gran claridad operativa: los modelos de asesoramiento, los elementos estructurales del asesoramiento, las fases del asesoramiento pedagógico, el asesoramiento desde una perspectiva transversal para atender las necesidades, comprender la institución y evaluar el proceso, la evaluación en y para el asesoramiento pedagógico y finalmente la caracterización de la figura asesora y las tendencias en el asesoramiento pedagógico. El trabajo termina con una representativa y cuidada bibliografía. 
Un libro tan ambicioso y completo como el presente sólo es realizable si su autora dispone de un hondo conocimiento directo de aquello que trata. La Dra. Pilar Iranzo, investigadora de reconocido prestigio en nuestro panorama pedagógico, ha tendido puentes fiables entre la investigación y el quehacer profesional y entre el asesor pedagógico y los docentes y los centros. Desde este trabajo puede ser más fácil ver cómo la Pedagogía, como ciencia de referencia de la educación, puede contribuir al desarrollo de la calidad educativa de los centros docentes y, desde ella, a la mejora social que desde la enseñanza más consciente en última y quizá en primera instancia siempre se pretende.

El trabajo se destina a todo agente comprometido con la mejora educativa: asesores, formadores, los orientadores, los profesores, directores, coordinadores y gestores. También será de gran valor para investigadores y estudiantes, porque encontrarán en este un conocimiento fundado, claro, pertinente y útil.

Agustín de la Herrán Universidad Autónoma de Madrid

\section{HARGREAVES, A. Y SHIRLEY, D. (2012).}

La cuarta vía. El prometedor futuro

del cambio educativo.

Barcelona: Octaedro, 182 pp.

Se presenta ahora para el público de habla hispana este relevante libro, cuya edición original es de 2009 (The Fourth Way. Corwin Press, 2009) Escrito cuando ya la crisis económica se sentía en el ámbito anglosajón, como describe en el prólogo, con una actualidad de primer orden en España: «los recortes no nos preparan para ser competitivos en el futuro. Estos mercados sin regulación que nos han metido en este lío financiero y nos han empujado a adoptar soluciones de mercado en el sector público no nos van a sacar de él» (p. 13). Por eso, señalan, es el momento de proponer una nueva vía del cambio educativo, que aproveche lo mejor de las antiguas y se deshaga de lo peor.

Por eso, el libro se estructura en un primer capítulo (Las tres vías del cambio) que describe las tres sucesivas vías del cambio desarrolladas tras la II Guerra Mundial, el legado que nos ha aportado cada una. Por su parte, en el capítulo 2 (Los tres senderos de la distracción) explican por qué la promesa de la tercera vía no se ha realizado, debido a diversos caminos de distracción. El capítulo 3 (Los cuatro horizontes de la esperanza) trazan las imágenes u horizontes sobre el camino más deseable. Todo ello conduce a proponer en el último capítulo la cuarta vía, los pilares en que se apoya, principios y catalizadores que le dan coherencia.

Escribir un libro como este con una visión comprehensiva de reflexión de segundo orden, basada en una revisión de las políticas educativas y de la investigación sobre el cambio, no puede hacerse si no se tiene detrás una amplia base de conocimientos, cultivada en trabajos anteriores de los autores, como reseñan al comienzo. Por lo demás, convendría reseñar que la investigación iniciada en este libro la acaban de proseguir los autores con uno nuevo: The Global Fourt Way. The Quest for Educational Excelence (Sage Publ., 2012).

La primera vía corresponde a los «treinta gloriosos» (1945-75) en que se ofrecen amplios recursos a los centros, sin una dirección coherente, que dejados a la discreción profesional, dan lugar a innovaciones inconsistentes. En 
las evaluaciones de las innovaciones, con la crisis del 1973, se constata un fracaso en la implementación. Tras un interregno, con los gobiernos conservadores, se instaura la vía de los mercados y estandarización. Con la regulación y las evaluaciones se pretendió subir el listón, pero se hizo poco porque muchos lo alcanzaran, aparte de los efectos desmoralizadores que tuvo sobre el personal docente. La tercera vía quiso "combinar lo mejor del apoyo del Estado y la competencia de mercado» (p. 40). Pero, al final, diversos distractores le hacen perder los propósitos iniciales, como describen en el siguiente capítulo.

La tentación de una cierta teocracia, dirigiendo e imponiendo los cambios, con un exceso de control gubernamental, da al traste a las mejores promesas. En segundo lugar, un sendero tecnocrático que conduce a cuantificar todos los procesos y a poner los datos e indicadores de progreso en el centro de la mejo$\mathrm{ra}$, igualmente distraen de ser medios a convertirse en fines. Finalmente, la confianza ilimitada en el interaccionismo y colaboración profesional tampoco da, por sí misma, los frutos deseados. Estamos pues, señalan los autores, en proponer una cuarta vía, recogiendo las lecciones aprendidas y abandonando los puntos débiles.

Se trata de volver a la innovación y creatividad de la primera vía, evitando la inconsistencia profesional; evitar la estandarización de la segunda vía, retener la relevancia de los datos y redes profesionales, evitando la autocracia y tecnocracia. Para eso se diseñan cuatro horizontes de esperanza, a modo de puntos cardinales, que orienten la vía de salida. El primero es un país (Finlandia) que ha logrado estar entre los primeros del mundo en indicadores educativos. El segundo es una red de escuelas que ha conseguido unos mejores resultados en un tiempo relativamente corto. El tercer horizonte de esperanza en una organización comunal, como fuerza positiva para el cambio educativo. El último horizonte que presentan es un distrito escolar, con graves déficits socioeconómicos y culturales, que ha logrado mejoras significativas. De estos cuatro casos emergen nuevos principios para la mejora, que delinean la cuarta vía: «una profesión cargada de energía con un público involucrado y un Gobierno que guiará pero no controlará, en una unión interactiva de iguales dedicados a servir y mejorar el bien común de la educación pública» (p. 108).

Por tanto, esta cuarta vía une las políticas gubernamentales con el compromiso profesional y el del público en torno a una visión de la educación y de la sociedad. Los seis pilares de propósito y alianza son: visión inspiradora e inclusiva, profundo compromiso público, logros mediante la inversión, responsabilidad educativa corporativa, alumnado como parte del cambio, personalización de la enseñanza y el aprendizaje. A su vez, requiere una profesionalidad basada en tres principios: profesorado de alta calidad, con asociaciones positivas y en comunidades vivas de aprendizaje. El problema es hacer esto sostenible en el tiempo. Para ello los autores proponen cuatro catalizadores que puedan dar una coherencia: liderazgo sostenible, redes integradoras, responsabilidad por encima del rendimiento de cuentas, diferenciación y diversidad. Como resumen, la cuarta vía es «un camino democrático y profesional hacia la mejora que construye desde la base, dirige desde las alturas y proporciona apoyo y presión desde los lados» (p. 157).

En una cierta encrucijada, en que los antiguos caminos no sirven, pero el contexto es complejo e incierto, hay que ensayar vías de mejora que integren diversas dimensiones que se han mostrado valiosas, aun cuando inicialmente pudieran parecer opuestas. El propósito, finaliza el libro, es «crear escuelas que afianzarán y catalizarán 
nuestros mejores valores para regenerar y mejorar la sociedad. Ha llegado el momento para ello». Como señalábamos antes, en su nuevo libro, globalizan esta cuarta vía con los ejemplos de otros países, aprendiendo de cómo hacen frente a la crisis del cambio educativo para potenciar la innovación y mejora.

Rosel Bolívar Ruano Universidad de Granada

\section{SANTOS REGO, M.A. Y LORENZO MOLEDO, M. (EDS.) (2012).}

Estudios de Pedagogía Intercultural. Barcelona: Octaedro, 190 pp.

La indagación y reflexión en torno a los factores culturales en su relación con los sistemas educativos ha cobrado una excepcional importancia desde los pasados años setenta. Sin duda, ya estaban presentes, como pusieron de manifiesto destacados comparatistas, pero fue en ese momento cuando el asunto comenzó a ser tomado en evidente consideración, también en el plano político, y por ello en debate entre varios polos, esto es, la educación fundamentada en las perspectivas ilustradas, reciamente republicanas y de vocación universalista, versus la educación pluricultural, relativista y culturalista. Se ha abierto también no una vía intermedia, sino un enfoque de educación y de pedagogía intercultural; un enfoque de más impreciso perímetro, que encierra mayores interrogantes, pero que contiene, creo, mayor potencialidad conceptual ante la ineludible cuestión de la gestión de la diversidad cultural.
Es en esta dirección en la que se encuadra la contribución dirigida por el profesor Santos Rego y por la profesora Mar Lorenzo, ambos de la Universidad de Santiago de Compostela y líderes de un equipo de investigación con años de trabajo eficaz alrededor de los interrogantes suscitados por la búsqueda de la igualdad de oportunidades educativas de las poblaciones inmigrantes incorporadas al sistema educativo español, con detenimiento en el caso gallego.

Parten, como premisas, de que caminamos hacia un horizonte de diversidad humana (p.11) y de que el diálogo intercultural se está abriendo paso ante audiencias cognitiva, social y moralmente diversas. Aquí toman asiento las tesis que se exponen en la primera de las «aportaciones» de estos Estudios, elaborada por Santos Rego, bajo el rótulo "Teoría de la educación, ciudadanía y pedagogía intercultural en la sociedad del aprendizaje» (pp. 1753), con el trasfondo de este problema: ¿Cómo abordar la integración del otro diferente cultural en la realidad social vigente?:

a) El ideal de democracia no repudia el ideal de interculturalidad, si se aúnan los valores de libertad e igualdad.

b) La igualdad de derechos y opciones entre los hombres y las mujeres es una clase de uniformidad deseable.

c) No hay culturas compactas, estáticas y homogéneas, por lo que la idea de una sociedad, vale decir también de un sistema educativo, estructurada en y desde una tradición cultural (compacta) no se sostiene hoy, ante los múltiples intercambios.

d) El aprendizaje de la ciudadanía y la competencia intercultural señalan un horizonte estratégico a las políticas educativas ante todo ello, un nuevo modelo de escuela integradora e inclusiva 
transcurre a través de un currículum, en principio, «más plural» (p. 25).

e) Los profesores precisan de formación en este campo y de una coherente "teoría de la educación», dada su intervención en los procesos de «encuentro» entre alumnos de diversas procedencias,

f) La competencia (educativa) intercultural ha de ser entendida como una genérica capacidad de participación activa y crítica en escenarios caracterizados por la diversidad cultural y la pluralidad identitaria de las personas, implicándose en ello dimensiones cognitivas, afectivas y comunicativas.

g) Y por todo lo dicho la educación intercultural se configura como una teoría pragmática del conocimiento y resorte estratégico de una educación democrática e inclusiva.

Más allá de la Introducción y de este inicial capítulo, argumentado y transitado por las posiciones intelectuales y estado de la cuestión dibujado por la literatura anglosajona, otras cinco «aportaciones» configuran estos oportunos Estudios. Así, la siguiente, sitúa a la educación, acompañada del concepto de "cooperación», como adecuado recurso estratégico al servicio del «codesarrollo», una imagen del desarrollo construido desde el empowerment de los y las participantes. Diana Priegue reflexiona, desde las contribuciones cognitivas, sobre la confluencia entre el aprendizaje cooperativo (entre personas distintas y como práctica situada) y la educación intercultural: «los espacios en los que se coopera (p. 93) crean comunidades de ayuda en el estudio", derivando de ahí precisas recomendaciones para la formación del profesorado. Santos y Lorenzo ponen de manifiesto en la cuarta aportación, sobre la base de un consistente entramado empírico, la relevancia de la escuela y de la educación intercultural en la representación que van construyendo los inmigrantes acerca de sus expectativas y posibilidades en la sociedad de acogida, lo que debe asociarse al principio de participación (de ellos mismos) en la esfera pública y en la específica escolar.

Los mismos autores y Diana Priegue se detienen también en la relevancia concedida a la educación por parte de las familias migrantes en España, poniendo de manifiesto una global satisfacción de éstas, confrontada con la insatisfacción y las prácticas de discriminación que en grado diverso patentizan las familias «españolas» y con hijos escolarizados, sobre todo, en los centros privados, constatando la presencia de «muchos elementos de diferenciación negativa» (p. 157), así como una muy apreciable distancia entre legalidad y realidad. Esta misma cuestión es profundizada en la sexta "aportación» (Santos, Moledo, A. Godás y Crespo Comesaña) al referirse a la condicionada presencia y reparto de alumnado inmigrante en los centros públicos y en los privados, con creciente riesgo de fragmentación social, lo que se afirma desde observaciones empíricas, reclamando, al caso, políticas de cohesión social.

A través de la lectura de este texto, argumentado y abierto, podemos observar aspectos de la metamorfosis teórica, discursiva, institucional y práctica que alrededor del concepto de la educación intercultural se fue gestando en las más recientes décadas, sus valores actuales, aunque también algunas elipses, dada probablemente la profundidad de las tareas que se proponen y las dificultades de su resolución, en confrontación con las realidades y contradicciones socio-políticas que se oponen desde el marco socio-económico, tanto español como internacional, en el que nos movemos; marco ante el que se viene suscitando, por otra parte, un denso y creativo conjunto de propuestas e intervenciones, a menudo no suficientemente elaboradas, que podríamos reunir bajo el acogedor concepto de 
alterglobalización, que quizás sea el mejor humus de la orientación educativa intercultural.

Antón Costa Rico

Universidad de Santiago de Compostela

\section{DOMÍNGUEZ GARRIDO, M.C. Y GARCÍA GONZÁLEZ, P. (2012).}

Tratamiento didáctico de las

competencias básicas.

Madrid: Universitas, 457 pp.

La obra que presentamos reúne un amplio elenco de colaboraciones de diversos profesores e investigadores universitarios, animados todos ellos por la común voluntad de aunar esfuerzos y sinergias integrales por presentar un enfoque didáctico ante la actualidad y necesidad de desarrollo de las competencias básicas, fundamento de la educación necesaria en la sociedad del conocimiento. El resultado de este libro es el esfuerzo de una línea de trabajo que se viene manteniendo en los últimos años, apoyada por diversos proyectos internacionales y avalada por la dirección de Antonio Medina, quien representa a un grupo de investigación interuniversitario consolidado. La obra Tratamiento didáctico de las competencias básicas es la continuidad del trabajo anterior de 2009, Formación y desarrollo de las competencias básicas, traducida al portugués y con gran acogida en nuestro entorno y aceptada ampliamente en Hispanoamérica.

Los coordinadores de esta nueva obra, la Profesora M. ${ }^{a}$ C. Domínguez Garrido, Catedrática de Didáctica de las Ciencias Sociales de la Universidad Nacional de Educación a Distancia, y el profesor Pedro García González, de la Institución Gredos San Diego, nos avisan -y con razón - ya en la introducción, que las competencias ya han sido formuladas teóricamente desde distintas perspectivas en la literatura científica, pero su tratamiento didáctico está poco desarrollado. Para ello la pretensión fundamental de la obra es ofrecer a los docentes modelos, esquemas, representaciones y orientaciones que permita una actualización didáctica adaptada al enfoque de la enseñanza por competencias, no sólo desde el punto de vista teórico-reflexivo, sino desde la práctica pedagógica y su dominio en el ámbito digital.

Los capítulos primero y segundo abordan la competencia comunicativa. En el primero de ellos, "Competencia comunicativa como base del desarrollo de las competencias de los estudiantes» (pp. 29-45), el Profesor Medina clarifica los retos didácticos del docente, sienta las bases y propone los métodos, medios y tareas que integrados y aplicados de modo interrelacionado permiten lograr un tratamiento adecuado de la competencia comunicativa. El segundo capítulo aborda la formación y práctica de la competencia comunicativa y presenta, a su vez, cuatro aportaciones. En la primera de ellas, el Profesor Gutiérrez Carbajo desarrolla la competencia comunicativa inter-textual siguiendo el aporte de García González, con un interesante trabajo sobre el desarrollo digital de la competencia comunicativa. En tercer lugar, la Profesora Ieva Margevica de la University of Latvia presenta una visión de la competencia comunicativa plurilingüística e intercultural y, finalmente, el Profesor Medina propone un modelo para el desarrollo de la competencia comunicativa del profesorado, situando a la interacción didáctica como base del proceso cuyos elementos fundamentales son: interiorizar el valor de la comunicación didáctica, emplear adecuadamente los códigos comunicativos y aplicar la metodología didáctica y heurística. 
Los capítulos tercero y cuarto se dedican a la formación y práctica de la competencia del conocimiento del medio y de la competencia social, respectivamente. Para la primera de ellas, la Profesora Díez Bedmar adapta su trabajo a la Educación Secundaria proponiendo un proceso para elaborar tareas focalizadas en el desarrollo de la competencia del conocimiento del medio, en sintonía con otras, y mostrando finalmente algunos ejemplos de tareas y actividades. Por su parte, las Dras. Domínguez y Medina Domínguez profundizan en la complementariedad de actitudes, valores y estilos de serconvivir que permitan al profesorado consolidar un estilo docente abierto al desarrollo de la competencia del conocimiento del medio y, fundamentalmente, a algunas de sus competencias identificadas (localización, geográfica, histórica, geo-histórica, ambiental, patrimonial-artística, intercultural) que permiten diseñar actuaciones para el dominio de la competencia. La formación y práctica de la competencia social se aborda con dos trabajos. El primero, del Profesor Pérez Navío, de la Universidad de Jaén, sobre cómo integrar las redes sociales para el desarrollo de la competencia social en estudiantes de secundaria y el segundo, del Profesor Medina, quien presenta las líneas de actuación más fecundas para desarrollar la competencia social, muy ligada a la dimensión intercultural.

Los capítulos quinto y sexto se dedican a la competencia matemática y al tratamiento didáctico de la competencia digital. Para el primero, el Profesor Ramos y la Profesora Leví proponen un modelo de componentes de las competencias, que para la matemática integra el saber matemático (lenguaje matemático, cantidad, espacio y forma, cambio e incertidumbre), las capacidades matemáticas (pensamiento y razonamiento, argumentación, comunicación, construcción de modelos, planteamiento y solución de problemas, representación, utilización de operaciones y lenguaje técnico, formal y simbólico, empleo de material y herramientas de apoyo) y las actitudes matemáticas (calidad, creatividad, crítica e innovación). Finalmente, ambos autores proponen un sistema inteligente de evaluación de competencias que integre pruebas y formularios de evaluación, así como las posibilidades reales de automatizar el proceso. Para ejemplarizar sus propuestas se valen de una experiencia de evaluación de la competencia matemática de los alumnos del curso de acceso para mayores de 25 años de la UNED. Continúa el capítulo dedicado al tratamiento de la competencia digital, en el que la Profesora Quero y el Profesor López presentan una aproximación teórica a la misma, seguida de una revisión de la literatura de las experiencias actuales en torno a la temática y de unas reflexiones sobre las implicaciones que en el ejercicio docente tiene el desarrollo de esta competencia. Finalmente muestran algunos ejemplos de tareas para su desarrollo así como un breve apunte sobre la creación de narrativas multimedia y el empleo de videojuegos para la enseñanza.

Finalmente, el capítulo séptimo está dedicado a la evaluación de las competencias y nos presenta los modelos, criterios y pruebas adaptados a la nueva situación formativa del desarrollo de competencias. Como concluye el Profesor Medina, la evaluación de las competencias docentes ha de tener en cuenta la intensidad de logro, su ajuste con los logros de aprendizaje esperados, la complementariedad y la armonía en la adquisición holística, la integración en el dominio, la autonomía y respeto al desenvolvimiento personal, en coherencia con el proyecto de vida de cada estudiante.

En suma, nos encontramos con una obra actual y pertinente cuya principal limitación es que no contempla específicamente algunas competencias básicas como aprender a aprender, autonomía e iniciativa personal y cultural 
y artística, si bien es cierto que todas ellas se trabajan de alguna manera en los capítulos ya mencionados. Animamos a su lectura y trabajo, sin duda, ya que sienta las bases de un nuevo estilo formativo, desde propuestas prácticas y aplicadas de una nueva visión didáctica de la enseñanza actual y, por supuesto, de la que está por llegar.

Celia Camilli Trujillo Centro Universitario Villanueva Universidad Complutense de Madrid

\section{GARCÍA AMILBURU, M.; GARCÍA GUTIERREZ J. (2012).}

Filosofía de la Educación.

Cuestiones de hoy y de siempre.

Madrid: Narcea-UNED, 211 pp.

Este libro con propósito de introducción a la disciplina, consigue un objetivo mayor y se configura como un manual didáctico de referencia sobre la misma gracias a la linealidad argumental que sigue, así como por las temáticas desarrolladas en las distintas exposiciones realizadas por los autores, que configuran un patrón desglosado en capítulos con interesantes síntesis sobre las cuestiones a tratar al comenzar cada uno de ellos.

Se aborda en primera instancia un acercamiento a la disciplina: sus características, su naturaleza y su relación con otros saberes pedagógicos. A continuación, los autores analizan los presupuestos antropológicos de la educación, partiendo de la premisa de que nadie puede realizarse plenamente sin una tradición y una cultura en la que basar el propio acto educativo, destacando así las dimensiones humanas educables -educabilidad-.
Haciendo un análisis axiomático, se abordan las propiedades del hecho educativo, donde se destaca que la educación no busca el perfeccionamiento de las capacidades de los humanos de manera aislada, sino que inquiere que la persona mejore en su totalidad, afirmación que dota de sentido a la propia educación, entendida como la transmisión de lo valioso, para alcanzar y conseguir el perfeccionamiento y mejora del educando. Ambos aspectos expuestos tras definir y diferenciar los distintos modelos de educación: formal, no formal e informal, dan paso al capítulo cuarto, en el que se analizan las distintas relaciones existentes entre los agentes educativos -educador y educando-, en función de la etapa o ámbito en el que se ubique su actividad, definiendo el concepto capital de educatividad como disposición o actitud que posee un determinado agente para educar.

A lo largo de los siguientes capítulos se expone la evolución de la disciplina a través de distintos pensadores, haciendo alusión en primer término a «los clásicos» como Sócrates, Platón o Aristóteles, cerrando esta etiqueta con San Agustín y Santo Tomás de Aquino. Un aspecto de valor que no se debe pasar por alto es la acertada inclusión de un capítulo dedicado al pensamiento de distintos autores, los cuales en la mayoría de ocasiones no se tratan en los manuales, ni por ende en las asignaturas relacionadas, como es el caso de Kierkegaard y su idea del pensamiento subjetivo, Newman y su reestructuración de la educación liberal universitaria, la importancia de la hermenéutica en la educación recogida por Gadamer, y el proyecto de Paideia de J. Adler, centrado en la consideración de que la educación no es una idea sino un problema práctico.

Tras esta panorámica histórica, los autores culminan su aproximación destacando la fundamental aportación realizada por S. Peters y su preocupación 
por el análisis lógico de conceptos, recalcando la expresión del autor inglés educación como iniciación, mostrando la amplitud de tendencias y perspectivas que actualmente existen en lo que se refiere a la concepción de la educación. A continuación, es posible apreciar una breve pero exquisita relación de distintos medios de difusión - sociedades, revistas científicas y congresosde mayor calado, donde se referencia y crece la propia filosofía de la educación bajo un panorama que los autores juzgan como de escasa atención política y decreciente presupuesto, con el que las disciplinas humanísticas deben de continuar su desarrollo en la actualidad.

Indicadas las bases y la tendencia del Manual, los autores se centran en lo restante en el estudio de aspectos más específicos, como la dimensión política y el derecho a la educación, entendiendo ambos conceptos como una relación bidireccional, planteando el derecho a la educación como una exigencia, por su concepción, y a su vez como una necesidad, pues posibilita la plenitud del individuo. Asimismo y haciendo hincapié en la diversidad de modelos democráticos existentes, los autores recalcan que la democracia se entiende como la adhesión a los valores espirituales y morales que son propiedad común de sus pueblos y se configura a su vez como la fuente de la libertad individual y política (p.143).

Mención especial hay que hacer del antepenúltimo capítulo del libro, dedicado a las convicciones, donde los autores se acercan a las distintas perspectivas vinculantes a la concepción de la educación: tradicionales religiosas, filosóficas y/o morales y pedagógicas, añadiendo una nueva categoría de gran interés, denominada convicciones culturales, que tiene como nexo la identidad cultural y el derecho a la educación. Por todo ello, parece oportuna la inclusión del undécimo capítulo, reservado a los profesionales de la educación, donde se pone de manifiesto la necesidad de un cierto perfeccionamiento como aspecto ético derivado de la propia tarea, favoreciendo así la creación de lo que los autores demandan como una cierta filosofía de la educación a nivel personal para los docentes.

El último capítulo, destinado a la ética del quehacer educativo y la formación de profesionales, muestra nuevamente la idea de que educar no es una técnica sino un arte, un saber hacer y por ello, los autores reflejan la necesidad de que los profesionales de la educación presenten una base ciertamente sólida en aspectos como su formación científica y pedagógica, humanística y su formación moral. Dado el perfil y actividad de los autores dentro de la UNED, así como por la emergente demanda y crecimiento de este tipo de educación, destaca un último apartado dedicado a la ética en espacios virtuales, en el que discurren y apuntan la necesidad de desarrollar competencias acordes al entorno educativo virtual, donde la libertad y la autorregulación juegan papeles fundamentales.

En síntesis, un libro muy completo, con referencias relevantes, que hace palpable su título de manera implícita, tal como refleja el Catedrático Emérito de filosofía de la educación de la Universidad de Oxford, Richard Pring en el prefacio, tratando temas esenciales sobre la educación e indagando en reflexiones de valor actuales. Un Manual muy recomendable para acercarse a la filosofía de la educación, su motivo, sus agentes y perspectivas, un recurso excelente para reflexionar sobre la realidad y los retos pedagógicos actuales.

Javier Bermejo Fernández-Nieto Universidad Complutense de Madrid 
MARTÍNEZ RODRÍGUEZ, F.M. (2013).

Educación, neoliberalismo y justicia social: Una revisión crítica del desarrollo humano desde la Carta de la Tierra y la economía social. Madrid: Pirámide, 168 pp.

Pocas veces una obra es más oportuna que esta en los tiempos que corren. Se centra justamente en el análisis del núcleo del problema global desencadenado por la peor versión del capitalismo, el neoliberal, que trascendiendo la economía, se hace presente en el poder político, en la ideología, en las instituciones, entre ellas la educación, en toda la vida social y personal. Se ha convertido en una forma de dominio integral, como sostiene en su Prólogo el profesor Juan Torres López, en una forma de ver el mundo, una visión que se postula como única. Esta es la obra que se presenta aquí y que tiene la especial relevancia de que enfoca un tema complejo desde un discurso multidimensional.

Está estructurada en cuatro capítulos, seguidos de unas reflexiones finales y referencias bibliográficas. Tiene también un interesante prólogo de Juan Torres, como se ha indicado, y una introducción del autor, profesor de la Universidad de Granada, pedagogo que trabaja en temáticas de educación social. El autor ofrece una visión diferente del desarrollo humano a la que se propone desde el discurso oficial del pensamiento liberal que pretende constituirse como "pensamiento único», mostrando que "otro desarrollo» no sólo es posible, sino deseable y necesario.

En el primer capítulo "¿Por qué se sigue negando la "crisis sistemática del modelo capitalista neoliberal"? Perspectiva histórica e intereses ocultos» se analizan las principales variables que han estado detrás de la crisis financiera y económica internacional. Se pasa revista a los intereses de un modelo económico que busca la desregulación, al servicio de las grandes corporaciones multinacionales y de las corrientes neoconservadoras liberales. Se analiza el paso de un capitalismo productivo a un capitalismo financiero de carácter especulativo, con las tremendas consecuencias para el conjunto de la población y del medio natural. Se expone el caso de España, con el colapso de la «burbuja inmobiliaria» y se cierra con un acertado análisis de cómo la filosofía neoliberal ha ido impregnando también a los sistemas educativos públicos, buscando una educación al servicio del mercado para así generar un tipo de ciudadano consumista que es modelado por valores como el individualismo, la competitividad, el eficientismo, la rivalidad... por encima de los verdaderos valores humanos como la solidaridad, la responsabilidad compartida, la conciencia ecológica o la ayuda mutua.

En el segundo capítulo «Del capitalismo neoliberal a una economía centrada en el mantenimiento y desarrollo de la vida». Para realizar este paso el autor propone realizar una revisión en profundidad de la noción de «desarrollo humano». Se indaga acerca de su origen y evolución y de su relación con el proceso de la Revolución Industrial. Se muestran las tendencias y la manipulación que el tema del desarrollo ha sufrido por parte de la ideología conservadora eliminando todo rastro de lo que significara cambio y transformación social. Esto posibilita dar a luz una noción de desarrollo que, más allá del liberalismo, se fundamente en una renovada economía social inspirada por los principios de la Carta de la Tierra, la cual se expone manifestando su carácter educativo.

En el capítulo tercero «Repensar la economía social y solidaria. Pautas para una economía más equitativa y sostenible», se expone el origen y la trayectoria de la economía social y 
solidaria, en pugna con un capitalismo excluyente y que aparece como una respuesta a la pobreza, marginación y exclusión de un sector importante del proletariado por parte del modelo capitalista de producción. Con puntos en común a este modelo se explica la interesante iniciativa de la «economía del bien común» de Felber. La intención es aportar ideas innovadoras que muestren la posibilidad y necesidad de trascender este capitalismo financiero especulativo y tóxico.

En el último capítulo "Otro pensamiento es posible: el papel de la educación y la Carta de la Tierra en la mejora de las empresas de economía social y solidaria», el más "educativo» de todos, se reflexiona acerca del papel de la escuela, y de cómo los sistemas educativos han contribuido a perpetuar la reproducción del statu quo, incumpliendo de esta forma la función que le fue asignada en los estados democráticos modernos, que consistía en favorecer la igualdad de oportunidades real con independencia de su estatus social o económico. Sin embargo, los valores que ha atravesado la escuela favoreciendo la competitividad y lo individual por encima de lo colectivo y del bien común, el consumismo del saber y de los títulos, la desmovilización social, política... son los típicos del modelo capitalista neoliberal y como sostiene el autor se encuentran en el centro de la actual crisis civilizatoria.

En este sentido es una necesidad urgente repensar la escuela para ir más allá del principio de igualdad de oportunidades que ha escondido una desigualdad de posiciones. Hay que repensar la educación para hacerla más integral, introduciendo las dimensiones emocional-afectiva, la ecológica y social que junto con la cognitiva permita construir la necesaria conciencia global. Esto se refleja en los valores y principios de la Carta de la Tierra, que pueden contribuir al desarrollo de una nueva economía social, una economía para el bien común en el contexto de la comunidad de la vida, promoviendo así un estilo de vida sostenible que necesitamos con urgencia para este siglo.

Con unas reflexiones finales el autor cierra este magnífico libro que recomiendo por su claridad, profundidad y aportaciones para entender el presente y para comprometernos activamente con nuestro futuro.

Alfonso Fernández Herrería Universidad de Granada

\section{ARBUÉS, E.; NAVAL, C.; REPARAZ, C.; SÁDABA, C. Y UGARTE, C. (2012).}

La competencia social y cívica. Guía didáctica.

Pamplona: Parlamento de Navarra, 79 pp.

El interés por la educación cívica sigue siendo uno de los temas en alza en educación. Su importancia como eje transversal lo encontramos ya en la propuesta de la LOGSE, sin embargo parece que no se ha logrado las expectativas y objetivos educativos que se perseguían con ello. Una de las grandes denuncias de la educación para la ciudadanía es la carencia de un marco teórico adecuado. Por eso las autoras hacen un estudio de los fundamentos teóricos que deben sustentar el planteamiento pedagógico y educativo de la competencia social y cívica. Con esta obra pretenden ayudar al profesorado de la etapa de educación secundaria en su trabajo como docentes y como educadores de futuros ciudadanos. 
Las autoras ven la necesidad de situar toda educación para la ciudadanía en el horizonte de una educación integral. En esta línea se sitúa el proyecto pedagógico de formación de la competencia social y cívica, parte esencial del contenido de esta guía. El fundamento teórico del planteamiento educativo que se presenta está basado en la propuesta que Naval (2009) recoge en su obra Educación de la Sociabilidad; donde se busca establecer las dimensiones personales básicas de la sociabilidad implicadas en el desarrollo de la competencia social y cívica, y las virtudes sociales a educar asociadas a dichas dimensiones. Todo ello con un objetivo concreto: potenciar la acción social.

Respecto a los contenidos escolares, las autoras afirman que existe un acuerdo casi general en tres cuestiones:1) la necesidad de una educación que promueva las virtudes necesarias para que los alumnos lleguen a ser miembros responsables de una sociedad democrática; 2) la conveniencia de promover la ciudadanía activa; y 3) un interés por adoptar medidas para hacer frente a los nuevos retos de la sociedad multicultural. Finalmente exponen la distribución de las unidades didácticas por áreas, los contenidos a tratar en cada una de ellas, así como la contribución de cada una a la evaluación del alumno, lo cual muestra la propuesta de transversalidad evaluable que sugieren.

En la primera parte se trata del concepto de competencia social y cívica; análisis de sumo interés puesto que es una de las ocho competencias que debe haber desarrollado el alumno al finalizar la ESO. Seguidamente se pasa a responder dos preguntas claves para el correcto desarrollo de este proyecto formativo: ¿qué es la competencia social y cívica? y ¿qué es ser un buen ciudadano? Con este fundamento teórico, llegamos a la segunda parte de la guía en la que se trata con detenimiento cada uno de los componentes del proyecto. Las autoras inciden sobre los tres pilares fundamentales en los que se asienta el aprendizaje cívico: transmitir conocimientos, promover en el alumno la actitud social y desarrollar las habilidades necesarias. Se afirma que no hay acuerdo ni en la práctica ni entre los expertos sobre cuáles son los contenidos propios de toda educación para la ciudadanía; pero sí se habla de tres grandes temas comunes relacionados entre sí: la democracia, la cohesión social, y la participación ciudadana (Naval y Arbués, 2008). Se determinan cinco actitudes sociales: altruismo optimista, responsabilidad social y política, el respeto, la lealtad y la justicia. Y respecto a las habilidades se distingue entre intelectuales y sociales.

La última parte contiene el proyecto pedagógico de educación de la competencia social y cívica. Se desarrolla con detalle la propuesta para que en el centro educativo se promueva una praxis generadora de civismo. Es una propuesta eminentemente práctica, donde se busca el fomento de actitudes de participación y de compromiso social del alumnado, mediante la inmersión de los alumnos en actividades reales. Se apuesta por unos principios metodológicos generales que deberán articularse tanto en el centro como en el aula, y que requerirán adoptar unas estrategias concretas. Estos son: clima de interacción y motivación positiva, transversalidad evaluable, intervención activa y participativa, trabajo cooperativo y service-learning y participación en actividades de voluntariado.

En cuanto a los agentes implicados se aboga por un docente creativo, contrario a rutinas intelectuales y mecánicas y que sea también modelo de comportamiento. De los alumnos se precisa un compromiso para implicarse en las actividades. Y se insiste en la idea de que entre la tarea del educador y el educando existe una reciprocidad, por lo que será necesario establecer una relación de colaboración entre ambos. 
Finalmente se aborda la evaluación, componente ineludible de todo proyecto educativo. Se apuesta por una evaluación formativa que contribuye a la valoración de todo el proyecto y de sus integrantes en sus diferentes fases. Se insiste en la idea de que ha de ser motivadora, generando actitudes de superación y expectativas de mejora y debe contribuir a que el alumnado se forje un autoconcepto ajustado a la realidad. Se considera de gran interés que el alumnado pueda llevar a cabo un proceso de autoevaluación. Para ello se aportan dos instrumentos: una escala de actitudes de compromiso social y un cuestionario de habilidades de participación, compromiso social y convivencia cívica.

El último apartado hace referencia a las medidas de atención a la diversidad. Se invita a tener en cuenta dos importantes cuestiones: 1) el desarrollo de cada virtud debe generarse respetando las características personales del alumno; y 2) será preciso considerar qué virtudes se prestan más a ser desarrolladas en función del momento de desarrollo psicológico y evolutivo del alumno.

En conclusión, diría que esta guía puede ser una buena herramienta didáctica para el profesorado. Tras un estudio detallado del tema se recogen ideas y planteamientos pedagógicos que avalan los materiales y recursos concretos y accesibles que contiene, y que el profesor puede usar para fundamentar el proceso de enseñanza-aprendizaje de esta materia.

María del Mar Martín Ayllón Universidad de Navarra
TORREGO, J.C. (Coord.) (2012).

La ayuda entre iguales para mejorar

la convivencia escolar.

Madrid: Narcea, 141 pp.

La progresiva irrupción en los centros educativos de procesos de violencia escolar, con episodios virulentos que en casos extremos ha llegado a la muerte de escolares, ha hecho que los educadores se preocupen por implantar estrategias e instrumentos que suavicen, rebajen o eliminen los episodios violentos, consiguiendo mejorar el clima del centro y las relaciones entre iguales en los centros educativos. En este libro el autor presenta los materiales que ya han sido testados y aplicados en un curso de Experto en Convivencia y mediación de conflictos de la Universidad de Alcalá que ya tiene varias ediciones y se ha difundido por varias comunidades autónomas así como en varios países de América Latina.

Se distribuye el libro en ocho capítulos y un anexo bibliográfico en el que recogen los distintos componentes del programa descrito partiendo de datos oficiales de violencia, pero también de la llamada conspiración del silencio que oculta muchos episodios por miedo. Se parte de la ayuda entre iguales como mecanismo poderoso para la prevención y resolución de conflictos que otorga protagonismo al alumnado y que propicia la erradicación de la cultura del silencio y la insolidaridad, pasando a formar parte de la cultura del diálogo y la cooperación. La capacidad de ayudar se muestra como una dimensión fundamental de la convivencia y a través de los sistemas de ayuda se expre- 
san valores como el respeto, el aprecio y la cooperación entre iguales. Sobre esos principios éticos se crean culturas de participación, responsabilidad, diálogo y solidaridad. Destaca en este aspecto la resiliencia como un proceso que corresponde a una dinámica dentro del ciclo vital por lo que se debe de potenciar que el ayudado sea un alumno con problemas y con pocas fuerzas para seguir adelante y superar los obstáculos. La tarea de los alumnos ayudantes en estos casos puede resultar de gran utilidad. Se trata de fomentar un apoyo conductual positivo poniendo el foco en el contexto y no en el alumno. Lo que se busca es promover expectativas de eficacia personal y sensación de control a través de la intervención personal.

El perfil de los alumnos ayudantes, dos o tres por grupo-clase, se manifiesta en que tienen una formación específica en resolución de conflictos y ayuda, gozan de la confianza de sus compañeros, están pendientes de la convivencia del grupo y apoyan a los compañeros con dificultades académicas o profesionales. Sus funciones son de acogida, de ayuda, de defensa de otros, detectar los conflictos y buscar soluciones a los mismos. Los valores del alumnado ayudante se fundamentan en el diálogo y la cooperación, la tolerancia, la disponibilidad, el compromiso, la solidaridad, la empatía, etc., con una base moral y ética y que reflejen también la diversidad étnica y cultural.

La relación de ayuda pasa para el autor por cinco fases: acercamiento, acompañamiento, profundización, seguimiento y distanciamiento. Para cada una de ellas se dan unos objetivos y estrategias culminando con ejemplos orales o situacionales. Luego se dan unas pautas para analizar y solucionar conflictos. La introducción de la ayuda en una institución educativa exige que todas las instancias estén coordinadas para afrontar los problemas. El reparto de roles pasa por identificar a los participantes: en primer lugar los que protagonizan el conflicto, los ayudados; luego los que intentan resolverlo, los ayudantes; después el profesor coordinador de convivencia, el equipo directivo como responsable de velar por el buen clima en el centro, el orientador como garante de que la convivencia forme parte del currículum del centro y finalmente, si existe, el educador social que debe aportar a la escuela flexibilidad y nuevas formas de trabajo en red.

Los límites y riesgos que el ayudante debe evitar en su relación con el alumnado se basan en la bondad y la caridad compartida, evitando la soberbia, el síndrome del salvador, el ser infiltrados del profesorado, chivatos, enchufados, o cualquier otra figura que lo separe de los que va a ayudar. Al implementar el programa de ayuda entre iguales pueden encontrarse resistencias por parte de un sector del profesorado; para evitarlo, el conocimiento del programa y la implicación de la mayor parte son elementos imprescindibles. La ayuda y la cooperación deben de figurar como ejes de la vida del centro, tanto desde la perspectiva académica como desde la personal. La amistad y el compañerismo deben ser llevados a toda actividad de la vida del centro. Modelos de ayuda como el aprendizaje cooperativo de tipo convivencial que mejora a la vez la vida del aula y el propio aprendizaje; alumnos tutores, asignando un alumno más aventajado a otro que tiene dificultades; club de deberes y tareas, donde un grupo de alumnos mayores tutoriza a otro grupo con necesidades, supervisado por un profesor; grupos interactivos, con talleres en los que participan personas externas al centro, suponen experiencias empíricas llevadas a cabo con éxito.

Para la formación de alumnos ayudantes, lo más habitual es poner en marcha programas específicos para los que se presentan los contenidos y los pasos a seguir para infantil, primaria, y secundaria, permitiendo a los interesados llevarlo a la práctica por ciclos. Contiene una revisión básica sobre el 
aprendizaje cooperativo, alumnos tutores, club de tareas o grupos interactivos. Para poner en marcha un programa de formación de alumnos ayudantes presenta seis módulos que considera imprescindibles conteniendo aprendizaje de técnicas, habilidades y valores que deben adquirir los alumnos ayudantes. $\mathrm{La}$ abundancia de ejercicios prácticos para el aprendizaje de los alumnos en formación pretende mostrar en la realidad lo que han de hacer en su tarea una vez responsabilizados de otros alumnos. Abarca desde solución de conflictos a la comunicación, la resolución de problemas o la escucha activa.

Se trata de un libro-manual de ayuda claramente volcado a la práctica de aula, ya que además de permitir formar alumnos para la mejora de la convivencia escolar, puede también ser un valioso auxiliar del profesor en las diversas situaciones que aborda. La gran experiencia del autor-coordinador en esta temática es una garantía de aplicabilidad y solvencia del libro.

Isabel Cantón Mayo Universidad de León

AZNAR, P.; ULL, M.A. (2013). La Responsabilidad por un mundo sostenible.

Bilbao: Desclée de Brouwer. 275 pp.

"¿Qué clase de educación servirá para dotar a la generación venidera de la capacidad para afrontar los problemas mundiales cada vez más complejos y graves?» Esta pregunta retórica que las autoras del libro formulan en la Introducción, recibe una inmediata respuesta, párrafos después, cuando afirman: «tiene que ser, independientemente de cómo se concrete, un tipo de educación que permita a los estudiantes vivir de una manera sostenible, competente y digna, reconociendo su dependencia del entramado de la vida; una educación que extienda su sentido de la responsabilidad en un horizonte temporal más lejano; una educación que posibilite la construcción de una nueva ética, centrada en la vida, orientadora de las relaciones entre los seres vivos y el medio, que permita, solidariamente, satisfacer las necesidades de la generación presente sin poner en peligro la satisfacción de las necesidades de las generaciones futuras» (p. 13).

Así, en estas breves líneas, queda expresado, en síntesis, el enfoque que de la educación para el desarrollo sostenible defienden las profesoras Aznar y Ull, ambas de la universidad de Valencia; enfoque que se verá ampliamente desarrollado en las páginas de un libro muy oportuno, que se suma a la escasa bibliografía escrita en nuestro contexto cultural sobre el papel de la educación en la transformación social hacia la sostenibilidad. Un tema que, a pesar de su interés y necesidad, reiteradamente reconocidos por los más altos organismos internacionales, con Unesco a la cabeza, no ha merecido hasta el momento sino una muy minoritaria atención de especialistas y estudiosos del campo de la teoría de la educación.

Es en el capítulo cuatro de la obra, titulado Referentes epistemológicos y éticos en educación para la sostenibilidad. La coherencia en las acciones educativas, donde de forma expresa se analizan los supuestos básicos que se proponen como soporte para diseñar e implementar acciones educativas con criterios pedagógicos fundamentados y coherentes con los principios y valores de la sostenibilidad. El enfoque sistémicocomplejo, el constructivismo, y la ética socio-ambiental son los tres pilares del modelo educativo que la obra suscribe. El primero de ellos se apoya en el corpus conceptual de la Teoría de la Complejidad, que Edgard Morin nos ofrece 
al contextualizar en el ámbito de las ciencias sociales los principios sistémicos y sus efectos. La formación de un pensamiento relacional es, desde esta perspectiva, una función prioritaria de la educación, encargada de facilitar las herramientas conceptuales y metodológicas para un ejercicio de conocimiento-comprensión, de consciencia y de compromiso. Conocimiento, como necesidad intelectual y vital a un tiempo, de la compleja red de relaciones e interacciones entre los cuatro subsistemas esenciales para la vida: biosfera, socioesfera, tecnosfera y noosfera; lo cual supone afrontar los desafíos de la complejidad y buscar la confluencia entre la unidad y la multiplicidad. Consciencia a propósito de la condición humana, de la identidad planetaria del ser humano y del sentido de pertenencia de la existencia humana con relación al sistema Tierra. Y, finalmente, compromiso de solidaridad, una solidaridad fruto de la comprensión planetaria.

Como segundo pilar del modelo educativo para la sostenibilidad, la obra propone el enfoque constructivista, que en el campo del aprendizaje nos obliga a situar el énfasis en los procesos de «aprender» más que en los de «enseñar»; y, por tanto, que exige al profesorado una atención cuidadosa a la planificación de los procesos formativos y al diseño de actividades facilitadoras del aprendizaje autónomo.

Y, en tercer lugar, el soporte ético, en cuya base se encuentra la reflexión sobre el lugar que ocupa el ser humano en el cosmos y en la cual las repercusiones de las acciones humanas sobre el medio forman parte del ámbito de significación ética, al tiempo que, al recuperar el sentido unitario de la realidad, enfatiza los vínculos entre el ser humano y el medio, en su doble condición, natural y artificial. En definitiva, una ética del cuidado a la que, ineludiblemente, nos aboca la conciencia de la interdependencia recíproca entre todos los componentes del sistema de la vida, tal como hoy la conocemos. Y una ética de la responsabilidad; diacrónica, con la especie humana en su devenir futuro, y sincrónica, inter e intra generacional, dentro de un mismo tiempo histórico.

Otros cinco capítulos se ocupan de distintos temas nucleares: los problemas socio-ambientales más acuciantes, el concepto de desarrollo sostenible e indicadores de sostenibilidad, la Agenda 21 en sus distintas concreciones, los procesos de cambio hacia la sostenibilidad en los centros educativos, o la responsabilidad de la familia y otros espacios sociales en materia de educación para la sostenibilidad. En total nos encontramos ante seis interesantes capítulos que en su conjunto ofrecen con tino un panorama amplio, donde se encuentran incluidos los principales tópicos a considerar en una aproximación acertada a los conocimientos más significativos que permiten entender en sus ejes axiales el modelo de la educación para el desarrollo sostenible, hoy tan necesario.

La obra, dirigida preferentemente a profesores, padres-madres y educadores en sentido amplio, está avalada por la reconocida trayectoria de sus autoras en el campo de la educación y la pedagogía ambiental. En el caso de la profesora Aznar, como Catedrática de Teoría de la Educación, desde hace años nombrada por su rector Coordinadora de la educación para la sostenibilidad de la Universidad de Valencia y, como tal, miembro del grupo de trabajo Sostenibilización curricular de la CADEP, comisión sectorial de la Conferencia de Rectores de las Universidades Españolas (CRUE). Mientras que la profesora Ull, doctora en bioquímica y biología molecular, ejerce su docencia e investigación en la misma universidad, a la vez que desempeña el cargo de presidenta de la Asociación Valenciana de Educación Ambiental y Desarrollo Sostenible (AVEADS).

$$
\begin{array}{r}
M \cdot{ }^{a} \text { Ángeles Murga-Menoyo } \\
\text { UNED }
\end{array}
$$




\section{NORMAS DE PUBLICACIÓN DE LA REVISTA EDUCACIÓN XX1}

1. La Revista Educación XX1 se configura como órgano de la Facultad de Educación de la UNED para la difusión de ensayos, trabajos de carácter científico y experiencias innovadoras relacionados con la educación en cualquiera de sus campos de acción. Así como bibliografía y recursos documentales significativos y actuales en este área. Las colaboraciones deberán reunir los siguientes requisitos: a) hacer referencia al campo de especialización propio de la Revista Educación XX1; b) constituir una colaboración original no publicada previamente; c) estar científicamente fundada y gozar de unidad interna; d) suponer una ayuda para la profundización en las diversas dimensiones y ámbitos de la educación.

La Revista Educación XX1 tiene una periodicidad semestral.

2. Los trabajos serán inéditos, no admitiéndose aquellos que hayan sido publicados total o parcialmente, ni los que están en proceso de publicación o hayan sido presentados a otra revista para su valoración. Los artículos (original y una copia) deberán enviarse por correo electrónico en formato word. En la copia deberán eliminarse todos los datos que puedan identificar al autor/es.

3. Los trabajos deberán atenerse a las normas de carácter formal que se recogen a continuación, y que se encuentran de forma completa en http://www.uned.es/educacionXX1/. Las colaboraciones enviadas a la Revista Educación XX1 que no se ajusten a ellas serán desestimadas en cualquiera de las fases del proceso editorial. Antes de su publicación serán valorados por dos miembros del Comité Científico, (doble ciego) que podrán realizar sugerencias para la revisión y mejora, si procede, en vistas a la elaboración de una nueva versión. Para la publicación definitiva se requiere la valoración positiva de ambos.

4. Al enviar el artículo definitivo a la Secretaría de Redacción de la Revista será necesario mencionar la conformidad expresa para la valoración y difusión por vía impresa y telemática de su artículo.

5. Todos los artículos tendrán una extensión entre 5.000 y 7.000 palabras (incluidos resumen, notas y bibliografía). Recensiones, entre 500 y 1.000 palabras. Serán remitidos en formato Word, fuente 12, interlineado 1,5 y con $3 \mathrm{~cm}$ de márgenes (superior, inferior, izquierdo y derecho).

6. Estructura de los artículos. Cada artículo se atendrá a la siguiente estructura:

Título del artículo en español - (Entre paréntesis título en inglés)

AUTOR/ES y lugar de trabajo

RESUMEN Y ABSTRACT (extensión máxima 300 palabras)

PALABRAS CLAVE Y KEYWORDS (máximo 6 descriptores)

TEXTO DEL ARTÍCULO

NOTAS (si existen)

REFERENCIAS BIBLIOGRÁFICAS, SEGÚN MODELO

PERFIL académico y profesional del autor/es (entre 50 y 75 palabras). Dirección completa del/os autor/es

7. Citas dentro del texto. Las referencias a artículos o libros figurarán en el texto entre paréntesis, indicando el apellido del autor y el año, separados por una coma. En el caso de que en una misma referencia se incluvan varios libros o artículos, se citarán uno a continuación del otro por orden alfabético y separados por un punto y coma. Si en la referencia se incluyen varios trabajos de un mismo autor bastará poner el apellido y los años de los diferentes trabajos separados por comas, diferenciando con letras (a, b, etc.) aquellos trabajos que haya publicado el mismo año. Si el nombre del autor forma parte del texto sólo irá entre paréntesis el año de publicación.

8. Citas textuales. Las citas textuales irán entrecomilladas y, a continuación y entre paréntesis, se indicará el apellido del autor del texto, el año y la página o páginas de la que se ha extraído dicho texto.

9. Referencias bibliográficas. Deberán ajustarse al siguiente formato:

a) Libro: Apellidos del autor/es, Iniciales. (Año). Título del libro. Lugar de publicación: Editorial.

b) Revistas: Apellidos del autor/es, Iniciales. (Año). Título del artículo. Nombre de la Revista, número o volumen y (número), páginas que comprende el artículo dentro de la revista.

c) Capítulo o artículo en libro: Apellidos del autor, Iniciales. (Año). Título del artículo o capítulo, en Apellidos del autor, editor o coordinador del libro Título del libro, páginas que comprende el artículo o capítulo dentro del libro. Ciudad: Editorial.

10. Referencias de formatos electrónicos

a) Documentos electrónicos: autor/es (fecha publicación). Título [tipo de medio]. Lugar de publicación: editor. Recuperado de especifique URL.

11. Gráficos. Las tablas, gráficos y cuadros deberán ser entregados en formato JPG y se enviarán acompañadas de su correspondiente título y leyenda, numeradas correlativamente, indicando en el texto el lugar y número de la figura que deberá insertarse en cada caso.

12. Recensiones. Deberán atenerse al siguiente formato: Apellidos del autor, Iniciales. (Año de publicación). Título del libro. Ciudad de publicación: Editorial, número de páginas del libro. El texto de la recensión irá procesado a doble espacio, con la extensión y forma indicada (entre 500 y 1000 palabras). Siempre serán publicaciones del año de la edición del volumen o el inmediatamente anterior.

13. Corrección de pruebas. La corrección de pruebas de imprenta o del formato electrónico, si fuera el caso, la hará la Revista Educación XX1 cotejando con el original.

14. Envíos de las colaboraciones. Toda la correspondencia deberá enviarse a: educacionXXI@edu.uned.es

Correo postal: Revista Educación XX1 - Decanato de la Facultad de Educación. UNED Cl. Juan del Rosal, n. 14 - 28040 - MADRID (España) Teléfono: + 34 91.398.69.11/87.69/72.16.

La Revista Educación XX1 no mantiene correspondencia sobre los originales no solicitados por la misma.

La Revista Educación XX1 no se hará responsable de las ideas y opiniones expresadas en los trabajos publicados. La responsabilidad plena será de los autores de los mismos. 


\section{INSTRUCTIONS FOR CONTRIBUTORS TO THE JOURNAL EDUCACIÓN XX1}

1. The Journal Educación XX1 stands as an official publication of the Faculty of Education of the UNED. It aims to the difussion of essays, scientific works and innovative experiences related with education in all professional dimensions. It also deals with the exchange of relevant bibliography and significative documental resources in this academic discipline. Articles submitted to the Editorial Board must comply with the following conditions: a) To refer expressely to the field of education or educational science. b) To be an original paper not published previously. c) To have a scientific foundation and internal cohesion. d) To be significant to the field of education. This Journal appears twice per year.

2. Articles will be unpublished, not admitting those who have been published in whole or in part, or those who are in press or have been submitted to another journal for evaluation. Articles (original and one copy) should be sent by email in Word format. The copy should be eliminated all data that could identify the author is.

3. Manuscripts must hold to the formal instructions to contributors below, that are also fully available online at:

http://www.uned.es/educacionXX1/ Contributions not complying with the specified norms will be rejected. Prior to publishment, articles will be assessed by two members of the Editorial Board (peer review) which can request any revisions to the presented version. Possitive assessment of both members is required for the definitive publication of the contribution.

4. At the time of sending the article to the Journal, authors must express their conformity with the fact that papers accepted become the copyright of the Journal, for its written and telematic diffusion.

5. all contributions will have an extension between 5.000 and 7.000 words (abstract, notes and bibliography included). Book Reviews will have between 500 and 1.000 words. They will be send in word format, font 12,1, 5 interlineal and with $3 \mathrm{~cm}$ margins (right, left, upwards and downwards).

6. Structure of articles. Articles will hold to the following structure:

- Title of article in Spanish - (Between brackets title in English)

- Author/s and working institution

- Abstract

- Keywords (maximum of 6 descriptors)

- TEXT OF THE ARTICLE

- Notes (if any)

- Bibliographical references, following standard form

- Short note of academic and professional biographical details (between 50 and 75 words)

- Author/s's address

7. Citations within the text. Articles or books citations within the text will appear between brackets, indicating the surname of the author and the year, separated by comma. In the case that a reference includes several books or articles, it will do so one by one following an alphabetical order and separated by semicolon. In the case that the reference includes several works of a same author, the surname will appear followed by the years of the different works separated by commas, distinguishing by letters (a, b, etc), those works published in the same year. If the name of the author relates to the text, brackets will contain only the year of publication.

8. Literal citations. Literal citations should appear in inverted commas, followed by the surname of the author of the text, the year and the page/s of the original work in brackets.

9. Bibliographical references. They must be adapted to the following standard form:

a) Book: Surname of author/s, Initials. (Year). Title of book. Place of publication: Editorial.

b) Journals: Surname of author/s, Initials. (Year). Title of article. Name of Journal, number or volumen (and number), pages of article within journal.

c) Chapter or article in book: Surname of author/s, Initials. (Year). Title of chapter or article, in Surnames of author, editor or coordinator of book Title of book, pages of chapter or article within book. Place of publication: Editorial.

10. References for online documents

a) Electronic documents: author/e (date of publication). Title. Place of publication: editor. Available in: URL specification.

11. Figures. Figures, captations and tables should be sent in JPG format and will be sent together with their correspondant title and leyend, correlatively numbered, indicating in the text the place and number of the figure that must be inserted in each case.

12. Book reviews. They must be adapted to the following standard form: Surname of author, Initials. (Year of publication). Title of book. Place of publication. Editorial, number of pages of the book. The text of the book review should be processed in double space, with the form and extension indicated (between 500 and 1.000 words)

13. Proofreading. Galley proof or from the electronic version will be done by the Journal Educación XX1 ckecking with the original.

14. Submission of colaborations. All contributions and queries must be sent to: E-mail: educacionxx1@edu.uned.es

Mail: Revista Educación XX1 - Decanato de la Facultad de Educación - UNED.- Cl. Juan del Rosal, 14 - 28040 - MADRID (España) Telephone: +34 91.398.69.11/87.69/ 72.16.

The Journal Educación XX1 will not maintain correspondence related to originals not requested by itself

Any views expressed in this publication are the views of the authors and are not the views of the Journal Educación XXI 
